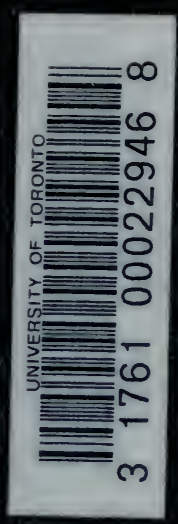




\section{SEWAGE AND THE}

BACTERIAL PURIFICATION OF SEWAGE 


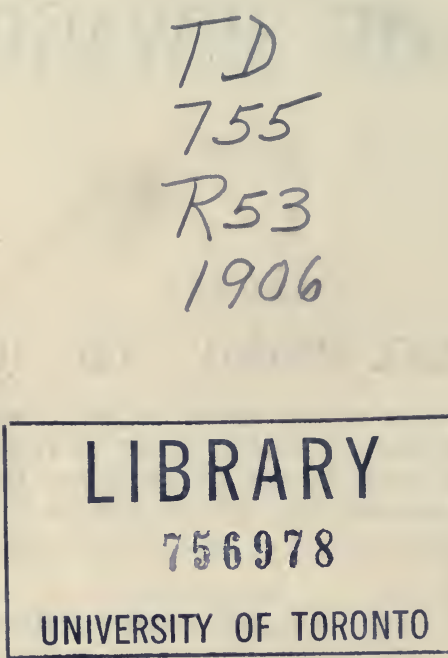


\section{PREFACE TO THE THIRD EDITION}

A Third Edition being called for by my Publishers, I have been able to incorporate the further experience which has been gained in the bacterial methods of sewage disposal during the past five years, and have embodied the conclusions of the Royal Commission so far as they have been published. We still await their final report, and, in England, hope that legislation will follow such report, in order that Local Authorities may have free scope in developing the newer methods of sewage disposal. The Local Government Board have relaxed some of the rules which had proved irksome in many districts, but as unfortunately works approved by them, and constructed out of loans on deposited schemes, have in certain cases given rise to serious complaints and law-suits, I hope that in the future it will be possible in England for Authorities to carry out works which are likely to be more successful, if the expert, after or during construction, is allowed to make such modifications in design or working as in his opinion will result in a proper disposal.

- I have to thank, as in former editions, many firms for lending me blocks. I am also indebted to the Main Drainage Committee of the London County Council and the Controller of His Majesty's Stationery Office for lending me the Plates for Figs. 4-I2, I5-I8, from Dr. Houston's Report and the 2nd Report of the Royal Commission on Sewage Disposal.

Samuel Rideal.

28, Victoria St., Westminster,

November, 1906. 



\section{PREFACE TO THE SECOND EDITION}

THE rapid sale and early exhaustion of the first edition, both in England and America, give an opportunity for the revision of the whole work and the inclusion of fresh matter that has since been published. Owing to kindly criticism, with contributed facts and suggestions trom professional friends in various countries, I have been enabled to add much further knowledge, both in theory and practice, of the remarkable development of bacterial treatment of sewage up to the present time. It has not been necessary to alter the statement of principles, such as those of the stages of purification, which are now almost universally acknowledged.

By condensation of parts of the earlier edition I have found room for much fresh matter, as the aim has been to convey within a small space as much information as possible.

I have to thank various firms who have lent blocks, and the Main Drainage Committee of the London County Council, who, through Dr. Clowes, have furnished the plates of bacteria to illustrate my accounts of their useful work.

\section{Samuel Rideal.}

28, Victoria Street, S. $\mathbf{~}$ -

June, I901. 


\section{PREFACE TO THE FIRST EDITION}

THE rapid development in modern ideas of sewage purification by bacterial processes necessitates a careful review of the methods of disposal at present sanctioned. The important reports published by the London County Council, Manchester, Leeds, and other towns in this country, as well as those of commissions appointed by sanitary authorities in the United States and on the Continent, and the frequent discussions and papers in the technical press, lead me to the view that a résumé would be acceptable to a wide class of readers in this country.

The Royal Commission at present engaged on this subject will, no doubt, carefully weigh the evidence which is being placed before it, and we may confidently expect that its conclusions will be in accord with those obtained from the experiments which have now been carried out on sufficiently large a scale to establish the safety of embarking on the treatment of sewage on bacterial lines for even the largest centres of population.

The theoretical basis of the bacterial changes, so far as they have been at present studied, must underlie all the practical schemes which may in the future be put forward, and it has been my endeavour in the following pages to deal with the subject from this point of view.

I have to thank many friends and firms for information and the loan of blocks, and also my assistant, Mr. C. G. Stewart, for helping me in preparing the work for the press.

\section{Samuel Rideal.}

28, Victoria Street, Westminster, May, 1900. 


\title{
CONTENTS
}

\author{
CHAPTER I
}

INTRODUCTION

\section{CHAPTER II}

\section{CHEMICAL ANALYSIS OF SEWAGE AND EFFLUENTS}

Methods of collecting samples-Gauging the flow-Samples should be collected proportional to the flow and corresponding to one anotherWeirs-Floats-V notch-Meters-Hourly variation of sewage-Official methods of collection and analysis-Recommendations of the British Association-Determinations of total solids-Chlorine-Free and albuminoid ammonia-Oxygen consumed-Mineral constituents $\quad \ldots \quad$ 22-42

\section{CHAPTER III}

\section{CHEMICAL ANALYSIS (continued)}

Determination of nitrates-Nitrites-Organic nitrogen-Dissolved oxygen -Carbonic acid-Incubator tests-Weights discharged per day-Proposed standards for effluents-Ratio of chlorine to total nitrogen, and of oxidized to unoxidized nitrogen

...

...

\section{CHAPTER IV}

\section{BACTERIA AND OTHER ORGANISMS IN SEWAGE}

Their identification and numbers and morphological characteristicsBacterial tests for the purity of effluents-Possibility of the survival of pathogenic organisms

$\begin{array}{lllll}\text {.. } & \ldots & \ldots & \ldots & 6\end{array}$

\section{CHAP'TER V}

\section{CHEMICAL CHANGES PRODUCED BY BACTERIA}

Hydrolysis and oxidation-Nature and order of the reactions-Symbiosis and antagonism-Enzymes-Classes of transformations-Utilization of gases produced-Sources of energy-Nitrosification, nitrification, and denitrification

\section{CHAPTER VI}

IRRIGATION AND SEWAGE FARMS

Broad irrigation - Soils - Application of lime or ashes - Trenching Organisms in soils-Suitable crops-Transpiration of water-Statistics of sewage farms-Systems of distribution-Ridge and furrow-Catchwater-Intermittent irrigation with under-drainage-Merthyr TydvilCalculation of dilution by subsoil water-Irrigation with previous treatment-Areas required-General aspect of land treatment $\quad \ldots \quad$ I32-I 49

\section{CHAPTER VII}

\section{SUBSIDENCE AND CHEMICAL PRECIPITATION}

Screens-Settling tanks-Roughing filters-Clarification-Lime-Aluminium sulphate-Ferric sulphate-Ferrous sulphate-Alumino-ferric-Sludge: its composition, volume, and disposal ... 


\section{CHAPTER VIII}

STERILIZATION BY HEAT, CHEMICALS, AND ELECTRICITY

Removing odour-Metallic salts-Action of manganates and permanganates -Oxynite process-Chlorine and hypochlorites-Bleaching powderHermite-Electrozone-Oxychloride-Acids-Bergé-Ozone-Liernur process-Disposal of refuse-Destructors

... $\quad \ldots \quad \ldots \quad$ I $68-20$

\section{CHAPTER IX}

\section{BACTERIAL PURIFICATION}

History of the idea and of early experiments-Mueller's process-Mouras' automatic scavenger - Massachusetts - London - Sutton - Oswestry -Leeds-Triple filtration or contact ... .. $202-225$

\section{CHAPTER X}

\section{BACTERIAL PURIFICATION (continued)}

Capacity of filters-Nature and size of materials-Gases in filters-Depth of beds - Aerating processes - Lowcock - Waring - Ducat - Artificial warming - "Thermal aerobic" - Continuous filtration - Salford -. Stoddart's filter

\section{CHAPTER XI}

\section{BACTERIAL PURIFICATION (continued)}

Unaided bacterial processes-Scott-Moncrieff's tank-Conditions of hydrolysis-The Exeter septic tank-Tank and filter deposits-Statistics of septic tank plants - Moncrieff's trays--Comparative nitration by different systems-Oxygen relations-Separate zones-Caterham-Manchester experiments-Birmingham-Sheffield-Leeds-American experience 249.28I

\section{CHAPTER XII}

\section{DISTRIBUTION AND DISTRIBUTORS}

Intermittent-Continuous-Stationary Sprayers - Moving Distributors$\begin{array}{llllllll}\text { Tippers-Testing Apparatus } & \ldots & \ldots & \ldots & \ldots & \ldots & \text { 282-309 }\end{array}$

\section{CHAPTER XIII \\ SEWAGE OUTFALLS AND DISCHARGE}

Rainfall and storm-water-Separate and combined systems-Storm overflows-Position of outfalls-Objections and legal remedies-Foreshore smells - Unsightliness - Mud banks - Fish - Water supplies - Con-

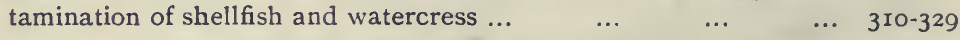

\section{CHAPTER XIV}

AGRICULTURAL VALUE OF BACTERIAL EFFLUENTS-TRADE EFFLUENTS

Conservation of the valuable constituents of sewage-Economic value of nitrated effluents - Trade effluents - Classification - Chemical and mechanical treatment-Recovery of products-Wool grease-Relation to the bacterial process-Recommendations of the Royal Commission $330-348$ 


\section{LIST OF ILLUSTRATIONS}

FIG.

I. V-Notch

2. Venturi Meter in closed pipe

3. Venturi Meter in open channel

4. Sewage proteus ...

5. Proteus vulgaris ...

6. Sewage proteus ...

7. Bacillus enteritidis sporogenes

8. $\quad$ membraneus patulus $\quad \ldots \quad \ldots$

PAGE

9. ", fusiformis

I0. " mesentericus. Sewage variety I. ...

II. ,

.

$\begin{array}{lll} & \\ \text { Sewage variety I. } & \ldots \\ & \text { E. } & \ldots\end{array}$

$\cdots \quad \cdots$

$\begin{array}{lll}\cdots & \cdots & 23 \\ \cdots & \cdots & 26\end{array}$

I 2

13. Beggiatoa alba ...

14. Crenothrix Kühniana

15. Leptomitus lacteus, showing constriction and nucleus

I6. showing branching

I7. Sphærotilus natans

18. Carchesium Lachmanni ...

$\cdots$

$\cdots$

$\cdots$

.. $\quad$... 26

19. Section showing underdrains in Irrigation ...

20. Rotary Screen for crude Sewage at Southall Sewage

2I . Contact, or "Dibdin " Filters at Sutton

22. Lowcock's Aerated Bacterial Filters

23. Section of Ducat's Filter ...

24. Filtering Material in Ducat's Filter

25. Caterham Cultivation Tank

26. Filter House at Caterham

27. Experimental Septic Tank and Filters, Belle Isle, Exeter

28. Working of Cameron's Automatic Gear

29. Sections of the Ashtead Cultivation Bed and Zonal Tray Filters
$\cdots$
$\therefore \quad \cdots$

... $\quad \ldots$

$\cdots$

$\cdots$

74

... 74

... 73

... 74

... 73

... 74

74

... 74

... 74

$\cdots, 74$

... 79

... 79

... 79

... 79

.. 79

... 80

... 142

30. Changes of Nitrogen in Oxidizing Trays

3r. Section of Intermittent Supply by Adams' Syphon ...

32. Plan of Intermittent Supply by Adams' Syphon

33. Section of Automatic Discharge by Adams' Syphon ...

34. Plan of ditto

35, 36, 37. Details of Stoddart's Continuous Filter

$\cdots$

ks, Isleworth I5I

38. " Acme" Fixed Sprays

... $\quad . .$.

...

...

$\cdots$

39. Nozzle Distribution at Birmingham : Tame and Rea Sewage Works ..

40. Ham and Baker's Nozzle, as used at Birmingham ...

.... 
42. Section of Bed, Columbus, Ohio ....

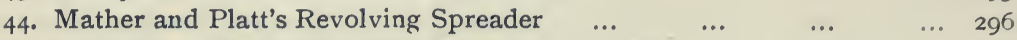

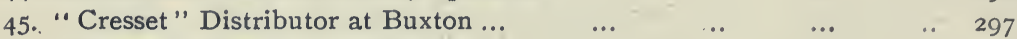

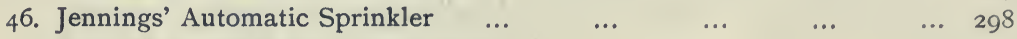

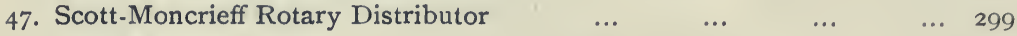

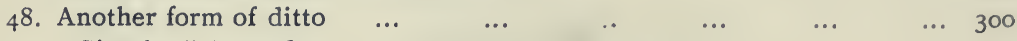

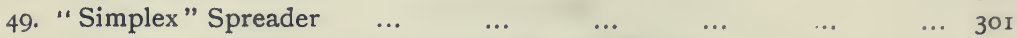

50. Revolving Sprinkler at Abbots Langley, near Watford $\quad \ldots \quad \ldots \quad 302$

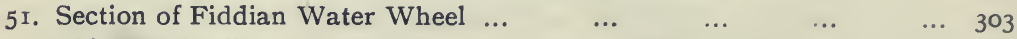

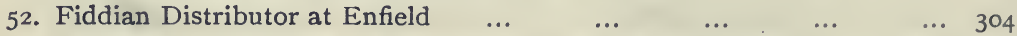

53. Travelling Distributor for Rectangular Beds at Wednesbury ... ... 305

54, 55, 56. Farrer's Automatic Distributor $\quad \ldots \quad \ldots \quad \ldots \quad \ldots 306,307,308$

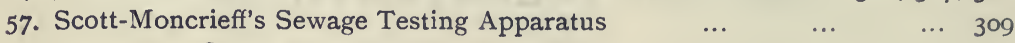

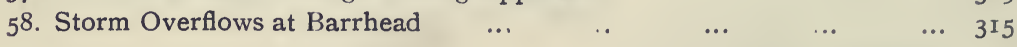




\title{
SEWAGE AND THE BACTERIAL PURIFICATION OF SEWAGE
}

\author{
CHAPTER I
}

I'N T ROD U C T IO N

ALL organisms are injuriously affected by the continued presence of their own excreta, so that if they are kept in a confined space they gradually die off. In the case of higher animals the earliest remedy for such self-poisoning has been migration, but with the increase of numbers the opportunity for this has become more and more limited, and "murrains" and other pests have set in as a consequence of overcrowding. With man there has been the additional burden of the refuse of his industrial occupations.

It was an injunction of Moses that unclean matters were to be carried outside the camp and burnt, and the necessity of this will be recognised by anyone who has seen in Eastern towns, and even in British villages, decomposing heaps of garbage. But the cremation of such products requires fuel and produces intolerable odours; hence the resort to a primitive and effective method which is still in use in dealing with the dead-namely, a committal to earth. Deut. xxiii. I2, I3, enjoins that all excreta shall be covered with earth, following the natural instinct of many animals. This instinctive effort to cover the dejecta is most prominent in the carnivora, in which the matters are nitrogenous, and therefore more highly offensive, whereas in the herbivora no such natural propensity is observed.

Pastoral populations depending on springs and wells found water too scarce and valuable to be purposely polluted. Those residing on the banks of rivers also refrained to a great extent from casting their refuse into the streams used for their bathing 
and drinking, and, having access generally to an ample amount of open and porous soil, employed what we may call the earth system. Following the aggregation into settlements, it was early found necessary to set aside special places for the reception of refuse; hence the midden heaps that have been widely discovered. After a time, for human excreta ditches or trenches were dug, from which the products of decomposition either sank into the surrounding soil or found an outlet to some watercourse. In many cases the trenches were at length filled in with earth, over which a rank vegetation grew, and the soil became gradually purified, a plan which is still followed in the case of temporary camps and in Eastern villages. At a later stage, when the progress of civilization necessitated the use for washing and cooking of a large quantity of water, isolated inhabitants found it difficult to dispose of the liquids; therefore great pits were dug to receive them, and to keep the rain out were roofed over with beams and earth. At a still later period these excavations were lined with brick, arched over, and connected with the houses by brick or flagstone drains. No cement, as a rule, was used in the construction, as it was found that if the sewage sank into the earth less frequent emptying was required. Moreover, if the receptacle or cesspool were made air and water-tight by cement, it was necessary to provide a vent for the large quantity of gas that was generated in the decompositions. I can record a case where a cemented cesspool in the North of England regurgitated a large quantity of sewage into the cellars of the house, although the pit had been recently erected, and was by no means full. In other cases unventilated cesspools have filled the basement of dwellings with sewer gas.

For houses in isolated positions the cesspool till lately was the only available means of sewage disposal, and architects and others spent considerable time and skill upon its design in the early Victorian period, when sanitary progress first drew attention to its importance. I give the following as an example of its successful use, which is interesting on account of its being antecedent both to the French "automatic scavenger," to be described in a subsequent chapter, and to the modern "septic tank":

In I858 a large school in Derbyshire, situate on the top of a lofty hill, surrounded by its own land, but at a distance of two miles from a small river which ran through other property, 
had to provide for the sewage of 250 to 300 persons and the drainage from a farm. The water-supply was adequate for ordinary needs, but not sufficient for water-carriage of the sewage. A very large cemented brick pit was constructed underground, and arched over, at the back of the buildings and 200 yards from them. Into this the whole sewage passed continuously. When the floating gauge indicated that the pit was full, the whole contents were pumped out from a point near the bottom, and discharged by pipes over cultivated slopes, finally filtering through a gravel and chalk soil into a moderatesized reservoir in a clayey valley at the foot of the hill, where it mixed with water derived from springs and a rivulet. The mixed water was clear and bright, except for an occasional turbidity from the clay. At the periods of emptying no nuisance occurred; sometimes a faint earthy odour was noticed when the wind was in the direction. The health of the school was good.

But in towns the crowding together of cesspools renders a large area of soil waterlogged with black and fœtid matter, which undergoes little or no oxidation; while the periodical clearing out may be an offensive, and sometimes dangerous, process. At Hampstead, for instance, in a sandy soil, cesspools were formerly almost universal, and were thickly distributed, so that the earth and often the basements were heavily infiltrated. It is needless to say that most of them have now been removed. A striking example of the pollution of a deep well by leaky cesspools occurred at Liverpool in 1872 . The Dudlow Lane well, in the new red sandstone, 443 feet deep, by continuous pumping, had dried up all the private wells in the neighbourhood. These were afterwards used as cesspools. As a result, the water in the deep well became polluted, and in a few years after its construction it had to be closed. On diverting the drainage from the cesspools, the water was so improved that it was considered safe to resume its use. But Dr. Campbell Brown reports in 1903 that the sandstone rock has become so saturated with the waste water of sewers and streets that Liverpool wells have one after another been disused, only three being still employed for public supply.

In France, and in some places in England, where cesspools are common, they are emptied on the "pneumatic system." A large barrel is exhausted by an air-pump, and a flexible tube connected with it is passed down into the cesspool. On open- 
ing the tap the liquid is forced up into the barrel without effluvium or exposure to air.

In London, cesspools were in general use till I847; thereafter water-closets with a sewerage system discharging directly into the Thames, until later (I865-1875), when intercepting sewers with storage tanks, discharging on the ebb-tide only, were constructed on the north and south banks of the river. In Paris it was not till I 884 that a law was passed ordering the discharge of all sewage directly into the sewers, and the abolition of all fixed or movable cesspools.

In I854 the first British General Board of Health reported that it was far less injurious to the public health to have the refuse of towns in water in the next river than underneath or amidst dwellings. ${ }^{1}$

For many reasons it was necessary to organize a regular system of drainage by sewers. But the difficulty was still not overcome. In the ramifications of these canals a good deal of leakage occurred. The construction of traps to intercept the gases, and of ventilators to remove them, was for a long time, and in many parts still continues to be, very imperfect; in fact, the ventilation question is only now showing signs of solution. The greatest difficulty, however, arose when an outlet had to be found for the immense volume of the sewage of modern towns. To discharge it untreated into rivers, unless of many times the capacity of the sewage and well oxygenated, converted the stream itself into an open sewer. It will be in the memory of many Londoners how black and offensive the Thames was formerly between the bridges, and even in I894 the Seine near Paris was so polluted that Dr. Billings observed "bubbles of gas from the putrefying slime at the bottom escaped from the dark surface, and no fish could live in it," affording an example of a bacterial process working naturally, but imperfectly, and under improper conditions. The Irwell, at Manchester, in i 892, was practically sewage, as the following analysis by Hepworth Collins ${ }^{2}$ will show: Total solids, $160^{\circ} 6$; consisting of organic, $59^{\circ} 6$; mineral, IOI'० ; suspended solids, $29^{\circ} 6$; ammonia free and albuminoid, O*900; chlorine, II*9; oxygen absorbed, $4^{\circ} 90$.

The danger of sewage mud-banks is well shown by an example from America. In I899, after a channel had been

1 A historical summary of the official inquiries in England is given by $\mathrm{Mr}$. Adrian, Assistant-Secretary to the Local Government Board, in the Interim Report of the Royal Commission on Sewage, I902 : Miuutes of Evidence.

${ }_{2}$ Transactions of the Sanitary Institute, 1892, p. 196. 
dredged through a bar of sewage deposit near Port Huron, the typhoid rate at Detroit, 60 miles below, showed a great increase, the first death occurring fifty days later. Professor G. S. Williams calculated that the probable periods required for the flow and distribution of water, for the development of the typhoid bacilli, and for the fever to terminate fatally, would be ten, fourteen, and twenty-five days respectively, making a total of forty-nine days. It was also learnt that every other case of dredging in the St. Clair River, above the Detroit intake, had been followed by a marked increase in the typhoid fever rate in that city.

Lortet ${ }^{1}$ showed that sewage mud-banks frequently contained living pathogenic forms of bacteria. Therefore the fact that thorough sedimentation may take place in a few miles' flow is no guarantee of safety at points below, but may be even a source of the greatest danger in times of flood.

But towns and cities are not the only sources of pollution, as the upper reaches of rivers and streams are contaminated by the filth from farmyards, which is, as a rule, allowed to gradually soak away in an unpaved and undrained yard, or is washed by repeated rains into the nearest water-course or pond.

The substances that have to be dealt with in the purification of sewage may conveniently be arranged under the heads of-

(a) Excretory Substances.-I. Solid fæces consist of nitrogenous partially digested matter, with vegetable non-nitrogenous residues of the food. The former are easily liquefied, but the latter are slow in dissolving, being gradually attacked, chiefly by anaerobic bacteria, and broken down into soluble compounds of fœid odour and into black amorphous flocculi, which slowly deposit as black sludge.

2. Urine is the main source of ammonia, from fermentation of the urea, the proportion of urine being approximately indicated by the content of chlorine in excess of the content of chlorine in the water-supply of the town.

(b) Household Waste.-The larger solids pass to the ash-pits, but the drainage of these, and sometimes their washings by rain, are received into the sewers together with the discharges from sinks. Vegetable refuse yields a liquid which is very foul and fermenting, developing butyric odours and sulphuretted

1 "Pathogenic Bacteria of the Mud of the Lake of Geneva," Centr. f. Bakteriol., ix. 709 . 
hydrogen. Fragments of animal food putrefy and furnish a product allied to that from fæces. The amount of soap-water varies with different days and times; its advent is often conspicuous in sewages of small volume through the white opalescence of the effluent, the alkalinity and odour-the latter occasionally indicating scents or disinfectants. Household discharges other than urine may also temporarily raise the amount of chlorine.

(c) Rain and Storm-water.

(d) Grit and Detritus.

(e) Manufacturing Waste Products.

The entire refuse will in practice be separated into fractions, which will differ in character according to the size of the community and the system of disposal adopted. I shall have occasion in Chapter VIII. to refer to the disposal of the grosser solids.

Street cleansing is also included in the general processes of scavenging, and results in a semi-fluid mixture, which often constitutes an important feature in the sewage. Besides the wear and tear of macadamized roads (less from granite and wood pavements, least from asphalt), together with the sand used to prevent slipperiness, there is the great bulk of horsedroppings, worked up by wheels into slush in wet weather and ground into dust in dry. Four tons of these per day have been stated to be gathered per mile in the Kensington Road. Droppings should be collected fresh, and would then form valuable manure, and the manufacture of much dust would be prevented. In trading streets there is a serious addition of animal and vegetable refuse, and the regulations for removal are often unsatisfactory. ${ }^{1}$ Clothes are fouled by street dirt, which is carried into houses in several ways, and has been shown to result in contamination of food.

The washings of roads contain abraded clothing and wood, castings and emanations of men and animals, and particles of soot, iron, earth, and stone, and are usually more impure, especially from wood pavements, than an average sewage. Samples taken during rain have contained 18 to 30 parts per Ioo, 000 of chlorine, 2 to 3 of albuminoid ammonia in solution, and as much as 80 to I 20 of organic solids suspended and dissolved, all of which were formerly swept into the sewers, and occasioned serious blocking and deposits. Before 1877 there

${ }^{1}$ See a debate on "The State of the London Streets," Sanitary Institute, January I3, I90I. 
were no catch-pits in the City of London except to gullies connected to small pipe-sewers; now, however, nearly all street gullies are formed with catch-pits, which are emptied at intervals by iron spoons and the contents transferred to mud-carts. The chief points to be attended to in these street gullies are: (I) Sufficiency in number and capacity to carry off all surface water. (2) They must not be easily choked, and should be readily cleared. (3) They should be of sufficient capacity to retain sand and road detritus, and should offer the least possible obstruction to traffic. (4) Effectual trapping to prevent the escape of sewer gas.

The wet mud from gullies occasions great difficulty in dealing with town refuse. Economically, it would seem preferable to rush all sewage down without deposition, except detritus, and treat it collectively at the sewage works. In some towns fæces and a certain amount of urine are removed by scavenging, after being deposited in privies, cesspools, or dry closets.

The methods in which refuse matters are kept for a time, as opposed to those in which they are got rid of as soon as possible by water-carriage, are classed together as "conservancy systems." In the country, privies, middens, and cesspools were formerly almost universal, and official reports, even up to the present, give striking details of the state of some of our villages and townships in this particular. In some cases water-carriage is crudely attempted by building the wooden closets over a running stream, which is used by inhabitants for drinking and washing lower down.

By-laws, such as that the privy must be a certain distance from dwellings, or from any well, spring, or stream, with certain provisos as to construction and cleansing, have been found to be frequently inoperative, as, in the words of a sanitary officer, " it is difficult to persuade an owner to spend sufficient money to build a proper privy. He tells you that the property does not pay, and he would prefer to close the houses." Consequently, in settlements built on alluvial ground or porous gravel the soil is frequently saturated with sewage and the wells heavily polluted, resulting at intervals in epidemics and in a general unhealthy state, especially in the children.

As an example of detail, the regulations enacted in 1899 by the Massachusetts Water Board prescribe a limit of " 50 feet from high-water mark of any lake, pond, reservoir, stream, ditch, watercourse, or other open waters used as a source, or 
for the conveyance, storage, or distribution of a water-supply, or flowing directly or ultimately into such water-supply," within which distance the following are specially prohibited to be located, deposited, or discharged: Cesspools, privies, any urinal or water-closet not discharging into a sewer; any human excreta or compost containing them; house-slops, sink-waste, or other polluted water; any stable, pig-sty, hen-house, barnyard, hog-yard, hitching or standing place for horses, cattle, or other animals. The last section would tend to prevent the common and dangerous practice of watering cattle in a stream which is afterwards used as a human water-supply. Other regulations relate to land-manuring, cemeteries, manufacturing waste, sewers, hospitals for infectious diseases, factories for working skins or hair, slaughter-houses, bathing, and cutting ice, in their connection with water-supplies.

The "model by-laws" of the Local Government Board prescribe that-

I. The privy must be at least 6 feet away from any dwelling.

This distance seems much too short, but is, unfortunately, limited by the amount of ground at disposal and the convenience of the householders.

2. That it must be 40 or 50 feet away from any well, spring, or stream.

The distance is not always sufficient to prevent infiltration into sources of water-supply, as, although the passage through 40 or 50 feet of porous soil is ordinarily sufficient to remove danger from polluted runnings, recorded cases, such as Maidstone, Worthing, and many I have found in my own analyses, have proved that, owing to the occurrence of cracks or the formation of channels, specific pollution has been able to traverse a much greater space. So that observance of the regulation would not attain safety without examination and inspection at intervals.

Cases are on record in which the water in a well at a brewery was polluted and the brewings spoilt by percolation of foul matter "through several yards of chalk," and of chalk itself being blackened by the passage of trade effluents through such fissures. ${ }^{1}$

Professor E. Pfuhl ascertained by direct experiment that certain bacteria could be carried in one hour through 26 feet

${ }^{1}$ See also Davies and Tyndale, "Sewage Disposal on Chalk Soils," Fournal of the Royal Sanitary Institute, I904, p. 643. 
of gravel soil ; further, that the supply of a tube-well became contaminated by $B$. prodigiosus when cultures of the latter were inserted into the surface I4 feet from the top of the well. ${ }^{1}$ Characteristic bacilli, like prodigiosus and violaceus, have frequently been used with success for testing filters and leakages. Where the suspected source is accessible, a quicker method is to add a quantity of some easily recognisable substance, either in solution, such as fluorescein, or in suspension, such as solid starch, and to look for it in the water affected. The presence of sewage will also reveal itself in the analysis. I will give an example that has lately come within my own experience of an infiltration that passed through a distance of about half a mile.

A public school on a hill in the country was supplied with a well-water (A), while its sewage was treated on a farm below. Near the lower end of the farm was a well (B), which served as a portion of the town supply. It was sunk in the Hythe beds of the lower greensand, and the ground-water flow was from the hill to the valley. My analyses were as follows :

Parts per 100,000.

I. Chemical.

Total solids

Chlorine ...

Nitrogen as nitrate $\quad \ldots$

Nitrite

Free ammonia ... $\quad \ldots$

Albuminoid ammonia ...

Oxygen consumed ...

Phosphate ... ...

Potassium $\quad \ldots \quad \ldots$
A. Upper Well. B. Lower Well. $29 \cdot 8$

I.78

$2 \cdot 05$

none

0.0046

0.0073

0.013

none

almost absent … heav tistinct

II. Bacterial.

Gelatine plates at $22^{\circ} \mathrm{C}$. Agar plates at $37^{\circ} 5^{\circ} \mathrm{C}$. Carbolic agar ...

Broth tube

$$
\begin{array}{lclc}
\text { C. } & \text { I27 colonies } & \ldots & 454 \text { colonies } \\
\text { no colonies } & \ldots & \text { I35 } \\
\ldots & \left.\begin{array}{c}
\text { clear } \\
\text { no indol }
\end{array}\right\} & \ldots & \begin{array}{c}
\text { turbid } \\
\text { indol reaction }
\end{array}
\end{array}
$$

proving distinctly the access of pollution from the sewage farm.

A somewhat similar case in December, Igor, led me from the chemical results to undertake a special and detailed search for the typhoid organism in the water of a shallow well in Surrey, and I succeeded in isolating typhoid bacilli. ${ }^{2}$

3. Means of access must be provided for the scavenger, so that the filth need not be carried through a dwelling.

1 Zeits. f. Hyg., 1897, p. 549.

2 Analyst, August, 1902. 
4. The privy must be roofed to keep out rain, and provided with ventilating openings as near the top as practicable; that part of the floor of the privy which is not under the seat must be not less than 6 inches above the level of the adjoining ground, must be flagged or paved with hard tiles, and must have an inclination towards the door of the privy of $\frac{1}{2}$ inch to the foot.

A properly laid cement floor is far preferable, as the spaces between tiles or flags, and the unevenness resulting from wear, render them difficult to keep clean and to repair.

5. The next regulation is intended to prevent the accumulation of filth in large pits that are still frequently found behind rows of cottages, and to secure at least a weekly removal.

"The capacity of the receptacle under the seat of the privy must not exceed 8 cubic feet (50 gallons); the floor of this receptacle must be in every part at least 3 inches above the level of the adjoining ground; its sides and floor must be made of impermeable material-they may be flagged or asphalted or constructed of 9 -inch brickwork rendered in cement; the seat may be hinged, or other means of access to the contents of the receptacle must be provided; and the receptacle must not communicate with any drain or sewer."

The chief utility of such regulations is to secure regular inspection and the power of using compulsory measures on definite lines where necessary. Almost all middens and privies are constantly offensive, especially in hot weather; that people, from habit, do not notice the nuisance does not prevent its being injurious to health. A sprinkling of dry cinders or ashes avoids to a certain extent the offensiveness.

The Pail System.-In Rochdale and some Northern towns the excreta are collected in iron or tarred-oak pails provided with lids. They are placed under the seat of the closet, which should be well ventilated; the contents are covered with cinders or ashes, and removed at least once a week, a clean pail being substituted. The contents should be kept as dry as possible, and if it is designed to convert the matter afterwards into manure, nothing but the excreta and a minimum of ashes should be thrown into the pail. Some villages and many Continental towns carry out the pail system more crudely, the pails being collected at night-time, and the contents-hence called " night-soil" - with or without a perfunctory disinfection, emptied into ditches or pits, which when full are covered up with earth. 
With the object of saving the manure, as well as immediately disinfecting the freces, Moule, in I863, introduced the system of earth closets. By a mechanical arrangement each discharge of fæces is covered by a shovelful, about $\mathrm{I} \frac{1}{2}$ pounds, of dry earth. Its absorbent character instantly removes all odour when only a light covering is spread over the solid discharge. The final effect is a bacterial one, by which paper and solid fæces are reduced to a loamy powder, which can be dried and used again several times. Two reasons, however, militate against success :

I. Urine or other moisture ruin the absorbent effect unless a large quantity of earth is used.

2. Owing to the rapid loss of nitrogen and the admixture of earth, the manure is of little value, containing only about $\frac{1}{10}$ per cent. of nitrogen and $\frac{1}{2}$ per cent. of phosphoric acid.

The process is rather a deodorizing than a disinfecting one, as pathogenic organisms are not killed; but for places without a copious water-supply this system has great advantages, and is much superior to privies. Dr. Vivian Poore, in his garden at Andover, elaborated this idea, and showed that it can be worked effectively without nuisance and with very satisfactory crops. As to the kind of earth, sand and gravel are inert, chalk feeble, and dry clay good, while garden soil, loam, and peat give the best results. In public urinals without a watersupply sawdust can be substituted.

The Goux-Thulasne method, called shortly "the Goux," is used frequently on the Continent, and has been worked successfully at Halifax in England. It is a combination of the earth and pail systems. In an iron barrel with handles a slightly conical core is held, and the intervening space packed with dry earth or a pulverulent disinfectant. When the core is withdrawn, a cavity of the same shape is left. These receptacles are carried round on a dray, and left at the houses. At the end of a few days they are collected, shaken so as to cover the excreta with powder, and closed by an air-tight iron lid before removal. Success here again depends on the exclusion as far as possible of moisture. This is a useful method for sickrooms when the excreta must remain for some time.

Places in which "conservancy systems" are in practice are classed together as "midden towns." Their sewage excludes a great part of the human excreta, and is made up of-

(a) Waste water from kitchens, highly charged with decomposable matters and grease. 
(b) Slop water, containing urine, soap, and the dirt from the surface of the body and from clothes.

(c) Liquid refuse and drainage from stables, cowsheds, piggeries, and slaughter-houses (the drainage from stables is very rich in urine; one horse excretes about fifteen times as much urine as an adult man).

(d) Street washings and sweepings.

(e) Urine and water from public urinals, and usually from a few water-closets.

(f) Waste liquors from factories.

(g) Drainage of land, rain and storm water, except where the "separate system" of sewage, which excludes these, is adopted.

The average figures for the sewage for midden and watercloset towns, as given by the Rivers Pollution Commissioners, show no very conspicuous difference in composition, while according to Sir E. Frankland in earth-closet localities a similar uniformity was observed.

PARTS PER IOO,OOO.

\begin{tabular}{|c|c|c|c|c|c|c|c|c|c|}
\hline & \multirow{2}{*}{ Solids. } & \multirow{2}{*}{$\mathrm{Cl}$. } & \multirow{2}{*}{ Org. C. } & \multirow{2}{*}{ Org. N. } & \multirow{2}{*}{$\mathrm{NH}_{3}}$. & \multirow{2}{*}{ 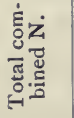 } & \multicolumn{3}{|c|}{ SUSPENDEd Matter. } \\
\hline & & & & & & & Mineral. & Org. & Total. \\
\hline $\begin{array}{l}\text { Midden towns } \ldots \\
\text { Water-closet } \\
\text { towns ... }\end{array}$ & $\begin{array}{l}82 \cdot 4 \\
72 \cdot 2\end{array}$ & $\begin{array}{l}\text { II.54 } \\
\text { Io.66 }\end{array}$ & $\begin{array}{l}4 \cdot 18 \\
4 \cdot 70\end{array}$ & $\begin{array}{l}2 \cdot 97 \\
2 \cdot 20\end{array}$ & $\begin{array}{l}5 \cdot 43 \\
6 \cdot 70\end{array}$ & $\begin{array}{r}6 \cdot 45 \\
7 \cdot 73\end{array}$ & $\begin{array}{l}17 \cdot 8 \\
24 \cdot 2\end{array}$ & $\begin{array}{l}2 \mathrm{I} \cdot 3 \\
20 \cdot 5\end{array}$ & $\begin{array}{l}39^{\circ} \mathrm{I} \\
44^{\circ} 7\end{array}$ \\
\hline
\end{tabular}

Water closets were first introduced in I8Io. In towns on this system the inclusion of solid excreta is balanced by the water used for their carriage, the result being that the two sewages are practically equal as regards subsequent disposal. At Oldham in I900 over 3,600 pan closets were converted to the watercarriage system, and the effect on the town sewage is shown by the following analyses in parts per I00,000:

\begin{tabular}{|c|c|c|c|c|c|c|c|}
\hline \multirow{2}{*}{ Year. } & \multicolumn{3}{|c|}{ Raw Sewage. } & \multicolumn{2}{|c|}{ TANK EFFLUENT. } & \multicolumn{2}{|c|}{ Filtrate. } \\
\hline & $\begin{array}{c}\text { Oxygen } \\
\text { consumed. }\end{array}$ & $\begin{array}{l}\text { Albuminoid } \\
\text { Ammonia. }\end{array}$ & $\mathrm{Cl}$. & $\begin{array}{l}\text { Oxygen } \\
\text { consumed. }\end{array}$ & $\begin{array}{l}\text { Albuminoid } \\
\text { Ammonia. }\end{array}$ & $\begin{array}{l}\text { Oxygen } \\
\text { consumed. }\end{array}$ & $\begin{array}{l}\text { Albuminoid } \\
\text { Ammonia. }\end{array}$ \\
\hline 1900 & $5^{\cdot 23}$ & 0.94 & $9 \cdot 3$ & $2 \cdot 9 I$ & 0.39 & 0.80 & 0.21 \\
\hline I9or & $6 \cdot 17$ & I'I9 & $10 \% 7$ & 3.46 & 0.46 & 0.96 & 0.20 \\
\hline
\end{tabular}


The sewage is about ${ }_{5}$ per cent. stronger; the final effluent shows 16 per cent. rise in the oxygen consumed and 5 per cent. decrease in the albuminoid ammonia. Water-carriage is now general in towns; the chief objection urged against it is the waste of the water-supply. But the amount used per day in closets, being rarely measured by meter, has often been overestimated. If we take the chlorine figures in Frankland's analyses as an approximate measure of the strength of the sewage (see Chapters II. and VI.), we find their ratio to be II 54 to I0 66 , or nearly II to Io-that is to say, an addition of onetenth to the ordinary water-supply has been sufficient to replace the carts and other apparatus, besides the labour, of the pail, earth, and other conservancy systems. Yet at Copenhagen it is stated that in several of the newer houses the water-closet system has been introduced; but there is a yearly tax of $£ 5 \mathrm{I} 2 \mathrm{~s}$. for every seat !

Another method of arriving at the amount used is by the volume of flush. Putting this at 2 gallons, and assuming two uses per day per individual, we reach a figure of 4 gallons, or from $\frac{1}{6}$ to $\frac{1}{10}$ of the water-supply per head. So that the volume of sewage will not be greatly increased, and its dilution may really favour bacterial treatment.

The slop-closet, in which the household slops alone are used to flush away the excreta, effects a saving of water. The relative amounts found in some experiments at Manchester were: Slop-closets $4^{\circ}$, water-closets $8 \cdot 8$, gallons per head of water consumption per day. ${ }^{1}$ The obvious fault is the danger of irregularity.

It may be concluded that wherever an adequate supply of water is attainable the water-carriage system is best.

Reports of medical officers of health-notably those of York and Durham in I900 and of Nottingham in I904-give statistics proving the connection of the incidence of typhoid with midden privies and with pail collection.

In one place in North Devon a Local Government Board report in 1902 states that the midden privies had been emptied only twice in the year, sometimes only once in two years, and occasionally there was a pig-sty in connection. ${ }^{2}$ Many of the houses had no water-closets or privy accommodation. At such houses, in some cases, commodes were kept in the bedrooms,

2 Public Health Engincer, April 5, 1902. 
and the contents were emptied on the beach at irregular intervals. "In other instances people ordinarily use the beach, or, in the event of the tide being up or the weather bad, any other spot convenient. At the shipbuilding yards there are wooden privies built out upon the quay, and used by the workmen employed in the yards. The excrement in these cases drops into the water at high tide, but on the beach at low water."

The infection that is disseminated by flies from collections of fæcal matter has been proved in South Africa and in India, and also by Dr. Martin in England. ${ }^{1}$

Majors Firth and Horrocks ${ }^{2}$ say that "Our investigations as to the vitality of the enteric bacillus in fæcally-fouled soils, whether wet or dry, demonstrate the risks attending the earth or pail closet system of excretal removal." They explain how these portable middens may be, and often are, foci of enteric infection, and conclude that any installations of the kind in towns and large communities are most objectionable.

At Leicester an inclusive estimate of costs gave a preference to water-carriage over the pail system in the ratio of $8 \mathrm{~s} .6 \frac{1}{4} \mathrm{~d}$. to 9s. 5 d. per closet per annum. ${ }^{3}$

\section{Effects of Dilution.}

With conditions that are favourable, the purifying action of rivers is known to be very great. Towns on the banks of rivers of considerable width, and having a fairly constant volume and velocity during all seasons, have discharged their raw sewage into the stream for many years, and investigation has proved that a few miles below the outlet of the sewers there is little or no trace of pollution. Any improvement by mere sedimentation would be on wrong lines, and should not be permitted, as it would result in filling up the river bed and formation of foul dirt banks (p. 4), although the increase in volume of mud-flats in estuaries cannot be attributed to sewage except in isolated and local cases. The amount of solids present in the sewage,

1 See Aldridge, "Enteric in India," Fournal of Hygiene, July, 1902, p. 367 ; also A. W. Martin, Public Health, August, 1905, p. 709 .

2 "Viability of the Enteric Bacillus in Soil and Sewage," Fonmal of the Sanitary Institute, vol. xxiii., part iv., p. 615, I, 03 .

3 "Collection, Disposal, and Utilization of Town Refuse in Leicester," by F. W. Allen, Assistant Borough Surveyor. Fournal of the Sanitary Institutc, vol. xxvi, April, 1904. 
even in large towns, when sedimented in an estuary, commonly forms a very thin film, and evidence of its formation is difficult to find. When, on the other hand, suspended organic matter is slowly removed to the river bed, and is attacked there, in the absence of air and light, by the organisms naturally fitted to the purpose, the products will dissolve and become available for the water bacteria in the river.

The standards of purity for sewage effluents have been frequently modified, ${ }^{1}$ but it would seem that the conditions for safe discharge into a flowing stream depend upon local circumstances now that methods have been found which, by natural agencies, allow us to carry the purification to a rational and harmless stage, when such factors as time, light, volume of oxygen, and various life of a river will be more than sufficient to deal with the effluent.

Pettenkofer, from investigations on the river Isar, at Munich, has concluded that if the sewage never amounts to more than $\frac{1}{15}$ of the river water, and the velocity of the latter is at least equal to that of the former, the raw sewage may be poured into the river without causing pollution.

From observations of the Massachusetts Board of Health, Rudolph Hering fixed a limit to the amount of free ammonia permissible in a stream, and stated that if the flow is less than $2 \frac{1}{2}$ cubic feet per second per I,000 persons (or I gallon per minute per person) "an offence is almost sure to arise," but when it exceeds 7 cubic feet per second per I,000 safety is assured. "In other words, when the free ammonia is greater than 0.12 part per I0o,000, the conditions are probably objectionable." These limits correspond to about 50 volumes of river water to average sewage in England. Mr. Stearns, engineer to the Board, concluded that if the average amounts to more than $\frac{1}{40}$, or 2.5 per cent., of the river water, it cannot be discharged into the river in its raw state; if less than $\frac{1}{40}$ and more than $\frac{1}{130}$, it is doubtful; if less than $\frac{1}{1 \frac{1}{0}}$, it may be admitted without any doubt in its raw state into the river. These conclusions are, of course, empirical, and have not been generally accepted; they would be greatly affected by the amount of solid matter present in the discharge. The sewage in America is much more dilute than in this country, the rivers have greater volume, and the limit is much higher than we have

1 Rideal, "Standards of Purity for Sewage Effluents," British Association Reports, Bristol, I898; also Chapter III. 
found necessary in England. The usual water-supply in the United States is given by Mr. Fuller in $1904,{ }^{1}$ as from 50 to 300 gallons per head, averaging 135 gallons. The mean rainfall is about twice as great as in England.

It is possible, however, to form an estimate as to the amount of sewage which can be dealt with by a flowing stream if one remembers that the bacteria, always naturally abundant in river water, are able by, the aid of the oxygen dissolved from the air to oxidize more or less rapidly any ammonia or organic matter that may be present. That the volume of the sewage and the oxygen required by the organic matter in it as measured by permanganate-i.e., the standard figure of "oxygen consumed"-should bear some relation to the free dissolved oxygen in the river and the flow of the river is obvious. But it is also desirable to take into account the amount of available oxygen as nitrate and nitrite, since it has been proved that, always with the help of bacteria, the oxygen of nitrates and nitrites is available for the burning up of organic matter.

From these factors the following formulæ may be deduced. Where $\mathrm{X}$ is the flow of the stream, $\mathrm{O}$ the amount of dissolved oxygen, $\mathrm{S}$ the volume of effluent, $\mathrm{M}$ the "oxygen consumed" by the latter, $\mathrm{N}$ the available oxygen as nitrate and nitrite, $\mathrm{C}$ the ratio between the amount of oxygen in the stream and that which is required to oxidize the organic matter in the effluent, then the equivalent will be-

$$
\mathrm{XO}=\mathrm{C}(\mathrm{M}-\mathrm{N}) \mathrm{S} .
$$

Where the sewage is fresh, and no nitrates have been formed,

$$
\mathrm{XO}=\mathrm{CMS} \text {. }
$$

If $\mathrm{N}$ be less than $\mathrm{M}, \mathrm{M}-\mathrm{N}=$ the deficit of oxygen in the effluent, requiring to be supplemented by the free oxygen in the river; such an effluent will throw a burden on the river, and cannot be considered in a satisfactory state, and it will be a question of volume and other circumstances whether it can be permitted to be discharged at all. This may be determined by the consideration that if the available oxygen of the river, $\mathrm{XO}$, be greater than the demand $(M-N) S$, there will be a chance of the stream dealing with the inflowing liquid; but if the reverse be the case, foulness will necessarily accrue. Or, as

1 Transactions of the American Society of Civil Engincers, liv., part E, 1905. 
Phelps remarks :1 " Rideal's formula serves to distinguish three possible cases. If $\mathrm{C}$ be negative, the effluent not only will not putrefy by itself, but by virtue of its excess of available oxygen will tend to improve the condition of the stream, if the latter be already polluted. If $\mathrm{C}$ be greater than unity, the effluent will draw upon the oxidizing power of the stream, diminishing the power of the latter to deal successfully with further pollution; but in this case the stream will not itself become foul from the effluent. If $\mathrm{C}$ be positive, but less than unity, the stream will be overburdened by the addition of the effluent, and will become foul."

In the favourable cases where bacteria and algæ are active, and the oxygen of the river is able, by their help, to deal rapidly with the incoming residues, the minimum ratio between the volume of the stream and the volume of effluent that could be allowed to be discharged into it would be indicated by the value of $\mathrm{C}$ in the above equation, which would also approximately denote how far the population might increase before the proportion could be seriously disturbed. The minimum figure will be reduced by the nitrites or nitrates of the river water itself, or the free oxygen which may be present in the effluent. River water often contains about 90 per cent. of its nitrogen in the oxidized form, and when saturated holds about 700 c.c., or, approximately, I gramme of dissolved free oxygen per Ioo litres. These materials for purification require to be supplemented by the agency of the natural bacteria, which, with the almost unlimited exposure and admixture in a flowing river, we may assume as certain to be present. Hence, in theory, comparatively few volumes of a river water will supply the requisite oxygen, which explains the well-known fact that in the lower reaches of a river the dissolved impurity is only a fraction of what has entered in its upper course. Dupré states that, on an average, dilution with thirty volumes of fully aerated water prevents sewage from fouling, and ultimately purifies it. Even a less proportion, in my experience, has been effectual.

For one town, then, on the banks of a large river, or even several towns, if they are sufficiently separated to allow natural recovery and aeration of the stream, the elementary method of discharging the sewage into the water direct has been successful p. 127 .

1 Earle B. Phelps, Amcrican Teclınologv Quarterly, vol. xxviii., June, 1905, 
in the past, with the proviso usually required that by screening, sedimentation, or precipitation, the suspended solids should be prevented from forming mud-banks and deposits of black sludge on the river bed.

Exeter, for example, a city which first gave a name to the septic tank system, has also the historical position of being the first to be sewered, and to discharge the combined sewage, untreated, into a river. As the volume of the Exe is about forty times that of the sewage, at the Local Government Board inquiries no chemical evidence of pollution a few miles below the city was obtainable.

Composition of River Exe, I894.

\begin{tabular}{|c|c|c|c|c|c|}
\hline & & & $\mathrm{NH}_{3}$. & $\begin{array}{l}\text { Alb. } \\
\mathrm{NH}_{3} \text {. }\end{array}$ & \\
\hline $\begin{array}{l}\text { Above Exe Bridge } \\
\text { Below the town at Trew's }\end{array}$ & $9^{\circ} \mathrm{I}$ & $I \cdot I 9$ & 0.007 & 0.016 & 0.29 \\
\hline $\begin{array}{llll}\text { Weir } & \ldots & \ldots & \ldots\end{array}$ & $10 \cdot 85$ & $I \cdot 22$ & 0.025 & 0.023 & 0.30 \\
\hline
\end{tabular}

But in countries thickly populated there is no such opportunity for the recovery of the river. Given even twenty-four hours for the completion of the natural process, the river would arrive at the next town denuded of its oxygen and in an unfit state for the reception of more sewage. The result has been such a condition as I have already mentioned in connection with the Seine and Irwell.

Even in America the distance between the cities and the volume of the waterways has not prevented the discharge of unpurified sewage from causing evils, which became specially acute in periods of drought, as the resulting concentration of refuse in their beds has made some of the rivers nothing better than neglected sewers. Partly as a result of this, and partly because recent court decisions have given encouragement to many persons who are injured by the pollution of streams, State Commissions have been in most places appointed to consider the methods of purification. The longer the delay in taking up this matter, the more expensive it will be when it becomes imperative. ${ }^{1}$ As a rule it is everywhere necessary for sewage to be prepared before it is discharged, and the methods for so doing constitute our present subject.

There can be no doubt that on the efficiency with which refuse matters, and especially human excretal refuse, are removed, the health of towns largely depends, and that im-

${ }^{1}$ Report, State of Connecticut, 1901. 
provement in health coincides with the completion of works of sewage and the introduction of a better water-supply. In Sydney, New South Wales (population 427,000), the deathrate, which was 26.8 per $I, 000$ in $I 875$, has fallen consistently as the sewered area has increased, and was $I 3$ per $I, 000$ in I902. At Melbourne it was $25^{\circ} 8$ in 1875 and $14^{\circ} 4$ in I9oo. In other towns similar reductions have been shown, and in most cases alterations or improvements in the methods of sewage disposal seem to be the main, if not the only, determining factor.

\section{Tidal Discharge.}

The Rivers Pollution Prevention Act, 1876, provides that before discharging domestic sewage or trade refuse water into any "stream" the public or private persons responsible shall duly see that "the means used for rendering harmless any sewage matter or poisonous, noxious, or polluting solid or liquid matter falling or flowing or carried into any stream are the best or only practicable and available means under the circumstances." The Act defines that "a stream includes the sea to such extent, and tidal waves to such point, as may, after local inquiry and on sanitary grounds, be determined by the Local Government Board . . . save as aforesaid, it includes rivers, streams, canals, lakes, and watercourses ;" virtually, the Act permits the discharge of crude sewage into the sea at extreme low-water mark, and into a tidal river with sufficient volume of dry-weather flow and tidal rise. The Local Government Board's report on sewage disposal of 1876 provided that "towns situate on the sea-coast or on tidal estuaries may be allowed to turn sewage into the sea or estuaries below the line of low water, provided that no nuisance is caused, and that such mode of getting rid of sewage may be allowed and justified on the score of economy."

Many seaside towns discharge their sewage on the foreshore near low-water mark, but a great portion is returned by the tides, and the serious nuisance often occasioned has led to a widespread agitation against the practice. Sea water is not a satisfactory medium for the purification of crude sewage, partly because it contains a comparatively small number of water bacteria, but mainly because the tidal disturbances prevent the suspended organic matter from undergoing the sedimentation which allows organisms growing in the absence of air and light to do their necessary resolving work. 
Some forty-six towns in England report in Igoo that they are able by their situation to discharge their sewage direct into the sea or into strong tidal rivers. Several have for various reasons inaugurated or are experimenting upon bacterial treatment.

The application of the law has varied even in places close together. As an instance, the Rathmines suburbs of Dublin, with a population of 60,000 , have been permitted for more than twenty years to discharge their sewage direct into Dublin Harbour during the first five hours of the ebb-tide, without any previous treatment except an imperfect sedimentation, whereas the city itself has had to lay down works for purifying its sewage by chemical precipitation. The alleged nuisance from the Rathmines outfall has been disputed, ${ }^{1}$ and from Dr. Adeney's analyses of the sewages and sea waters, especially with reference to the dissolved $\mathrm{N}, \mathrm{O}$, and $\mathrm{CO}_{2},{ }^{2}$ it was argued that the pollution was not serious. Parry and Adeney drew from their results the following principles as to the discharge of sewage into a tidal estuary similar to that of the Liffey:

"I. The discharge should be made into a definite deep water channel with a current setting seaward.

"2. The width of the water in the deep channel at low tide must be sufficient for the adequate dilution of the sewage.

"3. The whole of the sewage should reach open water before the turn of the tide.

" 4. The heavy solids and the floating matter should be separated from the sewage before its discharge. This can be done efficiently by simple subsidence and screening."

But it was precisely because these conditions had been only partly fulfilled that great dissatisfaction arose, leading to much litigation and to an inquiry by a Committee of the House. of Commons in I905, which has not yet led to a decision.

Sewage is lighter than sea water, therefore the discharge should always be below the surface, in order that mixture may occur by the agitation. ${ }^{3}$

It is necessary by careful float experiments to determine the directions of the currents round the shore, and these tests should be repeated at intervals, since changes are likely to occur. That

1 Parry and Adeney on "The Discharge of Sewage into a Tidal Estuary," Proceedings of the Institute of Civil Engineers, vol. cxlvii., part i., I902.

2 See Chapter III.

3 "On the Hydraulic Conditions of Discharge," vide G. B. Latham, Sanitary Record, September 14, 1905. 
float experiments, however, may be misleading is shown by an instance at Sydney, New South Wales, where it was found that the loats at the proposed Bondi outfall site drifted northward, whereas when the sewage came to be discharged it flowed to the south-east in a black stream, "widening until it gets about half a mile from the outlet, when it disappears." It is suggested that the influence of the air currents on the floats was greater than that of the water currents. ${ }^{1}$ This would show the utility of the deep-weighted tube float we recommend in the next chapter.

In many towns the sewage is stored in a culvert or intercepting sewer, or in a covered storage tank, and let out on the ebbing tide, with the object of being carried well out to sea before the return. But the disposal of crude sewage in this way is never satisfactory, especially where shellfish are gathered from the coast. Previous treatment by an approved method should always be adopted, and probably in the future will be made compulsory. In some places the sludge is intercepted in large catchpits before entering the tank, and either disposed of on land or carried out to sea.

It is rarely possible to extend a pipe line across the foreshore, and to discharge the sewage into deep water, even at the lowest ebb of spring tides, at a point where the tidal current has a seaward set, as has been lately accomplished with great expense and difficulty by the Llandudno Urban District Council. Here it was necessary to cover the pipes with a great quantity of stone for their protection, and the original estimate of cost was greatly exceeded. Where the geographical conditions are not so favourable, as in estuaries, and also on the almost unbroken shore-line of many coasts, there is almost a certainty that the sewage will be retained in the neighbourhood, or will be brought back by eddies and currents even if carried out some distance, as has happened at Brighton. In America, where the infection of oyster-beds by sewage has been a question of importance for the last eleven years, the great majority of cities discharge untreated sewage. ${ }^{2}$ Thus, out of an urban population of $28,000,000,6,500,000$ discharged raw sewage into the sea, harbours, or estuaries, 20,500,000 into inland streams or lakes, and only about $\mathrm{I}, 000,000$ had sewage purification works.

\footnotetext{
1 Davis on "Sewerage Systems of Sydney, N.S.W.," Proceedings of the Institute of Civil Enginecrs, 1902.

${ }^{2}$ Fuller, Transactions of the American Society of Civil Engincers, vol. liv., part E, 1905, pp. I48, I49.
} 
Methods of collecting samples-Gauging the flow-Samples should be collected proportional to the flow and corresponding to one another-Weirs-Floats-V notch-Meters-Hourly variation of sewage-Official methods of collection and analysis-Recommendations of the British Association-Determinations of total solids - Chlorine - Free and albuminoid ammonia-Oxygen consumed-Mineral constituents.

SAMPLES for analysis should be taken proportionately to the flow, and not in equal quantities, as is often done. The method of working that I have adopted is as follows :

A sample is collected and a gauging taken every hour, or, if possible, every half-hour, by any one of the following methods. The fluid may be passed over a sharp-edged horizontal weir, and the depth of liquid flowing over the weir measured in inches by means of a post placed behind. By Hawksley's formula, if $h=$ this depth, $l$ the length of the weir in feet, then $Q$, the flow in gallons per second, will be obtained by

$$
\mathrm{Q}=\frac{1 \mathrm{~h} \sqrt{\mathrm{h}}}{2}
$$

From these data tables are calculated giving the flow in gallons corresponding to decimals of an inch.

A practical difficulty in measuring the volume of raw sewage is that weirs or constrictions of any kind cause an obstruction to the flow, and therefore clogging or deposits. Where the channel admits of access at several points an estimate of the discharge can be obtained without retardation by the float method. A piece of wood is released at one point, and the time required for its appearance at another point is registered; the distance being known, the surface velocity of the stream is ascertained in feet per second. The surface velocity in the centre of a current is greater than the mean velocity of the whole, and correction for this variability is somewhat uncertain. A nearer approach to the average can be attained by using as the traveller a piece of glass tubing closed at the lower end 
and weighted with shot or mercury, so as to sink about threequarters of its depth, the upper end carrying a flag to make it conspicuous. Several preliminary trials should be made as to the length of the tube that can pass without obstruction, and in some cases a string may be attached for recovery, with care to avoid error. Formulæ for calculating the mean velocity from the surface velocity will be found in engineering books; in general, the volume of discharge is obtained by multiplying the mean sectional area of the channel (found by measuring at several parts) by the mean velocity in feet per second.

A method which dispenses with formulæ, and is quite accurate where applicable, is to measure the time in seconds required to fill a pail or zinc bath of known capacity. In a recent instance my average gauging by the pail was 15,886 gallons per twentyfour hours; the official figures afterwards received were $15,57 \mathrm{I}$.

A simple rule to remember is that cubic feet per minute $\times 9,000=$ gallons per twenty-four hours.

An effluent is easier to measure on account of the absence of

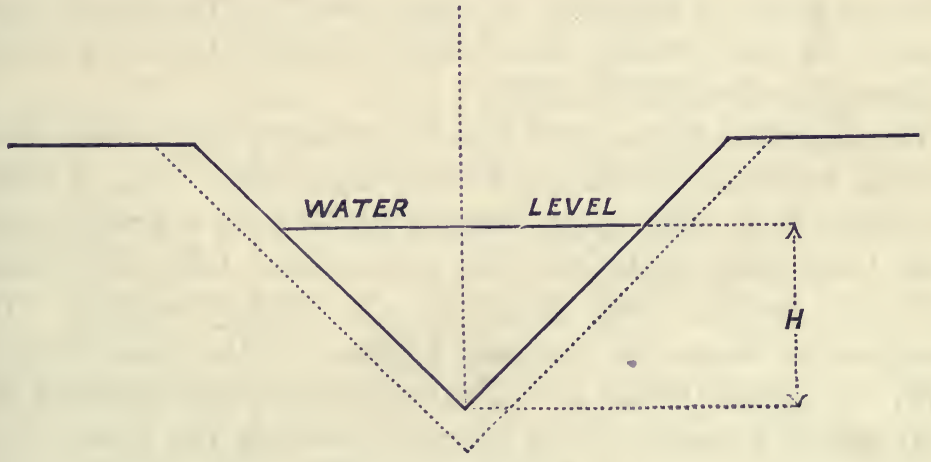

FIG. I. -V Norch.

solid matter. It may be made to flow through a $\mathbf{V}$ notch at an angle of 90 degrees in the side of a tank. The area of the orifice will be half the square of the side from the vertex to the water level. The amount of the effluent can be calculated, or may be determined experimentally, and tables prepared giving volumes of flow corresponding to the level of liquid in eighths of an inch. ${ }^{1} \quad$ The actual $\mathbf{V}$ notch should be a thin plate of zinc or thickly-galvanized iron; or, if of wood, it must be sawn to a clean bevel, with the sharp edge up-stream.

This form of notch has an advantage over a square weir, since, however small the flow of water, there is always a readable quantity. The variation in the area of water flowing 
in a $\mathbf{V}$ notch is as the square of the height from the vertex, and the volume discharged is given by the formula

$$
\mathrm{Q}=0.305 \mathrm{H} \frac{5}{2},
$$

where $Q=$ cubic feet per minute and $H$ the height in inches from the vertex of the notch up to still-water level. Thomson found that when $\mathrm{H}=\mathrm{I} 2$ inches the flow was $2^{\circ} 54$ cubic feet per second, so that by measuring $\mathrm{H}$ in feet, taking this figure to the $\frac{5}{2}$ power, and multiplying by 2.54 , the flow in cubic feet per second is obtained.

The formula in general use for discharge over a weir is $\mathrm{C}=3.5 \dot{6} \dot{6} \sqrt{\mathrm{H}^{3}}$ if the sewage above the weir is not in motion, or $3{ }^{\circ} \dot{6} \dot{6} \sqrt{\mathrm{H}^{3}+0^{\circ} 035 \mathrm{~V}^{2} \mathrm{H}^{2}}$ if it is in motion, $\mathrm{H}$ being the height of the surface of the sewage above the edge of the weir, $\mathrm{V}$ being the velocity in feet per second of sewage approaching the weir, and $\mathrm{C}$ being the cubic feet per second discharged over each foot in width of the weir.

In those cases in which a permanent record of the flow through pipes is required, a meter like the Parkinson's low pressure or the Venturi will, if read at fixed intervals, give the quantity of sewage dealt with.

The diagrams (Figs. 2 and 3 ) show various arrangements of the Venturi meter in connection with sewage works. Fig. 2 shows the meter in a closed pipe, running on so steep a gradiant that when the flow is small the pipe would not run full. To obviate this the tube has been placed in an inverted siphon. The recorder is, where the pressure permits, of the water column type, the result being given either by counter showing the total quantity passed, or by diagram showing the rate of flow at any time, or by a combined recorder giving both results. Fig. 3 illustrates a method of installing the instrument in an open channel. The tube is sunk below the low-water line to insure its being full at all times, and a low concrete dam is built across the channel, into which the mouth of the tube is placed. It is possible to employ the Venturi meter in the same works in both of the ways previously described, some of the meters being connected to closed pipes and others being placed in open channels.

A new form of water-meter of the proportional displacement type, known as the "Premier" meter, is in use in the United States. It consists of a large and a small Venturi tube merging into one at their throats, and having a common down-stream 
Table of the Flow of Water in the Right-angled V Notch.

\begin{tabular}{|c|c|c|c|c|c|c|c|c|c|c|c|}
\hline 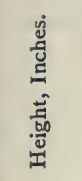 & 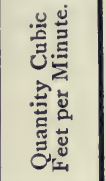 & 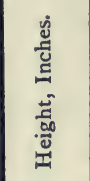 & 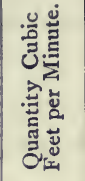 & 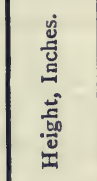 & 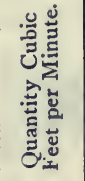 & 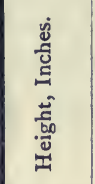 & 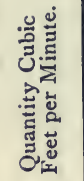 & 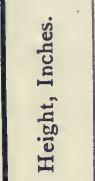 & 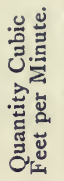 & 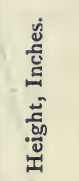 & 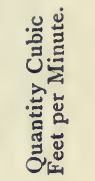 \\
\hline $\begin{array}{l}0.25 \\
0.375 \\
0.50\end{array}$ & $\begin{array}{l}0.0095 \\
0.0263 \\
0.054\end{array}$ & $\begin{array}{l}5.125 \\
0.25 \\
0.375 \\
0.50\end{array}$ & $\begin{array}{l}18.13 \\
19.26 \\
20.43 \\
21.64\end{array}$ & $\begin{array}{l}\text { IO.125 } \\
0.25 \\
0.375 \\
0.50\end{array}$ & $\begin{array}{r}99^{\circ} 5 \\
102^{\circ} 6 \\
105^{\circ} 7 \\
109^{\circ} 0\end{array}$ & $\begin{array}{c}\text { I5.125 } \\
0.25 \\
0.375 \\
0.50\end{array}$ & $\begin{array}{l}27 I^{\circ} I \\
277^{\circ} \mathrm{O} \\
282^{\circ} 5 \\
288^{\circ} 5\end{array}$ & $\begin{array}{l}20.125 \\
0.25 \\
0.375 \\
0.50\end{array}$ & $\begin{array}{l}554 \\
563 \\
571 \\
580\end{array}$ & $\begin{array}{l}25 \cdot 5 \\
26 \\
27 \\
28\end{array}$ & $\begin{array}{l}\text { IOOI } 5 \\
\text { I05 I } \\
\text { I } 55 \\
\text { I } 265\end{array}$ \\
\hline $\begin{array}{l}0.625 \\
0.75 \\
0.875 \\
I \cdot 00\end{array}$ & $\begin{array}{l}0.094 \\
0.143 \\
0.218 \\
0.305\end{array}$ & $\begin{array}{l}0.625 \\
0.75 \\
0.875 \\
6.00\end{array}$ & $\begin{array}{l}22 \cdot 89 \\
24^{\cdot} \cdot 18 \\
25^{\circ} \cdot 52 \\
26 \cdot 89\end{array}$ & $\begin{array}{l}0.625 \\
0.75 \\
0.875 \\
\text { I } 00\end{array}$ & $\begin{array}{l}\text { II } 2^{\circ} 2 \\
\text { II } 5^{\circ} 6 \\
\text { II } 8 \cdot 8 \\
\text { I } 22^{\circ} 4\end{array}$ & $\begin{array}{c}0.625 \\
0.75 \\
0.875 \\
16.00\end{array}$ & $\begin{array}{l}294^{\circ} \mathrm{I} \\
300^{\circ} 3 \\
306^{\circ} 5 \\
312^{\circ} 0\end{array}$ & $\begin{array}{l}0.625 \\
0.75 \\
0.875 \\
21 \cdot 00\end{array}$ & $\begin{array}{l}589 \\
598 \\
607 \\
616\end{array}$ & $\begin{array}{l}31 \\
32\end{array}$ & $\begin{array}{l}\text { I632 } \\
\text { I } 767\end{array}$ \\
\hline $\begin{array}{l}I \cdot I 25 \\
I \cdot 25 \\
I \cdot 375 \\
I \cdot 5\end{array}$ & $\begin{array}{l}0.409 \\
0.533 \\
0.676 \\
0.840\end{array}$ & $\begin{array}{l}0.125 \\
0.25 \\
0.375 \\
0.50\end{array}$ & $\begin{array}{l}28 \cdot 33 \\
29 \cdot 79 \\
31 \cdot 29 \\
32 \cdot 85\end{array}$ & $\begin{array}{l}0.125 \\
0.25 \\
0.375 \\
0.50\end{array}$ & $\begin{array}{l}\text { I25.8 } \\
\text { I } 29.5 \\
\text { I } 33^{\circ} \text { I } \\
\text { I } 36^{\circ} 8\end{array}$ & $\begin{array}{l}0.125 \\
0.25 \\
0.375 \\
0.50\end{array}$ & $\begin{array}{l}3 \mathrm{I} 8 \cdot 7 \\
324^{\circ} 7 \\
3 \mathrm{I}^{\circ} \cdot 2 \\
337^{\circ} 3\end{array}$ & $\begin{array}{l}0.125 \\
0.25 \\
0.375 \\
0.50\end{array}$ & $\begin{array}{l}626 \\
635 \\
644 \\
654\end{array}$ & $\begin{array}{l}33 \\
34 \\
35\end{array}$ & $\begin{array}{l}1900 \\
2056 \\
2210\end{array}$ \\
\hline $\begin{array}{l}I \cdot 625 \\
I \cdot 75 \\
I \cdot 875 \\
2 \cdot 00\end{array}$ & $\begin{array}{l}I \cdot 027 \\
I \cdot 23 \\
I \cdot 43 \\
I \cdot 73\end{array}$ & $\begin{array}{l}0.625 \\
0.75 \\
0.875 \\
7.00\end{array}$ & $\begin{array}{l}34^{\circ} \cdot{ }^{6} \\
36 \cdot 10 \\
37^{\circ} 80 \\
39^{\circ} .54\end{array}$ & $\begin{array}{l}0.625 \\
0.75 \\
0.875 \\
12.00\end{array}$ & $\begin{array}{l}\mathrm{I} 40^{\circ} 4 \\
\mathrm{I} 44^{\circ} 4 \\
\mathrm{I} 4^{\circ} \mathrm{I} \\
\mathrm{I} 5^{\circ} \mathrm{I}\end{array}$ & $\begin{array}{c}0.625 \\
0.75 \\
0.875 \\
17.00\end{array}$ & $\begin{array}{l}344^{\circ} 4 \\
350^{\circ} 2 \\
357^{\circ} 0 \\
363^{\circ} 4\end{array}$ & $\begin{array}{c}0.625 \\
0 \cdot 75 \\
0.875 \\
22 \cdot 00\end{array}$ & $\begin{array}{l}663 \\
673 \\
682 \\
692\end{array}$ & $\begin{array}{l}37 \\
38 \\
39 \\
40\end{array}$ & $\begin{array}{l}2540 \\
2715 \\
2897 \\
3086\end{array}$ \\
\hline $\begin{array}{l}2 \cdot 125 \\
2 \cdot 25 \\
2 \cdot 375 \\
2 \cdot 5\end{array}$ & $\begin{array}{l}2 \cdot 0 I \\
2 \cdot 32 \\
2 \cdot 66 \\
3 \cdot 01\end{array}$ & $\begin{array}{l}0.125 \\
0.25 \\
0.375 \\
0.50\end{array}$ & $\begin{array}{l}4 \mathrm{I}^{\mathrm{I}} \cdot 33 \\
43^{\circ} \mathrm{I} 7 \\
45^{\circ} \cdot 05 \\
4^{\circ} \cdot 98\end{array}$ & $\begin{array}{l}0.125 \\
0.25 \\
0.375 \\
0.50\end{array}$ & $\begin{array}{l}156^{\circ} 0 \\
160^{\circ} 2 \\
164^{\circ} 2 \\
168^{\circ} .5\end{array}$ & $\begin{array}{l}0.125 \\
0.25 \\
0.375 \\
0.50\end{array}$ & $\begin{array}{l}370^{\circ} \tau \\
376^{\circ} 9 \\
384^{\circ} 1 \\
390^{\circ} 8\end{array}$ & $\begin{array}{l}0.125 \\
0.25 \\
0.375 \\
0.50\end{array}$ & $\begin{array}{l}702 \\
712 \\
722 \\
732\end{array}$ & $\begin{array}{l}4 \mathrm{I} \\
42 \\
43 \\
44 \\
45\end{array}$ & $\begin{array}{l}3283 \\
3487 \\
3698 \\
3917 \\
4 \mathrm{I} 43\end{array}$ \\
\hline $\begin{array}{l}2 \cdot 625 \\
2 \cdot 75 \\
2 \cdot 875 \\
3 \cdot 00\end{array}$ & $\begin{array}{l}3.41 \\
3.82 \\
4.27 \\
4^{\circ} 75\end{array}$ & $\begin{array}{l}0.625 \\
0.75 \\
0.875 \\
8.00\end{array}$ & $\begin{array}{l}4^{8} \cdot 97 \\
5^{\circ} \cdot 0 \\
53^{\circ} \mathrm{I} \\
55^{\circ} 2\end{array}$ & $\begin{array}{c}0.625 \\
0.75 \\
0.875 \\
13.00\end{array}$ & $\begin{array}{l}\text { I } 72^{\circ} 6 \\
\text { I } 77^{\circ} 0 \\
\text { I } 81^{\circ} 2 \\
\text { I } 85^{\circ} 8\end{array}$ & $\begin{array}{l}0.625 \\
0.75 \\
0.875 \\
18.00\end{array}$ & $\begin{array}{l}397 \\
404^{\circ} 9 \\
4120^{\circ} \\
4^{1} 9^{\circ} 0\end{array}$ & $\begin{array}{l}0625 \\
0 \circ 75 \\
0.875 \\
23^{\circ} 00\end{array}$ & $\begin{array}{l}743 \\
753 \\
763 \\
774\end{array}$ & $\begin{array}{l}46 \\
47 \\
48 \\
50\end{array}$ & $\begin{array}{l}4377 \\
4619 \\
4869 \\
5092\end{array}$ \\
\hline $\begin{array}{l}3 \cdot 125 \\
3 \cdot 25 \\
3 \cdot 375 \\
3 \cdot 5\end{array}$ & $\begin{array}{l}5 \cdot 27 \\
5 \cdot 8 \mathrm{t} \\
6 \cdot 38 \\
6 \cdot 99\end{array}$ & $\begin{array}{l}0.125 \\
0.25 \\
0.375 \\
0.50\end{array}$ & $\begin{array}{l}57 \cdot 4 \\
59^{\circ} \cdot 6 \\
6 I^{\circ} 9 \\
64^{\circ} \cdot 2\end{array}$ & $\begin{array}{l}0.125 \\
0.25 \\
0.375 \\
0.50\end{array}$ & $\begin{array}{l}190^{\circ} \mathrm{I} \\
194^{\circ} 9 \\
199^{\circ} 3 \\
204^{\circ} 2\end{array}$ & $\begin{array}{l}0.125 \\
0.25 \\
0.375 \\
0.50\end{array}$ & $\begin{array}{l}427 \\
434 \\
442 \\
449\end{array}$ & $\begin{array}{l}0.125 \\
0.25 \\
0.375 \\
0.50\end{array}$ & $\begin{array}{l}784 \\
795 \\
806 \\
817\end{array}$ & $\begin{array}{l}52 \\
54 \\
56 \\
58\end{array}$ & $\begin{array}{l}5947 \\
6536 \\
7158 \\
7814\end{array}$ \\
\hline $\begin{array}{l}3 \cdot 625 \\
3^{\cdot} \cdot 75 \\
3^{\cdot} \cdot 875 \\
4^{\circ} .00\end{array}$ & $\begin{array}{l}7 \cdot 63 \\
8 \cdot 30 \\
9 \cdot 11 \\
9 \cdot 76\end{array}$ & $\begin{array}{l}0.625 \\
0.75 \\
0.875 \\
9.00\end{array}$ & $\begin{array}{l}66 \cdot 6 \\
69 \cdot I \\
7 I \cdot 6 \\
74^{\circ} I\end{array}$ & $\begin{array}{l}0.625 \\
0.75 \\
0.875 \\
14.00\end{array}$ & $\begin{array}{l}208 \cdot 8 \\
213 \cdot 8 \\
218.8 \\
223^{\circ} 7\end{array}$ & $\begin{array}{c}0.625 \\
0.75 \\
0.875 \\
19.00\end{array}$ & $\begin{array}{l}457 \\
464 \\
472 \\
480\end{array}$ & $\begin{array}{c}0.625 \\
0.75 \\
0.875 \\
24^{\circ} 00\end{array}$ & $\begin{array}{l}827 \\
838 \\
849 \\
861\end{array}$ & $\begin{array}{l}62 \\
64 \\
66\end{array}$ & $\begin{array}{r}9231 \\
9994 \\
\text { I0793 }\end{array}$ \\
\hline $\begin{array}{l}4^{\circ} 125 \\
4^{\circ} \cdot 25 \\
4^{\circ} 375 \\
4^{\circ} 50\end{array}$ & $\begin{array}{l}\text { I0:54 } \\
\text { II } \cdot 35 \\
\text { I2.2I } \\
\text { I } 3 \cdot 10\end{array}$ & $\begin{array}{l}0.125 \\
0.25 \\
0.375 \\
0.50\end{array}$ & $\begin{array}{l}76 \cdot \mathrm{I} \\
79 \cdot 4 \\
82 \cdot \mathrm{I} \\
84 \cdot 8\end{array}$ & $\begin{array}{l}0.125 \\
0.25 \\
0.375 \\
0.50\end{array}$ & $\begin{array}{l}228 \cdot 5 \\
233 \cdot 8 \\
238 \cdot 8 \\
244 \cdot 2\end{array}$ & $\begin{array}{l}0.125 \\
0.25 \\
0.375 \\
0.50\end{array}$ & $\begin{array}{l}488 \\
496 \\
5 \mathrm{C} 4 \\
5 \mathrm{I} 2\end{array}$ & $\begin{array}{l}0.125 \\
0.25 \\
0.375 \\
0.50\end{array}$ & $\begin{array}{l}872 \\
883 \\
895 \\
907\end{array}$ & $\begin{array}{l}72 \\
75\end{array}$ & $\begin{array}{l}13416 \\
14858\end{array}$ \\
\hline $\begin{array}{l}4^{\cdot 625} \\
4^{\cdot} \cdot 75 \\
4^{\cdot} \cdot 875 \\
5^{\circ} \cdot 00\end{array}$ & $\begin{array}{l}14.03 \\
14.99 \\
16.00 \\
17.05\end{array}$ & $\begin{array}{l}0.625 \\
0.75 \\
0.375 \\
10.0\end{array}$ & $\begin{array}{l}87.7 \\
90.5 \\
93.5 \\
96.4\end{array}$ & $\begin{array}{l}0.625 \\
0.75 \\
0.875 \\
15.00\end{array}$ & $\begin{array}{l}249^{\circ} 5 \\
254^{\circ} \cdot 8 \\
260^{\circ} 1 \\
265^{\circ} 8\end{array}$ & \begin{tabular}{|c|}
0.625 \\
0.75 \\
0.875 \\
20.00
\end{tabular} & $\begin{array}{l}520 \\
529 \\
537 \\
546\end{array}$ & $\begin{array}{c}0.625 \\
0.75 \\
0.875 \\
25.00 \\
0.25\end{array}$ & $\begin{array}{l}918 \\
929 \\
941 \\
953 \\
977\end{array}$ & $\begin{array}{r}81 \\
84 \\
87 \\
90 \\
96 \\
\text { IOO }\end{array}$ & $\begin{array}{l}\text { I } 8010 \\
19724 \\
21533 \\
23437 \\
2754 \text { I } \\
30500\end{array}$ \\
\hline
\end{tabular}




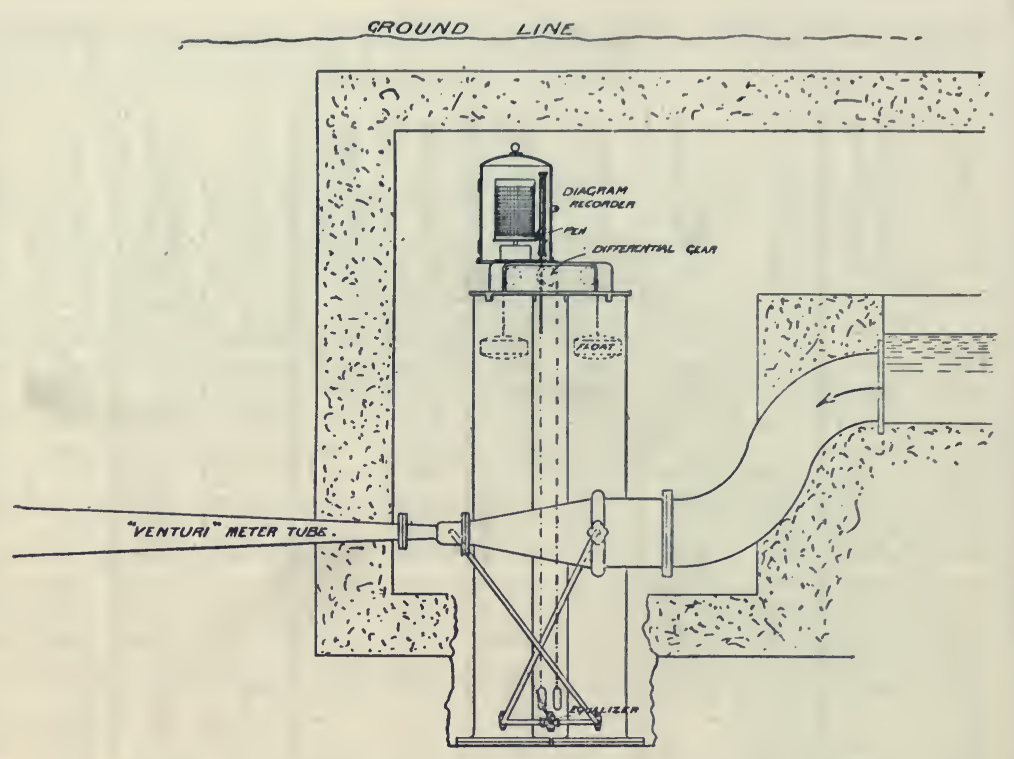

Fig. 2.-Venturi Meter in Closed Pipe.

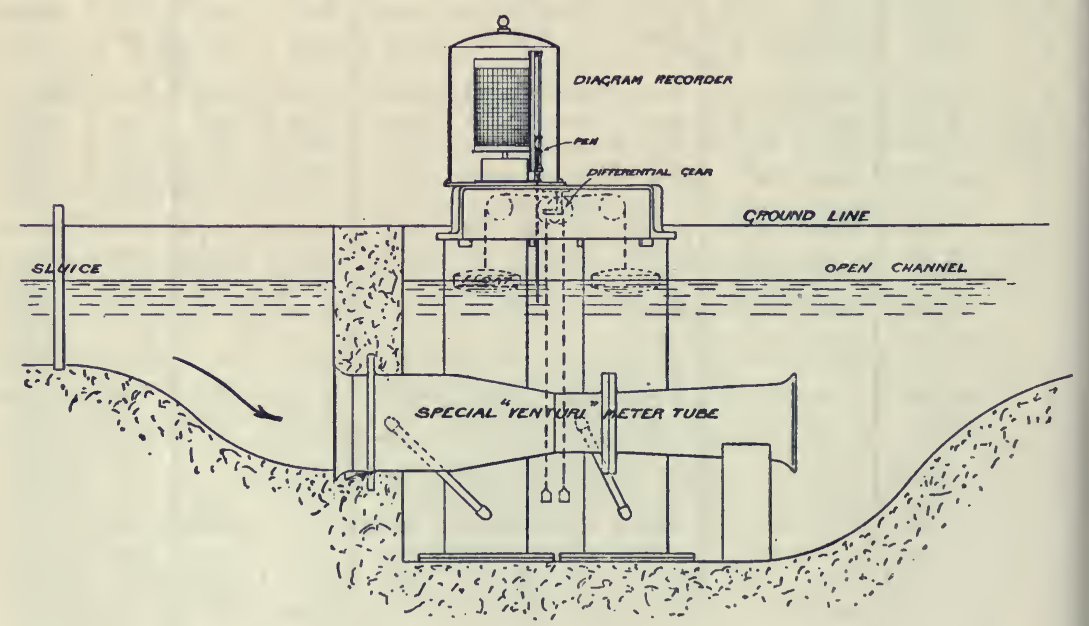


cone, with a recording apparatus placed on the pipe leading to the smaller Venturi, but measuring the total flow through both tubes, which is equivalent to that of the main. The accuracy of the register can be tested at any time by opening a connection on the outlet side, so that the flow can be diverted through a hose into a measuring tank.

Samples of effluents should be taken corresponding to the raw sewage. This is sometimes rendered difficult by the time of passage through the tanks or filters not being accurately known. The capacities of the beds and tanks and the flow at the time of sampling will, in most cases, give the necessary data, but even then allowance must be made for streaming. I have found the only accurate method is to spread the sampling over successive days, choosing different times each day until the cycle of twentyfour hours is complete; in this way, even on small systems, irregular discharges do not cause error.

\section{Collection of SAMPles}

in a representative manner requires considerable labour and attention. Many published analyses are based on specimens taken casually, and the opinions formed are of little or no value. The sewage is continually flowing, but varies both in volume and quality from hour to hour. I found, for instance, in a town sewage-

PARTS PER IOO,OOO.

Time and Circumstances.

Dry weather, no rain :

Io a.m to 5 p.m. 6 p.m. to I a.m. 2 a.m to 9 a.m.

\begin{tabular}{|c|c|c|c|c|c|c|c|}
\hline 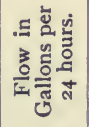 & 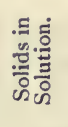 & $\dot{U}$ & 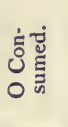 & $\begin{array}{l}\dot{\infty} \\
\dot{z} \\
\dot{z} \\
\dot{z}\end{array}$ & 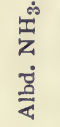 & 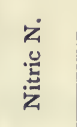 & 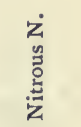 \\
\hline 54,000 & $\left\{\begin{array}{l}77^{\circ} 5 \\
45^{\circ} \mathrm{O} \\
34^{\circ} \mathrm{O}\end{array}\right.$ & $\begin{array}{r}12 \cdot 25 \\
6 \cdot 25 \\
4 \cdot 25\end{array}$ & $\begin{array}{l}7^{\circ} 23 \\
6^{\circ} 91 \\
5^{\circ} 57\end{array}$ & $\begin{array}{l}8^{\circ} \mathrm{O} \\
2^{\circ} 90 \\
0^{\circ} 90\end{array}$ & $\begin{array}{l}I \cdot 5 \\
0 \cdot 6 \\
0 \cdot 35\end{array}$ & $\begin{array}{c}\text { None. } \\
\text { ", }\end{array}$ & $\begin{array}{c}\text { None. } \\
\text { ", } \\
\text { ", }\end{array}$ \\
\hline
\end{tabular}

Total chlorine, 4 I pounds per day.

Heavy storm :

Io a.m. to 5 p.m. 6 p.m. to I a.m. 2 a.m. to 9 a.m.

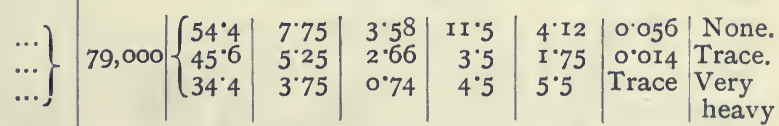

Total chlorine, 44 pounds per day.

Physical Characters.-Dry weather: Thick and fotid; fragments of paper and lumps of fæcal matter abundant.

Heavy storm: Turbid, yellow-brown; earthy odour.

In the morning urine is prominent, as shown by the chloride and by other signs; later on, soapy water makes its appearance, 
with a white scum of fatty lime salts that tends to clog filters and leave a greasy deposit on channels. Fixed alkalinity also appears, with an increase in the sodium salts; subsequently the sulphuretted odour of vegetable washings is evident, and the liquid may even become temporarily acid. The road detritus and heavier matters are usually caught in a grit chamber, while paper, string, and animal and vegetable fragments are commonly carried forward with the mixture, which rapidly becomes black, alkaline, and putrescent. The effect of mere mechanical straining or filtration is shown by the following table of averages of thirteen hourly samples from 6 a.m. to 6 p.m. from different sewers of a large town on the water-closet system.

The suspended solids contain about one-third the organic nitrogen and half the carbonaceous matter of the sewage.

Table showing Variation in Quality of Sewage in Different Sewers of the Same Town.

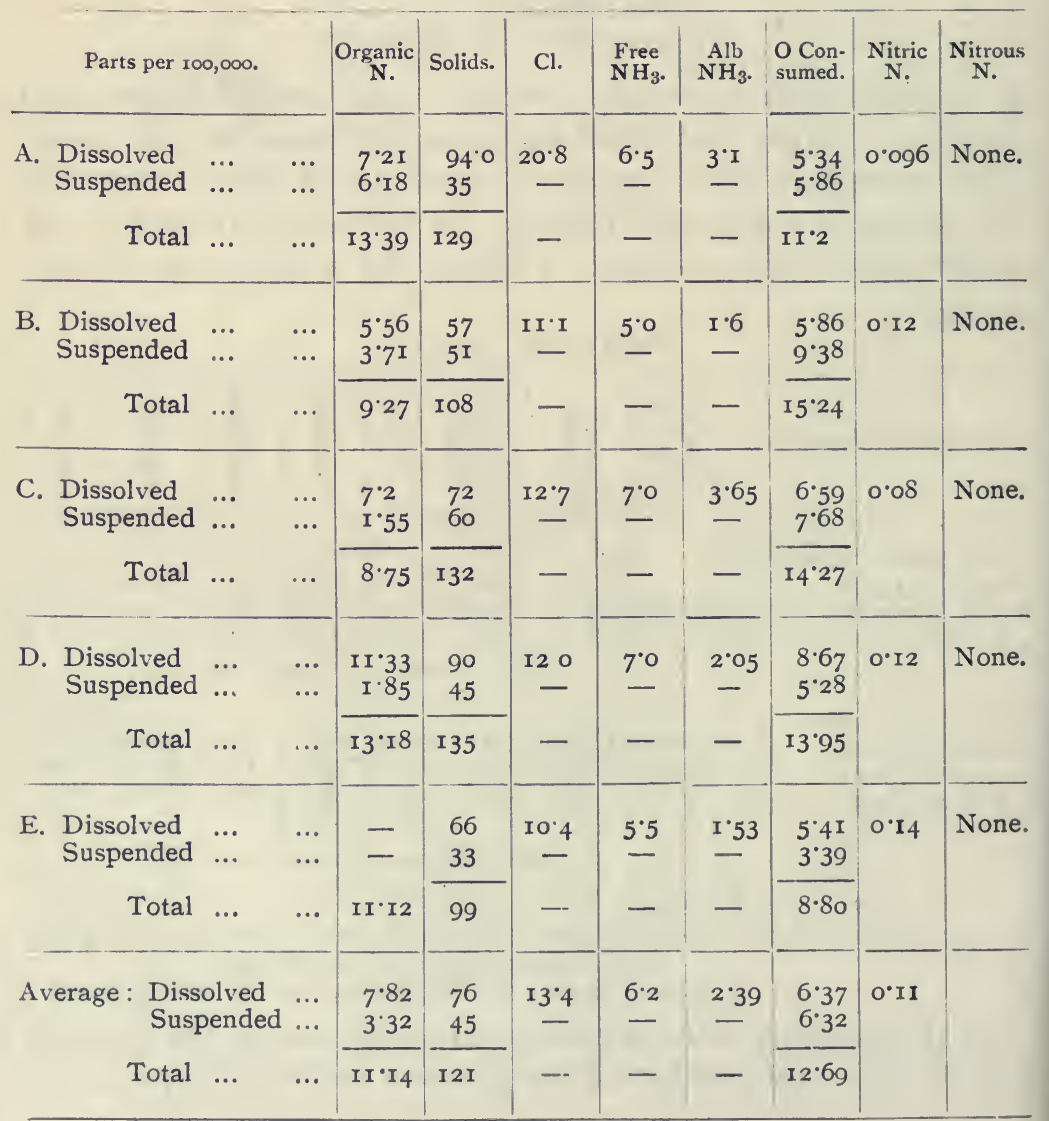


In dry countries the sewage is often very concentrated. An example that I received in IgoI from Bloemfontein, Orange Colony, ${ }^{1}$ contained, in parts per 100,000, $5,25^{6}$ of total solids, of which 4,2I2 were organic; the oxygen consumed was II $3 I^{\circ} 2$, the organic nitrogen $457^{\circ} \mathrm{I}$, ammoniacal nitrogen $537^{\circ} 6$, and chlorine $273^{\circ} 6$.

To take a fair average sample of raw sewage in a bottle is obviously hopeless, owing to the large pieces of solid matter that at intervals come down. The only thing to be done is to roughly strain the sample for analysis, and to ascertain on a larger scale the amount and nature of the solids.

Opinions on sewages and effluents must be based on a number of examinations extending over several days and embracing every hour of the day. At the same time, opportunity must be given for immediate analyses simultaneously, as delay produces change. I will give an example of the procedure by which I attained this in October, I899. A strong sewage was gauged every half-hour, and a sample collected in cubic centimetres proportional to the number of gallons flowing; these half-hourly samples were at once poured into a large vessel, and at the end of three hours were thoroughly mixed, and the average of the six samples taken in a stoppered glass bottle for analysis. The results and the times are given below, and it will be seen

PARTS PER IOO,OOO.

\begin{tabular}{|c|c|c|c|c|c|}
\hline Time. & Chlorine. & $\stackrel{\underset{N}{N}}{\text { as }} \mathbf{N H}_{3}$. & $\begin{array}{c}\text { Total } \\
\text { Nitrogen. }\end{array}$ & $\begin{array}{c}\text { Oxygen } \\
\text { consumed. }\end{array}$ & $\begin{array}{c}\text { Gallons dis- } \\
\text { charged in } \\
\text { the Three } \\
\text { Hours. }\end{array}$ \\
\hline Monday, 9 to I2 a.m. ... & $15^{\circ} \mathrm{O}$ & $22 \cdot 7$ & $34^{\circ} 6$ & $34^{\circ} I$ & $435^{8}$ \\
\hline , $\quad 3$ to 6 p.m. $\quad \ldots$ & I6.० & II $\cdot 5$ & $13 \cdot 2$ & $20 \cdot 7$ & I $49 \mathrm{I}$ \\
\hline Tuesday, 6 to 9 a.m. $\quad \ldots$ & $15^{\circ} 6$ & $26 \cdot 3$ & $33^{\circ} \circ$ & $20 \cdot 8$ & 5450 \\
\hline$\because \quad 12$ to 3 p.m. ... & 19.4 & II 5 & $14 \cdot 8$ & $16 \cdot 6$ & 1762 \\
\hline Wednesday, 3 to 6 a.m. & $6 \cdot 4$ & $7 \% 7$ & $10^{\circ} 0$ & $3 \cdot 5$ & 434 \\
\hline$\quad, \quad 9$ a.m. to noon $\quad \ldots$ & 12.4 & $8 \cdot 4$ & 12.4 & $16 \cdot 2$ & 2529 \\
\hline Thursday, midnight to 3 a.m.... & 4.5 & $2 \cdot 2$ & $3 \cdot 4$ & $9^{\circ} 6$ & 1904 \\
\hline ," 6 to 9 a.m. ... $\quad \ldots$ & $9 \cdot 5$ & $9 \cdot 7$ & 13.4 & $10 \cdot 2$ & 6690 \\
\hline " 9 p.m. to midnight ... & II I I & $10 \% 4$ & $12 \cdot 5$ & $7 \cdot 8$ & 1054 \\
\hline Friday, 3 to 6 a.m. $\quad \ldots \quad \ldots$ & $3 \cdot 8$ & $2 \cdot 1$ & $2 \cdot 9$ & $\mathrm{I} \cdot 2$ & 432 \\
\hline " 6 to 9 p.m. $\quad \ldots \quad \quad \ldots$ & $19 \cdot 6$ & $17 \cdot 8$ & $24 \cdot 6$ & $18 \cdot 7$ & 888 \\
\hline Saturday, midnight to 3 a.m.... & $23^{\circ} 5$ & $18 \cdot 0$ & $22 \cdot 3$ & $10 \cdot 3$ & 563 \\
\hline , $\quad 3$ to 6 p.m. ... & $12 \%$ & $10 \% 4$ & 12.4 & $24 \cdot 8$ & I $75 \mathrm{I}$ \\
\hline . 9 p.m. to midnight ... & $24 \cdot 8$ & 18.5 & $26 \cdot 3$ & $2 I \cdot 2$ & $61_{4}$ \\
\hline Sunday, noon to 3 p.m. & $23 \cdot 3$ & $16 \cdot 6$ & $18 \cdot 2$ & $12 \cdot 2$ & I 535 \\
\hline , $\quad 6$ to 9 p.m. $\quad \ldots$ & $24^{\circ} I$ & I 7.4 & 2 I 5 & II'I & 678 \\
\hline
\end{tabular}

Nitrites and nitrates were only present in traces.

1 Fournal of the Sanitary Institute, xxiv., part i., p. II6. 
that they include each hour of the twenty-four, taken twice, extending over seven days. The periodic fluctuations that I have mentioned are also shown.

In I898, a British Association Committee, after having had the advantage of considering the earlier reports of the Royal Commission on Sewage Disposal, recommended as follows $:^{1}$

"That it is desirable that results of analysis should be expressed in parts per 100,000, except in the case of dissolved gases, when these should be stated as cubic centimetres of gas at $0^{\circ} \mathrm{C}$. and 760 millimetres in I litre of water. This method of recording results is in accordance with that suggested by the Committee appointed in 1887 to confer with the Committee of the American Association for the Advancement of Science, with a view to forming a uniform system of recording the results of water analysis. ${ }^{2}$

"2. The Committee suggest that in the case of all nitrogen compounds the results be expressed as parts of nitrogen per Ioo,ooo, including the ammonia expelled on boiling with alkaline permanganate, which should be termed albuminoid nitrogen. The nitrogen will therefore be returned as-

(I) Ammoniacal nitrogen from free and saline ammonia.

(2) Nitrous nitrogen from nitrites.

(3) Nitric nitrogen from nitrates.

(4) Organic nitrogen (either by Kjeldahl or by combustion, but the process used should be stated).

(5) Albuminoid nitrogen.

"The total nitrogen of all kinds will be the sum of the first four determinations.

"The Committee are of opinion that the percentage of nitrogen oxidized-that is, the ratio of (2) and (3) to (I) and (4)-gives sometimes a useful measure of the stage of purification of a particular sample. The purification effected by a process will be measured by the amount of oxidized nitrogen as compared with the total amount of nitrogen existing in the crude sewage.

"In raw sewage and in effluents containing suspended matter

1 British Associałion Report, I899. Parts per I00,000 can be converted into grains per imperial gallon ( $277 \frac{1}{4}$ cubic inches) by multiplying by $0 \% 7$, and into grains per United States gallon (23I cubic inches), by dividing by $\mathrm{I} \cdot 7 \mathrm{I}$.

2 "It would be a great convenience if this mode of expressing results were generally agreed to and adopted by chemists throughout the country, and by managers of sewage farms or works."-Reports to the Roval Commission on Sewage, vol. iv., part v., I904, p. 9. 
it is also desirable to determine how much of the organic nitrogen is present in the suspended matter.

"In sampling, the Committee suggest that the bottles should be filled nearly completely with the liquid, only a small airbubble being allowed to remain in the neck of the bottle. The time at which a sample is drawn, as well as the time at which its analysis is begun, should be noted. An effluent should be drawn to correspond as nearly as possible with the original sewage, and both it and the sewage should be taken in quantities proportional to the rate of flow when that varies (e.g., in the emptying of a filter-bed).

"In order to avoid the multiplication of analyses, the attendant at the sewage works (or any other person who draws the samples) might be provided with sets of twelve or twenty-four stoppered $\frac{1}{4}$ Winchester bottles, one of which should be filled every hour or every two hours, and on the label of each bottle the rate of flow at the time should be written. When the bottles reach the laboratory, quantities would be taken from each, proportional to these rates of flow, and mixed together, by which means a fair average sample for the twenty-four hours would be obtained.

"The Committee at present are unable to suggest a method of reporting bacterial results, including incubator tests, which is likely to be acceptable to all workers."

\section{Processes of Analysis.}

Since samples of sewages and of effluents are usually in a condition of rapid change, the chemical examination must be carried out as quickly as possible after collection; therefore such processes as admit of rapid working must be chosen in preference to those which are longer, even if the latter be slightly more accurate, more especially as a large number of specimens have often to be examined at once.

Physical character, as smell, colour, and turbidity, ${ }^{1}$ must first be noticed, then the reaction to test-paper. Ordinarily this is more or less alkaline, the alkalinity being of two kinds-volatile, owing mainly to free ammonia; fixed, due to washing soda and soap and, more rarely, lime. These can be determined, if necessary, by taking two measured quantities, say Io to 50 c.c.,

1 Clark uses as a standard for turbidity a suspension containing a known amount of sewage deposit of average character (Fourn. Amer. Assoc. Eng. Soc., I904, xxxiii., p. 356). 
titrating one of them directly with standard acid, evaporating the other to a low bulk (not to dryness, since the fixed alkali is capable of decomposing many organic compounds and of neutralizing itself) over the water-bath to drive off ammonia, and titrating again. The first titration gives the total alkalinity, the second the fixed; the difference is the volatile alkalinity. The fixed alkalinity is ordinarily calculated into soda, the volatile into ammonia. Each cubic centimetre of centinormal standard acid solution required for neutralization corresponds to $0^{\circ} 0003 \mathrm{I}$ gramme of sodium oxide, $\mathrm{Na}_{2} \mathrm{O} ; 0^{\circ} 00040$ of caustic soda, $\mathrm{NaOH} ; 0.00053$ of sodium carbonate, $\mathrm{Na}_{2} \mathrm{CO}_{3}$; and $0 \cdot 000 \mathrm{I} 7$ of ammonia, $\mathrm{NH}_{3}$. For a fairly clear liquid, methyl orange may be used as an indicator of the end of the titration; for a thick or coloured one, delicate litmus-paper is the best. Moderate alkalinity is favourable to the action of bacteria; therefore it is rarely necessary to make the above determination in sewage, except where liquors from gasworks or chemical factories are present.

Occasionally the sewage is locally rendered acid by trade discharges; the degree of acidity must be determined by standard alkali run in from a burette in the same way as in the determination of alkalinity. Acidity due to $\mathrm{CO}_{2}$ disappears on boiling the liquid or on drying the litmus-paper. An acid sewage would be unfavourable to bacterial action, but the acidity is usually at once neutralized by admixture with the larger volume of sewage. (See later, Trade Effluents.)

Oxidation in bacterial sewage treatment is accompanied by a change of basic substances, like amines and ammonia, into acid bodies such as carbonic, acetic, and nitric acids, which combine with lime or soda. Therefore the effluent will become less alkaline than the sewage, and the reduction of alkalinity has been proposed as a measure of the degree of change, but the figure will be greatly affected by the volatilization of ammonia, and in some cases by the presence of added lime or other chemicals.

Solid Matter.-It is generally only necessary to ascertain (I) the total solids, (2) the suspended matter.

The total solids are determined by evaporating 50 or Ioo c.c. in a porcelain or platinum dish (or a thin glass basin if it has not afterwards to be burnt), drying at $120^{\circ} \mathrm{C}$., cooling in a desiccator, and weighing. It is often difficult to obtain a constant weight, owing to decomposition of the solids and to 
their deliquescent character; therefore some operators add before evaporation 2 or 3 c.c., accurately measured, of $\frac{N}{10}$ sodium carbonate, and subtract the weight $\left(0^{\circ} 0053\right.$ gramme for each c.c.) from the residue, but this should be called a "carbonated residue."

The ash can be determined (in porcelain or platinum) by gently igniting and again weighing, but, from the presence of ammonium salts and for other reasons, the "loss on ignition" does not measure simply the organic matter. It is very difficult to burn off all the carbon without volatilizing inorganic matter. At Berlin the ash is moistened with distilled water, and again evaporated and ignited, and the process is repeated four to six times until the black particles have all been burnt away. ${ }^{1}$

Suspended matter can be estimated in five different ways :

I. By Difference.-Well shake the sample, measure out a portion, evaporate, dry, and weigh as above. Filter another portion through paper (rejecting the first runnings), and evaporate, dry, and weigh a measured portion of the filtrate. The difference between the weights gives approximately the suspended matter separated by filtration. But it is difficult to dry to the same degree.

2. A Swedish filter-paper of 12.5 millimetres diameter is dried for half an hour at $100^{\circ} \mathrm{C}$. in a weighing-bottle-a couple of test-tubes sliding into one another answer very well-cooled in the desiccator, and accurately weighed. A measured volume of the shaken sample is filtered through, dried at $100^{\circ} \mathrm{C}$., and weighed. The difference gives the total suspended matter. Gently incinerated in a platinum dish it gives the inorganic suspended matter, which can be examined for sand, oxide of iron, and other matters in the ordinary way. Many sewages block filter-paper hopelessly; hence the next processes.

3. The sample is drawn through a hardened filter-paper by means of an exhaust pump. If not allowed to get dry, the solids can be transferred by a fine jet of water from a washbottle to a weighed dish, evaporated, weighed, then burnt, and again weighed as above. An advantage of this method is that the suspended matters can be examined microscopically. It is not, however, accurate as to weights.

4. The Gooch crucible with prepared asbestos gives accurate results in the minimum time with the use of a filter-pump, and

1 Report of Royal Bureau of Sewage Disposal and Water Purification, Berlin, I904. 
has been adopted by Dr. McGowan in his work for the Royal Sewage Commission. ${ }^{1}$

A stock of commercial elastic asbestos is shredded, purified by digestion with warm concentrated $\mathrm{HCl}$ and washing till free from acid, and stored under distilled water. An even mat of the asbestos 2 to 3 millimetres thick is made on the bottom of a Gooch crucible about $I \frac{3}{4}$ inches high and $I_{2} \frac{1}{2}$ inches diameter at the top, which is then fitted by means of a ring of wide indiarubber tubing into the neck of a filter-flask connected with a pump. Distilled water is then poured on carefully and drawn through two or three times, and the crucible filter is dried at $\mathrm{IIO}^{\circ} \mathrm{C}$., cooled in a desiccator, and weighed. Fifty to 500 c.c. of the sample, according to its character, are now filtered, at first without using the pump, refiltering until the liquid passes clear, and reserving the sediment as much as possible to the last. Finally, wash three or four times, dry, cool, and weigh as before. Careful ignition and weighing gives the mineral suspended matters (the odours evolved should be noticed). If necessary, the ash can be chemically examined, as the asbestos is almost unaffected by $\mathrm{HCl}$.

5. Centrifugal method for approximate comparison of muddy samples. A measured quantity is allowed to settle, and the lower fraction transferred to a tube drawn out into a narrower portion graduated in tenths of a c.c., centrifugalized for a certain time, and readings taken of the volume of moist deposit per I00,000.

In a full analysis both the dissolved and suspended solids are divided into (I) "organic and other volatile matters," and (2) "inorganic or mineral matters."

Chlorine is present in the form of chlorides, chiefly of sodium, with less quantities of potassium and ammonium, but is always recorded in terms of chlorine. It is estimated volumetrically with a standard solution of nitrate of silver, adding a drop of neutral potassium chromate, when the appearance of a slight persistent red colour, due to chromate of silver, indicates the complete precipitation of the chloride. It is in all cases advised to evaporate the measured volume of the sewageIo to 25 c.c.- to dryness on the water-bath before titration; the end reaction is then sharp. For the standard silver solution,

${ }^{2}$ Fourth Report, 1904, vol. iv., part v., p. 45. Also see an investigation by Kimberley and Hommon (Journal of Infectious Diseases, Chicago, February, 1906), who use the Gooch as the standard method for sewages at the Testing Station, Columbus, Ohio. 
2.3944 grammes of pure recrystallized silver nitrate are accurately weighed out, dissolved, and made up to I litre with pure distilled water. If 50 c.c. of the sample be taken, each c.c. of the standard solution=I part per I0o,000 of $\mathrm{Cl}$. When a less quantity is taken, the calculation is simple; thus, if ro c.c. of the sewage had been evaporated, and had required 2.5 c.c. of nitrate of silver, the chlorine is $2.5 \times 5$, or 12.5 parts per 100,000 .

This determination is of special value, as giving the chief and readiest clue to the strength or dilution of sewage, because (I) the most important liquid ingredient of sewage is urine, which averages about $\mathrm{I} \frac{1}{2}$ litres per head per day, and contains about 0.45 per cent. of chlorine, or 450 parts per 100,000. (2) Ordinary water-supplies contain little chlorine, generally from I to 2 per 100,000 . (3) Weak domestic sewages contain 7 parts; stronger ones up to 40 or 50 ; an ordinary average may be taken to be ro parts of chlorine per 100,000. See also Calculation of Dilution, Chapter XXXVI.

\section{Free Ammonia: Direct Determination.}

The ordinary method of determining free ammonia is by distillation, combining it with the estimation of "albuminoid." But as it has been proved that the organic matter in water is altered by distilling, it is advisable to make a control estimate of the free and saline ammonia actually present by diluting an appropriate fraction to 50 c.c. with pure ammonia-free water and then Nesslerizing. The amount used for dilution should be such as to produce a measurable brown colour; in that case I have found that the estimation, if done quickly, can be effected without any turbidity from lime salts interfering. One c.c. of sewage, or Io to 20 c.c. of effluent, diluted to 50 c.c. with ammonia-free water, usually gives a suitable tint for Nesslerizing. Difficulties are sometimes caused by sulphuretted hydrogen or by a deep colour in the sewage. The former can be removed, without appreciable loss of ammonia, by bubbling air through the liquid after dilution; the latter can be allowed for by subtracting a blank. In some laboratories the sewage is clarified by diluting slightly, adding pure soda or potash and a small quantity of potassium oxalate, cupric sulphate, zinc or lead acetate, making up the volume required, and decanting the clear liquid for Nesslerizing. The heavy metal precipitates are apt to carry down traces of ammonia. 


\section{Free and Albuminoid Ammonia by Distillation.}

The apparatus must first be freed from ammonia by distilling water through it till the distillate shows no reaction with Nessler's test. Then 500 c.c. of pure water, or of good tap water in which the free and albuminoid ammonia are known, are placed in the retort, and Ioo c.c. (or a less quantity according to the strength) of the sewage added. The distillation is then carried on till free ammonia ceases to come over except in traces, which will generally happen when 200 c.c. have been collected. Fifty c.c. of alkaline permanganate solution are next added, and three pieces of ignited pumice, and the distillation is continued until another 200 c.c. have been collected. Suitable fractions of the two distillates are then diluted with ammonia-free water to 50 c.c. and Nesslerized, the first result being put down as free ammonia, the latter as albuminoid. The ammonia is preferably calculated to nitrogen, as mentioned in the British Association Report. In the case of acid trade effluents, ignited carbonate of soda, in slight excess, must be added before the first distillation.

In distilling sewage there is no exact point when the "free ammonia" ceases to come over, on account of the gradual decomposition of various nitrogenous matters by heat. Phelps distilled the following pure substances with water and a little sodium carbonate, and the percentage of the total nitrogen coming over as free ammonia was: Urea, 2; gelatin, $\mathrm{I}^{\circ}$; casein, 0.68 ; egg albumin, $3 \cdot 2$; Witte's peptone, I*4; naphthylamine, $0^{\circ} .^{1}$ These proportions are small, though they are lower than would be yielded by some of the intermediate products of decomposition, and they depend upon concentration and on the duration of heating. Wanklyn showed, in r86\%, that with urea in prolonged boiling there was a very slow evolution of ammonia, and the greater part was finally decomposed. Phelps found (loc. cit.), as the average of fifty analyses of sewage, that the excess of "free ammonia" by distillation over that by direct titration was $13^{\circ} 2$ per cent. of the latter.

The action of the alkaline permanganate is also not definite; therefore it is necessary to proceed in a defined manner to obtain comparative results. For some time I determined the " total ammonia" by adding to the dilute sewage alkaline per-

1 American Public Health Association, Journal of Infectious Diseases, Chicago, March I9, I904. 
manganate at once, distilling and Nesslerizing, then deducting the free and saline ammonia obtained by direct titration, recording the difference as " albuminoid $\mathrm{NH}_{3}$." In this way more ammonia is obtained, but the results are not comparable with published analyses, and in effluents are more unfavourable when referred to the limits laid down by various Boards; therefore it seems best to keep to the older conventional method as originally laid down by Wanklyn. We shall have to refer again to the standards officially prescribed. To show the great variation, I have found the free ammonia in ordinary raw sewages to range from 35 to less than I per 100,000, and the albuminoid from 6 to $0^{\circ} \mathrm{I}$ per 100,000, the latter, of course, being largely subsoil or rain-water.

Oxygen Consumed.-This test has been variously called the "oxygen absorbed figure," the "oxygen test," or simply the "permanganate test." While in the ordinary " albuminoid" method permanganate is used in a strongly alkaline solution, and only the ammonia evolved is measured, in this process the permanganate solution is acidified with sulphuric acid, digested with the water or sewage, and after a certain time the amount of permanganate remaining is determined volumetrically. The original quantity of permanganate added being known, the loss indicates the oxygen which has been absorbed by the organic matter and other oxidizable bodies present.

This process, originally devised by Forschammer about I 865 , was subsequently improved by Letheby and Tidy, and has attained importance as a standard comparative method on account of the ease and rapidity of its performance.

Opinions have in many cases been founded almost solely on the permanganate process of oxidation; but such a proceeding is to be condemned, as, although decidedly valuable, the test is open to the following objections :

I. So many modifications have been introduced in procedure that the figures obtained by various observers are seldom comparable.

2. It mainly measures the carbonaceous matters, which are not the most dangerous.

3. It is incomplete even in measuring these, since it has been found on trials with various definite organic matters that they varied greatly in their reducing power, and some of them were very resistant to permanganate when used, according to the ordinary prescription, at low temperatures. For this reason, in 
the Kübel modification, in order to intensify and shorten the reaction, the liquid is boiled, in Germany usually for ten, in America for two to five, minutes, with the objection that boiling is apt to cause a spontaneous and irregular loss of oxygen from the permanganate and acid alone, due to the variation in the chlorides. Many years ago I found it safe to work at a temperature of $80^{\circ} \mathrm{C}$. on an ordinary water-bath, instead of the customary heat of $80^{\circ} \mathrm{F}$., thereby shortening the time to two and a half hours, in place of the usual four hours in the cold.

4. The greatest disturbing influence is the interference of nitrites, which are abundant in certain stages of purification, of high chlorides, and of iron and occasionally various other salts derived from a chemical treatment. This objection has not been satisfactorily eliminated, even by the adoption of the different time limits proposed, such as three minutes, fifteen minutes, two and a half or four hours.

The process, as common to all modifications, is as follows: A measured volume of the water or sewage is placed in a carefully-cleaned stoppered bottle of about double the capacity, and acidified strongly with a uniform amount of pure sulphuric acid; then an excess of a standard solution of potassium permanganate is measured in, and the whole mixed by rotation. At the same time a blank is mounted with equal volumes of pure water and the reagents. Both are exposed to the same temperature for the same time. The effect on the permanganate must be watched; should it happen that the red colour pales rapidly, a further measured quantity of permanganate and of acid must be at once added, as it is necessary that the oxidizing agent should be present in excess up to the end of the time. At the end both bottles are cooled, and a few drops of freshly-prepared potassium iodide solution is added to each, or a small crystal of the pure solid. Iodine is immediately liberated in proportion to the amount of permanganate that has remained unreduced by the organic matter. A centinormal solution of sodium thiosulphate $\left(2 \cdot 4827\right.$ grammes $\mathrm{Na}_{2} \mathrm{~S}_{2} \mathrm{O}_{3}, 8 \mathrm{H}_{2} \mathrm{O}$ per litre) is then run in from a burette till the brown colour of the iodine has nearly disappeared. A few drops of fresh, thin starch solution are then added, and the addition of thiosulphate continued till the blue colour has just disappeared. This titration must be accomplished rapidly, as it will be noticed that the blue colour will reappear after standing. 
Subtracting the amount of thiosulphate required by the sample from that used by the blank, and multiplying this number of cubic centimetres by $0^{\circ} 00008$, will give the weight of oxygen consumed in the time by the volume of sample used, and this is calculated to parts per 100,000. The standard strength of permanganate solution is $0^{*} 395$ gramme of the pure crystallized salt per litre: I c.c. $=0^{\circ}$.0oo gramme of available oxygen.

The acid used is I part by volume of pure $\mathrm{H}_{2} \mathrm{SO}_{4}$ to 3 parts of pure distilled water. Permanganate solution is added till a faint red tint remains for some hours.

As the oxidation is never quite final, it is important that standard conditions of time and temperature should be observed. Unfortunately, a uniform method of working has not yet been agreed on between all observers; therefore the exact method used should be stated. The chief modifications are :

I. Society of Public Analysts' standard, originally proposed for waters. Two equal samples maintained at $80^{\circ} \mathrm{F}$, one titrated after fifteen minutes, the other after four hours: 250 c.c. liquid, ro c.c. acid, ro c.c. permanganate.

2. Mersey and Irwell Joint Committee, specially for sewages and effluents. Temperature $60^{\circ} \mathrm{F}$. Two portions of 70 c.c. of the sample with Io c.c. of acid and 50 c.c. permanganate are titrated, the one after three minutes, the other after four hours.

The three minutes' test shows nitrites, ferrous salts, sulphuretted hydrogen, and putrefying matter decomposing permanganate at once with acid. The difference between three and fifteen minutes shows matter readily putrefying and rapidly decomposing acid permanganate. The difference between fifteen minutes and four hours gives matter capable of putrefying, though slow to decompose. ${ }^{1}$

Inasmuch as the important point is to discover how far the sewage or effluent is deficient of complete oxidation, I have preferred to obtain as quickly as possible a final figure by taking 50 or roo c.c. of the sample, making up to 250 c.c. with pure water (a good tap water answers in most cases), adding 25 c.c. acid and 25 c.c. permanganate, heating on a water-bath (along with a blank) to $80^{\circ} \mathrm{C}$. for two and a half hours, and titrating as described in the above example.

${ }^{1}$ F. Scudder, Journ. Soc. Chem. Ind., January and May, 1898. 
Mineral Constituents. - When there is time, much further information can be gathered from an examination of the inorganic ingredients of sewage. Where trade effluents are concerned this often constitutes a principal part of the inquiry. The processes are the same as those of ordinary analysis, but on account of the changes that occur on incineration, many of the estimations must be made on the original, and not on the ash.

Based on an average water-supply of 33 gallons, Wanklyn gives the following amounts per head per day in grammes:

\begin{tabular}{c|c|c|c}
\hline Total Sewage. & $\begin{array}{c}\text { Total Excretal Products, } \\
\text { Dry. }\end{array}$ & $\begin{array}{c}\text { Urinary } \\
\text { Solids. }\end{array}$ & $\begin{array}{c}\text { Fæcal } \\
\text { Solids. }\end{array}$ \\
\hline I 50,000 & 90 & 60 & 30 \\
\hline
\end{tabular}

Sulphates are often of great importance; they are naturally derived, with sulphides, from the breaking down of albuminous matters, and also are artificially added in various forms of chemical treatment. Here is an instance from my own experience, the river being a small one:

Sulphates as $\mathrm{SO}_{3}$ in Parts per ioo,ooo.

\begin{tabular}{|c|c|c|c|c|}
\hline \multicolumn{3}{|c|}{ Sewage Farm Effluents. } & \multicolumn{2}{|c|}{ Water of the River. } \\
\hline I. & II. & III. & $\begin{array}{l}\text { Above the } \\
\text { Discharge. }\end{array}$ & $\begin{array}{l}\text { Below the } \\
\text { Discharge. }\end{array}$ \\
\hline $25^{\cdot 8}$ & $27^{\circ} 6$ & $32 \cdot 8$ & $4 \cdot 62$ & $8 \cdot 64$ \\
\hline
\end{tabular}

It can be calculated from these figures that the effluents contaminated the river to the extent of one-eighth of its volume. On an average the larger quantity of diluent water contributes at least as much sulphuric acid as the smaller volume of urine; therefore in domestic sewages the measurement of sulphates is of less value than the measurement of chlorine. Wanklyn gives the following averages for sulphates as $\mathrm{SO}_{3}$ in various waters and in what he names "typical sewage"-i.e., urine diluted with pure water to Ioo times its volume. This phrase is based on the estimate of the average urine per person per 
day being $I^{\prime} 5$ litres, and the average water-supply ${ }_{5} 5$ litres, or 33 gallons per head per day.

Sulphates as $\mathrm{SO}_{3}$ in Parts per ioo,ooo.

\begin{tabular}{|c|c|c|c|c|c|}
\hline Urine & $\ldots$ & ... & .. & ... & I6o \\
\hline "Typical sewage" & $\ldots$ & ... & . & .. & $I \cdot 6$ \\
\hline ondon waters: & & & & & \\
\hline West Middlesex & $\ldots$ & $\ldots$ & .. & ... & $2 \cdot 46$ \\
\hline Kent ... $\quad \ldots$ & ... & $\cdots$ & .. & ... & 54 \\
\hline New River ... & ... & ... & . & ... & I'33 \\
\hline Loch Katrine (Glasgc & & & & .. & 0.47 \\
\hline
\end{tabular}

Phosphates.-Both urine and fæces contain, in proportion to the solid matter, a large quantity of phosphates both of the alkalies and of lime and magnesia; hence, in testing drinkingwaters for sewage contamination the phosphate test is of great value. But in examining sewage effluents both from coke filters and from chemical treatment, I have found that the phosphates have sometimes almost entirely disappeared, owing to the fact that they are precipitated by iron present in the materials, or by lime in the water or precipitants, or that they are absorbed by various organisms. Therefore in this case the determination is of less value.

\section{Potassium and Sodium.-}

$\begin{array}{lll}\text { In urine } & \ldots & \ldots\end{array}\left\{\begin{array}{lllc}\mathrm{Na} & \ldots & 0.4 & \text { per cent. } \\ \mathrm{K} & \ldots & 0.8 & ,\end{array}\right.$

In fæces $\quad \ldots \quad \ldots \quad$ More $\mathrm{K}$ than Na.

Porter found in the ash of human excrement 6.1 per cent. of $\mathrm{K}_{2} \mathrm{O}$ and $5^{\cdot 07}$ per cent. of $\mathrm{Na}_{2} \mathrm{O} .^{1}$

Therefore, the ratio of the alkalies sometimes furnishes information as to the character, whether fæcal or urinous. It must be remembered, however, that the urine of horses and cattle contains a considerable amount of potassium.

From a large number of analyses of London sewage by Letheby, Fuller calculates the amount of phosphoric acid and potash discharged in the sewage per head of population per day to be in grammes: ${ }^{2}$

1 Ann. Chem. Pharm., lxxxi., rog.

2 American Technology Quarterly, XVI., ii., I903, p. I38; Letheby, "The Sewage Question," Baillière, Tindall and Cox, I872, p. I37. 


\begin{tabular}{|c|c|c|c|c|}
\hline & & Total. & From Excreta. & From other Refuse. \\
\hline \multicolumn{5}{|l|}{ Phosphoric acid : } \\
\hline Dissolved ... & $\ldots$ & $2 \cdot I$ & $I \cdot 4$ & 0.7 \\
\hline Suspended... & ... & $2 \cdot 2$ & $\mathrm{I} \cdot \mathrm{O}$ & $I \cdot 2$ \\
\hline Total & ... & $4 \cdot 3$ & $2 \cdot 4$ & I'9 \\
\hline \multicolumn{5}{|l|}{ Potash : } \\
\hline Dissolved ... & $\ldots$ & $3^{\circ} 0$ & $\mathrm{I} \cdot 5$ & $I \cdot 5$ \\
\hline Suspended... & $\ldots$ & 0.4 & 0.4 & - \\
\hline Total & $\ldots$ & $3 \cdot 4$ & $I \cdot 9$ & $\mathrm{I} \cdot 5$ \\
\hline
\end{tabular}




\section{CHAPTER III}

\section{CHEMICAL ANALYSIS (continued)}

Determination of nitrates-Nitrites-Organic nitrogen-Dissolved oxygen-Carbonic acid-Incubator tests-Weights discharged per day-Proposed standards for effluents - Ratio of chlorine to total nitrogen, and of oxidized to unoxidized nitrogen.

Nitrates.-This determination is of very great importance. Sewages, as a rule, unless very fresh, contain no nitrate, and only traces of nitrite, while effluents may contain large amounts of both.

I have adopted a slightly modified indigo process, which determines nitrates only, the $m$-phenylene-diamine method being used for nitrites. Duplicates with the Crum method and with the copper-zinc couple, giving the total oxidized nitrogen, have agreed closely with the above.

For the indigo titration, a standard indigo is made by dissolving 0.5 gramme of crystallized indigotine in 20 c.c. Nordhausen sulphuric acid, allowing to stand twenty-four hours, diluting very cautiously, filtering if necessary, and making up to I litre. This solution keeps well in the dark; its strength is determined, and controlled at intervals, by means of $\mathrm{KNO}_{3}$ solutions of different strengths, and a curve is constructed giving directly the relation between the number of the c.c.'s used and the grammes of nitric nitrogen present in the quantity taken, since the ratio between the c.c.'s of indigo and the nitric nitrogen diminishes gradually in a curve as the solutions become stronger. The quantity of water or effluent used should not require more than Io c.c. of indigo, and is better kept at about 5 to 6 c.c., or even less. In titration the strength is uniformly arranged at 25 c.c. liquid to 50 c.c. $\mathrm{H}_{2} \mathrm{SO}_{4}$ free from nitrate; and it is important to make blank estimations, as several samples of acid have been found to be faulty. The quantity of liquid found suitable, and made up to the 25 c.c. with distilled water, is mixed rapidly in a thin flask with the acid (over a sink or dish, in case of fracture), and is immediately titrated, while still hot, with the indigo. The rapidity with which this 
can be done has enabled me to determine nitrates in situ, at intervals of a few minutes, on river banks or in runnings from filters, so as to ascertain the fluctuations. If samples were simply collected, transferred to the laboratory, and determined by a longer process, they would have undergone such changes as to make the results erroneous.

Nitrites in comparatively large quantities do not interfere with this test; 25 c.c. of a solution containing 5 parts per I00,000 of nitrous nitrogen, an amount not often met with, require only $0^{\circ} 2$ c.c. of standard indigo solution to produce a blue colour, whereas the same quantity of a liquid containing I part per I0o,000 of nitric nitrogen would require over 5 c.c. R. Warington ${ }^{1}$ and others have stated that the indigo method measured both nitric and nitrous acids, but conducted in the way I adopt, it only measures the former. The mistake has probably arisen from the sodium nitrite, reputed pure, of commerce containing a considerable proportion of nitrate or chloride; when prepared fresh from pure silver nitrite by reaction with pure sodium chloride I obtained the above negative results with indigo.

The amounts usually found to be suitable for a determination are-For ordinary drinking-waters, 25 c.c.; for highly nitrated waters or effluents, Io or 5 c.c. made up to 25 c.c. ; for sewages or low nitrated effluents, 50 or even Ioo c.c., with Ioo or 200 c.c. of $\mathrm{H}_{2} \mathrm{SO}_{4}$, may be used. With practice the slight tint of blue produced by $0^{\circ} \mathrm{I}$ c.c. excess of indigo is distinctly perceptible, even when the liquid acquires a brown tint after the acid is added. Occasionally the flask cracks when the mixture is made-as it should be-suddenly, so this contingency must be provided for. The titration should be done as quickly as possible, but a blue that is permanent for two minutes remains as a rule for half an hour.

Nitrites.-The solutions required are-

I. A half per cent. solution of metaphenylene-diamine in dilute sulphuric acid; if much coloured it can be bleached by filtration through purified animal charcoal.

2. Diluted sulphuric acid-I part to 2 parts of water.

3. Standard $\mathrm{NaNO}_{2}$ solution. Fifty c.c. of the sample are placed in a Nessler glass, I c.c. of the metaphenylene-diamine and I c.c. of acid added; on standing, a yellow brown colour slowly develops even with traces of nitrite. The colour is

1 “Detection of Nitrous and Nitric Acids," Chemical News, li., 39. 
imitated with standard nitrite solution in the same way as Nesslerizing, ${ }^{1}$ taking care that the original and the imitation are started at the same time, and read off in not less than twenty minutes.

Organic Nitrogen.-As it has been proved that the organic matter in water is altered by distillation, and also changes rapidly on standing, I sought to devise a process which should, without distilling, obtain the results of a number of sewages quickly and comparatively, and yet with sufficient accuracy. I adopted the following modification of the well-known Kjeldahl process to ascertain the unoxidized nitrogen, to which I attach great importance in its relation to the oxidized nitrogen represented by the nitrates and nitrites. The quantities used for analysis are regulated by the strength of the liquid, and are, of course, larger for an average effluent than for a raw sewage. The amount aimed at in the final Nessler titration is such as will correspond to I c.c. of the original sewage or 5 c.c. effluent, as that quantity, made up to 50 c.c. with ammoniafree water, generally gives a suitable colour.

Free Ammonia.-One c.c. of the settled sewage or effluent is diluted to 50 c.c. and Nesslerized, as in Chapter II., p. 35. The figure obtained is the actual saline ammonia present.

Kjeldahl.-Ten c.c. of a sewage, or, say, roo c.c. of an effluent +4 c.c. of pure sulphuric acid are heated in a pear-shaped hard glass flask in a slanting position until the liquid becomes colour. less. When about 3 c.c. remain, the flask is cooled and washed out with small quantities of ammonia-free water into a Ioo c.c. measure, until the volume of the liquid reaches about 40 c.c. An excess-i.e., about 25 c.c.-of soda solution (25 per cent.) free from ammonia is now added, when a flocculent precipitate is thrown down. After cooling, the liquid is made up to roo c.c., transferred to a clean and dry stoppered bottle, and rotated at intervals until the flocculi-which at first float entangled with air-bubbles-subside. A suitable fraction of the clear liquid is then pipetted into a Nessler glass, diluted to 50 c.c., and Nesslerized. This gives the total unoxidized nitrogen in terms of ammonia. The free $\mathrm{NH}_{3}$, as found above, is subtracted, and the remainder calculated into "organic nitrogen (Kjeldahl)." A blank is done with the reagents.

1 See Sutton's "Volumetric Analysis," r896, pp. 404, 435; also Rideal on " Nitrites in Waters and Sewages," Journal of State Medicine, June, 1902, p. 333. 
The organic $\mathrm{N}$ is always higher than the $\mathrm{N}$ as albuminoid ammonia. Dr. McGowan proposes to call the difference the " $\mathrm{X}$ " nitrogen. This quantity is considerably lower in a good effluent than in a raw sewage, showing that the organic matter in the effluent is more easily broken up by the permanganate.

With sewages and tank effluents the results thus easily and rapidly obtained were useful, though they had a tendency to be too low. But now and then, especially with good effluents, the figures came out lower than the free ammonia. To see whether the presence of nitrates or nitrites was the cause, I made some experiments, of which the details are given in the former edition, by adding these to an effluent containing much ammonia, and found that a large excess of sulphuric acid (4 c.c. as above) prevents loss of nitrogen by secondary action.

Accuracy is greatly affected by the fact that, in Nesslerizing, the few c.c.'s of solution have to be multiplied by such a large number to obtain the analytical figures. If time and quantity allow, the Kjeldahl can be conducted in the ordinary way with larger quantities-say, Ioo c.c. of sewage, 200 or more of effluent, with Io c.c. of $\mathrm{H}_{2} \mathrm{SO}_{4}$, a globule of mercury, and about $\frac{1}{2}$ gramme of potassium sulphate, finally distilling with pure soda and a little sodium sulphide into standard acid, and titrating the loss of acidity. ${ }^{1}$

It is evident that among the unlimited number of organic compounds that may be present in sewage there are some that are very difficult to decompose, and Phelps ${ }^{2}$ finds this the main cause of deficient organic nitrogen in Kjeldahls. $\mathrm{He}$ records good results, usually within $0^{\circ} 05$ part per 100,000, by the following procedure, which has been adopted by the Massachusetts Institute: Ioo c.c. of the sample are heated with 5 c.c. of sulphuric acid and about O'I gramme of copper sulphate until perfectly colourless. He shows that stopping at "pale yellow" or "faint straw colour," as sometimes allowed, is not sufficient. Condensing the vapours proved that a little nitrogenous organic matter was volatilized, but the quantity was negligible. In some cases the colourless residue still contains some organic matter unresolved; therefore he adds in all cases small crystals of potassium permanganate until there is a permanent colour. Experiments showed that while

1 For details see Sutton's “ Volumetric Analysis," I 896, p. 85.

2 Report of the Massachusetts Institute of Technology, Boston, I905, p. I ro. 
permanganate, if used at an early stage, caused a loss of nitrogen, added at the end it completed the reaction and gave a higher ammonia. ${ }^{1}$ The residue is cooled, diluted, neutralized with saturated sodium carbonate, distilled and Nesslerized. Chlorides in large quantities, nitrates and nitrites up to I.5 parts per I00,000 together, did not cause loss of organic nitrogen in the process.

Dr. McGowan ${ }^{2}$ undertakes a determination of the total nitrogen in all forms. He adds sugar solution, then slowly reduces the nitrate and nitrite to ammonia by $\mathrm{Zn}$ and dilute $\mathrm{H}_{2} \mathrm{SO}_{4}$, Kjeldahls with $\mathrm{H}_{2} \mathrm{SO}_{4}$ and sodium sulphate, and distils with potash into standard acid as above. But he describes the process as taking about six days with continual attention, and says at the end that it answers "in sewages, tank or precipitation liquors, and (with care) in effluents of average quality. With very pure effluents ... the errors of experiment are too great for this indirect method for the determination of ' $\mathrm{X}$ ' nitrogen and total organic nitrogen to be of value at present." The process is not, therefore, better than the simple one we have first given.

Dissulved Oxygen.-I have described and reviewed a number of processes for the determination of the oxygen in sewage and waters in the Analyst of June, Igor ; most of them, like Schutzenberger's and Thresh's, are not convenient for general use away from the laboratory. ${ }^{3}$ As it is very important to be able to ascertain quickly on the spot the absorption or disappearance of free oxygen in a sewage or effluent, I have adopted the simple process introduced by Winkler, which gives sufficiently near results. An accurately stoppered bottle, of which the contents are known when full, is completely filled with the sample. A convenient volume is 250 to 300 c.c. One c.c. of a nearly saturated solution of manganous chloride is passed to the bottom by a long pipette, then 3 c.c. of 33 per cent. caustic soda containing Io per cent. of KI are similarly added. The stopper is inserted, and the bottle moved round so as to $\mathrm{mix}$ the whole. The $\mathrm{MnO}$ absorbs the free $\mathrm{O}$ and becomes brown. The whole is allowed to settle, then 3 c.c. of concentrated $\mathrm{HCl}$ are passed to the bottom without any bubbling of air, when iodine is liberated in proportion to the free O. The contents,

1 Permanganate is liable to contain ammonia, and give turbid Nesslers.

2 Report to Royal Sewage Commission, vol. iv., part v., I904, p. 26.

3 fourn. Soc. Chem. Ind., xv., 15, xviii., 340; Chemical News, May 30, 1902. 
after mixing, are poured into a porcelain dish and rapidly titrated with centinormal thiosulphate and starch, as already described under "Oxygen consumed."

The calculation is as follows. For this purpose a correction for temperature and pressure is not necessary :

I c.c. of $\mathrm{O}=0.001434$ gramme.

I c.c. centinormal thiosulphate $=00^{\circ} 00008$ gramme $\mathrm{O}$.

$\therefore$ I c.c. centinormal thiosulphate $=\frac{0.00008}{0.001434}=0.055^{8}$ c.c. O.

The volume of liquid taken being known, the result is calculated to c.c.'s of dissolved oxygen per litre of the sample. To simplify the calculation, a coefficient should be obtained, converting the c.c. of thiosulphate required, by the volume in the bottle used, directly into c.c. of O per litre.

Example.-The bottle held 342 c.c. when full (this volume is etched on the bottle):

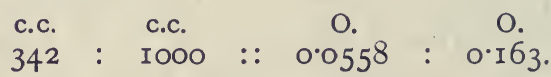

Therefore, for this bottle, I c.c. thiosulphate $=0^{\circ} 163$ c.c. $O$ per litre.

A table can then be constructed giving the direct reading. The value of this determination can be gathered from the fact that in all the later purifying changes of sewage oxygen is absorbed. It has been too much neglected, owing to the difficulty of the methods usually proposed and the complication of the apparatus. To be of practical value it must be done on the spot, within a few minutes of collection, and without change of temperature, agitation, or exposure to air, so that, of course, accuracy must be to a certain extent subordinate to rapidity.

To begin with, a trial should always be made with the ordinary tap water, which may be assumed to be fully aerated. It will be found to contain about 7 c.c. of $O$ per litre. According to the laws of solution of gases, at higher temperatures in summer rather less, in winter more, will be dissolved. Roscoe and Lunt in their table give at $5^{\circ} \mathrm{C} ., 8.68$; at $10^{\circ} \mathrm{C} ., 7^{\circ} 77$; at $15^{\circ}$ C., 6.96 ; at $20^{\circ}$ C., 6.28 c.c. of $\mathrm{O}$ per litre in saturated water. ${ }^{1}$ It is rarely that the temperature of good effluents falls below $10^{\circ} \mathrm{C}$., owing to the heat produced by the oxidation of the organic matter. I have found in trials of the tap water in

1 Journal of the Chemical Society, 1889, p. 552. 
different parts of England $7^{\bullet} 2,7^{\bullet} 33,7^{\bullet} 24$, and similar numbers of c.c. of dissolved oxygen per litre at ordinary temperature.

Useful data to record are-

7 c.c. of oxygen per litre $=1$ part by weight in $100,000 .^{1}$

I cubic foot of $\mathrm{O}=40^{\circ} 6$ grammes,

Or, I gallon of $\mathrm{O}=5^{\circ} 5^{2}$ grammes.

This process is interfered with by the presence of large quantities of organic substances, .which absorb the liberated iodine, and by the nitrites, which occur in many effluents, themselves setting free iodine when acidified. Such interference can be to a great extent prevented by working very rapidly, running in the thiosulphate till the brown colour of iodine has just disappeared, not using starch, and can be completely eliminated by Rideal and Stewart's modification (Analyst, June, IgoI), which also has the advantage of giving a determination of the immediate oxygen consumed. Fifty or Ioo c.c. of the original liquid, acidified with I c.c. of $\mathrm{H}_{2} \mathrm{SO}_{4}$, are first titrated with decinormal permanganate, till a faint pink colour persists after ten minutes. The c.c. required is calculated to the volume of the bottle in which the free oxygen determination is to be done. This amount is then placed in the bottle, together with I c.c. of sulphuric acid (if more than Io c.c. of permanganate are required, 2 c.c. of acid must be added), the bottle is filled with the liquid under examination, mixed by rotation, and allowed to stand five or ten minutes. It is advisable to add about $0^{\prime} I$ c.c. of permanganate in excess, so that the liquid remains faintly pink. If this addition should be overdone, the bottle is opened, $\frac{1}{2}$ c.c. of a 2 per cent. solution of neutral potassium oxalate added with a pipette, the neck filled up with the water under examination, the stopper inserted, and the bottle rotated as before. The colour quickly disappears, and the solution is ready for the manganous chloride, etc., as in the ordinary determination. To balance the sulphuric acid, a rather larger proportion of soda is required. When working with sewages and effluents we use a 50 per cent. soda + Io per cent. KI ; after oxidizing with permanganate, 3 c.c. of this, and afterwards 5 c.c. of $\mathrm{HCl}$, are added.

The volume correction for the reagents is small, and can

1 This enables us to easily translate the ordinary figures of c.c. of O per litre into parts by weight per 100,000 ; the latter mode of recording is adopted commonly in America, and has the advantage of uniformity with the other analytical figures. 
usually be neglected. When, however, the oxygen is low, the reagents, being presumably saturated with oxygen under atmospheric conditions, will make the result too high. The correction then to be applied is :

$$
\text { Corrected oxygen in c.c. per litre }=\frac{1000 a-\mathrm{R} n}{\mathrm{~V}-n},
$$

where $a=$ c.c. of oxygen found by titration, $\mathrm{V}=$ volume of bottle, $n$ that of reagents, while $\mathrm{R}$ is the c.c. of oxygen in a litre of saturated water at the temperature of the experiment, which is preferably actually determined, or can be obtained from a table such as Roscoe and Lunt's.

The approximate "percentage of saturation," or "aeration figure," is calculated by multiplying the dissolved oxygen in the sample by Ioo, and dividing by the normal dissolved oxygen -at the temperature, as obtained by testing tap water, or from a table. The figure becomes much less reliable if any great changes of temperature (or pressure) have occurred during the sewage treatment.

The rate of change of the free oxygen and of the nitrates and nitrites, and the "oxygen consumed," when controlled by a chlorine determination, measure the activity of bacterial processes.

Dissolved Nitrogen and other Gases. - When these can be separated and measured in a gasometric apparatus, they give further indications, as Adeney has pointed out, of the nature of the changes in sewage and in river and sea water. But his figures show that the proportional range of variation of the nitrogen (usually I 3 to $15^{\circ} 5$ c.c. per litre) is much less than that of the oxygen $\left(7^{\circ} 5\right.$ to nothing), and that the amount of $\mathrm{CO}_{2}$ is largely affected by rain. Dr. Adeney assumes that the $\mathrm{N}$ and $\mathrm{O}$ are derived entirely from the atmosphere, and should have the ratio of nearly 2 to I in which they are dissolved by pure water exposed to the air. He then calculates the percentage of saturation with oxygen (taken as an index of the rate at which the liquid is absorbing oxygen, and therefore the degree to which it is polluted) from the dissolved nitrogen found. Thus:

$$
\frac{\text { Dissolved O found } \times \text { 100 }}{\frac{1}{2} \mathrm{~N} \text { found }}=\text { "percentage of saturation." }
$$

This is not safe, because (I) the dissolved nitrogen is increased by bacterial action-in some cases he records more nitrogen 
than could have been taken up from the air at the temperature, showing that another agency was causing supersaturation; (2) oxygen is given off by vegetation; temperature may have changed.

Nitrous and nitric oxides and methane have also been found in small quantities among the dissolved gases. (See Chapter V.)

Carbonic Acid in Sewage and Effuents.-In I859 W. A. Miller pointed out the value of the determination of this and other dissolved gases, and gave analyses of the "sewage-laden " water of the Thames at Woolwich and in the clearer upper reaches at Kingston, showing dissolved gases per litre:

\begin{tabular}{|c|c|c|c|c|c|}
\hline & & & & Kingston & Woolwich. \\
\hline $\mathrm{CO}_{2}$ & $\cdots$ & $\cdots$ & $\cdots$ & .. $30 \cdot 3$ & $4^{8 \cdot 3}$ \\
\hline N & $\cdots$ & $\cdots$ & $\ldots$ & I $5^{\circ} \mathrm{O}$ & 14.5 \\
\hline $\mathrm{O}$ & $\ldots$ & $\cdots$ & $\ldots$ & $7 \%$ & 0.25 \\
\hline & & & & $5^{2 \cdot 7}$ & 63.05 \\
\hline
\end{tabular}

Dibdin found that aeration falls from $\delta_{5}$ per cent. of the possible at Teddington to about 22 per cent. at Woolwich, and rises again to about 90 per cent. at the Nore. The organic matter of the sewage entering the lower reaches of the river is thus oxidized at the expense of the dissolved oxygen, producing nitrogen and carbonic acid. As the former is always near the saturation point in a liquid freely exposed to the air, we cannot gather from its determination how much has been evolved as gas. But the amount of dissolved $\mathrm{CO}_{2}$ in a sewage or effluent will be always much lower than the organic matter which has produced it, on account of the loss by diffusion. Useful information, however, may be sometimes obtained in the following way :

Equal volumes (about roo c.c.) of the sewage and of the corresponding effluent are precipitated in closed vessels with excess of clear lime-water, and, after settling, filtered; the precipitated carbonate of lime is washed with boiled distilled water, transferred to a dish, and titrated with decinormal $\mathrm{HCl}$, using methyl orange as indicator. The increase in the amount of carbonic acid found in the effluent will indicate the minimum amount of carbon that has been oxidized in the purification process. One c.c. of decinormal acid $=0^{\circ} 022$ gramme of $\mathrm{CO}_{2}$, or 0.0006 gramme of carbon.

I will give some examples from my own experiments : 


\begin{tabular}{|c|c|c|c|c|c|c|}
\hline \multirow{2}{*}{ Sample. } & \multicolumn{3}{|c|}{ C.C. ACID PER LITRE. } & \multirow{2}{*}{$\begin{array}{l}\text { Grammes } \\
\mathrm{CO}_{2} \text { pro- } \\
\text { duced per } \\
\text { 100, } 000 \text {. }\end{array}$} & \multirow{2}{*}{$\begin{array}{l}\text { Equal to Grammes } \\
\text { Carbon oxidized } \\
\text { per 100,000. }\end{array}$} & \multirow{2}{*}{$\begin{array}{l}\text { Equal to Pounds of } \\
\text { Carbon oxidized per } \\
\text { 1,000,000 Gallons } \\
\text { Sewage. }\end{array}$} \\
\hline & Sewage. & Effluent. & Gain. & & & \\
\hline I & $25^{2} 2$ & $82 \cdot 0$ & 568 & 12.5 & $3.4 \mathrm{I}$ & $34 \mathrm{I}$ \\
\hline 2 & $38 \cdot 0$ & $94^{\circ} 4$ & 56.4 & $124^{\circ} \mathrm{I}$ & $3 \cdot 38$ & 338 \\
\hline 3 & $60^{\circ} 0$ & $105 \cdot 6$ & $45^{\circ} 6$ & $10{ }^{10} 3$ & $2 \cdot 74$ & 274 \\
\hline
\end{tabular}

The last column illustrates one advantage of stating the results in parts per 100,000. As a gallon of water is ro pounds, they are translated at once into pounds per million gallons by multiplying by 100 .

Incubator Tests.-From the very beginning it has been known that a water which was good and sweet would "keep," and that another which was bad in origin would "foul." C. Heisch, in his "sugar test" of I870, added pure cane-sugar to the sample, and exposed it to sunlight, noticing growths and odours developed. The incubation test was first developed by Dupré in I884. He stated in reports to the Local Government Board that if a pure thoroughly aerated water be kept out of contact with air for, say, ten days it will be found to have remained fully aerated. Sewage-polluted water also, when sterilized hy heating, remains fully aerated. But if the water contained any impurity capable of combining with oxygen, and also contained living organisms, the amount of aeration would diminish. It was hoped that the degree of diminution would give some measure of the number of organisms present. This was at a time when the number of organisms was more considered than their species, functions, or activity. The process involved determinations of free dissolved oxygen similar to those we have described, and is still of considerable value.

The fermentation in closed vessels resembles that at the bottom of rivers and of deep ponds. But the dissolved oxygen in saturated water only amounts to about I part by weight in I00,000, so could not be sufficient to oxidize the organic matter of mixed liquids which, exposed to the air, would rapidly improve. Thus a town sewage gave the following figures under open and closed conditions, before and after passing through a septic tank :

Dissolved OXYGen in C.C. PER LITRE.

Kept six days in closed full bottles Exposed to air in a layer I foot deep :

$\begin{array}{lllll}\text { Twenty-four hours } & \ldots & \ldots & \ldots & \text { I.8I } \\ \text { Forty-eight hours } & \ldots & \ldots & & 3.02\end{array}$

$\begin{array}{ccc}\begin{array}{c}\text { Raw Sewage. } \\ \ldots\end{array} & 0.59 & \begin{array}{c}\text { Tank Effluent. } \\ 0.43\end{array} \\ \ldots & \text { I.81 } & 2.06 \\ \ldots & 3.02 & 4.74\end{array}$


The odour in the closed bottle increased; in the second case of exposure to air it was very slight after twenty-four hours, and none after forty-eight hours. Under natural conditions, therefore, the sewage would have become inoffensive.

The open aeration test indicates approximately what takes place in shallow or moving bodies of liquid. Dibdin and Thudichum ${ }^{1}$ allow a mixture of I part of effluent and I of fully aerated water to stand in an open vessel of diameter equal to the depth, and estimate the dissolved $\mathrm{O}$ daily ; it should not fall below 50 per cent. of saturation. When Thames water was up to this limit they found no suggestion of nuisance, and fish migrated freely. When, however, the large quantity of organisms and organic matter take up oxygen more quickly than it can be absorbed from the atmosphere the water becomes foul.

I have examined this test very carefully, ${ }^{2}$ as it is nearer to ordinary conditions than closed incubation. The relation of surface to volume must be uniform in different experiments. Dibdin's suggestion of "diameter equal to the depth" is unsatisfactory, since calculation will show that in that case the surface-volume ratio varies with vessels of different diameters. I recommend as the best directions for carrying out the test uniformly " the samples should be kept at a uniform temperature in cylinders 6 inches deep and 3 inches wide, exposed to air and light, but protected from dust. The volume will then be about 600 c.c., and the ratio of surface to volume I to 6."

Even with uniform physical conditions the action varies greatly with the nature of the organisms in the sewage, and in the water used for dilution. A filtered water-supply is far less active than river water.

Distilled water and sewage, when sterilized and air-free, absorb oxygen from the air at very nearly the same rate until they are saturated, whereas with raw sewages the absorption is at first normal. After a few hours the consumption of oxygen overpowers the absorption from the air, so that the amount in solution sinks considerably below 50 per cent. in twenty-four hours.

The closed incubator test made prominent at the Manchester inquiry of 1899 is differently carried out: "A determination is first made of the $\mathrm{O}$ absorbed from permanganate by the original sample in three minutes. A bottle is then completely filled with the sample, and closed and placed in the incubator at

1 Fournal of the Socicty of Chenical Industry, June 30, I900.

2 Analyst, xxvi., 305, August, I901. 
$80^{\circ} \mathrm{F}$. for five days. The three minutes absorption of $\mathrm{O}$ is then again determined. If any putrefaction has taken place the oxygen absorbed in three minutes will increase in amount, owing to the more ready oxidizability of the products of putrefaction. On the other hand, if the sample keeps sweet there will be a slight decrease in the three minutes absorption after incubation, owing to the slight oxidation of the impurities which has taken place during the five days by means of air dissolved in the sample." Any change of odour or appearance of putridity is also carefully noticed.

This test, although extremely useful, is arbitrary in character, as an effluent is not intended to be stored by itself, but when finished to be discharged at once into water which is moving and aerated. If an effluent passes the incubator test it can be discharged into a dry ditch without fear of subsequent putrefaction. At Manchester they determined the behaviour of mixtures of equal volumes of bacterial filtrate and Ship Canal water, and have found that almost invariably such mixtures remain sweet. The Ship Canal water alone, when tested in this way, frequently gives an unsatisfactory result, so that the effluent actually improves the waters of the canal.

The Mersey and Irwell Joint Board incubate at $65^{\circ} \mathrm{F}$. for seven days, but by working at the higher temperature of $80^{\circ} \mathrm{F}$., as above, results are obtained in a shorter time.

Weights of Excreta discharged per Day per Average Person.These have been given as follows : ${ }^{1}$

\begin{tabular}{|c|c|c|c|c|}
\hline \multirow[b]{2}{*}{ 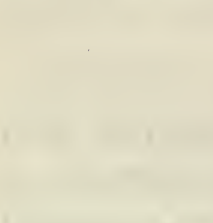 } & & \multirow{2}{*}{$\begin{array}{l}\text { Grammes } \\
\text { per Day. }\end{array}$} & \multicolumn{2}{|c|}{$\begin{array}{l}\text { CORRESPONDING TO PARTS PER IOO,000 } \\
\text { IN THE SEWAGE. }\end{array}$} \\
\hline & & & $\begin{array}{l}\text { With a Water-Supply } \\
\text { of roo Litres } \\
\text { (22 gallons) per Head. }\end{array}$ & $\begin{array}{l}\text { With a Water-Supply } \\
\text { of } 150 \text { Litres } \\
\text { (33 gallons) per Head. }\end{array}$ \\
\hline 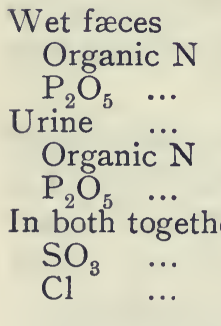 & $\begin{array}{c}\ldots \\
\ldots \\
\ldots \\
\ldots \\
\ldots \\
\ldots \\
\mathrm{r}: \\
\ldots \\
\ldots\end{array}$ & $\begin{array}{c}90 \cdot 7 \\
I \cdot 34 \\
I \cdot 88 \\
\text { I I } 74 \\
\text { IO } 52 \\
2 \cdot 1 \text { I I }\end{array}$ & $\begin{array}{c}90 \cdot 7 \\
I \cdot 34 \\
\text { I } \cdot 88 \\
\text { I I } 74 \\
\text { IO } \\
2 \cdot 52 \\
2 \cdot 1 \text { I } \\
\\
\text { I. } 88 \\
5 \cdot 04\end{array}$ & $\begin{array}{c}60^{\circ} 4 \\
0 \cdot 92 \\
I \cdot 26 \\
783 \\
7^{\circ} \cdot 0 \\
I^{\circ} \cdot 4^{I}\end{array}$ \\
\hline
\end{tabular}

1 Frankland, Rivers Pollution Commission, I890. 
The amount of fæces given in the above figures includes the water associated with them; the fæcal solids insoluble in water and dried free from associated water amount to from one-half to one-third the above, and therefore the quantity of matter required to be brought into solution by a liquefying or hydrolytic process is approximately 20 to 45 parts per roo,ooo. In chemical processes where sludge is formed, this, being still wet and associated with water, will amount to 60 to 90 parts per I00,000. These are minimum figures, and, of course, in precipitation processes the weight of sludge is increased by the weight of lime or other precipitant mixed with the fæcal solids. Road detritus, in the absence of settling tanks. and solids of non-excrementitious origin also frequently cause the above amounts to be exceeded.

Proposed Standards.-Sewage does not properly include manufacturing waste liquids. Many authorities prohibit the admission of such refuse into the sewers without preliminary treatment. For example, the West Riding of Yorkshire Act for 1894 included as sewage to be treated by the local authority "unpurified urine, excrementitious matter and liquid refuse of any house or premises, blood and the washings of the slaughter-house containing urinary or fæcal matter," but excluded any liquid rendered poisonous, noxious, or polluted in the course of some manufacturing process.

Amongst the standards which have been proposed in the past, or have been adopted by local bodies, are the following, some of which have been repeatedly quoted in papers on the subject, while others are gathered tentatively from published documents, or from a consideration of decisions in disputed cases. None of them, however, have strictly the force of law; in fact, some have actually been disclaimed by the bodies to which they were attributed. The proportions are parts per I00,000: Rivers Pollution Commissioners-organic carbon, 2*0; organic nitrogen, $0 \cdot 3$. Thames Conservancy-organic carbon, $3^{\circ} \mathrm{O}$; organic nitrogen, $I^{\cdot} I$. The Thames Conservancy state that they require a higher standard for effluents above the intakes of the London water-supply than for those below. Derbyshire County Council-albuminoid ammonia, $0^{\circ} \mathrm{I}$; oxygen absorbed, $I^{\bullet} 0 .{ }^{1}$ Ribble Board - albuminoid, O'I ;

1 This Council now add: "An effluent should contain more than 0.5 part per I00,000 of $\mathrm{N}$ as nitrates; it should be so thoroughly oxidized that it does not absorb more $\mathrm{O}$ after incubation for one week than it does at the time of collection; and-'Shake Test ${ }^{\circ}$ : when shaken vigorously for one minute in a half-filled 
oxygen absorbed, $2^{\circ}$. . Mersey and Irwell-albuminoid, 0.I4; oxygen absorbed, I*40. Provisos as to amount of suspended solids, acidity, alkalinity, metals, etc., are inserted in some, and have special reference to manufacturing effluents. But in all these arbitrary limits no account is taken of the volume of the river into which the effluents are discharged, although attention was long ago drawn to the purifying action of river water.

The Local Government Board have often been asked to lay down a standard of purity for sewage effluents, but have refused, on the ground that all the circumstances of each case should be taken into consideration.

The London County Council many years ago recognised the fact that an oxidizing agent added to the effluent at the time of contact with the river prevents any foulness. Provided, therefore, a river is well aerated, or an effluent is well nitrated, or an oxidizing agent is supplied in sufficient quantity at the time of contact, an effluent may contain a larger quantity of organic matter than has been sanctioned in the past, and variations in such quantities are permissible under conditions varied in the above way. The limits recommended in the United States by R. Hering and the Massachusetts Board for the amount of free ammonia that may be allowed in discharges into a stream correspond to about 50 volumes of river water to average sewage in this country. Such conditions are only possible under very special circumstances, while the limit is much greater than we have found necessary in England. In other words, most experts now agree that the quality of the stream, and not of the effluent, should be taken as a basis, and that some fixed distance below the outfall in mid-stream should be specified as the locality at which samples should be taken.

Dibdin's Fish Test.-Mr. Dibdin describes this test as follows : "He had long since adopted in his own mind a physiological standard-viz., that the quality of an effluent should be such that fish could live healthily in it. . . . Such a definition involves necessarily the absence of poisons and the presence of oxygen." But while an effluent which kills fish is obviously unhealthy, it does not follow that one where fish will live is therefore a good one. It is well known that fresh-water fish are gross feeders, and fish in large numbers are often seen to 
congregate at the mouths of sewers where fæcal matter is visibly floating, being attracted by the fragments of food and insects carried down by the sewage. Fish, in fact, are more affected by muddy water and by chemicals from factories than by excreta. Duncan and F. Hoppe Seyler found that perch, trout, etc., could thrive in water holding 3 or 4 c.c. of oxygen in solution per litre, but soon died when only $I$ "7 c.c. was present. $^{1}$

Many waters are inoffensive which contain a comparatively high amount of albuminoid ammonia. The following, on the other hand, is an example of a putrescent and otherwise objectionable liquid which did not show a corresponding excess of albuminoid. I diluted a putrid meat solution with water in the proportion of I to 6,000 , and the fluid, which smelt strongly like sewage, was analyzed like an ordinary sewage effluent. It gave in parts per 100,000-free $\mathrm{NH}_{3}, 0.025$ albuminoid $\mathrm{NH}_{3}, 0.083$; oxygen consumed, 0.044 ; no nitrite or nitrate. This liquid remained putrid and foul-smelling for more than a week. Dr. Kenwood experienced "that the albuminoid ammonia in offensive effluents was initially materially below that of several of the inoffensive effluents."2

It is obvious, therefore, that an arbitrary standard based upon the albuminoid figure is valueless.

The processes at work in destroying putrescible matter in sewage involve its transition into products yielding albuminoid and free ammonia ; an increase in the free ammonia, therefore, is actually a proof that so much destruction of nitrogenous organic matter has occurred. Albuminoid ammonia in an effluent may also be a good sign, indicating either that organic matter as sediment has gone into solution, or that stable soluble matter has been partially broken up. ${ }^{3}$

In I893 I showed that different kinds of "albuminoid ammonia" are possible, since waters containing fresh sewage which has been partly oxidized by sodium peroxide yield the remainder of their ammonia to alkaline permanganate much more rapidly than when the water has not been so treated. This suggests the presence in waters of organic nitrogenous matters which, when partially oxidized, are then in a condition to be completely broken up by the stronger reagent. When

1 Zeit. physiol. Chemie, xvii., I65.

2 Fournal of the Royal Sanitary Institute, vol. xxii., part ii., p. 108.

3 Rideal, British Association Reports, 1893. 
the albuminoid ammonia process was introduced it was well known that there was a varying relation between the quantities of albuminoid ammonia and the amount of organic nitrogenous matter. Too much importance must not, therefore, be placed on this item of the analysis.

An effluent that is in an active state of wholesome bacterial change, in presence of free and potential oxygen, will conform to Adeney's proposed test: "The limit of impurity to be allowed in a water should be such that when a given volume of it is mixed with a given volume of fully aerated river water, and the mixture kept out of contact with air, a decided oxidation of the ammonia originally present into nitrous or nitric acid shall be indicated." It will be seen that this proposal is practically an incubation test, and the result obtained by it should be similar to those given by the incubator test already described.

\section{Ratio of the Chlorine to the Total Nitrogen.}

In perfectly fresh excreta, taking the solids and liquids together, the total nitrogen somewhat exceeds the chlorine. This proportion will remain unchanged when diluted with water containing only the ordinary small amount of chlorine, as long as the nitrogen remains in fixed forms. Therefore the ratio is applicable to fresh sewages generally, independent of dilution, but will be immediately altered by the production of gas. Let $\mathrm{Cl}$ and $\mathrm{N}$ be the parts of chlorine and nitrogen respectively, the "residual ratio" will be-

$$
\mathrm{R}=\frac{\mathrm{N} \times 100}{\mathrm{Cl}}
$$

or, in cases of great dilution, with a high chlorine $\mathrm{W}$ in the water-supply,

$$
\mathrm{R}=\frac{\mathrm{N} \times 100}{\mathrm{Cl}-\mathrm{W}}
$$

The simpler formula is usually sufficient. In the original excreta the number $\mathrm{R}$ will be somewhat over 200, in fairly fresh sewage it will be about Ioo; in bacterial effluents, on the other hand, the fall of $\mathrm{R}$ will indicate the gaseous dispersal of nitrogen. With chemical or mechanical treatment $\mathrm{R}$ will fall, owing to the abstraction of matter as sludge. Where heavy nitrification has been the main feature there may be little or no fall, this afterwards occurring rapidly in the process 
of denitrification, when the effluent is admixed with other water.

The following table bears on this point $:^{1}$

Table of the Relation of Nitrogen to Chlorine and of Oxidation.

\begin{tabular}{|c|c|c|c|c|}
\hline & Chlorine. & $\begin{array}{c}\text { Total } \\
\text { Nitrogen }\end{array}$ & $\left(\begin{array}{c}\mathrm{R} \\
\left(\frac{\mathrm{N} \times \text { I0O }}{\mathrm{Cl} .}\right)\end{array}\right.$ & $\begin{array}{l}\text { Percentage } \\
\text { of } \\
\text { Oxidation. }\end{array}$ \\
\hline \multicolumn{5}{|l|}{ Raw sewages: } \\
\hline Exeter & $7 \cdot 5$ & $6 \cdot 37$ & 85 & Trace. \\
\hline Sutton & 8.99 & $8 \cdot 8 \mathrm{I}$ & 98 & 0.2 \\
\hline London $\quad \ldots \quad \ldots$ & $10 \% 4$ & $7 \cdot 06$ & 68 & Trace. \\
\hline \multicolumn{5}{|l|}{ Effluents and filtrates: } \\
\hline $\begin{array}{l}\text { London outfall (removal of } \\
\text { the } \mathrm{N} \text { by precipitation) }\end{array}$ & 10.5 & $4 \cdot 26$ & $4 \mathrm{I}$ & Trace. \\
\hline Exeter septic $\tan k \ldots \ldots$ & $7 \cdot 5$ & $5 \cdot 96$ & 80 & $0 \cdot 3$ \\
\hline Exeter coke breeze filtrate & $7 \cdot 5$ & $3 \cdot 42$ & 46 & $3^{2}$ \\
\hline Sutton bacterial tank $\quad \ldots$ & $6 \cdot 94$ & $2 \cdot 97$ & 43 & I9 \\
\hline Sutton coke breeze filtrate ... & $6 \cdot 84$ & 2.00 & 30 & $5^{6}$ \\
\hline Ashtead tank effluent (I) ... & $6 \cdot 3$ & $6 \cdot 60$ & IO5 & - \\
\hline Ashtead filtrate $\quad \ldots \quad \ldots$ & $6 \cdot 4$ & $7 \cdot 16$ & I 12 & $84 \cdot 3$ \\
\hline Ashtead tank effluent (2) ... & $5 \cdot 5$ & $5 \cdot 35$ & 97 & \\
\hline Ashtead filtrate $\quad \ldots \quad \ldots$ & $5 \cdot 5$ & $4^{\circ} 5^{2}$ & 82 & $96 \cdot 7$ \\
\hline
\end{tabular}

As unoxidized nitrogen is a constituent of the more dangerous kinds of natural pollution, the ratio between the different forms of nitrogen furnishes more useful information than a mere consideration of its amount, since nitrogen compounds when oxidized are harmless, but when unoxidized are liable to occasion smells, and to be in other respects deleterious. A certain quantity of $\mathrm{N}$ is lost as gas during the changes, but the residue will give a minimum measurement of the original sewage strength. The proportion between the oxidized and unoxidized $\mathrm{N}$ will then denote the extent to which the sample has been purified. A judgment can therefore be formed from the sample without an analysis of the original sewage, as the chlorine contents also give a clue to the strength, and thus such a method has an advantage over the ordinary systern of calculating sewage purification, as it obviates the difficulty of obtaining conformable samples. It is useful also to make a correction to a standard chlorine value in comparing the

1 Phelps has drawn up a table showing the application of this formula to American Sewages (American Technology Quarterly, March and June, 1905). 
sewage entering and the effluent leaving a works. As ammonia must be considered a preparatory or transition, and not a finished product, it must be counted as part of the residual unoxidized sewage, and only indicates progress towards complete purification, and gives a criterion as to whether a process is working satisfactorily. A few examples to show how the percentage of oxidation reveals the purification effected by different agencies may be quoted here:

\begin{tabular}{|c|c|c|c|c|c|c|}
\hline & \multirow{2}{*}{$\begin{array}{l}\text { Oxygen } \\
\text { con- } \\
\text { sumed. }\end{array}$} & \multicolumn{4}{|c|}{ PARTS PER 100,000 of NITROGEN. } & \multirow{2}{*}{$\begin{array}{l}\text { Percentage } \\
\text { of } \\
\text { Oxidation. }\end{array}$} \\
\hline & & As $\mathrm{NH}_{3}$. & Organic. & $\begin{array}{c}\text { Total } \\
\text { Un- } \\
\text { oxidized. }\end{array}$ & $\begin{array}{c}\text { As Nitrate } \\
\text { and } \\
\text { Nitrite. }\end{array}$ & \\
\hline $\begin{array}{l}\text { A raw sewage.. } \\
\text { A filtrate effluent } \quad . . \\
\text { Another filtrate effluent } \\
\text { London river water ... } \\
\text { Same filtered ... } \\
\text { Deep well in chalk } \quad . .\end{array}$ & $\begin{array}{l}6 \cdot 66 \\
0.78 \\
0 \cdot 36 \\
0 \cdot 20 \\
0 \cdot 176 \\
0 \cdot 013\end{array}$ & $\begin{array}{l}3 \cdot 0 \\
2 \cdot 4 \\
0.92 \\
0 . \text { oor } 6 \\
\text { None } \\
\text { None }\end{array}$ & $\begin{array}{l}6 \cdot 12 \\
0 \cdot 92 \\
0 \cdot 44 \\
0 \cdot 049 \\
0 \cdot 026 \\
0 \cdot 008\end{array}$ & $\begin{array}{l}9^{\circ} \mathrm{I} 2 \\
3^{\circ} 32 \\
I \cdot 36 \\
0 \cdot 05 \mathrm{I} \\
0 \cdot 026 \\
0.008\end{array}$ & $\begin{array}{l}\text { None } \\
I \cdot I 6 \\
I \cdot 09 \\
0 \cdot 305 \\
0 \cdot 254 \\
0 \cdot 450\end{array}$ & $\begin{array}{l}\text { None. } \\
26 \cdot 0 \\
44^{\circ} 5 \\
86 \cdot 0 \\
91^{\circ} 0 \\
97^{\circ} 6\end{array}$ \\
\hline
\end{tabular}

I may remark that "percentages of purification," the only figure given in some statements, indicate the work done by the sewage installation, but not necessarily the quality of the effluent. 


\section{CHAPTER IV}

\section{BACTERIA OCCURRING IN SEWAGE}

Their identification and numbers and morphological characteristics -Bacterial tests for the purity of effluents-Possibility of the survival of pathogenic organisms.

THE enormous number and variety of organisms present causes some difficulty in the bacteriological examination of sewage. In London, for example, in 1898 the number of bacteria per c.c. in the crude sewage at Barking varied between 500,000 and $7,000,000$, and at the Crossness outfall between 2,500,000 and $5,000,000$. Obviously millions cannot be dealt with, and therefore a minute average fraction of the sample, bearing a definite relation to the whole, has to be examined. If we attempted to measure such small quantities directly it would neither be accurate nor representative of the whole; a systematic dilution of the sewage has therefore to be followed.

Collection of Samples.-These are collected in previously sterilized glass-stoppered, or, better, rubber-stoppered, bottles holding about Ioo c.c., which are filled so as to allow a small air-space, placed in water-tight tins, at once packed in ice, and despatched to the laboratory. If possible, the culture plates for counting the number of bacteria should be started on the spot, and then conveyed to the laboratory for incubation, as organisms multiply exceedingly rapidly in sewage, owing to the quantity of organic matter that is present, though this is to a great extent retarded by the ice.

Dilution of the Sewage.-To inoculate the different cultures for isolating and counting the various bacteria present, the sewage is diluted in the following manner :

A number of I-c.c. pipettes and flasks, holding about I5O c.c., are plugged with cotton-wool and sterilized. Ninety-nine c.c. of sterile water are then placed in each of the flasks, and I c.c. of the sewage is then added to No. I flask and well shaken; with another pipette I c.c. of this dilution (corresponding to 
o.or c.c. of the original) is transferred to No. 2 flask, and so on. In this manner minute fractions of a c.c. of the original can be taken with great accuracy, provided that each dilution is well shaken so as to evenly distribute the bacteria.

Nutrient Media.-Cultivations are made with various media, such as nutrient gelatine, agar-agar, meat broth, milk, bloodserum, potatoes, albumin, etc. The most important of these is the nutrient gelatine, which consists of meat broth mixed with Io to 15 per cent. of gelatine, I per cent. of peptone, and 0.5 per cent. of common salt; it is rendered neutral or very faintly alkaline, and clarified with egg-albumin. While hot, quantities of about Io c.c. are run into test-tubes fitted with cotton-wool plugs, the cotton-wool and tubes having been previously sterilized by heat. These tubes are then fractionally sterilized by steaming for half an hour on three successive days. When properly prepared the jelly is quite bright, should not melt at $22^{\circ} \mathrm{C}$., and should undergo no alteration on keeping, as the cotton-wool plugs, while admitting air, exclude the micro-organisms floating in it. Agar-agar is prepared in a similar manner, I $\frac{1}{2}$ to 2 per cent. of agar being substituted for the gelatine; this remains solid at blood heat, and is therefore used for cultures at the higher temperatures. Tubes of gelatine and agar are always stocked, and are employed for the following cultivations :

I. Plate cultures, originally devised by Koch, are almost invariably resorted to for the isolation of bacteria. A gelatine tube is melted at a temperature of about $30^{\circ}$ C., I c.c. of the sufficiently diluted sewage is added with a pipette, the tube is gently shaken, and the contents poured into a shallow glass dish with a close-fitting lid, this "Petri dish" and the pipette having been previously sterilized in a hot-air sterilizer. The gelatine is now allowed to set, the Petri dish being placed on a levelled plate, incubated at $20^{\circ}$ to $22^{\circ} \mathrm{C}$., and examined from day to day. If the sewage has been properly diluted, after about forty-eight hours, according to the temperature, a number of centres of growth become visible in the gelatine. These "colonies," which are due to proliferation of single scattered organisms, will usually consist of pure cultures of the original germ, and soon exhibit characteristic differences. Some form cup-shaped depressions of liquid, others refuse to liquefy the gelatine. The colonies may be either raised above the surface or penetrate deeply into the gelatine; their outline may be 
ragged or circular, branchings from the centre or concentric circles may appear, they may remain colourless, or develop peculiar pigments.

If there is no guidance as to the strength of the sample under examination, a large number of these gelatine plates has to be prepared from varying quantities of the sewage in order to hit off the right dilution. In sewage and effluents a great many putrefactive species are capable of very quickly liquefying the nutrient gelatine, and therefore, if the plate be too crowded -containing, say, more than 200 colonies-the whole may become fluid, owing to the junction of the liquefying areas, before many colonies which do not develop so rapidly are visible to the naked eye. In order to obtain comparable results from plate cultures, it is important that the nutrient material employed should conform to a definite degree of alkalinity. The American Public Health Association adopted a standard of $+\mathrm{I}^{\circ} 5$ per cent. as yielding the best results; that is to say, the medium, which is alkaline to litmus, would require the addition of $\mathrm{I}^{\cdot} 5$ per cent. of normal soda solution to produce a pink tinge with phenolphthalein indicator. Nährstoff agar, which contains about I per cent. of Heyden's Nährstoff, incubated at room temperature, will yield nearly twice as many colonies as nutrient gelatine.

The colonies are counted with the aid of a magnifying-glass, the Petri dish being placed on a glass plate ruled in centimetre squares (Wolffhügel's apparatus), and as each colony originates from one individual, a factor is obtained from which the number of organisms present in the original sewage can be calculated. This is returned as "organisms per c.c.," stating the temperature of incubation and the nutrient medium employed.

The results so obtained, however, from such a material as sewage are below the total number of organisms, (I) because of the difficulty of insuring that each colony has arisen from a single organism, and (2) because many which are incapable of sufficient development on the nutrient medium will be omitted in the enumeration, such as some of the nitrifying, thermophilic, and anaerobic species. In my own experience, plates that have shown no colonies after three days' incubation have a little later developed numerous growths of cladothrix. The direct determination of the number of organisms in sewage by microscopic counting invariably yields results many times greater than those obtained by plate culture; this ratio increases with 
the purest effluents containing the nitrifying bacteria, which do not appear on ordinary media. When a minute fraction ( $0^{\circ} 05$ c.c.) of the sample is dried, fixed, and stained on a coverslip of known area, and the counts made with a micrometer on representative fields, Winslow and Willcomb, who have investigated this method, working with pure cultures of organisms thriving on ordinary nutrient media, found that the microscopic counts closely correspond to those obtained by plate cultivation, even when the number of bacteria is rapidly decreasing, and conclude that the presence of lifeless forms introduces no serious error, owing to the inability of the dead cells to take up the stain.

The number of spores of bacteria is determined by heating the nutrient material containing the sewage to $80^{\circ} \mathrm{C}$. for ten minutes before incubating.

The organisms which multiply at blood heat are examined by means of agar plate cultures prepared similarly to the gelatine plates, and incubated at $37^{\circ}$ to $38^{\circ} \mathrm{C}$. for one or two days.

2. Anaerobic Cultures.-As I have already stated, there are a number of organisms in sewage which do not thrive in the presence of oxygen, and in order to develop these anaerobes they must be incubated in an atmosphere of some indifferent gas, such as hydrogen, or preferably nitrogen. The cultures may be enclosed in a jar filled with gas, or containing a solution of alkaline pyrogallate to absorb the oxygen in the air.

I find that a certain amount of confusion has arisen from the application of the words "aerobic" and "anaerobic" in two slightly different meanings-one with reference to the chemical changes that occur, the other with regard to the organisms that produce them. As the words simply mean "living with air" and "living without air," the chemist has applied the term "anaerobic" to changes occurring by life in which free oxygen takes no part. Many of these are due to hydrolysis or the addition of water, like that of urea into ammonium carbonate, or cellulose into starch, dextrin, and sugar. In this sense the word "anaerobe" implies an organism that effects its changes in surrounding matter without oxidation. But a bacteriologist often uses the term " anaerobe" in the sense of "obligate anaerobe"-i.e., one that not only does not require oxygen, but is actually inhibited, or even killed, by its presence. The obligate anaerobes, as is shown by our table of bacteria in 
sewage, are, though exceedingly active, comparatively few. The facultative anaerobes, on the other hand-those that can live either with or without oxygen-are much more numerous, as being the ones most suited to a liquid which contains little or no oxygen, but may at any time become oxygenated. Thus yeast, which was classed by Pasteur as "both an aerobian and an anaerobian"-i.e., as facultatively anaerobic-when in presence of excess of oxygen multiplies vigorously, but does not act as a ferment; whereas in sugar solutions containing no oxygen it multiplies with less activity, but the fermentive character is most marked, the yeast attacking the sugar, and obtaining any oxygen it requires from it or from the water present. Boussingault found that normal fermentation could be carried on in vacuo, and was greatly promoted by removing the carbonic acid and alcohol as fast as they were formed, and thus preventing their retarding action. In the same way with bacteria a better result is attained when the liquid products are continuously removed, as in the bacterial tanks of Cameron and Moncrieff and the nitrifying trays of the latter, than where periods of stagnation occur, as in the intermittent system.

In order to preserve pure cultures and to identify growths obtained in the different plates, as soon as the colony is sufficiently developed it is carefully examined under a low power with the microscope, and minute portions transferred with a sterilized platinum needle to various culture media, and the development of these subcultures noted from time to time.

3. Streak Cultures.-A tube of melted gelatine or agar is allowed to solidify in a slanting position so as to expose a long surface; the tube is then inverted, the cotton-wool plug carefully removed, and the surface of the jelly lightly scratched with the infected platinum wire. The plug is then singed and quickly replaced. Streak cultures are specially adapted for the development of pigments, which generally require free access of air for their production.

4. Stab Cultures. - The tube is held horizontally, the inoculated wire plunged steadily nearly to the bottom, withdrawn, and the cotton-wool plug replaced. Certain ramifying growths show themselves better under this method, and, moreover, the occurrence of a growth in the deep layers will often reveal the presence of facultative anaerobic organisms, which can afterwards be dealt with.

5. Shake Cultures. - The fluid gelatine or agar is inoculated 
with the organism, gently shaken, so as not to produce airbubbles, and then allowed to solidify. If the organism produces gas during its growth, the jelly will soon become impregnated with small bubbles of the gas, which gradually increase in size and number. B. coli communis, a non-liquefying bacterium present in large numbers in sewage, gives the shake reaction after six hours' incubation at $38^{\circ} \mathrm{C}$. (See Fig. 4.)

6. Roll Cultures can be employed in the place of gelatine plates when it is required to start the cultures in situ, but they must be kept cool, and are soon spoilt by the liquefying bacteria of sewage. Quantities of about Io c.c. of nutrient gelatine are sterilized in wide test-tubes; these are inoculated in the usual manner, and a rubber cap is drawn over the cotton-wool plug. The tube is then held horizontally in cold water, and rotated with the fingers till an even layer of the gelatine has set round the walls of the tube.

7. Surface Plate Cultures. - A tube of gelatine is melted and poured into a Petri dish; the dish is then covered and set aside in a cool place, so that the gelatine shall become quite firm. One c.c. of the diluted sewage is then added, and rapidly spread over the surface of the gelatine with a sterile bent glass rod, and the cover replaced. After a few hours the nutrient gelatine will have absorbed the water, depositing all the bacteria on its surface, and thus preventing any colonies from starting in the depth of the gelatine. In this manner, after some days' incubation, the growths are all obtained as surface colonies, and, consequently, are easy to examine and subculture, whereas deep-seated colonies often remain mere dots, and in many cases do not show any differences. (See Fig. 6.)

In addition to the several methods of cultivation which I have described, special reagents may be incorporated with the nutrient media, such as litmus to demonstrate the production of acidity or alkalinity, an iron salt for $\mathrm{H}_{2} \mathrm{~S}$, magenta to detect any bleaching action, sugar to aid the production of gas, hydrochloric and carbolic acids to inhibit the growth of certain bacteria. Also, a number of micro-organisms, including many pathogenic forms, grow luxuriantly in a particular medium, their development in other culture materials, if any, being poor and not characteristic; indeed, all attempts to cultivate some have hitherto entirely failed, among which were the nitrifying bacteria, until it was found that they required food material practically free from fermentable organic matter. These 
organisms have, therefore, to be isolated by means of a silicajelly plate, proceeding, according to Kühne, as follows :

A solution of potassium silicate of about 5 per cent. strength is mixed with ro per cent. hydrochloric acid, placed in a parchment-paper dialyzer, and floated for two or three days on running water, protected from dust, until, after floating the dialyzer on distilled water for thirty minutes, the water is practically neutral, and gives only a faint reaction with nitrate of silver, showing that the chloride and free acid have been washed out. The solution of silicic acid should be clear and mobile. If there are a few white flocks in it they may be strained out; if many, the solution is spoilt. Two solutions are made, containing the following quantities of nutritive inorganic constituents in grammes:

(a) Ammonium sulphate, 0.4; magnesium sulphate, 0.05; calcium chloride, $0^{\circ} 0005$; distilled water, 50 c.c.

(b) Potassium phosphate, $0^{\circ} \mathrm{I}$; sodium carbonate, $0^{\circ} 075$; distilled water, 50 c.c.

They are separately sterilized, mixed in a sterile flask, and closed with a sterilized stopper. The silicic solution is boiled gently down till a sample, on cooling and mixing with onethird of its volume of the above saline solution, sets in about ten minutes into a sufficiently firm jelly. The saline solution is apt to deposit slightly, but, if kept sterile, is not rendered unfit for use. The liquid to be tested is mixed with the two solutions, and at once poured into Petri dishes to set, provision being made for an ample supply of oxygen. Plates of magnesiagypsum containing the above salts are used by Omeliansky. ${ }^{1}$

MacConkey's medium, which has to a great extent displaced the use of carbolic acid for determining coli organisms, depends upon the inhibitive action of bile salt. It may be prepared as follows: To distilled water add 2 per cent. of peptone and 0.5 per cent. of sodium taurocholate; dissolve as far as possible by heating, then add $0^{*} 5$ per cent. of glucose, and, after filtering, tint with litmus solution. The fluid should be clear and distinctly blue. It is sterilized in quantities of about ro c.c. in test-tubes containing a small inverted test-tube or "fermentation tube." During sterilization the latter is completely filled with the culture material, so that subsequently, if the growth of an organism is accompanied by the production of gas, it will collect, partially displacing the fluid.

\footnotetext{
${ }^{1}$ Chen. Centr., 1899, ii. 725.
} 
By cultivation in this material large numbers of bacteria are eliminated, and those capable of thriving are mainly of intestinal origin. After one or two days' incubation at blood heat, if organisms of the coli group are present, the fluid will have become turbid, the blue will be reddened and later may be bleached, and the fermentation tube will contain gas; the culture may be then plated and pure subcultures prepared. The great delicacy of this test in the bacteriological examination of drinking-waters has considerably modified proposed limits for the frequency of $B$. coli.

A convenient method of testing the bacterial efficiency of a process is to add a portion of the liquid to sterile sewage, obtained by means of a Pasteur filter, and to analyze it after a certain time. Thus, Dr. Sims Woodhead, in November, 1896 , isolated at Exeter five distinct species of bacteria from the crude sewage and three from the tank effluent, and found that these were practically the only ones which could grow freely in the sewage. He filtered samples of the tank effluent through a Pasteur-Chamberland filter into sterile flasks and tubes, and inoculated them in duplicate with cultures of the various organisms separated by the plate culture method. After six days' growth at the ordinary temperature, I determined for him the nitrate and nitrite, with the following results:

\begin{tabular}{|c|c|c|c|}
\hline & $\begin{array}{l}\text { Nitric N, Parts } \\
\text { per xoo,ooo. }\end{array}$ & $\begin{array}{l}\text { Percentage } \\
\text { increase of } \\
\text { Nitric Acid. }\end{array}$ & $\begin{array}{l}\text { Relative Amount } \\
\text { of Nitrous N, } \\
\text { ro being taken as } \\
\text { the Standard of } \\
\text { Measurement. }\end{array}$ \\
\hline $\begin{array}{l}\text { Sterile tank effluent } \ldots \\
\text { Sterile tank effluent }+ \text { crude }\end{array}$ & $0.66 \mathrm{I}$ & o & I0 \\
\hline $\begin{array}{l}\text { organism, No. I. } \ldots \\
\text { Sterile tank effluent }+ \text { crude }\end{array}$ & $\mathrm{I}^{\circ} 4^{\mathrm{I}} 7$ & $+\mathrm{II}_{4}$ & 6 \\
\hline $\begin{array}{l}\text { organism, No. }{ }^{2} \quad \ldots \quad \ldots \\
\text { Sterile tank effuent }+ \text { crude sewage }\end{array}$ & $1 \cdot 386$ & +109 & Io \\
\hline $\begin{array}{l}\text { organism, No. } 3 \\
\text { Sterile tank effluent }+ \text { crude }\end{array}$ & $I \cdot 29 I$ & +95 & 4 \\
\hline $\begin{array}{l}\text { organism, No. } 4 \\
\text { Sterile } \operatorname{tank} \text { effluent }+ \text { crude }\end{array}$ & I. $4 \mathrm{I} 7$ & $+\operatorname{Iin} 4$ & 6 \\
\hline $\begin{array}{ccc}\text { organism, No. } 5 & \ldots & \ldots\end{array}$ & $\begin{array}{l}1 \cdot 638 \\
0.3\end{array}$ & $\begin{array}{l}+147 \\
-\quad 55\end{array}$ & $\begin{array}{l}\text { I } \\
\text { Excessive }\end{array}$ \\
\hline 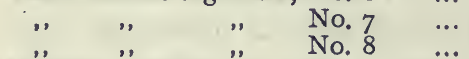 & $\begin{array}{l}0.819 \\
0.567\end{array}$ & $\begin{array}{l}+24 \\
+\quad 15\end{array}$ & $\begin{array}{l}8 \\
8\end{array}$ \\
\hline $\begin{array}{l}\text { Mixture of three organisms } \ldots \\
\text { Mixture of all the organisms }\end{array}$ & $\begin{array}{l}I \cdot 449 \\
I \cdot 23\end{array}$ & $\begin{array}{l}+119 \\
+\quad 86\end{array}$ & $\begin{aligned} 8 \\
\text { 10 }\end{aligned}$ \\
\hline
\end{tabular}

It is evident from these experiments that the sewage contained organisms (No.6) which reduced nitrate to nitrite, and others (No. 5) which oxidized nitrites to nitrates, so that under practically the same conditions two different changes can take place. 


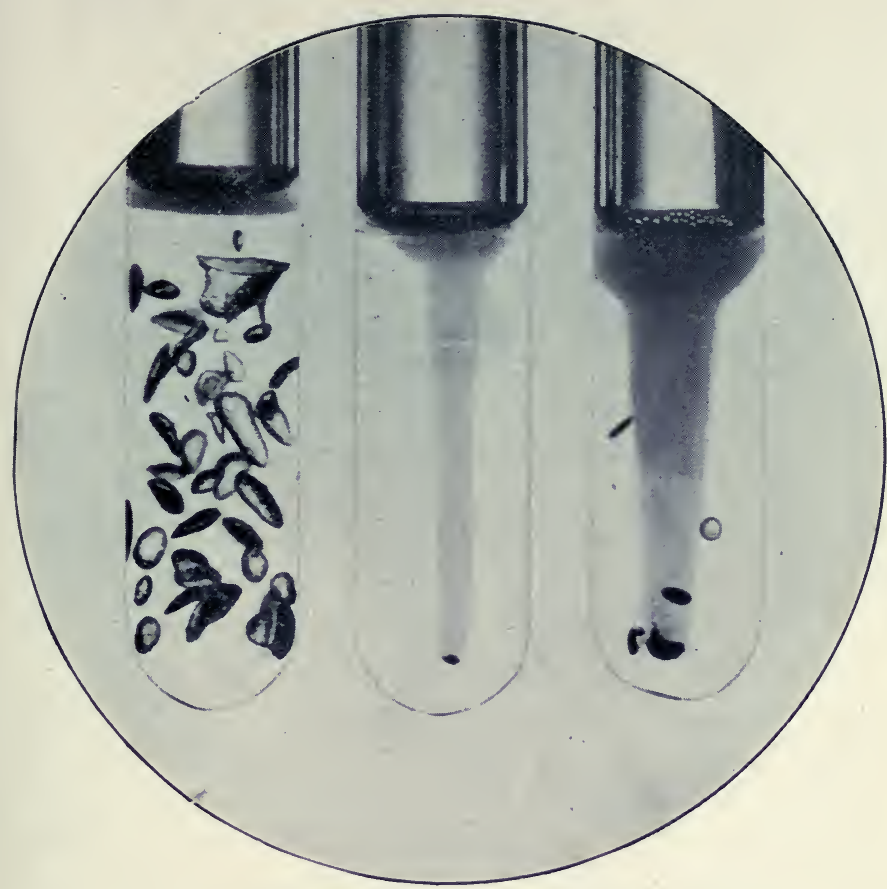

lig. 4.- Seivage l'roteus. (About natural size.)

(a) Gelatine "shake " culture. 24 hours' growth at $20^{\circ} \mathrm{C}$. Gas bubbles.

(b) Gelatine " stab" culture. Twenty-four hours' growth at $20^{\circ} \mathrm{C}$.

(c) Gelatine ' stab' culture. Forty-eight hours' growth at $20^{\circ} \mathrm{C}$.

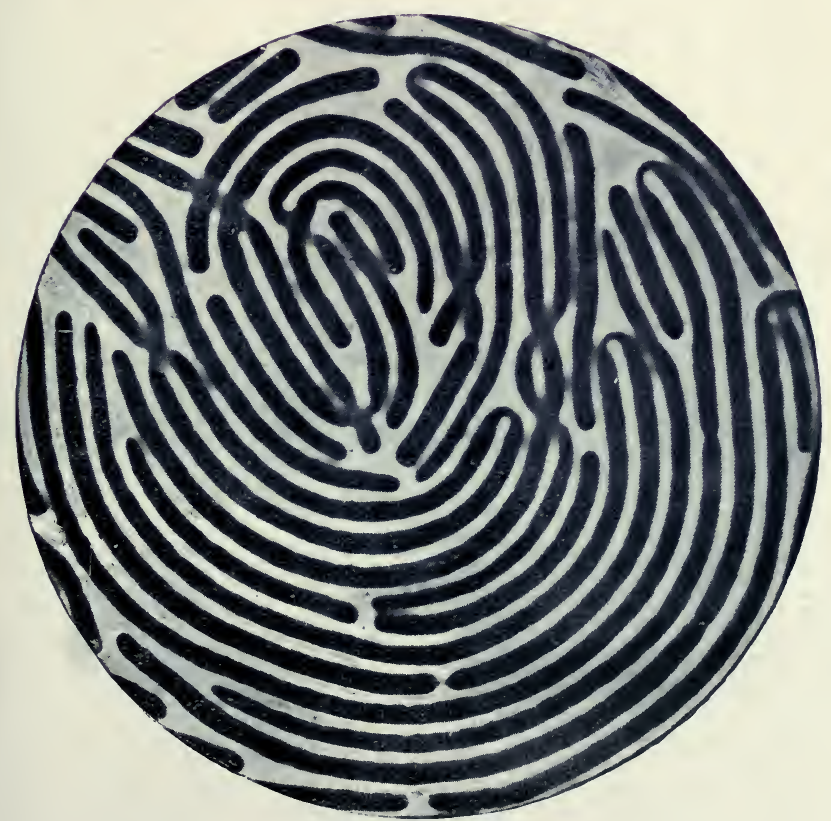

Fig. 5. - Proteus Vulgaris. ( $\times 3$,000.)

Impression preparation from "swarming islands" on gelatine. Twenty hours growth at $20^{\circ} \mathrm{C}$. 

Microscopical Examination and Staining. - Colonies are examined with a low power-about I inch-the Petri dish being inverted under the microscope, or, if necessary, the cover is removed. A minute portion of the growth is then mixed with a drop of pure water on a cover-glass, dried by a very gentle heat, and it is fixed by rapidly passing twice or thrice through a flame with the residue upwards. A drop of the stain is then spread over the preparation, or it may be floated face downwards on the staining solution, which sometimes requires warming, and after a few minutes the specimen is carefully rinsed with water, dried, and examined under the microscope with a $\frac{1}{12}$-inch immersion lens. For such rapid work methyl blue is a most useful stain; fuchsine, gentian violet, and other dyes are also used, sometimes with a mordant for demonstrating flagella, spores, etc. Many bacteria do not stain readily, and the manner in which an organism takes up a stain often helps in its identification. In London sewage and in the bacterial beds there are some bacteria which, after being stained with hot carbol fuchsin, are "acid fast," and thus resemble the tubercle bacillus. An impression preparation is taken by gently pressing the cover-glass on the colony, which must be on the surface, and not too advanced in growth. The cover-glass is then removed with the aid of the forceps, and after being allowed to dry, the preparation is fixed, stained, and mounted. When examined in this manner, the bacteria often show their natural grouping, which is not defined in an ordinary preparation from the colony. (See Figs. 5, 8 and I2.)

To study the growth of an organism, and to decide whether it is motile, a "hanging-drop" examination should be made. A drop from a fluid culture is transferred by a platinum loop to the centre of a thin cover-glass held by forceps, and this is inverted over the well of a hollow-ground slide, round which a ring of vaseline has been painted so as to lute down the coverslip. The edge of the drop is at first focussed with a low power, and then with the immersion lens.

Many devices are employed for the rough separation of the motile bacteria from non-motile forms, such as a capillary communication between the mixed culture and a sterilized medium, or placing the impure culture in a small parchment bag, surrounded with sterile water, the actively motile organisms being found to rapidly penetrate into the fresh culture material. 
The staining and microscopical examination of the various bacteria occurring in sewages require great care and experience, and beyond the rough outlines which I have given we cannot attempt to enter into the different processes.

The size of organisms is recorded in micro-millimetres $=\frac{1}{1000}$ of a millimetre (about $\frac{1}{25000}$ of an inch), commonly abbreviated $\mu$. In the absence of a scale, a comparison may be made with bodies of known size, such as red blood-corpuscles.

Sterile water, which is required in large quantities, can be obtained by a Pasteur-Chamberland or Berkefeld filter. Apparatus, cover-glasses, etc., must be carefully freed from grease and dust, and all vessels for cultures are sterilized before use by heating for some hours above $100^{\circ} \mathrm{C}$. Perishable articles, like rubber corks, are soaked in a I per cent. solution of formalin, and then thoroughly rinsed with hot sterile water.

The enumeration of all the bacteria occurring in a sewage would, of course, be impossible, and a bacteriological examination is usually confined to the following items :

I. Number of organisms per c.c. capable of growing at room temperature- $(a)$ aerobic, $(b)$ anaerobic.

2. Number of organisms per c.c. at blood heat- $(a)$ and $(b)$.

3. Number of organisms per c.c. that liquefy gelatine.

4. Special tests for spores and their number per c.c.

5. Identification of important species and number per c.c.

6. Special tests for pathogenic forms.

\begin{tabular}{|c|c|c|c|}
\hline & Organisms per c.c. & Organisms Liquefying. & Observers. \\
\hline $\begin{array}{l}\text { London. } \\
\text { Barking outfall, crude }\end{array}$ & & & t. \\
\hline $\begin{array}{l}\text { sewage } \ldots \\
\text { Crossness outfall, } \\
\text { crude sewage ( } 2 \text { nd }\end{array}$ & 5 to 7 millions & 220,000 to 900,000 & $\begin{array}{l}\text { Clowes and } \\
\text { Houston. }\end{array}$ \\
\hline $\begin{array}{c}\text { report) } \\
\text { Crossness, } 4 \text {-foot coke }\end{array}$ & 6 & 860,000 & \\
\hline bed effluent $\quad \ldots$ & $4 \frac{1}{2} \quad$. & 762,100 & \\
\hline $\begin{array}{l}\text { Exeter. } \\
\text { Crude sewage } \\
\text { Septic tank .... } \\
\text { Tank effluent } \\
\text { Filter effluent (end of } \\
\text { filtration) ... } \\
\text { Filter effluent (Well } \\
\text { after running off } \\
\text { three minutes) ... }\end{array}$ & $\begin{array}{l}3 \text { to } 5 \\
3 \text { to } 5 \text { million } \\
\text { I millo } \\
900,000 \\
3 \text { to } 5 \text { millions }\end{array}$ & $\begin{array}{c}300,000 \text { to } 500,000 \\
150,000 \text { to } 200,000 \\
300,000 \text { to } 400,000 \\
100,000 \\
30,000\end{array}$ & Sims Woodhead. \\
\hline $\begin{array}{l}\text { Columbus, Ohio. } \\
\text { Crude sewage } \\
\text { Septic tank effluent } \\
\text { Sand filter effluents }\end{array}$ & $\begin{array}{c}\text { Aver. } 3 \frac{1}{2} \text { millions. } \\
60, \quad 4 \\
60,000 \text { to } 800,000\end{array}$ & E & $\begin{array}{l}\text { Copeland and } \\
\text { Willcomb. }\end{array}$ \\
\hline
\end{tabular}


PLATE II.

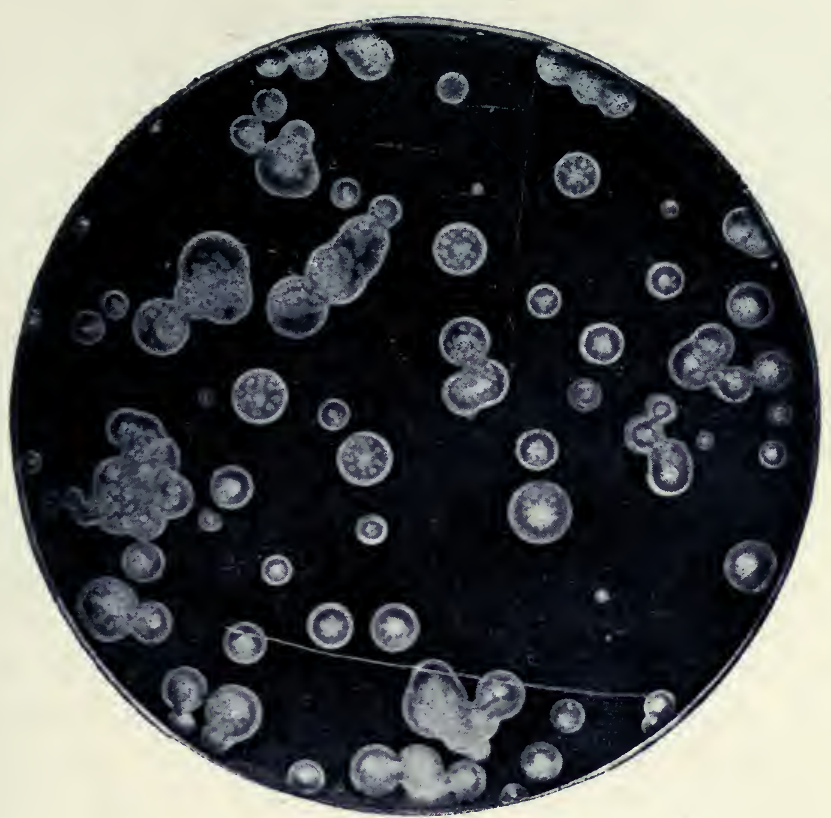

Fig. 6.-Sewage Proteus. (About natural size.) Gelatine plate culture. Two days' growth at $20^{\circ} \mathrm{C}$.

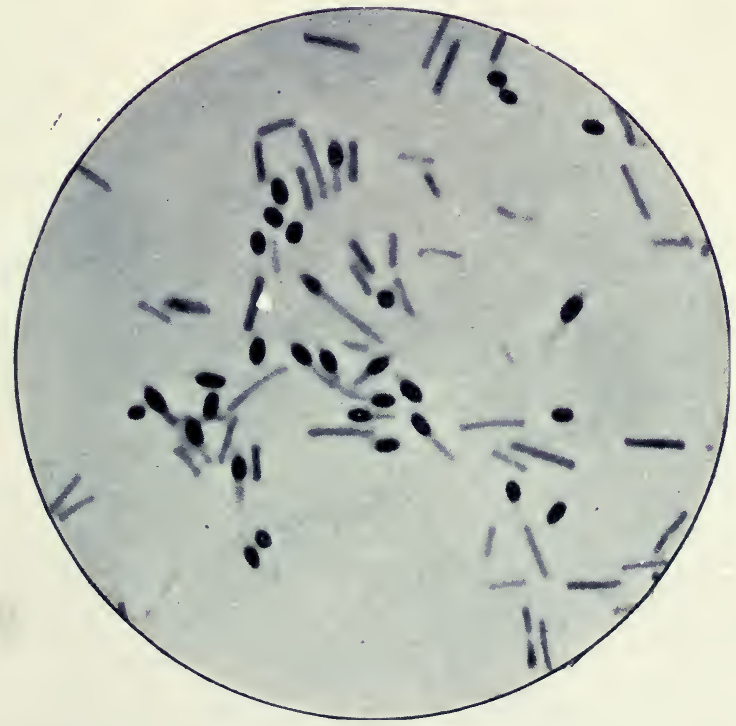

Fic. 7.-Bacillus Enteritidis Sporogenes (KLlein). ( $\times 2,000$. Microscopic double-stained preparation from a serum culture, showing spores. 

The number of organisms per c.c. is obtained from the gelatine plate cultures. As pointed out previously, this figure varies enormously, and to give some idea of what may be expected, I have tabulated a few results obtained by various observers from raw sewages and effluents (see Table, p. 70).

Experiments conducted at Chorley for the Royal Commission upon the average number of organisms present in the sewage during the successive stages of treatment gave the following results :

\begin{tabular}{|c|c|c|c|}
\hline & $\begin{array}{l}\text { Number of } \\
\text { Samples. }\end{array}$ & $\begin{array}{c}\text { Number of } \\
\text { Gelatine Plates. }\end{array}$ & $\begin{array}{l}\text { Average Number of } \\
\text { Bacteria per c.c. }\end{array}$ \\
\hline $\begin{array}{lll}\text { Crude sewage } & \ldots & \ldots \\
\text { Sewage and precipitate } & \ldots \\
\text { Tank effluent } & \ldots & \ldots \\
\text { Filter effluent } & \ldots & \ldots\end{array}$ & $\begin{array}{r}\text { II } \\
8 \\
9 \\
\text { II }\end{array}$ & $\begin{array}{r}124 \\
93 \\
107 \\
127\end{array}$ & $\begin{array}{r}4,084,827 \\
1,344,925 \\
398,695 \\
45,755\end{array}$ \\
\hline
\end{tabular}

The number of liquefying bacteria varied from 20,000 to I,000,000 per c.c. in the crude sewage, and from 470 to 60,000 per c.c. in the filter effluent. In examining beds at Leeds worked on the Dibdin principle, it was noticed "that a multiplication of organisms occurs in the sewage during its passage from the entrance to the works on to the beds. The cause of this increase has not yet been ascertained, but the following table suggests that the addition of lime to the crude sewage tends to inhibit the multiplication of organisms":

\begin{tabular}{|c|c|c|c|}
\hline Date, r899. & Crude Sewage. & Treatment. & Settled Sewage. \\
\hline $\begin{array}{l}\text { February } 27 \text { to March } 6 \ldots \\
\text { March } 6 \text { to March } 20 \\
\text { March } 20 \text { to June I }\end{array}$ & $\begin{array}{l}2,518,500 \\
2,597,950 \\
2,862,500\end{array}$ & $\begin{array}{l}\text { Limed. } \\
\text { Unlimed. } \\
\text { Limed. }\end{array}$ & $\begin{array}{l}2,746,030 \\
6,109,000 \\
1,128,100\end{array}$ \\
\hline
\end{tabular}

The dilutions employed in these experiments were as follows : I in $1,000,000$ for sludge, I in 100,000 and 50,000 for the crude sewages, and $I$ in $10,000, I, 000,500$, and I00 for the filter effluents. The examination of the gelatine plates was made as follows: "The temperature of incubation was from $18^{\circ}$ to $20^{\circ} \mathrm{C}$. No fixed interval of time was selected for the incubation and counting, but they were carefully watched, and every endeavour made to count the colonies when the maximum number had developed. This was sometimes, but by no means always, rendered difficult by the number of liquefying colonies. The plate was counted by placing it upon a ruled 
disc, and a hand lens used to assist the operation. To eliminate, as far as possible, errors in counting, not only was the large number of twelve plates made from each sample, but the plates were divided into two batches .... and it was found that the figures obtained by the two observers, worked independently, varied but a very little, and showed a close correspondence."

The method employed for determining the liquefying organisms in the Chorley experiments has not been described, and presumably the counts were made from the ordinary gelatine plates. Clowes and Houston, in their examination of the London sewage, prepared extra "surface" plates for determining the liquefiers, and they remark in their report that, "although this method is the best one available, it must be remembered that some bacteria liquefy the gelatine so very slowly that they might readily escape being counted as liquefying germs under these conditions of experiment. This matters the less since bacteriologists are in the habit of classing some, at all events, of these bacteria as non-liquefiers."

The following is a list of some of the sewage bacteria which have been found by various observers:

\section{BACTERIA OCCURRING IN SEWAGE.}

Note._L, Liquefying gelatine; NL, not liquefying; SL, slightly liquefying.

\section{Obligatory Anaerobes.}

Bacillus amylobacter, L (Clostridium butyricum).

$B$. enteritidis sporogenes, L; cadaveris sporogenes, L; butyricus, L. Give much gas.

Spivillum vugula, L. Very active; gives rise to fæcal odour.

S. amyliferum. Acts as a vigorous ferment.

\section{Facultative Anaerobes or Aerobes.}

B. fuovescens liquefaciens, L, and non-liquefaciens, NL ; megaterium, L ; magnus, spinosus, liquefaciens, L; mesentericus, L. Several varieties in London sewage produce $\mathrm{H}_{2} \mathrm{~S}$.

B. vermicularis, L ; liquidus, L ; vamosus, L; mycoides, L; fuscus, NL; nubilus, L; cloaca, L; ubiquitus, NL; veticularis, SL ; cereus, L; circulans, L; hyalimus, L. All reducing nitrates to nitrites and $\mathrm{NH}_{3}$.

B. aquatilis, SL (grows luxuriantly in ammonia solutions); brunneus, NL; helvolus, L; and superficialis, SL. Not reducing nitrates.

B. saprogenes, I., II., III. ; pyogenes and coprogenes fetidus.

B. putrificus coli, NL; fluovescens putvidus, L. Decompose albuminous substances, liberating $\mathrm{NH}_{3}$.

B. coli communis, NL; acidi lactici, NL; lactis aerogenes, NL. All producing gas. 
PLATE III.

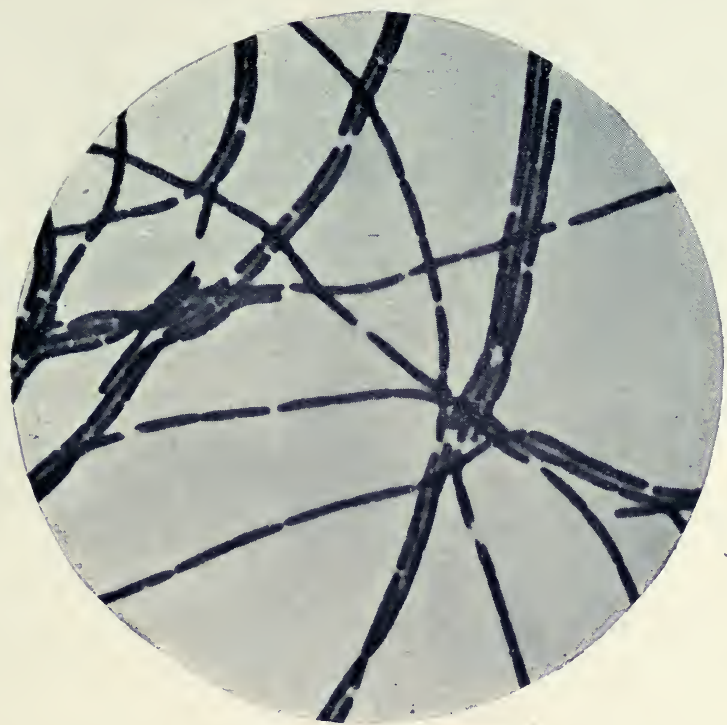

Fig. 8.-B. Membraneus Patulus. ( $\times$ I,00o.)

Impression preparation from a gelatine plate culture.

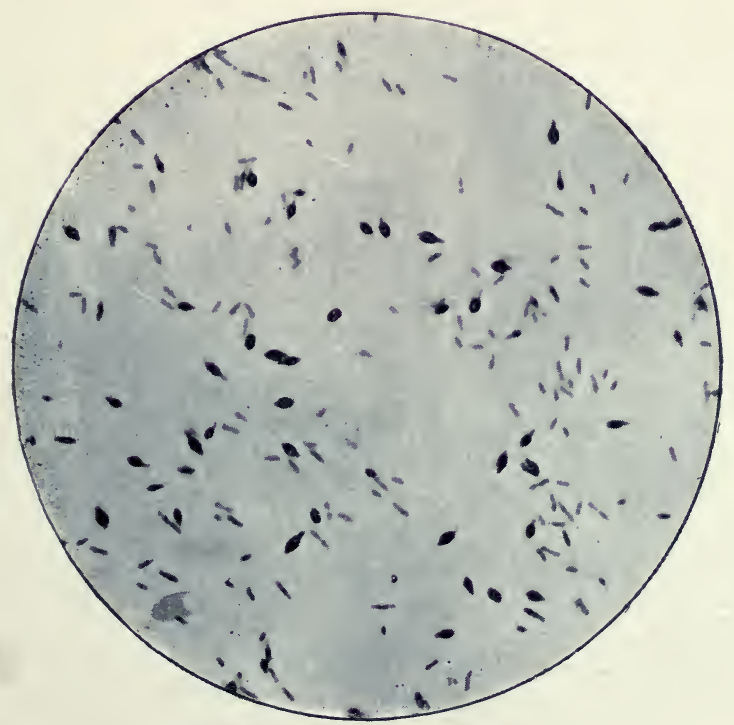

FiG. 9.-B. Fusiformis. $(\times$ I,000.

Microscopic double-stained preparation, showing spores. 

B. subtilis, L. Forms highly resistant spores; rapidly consumes oxygen.

B. sulphureum, L. Liquefies casein; produces $\mathrm{H}_{2} \mathrm{~S}$.

$B$. lactis cyanogenus, NL; erythrosporus, NL; vibescens, NL; pyocyaneus, L. (a culture from London sewage proved extremely virulent).

Several varieties of thermophilic bacilli, capable of luxuriant growth at temperatures above $50^{\circ} \mathrm{C}$., and producing spores.

Micrococcus (and Bacillus) urea, NL; uvea liquefaciens, L. Converting urea into ammonium carbonate.

$M$. tetragenus mobilis ventriculi, NL. Reduces nitrates.

M. casei, NL. ; albicans amplus, $L$; fervidosus, NL.

Streptococcus mivabilis, NL; vermiformis, L; coli gracilis, L; liquefaciens coli, L.

Spivillum plicatile, serpens, undula, tenue, and volutans.

Sarcina alba and hutea, SL.

Proteus vulgavis, L. Produces $\mathrm{NH}_{3}$ from nitrogenous organic matter.

Protens mirabilis, L; zenkeri, L; sulphureus, L. (produces $\mathrm{NH}_{3}$ and mercaptan).

Beggiatoa alba. Secretes granules of sulphur, formed, according to Winogradsky, by oxidation of $\mathrm{H}_{2} \mathrm{~S}$, and finally turned into $\mathrm{H}_{2} \mathrm{SO}_{4}$ by the plant.

Klein's B. enteritidis sporogenes is pathogenic to small animals, and has been associated with infantile diarrhœa. As a type of a pathogenic anaerobe invariably present in sewage, its isolation acquires special importance. Tubes of recently sterilized milk are inoculated with the diluted sewage and heated to $80^{\circ} \mathrm{C}$. for ten minutes, in order to eliminate all nonsporulating bacteria. The milk cultures are then incubated anaerobically at $38^{\circ} \mathrm{C}$, either by placing the tubes over alkaline pyrogallate, or excluding air from the surface of the milk with a few c.c. of sterile vaseline. After some twenty hours' incubation the cultures are examined for the "enteritidis reaction" -i.e., the milk is completely coagulated with abundant gas production, the fluid is nearly clear, the small dense clots are shattered by the gas, and often forced up above the liquid, acquiring a slight pink tinge. The culture is then examined microscopically, the absence of spores proved, and conclusive inoculation tests may be made with guineapigs. Other sewage organisms yielding the "enteritidis milk reaction" are $B$. butyricus-produces spores in anaerobic milk cultures at blood heat-and $B$. cadaveris sporogenes-requires some forty-eight hours' incubation to coagulate the milk.

The author has recently had occasion to make almost daily bacteriological examinations at the Guildford Sewage Works during the summer months. The tests were conducted as far 
as possible on the spot, and the following tables, giving the maximum and minimum results obtained, show the frequency of certain organisms in the various effluents :

\begin{tabular}{|c|c|c|c|c|c|}
\hline & \multicolumn{5}{|c|}{ ORGANISMS PER C.C. } \\
\hline & $\begin{array}{c}\text { Raw } \\
\text { Sewage. }\end{array}$ & $\begin{array}{l}\text { Septic } \\
\text { Effluent. }\end{array}$ & $\begin{array}{l}\text { Primary } \\
\text { Effluent. }\end{array}$ & $\begin{array}{l}\text { Secondary } \\
\text { Effluent. }\end{array}$ & $\begin{array}{l}\text { Tertiary } \\
\text { Effluent. }\end{array}$ \\
\hline 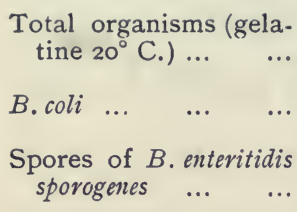 & $\begin{array}{l}23 \text { millions } \\
\text { I to Io } \\
\text { millions } \\
\text { I00 to I,000 }\end{array}$ & $\begin{array}{l}2 \frac{1}{2} \text { to } 4 \\
\text { millions } \\
\text { I0o, ooo to } \\
\text { I million } \\
\text { Ioo to } \mathrm{I}, 000\end{array}$ & $\mid \begin{array}{c}4 \frac{1}{2} \text { millions } \\
100,000 \\
20 \text { to } 100\end{array}$ & $\begin{array}{l}\text { I to } 2 \\
\text { millions } \\
\text { Io, ooo to } \\
\text { I million } \\
\text { Io to Ioo }\end{array}$ & $\begin{array}{l}10,000 \text { to } \\
700,000 \\
1,000 \text { to } \\
10,000 \\
\text { 10 to 100 }\end{array}$ \\
\hline
\end{tabular}

The London County Council Report of I $\delta 99$ describes some new species in London crude sewage which, after comparison with all others of their class, appear distinct.

$B$. mesentericus, two varieties, I and $E$ (Figs. Io and II, Plate IV.). Variety I rapidly liquefies gelatine and bloodserum, apparently peptonizes milk without subsequent coagulation, and has no reducing action on nitrates. Variety $E$ is longer, liquefies gelatine very slowly, liquefies blood-serum fairly rapidly at $37^{\circ} \mathrm{C}$., and produces a weak clot in milk which appears to subsequently redissolve. It reduces nitrate to nitrite in twenty-four hours at $37^{\circ} \mathrm{C}$. From ten to thirty spores per c.c. exist in London sewage.

Sewage proteus, differing from Proteus vulgaris, mirabilis, and zenkeri, liquefies gelatine and serum; and peptonizes milk without coagulation. It was present in great numbers (usually over I00,000 per c c.) in both crude sewage and effluents, and is suspected to be pathogenic, judging from some experiments on guinea-pigs (Figs. 4, 5, and 6, Plates I. and II.).

$B$. frondosus, SL, a large bacillus, giving a leafy appearance at the edge of the colonies.

$B$. fusiformis, NL, with spindle-shaped spores and somewhat negative culture characters, seems to be a new species (Fig. 9, Plate III.).

B. subtilissimus, NL, resembles a large micrococcus (Fig. I2, Plate IV.).

B. subtilis, L. Several varieties occur in sewage. Two$\mathrm{A}$ and $\mathrm{B}$-are specially described in the report.

$B$. membraneus patulus, SL, a very large species, which forms long chains (Fig. 8, Plate III.). 
PLATE IV.

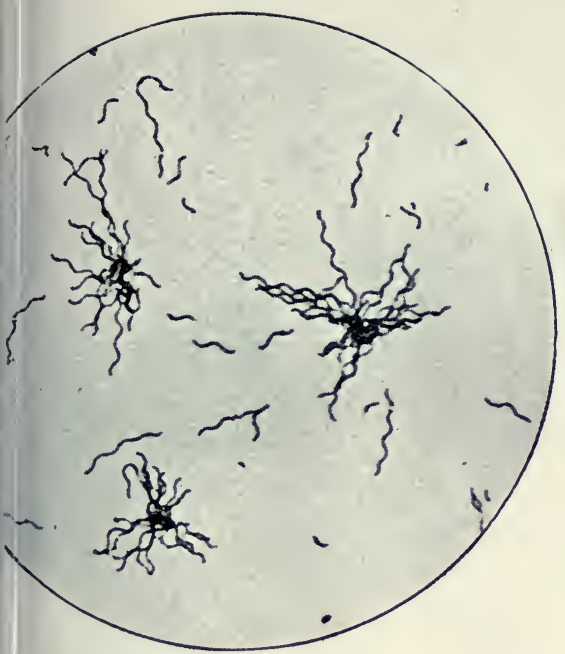

3. io.-B. Mesentericus. ( $\times$ I,00o.)

, ge variety I. Microscopic preparation in 'by V. Ermengem's method, showing n us flagella. From a twenty hours' agar ti at $20^{\circ} \mathrm{C}$.

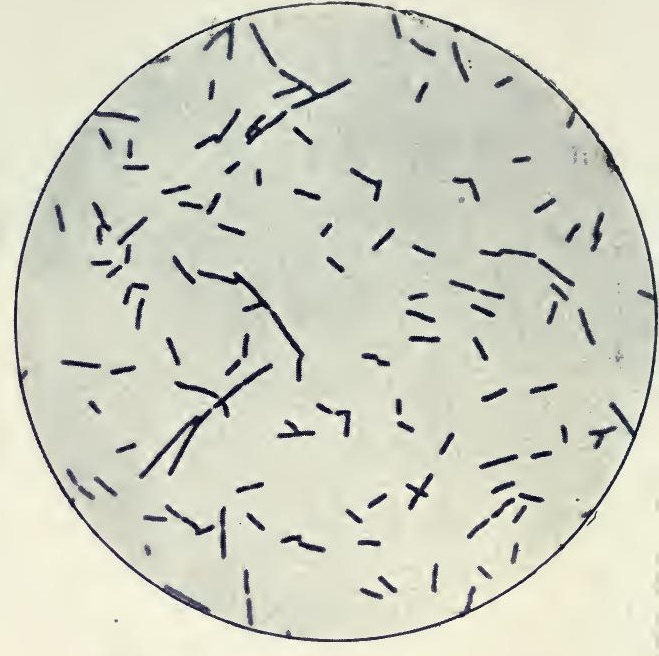

Fig it.-B. Mesentericus. ( $\lambda$ iooo.)

Sewage variety E. Microscopic preparation from a twenty hours' agar culture at $20^{\circ} \mathrm{C}$.

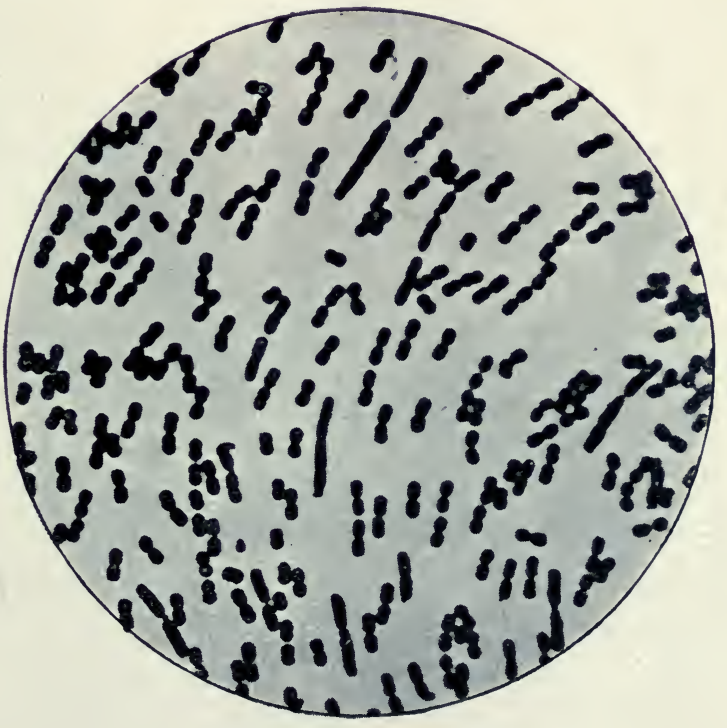

Fig, 12.-B. Subtilissimus. ( $x$ i,00o.)

Impression preparation from a gelatine plate culture. 

B. capillareus, L, similar, but growing differently.

With reference to streptococci, Dr. Houston, in a subsequent report (July, I90o), describes twenty species or varieties found by him both in London sewages and in effluents, and says that as a class (I) they are the most pathogenic of all bacteria at present known; (2) they are delicate germs, and very readily lose their vitality; (3) they are present in the intestines of animals; (4) they are absent from water and soil, except where there has been recent contamination with sewage or other objectionable matter. (See also Report of Medical Officer to Local Government Board, I898-I899.) He considers the search for streptococci a valuable test in the bacterioscopic examination of waters, but it is tedious and uncertain.

It is obvious that in such a fertile field as raw sewage new species are likely to be continually discovered.

\section{Organisms in Bacteria Beds.}

The organisms in anaerobic beds are chiefly bacilli, but cocci are not absent. The "clostridium forms" are very numerous, meaning such bacilli as develop spores in the middle, so that, owing to the bulging there and tapering of the ends, figures of a distinctly spindle shape are produced. This is characteristic of several species that are obligatory anaerobes, such as Clostridium fotidum, which liquefies gelatine and develops an odorous gas, and C. butyricum, or B. amylobacter. The latter, on account of its importance and its wide distribution, requires a special description. Prazmovsky, who first studied its character, found it in almost all animal and vegetable matters decomposing in absence of air, while Nothnagel discovered it continually in fæces. The specific name "amylobacter" (amylum, starch) was derived from its being coloured blue by iodine. It liquefies both albuminoids and carbohydrates like cellulose, producing butyric acid and gases, chiefly hydrogen, carbonic acid, and methane.

The Sutton beds were seeded at first with a culture of Micrococcus candicans, obtained by Dibdin from his coke breeze filters, but we now know that such seeding is unnecessary, as the mixed "flora" of sewage does not allow of the development of a pure culture of any specific organism. ${ }^{1}$ When zonal filters are used, a natural differentiation of the organisms occurs. For

1 Experimental inoculations of the 13 -foot coke bed at Crossness with a pure culture of a "sewage proteus," liquefying rapidly, gas-forming, but non-pathogenic, gave " quite negative results."-London County Council Report, 1900, p. 76. 
instance, in well aerated filtering trays the absence of nitrites shows that the organisms producing these compounds from ammonia are absent, unless the filtrate is so far free from ammonia that they might be present, but inactive from want of food-supply; or it may be that the nitrite is transformed at once to nitrate by the nitrobacter.

\section{Organisms in Oxidizing Filters.}

At this stage, if the working be efficient and the aeration thorough, the organisms which are exclusively anaerobic will disappear, while others will be reduced in numbers and replaced by new varieties, including those which produce nitrites and nitrates.

Their action, which is similar to that occurring in soils, was first studied by Müntz and Schloesing in 1877, who proved that soil sterilized by heat or by antiseptics such as chloroform would not nitrify, that the organic matter must be first converted into ammonia, and that certain conditions were necessary. Warington, Müller, Marie Davy, Heraeus, Munro, and others, elaborately investigated the subject, but failed to discover the specific organisms. These were first isolated and described by Winogradsky and P. Frankland in I89o, the former growing them in media almost absolutely free from organic matter. Kühne afterwards found that they were easily cultivated on silica jelly (p. 67), and others have since succeeded in acclimatizing them on agar plates prepared by Beyerinck's method.

Nitrosomonas (Winogradsky) oxidizes ammonia to nitrite, requiring no organic matter for its nutrition, as it assimilates carbon from acid carbonates. It appears as circular corpuscles less than I $\mu$ in diameter, and sometimes as oval cocci. ${ }^{1}$ The organisms from different parts of the world appear to be the same. ${ }^{2}$

Nitrobacter (Winogradsky) was isolated by P. Frankland, by dilution from ammoniacal broth, as a bacillo-coccus which refused to grow in gelatine; but as it is unable to oxidize ammonia, the best medium for its growth is an inorganic solution containing potassium nitrite and an acid carbonate. Omeliansky has confirmed the fact that both types of organisms

1 Warington, Fournal of the Chemical Society, 1891, p. 484.

2 Burri and Stutzer, Chem. Centr., I896, ii., p. I13. 
are necessary to convert ammonia to nitrate, nitrite being an intermediate state (see Chap. V.).

Nitrification in filter-beds will be considerably promoted by the organic matter present being greatly reduced in quantity, and the number of organisms producing ammonia should consequently diminish if this work has been done at an earlier stage. Thus at present in the working of the Crossness beds the numbers reported per c.c. are :

\begin{tabular}{|c|c|c|c|c|c|}
\hline & & & & Sewage. & Effluent. \\
\hline $\begin{array}{l}\text { Gelatine plates at } 20^{\circ} \mathrm{C} \text {. } \\
\text { Agar plates at } 37^{\circ} \mathrm{C} . \ldots\end{array}$ & $\begin{array}{l}\cdots \\
\ldots\end{array}$ & $\begin{array}{l}\cdots \\
\ldots\end{array}$ & $\begin{array}{l}\cdots \\
\ldots\end{array}$ & $\begin{array}{r}\left\{\begin{array}{l}6,400,000 \\
3,670,000\end{array}\right. \\
4,100,000\end{array}$ & $\begin{array}{l}1,170,000 \\
1,260,000 \\
1,630,000\end{array}$ \\
\hline
\end{tabular}

But the mere counting of the number of bacteria furnishes little information of the character of an effluent, as is shown by the following observations :

I. Meade Bolton and others have proved that some organisms commonly occurring in water, such as $M$. aquatilis and $B$. erythrosporus, can multiply enormously even in sterilized distilled water free from almost every particle of organic matter.

2. The nitrifying organisms will live in the absence of all organic matter, and will not grow in the ordinary culture media; hence would be entirely omitted in the ordinary counting.

3. During the purification carbonic acid is produced in considerable quantity. This gas is inimical to a large number of bacteria.

\section{Other Organisms which affect Purification.}

Besides bacteria in sewage, there are generally found many organisms of a higher grade. Water-worms, such as Anguillula and Nais, are stopped or killed in efficient purification ; in fact, one of the causes that calls for an anaerobic stage is that these animals require oxygen, and perish rapidly under the air-free conditions. At the same time, their preliminary agency in consuming and breaking down organic débris is almost certainly of value. Though bacteria are the chief workers in the purification of rivers, it must be borne in mind that fish, rats, and birds act as scavengers, and that the larger flora of the river also plays an important part. Letts remarks on the absorption of nitrogen into the tissues of animals or plants which feed on the sewage: "The bacteria beds at Belfast and 
elsewhere swarm with minute insects (Podura aquatica), which, escaping in myriads, often form a thick layer like soot on the surface of the effluent. In thus escaping these animals carry with them some of the nitrogenous constituents of the sewage which they have devoured, but as yet there has been no estimate of the quantity so removed. There are also species of worms always present in the bacteria beds in considerable numbers, which no doubt also feed on the sewage."1

Infusoria and other minute animals assist in the work of purification by acting as scavengers; their presence in vigorous activity is a proof of good aeration. Amœbæ require scarcely any oxygen; I have even found them in small numbers in the sediment of the Exeter septic tank, which is practically anaerobic. They also must act usefully in attacking nitrogenous matter.

Algæ and water-plants assist in the purification of an effluent by the nascent oxygen which they disengage from their green parts. They can also absorb by their roots and white parts ammonia and putrescent nitrogenous matter; they require, of course, clearing out at intervals to prevent the decayed portions from reversing the process. J. König ${ }^{2}$ has found that the higher water-plants, Elodea canadensis (Anacharis), Potamogeton, Myriophyllum, and Ceratophyllum, take up the nitrogen they require from organic substances in the water, such as asparagin or albumose, but not urea; and that the same is probably true for Salvinia and Azolla. All these plants, together with Lemna minor and $L$. polyrhiza, assimilate carbon from organic carbon compounds when the water is free from $\mathrm{CO}_{2}$.

Much trouble is sometimes caused by the clogging of conduits and pipes by growths of Beggiatoa, Cladothrix, Crenothrix, and other filamentous organisms allied to fungi, and producing earthy, sulphuretted, and other odours. These organisms are undesirable, and an indication of faults in the management of the process.

Beggiatoa (Fig. I3), however, although it has been called the "sewage fungus," seems, according to Winogradsky (p. 73), to have really oxidizing functions. It lives in water containing sulphuretted hydrogen, such as sulphur springs, as well as in sewage.

Crenothrix (Fig. I4), Pylobolus, and fresh-water sponges, are

1 British Association Refort, Glasgow, I90I, p. 60I.

2 Zeits.f. Untersuch. Nahr. u. Genussmittel, I900, vi., 377. 
PLATE V.

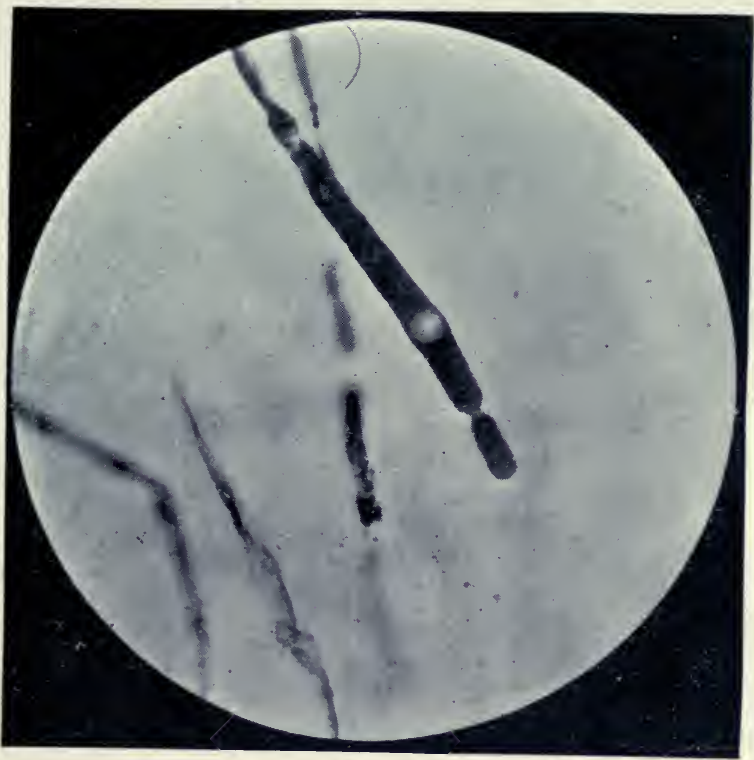

Fig. I5. - Leptonitus Lacteus, showing Constriction and Nucleus.

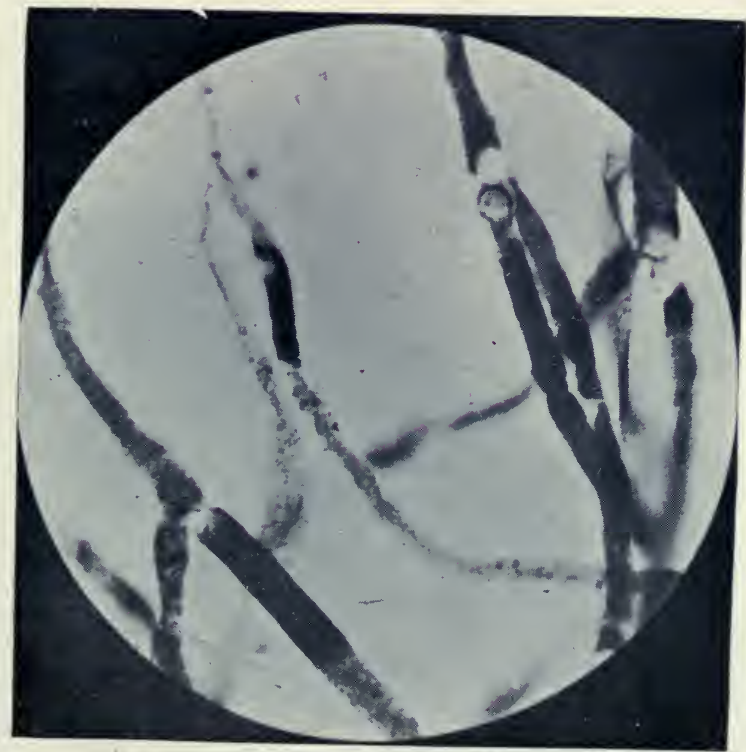

Fig. i6.--Eeptomitus Lactels, showing Branching. 

more common in continuous than in intermittent filtration. Crenothrix only grows rapidly when the dissolved oxygen is low and when certain metals are present, and is favoured by the presence of much organic matter and of carbonic acid and the absence of light. Jackson ${ }^{1}$ distinguishes three species: (I) The common $C$. Kühniana, red or reddish brown, precipitating ferric hydrate; (2) C. (formerly Leptothrix) ochracea, white or yellowish, precipitating alumina; and (3) C. manganifera, dark brown or black, precipitating manganese.

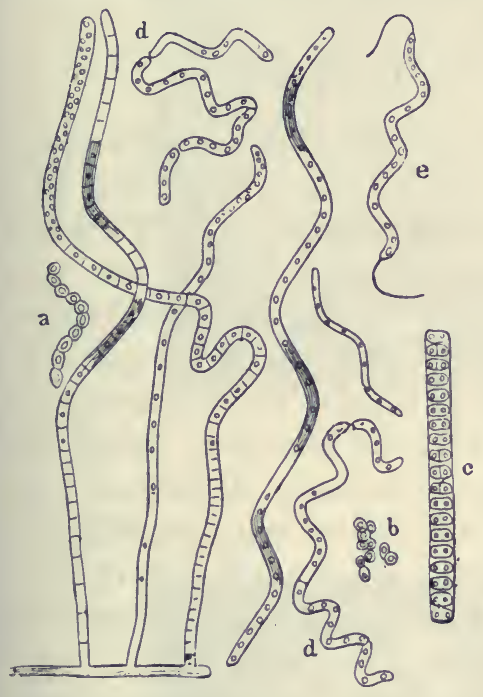

Fig. I3.-Beggiatoa Alba.

Showing attached, free, curved, and spiral forms. (a) Chain of spores; (b) free spores (motile); (c) portion under a higher power, showing transverse and longitudinal division; $(d)$ filaments breaking up (the small dark circles are granules of sulphur highly refracting); (e) free motile segment with terminal flagella.

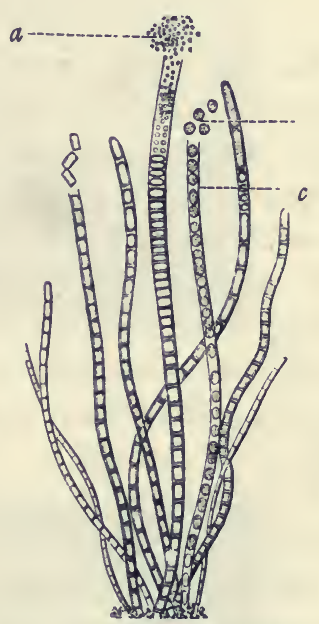

Fig. I4.-Crenothrix KüHNiANA. $(\times 600$.

(a) Arthrospores; (b) single seg. ments; (c) common sheath surrounding the separate spores.

Among the species that have been identified as constituting masses of "sewage fungus" are: Leptomitus lacteus (Saprolegniæ), soft, gelatinous, white, rusty, or black masses of longbranching filaments, constricted at intervals, each segment having a refractile nucleus. Spharotilus natans, allied to the leptothrix forms of bacteria, and possibly identical with Beggiatoa. It is more gelatinous than Leptomitus; like it, forms long wavy masses, usually whitish, but, according to

1 Fournal of the Socuety of Chemical Industry, 1902, p. 68I. 
Boyce, indicates much greater pollution (he states that it is favoured by warmth and the presence of $\mathrm{H}_{2} \mathrm{~S}$, but requires oxygen for its development, therefore will not grow in crude sewage, but may cause blocking of aerobic contact beds). Carchesium lachmanni, a protozoon allied to Vorticella, found in great masses under similar conditions to those of the Sphærotilus. The occurrence of these organisms is described by Boyce in the Second Report of the Royal Commission on Sewage, I902, p. I04, by whose kind permission I reproduce the figures in Plates V. and VI.

\section{Organisms CAUSing Odours.}

I have found in some cases that foreshore odours have been attributed to the entrance of effluents when they have been really caused by ordinary marine and fluviatile life. Thus in a harbour scum which I recently examined the odour was very powerful, being described as strongly earthy, weedy, and somewhat fishy, and was undoubtedly due to the organisms. Among those specially mentioned as causing unpleasant odours which were identified were the diatoms Melosira, Tabellaria, Diatoma, Meridion, with Volvox, Oscillaria, Ulothrix, Beggiatoa, and Spongilla. Similar occurrences were described by Sir E. Frankland in his report on the alleged pollution of Loch Long and Loch Goil in I889, and he was of opinion they were not due to contamination by sewage.

A green frondose seaweed, Ulva lactuca or latissima, "sealettuce," widely distributed on the coast, is sometimes washed ashore, and forms banks of a strongly fishy odour, which in decaying emit a putrid gas. As this evil is acute in Belfast Lough, Professor Letts has subjected the plant to examination. ${ }^{1}$ The mean results of analysis of the dried substance were, in

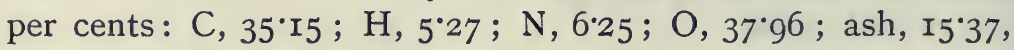
containing $\mathrm{S}, 3 \cdot 2 \mathrm{I}$, and $\mathrm{Fe}, 2 \cdot 20$; and the proximate analysis showed in per cents: Chlorophyll, fats, etc., I7 ; albuminoids or proteids, 33 ; cellulose, 50. No carbohydrate beyond cellulose was identified. In fermentation the weed at first evolves about equal volumes of $\mathrm{CO}_{2}$ and $\mathrm{H}$, while fatty acids are produced, chiefly propionic, with butyric and probably acetic.

1 "Absorption of Ammonia from Water by Algæ," Report of British Association, 1900, p. 935 ; "Ulva latissima and its Relation to the Pollution of Sea-water by Sewage," Letts and Hawthorne, Proceedings of the Royal Society of Edinburgli, March 4, I90I ; Report of Commission on Servage, vol ii., I902, p. 469 ; Second Report on the Scheme of Scwage Purification for Belfast, by Dr. Letts, I904. 
PLATE VI.

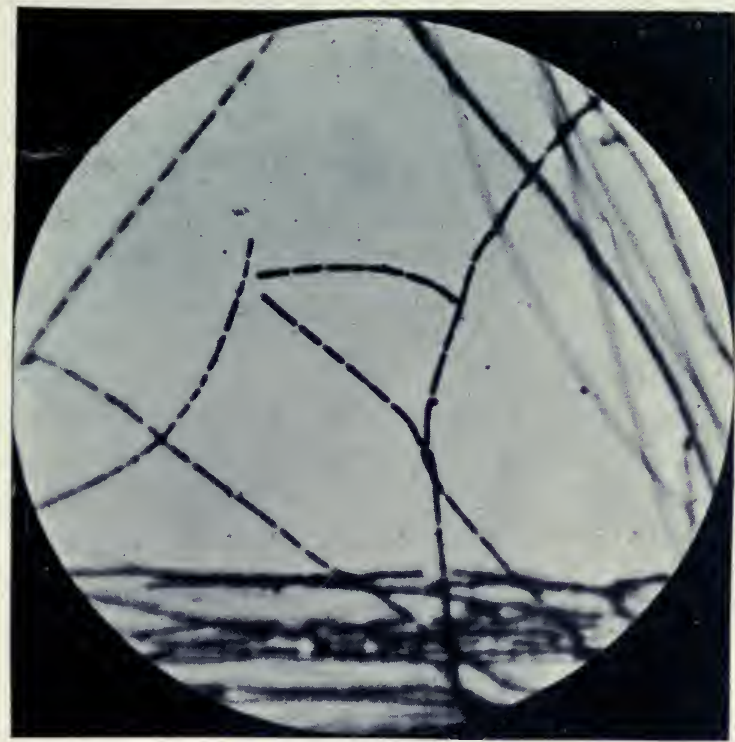

Fig. I7.-Sphaerotilus Natans.

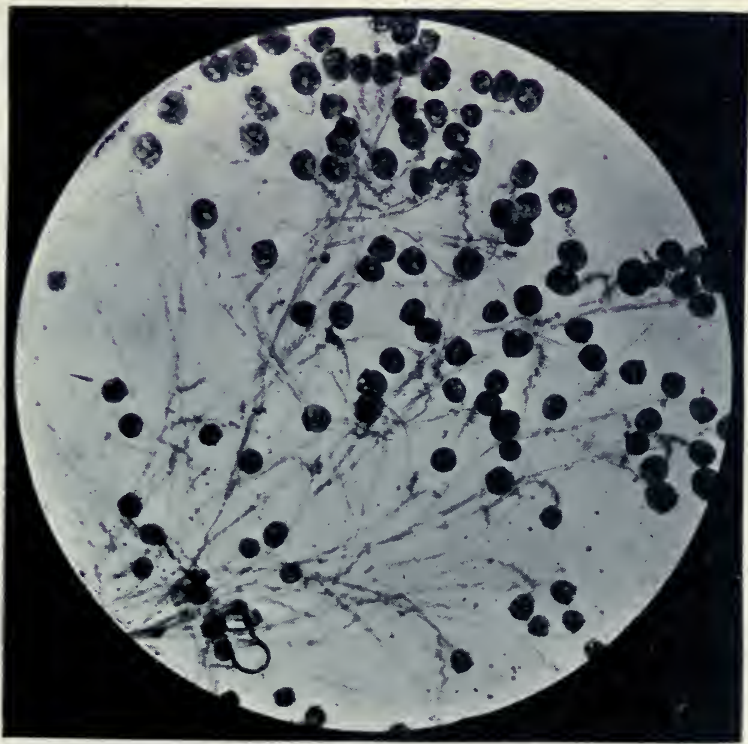

Fig. I8. - CARCHESIUM LachmaNis. 

Later, sulphides are formed, probably by the reduction of the sulphates in the sea water, and the seaweed blackens from the formation of ferrous sulphide, which disengages sulphuretted hydrogen by the action of the fatty acids. Two species of bacteria seem specially concerned.

Letts and others consider the occurrence of this alga in quantity to be associated with sewage pollution-first, on account of its nitrogen being in excess of that recorded in any other seaweed; secondly, because by cultivation experiments it was found that its power of absorbing nitrogen was remarkably high (thus in one experiment it absorbed in seventeen hours the whole of the free ammonia from a polluted sea water containing $0^{\circ} 05$ part per 100,000 ; nitrates were also rapidly absorbed, but not albuminoid matters; the plant remained healthy); thirdly, it grows most abundantly where sewage is discharged. He remarks that, "while thus acting as scavenger, it may itself give rise to a very extensive nuisance," and that in this case biological effluents rich in nitrates and non-putrefactive also supply the nitrogen for the growth of the Ulva and other plants.

Many varying odours occur on shores unpolluted by sewage, and can arise from either animal or vegetable sources. In some parts the deposits of birds evolve an ammoniacal and pungent odour. The smell of seaweeds is frequently strong even in the fresh state, and when thrown up on shore and decaying they may be very offensive. Dead marine animals are often drifted in quantities into hollows in the coast; and large numbers of jelly-fish (medusæ), shells, and crabs frequently putrefy on the sands, and sea-anemones on the rocks. Littoral flowering plants when growing profusely, as in salt marshes, sometimes produce very distinct odours, which may be strong and unpleasant in addition to the smell from masses of decaying vegetation. In this latter connection it must be remembered that brine of the strength of sea water has no antiseptic power.

Besides the above occasional causes of local nuisance, there are a number of vegetable and animal microscopic organisms which in their growth develop odours of various kinds, while any of the species, when unusually abundant, can after their death render wide areas of water offensively putrid. Apart from these peculiarities, large groups of "macroscopic" life, including diatoms, the smaller algæ, the infusoria, and minute crustaceans, act harmlessly as scavengers in waters which may 
contain only small quantities of vegetable matter. But the difficulties from the smells that they produce have often arisen in lakes and reservoirs in different parts of the world. Odours produced by the living forms have proved to be due in many cases to the secretion of compounds analogous to the essential oils, which have been actually extracted by ether or gasolene; the oil globules may be seen in many species under the microscope, and the effect on the water increases when the organisms divide or disintegrate, especially in the autumn.

Crenothrix Kühniana or polyspora was first observed in 1852 in the drains from a cultivated field in Silesia, and was described by Kühn. It is capable of very rapid multiplication and of fouling large quantities of water, which must, however, contain a certain quantity of ferrous iron. Thresh mentions that a few years ago a number of wells in Essex developed smells in the autumn, which he traced to species of Crenothrix; most of them were free from suspicion of sewage pollution, although the odour was strongly suggestive of sewage. A similar result, with a reddish colour and turbidity, occurred in the reservoirs at Cheltenham in 1896 from a variety of $C$. polyspora. This or allied species have been connected with an unpleasant odour and appearance in many subsoil waters, but Dr. Garrett has found that the organism has no effect on health. The luxuriant growth of $C$. Kühniana at the Berlin waterworks in 1878 proved so troublesome that fresh filter-beds were constructed. It developed to a thickness of some feet in the streams supplying the reservoirs, although the organic matter dissolved in the water was small. Nine years later Rotterdam was similarly affected, and United States records contain numerous examples. In I89I a strong foetor was communicated to the water-supply of Bolton, Lancashire, by a copious growth of Conferva bombycina in the reservoirs, and the same occurred in another Lancashire town in 1898 . Treatment with minute quantities of copper sulphate has been found to be successful; I have also noticed that the presence of a very small quantity of available chlorine inhibits many of these growths.

The following organisms have been specially offensive at various times :

Cyanophycea. Anabana, a bluish-green or brownish filamentous alga, family Nostocaceæ, accompanied by an odour described as like "horse-dung" in England, "pig-pen" in America. It is remarkable that in A. circinalis, according to 
Jackson and Ellms, ${ }^{1}$ the dry substance contains $9^{\cdot 66}$ per cent. of nitrogen, a higher percentage than that found by Letts in Ulva latissima $(6 \cdot 18$ per cent.), and much higher than is recorded for others of the larger algæ ( $I^{*} 3$ to $\left.4^{*} 6\right)$. The "pigpen" odour is attributed to "the breaking down of highly organized compounds of sulphur and phosphorus, and to the presence of the high percentage of nitrogen." Analysis of the gas evolved during decomposition gave in volumes per cent.: hydrogen $82^{\circ} 4, \mathrm{CH}_{4} 0^{\circ} 8, \mathrm{~N} \times 2^{\circ} 4, \mathrm{CO}_{2} \mathrm{I}_{5}, \mathrm{O}_{2 \cdot} \cdot 9$; the oxygen and a portion of the nitrogen probably represented residual air, and a large quantity of the $\mathrm{CO}_{2}$ produced remained dissolved in the water surrounding the plant. Oscillaria, Nostoc, and Lyngbya (the latter with "a peculiar suffocating odour") belong to the same family, and have a similar effect. I have found the two former and Anabæna in some English watersupplies, notably in June, I905, in a portion of a Surrey supply of high organic and bacterial purity. Lyngbya was present in the Cheltenham reservoir. Colospharium is mentioned in the Brooklyn Board of Health reports as having caused smells, and as being one of the worst of its class. Many of the Chlorophycea, or green microscopic algæ, impart strong fishy or seaweed odours. Volvox, formerly classed among the protozoa, is conspicuous in its fishy smell; I found this organism in the harbour water at Chichester, and there are records of its effect on English public water-supplies.

"Aromatic" is the general term applied to the volatile products of the Diatomacea, and in foreshore muds I have noticed that a peculiar aromatic smell was associated with large numbers of these organisms. But many of them are much more unpleasant, and I discovered several of the odorous forms at Chichester in I9oI (see Chap. XIII.). Asterionella causes a disagreeable fishy smell. Like other green organisms, it grows most luxuriantly in ground water exposed to the light. In the States it has occasioned great inconvenience; in 1896 the reservoir supplying Brooklyn contained 25,000 to 30,000 per c.c. I have found it in a few English drinking-waters, as also Synedra, which is credited with a disagreeable "grassy" smell. Whipple records an instance of a large mass of water being rendered offensive by the breaking up by a storm of a thick marginal growth of Melosira varians.

1 "Odours and Tastes of Surface Waters," Unitcd Statcs Technology Quarterly, x., December, 1897 . 
Among aquatic animal forms that have caused serious nuisance in their growth are the protozoa Uroglana and Symura, the former fishy and oily, the latter the origin of the so-called " cucumber" smell at Boston, U.S.A., in I88I and 1892 ; other protozoa are Bursaria gastris (strong seaweed smell), Cryptomonas (sweetish), Mallomonas (fishy). Fresh-water sponges and Bryozoa have also given trouble, mainly in their decay.

Whipple gives a classification of organisms and odours. ${ }^{1}$ Of I,404 waters examined in Massachusetts, only 275 were inodorous; the smell of Ioo was reported as offensive, 92 disagreeable, $45^{8}$ vegetable or sweetish, 202 grassy, 84 mouldy, 47 fishy, and 146 aromatic.

In an investigation as to the origin of the smell in Chichester Harbour in Igor, that of the scum was undoubtedly due to diatoms. The mud contained an abundance of confervoid algæ and of diatoms belonging to species known to be objectionable in this sense, and the very marked odours noticed in the samples I collected at different points were certainly produced by these organisms, which, as we have seen, grow independently of sewage, and some of them preferably in clean waters. Diatoms flourish best in shallows with a muddy bottom, and the periods of stagnation and aeration characteristic of such mud-banks are distinctly favourable to these kinds of life.

The Cladothrix so frequently noticed in mud samples is a fungoid organism, often present in large numbers both in fresh and brackish waters, whether running or stagnant, and in its growth it generates a mouldy smell, which was well marked in many of these specimens.

The city sewage in the above case had been precipitated by aluminoferric and lime, settled in tanks, then passed over land into a tidal basin, and stored till the state of the tide admitted of its discharge into the creek. It contained oniy 3 to 7 parts per I00,000 of suspended matter, and the smells and deposition in the harbour seemed to be derived from other sources.

\section{Survival of Pathogenic Organisms.}

This important point was raised at the Exeter Local Government Board Inquiry, referring to the pathogenicity of the product after anaerobic treatment, since it has been suggested that, whilst cultivating the bacteria necessary for the destruction of the organic matter in sewage, the pathogenic organisms

1 “Microscopy of Drinking-Water," p. 125. 
present in the crude sewage will not only survive, but may possibly multiply, and so cause the effluent to be dangerous to health. It is important, however, to remember that the bacterial processes are not novel, but are identical with those which obtain in Nature, so that effluents from sewage farms are strictly comparable with filtrates obtained after either a "coarse bed" or a tank treatment.

It must be recollected that hitherto little attention has been paid to the study of land effluents from this point of view, and until sewaye-farm drainage waters have been investigated in a similar manner to those derived from continuous well-aerated filters, no definite conclusion on this point can be formed.

It seems to be accepted that the treatment of sewage on land, though formerly urged to be more satisfactory from the bacteriological point of view than its treatment in bacterial beds, would not seem to by any means entirely remove the danger arising from the discharge of effluents into potable rivers. Experiments on the subcutaneous inoculation with crude sewage and with effluents for the Royal Commission show that "the pathogenic qualities of most effluents point to the improbability of sewage being so modified by treatment on land or by artificial processes as to be other than a liquid potentially dangerous to human beings. The absence of any pathogenic result when sewage is rendered germ-free by filtration, on the other hand, tends to show that the chemical products of the vital activity of the bacteria in sewage are not of a markedly poisonous nature."

Although with any new scheme it is difficult to obtain direct evidence as to its ultimate effect upon a river water which is subsequently to be used as a drinking supply, one must recollect that under existing circumstances the removal of all kinds of bacteria from the river water is attempted by those who desire to use such water for drinking purposes, so that, even assuming that bacterial systems tend to increase the bacteria in the river, they do not make any new departure necessitating a reconsideration of our methods of water purification. Even if an anaerobic treatment alone resulted in an effluent which possessed toxic properties disastrous to a small river, it must be recollected that no process is at present suggested which does not involve a full and efficient aerating filtration as a final method of purification, and it is the pathogenicity of such filtrates upon which information is wanted. Satisfactory 
evidence on most of the systems is now available, from which, I think, we are justified in concluding that, even if towns on a river like the Thames adopted bacterial schemes, the pathogenicity of the London water-supply would not be adversely affected. That the health of fish is not injured appears from the fact that, with intermittent fine-bed filters following coarsebed or chemical treatment, as at Leeds and London, they have lived in the filtrate.

At Exeter the tank effluent, the filtrate, and the river water were examined before and after admixture. Broth inoculated with these fluids and incubated for forty-eight hours had no effect upon rabbits or guinea-pigs when 2 c.c. was injected subcutaneously. Incubated for eleven days, the tank effluent, and the water at Belle Isle contaminated with the untreated town sewage, were found to be morbific, but the filtrate and the water at Salmon Pool Weir, some little distance below the town, contained so little morbific material of any kind that even with this severe test both kinds of animals remained alive and perfectly well. Dr. Woodhead in his report concludes "that none of the organisms found in the tank effluent are themselves capable, in the quantities present or in which they can grow even in broth, of setting up any morbid changes."

With regard to typhoid fever, Lawes and Andrews showed that some liquefying organisms have a germicidal effect upon typhoid bacilli, so that their sojourn in a septic tank, or their arrest in an anaerobic upward filter, with such organisms diminishes instead of increases their chances of survival. Dr. Pickard, of Exeter, has proved this fact again experimentally by introducing an emulsion of the typhoid bacilli into a septic tank, when he found that, instead of increasing, they rapidly diminished, until after fourteen days less than I per cent. of the number introduced were surviving. The same investigation also proved that filtration was even more efficient in removing typhoid bacilli, as he found that filtration, as conducted at Exeter, removed about 90 per cent. of typhoid bacilli from sewage inoculated with this organism, and that subsequent filtration of tank effluent containing no typhoid through the same filter yielded filtrates containing only about I per cent. of the bacilli introduced in the first filtration, showing that the environment was unsuitable for their development if their absence from the first filtrate was due only to a straining action. 
Dr. Houston, with the Ducat filter, has shown that with sewage containing $\mathrm{I}, 200,000 \mathrm{~B}$. coli per c.c. a filtrate is obtained which contained no colonies resembling the organism in this quantity; and that sewage containing between $\mathrm{I}, 000$ to ro,000 spores of $B$. enteritidis sporogenes per c.c. contained after filtration less than Io per c.c., whilst the aerobic bacteria causing liquefaction of gelatine were likewise reduced from 22 to less than I per unit.

Professor Boyce found that B. coli diminishes in the septic tank, the liquid being inimical to it, and therefore to the other more delicate pathogenic bacteria. In one series of experiments the average number of coli per c.c. was-crude sewage, 5,OII; open septic tank, 2,I30; Cameron closed tank, 2,099. In another series the average was-crude sewage, 45,600; septic tank, 3,433; keeping the liquor for two days, the number had gone down to $2,025 .^{1}$

On p. 74 a table is given showing the maximum and minimum numbers of coli organisms and spores of $B$. enteritidis sporogenes obtained recently at the Guildford Sewage Works; it will be seen that coli organisms are in each effluent reduced as the purification of the sewage proceeds, the total reduction amounting to over $99^{\circ} 9$ per cent. of those present in the original crude sewage. As would be expected, the anaerobic $B$. enteritidis does not show any reduction during the septic tank treatment, but finally the spores are reduced to one-tenth the original numbers.

Before this evidence of the comparatively innocuous character of the filtrates from bacterial systems was available, I pointed out that subsequent chemical treatment could be used for sterilizing the filtrate if necessary. Such reagents as may be conveniently employed may be called "finishers," as when employed the resulting purified sewage is satisfactory both from the chemical and bacterial points of view. Chlorine is one of such reagents, and the late Dr. Kanthack established the fact that with I grain of free chlorine to 4 gallons of the tank effluent or to 5 of filtrate, with a contact of about five minutes, the number of bacteria can be reduced from any number (even millions) that may be present to ten to fifty per cubic centimetre, and that no pathogenic organisms were found in any of the numerous samples of Maidenhead sewage finished in this way. I found at the same inquiry that on adding $I^{\circ} 77$ parts of avail-

1 Royal Commission on Sewage, Second Report, I902, p. II. 
able chlorine per 100,00o, although about half the amount immediately combines with any organic matter present, if the aerating filter has not worked efficiently, the micro-organisms by contact with the remainder are gradually killed, so that plate cultivations of such sewage taken after fourteen minutes showed no growth with three and a half days' incubation.

Later, in 1904, an experimental plant was installed at the Guildford Sewage Works for treating the sewage at its various stages of purification with an electrolytic chlorine solution, in order to determine the amounts of available chlorine required to deodorize and sterilize the various effluents. It was found that chlorine had very little precipitating or coagulating effect, the only visible change being a slight bleaching, the deposited sludge becoming dense and more amenable to treatment. The destruction of odours was complete and very rapid, provided the addition of available chlorine was equivalent to the immediate oxygen-consumed figure of the effluent. Absolute sterilization was not found to be practicable; in a cubic centimetre of sewage spores are present which will resist several minutes' steaming, and the quantity of available chlorine required to destroy these would of itself be objectionable, irrespective of the high cost. But it was found that the addition of available chlorine in excess of that immediately taken up by the organic matter, as indicated by an oxygen-consumed determination, rapidly destroyed the vast majority of organisms, so that after a few hours' contact the bacteriological condition of the effluent was almost comparable with standards for potable waters.

In Chapter VIII. further details will be found.

In the report of the London County Council, October, I899, Dr. Houston specially studied the possibility of the survival of pathogenic organisms after passage through bacterial filter beds, and from his investigation of the intermittent filters under experiment, he summarizes his opinion as follows :

"It is to be noted, in the first place, that the biological treatment of sewage is conducted under control; secondly, that the process always gradually secures the destruction of the pabulum on which bacteria feed, and hence leads to their death; thirdly, that the balance of evidence points to the probability that some, at all events, of the pathogenic organisms are crowded out in the struggle for existence in a nutritive medium containing a mixed bacterial flora, their vitality being weakened or destroyed by the enzymes of the saprophytic species; fourthly, that while it is true that bacteria produce poisonous substances in their growth, it also is true that 
their chemical poisons are toxic in proportion to the dose, and, moreover, are highly unstable, and readily break down into their elementary and innocuous constituents; and, lastly, that in some cases it may not be necessary to attempt to complete purification of the sewage, the solution of the suspended matters and partial destruction of the putrescible matter in solution being all that is urgently called for, as, for example, where the effluent is of relatively small bulk and is turned into a stream, the water of which is not used for domestic purposes (as is the case in the Lower Thames), or else when the effluent is to be subsequently treated by land irrigation."

He does not imply that such organisms as the typhoid bacillus or the choleva vibrio would necessarily lose their vitality, or even suffer a diminution in virulence, under the conditions prevailing in a biological filter. In the absence of actual experiments with the particular sewage in question, he is not prepared to say more than that he believes that if these germs did gain access to the sewage they would suffer diminution in numbers, primarily in the sewers, and secondarily in the coke-beds.

Dr. Houston, early in 1898 , isolated from Thames mud four organisms, named by him B. typhosus simulans a, b, c, d, which differed from the true typhoid organism in failing to sediment with typhoid serum and in possessing a less number of flagella. They might, therefore, possibly be degenerate varieties of active typhosus caused by prolonged existence in sewage-polluted water. Horrocks ${ }^{1}$ studied the behaviour of the B. typhosus in sewage, and concludes that the bacillus will usually be found alive after sixty days' immersion in sewage freed from other living organisms. The power of sedimentation will be unchanged, but the colonies may present a dark, granular, crumpled appearance, and the bacillus will show diminished resistance to carbolic acid. In unsterilized sewage he failed to obtain any evidence of their survival after fourteen days, and inferred that the life of the bacillus is much shorter in unsterilized than in sterile sewage.

Among the organisms which can be easily identified as directly derived from sewage, and which are either themselves pathogenic or are associated with organisms causing disease, the B. enteritidis sporogenes of Klein (Fig. 8, Plate II.) and $B$. coli communis are the most important.

At Crossness, in the crude sewage and the effluents from the

1 Fournal of the Sanitary Institute, xx., part iv., I899. See also "Enteric Fever and Sewage Disposal in Foreign Countries," by Major Aldridge (Fournal of Hygiene, July, I902, p. 360). 
4-foot bed, the spores of $B$. enteritidis varied from Io to $I, 000$ per c.c. In the effluents from the 6 -foot coke-bed and from the laboratory vessel they varied from to to roo per c.c.; but there may have been more spores present, as the minimum amount of liquid added to the milk-tubes was o.or c.c. Houston continues :

" Judging the results as a whole, it cannot be said that the biological processes at work in the coke-beds produced any significant alteration in the number of spores of this pathogenic anaerobe. This is the less to be regretted, since the effluents are discharged into a large tidal river below locks, the water of which is not used for drinking purposes. Still, it is to be thought of that the cultures of B.enteritidis sporogenes are extremely virulent, and that Dr. Klein's results seem to prove that this anaerobe may be causally related to acute diarrhøa. At all events, it is highly important from a practical as well as from a scientific point of view to continue these observations on the number of spores of $B$. enteritidis in crude sewage and in the effluents from the coke-beds." (This was done in $1899,{ }^{1}$ and it was noted that, although the number of these spores was frequently less in effluents than in the sewage, it was still between Ioo and I,, 00 per c.c.)

On the other hand, in a preliminary Report to the Royal Commission, Professor Boyce, from experiments with this organism, concludes as follows:

"Filtration has a marked effect in keeping back this bacillus, especially when combined with precipitation. It was not found in the filter effluent from the septic tank at Manchester, nor in the pure filter effluent at Chorley or Oldham. It was, however, obtained in the former by filtering a quantity through a porcelain filter, and subsequently scraping the surface. The addition of lime and copperas does not appear to have much effect on this bacillus."

\section{In concluding, Dr. Houston adds :}

"Judging the experiments as a whole, it cannot be said that the biological processes at work in the coke-beds effected any marked alteration in the number of $B$. coli. It must not, however, be too lightly considered that this implies that the effluent was necessarily of an offensive and putrescible character. B. coli and other putrefactive bacteria no doubt work in the direction of purifying the sewage, and their presence in the effluent might only mean that the purification had not been carried sufficiently far to allow of a decrease in their numbers, owing to the incomplete reduction of the organic matters on which they feed, and which allow of their continued multiplication. Yet, when this has been said, it must also be admitted that the passage of an aerobic non-spore-forming

1 London Connty Conncil Refort, July, I900. 
bacillus typical of excremental matters through the coke-beds in practically unaltered numbers is not a desirable state of things. It is true that $B$. coli is not pathogenic in the ordinary meaning of the word, but its presence in the effluents implies the possible presence of other bacteria-it might be of a dangerous sort. Still, on the whole it may be said that the balance of evidence points to pathogenic aerobic bacteria being liable to be crowded out in the struggle for existence in a nutrient fluid containing a mixed bacterial flora and one rich in saprophytic micro-organisms. Lastly, it must be remembered that the effluent is discharged into a large tidal river at a point far below the lowest 'intake' of water for waterworks purposes. Moreover, the Thames before it reaches the outfalls of the sewage works is already grossly polluted with excremental matters."

A subsequent report ${ }^{1}$ of July, I900, confirms most of these conclusions, but points out that the effluents from the experimental beds at Barking and Crossness cannot be reasonably assumed to be more safe in their possible relation to disease than diluted raw sewage. This must, however, be regarded as only applicable to beds worked in the way described. The chemical results taken generally show that nitrification was never pushed to a satisfactory point, and the main object of the whole inquiry in London has been to produce an effluent suitable to discharge into tidal waters.

I examined the effluents from the Scott-Moncrieff filters at Caterham with a view to ascertaining whether the sewage organisms survived the oxidizing influence to which they were subjected in their passage through the nitrifying trays, and found that the number of organisms capable of growing on carbolized gelatine surface plates, amongst which the $B$. coli communis is found, was reduced from $2,180,000$ per c.c. to 100,000 in the filtrate from filter $\mathrm{C}$, to 50,000 in that from $\mathrm{D}$, and 80,000 in the filtrate from $F$, so that, whilst the least efficient of the filters removed 95 per cent. of these organisms, the filter $\mathrm{D}$ removed $98^{\circ} 5$ per cent.

Although the addition of $0^{\circ}$ ooor c.c. of the tank effluent to a broth tube and incubation at blood heat for four days produced indol, the same dilution of the filtrate from $\mathrm{D}$ gave no turbidity or indol, whilst the filtrates from $\mathrm{C}$ and $\mathrm{F}$, although producing turbidity, also failed to give any indol reaction.

A disappearance of spores of $B$. enteritidis also occurred, and may be best seen from the following table, where + indicates the presence of such spores, and-their absence.

1 Royal Commission on Sewage, vol. iii., I904, pp. 95, 96. 


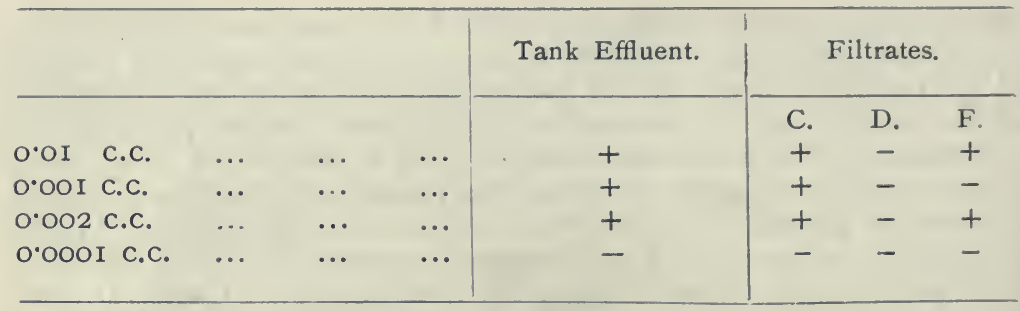

The nitric nitrogen and the ammoniacal nitrogen present in the filtrates when the bacterial samples were collected are shown in the following table:

\begin{tabular}{|c|c|c|c|c|c|}
\hline & & Tank Effluent. & \multicolumn{3}{|c|}{ Filtrates. } \\
\hline $\begin{array}{l}\text { Nitric nitrogen } \\
\text { Ammoniacal nitrogen }\end{array}$ & $\begin{array}{c}. . \\
\ldots\end{array}$ & $\begin{array}{l}\text { Nil. } \\
\text { I } 2 \cdot 3\end{array}$ & $\begin{array}{c}\mathrm{C} \\
5.48 \\
4^{\circ} 5^{6}\end{array}$ & $\begin{array}{l}\text { D. } \\
\text { I I.6 } \\
2.05\end{array}$ & $\begin{array}{l}\text { F. } \\
\text { IO.96 } \\
3.28\end{array}$ \\
\hline
\end{tabular}

It may therefore be concluded that the greater the aeration and nitrification, the less is the possibility of the survival of pathogenic organisms.

Johnson and Whipple have shown ${ }^{1}$ that the colon bacillus is taken up by fish, and multiplies rapidly in their intestinal tract, whereas fish caught in an unpolluted water failed to reveal the presence of this organism. It would seem possible, therefore, that fish, having taken up the colon bacillus from a polluted water, might migrate to a water of comparative purity, where they would naturally discharge the greatly increased number of these organisms. If the colon bacillus can be thus easily transferred from one water to another, the transportation of the typhoid bacillus may be considered quite as likely. This may explain the phenomenon frequently noted where $B$. coli communis is found in comparatively large numbers in waters apparently open to but remote chances of fæcal contamination.

In the subcutaneous injection of guinea-pigs (Royal Commission, Second Repurt, I902, p. 57) Dr. Houston found that crude sewage always produced a local reaction, and not uncommonly death. Street washings, storm water, overflow liquid from sewage works, and, in general, bad effluents, were apt to be pathogenic. Good effluents could be injected in relatively large amounts without producing a fatal result. His opinion

${ }^{1}$ A merican Public Health Association, Fournal of Infections Diseases, Chicago, March 19, 1904. 
that land effluents are usually less pathogenic than those from bacteria beds is very inadequately supported by his one fatal result on injection of an effluent from a single bacterial process (Report, p. 49). In the only other case quoted, from a different bacterial process, the animal recovered. Crude sewages and effluents, which had been heated to $100^{\circ} \mathrm{C}$. for one hour, or passed through a Pasteur filter, did not produce any injurious effect, even in large doses. It would follow that the ptomaines, which have sometimes been suggested as a danger of bacterial processes, are not of significance.

In the same Report, Dr. MacConkey ("Longevity of B. typhosus in Sewage and Sewage Effluents," ibid., p. 62) sums up his results as follows:

"We know that typhoid bacilli must find their way into the sewage from the excreta of persons suffering from typhoid, but they cannot be in large numbers, and in the various samples of crude sewage which we have examined we have not found any. Therefore it may be concluded that, allowing that these bacilli do reach biological beds or septic tanks, they are present in such small numbers, and the conditions are so adverse to their existence, that they will not survive the treatment. But if from any cause they arrived at the beds or tanks in such numbers as the $B$. coli, then certainly they might appear in the effluent just as the $B$. coli does. But as in the case of the latter bacillus, so also in the case of the $B$. typhosus, there is no tendency to multiplication in the effluent."

From some sewages and effluents Dr. Houston records his isolation of B. pseudo-tuberculosis and B. pyocyaneus, "both highly pathogenic to lower animals, and also related to morbid processes occurring in the human subject" (ibid., p. 58). He has discovered $B$. anthracis at Yeovil in sewage and some effluents connected with hide factories (ibid., p. 3I). In crude sewage he finds $B$. coli and allied forms are apt to be at least I00,000, spores of $B$. enteritidis sporogenes at least I00, and streptococci at least I,000 per c.c. (p. 25). He urges the importance of a streptococcus test (further explained at p. I44 of the Report), and remarks (p. 29) that, although both bacteria-bed and land processes can yield effluents seemingly non-putrescible, these are not to be thought of as safe in the case of drinkingstreams. Chemical standards are always essential. A bacterial standard is required for drinking-streams, and is of more importance than the chemical one; for non-drinking streams it is useful as an adjunct to the chemical standard (ibid., p. 29).

The effect of subsequent filtration on a biological effluent was investigated by the Commission, and it was_.. concluded that 
"when an effluent containing upon an average 800,000 bacteria per c.c. is passed through a depth of 4 feet of soil at a slow rate ( 50,000 to 400,000 gallons per acre per twenty-four hours) there is a very great reduction in the total numbers and in the B. coli."

When the effluent was inoculated at intervals with cultures of $B$. typhosus or of $B$. anthracis, tests for these organisms in the filtrate were negative. $B$. pyocyaneus, similarly added, was observed to die out in the filter. 


\section{CHAPTER V}

\section{CHEMICAL CHANGES PRODUCED BY BACTERIA}

Hydrolysis and oxidation-Nature and order of the reactionsSymbiosis and antagonism-Enzymes-Classes of transformations-Utilization of gases produced-Sources of energyNitrosification, nitrification, and denitrification.

Some thirty-five years ago trials of upward filtration (Chap. XI.) in the place of chemical precipitation gave such satisfactory results that it is difficult to understand why chemical treatment was almost universally adopted. In slow upward filtration of sewage the arrested suspended matter slowly disappears just in the same way as when the solids, after being removed by straining or by chemical precipitation, subsequently disappear when buried in the soil. Similar changes take place in mud-banks in estuaries, below the surface of the water, and the conversion of organic matter of vegetable or animal origin at the bottom of a stagnant pool into harmless gases is of the same nature. Such transformations formerly almost escaped attention, yet are as important as those which take place in the presence of light and air. In nearly all cases of destruction of organic matter preliminary disintegration takes place before the final oxidation of the elements. Solid organic matter capable of undergoing change can only be oxidized by air directly on its surface, whereas in a rotten apple or cheese changes take place beneath the surface, which pave the way for oxidation. Similarly, organic matter in solution seldom oxidizes directly to its final oxidation products, but passes through intermediate conditions until the complex organic forms are resolved into others of more simple structure, and these are subsequently burnt up to the stable oxidized compounds-water and carbonic acid.

The older terms for these phenomena-“decay," "putrefaction," "eremacausis" 1 - did not sufficiently differentiate

1 From $\dot{\eta} \rho \epsilon \mu \alpha$, quietly ; $\kappa a \hat{v} \sigma \iota s$, burning. 
between them and the combustion which follows so closely. "Bacteriolysis" refers to the principal living agents of the changes. "Hydrolysis" signifies a chemical breaking down by combination with the hydrogen and oxygen of molecules of water. Other cases, in which the decomposition takes place without any absorption of water, are grouped under the general term "fermentation." Sometimes oxidation is simulated, since the organic matter is partly converted into oxidized compounds; but the oxygen is not derived from the air, being that which was originally present in the organic matter or in the water taking part in the reaction. As an example, albumin contains the elements $\mathrm{C}, \mathrm{H}, \mathrm{N}$, and $\mathrm{O}$ in the ratio represented by the empirical formula $\mathrm{C}_{8} \mathrm{H}_{13} \mathrm{~N}_{2} \mathrm{O}_{3}$. An anaerobic change, due to hydrolysis, could be expressed thus :

$$
{ }_{4} \mathrm{C}_{8} \mathrm{H}_{13} \mathrm{~N}_{2} \mathrm{O}_{3}+\mathrm{I}_{4} \mathrm{H}_{2} \mathrm{O}={ }_{4} \mathrm{~N}_{2}+\mathrm{I}_{9} \mathrm{CH}_{4}+\mathrm{I}_{3} \mathrm{CO}_{2}+2 \mathrm{H}_{2} \text {. }
$$

Such an ideal change would result in the production of all the gases which are commonly met with in these decompositions, and leave no soluble organic matter for oxidation. Non-nitrogenous substances like cellulose and woody fibre can similarly break down into starch, sugar, etc., and then, in presence of yeast, into carbonic acid and alcohol. In most natural anaerobic changes of this character it is found, however, that there are residual compounds containing nitrogen, of a humus-like character, which are very stable, and resist chemical action. ${ }^{1}$ In peaty soils they exist in appreciable quantity. Adeney has noticed their formation in his experiments, and in the Exeter septic tank the dark suspended matter is of allied nature. That it does slowly disintegrate is shown from the experiments at Harpenden, where crops have grown on unmanured land for long periods under such conditions that it is difficult to ascribe any other source for their nitrogen. Humus slowly undergoes oxidation to $\mathrm{CO}_{2}$ and nitrate.

I was one of the first to point out that when changes are brought about by organisms which are facultative anaerobes, the breaking down of gelatine to albumoses, ammonia, peptones, etc. ${ }^{2}$ is not accompanied by any absorption of oxygen or the formation of any oxidized products, and it is, moreover, obvious that in the natural process of digestion solid foods,

1 See Chap. XI. ; also the author's paper on "Humus and the So-called Irreducible Residue in Bacterial Treatment of Sewage" (British Association, I90I ; Chemical News, vol. lxxxiv., p. I49).

2 See also Selitrenny, Monatsch., x., 908. 
both nitrogenous and non-nitrogenous, are digested in the stomach and intestines before the products are absorbed by the blood, and so rendered useful by oxidation.

The amount of oxygen required to render inoffensive the substances occurring in sewage depends on the species of the bacteria which are acting, as they determine whether the result should be a complete burning to $\mathrm{CO}_{2}, \mathrm{H}_{2} \mathrm{O}$, and $\mathrm{N}$, or a partial decomposition to equally harmless compounds like $\mathrm{NH}_{3}$ and $\mathrm{CH}_{4}$. There are a number of intermediate products; thus, Streptococcus longus liquefies fibrin to ammonia, methylamine, trimethylamine, tyrosine, leucine, fatty acids, succinic acid, collidine, and peptones. ${ }^{1}$

Elastin, with anaerobic organisms, evolves $\mathrm{CO}_{2}, \mathrm{H}, \mathrm{CH}_{4}$, and $\mathrm{N}$, whilst the sulphur remains in solution as mercaptan, and is not evolved as $\mathrm{H}_{2} \mathrm{~S}^{2}$ Grass similarly evolves $\mathrm{CO}_{2}$ and $\mathrm{N}$ under the action of $B$. subtilis and other organisms. B. $m y$ coides also acts upon the carbohydrates in grass, ferments glucose to inactive lactic acid, and hydrolyses cane-sugar, maltose, and glycogen. ${ }^{3}$ Pakes and Jollyman ${ }^{4}$ describe an apparatus for examining the gas generated by bacteria, and have specially investigated $B$. pyocyaneus and $B$. coli communis, which produce $\mathrm{CO}_{2}$ and $\mathrm{H}$, or $\mathrm{N}$ if nitrate be present.

The gases found in the septic tank at Exeter are as follows:

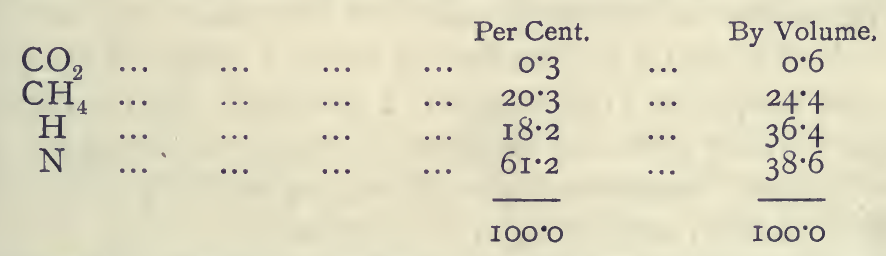

According to Wood and Wilcox, similar gases are produced in the manufacture of leather by Bacterium furfuris, which does not attack cellulose, but only starch and nitrogenous matter. A sample of the gas contained in per cents. : $\mathrm{CO}_{2}$ and traces of $\mathrm{H}_{2} \mathrm{~S}, 25^{\circ} 2 ; \mathrm{O}, 2^{\circ} \mathrm{I} ; \mathrm{H}, 4^{\circ} 7$; N, $26^{\circ} \mathrm{O}$; while formic, acetic, butyric, and lactic acids were produced: these in sewage would combine with ammonia. Much of the $\mathrm{CO}_{2}$ dissolves in the water, as does also the ammonia formed, whilst the hydrogen, from its easy diffusibility, escapes from the tank more rapidly than the heavier gases. As to $\mathrm{H}_{2} \mathrm{~S}$, see p. II4.

1 Emmerlich, Ber., I897, xxx., p. I863.

2 Zoja, Zeit. Physiol. Chem., I897, xxiii., 236.

3 Emmerlich, Ber., I897, xxx., p. I896.

4 Fournal of the Chemical Socicty, I9OI, pp. 322, 459. 
The further important change necessary for the complete destruction of the organic matter involves the essential that free or available oxygen, either from the air or oxidized compounds, shall be present. The following table shows the weight required to oxidize some typical organic compounds completely to their final stable products:

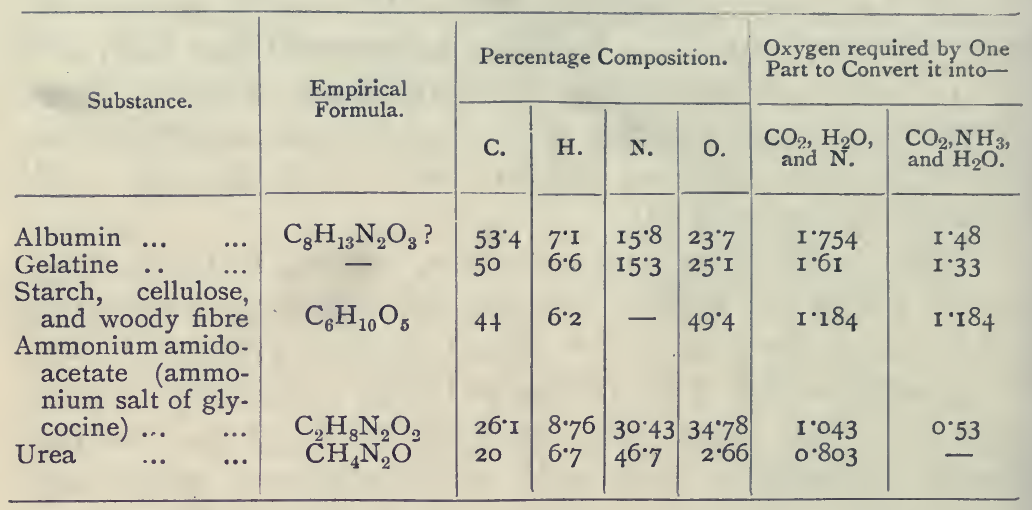

Fatty acids require a higher amount of oxygen. Thus, a molecule of stearic acid, $\mathrm{C}_{18} \mathrm{H}_{36} \mathrm{O}_{2}=284$, requires 832 of $\mathrm{O}$, or nearly three times its weight. But most of these are insoluble, and none of them are putrescent or dangerous.

The action which takes place in filter-beds and in rivers, as well as beneath the surface of sewage farms, is sometimes referred simply to " nitrification"; but since organic carbon is oxidized along with the nitrogen in these processes, the more general term "oxidation" should be employed as indicative of both the carbon and nitrogen purification.

The experiments of the Massachusetts Board of Health and of the London County Council at Barking have been directed almost entirely to the second and final stages in sewage treatment. The Barking I-acre filter-bed only dealt with sewage which had been chemically precipitated. It is also important to recollect that the anaerobic or hydrolytic change takes place very rapidly under favourable conditions, and that it is not unusual to find, especially in towns in which the sewers are old and tortuous, a crude sewage in which the preliminary disintegrating changes have taken place to a very considerable extent.

Anaerobic fermentation is called by the Germans true putrefaction (Faulniss), while aerobic is termed mouldering (Verwe- 
sung). It seems sufficient to recognise the first as a hydrolytic and the second as an oxidation change.

Calculating from the discharges (p. 54), an average sewage from a water-closet town with a water-supply of, say, 25 gallons per head should, when fresh, contain about Io parts of organic nitrogen per 100,000; yet in most cases the sewage of a town contains only from I to 2 parts of organic nitrogen, and frequently less than this amount. The difference must be due to the very rapid breaking up of the organic matter by the anaerobic changes described, and is accompanied by a corresponding increase in the ammonia from mere traces up to 8 parts per 100,000 , and a loss from the evolution of free nitrogen gas and possibly oxides of nitrogen.

When fæcal and other solid matters are first discharged, the earliest changes must be aerobic, because of the free oxygen dissolved in the water and contained in the air. The effect is mainly the same as the last stage-i.e., the organisms acting in a normal manner upon those simpler constituents like ammonia, already present in small quantities, into which the process itself afterwards resolves the main ingredients of the sewage. Nitrates in small quantities are consequently often observed in moderately fresh discharges.

As soon as the free $\mathrm{O}$ has been exhausted, these oxidation changes come to an end, and the bacteria which require air in part disappear and in part remain quiescent, to resume their functions at a later stage. On the other hand, the anaerobic organisms will commence to multiply, the nitrate will be reduced to nitrite, and this to nitrogen, according to reactions we shall explain later, and the liquefaction and hydrolysis changes will proceed. This is the usual condition when the sewage arrives at the works, and the first, or anaerobic, stage of the treatment proper commences.

In the second stage aeration is to be encouraged, so that the aerobic bacteria may act and ammonia and carbonic acid be produced with the help of some of the facultative anaerobes.

In the third stage, with provision of a still larger quantity of oxygen, the nitrifying group will get rid of the remaining products.

We may summarize the order of the changes as follows: 


\begin{tabular}{|c|c|c|}
\hline & Substances dealt with. & Characteristic Products. \\
\hline Initial. & & \\
\hline $\begin{array}{l}\text { Transient aerobic changes } \\
\text { by the oxygen of the } \\
\text { water-supply, rapidly } \\
\text { passing to- }\end{array}$ & $\begin{array}{l}\text { Urea, ammonia, and } \\
\text { easily decomposable } \\
\text { matters. }\end{array}$ & \\
\hline First Stage. & & \\
\hline $\begin{array}{l}\text { Anaerobic liquefaction and } \\
\text { preparation by hydro- } \\
\text { lysis. }\end{array}$ & $\begin{array}{l}\text { Albuminous matters. } \\
\text { Cellulose and fibre. } \\
\text { Fats. }\end{array}$ & $\begin{array}{l}\text { Soluble nitrogenous com. } \\
\text { pounds. Phenol de- } \\
\text { rivatives. Gases. Am. } \\
\text { monia. }\end{array}$ \\
\hline Second Stage. & & \\
\hline $\begin{array}{c}\text { Semi - anaerobic breaking } \\
\text { down of the intermediate } \\
\text { dissolved bodies. } \\
\text { Third Stage. }\end{array}$ & $\begin{array}{l}\text { Amido - compounds. } \\
\text { Fatty acids. Dis- } \\
\text { solved residues. Phe- } \\
\text { nolic bodies. }\end{array}$ & $\frac{\text { Ammonia. }}{\text { Gases. }}$ Nitrites. \\
\hline $\begin{array}{l}\text { Complete aeration : oxida- } \\
\text { tion and nitrification. }\end{array}$ & $\begin{array}{l}\text { Ammonia and carbon- } \\
\text { aceous residues. }\end{array}$ & $\mathrm{CO}_{2}, \mathrm{H}_{2} \mathrm{O}$, and nitrate. \\
\hline
\end{tabular}

In ordinary bacteria beds these reactions are often reversed and confused, according to the periods of filling or rest, which allow the different bacteria to act in the same filter. Although it is practically impossible to confine the bacterial action to one species, by seeding or otherwise, in view of the immensely varied character of the organisms that are present-nor would such a proceeding be advantageous-yet the best conditions are attained when a sewage plant is so arranged as to afford separate areas favourable to groups of organisms which work similarly. This principle will be further discussed in Chapter XI. We have seen that the disappearance of pathogenic bacteria in cultivation beds, through the crowding out of these special forms by the more numerous harmless varieties which thrive at ordinary temperatures, is also an important part of natural purification.

\section{Symbiosis And Antagonism.}

Organisms growing together either antagonize each other's development or, more rarely, encourage it, or even are necessary to one another. The former is "antagonism," the latter "symbiosis." In mixed cultures certain species develop rapidly, to be supplanted later by those of slower growth, and the more vigorous organisms are not always the most useful. Some species prevent the growth of others by (I) exhausting 
their special food, or (2) by excreting products which are injurious; the latter is true antagonism. Thus Freudenreich found that B. pyogenes fetidus (p. 72) prevented the growth of the cholera spirillum, that Micrococcus roseus similarly inhibited $M$. tetragenus, whilst B. pyocyaneus, phosphorescens, and prodigiosus caused a change in broth which prevented the growth of other species. Garré demonstrated antagonism by making streak cultures of various bacteria on gelatine plates, in parallel or intersecting lines. ${ }^{1} \quad$ Lewek inoculated gelatine or agar with equal numbers of different varieties, adjusted by counting and appropriate dilution. ${ }^{2}$ K. B. Lehmann draws the practical inference that in counting bacteria very dense plates should be avoided.

Symbiosis is the condition when two or more kinds of bacteria act together and effect decompositions which neither of them could do separately. Each may live independently, but they thrive better and more continuously in company than alone, and are said to be synergetic. Lehmann states that some organisms ordinarily anaerobic can thrive on the admission of air if certain aerobes be also present, which is one reason accounting for the presence of anaerobes in oxidizing beds or filters.

The cause of symbiosis is generally found in each of the organisms taking one part in a sequence of chemical actions. ${ }^{3}$ Thus, Omeliansky, by pure cultivations, explained some results that Adeney and others had previously noticed. When three organisms, B. racemosus, nitrosomonas, and nitrobacter, are added to bouillon, the first bacillus produces ammonia from the organic nitrogen, the second converts it into nitrite, and the third the nitrite into nitrate. The first change requires no oxygen, the second requires some oxygen, and the final change a still greater quantity. With a culture of the first two, nitrite and no nitrate was produced. With a mixture of $B$. racemosus and nitrobacter, ammonia was the only product, as the absence of the nitrite-forming organism prevented the conversion of the ammonia into food for the nitrifying organism. A mixture of the two last species failed to determine the decomposition of the original culture medium even after ten months. Otto Künnemann ${ }^{4}$ found that Burri and Stutzer's B. denitrificans $I$.

1 Corresp. für Schweizer Aertze, I897.

2 Centr. f. Bakt., vii., 107. ${ }^{3}$ Kossowicz, Woch.f. Brau., I906, xxiii., 262.

${ }^{4}$ Landw. Versuchs Stat., 1898, 65. 
is effective only in symbiosis with $B$. coli: the latter supplies it with its necessary ammoniacal food. $B$. coli ${ }^{1}$ reduces nitrate to nitrite, which in turn is denitrified by the organism I.

\section{ENZYMES.}

A great number of changes, most of them hydrolytic, are accomplished by the large class of organic substances termed "enzymes," which, though not living, are products of animal and vegetable life. They have been defined by Lehmann and Neumann as "chemical bodies, which in minimum amounts and without being used up are able to separate large amounts of complicated organic molecules into simpler, smaller, more soluble and diffusible molecules." The definition is not quite accurate, as the milk ferment, for instance, actually coagulates casein, or renders it insoluble, but it gives an idea of the immense power that these enzymes possess, and the economy of their use as distinguished from ordinary chemical or mechanical means. Many of them are products of bacteria or other fungi, and are powerful agents in resolving action, as a bacillus is not only able to act in its immediate neighbourhood, but also at a considerable distance, through the soluble ferments it forms and disengages.

The enzymes are soluble nitrogenous bodies, which can be precipitated and rendered inert by strong alcohol, mercuric chloride, and by boiling. They can be separated from bacteria by filtration, when the enzymes pass through, while the bacteria are retained. Other distinctions from the organisms which produce them are :

I. Enzymes can often work at a greater range of temperature ; that is, are less susceptible to heat and cold than the living bacteria. Therefore it is possible to find temperatures which will inhibit, if not kill, bacteria without affecting enzymes. ${ }^{2}$

2. Antiseptics, like chloroform, thymol, etc., which kill or inhibit bacteria, do not prevent enzymes from acting. Thus

1 Weissenberg, Archiv. f. Hygiene, 1897, xxx., 3.

2 Brunton and Macfadyen (Proceedings of the Royal Society, I89o, xlvi., 542), working on the liquefaction of gelatine by a variety of micro-organisms, found that a temperature of $100^{\circ} \mathrm{C}$. destroyed both the bacteria and the power of liquefaction, while a temperature of $50^{\circ}$ destroyed neither. Between $60^{\circ}$ and $75^{\circ}$ the organisms were destroyed, but not the liquefying action, showing that it was due to an enzyme secreted by the bacteria. They succeeded in isolating this enzyme, and demonstrated its peptonizing effect apart from the bacteria which produced it. It was hindered by acidity, and favoured by alkalinity. A diastatic enzyme was also identified. These bacteria evinced adaptiveness to the media in which they grew, and could digest animal fibre and carbohydrates, but not fats. 
Salkowski ${ }^{1}$ inoculated fibrin with putrefactive bacteria and kept it in chloroform water. It remained sterile for an unlimited time, but nevertheless underwent solution with the usual products, due to an enzyme secreted by the bacteria at first. Hoppe-Seyler describes several fermentations which are initiated by bacteria, but continue after the destruction of the organisms by ether. ${ }^{2}$

Dr. Armstrong ${ }^{3}$ proposes the terms zymosis for fermentation by living organisms, and enzymosis for change by enzymes or unorganized ferments. The former class of changes would be intracellular, or within the cell, under the immediate action of the protoplasm ; ${ }^{4}$ the latter class would be external or extracellular. By such means bacteria are able to produce effects which are quite out of proportion to their size or numbers. As an example of intracellular action, Wroblewski ${ }^{5}$ states that with Buchner's yeast-extract filtration through a Berkefeld or sandstone filter diminishes, and through a Chamberland filter entirely removes, the fermenting power; this shows that in fermentation by yeast cells the zymase remains in the cells and does not diffuse into the sugar solution. If the cells are collected on a sandstone filter, fermentation in the sugar solution ceases; Wroblewski is therefore of the opinion that the sugar solution passes into the cells and is there fermented. Alcohol and carbonic acid, accordingly, are true excreta of the yeast cells.

Enzymes are formed not only by bacteria, but by moulds, larger fungi, and also by plants and animals, but have not as yet been prepared artificially. Free oxygen is not necessary for their production. ${ }^{6}$ The mode of action is still imperfectly understood; probably they act like some inorganic bodies by forming unstable compounds with portions of the organic molecule, which then break up, leaving the substance hydrolysed, and freeing the enzyme to act again. As they are of such value, it will be useful to give a list of the more important; many of them, or their analogues, must occur in sewage, since the changes they produce are present. We may divide them into groups.

1 Zeit. Phys. Chem., 1899, xxvii., 305.

3 Transactions of the Chemical Society, June, I 890, p. 528.

"Martinus Beyerinck uses the term "katabolic" for changes brought about by the direct action of living protoplasm, having proved that dead bacteria have no effect on certain compounds which are decomposable by enzymes (Proc. K. Akad.

Wetensch., Amsterdam, I900, ii., 495).

5 fourn. Prakt. Chemie., Igor, ii., 64, p. I.

6 Godlewski, Bull. Acad. Sci. Cracow, Igor, 227. 
I. Enzymes which break up Albuminous Bodies. - The ordinary digestive ferments, pepsin, pancreatin, etc., are of this class. Bodies identical or similar are secreted by many bacteria, and Lehmann believes that the body which liquefies gelatine in cultivations is the same as trypsin from the pancreas. They form albumoses, then peptones. Papain is an example of a vegetable enzyme which hydrolyses nitrogenous matter. I found that the enzyme ${ }^{1}$ produced by $B$. fluorescens liquefaciens, when separated from the organism by a Pasteur filter, is capable of causing liquefaction of gelatine. Boyce has confirmed this observation, and has observed that $B$. enteritidis sporogenes forms a similar enzyme.

2. Enzymes which attack Carbohydrates. - Diastase, which dissolves starch, forming dextrine and sugar, ${ }^{2}$ is a type of a class of amylases, comprising glucase, ${ }^{3}$ granulase, maltase, and dextrinase, described as having slightly different functions. Invertase and lactase alter the sugars. Zymase (Buchner), from yeast and some other fungi, converts sugar into alcohol and $\mathrm{CO}_{2}$. Cytase, which dissolves cellulose, we shall describe later.

3. Enzymes which decompose Fats.-Lipase and others will also be further described.

4. Special Actions are very numerous, and will be separately alluded to.

Enzyme changes are arrested when the products reach a certain amount, and the existence of points of equilibrium between a direct and inverse change has been proved by Hill,4 in the case of the conversion of maltose into glucose by maltase. With a 40 per cent. solution he shows that equilibrium is reached when 84 per cent. of sugar is maltose and 16 per cent. glucose.

Maltose

84 per cent.

$\left.\longleftrightarrow \begin{array}{c}\text { Glucose } \\ \text { I6 per cent. }\end{array}\right\}$ in 40 per cent. solutions. .

In weaker solutions the equilibrium point for maltose increases, so that in a 2 per cent. sugar solution it is almost completely converted. In a solution so dilute as a sewage the influence of the products might hardly be felt, so that the enzyme changes would proceed to completion. Still, the

1 Rideal and Orchard, Analyst, Oct, I897; Fermi., Centr. Bakt., 1906, 176.

2 A. R. Ling shows that diastase can directly dissolve raw starch granules (British Association Report, 1903; Chemical News, October 2, 1903).

3 Beyerinck, Bied. Centr., r896, xxv., 753.

${ }^{4}$ Journal of the Chemical Society, August, 1898 . See also Kastle and Loevenhart, American Chemical Journal, xxiv., No. 6, and Chemical News, March 8, I90I, pp. II3, 127. Further observations by Hill and others show that reversibility is general (ibid., April 24, I903). Slator, Proc. Chem. Soc., Jan. 4, Igo6. 
action is more energetic when the products are removed as formed, and the bacteria are supplied with fresh food. ${ }^{1}$

The fermentations occurring in the first or hydrolytic part of the process may be chemically classified as follows:

I. Solution and decomposition of albuminous bodies.

2. Fermentation of urea.

3. Fermentation of the amido-compounds formed from the albuminous bodies.

4. The formation of organic acids and fermentation of their salts.

5. Cellulose or methane changes.

6. Fermentation of carbohydrates.

7. Decomposition of fats.

8. The formation of small quantities of sulphur compounds, like $\mathrm{H}_{2} \mathrm{~S}$, mercaptan, etc. This, from the odour of the products, often attracts the most attention.

These, as a rule, are brought about in sewage by bacteria, rather than by moulds and yeasts, which, as Andreasch showed, may be distinctly prejudicial to normal bacterial action.

I. Hydrolysis of Albuminous Bodies is caused by a large number of organisms, and the first action is parallel to ordinary digestion-that is, the so-called peptonization, or conversion into a soluble form. The peptones are then split up, amido-acids are formed, together with a number of substances of the aromatic group.

L. Geret and Martin Hahn ${ }^{2}$ describe proteolytic enzymes existing in yeast and also in such bacteria as Sarcina rosea, $B$. tuberculosis, and B. typhosus, and state that they not only decompose and dissolve the albumin already present, but also attack additional quantities of albumin from other sources.

Bilt $z$ and Kröhnke, ${ }^{3}$ Fowler and Andern, ${ }^{4}$ have shown that some of the sewage solids are not dialysable, so that part of the organic nitrogen causing opalescence in the liquid is in the colloidal state. Johnston, ${ }^{5}$ working with Jones and Travis, suggests that surfaces determine the separation of this colloidal matter from solution, so that a mechanical or physical change

1 The conditions are further worked out by E. Frankland Armstrong (Proceedings of the Royal Society, I904, Ixxiii., 500-542); also, as to the hindrance of fermentation by chemically indifferent substances, see H. Braeuning, Zeit. Phys.

Chem., I904, xliv., 70.

2 Berichte, 1899, xxxi., 2335 ; also Emmerlich and Löw, Zeits.f. Hyg., I899, I.

3 Berichte d.Chem. Gesell., xxxvii., 1745 .

4 Fournal of the Society of Chemical Industry, xxiv., 483.

5 Fournal of the Royal Sanitary Institute, 1906. 
may accompany a hydrolytic change due to bacterial activity. He recognises that, as shown by Sonstadt, ${ }^{1}$ crystalloids as well as colloids are separated from solutions by surfaces, but insists on the importance of the natural tendency of colloids to flocculation, especially in contact with surfaces, as aiding and determining bacterial decomposition of albuminoids.

2. The Fermentation of Urea. - In the ordinary hydrolysis by $B$. urea and $M$. urea- $\mathrm{CO}\left(\mathrm{NH}_{2}\right)_{2}+\mathrm{H}_{2} \mathrm{O}=\mathrm{CO}_{2}+2 \mathrm{NH}_{3}$ - the $\mathrm{CO}_{2}$ and $\mathrm{NH}_{3}$ combine to form carbonate of ammonium, which dissolves; therefore none is evolved as gas, and no oxygen is required beyond that derived from the water, even for the bacteria, since these are facultatively anaerobic. $M$. urece, for example, grows equally well in oxygen and hydrogen, and we know that urine putrefies in closed bottles. Miquel found that several water bacteria readily converted urea into ammonium carbonate, and that $M$. urea was constantly present in the atmosphere.

3. The Disposal of Amido-Compounds derived from Albuminous Bodies. - It will be seen from the table (p. 98) that either nitrogen or ammonia can be produced by bacterial action. That both transformations occur is proved by the composition of the gases from a closed tank, and also by the liberation of $\mathrm{H}$ and $\mathrm{CO}_{2}$ in anaerobic cultures. ${ }^{2}$

Every 8 parts by weight of oxygen absorbed from water would involve the liberation of an equivalent, or I part by weight of hydrogen, so that the weights, if increased by oneeighth, give the weight of water taking part in the hydrolysis. Both the transformations given in the last two columns of the table on p. 98 occur in sewage purification. The first or more complete change is one in which the gases evolved are entirely without odour, but the $\mathrm{N}$, being in the free state, is lost. In the second or less complete anaerobic change the gas will have an ammoniacal odour, and would be offensive if allowed to escape into the air. The effluent also will contain combined $\mathrm{N}$ in the form of $\mathrm{NH}_{3}$ and compound ammonias, and make it absolutely necessary to insure that adequate nitrification should follow. In this case the final effluent theoretically contains all

1 Fournal of the Chemical Society, 1xxxix., 339.

2 Hugounenq and Doyon found that under these conditions $B$. coli communis generated $\mathrm{H}$ and $\mathrm{CO}_{2}$ (the gas bubbles), B. tetani also $\mathrm{H}$ and $\mathrm{CO}_{2}, B$. typhosus $\mathrm{N}$ and $\mathrm{CO}_{2}$ (Ann. Clim. Phys. 1898, vii., 45). According to Pennington and Küsel, $B$. coli evolved in per cents. 62 to $70 \mathrm{H}, 23$ to $34 \mathrm{CO}_{2}$, I to 4 methane (not formed when $\mathrm{O}$ excluded), and I to $5 \mathrm{~N}$ (Fournal of the American Chemical Society, I900, xxii., 556). See also Pakes and Jullyman (loc. cit.). 
the original organic $\mathrm{N}$ in the form of nitrate, which is available for plant nutrition. As compared to the voluminous "sludge" of chemical or mechanical treatment, anaerobic liquefaction leaves only the small quantity of humus residue already alluded to.

The amido-acids formed in liquefaction break up into fatty or aromatic acids and ammonia. Since many of them are very stable bodies, the decomposition is slow. Following the general rule, being products of bacterial action, they hinder the activity of the bacteria themselves, furnishing an additional argument for the constant removal of the products by a continuous as opposed to an intermittent system. Examples are:

\begin{tabular}{|c|c|c|c|}
\hline Name. & Constitution. & Formula. & Products. \\
\hline Glycocine ... & Amido-acetic acid & $\mathrm{CH}_{2}\left(\mathrm{NH}_{2}\right) \mathrm{COOH}$ & $\begin{array}{l}\text { Ammonia and acetic } \\
\text { acid. }\end{array}$ \\
\hline Leucine $\quad \ldots$ & Amido-isocaproic & $\left\{\begin{array}{l}\mathrm{C}_{5} \mathrm{H}_{10}\left(\mathrm{NH}_{2}\right) \\
\mathrm{COOH}\end{array}\right.$ & $\begin{array}{l}\text { Ammonia and iso- } \\
\text { caproic acid. }\end{array}$ \\
\hline Tyrosine $\ldots$ & $\begin{array}{l}\beta \text {-oxyphenyl-amido- } \\
\text { propionic }\end{array}$ & $\left\{\begin{array}{l}\mathrm{CH}_{2} \mathrm{C}_{6} \mathrm{H}_{4}(\mathrm{OH}) \\
\mathrm{CH}\left(\mathrm{NH}_{2}\right) \mathrm{COOH}\end{array}\right.$ & As below. \\
\hline Aspartic $\quad \ldots$ & Amido-succinic & $\left\{\begin{array}{l}\left.\mathrm{CH}_{2} \mathrm{COOH}\right) \\
\left(\mathrm{CH}\left(\mathrm{NH}_{2}\right) \mathrm{COOH}\right.\end{array}\right.$ & $\begin{array}{l}\text { Ammonia and malic } \\
\text { acid, then succinic. }\end{array}$ \\
\hline Asparagin ... & Amido-succinamic & $\left\{\begin{array}{l}\mathrm{CH}_{2} \mathrm{CO}\left(\mathrm{NH}_{2}\right) \\
\mathrm{CH}\left(\mathrm{NH}_{2}\right) \mathrm{COH}\end{array}\right.$ & $\begin{array}{l}\text { Ammonia and malic } \\
\text { acid, then succinic. }\end{array}$ \\
\hline Glutamic ... & & $\left\{\begin{array}{l}\mathrm{C}_{3} \mathrm{H}_{5}\left(\mathrm{NH}_{2}\right) \\
(\mathrm{COOH})_{2}\end{array}\right.$ & $\begin{array}{l}\text { Ammonia and prob. } \\
\text { ably succinic acid. }\end{array}$ \\
\hline
\end{tabular}

Tyrosine has been said to be strongly antiseptic, but its quantity in fæces is small, and it is largely diluted in the sewage. It breaks up into indol, skatol, phenol, and acids related to benzoic. Spirillum rugula and the B. coprogenes group develop a strong fæcal odour, probably owing to this reaction. In the Exeter and Ashtead hydrolysed effluents I only found leucine unchanged; acetic, butyric, and caproic acids were, however, isolated, and traces of succinic as well as indol and skatol.

The development of these more or less antiseptic substances in the intestines probably accounts for the excreta not being further liquefied in the body, although large numbers of the necessary organisms are present. On emerging, however, and undergoing dilution the bacteria at once become active. 
The basic amines are of two classes:

(I) Non-volatile crystalline compounds known as ptomaines and leucomaines. They are poisonous, but that they are destroyed in the subsequent aerobic treatment is shown by the fact that the final effluents are not poisonous to fish.

(2) Volatile bases or substituted ammonias, usually of strong odours and alkaline. These, in the ordinary method of analysis by distillation, are partly put down as "free ammonia," which includes not only the ammonia existing as carbonate, but also that combined with the organic acids as salts, as well as such compound ammonias as react with Nessler test. Many years ago Young pointed out that in the usual mode of distillation a great deal of volatile nitrogenous matter escaped which was not recorded by Nessler test. The Wanklyn determination also gives an "albuminoid ammonia" which is far short of the fixed organic nitrogenous matter, probably accounting for such low figures as 0.34 (with 13.8 of chlorine) and 0.24 (with $10^{\circ} 3$ of chlorine) for raw sewages in the recent Manchester and other reports. The Kjeldahl process can be made to give the whole of the ammoniacal and organic nitrogen.

In a septic tank effluent I lately found by fractionation of the hydrochlorides, in parts per 100,000: actual ammonia, $3{ }^{*} 48$; monomethylamine $\left(\mathrm{CH}_{3} \mathrm{NH}_{2}\right), 0.844$; trimethylamine, traces; the original having given $4^{.6}$ parts of "free ammonia" and (by Kjeldahl) I.98 parts of fixed organic nitrogen, with a chlorine content of $6 \cdot 2$.

Trimethylamine has a fishy smell, which is very marked in some sewages. B. uree, B. prodigiosus, and B. fluorescens putridus develop this compound during putrefaction. Amylamine and others are also found. The chief importance of the group lies in - (I) their volatility and odours; (2) their removing carbon as well as nitrogen; (3) the toxic nature of some, by which they hinder the subsequent nitrification. These points would indicate that:-

(a) The preliminary liquefaction should be conducted in a closed chamber:

(b) The amines must be removed by a nitrous or other oxidation in the second part of the process, before reaching the nitric organisms.

4. The Formation of Organic Acids and Fermentation of their Salts. - In the resolution of complex organic molecules a number of organic acids are set free, and combine with any 
bases present, their salts being afterwards further broken down by such fermentations as are given in the annexed table. ${ }^{1}$

\section{Table of Fermentation of Organic Acids.}

(For simplicity, the sodium salts are taken, though the lime salts are rather more fermentable.)

\begin{tabular}{|c|c|c|}
\hline Salt Fermented. & Cause of Fermentation. & Products. \\
\hline Formate & $\begin{array}{l}\text { "Bacteria from sewage } \\
\text { slime." }\end{array}$ & $\begin{array}{l}\text { Acid sodium carbonate, } \mathrm{NaHCO}_{3} \text {, car- } \\
\text { bonic acid and hydrogen. }\end{array}$ \\
\hline Acetate & $\begin{array}{l}\text { "Bacteria from sewage } \\
\text { slime." }\end{array}$ & $\mathrm{NaHCO}_{3}, \mathrm{CO}_{2}$, and methane, $\mathrm{CH}_{4}$. \\
\hline $\begin{array}{l}\text { Lactate } \\
\text { (Undergoes } \\
\text { four different } \\
\text { fermenta- } \\
\text { tions.) }\end{array}$ & $\begin{array}{l}\text { "Thin bacillus"(Fitz). } \\
\text { "Other species of } \\
\text { bacteria; short aero. } \\
\text { bic butyric bacteria" } \\
\text { (Fitz). }\end{array}$ & $\begin{array}{l}\text { I. Propionic acid, and as by-products } \\
\text { acetic and succinic acids and alcohol. } \\
\text { 2. Propionic and valeric acid. } \\
\text { 3. Butyric and propionic acid. } \\
\text { 4. Butyric acid and hydrogen. }\end{array}$ \\
\hline $\begin{array}{l}\text { Malate } \\
\text { (Different fer. } \\
\text { mentations.) }\end{array}$ & $\begin{array}{l}\text { Bacteria not described. } \\
\text { "Thin bacilli." } \\
\text { B. lactis aerogenes (O. } \\
\text { Emmerling). }\end{array}$ & $\begin{array}{l}\text { I. Chief product, propionic acid; by- } \\
\text { product, acetic acid. } \\
\text { 2. Chief product, succinic acid; by- } \\
\text { product, acetic acid. } \\
\text { 3. Butyric acid and hydrogen. } \\
\text { 4. Lactic acid and } \mathrm{CO}_{2} \text {. }\end{array}$ \\
\hline Tartrate & $\begin{array}{l}\text { Different species of } \\
\text { bacteria. }\end{array}$ & $\begin{array}{l}\text { I. Chief product, propionic acid; by- } \\
\text { product, acetic acid. } \\
\text { 2. Butyric acid. } \\
\text { 3. Chief product, an acetate; by-pro- } \\
\text { ducts, alcohol, butyric and succinic } \\
\text { acids. }\end{array}$ \\
\hline Citrate & "Small, thin bacilli.", & $\begin{array}{l}\text { Acetic acid in large quantities, with } \\
\text { small quantities of alcohol and suc- } \\
\text { cinic acid. }\end{array}$ \\
\hline Glycerate ... & $\begin{array}{l}\text { Micrococci ; medium. } \\
\text { sized bacilli. }\end{array}$ & $\begin{array}{l}\text { I. An acetate, with small quantities of } \\
\text { succinic acid and alcohol. } \\
2 \text { Formicacid, with some methyl alcohol } \\
\text { and acetic acid. }\end{array}$ \\
\hline
\end{tabular}

Under active microbic fermentation all eventually pass into $\mathrm{CO}_{2}$ and $\mathrm{H}$, or $\mathrm{CH}_{4}$. The $\mathrm{CO}_{2}$ is partly free and partly as bicarbonate of the base. Acetic acid is generally the penultimate product, therefore the common production of methane.

${ }^{1}$ Herfeldt, Centr. f. Bakt., February, I895; Fournal of the Socicty of Chemical Industry, May, I895. 
Any amides of the acids are hydrolysed, with liberation of ammonia.

Hoyer ${ }^{1}$ has shown that acetic acid bacteria can live in absence of air, and then reduce colouring matters such as indigotin, methylene blue, and litmus, with liberation of $\mathrm{CO}_{2}$. They can obtain their nitrogen from peptone, asparagin, nitrites, and ammonium salts, and their carbon from acetates, lactates, and sugar. This shows that aerobic and anaerobic species are by no means rigidly separated; very few are obligatory in either sense.

Fungi and most vegetables secrete ferments, called by Bertrand "oxydases," which are capable of acting on phenol and the aromatic compounds in the second stage. W. H. Perkin states that pyridine, benzene, and naphthalene derivatives disappear in the contact beds at Manchester.

Rapid oxidation of organic acids in presence of traces of ferrous salts, which always exist in sewage, seems to take place without the agency of bacteria. ${ }^{2}$

5. Solution of Cellulose and Fibrous Matters.-Mitscherlich in I $85^{\circ}$ proved that cellulose was dissolved by fermentation; and Van Tieghem, ${ }^{3}$ in 1870 , describes the most active organism as $B$. amylobacter, anaerobic, and derived principally from the intestines of animals. It is always found in putrefying infusions, and hydrolyses sugars and starch as well as cellulose, yielding butyric acid and hydrogen, whence its later name of $B$. butyricus. Tappeiner ${ }^{4}$ fermented cotton-wool and paper pulp in a weak nitrogenous solution, and obtained $\mathrm{CO}_{2}$ and methane in neutral, and $\mathrm{CO}_{2}$ and $\mathrm{H}$ in alkaline solution. Hoppe-Seyler ${ }^{5}$ in $\mathbf{1 8 8 6}$, finding only traces of residue, concluded that at first a soluble carbohydrate was formed by the action of water, and then split up into $\mathrm{CO}_{2}$ and $\mathrm{CH}_{4}$ :

$$
\begin{gathered}
\mathrm{C}_{6} \mathrm{H}_{10} \mathrm{O}_{5}+\mathrm{H}_{2} \mathrm{O}=\mathrm{C}_{6} \mathrm{H}_{12} \mathrm{O}_{6} . \\
\mathrm{C}_{6} \mathrm{H}_{12} \mathrm{O}_{6}={ }_{3} \mathrm{CO}_{2}+{ }_{3} \mathrm{CH}_{4} .
\end{gathered}
$$

If more water took part, less $\mathrm{CH}_{4}$ and more $\mathrm{H}$ would be obtained. Horace Brown ${ }^{6}$ found that a cellulose-dissolving enzyme in the digestive tract of herbivora was secreted by the food plants themselves, and came into activity under favour-

1 Chem. Centralblatt, I899, i., 854 .

2 Fenton and Jones, Chemical Society's Transactions, January, I900, 69.

3 Zeit. Phys. Chem., vi., 287, and De Bary's Lectures.

4 Zeits. $f$. Biol., xxiv., I05.

6 Fournal of the Chemical Society, I892, 1xi., 352. 
able conditions. "Rot-steep," or retting of flax, and skeletonizing of leaves, are processes of similar character.

Von Senus, in I89o, proved the fermentation of fibre to be anaerobic, that it was occasioned by a symbiosis, or concurrent action of $B$. amylobacter with other organisms, and that gaseous products of the above character finally remained. He isolated an enzyme which dissolves fibre, and also a group of the resolving bacteria from mud, stomach contents, and decaying vegetable matter. Brown and Morris ${ }^{1}$ have also isolated from fungi a similar or identical ferment called "cytase," quickly dissolving celluloses. ${ }^{2}$ Vignal found it in B. mesentericus vulgatus. It is well known how rapidly Merulius lachrymans, or "dry rot," softens the fibre of hard wood.

In laboratory experiments with different kinds of cellulose, paper, cotton-wool, etc., in water inoculated with sewage organisms, I have observed gradual liquefaction with the production of inflammable gases. Omeliansky believes that B. amylobacter is not a separate species, but includes a number of forms that act as butyric ferments, and that none of them separately dissolve pure cellulose to any marked extent. Swedish paper in a solution containing chalk, magnesium, and ammonium sulphates and potassium phosphate, inoculated with Neva mud, fermented actively, and both it and the chalk dissolved. By Winogradsky's elective cultures he isolated the chief bacillus causing the change, which he describes. ${ }^{3}$

The changes occurring in silos and in manure heaps may be noticed as examples of the anaerobic breaking down of cellulose and fibrous matters. Macfadyen and Blaxall show that these results are due to an extensive group of thermophilic bacteria, which are widely distributed in Nature, and especially in sewage and in ensilage. The majority reduce nitrates and decompose proteid matter, but, in addition, they possess the important property of decomposing cellulose into probably $\mathrm{CO}_{2}$ and marsh gas. Swedish filter-paper in ten to fourteen days was completely disintegrated by these organisms. Omeliansky describes a $B$. fermentationis cellulose, yielding 70 per cent. of fatty acids, chiefly acetic and butyric, and 30 per cent. of gases $\left(\mathrm{CO}_{2}\right.$ and $\left.\mathrm{H}\right){ }^{4}$ His subsequent work differentiates two organisms, which occur

1 Transactions of the Chemical Society, 1890, p. 497.

2 Annals of Botany, vii., I20 ; also see J. G. Green, Phil. Trans., I887, clxxviii., 57 ; Marshall Ward, Annals of Botany, I888, ii., 319; Reinitzer, Zeit. Phys. Chem., 1897, xxiii., I75 ; Biedermann and Moritz, Pflüger's Archiv, I898, 1xiii., 2 I9.

3 Comptes rendus, cxxi., 653 .

4 Arch. Sci.Biol. St. Petersburg, I899, vii., 4 II. 
very widely, and do not grow on ordinary media, but can be isolated by the method of accumulation. ${ }^{1}$ One species evolves hydrogen, $3^{\circ} 22$ grammes of cellulose yielding 0.0I 4 gramme of hydrogen, $0^{*} 9722$ gramme of $\mathrm{CO}_{2}$, and 2.24 grammes of fatty acid (I part butyric and I'7 parts acetic). The second evolves $\mathrm{CH}_{4}, 2^{\circ} \mathrm{O} 3$ grammes of cellulose yielding $0^{\circ} \mathrm{I}_{4}$ gramme of $\mathrm{CH}_{4}$, 0.87 gramme of $\mathrm{CO}_{2}$, and $\mathrm{I}^{\circ} \mathrm{O} 2$ grammes of fatty acids ( $\mathrm{I}$ part butyric and 9 parts acetic). Both grow best at $35^{\circ}$ to $40^{\circ} \mathrm{C}$. This explains the presence of $\mathrm{H}$ and $\mathrm{CH}_{4}$ in the septic tank in different proportions.

Vasculose (Fremy), constituting the harder parts of plants, is also slowly disintegrated by organisms.

The smaller remains of vegetable matter which pass down sinks occasion considerable nuisance when an attempt is made to remove them by screens, or on the top of a coarse filter. They act objectionably in three ways:

I. They set up acid fermentation and corrode iron.

2. A large proportion of domestic vegetable débris (cabbage, etc.) contains sulphur compounds, and evolves on decomposition very offensive odours.

3. They form a pulp which blocks the strainers.

Under anaerobic conditions in a closed space they rapidly rot away and disappear, their pectose first dissolving and then their cellulose, while the ammonia takes up the acids.

Cellulose can also be brought into solution by the action of denitrifying, non-sporulating bacteria with restricted access of air. $^{2}$ The presence of considerable quantities of soluble organic matter prevents the nitrification process, but cellulose is without influence if the aeration be good. The conjoint action of nitrification and denitrification processes must play an important part in the destruction of cellulose in the self-purification of waters and soils and the biological purification of effluents. Cellulose is also decomposed by aerobic, non-sporulating bacteria, of which a brown pigment bacterium ( $B$. ferrugineus) is the most important. This bacterium is particularly active in symbiosis with a yellow micrococcus, which by itself is inactive. In nutritive solutions, in which the cellulose is decomposed by the aerobic bacteria of mud or garden soil, spirilla cultures are always formed abundantly. The property of attacking cellulose is a general one among the fungi, and is

1 Journal of the Chemical Society, abstract, 1902, 468.

2 C. van Iterson, Centr. Bakt. Par., xi., 689; Chem. Centr., I904, i., г388. 
due to the enzyme, "cellulase" or cytase. One of the causes of the formation of humus colouring matters is the production of pigments from cellulose by the action of bacteria and fungi, such as the "Bismarck-brown" cladothrix found in dust-heaps. Anaerobically, in absence of nitrates, $\mathrm{CO}_{2}$ and hydrogen or methane, together with acetic and butyric acids, are formed; whilst in presence of a nitrate the cellulose is decomposed by denitrifying bacteria, with formation of nitrogen, $\mathrm{CO}_{\mathfrak{s}}$, and water.

6. Fermentation of Other Carbohydrates. - Starch; different sugars, and gummy substances undoubtedly enter into sewage, but their hydrolysis is so rapid that very little trace of them is found after a short period. The ferments in human fæces allied to diastase and invertase were investigated in I887-I888 by O. Loew, ${ }^{1}$ Pavy, ${ }^{2}$ and $\mathrm{R}$. von Jaksch, ${ }^{3}$ and later by MacConkey ${ }^{4}$ and others. Those fermentations, such as the alcoholic, which are usually occasioned by higher fungi like yeasts and moulds, do not present themselves distinctly, although the $B$. coli communis is capable of fermenting sugars and producing lactic acid, alcohol, and a volatile acid. The changes are either lactic, from $B$. acidi lactici, or butyric, from Clostridium butyricum or $B$. butyricus (both anaerobic), and give, besides the respective acids, carbonic acid, hydrogen, and water.

7. Decomposition of Fats. - Soapsuds and greasy matters occasion considerable trouble in the mechanical treatment of sewage. At Bradford the refuse of wool-scouring has been the chief difficulty for years, and has led to several special processes (see later, Chap. XIV.).

In a bacterial tank the grease is first emulsified by the ammonia. There are several bacteria that attack fats in presence of nitrogenous substances, ${ }^{5}$ breaking them up into the simpler acids of the fatty series, like acetic and butyric, which in their turn are finally resolved, as on p. Iog. Mucor mucedo, a common mould, resolves glycerides into their constituent parts, and at the same time produces a secondary change, giving bodies of an aldehydic character, ${ }^{6}$ which would be subsequently oxidized. Many other moulds also act on fats, notably the

1 Pflüger's Archiv., xxvii., 203.

2 Maly's Jahresb., xiv., 294.

1 Fournal of Hygiene, I905, v., 333.

5 Sommaruga, Zeits. Hyg., xvii. 44 I.

6 "Fat-consuming Organisms," König, etc. (Analyst, January, I902, p. IO) ; also Hanns and Stocky (ibid., Igor, p. I5). 
ordinary green Penicillium glaucum, which Hanriot found to contain lipase, ${ }^{1}$ besides emulsin and other ferments. Moulds are not commonly present in the anaerobic stage, but occur in the second or limited aeration. Ritthausen and Baumann found that a great destruction of fat occurred by the action of moulds and bacteria in a substance containing proteids as well. The substance they experimented on was rape-cake. ${ }^{2}$ The glycerine also ferments. R. Sazerac discovered a bacterium which has the power of rapidly oxidizing glycerine. ${ }^{3}$

8. The Sulphur Fermentation. - Sims Woodhead found Bacterium sulphureum in the Exeter tank. It liquefies gelatine, casein, and other albuminoids, and produces sulphuretted hydrogen. Several observers did not, however, find $\mathrm{H}_{2} \mathrm{~S}$ in the tank gases. I have found that a mercaptan (methyl hydrosulphide) and other ethereal compounds are undoubtedly present in small quantities. They are very soluble and easily oxidized.

The sulphur fermentations seem to have many stages. Zelinski obtained from Black Sea ooze an organism which he named Bacterium hydrosulphureum ponticum: it reduced sulphates to sulphides, and evolved $\mathrm{H}_{2} \mathrm{~S}$. He cultivated it in a special medium containing I per cent. ammonium tartrate, one to 2 per cent. glucose, $0^{\circ} 5$ to I per cent. sodium thiosulphate, $0^{\circ} \mathrm{I}$ per cent. potassium phosphate, and a trace of calcium chloride. ${ }^{4}$ Letts, using this solution, succeeded in cultivating a similar organism from the foreshore mud of Belfast Lough. ${ }^{5}$ Martinus Beyerinck ${ }^{6}$ groups in a new genus Aerobacter - bacteria derived from air, but facultatively anaerobic, which cause fermentations, giving $\mathrm{H}, \mathrm{CO}_{2}$, and lactic acid, and also form sulphuretted hydrogen from proteids and from sulphur compounds other than sulphates. They are detected by the blackening of white lead diffused in the cultures. They reduce nitrates to nitrites, but the presence of the former prevents fermentation and gas formation. In air they may act as oxidizers, except the aerobacter known as B. coli communis. "The nauseous odours of putrefaction are not due to sulphides. The reduction of sulphates is due to Spirillum desulphuricans." Saltet isolated a $B$. desulphuricans which reduces sulphates to sulphites, but produces no $\mathrm{H}_{2} \mathrm{~S}$.

1 See Kastle and Loevenhart, American Chemical foumal, xxiv., No. 6.

2 Landw. Versuchs. Stat., xlvii., 386, 1896.

3 Bull. Soc. Chim. de Paris, [3], xxix., No. 16, 1903.

4 Proceedings of the Russian Physical and Chemical Society, xxv., [5], 1893.

5 Proceedings of the Royal Society of Edinburgh, March 4, I90I.

${ }^{6}$ Arch. Nederland Sci. nat., 19oo, [2], iv., I. 
Most of the sulphur, however, enters into combination with the iron present in the sewage, forming insoluble ferrous sulphide, and giving a black colour to the suspended matter. When the black matter is treated with acids, sulphuretted hydrogen is evolved and the substance becomes brownish, just as when strong acid effluents from factories are discharged into ditches or on to the black mud-banks of neglected rivers a liberation of $\mathrm{H}_{2} \mathrm{~S}$ occurs. In the tank, however, the ferrous sulphide is protected by the ammonia; on reaching the oxidation stage it is converted into a basic ferric sulphate, forming an ochreous coating on the materials, which considerably assists in the transfer of oxygen and absorption of organic matter.

At Melbourne a large proportion of sulphuretted hydrogen is produced during the passage of the sewage through the $2 \frac{3}{4}$ miles of pipes from the pumping-station. Being protected from light and air during transit, a septic action is set up, and much local complaint arose as to escaping smell. Sulphur has been burnt and the $\mathrm{SO}_{2}$ forced into the sewage, with the result that complaints ceased; but directly the process is stopped the smell returns. A remedy has been found in ventilation. ${ }^{1}$

A proportion of the bacteria escape from the septic tank or other anaerobic chamber, but a large number remain entangled in a zooglcea mass either at the top or bottom of an unobstructed tank, or as a layer on the surface of the flints or other filling material.

With the exception of not requiring extraneous heat, the first stage of anaerobic resolution of organic substances is analogous to the decomposition of coal in gas retorts, the chief products, free hydrogen and methane $\left(\mathrm{CH}_{4}\right)$ being identical ; in fact, the latter has been called "marsh gas," from its being produced in stagnant pools, where hydrolytic changes occur beneath the surface. As disengaged from closed tanks, the gas is found to burn with a blue flame, like that of an ordinary atmospheric burner, giving great heat, which can either be utilized under boilers or, by means of incandescent mantles, be applied to the lighting of the works. At Exeter a gas-lamp of the usual street pattern is fed from the gases of the septic tank (see Fig. 26).

Even from open tanks gas can be collected. At Manchester a small gasometer, about 4 feet in diameter, was floated on the surface of one of the tanks, and from the spherical head of this

1 Thwaite's Report to Melbourne Board of Works, I9or. p. 55. 
receiver a pipe conveyed the gas to the attendant's hut, where it was used efficiently for light in an incandescent burner, or for heat in a small gas-stove. The volume generated is tested by this gasometer, and it is stated that about a cubic foot is produced in twenty-four hours for every square foot of surface, and that it is equal in heating power to good coal-gas ${ }^{1}$ (see further, Chap. XI.).

The residual gaseous energy that is available in this way can be approximately calculated from the consideration that the organic matter removed from the sewage and converted into gas in the tank is, for the most part, not oxidized or burnt therein. The oxygen-consumed figure of the raw sewage, with its suspended matter, less the oxygen-consumed figure of the tank effluent, gives a measure of the combustibility of the gases produced. For example:

PARTS PER IOO,OOO.

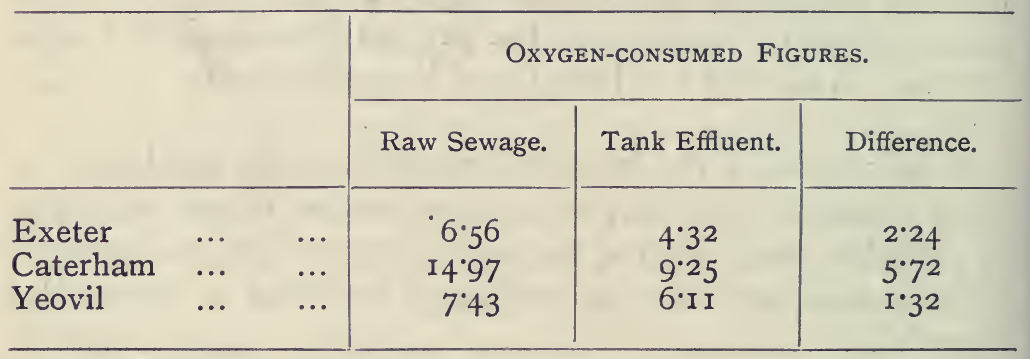

It is easy to understand, bearing in mind ordinary burning, how, in oxidation changes, energy is obtained for the continuance of the reaction. In hydrolytic changes the source of energy is not so clear, but it is certain that there occurs a distinct evolution of heat, small in amount, and almost imperceptible in the bulk of water, but sufficient to continue the reaction, which is therefore exothermic, or containing within itself the conditions of its own propagation. ${ }^{2}$ Thus in the case of urea-

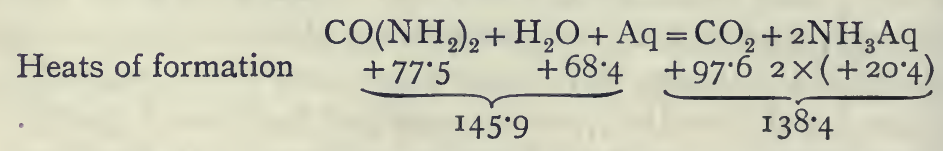

but the $2 \mathrm{NH}_{3}$ and $\mathrm{CO}_{2}$ neutralize one another, resulting in a further evolution of about 20 units.

\footnotetext{
1 Water, June I6, I902. $\quad 2$ Cf. Berthelot, Comptes rendus, lix., 901, 1864.
} 
Hence $145^{\circ} 9$ must be absorbed, while $15^{\circ} 4$ must be evolved, giving a balance of $\mathrm{I}^{\circ} 4$ units evolved.

[The units are kilogramme-centigrade, and the substances are taken in gramme-molecules.]

Heat of formation

\section{Cellulose.}

$$
\mathrm{C}_{6} \mathrm{H}_{10} \mathrm{O}_{5}+\mathrm{H}_{2} \mathrm{O}={ }_{3} \mathrm{CO}_{2}+{ }_{3} \mathrm{CH}_{4}
$$

Heat absorbed, 3I4. Heat evolved, $340^{\circ} 5$.

Evolution of heat, $26 \cdot 5$ units.

The heat of formation of cellulose is calculated thus :

Complete combustion of $6 \mathrm{C}$ and $10 \mathrm{H}$ to $\mathrm{CO}_{2}$ and water :

$$
\begin{aligned}
6 \mathrm{C}+{ }_{5} \mathrm{H}_{2}+\mathrm{O} \text { in excess }= & 6 \mathrm{CO}_{2}+{ }_{5} \mathrm{H}_{2} \mathrm{O} \\
& \underbrace{6 \times 975 \times 68 \cdot 4}_{924 \text { units. }}
\end{aligned}
$$

Combustion of cellulose $\left(\mathrm{C}_{6} \mathrm{H}_{10} \mathrm{O}_{5}\right)$ gives 678 units (Stohmann).

$$
924-678=246 \text {. }
$$

\section{Albumin.}

Berthelot and André ${ }^{1}$ state that I gramme of albumin dried at $100^{\circ} \mathrm{C}$. gives $5,69 \mathrm{I}$ calories (gramme-centigrade units).

Hence $\mathrm{C}_{8} \mathrm{H}_{13} \mathrm{~N}_{2} \mathrm{O}_{3}=\mathrm{I} 85$ of albumin give $\mathrm{I} 85 \times 5,69 \mathrm{I}=$ $\mathrm{I}, 052,835=\mathrm{I}, 053$ kilogramme units.

We must first calculate from this the heat of formation of albumin :

$$
\begin{aligned}
\left(8 \mathrm{C}+\mathrm{I}_{3} \mathrm{H}+2 \mathrm{~N}+3 \mathrm{O}\right) \text { burnt }= & 8 \mathrm{CO}_{2}+6 \mathrm{H}_{2} \mathrm{O}+\mathrm{N}_{2}+\mathrm{H} \\
8 & \times 97 \quad 6 \times 68 \\
& 776+408=\mathrm{I}, \mathrm{I} 84 .
\end{aligned}
$$

Hence heat of formation $=I, I 84-I, 053=I 3 I$ units. ${ }^{2}$

Now, assuming a complete hydrolytic change :

$$
{ }_{4} \mathrm{C}_{8} \mathrm{H}_{13} \mathrm{~N}_{2} \mathrm{O}_{3}+\mathrm{I}_{4} \mathrm{H}_{2} \mathrm{O}=4 \mathrm{~N}_{2}+\mathrm{I}_{9} \mathrm{CH}_{4}+\mathrm{I}_{3} \mathrm{CO}_{2}+4 \mathrm{H}
$$

Thermally $4 \times \mathrm{I}_{3} \mathrm{I} \quad \mathrm{I} 4 \times 68$

$$
\begin{gathered}
\mathrm{I} 9 \times 16^{\circ} 5 \text { I } 3 \times 97 \\
3 \mathrm{I} 44^{\circ} 5+\mathrm{I}, 26 \mathrm{I}
\end{gathered}
$$

$$
524+95^{2}
$$

I, 476 absorbed.

I $575^{\circ} 5$ evolved.

Giving a balance of $1,576-1,476=$ Ioo units evolved.

1 Chemical Society Abstracts, I89o, p. 937.

2 I have left out one hydrogen atom in this calculation, because in the enzyme reaction one hydrogen per molecule of albumin is set free. 
It is curious that the percentage of the heat evolved in the products is in each case nearly the same:

\begin{tabular}{lll|c|c|c}
\hline & & & $\begin{array}{c}\text { Heat in } \\
\text { Products. }\end{array}$ & Heat evolved. & Per Cent. \\
\hline Urea ... & $\ldots$ & $\ldots$ & $\mathrm{I} 58 \cdot 4$ & $\mathrm{I} 2 \cdot 4$ & 8 \\
Cellulose & $\ldots$ & $\ldots$ & 340 & $26 \cdot 5$ & 8 \\
Albumin & $\ldots$ & $\ldots$ & $\mathrm{I}, 575$ & I00 & 7 \\
\hline
\end{tabular}

These enzyme reactions follow the ordinary chemical law of going in the direction of an evolution of heat. They occur at atmospheric temperature, and it has been pointed out by Van t'Hoff that the lower the temperature the more nearly will Berthelot's law of maximum work be obeyed.

\section{The Second Stage, or Semi-Aerobic Breaking-Down of the Intermediate Dissolved Bodies,}

is not generally distinguished sufficiently from the first, nor allowed adequate time to develop. It occurs in the upper layers of bacterial filters, as requiring little oxygen, and results generally in the production of nitrites, the conditions being favourable to the growth of $B$. nitrosomonas. In this stage the amido-compounds, fatty acids, and dissolved residues of hydrolysis undergo a further resolution.

Nitrosification, or the production of nitrites, and secondarily of nitrogen and its lower oxides, by partial oxidation, should normally occur in the second stage of bacterial purification. Wherever we find a final filter acting badly, either from deficient aeration or other cause, the fault is at once indicated by the appearance of a high proportion of nitrites, as nitrosification is not nearly so delicate a process or so difficult to initiate or control as nitrification, or the production of nitrates, which it would naturally precede. For example, P. F. Richter isolated a coccus of medium size, which in twenty minutes produced a very intense nitrite reaction in fresh urine, and in addition reduced nitrate to nitrite-a retrograde change which I have already remarked as common to many bacteria, and characteristic of crude attempts to introduce nitrification before the sewage is properly hydrolysed and prepared. Nitrosification proceeds most rapidly in the presence of diffused light and of 
a moderate amount of air. In many processes the purification goes no farther, when nitrification is not subsequently active.

The nitrosification change in the second stage gets rid of the transition products-ammonia, amido-acids, and the amidesby double decomposition into water, or hydroxy-compounds (which are afterwards broken up by fermentation) and nitrogen gas. As simple instances we have :

$$
\begin{array}{ccc}
\mathrm{NH}_{3}+\mathrm{HNO}_{2} & = & 2 \mathrm{H}_{2} \mathrm{O}+\mathrm{N}_{2} \\
\left(\mathrm{NH}_{2}\right) \mathrm{CH}_{2} \mathrm{COOH}+\mathrm{HNO}_{2} & = & (\mathrm{OH}) \mathrm{CH}_{2} \mathrm{COOH}+\mathrm{H}_{2} \mathrm{O}+\mathrm{N}_{2} \\
\text { Amido-acetic acid. } & \text { Glycolic acid. } \\
\left(\mathrm{NH}_{2}\right) \mathrm{C}_{2} \mathrm{H}_{5}+\mathrm{HNO}_{2} & = & \mathrm{C}_{2} \mathrm{H}_{5} \mathrm{OH}+\mathrm{H}_{2} \mathrm{O}+\mathrm{N}_{2} \\
\text { Ethylamine. } & & \text { Alcohol. }
\end{array}
$$

In the process, which takes place especially in the restingfull period of filters, nitrogen, and sometimes secondarily $\mathrm{CO}_{2}$, are evolved, but scarcely any hydrogen or methane. It is therefore accompanied by a great loss of nitrogen, a smaller loss of carbon, and a removal of odour.

Grimbert ${ }^{1}$ has shown that $B$. coli communis and $B$. typhosus do not disengage gas in I per cent. solution of peptone plus I per cent. potassium nitrate, but the gas is produced when the peptone is replaced by meat extract, which contains simpler amido-compounds. The volume of nitrogen evolved is always about double the amount which the nitrate destroyed could. possibly produce, proving that the gas is derived from the secondary reaction between amido-substances and the nitrous acid produced by denitrification. The bacilli develop very well in a medium containing I per cent. of nitrites, and disengage an equal or even larger quantity of nitrogen than in the same medium containing I per cent. of nitrates. He believes that this is the explanation of the loss of nitrogen in the soil.

Nitrous compounds also serve as carriers of oxygen from the air to the organic matter in a way similar to their well-known action in vitriol chambers. Münt $z^{2}$ found that the calcium nitrite in sterilized soil, when $\mathrm{CO}_{2}$ was passed over it, gave off nitrous acid rapidly, but on exposure to air, or on passing $\mathrm{CO}_{2}$ largely diluted with air, it was quickly oxidized to nitrate. The following are examples from my own experience of the changes in filter effluents (parts per 100,000 ): 


\begin{tabular}{l|c|c|c|c}
\hline Number. & $\begin{array}{c}\text { Original N as } \\
\text { Nitrate. }\end{array}$ & $\begin{array}{c}\text { After Twelve } \\
\text { Days. }\end{array}$ & $\begin{array}{c}\text { Original N as } \\
\text { Nitrite. }\end{array}$ & $\begin{array}{c}\text { After Twelve } \\
\text { Days. }\end{array}$ \\
\hline VI. & I.OI & I.I5 & About O.I & 0.48 \\
VII. & 0.59 & 0.62 & About 0.05 & 0.67 \\
VIII. & 0.70 & 0.77 & About 0.05 & 0.55 \\
\hline
\end{tabular}

Another filter effluent illustrates a usual rule-that while nitrosification is active nitrification is almost stationary; but when the nitrites begin to decline the nitrates rapidly rise:

\begin{tabular}{|c|c|c|c|}
\hline $\mathrm{Vi}$ & $\ldots$ & $\begin{array}{l}\text { ember ro. } \\
0.03\end{array}$ & $\begin{array}{c}\text { November } 18 . \\
0.74\end{array}$ \\
\hline$N$ & $\ldots$ & I. 49 & I. 5 I \\
\hline
\end{tabular}

In a septic tank effluent on November Io the nitrate was 0.030 , the nitrite none; on December 2 the nitrate was 0.060 , the nitrite excessive; the nitrite had obviously been formed from ammonia, and not by reduction of nitrate. An instance of the transfer of oxygen by means of the oxidized nitrogen compounds, resulting in a reduction of the organic carbon, without a corresponding decrease in the amount of total nitrogen, was given by my analyses of the Caterham effluents in I899, when kept for a short time in stoppered bottles partially full.

\begin{tabular}{|c|c|c|c|c|c|c|c|c|c|c|}
\hline \multirow{2}{*}{ Samples. } & \multicolumn{2}{|c|}{ No. I. } & \multicolumn{2}{|c|}{ No. 2.} & \multicolumn{2}{|c|}{ No. 3 . } & \multicolumn{2}{|c|}{ No. 4 . } & \multicolumn{2}{|c|}{ No. 5.} \\
\hline & Jan. 26 & Feb. I & Jan. 27 & Feb. I & Jan. 28 & Feb. I & Jan. 30 & Feb. I & Jan. $3 \mathrm{I}$ & Feb. I \\
\hline 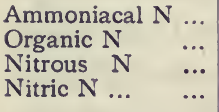 & $\begin{array}{c}12.15 \\
0.618 \\
0.148 \\
7.68\end{array}$ & $\begin{array}{l}\text { II.9 } \\
0.412 \\
0.074 \\
9^{\circ} 0\end{array}$ & $\begin{array}{c}12 \cdot 56 \\
0.823 \\
1.924 \\
4^{\cdot} \cdot 14\end{array}$ & \begin{tabular}{|l|}
$12 \cdot 1$ \\
$\mathbf{I} \cdot 03$ \\
$\mathbf{I} \cdot 702$ \\
$4 \cdot 36$
\end{tabular} & $\begin{array}{c}12 \cdot 35 \\
0 \cdot 618 \\
1 \cdot 184 \\
5 \cdot 60\end{array}$ & $\begin{array}{r}I I: 54 \\
0: 41 \\
I \cdot 40 \\
6 \cdot 46\end{array}$ & \begin{tabular}{c|}
$2 \mathrm{r} \cdot 4$ \\
$\mathrm{I} \cdot 23$ \\
$0 \cdot 407$ \\
$\mathrm{IO} \cdot 3$
\end{tabular} & $\begin{array}{c}20 \% 6 \\
1 \cdot 44 \\
0.41 \\
10 \cdot 64\end{array}$ & $\begin{array}{l}23.8 \\
0.82 \\
0.59 \\
6.46\end{array}$ & $\begin{array}{l}0.666 \\
5 \cdot 5^{2}\end{array}$ \\
\hline $\begin{array}{l}\text { Total nitrogen } \\
\text { Oxidized nitrogen } \\
\text { Percentage of } \\
\text { nitrification }\end{array}$ & $\begin{array}{c}20 \cdot 596 \\
7 \cdot 828 \\
38 \cdot 0\end{array}$ & $\begin{array}{c}2 r \cdot 386 \\
9 \cdot 74 \\
45 \cdot 5\end{array}$ & $\begin{array}{r}19 \cdot 447 \\
6 \cdot 064 \\
\\
3 x^{\circ} \cdot 0\end{array}$ & $\begin{array}{r}19 \cdot 192 \\
6.062 \\
32 \cdot 0\end{array}$ & $\begin{array}{c}19.752 \\
6.784 \\
34^{\circ} 5\end{array}$ & $\begin{array}{c}19 \cdot 81 \\
7 \cdot 86 \\
39 \cdot 6\end{array}$ & $\begin{array}{l}33 \cdot 337 \\
10 \cdot 707 \\
32 \cdot 0\end{array}$ & $\begin{array}{l}33^{\circ} 09 \\
\text { II.05 } \\
33^{\circ} 4 \\
\end{array}$ & $\begin{array}{c}3 r \cdot 67 \\
7 \cdot 05 \\
22 \cdot 3\end{array}$ & 19.5 \\
\hline $\begin{array}{l}\text { xygen consumed } \\
\text { Ohlorine ... } \quad \ldots\end{array}$ & $\begin{array}{r}3.3^{32} \\
18 \cdot 5\end{array}$ & $2 \cdot 24$ & $\begin{array}{r}6 \cdot 27 \\
19.75 \\
\end{array}$ & $\stackrel{443}{-}$ & $\begin{array}{c}4.19 \\
21^{\circ} 5\end{array}$ & 3.47 & $\begin{array}{r}4 \cdot 85 \\
22 \cdot 15\end{array}$ & 278 & $\begin{array}{r}4 \cdot 52 \\
24 \cdot 35\end{array}$ & \\
\hline $\begin{array}{l}\text { Percentage of re- } \\
\text { duction in the } \\
\text { oxygen consumed }\end{array}$ & - & 32.5 & - & $30^{\circ} 0$ & - & $17^{\circ} \circ$ & - & 43 & - & \\
\hline
\end{tabular}

The chief change seems to have been a transfer of the oxygen of the air by means of the nitrous acid to the carbonaceous matter. The nitrifying and nitrosifying changes appear to have gone on continuously, the nitric being reduced to nitrous 
by the carbonaceous matter, which was thereby oxidized, and the nitrous again absorbing oxygen and re-forming nitric. In Nos. I and 3 the nitrogenous organic matter has taken part; but the change, as a rule, is not a Gayon and Dupetit one (see p. I26), as no loss of total $\mathrm{N}$ as gas has occurred. It is simply an oxidation of carbon.

\section{The Third Stage, that of Complete Aeration,} comprises the final oxidation of the nitrogenous and carbonaceous residues, and includes the formation of nitrates, or nitrification.

The amount of oxygen required for the processes of nitrification and nitrosification is shown in the following table:

One Gramme of Nitrogen requires-

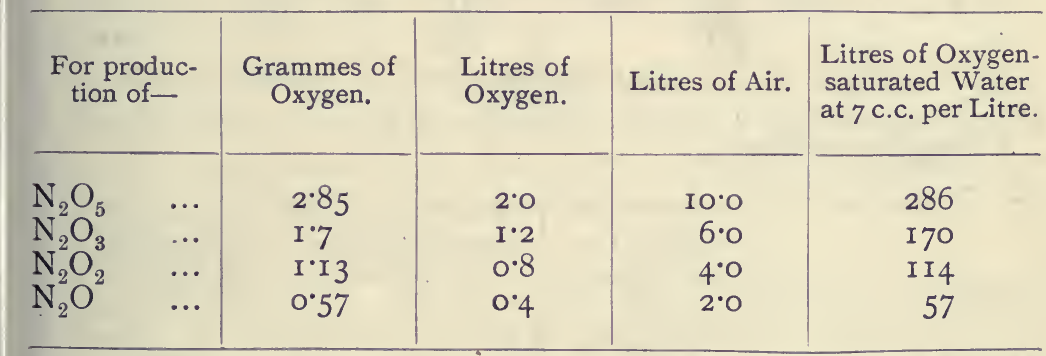

So that to nitrify in an effluent 5 parts of nitrogen per I00,000 (I gramme in 20 litres) will demand about half its volume of air, or about I $_{5}$ volumes of fully aerated water. This explains the comparative failure and frequent collapse of filter-beds in large masses, especially if the fluid is a raw sewage. or a merely screened or precipitated effluent without preliminary hydrolytic change, as with every 100,000 gallons of sewage about 50,000 gallons of air must be continuously supplied.

Contrivances like fountains, cascades, and weirs can only raise the dissolved oxygen to the saturation of about 7 c.c. per litre, or 700 gallons per 100,000; although useful, if simple, like the aerator at Exeter, ${ }^{1}$ they are quite inadequate.

At Manchester in $1897 \mathrm{Mr}$. Fowler investigated the purification of chemically precipitated effluents by simple exposure to air. He found that shallow layers and a considerable period of time were necessary, and that "it is not probable that aeration sufficient to at all adequately oxidize an effluent could

1 In November, I896, I found that while the septic tank effluent contained no oxygen, after passing over this aerator it had dissolved $0{ }^{\circ} 56$ c.c. per litre. 
be produced by any system of cascades which could be applied in a practical form."

The following table summarizes some of his experiments:

\begin{tabular}{|c|c|c|c|c|c|}
\hline \multicolumn{3}{|c|}{ Air passing over Surface. } & \multicolumn{3}{|c|}{ AIR DRAWN THROUGH LIQUID. } \\
\hline $\begin{array}{c}\text { Hours } \\
\text { exposed. }\end{array}$ & O consumed. & $\begin{array}{l}\text { Per cent. } \\
\text { Reduction. }\end{array}$ & $\begin{array}{l}\text { Hours } \\
\text { exposed. }\end{array}$ & O consumed. & $\begin{array}{l}\text { Per cent. } \\
\text { Reduction. }\end{array}$ \\
\hline 0 & $2 \cdot 52$ & - & $\mathrm{o}$ & $2^{\circ} \mathrm{OO}$ & - \\
\hline $2 I$ & $2 \cdot 58$ & - & 4 & $2 \cdot 08$ & - \\
\hline 27 & $2 \cdot 57$ & - & 6 & $2 \cdot 00$ & - \\
\hline 72 & $I \cdot 44$ & 43 & 23 & $I \cdot 62$ & I9 \\
\hline 95 & $I \cdot 26$ & 50 & 27 & $I \cdot 50$ & 25 \\
\hline IOO & $I \cdot 2 I$ & 52 & 47 & $I \cdot 3 I$ & 35 \\
\hline I I 7 & $I \cdot I 6$ & 54 & $5 \mathrm{I}$ & $I \cdot 20$ & 40 \\
\hline \multirow[t]{2}{*}{$\mathrm{I}_{4} \mathrm{I}$} & 0.80 & 68 & $7 \mathrm{I}$ & 0.90 & 55 \\
\hline & & & 95 & $0.5 \mathrm{I}$ & 74 \\
\hline
\end{tabular}

Complete analyses :

\begin{tabular}{ll|c|c|c}
\hline & $\begin{array}{c}\text { O consumed in } \\
\text { Four Hours. }\end{array}$ & $\begin{array}{c}\text { Free and Saline } \\
\text { Ammonia. }\end{array}$ & $\begin{array}{c}\text { Albuminoid } \\
\text { Ammonia. }\end{array}$ \\
\cline { 1 - 4 } August 9 & $\ldots$ & $3 \cdot 38$ & $\mathrm{I} \cdot 25$ & 0.18 \\
August I I & $\ldots$ & $\mathrm{I} \cdot 46$ & $\mathrm{I} 55$ & 0.10 \\
\hline
\end{tabular}

I may remark that the change conforms at first to what I have called Stage II., the partially aerobic, in which the nitrites formed increase the "oxygen consumed." A steady reduction of the carbonaceous matter then occurs from the double decompositions we have indicated, and the inception of nitrification in Stage III. probably follows, though, as the nitrates are not given, the point cannot be ascertained. A slight acceleration is produced by forcing the air through the liquid, as against simply passing over the surface of shallow layers (see 72 and 95 hours above), but the improvement by aeration alone for four or six days is inferior to that effected by bacterial filters in eight hours. The determinations, being limited to the "oxygen consumed," are not really sufficient to reveal the character or amount of the purification. The third stage, in fact, includes much more than a simple process of oxidation, although it demands a supply of oxygen in excess. 
Nitrification proper, or the production of nitrates, is due to one or more organisms capable of growing in culture solutions which are practically free from organic carbon. But under natural circumstances they act in succession to nitrous organisms, and in the presence of organic material, which they do not, however, by themselves decompose. ${ }^{1}$ Some of the difficulties of the subject have been cleared up by the researches of Adeney, who, by cultivation in known solutions, has eliminated disturbing factors. His conclusions are :

I. In inorganic solutions containing ammonia nitrous organisms thrive, but nitric organisms gradually lose their vitality.

2. Nitrous organisms cannot oxidize nitrites to nitrates in inorganic solutions.

3. Nitric organisms thrive in inorganic solutions containing nitrites.

4. The presence of peaty or humous matter appears to preserve the vitality of nitric organisms during the fermentation of ammonia, ${ }^{2}$ and establishes conditions whereby it is possible for the nitric organisms to thrive simultaneously in the same solution as the nitrous organisms.

In corroboration of this, Beddies ${ }^{3}$ cultivated nitrifying bacteria in a nutrient solution containing I per cent. of a strong solution of humus and 0.25 per cent. of sodium silicate, and found the organisms much more stable than those obtained by Winogradsky in the absence of organic matter (p. 76). Four stable varieties of nitric and three of nitrous bacteria were isolated, the stronger forms being singularly unaffected by changes of temperature, and growing freely together without interference. When nitrifying organisms are abundant, denitrification is hindered, and there is no loss of free nitrogen; but when the denitrifying forms predominate, the nitrifying bacteria are injured, especially if aeration is limited. This is in accordance with what we have observed in connection with some bacterial filters.

In an effluent which is properly prepared and well aerated nitrification can often be encouraged by seeding with a small

1 Winogradsky, Centr. Bakt. Par., I896, (2), ii., 4I 5 and 449. Omeliansky, ibid., I899, II., v., 473. See also Centr. Bakt., 1899, 652; Mitt. Landw. Breslau, (1), 75 ; (2), I97; Comptes vendus, 1899,566 .

As to the production of peaty matter by $B$. mesentericus, see Julius Stocklasa (Bied. Centr., I899, xxviii., 588). Streptothrix chromogena is a humus-producing organism in soils (Journal of the Chemical Society, I900, ii., 425).

${ }^{3}$ Chem. Zeit., I899, xxiii., 645. 
quantity of a fertile garden soil. The general conditions of nitrification may be recapitulated:

(a) In every case the formation of ammonia by some other organisms precedes the appearance of nitrous or nitric acid (p. IOI).

(b) Some fixed base must be present to combine with the acid formed. Therefore, in a sewage farm, if the soil is devoid of lime, it must be added. Ordinary sewage contains fixed alkali derived from washing soda, and any acid discharges are generally neutralized by this and by the free ammonia. E. Chuard ${ }^{1}$ observed that nitrification may occur in an acid medium, but that it was very slow. Hence in strong manufacturing effluents a treatment with lime may be necessary before nitrification will take place.

(c) The solution must not be too strong nor too alkaline. According to Warington, a I2 per cent. solution of urine is the highest strength nitrifiable, and the highest alkalinity not prohibitive corresponds to $44^{\circ} 6$ parts per I00,000 $\mathrm{NH}_{3}$. Such a strength only under such special circumstances would be approached in sewage, and in runnings from urinals, stables, etc., dilution would be necessary. Letts' experiments tend to show that large quantities of chlorides retard nitrification. ${ }^{2}$ Winogradsky and Omeliansky ${ }^{3}$ found that sodium carbonate is essential to nitric and nitrous organisms, and that the oxidation of the nitrite and the growth of the former microbe are inseparable. As to the products of hydrolysis, "peptone in excessive amount cannot alter the specific function of the microbe, but destroys or completely checks it under certain conditions "; asparagin (p. I07) is injurious; urea is inert below 0.05 per cent.; infusion of hay (I4 per cent.) is beneficial; broth ( 8 per cent.) had no effect. Two per cent. of urine increased the time required for oxidation five times. Iron salts assist the process. "The nitrite is much more sensitive than the nitrate bacterium to nitrogenous substances such as peptone and asparagin. The more complex, unstable, and for most microbes the more assimilable the substance, the more injurious is its effect on nitric organisms."

(d) Darkness and free admission of air.

In natural soil Warington proved that nitrification rapidly

1 Comptes rendus, cxiv., I8I.

2 Royal Commission on Sewage, I902, vol. ii., pp. 48r, 483.

3 Chem. Centr., ii., I32, 2 I 7, 264. The use of soap-water in plant cultivation is well known. 
diminishes after 3 feet, and that there is no nitrification below 6 feet. The best results from bacterial filter-beds are obtained with a depth of 3 to $3 \frac{1}{2}$ feet, and an alteration to 5 feet is generally accompanied by a reduction in the quality of the effluent. Here I may draw attention to a fact that awaits explanation. In nearly all published analyses the chloride in the effluent is slightly lower than that in the corresponding sewage. Müntz pointed out that in nitrification bromides and iodides were oxidized to bromates and iodates. Chili saltpetre, nitrate of soda which has been produced by natural nitrification, often contains a small percentage of perchlorates. Dr. Tidy, some twenty years ago, found a loss of chloride in waters running over aerating wooden shelves, and suggested that it might be due to the formation of chlorates. I have not yet been able to find them in effluents.

Both in nitrification and in the fermentations producing organic acids the alkalinity is diminished, and the extent to which this occurs gives some measure of the degree of the change ${ }^{1}$ (p. 32). Carbonates of lime and magnesia and other earthy salts may be dissolved, the former with liberation of $\mathrm{CO}_{2}$; in both cases the mineral matters in solution will be increased. Dibdin's averages of the "fixed dissolved solids" at Exeter in 1897 were, in parts per I00,000: Raw sewage, 20\% ; tank effluent, $23^{\circ} 0$; filtrate, $29^{\circ}$. Such reactions also have a tendency to disintegrate some filtering materials (see Chapter X.).

At this stage an abundance of carbonic acid is formed by fermentations due to other classes of bacteria. 1 have found in several bacterial filters intended to be aerating and final such a large quantity of carbonic acid as must seriously retard their nitrifying action, the result being a deficiency of nitrates in the effluent. Especially is this the case where the final beds are made by a process often recommended for economy-that of simply digging out the clay to form a pit about 3 feet deep, and filling it up with the same clay after burning.

Boulanger and $\mathrm{Massol}^{2}$ have confirmed the fact that nitrous and nitric organisms (I) are each hindered when the products of their own action accumulate; (2) tend to hinder one another, and therefore should be kept as far as possible in separate areas. See also H. Chick on Nitrification, Proc. R. Soc., rgo6, p. $24 \mathrm{I}$.

Denitrification has been largely investigated for the reason

1 Massachusetts Report, 1905, p. 227.

2 Ann. Inst. Pasteur, I903, 492. 
that in agriculture it is a retrograde change, involving great loss in the value of manure. But in the treatment of sewage it is capable of rapidly effecting a great amount of purification. Gayon and Dupetit ${ }^{1}$ isolated two organisms from sewage which, in the presence of organic matter, decomposed nitrates with production of nitrogen and nitrous oxide. In a nitrated medium they were anaerobic, taking oxygen from the nitrate, and in certain solutions as much as 9 grammes per litre of nitrate could be decomposed. It was proved that the nitrate evolves all its $\mathrm{N}$ as gas, and that its oxygen combines with the carbon of the organic matter to form $\mathrm{CO}_{2}$, a portion of which may be evolved as gas, while the remainder combines with the base to form an acid carbonate. Organic matter is essential, and "I gramme $\mathrm{KNO}_{3}$ requires $0.148 \mathrm{C}$ or 0.273 gramme of albuminoid matter for its complete decomposition." The $\mathrm{N}+\mathrm{N}_{2} \mathrm{O}+\mathrm{CO}_{2}$ account for all the nitrogen and carbon, and for the available oxygen of the nitrate. The denitrifying bacteria will not develop in liquid deprived of nitrate and out of contact with air, nor will they attack organic matter under these circumstances. The authors further proved denitrification to be a fermentation which consists in the direct burning up of organic carbon at the expense of the oxygen of a nitrate. ${ }^{2}$ Ampolla and Ulpiani ${ }^{3}$ isolated two of the bacteria which decompose organic matter (such as sugars, fats, and amido-acids) and nitrate to $\mathrm{CO}_{2}$ and $\mathrm{N}$ without intermediate production of nitrite; for example :-

$$
{ }_{5} \mathrm{C}_{6} \mathrm{H}_{12} \mathrm{O}_{6}+24 \mathrm{NaNO}_{3}=24 \mathrm{NaHCO}_{3}+6 \mathrm{CO}_{2}+\mathrm{I} 8 \mathrm{H}_{2} \mathrm{O}+\mathrm{I} 2 \mathrm{~N}_{2} \text {. }
$$

Thus 5 of oxygen are taken from $\mathrm{N}_{2} \mathrm{O}_{5}$ instead of 4 , as in the production of $\mathrm{N}_{2} \mathrm{O}$. This is an even greater utilization of the "available oxygen," and is the reason why an effluent that has been properly fermented and heavily nitrated is capable of rapid self-purification, and also of improving the condition of a river into which it may be discharged. Adeney, in fact, introduced a process in which he added nitrate of soda at the third stage to accomplish by denitrification the final removal of any organic matter present; but as we have seen that the effluent

\footnotetext{
1 Station Agronomique de Bordeaux, I886; "Réduction des Nitrates par les infiniment petits" (Nancy, I886).

2 My calculation of the "available oxygen" (pp. 16 and I30), is supported by numerous proofs that a large number of bacteria can transfer oxygen as freely from nitrates as from air. Pakes and Jollyman (Jour.Chem. Soc., March, Igor, p. 324) have actually modified the definition of an anaerobic organism to "one which will not grow in the presence of either free oxygen or of available oxygen in the form of nitrates," and give instances, aerobes being vice versa

${ }^{3} \mathrm{Gaz}$. Chim. Ital., xxviii. (I), 4 ro; fourn. Soc. Chem. Ind., p. I I6o, December, 1898.
} 
can be naturally nitrified by properly-constructed filters, the expense of artificial nitrate should not be required. Hugounenq and Doyon ${ }^{1}$ first noticed that $B$. coli communis could decompose nitrates, setting free nitrogen and utilizing the oxygen; and Warington proved that the loss of nitrogen from manure increased in proportion to the fermentable organic matter. ${ }^{2}$

Burri and Stutzer's B. denitrificans II. liberated 90 per cent. of the nitric nitrogen from Giltay's solution as free N. Giltay himself obtained 80 per cent., Stutzer as much as $98^{\circ} 9$ to $99^{\circ} 6$, some of the nitric $\mathrm{N}$ being converted into organic $\mathrm{N}$ in the protoplasm, etc. Much $\mathrm{CO}_{2}$ and some $\mathrm{H}$ was produced. The organisms could thrive without air, but seemed to require air when they first began to develop. In one of my own observations a tank effluent, free from nitrite and nitrate, was mixed with a ninth of its volume of a coke-breeze filtrate containing 4.34 parts per 100,000 of $\mathrm{N}$ as nitrate and no nitrite, and the mixture kept out of contact with air for five days at $I 5^{\circ} \mathrm{C}$. By this time the whole of the 0.434 part of nitric $\mathrm{N}$ in the mixture had disappeared without the formation of either nitrite or free nitrogen. The same liquid exposed to air and light afterwards yielded nitrites in abundance. The loss of organic nitrogen was not accounted for by the production of either nitric acid, ammonia, or nitrogen gas. Other possible products are nitrous and nitric oxides, $\mathrm{N}_{2} \mathrm{O}$ and $\mathrm{N}_{2} \mathrm{O}_{2}$ (p. I2I) ; the occurrence of the former was recorded by Gayon, of the latter by Adeney. Both, being soluble and neutral, have no doubt often been overlooked. In my experiment the rapid production of nitrite on exposure to air appears to indicate the presence of nitric oxide. $P$. Frankland notes that the common $B$. aquatilis does not form nitrites, yet in its growth causes a considerable disappearance of nitric nitrogen. ${ }^{3}$ A large number of organisms reduce nitrate to $\mathrm{N}$ or $\mathrm{N}_{2} \mathrm{O}$, acting generally by symbiosis, the intermediate production of nitrous acid not being detectable, probably because it is destroyed as soon as formed. Jensen ${ }^{4}$ restricts the term "denitrification" to this reaction, and mentions eleven species of bacteria which effect it, including the pathogenic B. pyocyaneus, and A. Stutzer ${ }^{5}$ confirms and extends these results, early observed by Jordan and Richards.

\footnotetext{
1 Ann. Chim. Phys., r898, vii., 45.

2 Fournal of the Koyal Agricultural Society, I897, III., viii., 577.

3 Chemical Society's Transactions, 1888, 391.

4 Bied. Central., I900, xxiv., 273.

5 Centr. Bakt. Par., 19or, ii., $78 \mathrm{r}$.
} 
Another form of denitrification is the reduction of nitrate to nitrite. Meusel ${ }^{1}$ first showed in 1875 that well-water containing nitrates on standing soon developed a reaction for nitrites - a change that was prevented by sterilization or by certain antiseptics - and Wagner of Darmstadt first elucidated the importance of the reaction. According to Abelous a soluble ferment exists in both animal and vegetable organisms which is able to convert nitrates into nitrites. ${ }^{2}$

Percy Frankland ${ }^{3}$ gives the following list of thirty-two species that he examined:

I. Reducing Nitrate to Nitrite.-B. ramosus, violaceus, vermicularis, liquidus, cereus, pestifer, plicatus, prodigiosus, chlorinus, citreus $^{4}$ (strongly). B. mubilus, aurescens, fluorescens, aureus, profusus (slightly). Micrococcus carnicolor, rosaceus (very slight).

2. Not Reducing Nitrate to Nitrite. $-B$. viscosus, arborescens, aurantiacus, subtilis, ${ }^{5}$ aquatilis, lavis, polymorphus; Sarcina aurantiaca, lutea, liquefaciens; Streptococcus liquefaciens; Micrococcus gigas, albus, candicans, chryseus.

He concluded that the chemical behaviour of these organisms was the same, whether air was present or excluded, and that none of them could either produce ammonia from nitrate or oxidize ammonia to nitric acid.

R. Warington ${ }^{6}$ states that his results in cultivation did not bear out the general opinion that wheat straw promoted denitrification. Probably this is explained by the observation of Matz and Wagner, ${ }^{7}$ connected with what we have said about humus, that as "humification" proceeds the power of destroying nitrates diminishes. W. Kruger and Schneidewind attribute the action of straw to the pentosans present, while sugars, glycerol, citrates, malates, etc., also promote the activity of denitrifying organisms, as well as excess of moisture

1 Berichte, viii., I2I 5 .

2 Comptes rendus Soc. Biol., I903, lv., 1080.

3 Loc. cit., 372. See also on the same subject: Hatton, Chemical Society's Transactrons, I88I, 266 et seq. Gayon and Dupetit, Berichte, I882, xv., 2736; I883, xvi., 221 (anaerobic organisms.) Déhérain and Maquenne, Bevichte, 1882, xv., 308I (B. butyricus). R. Warington, and Munro, Chemical Society's Transactions, 1886, 632 (organisms generally). Heraeus, Zeits. f. Hyg., 1886, 193 (pure cultivations). Also Clark and Gage, Eng. News, N.Y., I905, p. 27 ; Techn. Quarterly, xviii., 1905, p. 5 ; J. Amer. Chem. Soc., xvii., 327, 1905.

4 To these must be added Proteus mirabilis and vulgaris, B. mycoides, megaterium, and acidi lactici, which powerfully reduce nitrates to nitrites, and sometimes even to ammonia, and are frequent in sewage.

${ }_{5}$ Houston states that several varieties of $B$. subtilis occur in sewage (Second Report of the London County Council, I899).

6 Journul of the Royal Agricultural Society, I897, III., viii., 577.

7 Landw. Versuchs Stat., I897, xlviii., 247. 
(as in sewage) and a high temperature. ${ }^{1}$ Th. Pfeiffer ${ }^{2}$ showed that denitrification did not generally take place in the absence of particles of straw, fæces, or vegetable tissue which act as food to the denitrifying organisms, and considered their chief food substance to be xylane, or wood-gum $\left(\mathrm{C}_{6} \mathrm{H}_{10} \mathrm{O}_{5}\right)$, isomeric with cellulose, but soluble in alkalies, therefore removed by the first alkaline fermentation. This is an additional fact, explaining why the sewage should be properly fermented before entering the final nitrifying filters (see further, the London results, Chapter IX.).

Denitrifying bacteria are of three classes: (I) Those which destroy nitrites, but not nitrates-namely, Bacterium denitrificans I. of Burri and Stutzer. (2) Those destroying nitrates, but not nitrites-B. pyocyaneus and Bacterium denitrificans $V$. (and also many of those already quoted from Percy Frankland). (3) Other denitrifying bacteria which destroy both nitrites and nitrates. From Adeney's and other researches, the last are not common, though among them sometimes appear $B$. fluorescens liquefaciens, ${ }^{3}$ B. pyocyaneus, and Vibrio denitrificans. ${ }^{4}$ They rapidly produce $\mathrm{N}$, and perhaps $\mathrm{N}$ oxides, in presence of much $\mathrm{CO}_{2}$, but are antagonized by abundant aeration. Jensen describes six others. ${ }^{5}$

Houston, in the London County Council Report, I899, records: B. Coli Communis.-In twenty-four hours at $37^{\circ} \mathrm{C}$., reduction of nitrates to nitrites well marked (broth, 5 per cent.; potassium nitrate, $0^{\circ} \mathrm{I}$ per cent.; water, $94^{\circ} 9$ per cent.). B. Mesentericus.-Sewage variety E.: Great reduction of nitrates to nitrites in twenty-four hours at $37^{\circ} \mathrm{C}$. Sewage variety I.: No reduction of nitrates (showing the value of the nitrite test for diagnosis). He also gives $B$. frondosus fusiformis as negative, $B$ membraneus patulus and $B$. capillareus as active, in formation of nitrites from nitrates.

A large number of organisms found in sewage exert a distinct influence in bringing about nitrification, besides the species specially described as "nitrifying," since many which grow rapidly and break up sewage material have the power of

1 Landw. Jahrb., I899, 217. Dr. Hugo Weissenberg has also some elaborate studies on "Denitrification," in the Archiv $f$. Hygiene, 1897, xxx., 3.

${ }^{2}$ Deut. Landw. Presse, I897, 9 I I ; also J. Stocklasa, Bied. Centr., I899, xxvii.,

707 : Stutzer and Hartleb, ibid., I9oo, xxix., I26; Jensen, Centr. Bakt., iv., $40 \mathrm{r.}$

3 Hygien. Rundsch., I899., ix., 538; Chem. Centr., I900, i., 52.

4 Bied. Cientr., r899, xxv., 854.

${ }^{5}$ Centr. f. Bakt., I898, iv., 401. 
inducing or commencing this process if sufficient oxygen be present. Those mentioned on p. 68 had been separated by plate cultivation in gelatine; therefore the ordinary nitrifying organism, which will not grow in gelatine, could not have been concerned.

The Massachusetts Report of 1890, p. 788 , states that "an effluent from a sewage filter, where nitrification is complete, containing 2 per cent. of the total organic matter of the sewage, will not serve as food for bacteria, because it has been worked over already by bacteria in the filter, nearly everything available having been removed." This is true of most species, but we have seen that denitrifying organisms in presence of nitrates can freely attack this residual organic matter, and that after partial nitrification in a filter the action of these bacteria, which absolutely require a certain amount of organic food, converts it into carbonic acid and harmless gases, taking the requisite oxygen from the nitrates dissolved in the water. I refer later to the $\mathrm{CO}_{2}$ evolved in the "resting empty" stage of intermittent filtration.

The weight of dissolved oxygen in well-aerated river water being approximately I part per I00,000, the oxygen-consumed figure in a sewage or effluent indicates the minimum quantity of such water required to destroy the organic matter by means of the free dissolved oxygen alone. In raw sewages this may amount to as much as 20 volumes. In the raw sewages yielding the effluents referred to in the table on p. I3I, the oxygen-consumed figure was as follows in parts per 100,000 :

$$
\text { Exeter, 6.56. Sutton, } 2 \cdot 94 \text {. Caterham, } 14 \cdot 97 \text {. }
$$

The "available oxygen" is that present as nitrate or nitrite, and the amount of carbonaceous matter requiring destruction is measured by the ordinary figure of "oxygen consumed " as determined by permanganate, since after four hours' heating with permanganate no dangerous matter can be left. The table shows that the available oxygen as nitrates and nitrites is in good effluents quite sufficient to deal with the organic matter, even without help from the oxygen dissolved in river water. A large number of the published analyses of effluents are vitiated by the fact that the samples have not been analysed until some days after collection, frequently at the end of a long transit by rail or other conveyance, during which the agitation and inevitable contact with air will have considerably 
altered the composition in a favourable sense. It is therefore desirable, wherever possible, to analyse an effluent within a very brief time from its collection, and the more important determinations should be made on the spot within a few minutes of the discharge. Although this is undoubtedly the only fair procedure, such analyses are not, of course, comparable with those carried out under the usual conditions, which give an apparently higher quality to the effluent, but they demonstrate the existence of the rapid and beneficial improvement in some effluents which I consider, with Adeney, one of the main criteria of safety.

Typical Examples of the Oxygen Relations.

Parts per 100,000.

Wembley sewage farm effluent, 1 896

Croydon sewage farm effluent, 1895

River Brent, polluted, I896 ... ... ... breeze filter, Dibdin, $1894 \ldots$

Tank effluents:

Exeter, $1896 \quad \ldots .0 .04 \mathrm{I}$

Ashtead, $1898 \quad \ldots .0 .12$

Caterham, I 899 ... $00^{\circ}$

Coarse bed, Sutton, $18990^{\circ} 73$

Filtrates (final effluent) averages :

$\begin{array}{lllll}\text { Exeter, } 1897 & \ldots & 0.848 & 2.44\end{array}$

$\begin{array}{lllll}\text { Ashtead, } 1898 & \ldots & 6.44 & \text { 1 } 8.4\end{array}$

$\begin{array}{lllll}\text { Caterham, I } 899 & \ldots & 9^{\circ} 0 & 25^{\circ} 74\end{array}$

Sutton, r899

.. $3.33 \quad 9{ }^{\circ}{ }^{\circ}$

\begin{tabular}{|c|c|c|c|c|c|c|}
\hline 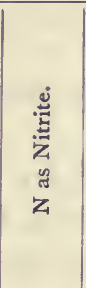 & 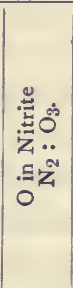 & 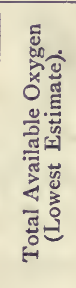 & 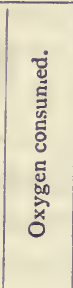 & 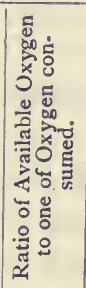 & 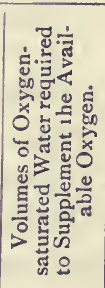 & 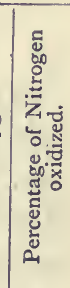 \\
\hline heavy & - & $2 \cdot 14$ & I.79 & $I \cdot 2$ & 0.0 & $48 \cdot 7$ \\
\hline heavy & - & $2.5 \mathrm{I}$ & I. 29 & I'94 & 0.0 & $63^{\circ} \circ$ \\
\hline $\begin{array}{l}\text { faint } \\
\text { trace }\end{array}$ & - & 0.0 & $2 \cdot 32$ & 0.0 & $2 \cdot 32$ & 0.0 \\
\hline - & - & 0.577 & I.04 & 0.55 & 0.46 & -- \\
\hline trace & - & 0.117 & 4.32 & 0.027 & $4 \cdot 2$ & I.O \\
\hline $\begin{array}{l}0.0 \\
\text { trace }\end{array}$ & O.0 & 0.343 & $\begin{array}{l}9 \cdot 84 \\
9.25\end{array}$ & $\begin{array}{l}0.035 \\
0.0\end{array}$ & $\begin{array}{l}9.5 \\
9 \cdot 25\end{array}$ & $\begin{array}{r}1.0 \\
\text { trace }\end{array}$ \\
\hline 0.1860 & 0.316 & $2 \cdot 4 \mathrm{I}$ & I. 46 & $x \cdot 65$ & 0.0 & $27^{\circ} 0$ \\
\hline $\begin{array}{l}0.5650 \\
0.03\end{array}$ & $\begin{array}{l}0.970 \\
0.05 \mathrm{I}\end{array}$ & $\begin{array}{r}3.41 \\
18.45\end{array}$ & $\begin{array}{l}0.966 \\
0.609\end{array}$ & $\begin{array}{c}3.53 \\
30.0\end{array}$ & $\begin{array}{l}0.0 \\
0.0\end{array}$ & $\begin{array}{l}33^{\circ} 0 \\
91.6\end{array}$ \\
\hline 0.3460 & 0.59 & $26 \cdot 33$ & $\begin{array}{l}2.7 \mathrm{I} \\
0.82\end{array}$ & 97 & $0 \circ 0$ & 62.0 \\
\hline & & & 0.8 & & $0^{\circ} 0$ & 82 \\
\hline
\end{tabular}




\section{CHAPTER VI}

\section{IRRIGATION AND SEWAGE FARMS}

Broad irrigation-Soils-Application of lime or ashes - TrenchingOrganisms in soils-Suitable crops-Transpiration of waterStatistics of sewage farms-Systems of distribution-Ridge and furrow - Catchwater - Intermittent irrigation with underdrainage-Merthyr Tydvil-Calculation of dilution by subsoil water-Irrigation with previous treatment-Areas requiredGeneral aspect of land treatment.

EARTH-disposal is the main factor in the three forms of irrigation :

A. Broad Irrigation, defined by the Royal Commission on Metropolitan Sewage Discharge, I884, as "the distribution of sewage over a large surface of ordinary agricultural land, having in view a maximum growth of vegetation (consistent with due purification) for the amount of sewage supplied."

B. Irrigation with Copious Underdrainage, similarly defined under the head of "Filtration" as "the concentration of sewage, at short intervals, on an area of specially-chosen porcus ground, as small as will absorb and cleanse it, not excluding vegetation, but making the produce of secondary importance. The intermittency of application is a sine quâ non even in suitably constituted soils, wherever complete success is aimed at."

c. Mixed Systems, including Previous Sedimentation or Chemical Preparation.-These, which may be called shortly the broad, the intermittent, and the mixed systems of irrigation, are "sewage farm" schemes, and are jointly saddled with the following difficulties :

(I) The unsuitability of the only land often attainable.

(2) Local opposition, and the very high prices generally demanded for the area.

(3) The failure, under these conditions, of making the sale of the produce remunerative.

A. Broad Irrigation. This, the oldest method, demands a very large extent of land (approaching I acre per Ioo of population), 
since it chiefly depends on the surface for purification, and especially on the nitrifying organisms, which, as requiring air, do not work well in the depth, and disappear altogether at a certain distance below the surface. $\mathrm{R}$. Warington tested for them in the heavy soil at Rothamsted by their power of nitrifying weak urine. Thirty-eight out of thirty-nine samples down to 3 feet were active; at 5 feet half were inert, and below 6 feet the organisms seemed to be absent. The action extended for only 18 inches in clay, but to a greater depth in sand, and, besides the scanty aeration, the deficiency of phosphates in the lower layers adversely affected nitrification. Soil which rapidly nitrified when in a moist, aerated condition became a vigorous denitrifying medium when water-iogged.

Very near the surface aerobic organisms greatly predominate; deeper down the anaerobes increase until we come to a layer in which practically only anaerobic bacteria are found, while deeper still there may be no organisms. ${ }^{1}$

For these reasons sewage is preferably made to pass obliquely, by digging deep trenches at the lower end of the farm, and the feeders are made to follow the contour of the ground. When, owing to geological structure, the liquid can rise again as springs, the absence of the first nitration may be concealed by a second process occurring in the ascent to the surface. On areas at a distance from habitations, with a porous soil (especially under rice cultivation, as in India), broad irrigation has been successful, ditches and intercepting drains being provided, and all wells on the sewage area, or within a radius likely to be affected, being closed.

The action of soil on sewage consists of (I) mechanical straining ; (2) mordant or " adsorptive" effect, chiefly possessed by the hydrous silicates of clay, which, if it be made sufficiently porous, takes up soluble matters, but soon becomes saturated; (3) biological changes. While it was originally held that the "cleansing power" of a soil was determined solely by its physical condition, porosity, freedom from clogging and water retention, it has since been proved that chemical composition and bacterial efficiency have a high influence. Sir E. Frankland, in 1870 , comparing the soil of the Barking sewage farm, in which nitrification was absent or very slow, with a loam from Dursley, in Gloucestershire, which showed his highest efficiency (purifying sewage at the rate of nearly I00,000 gallons

' Sims Woodhead, Baltimore Sewerage Commission, I899, p. I05. 
per acre per day), notes that the latter contained $8 \cdot I$ per cent. of carbonate of lime, the former under 2 per cent.; and we now know that the lime is favourable to the nitrifying organism. Effluents which have been chemically treated with lime may acquire sufficient alkaline base to favour the growth of the nitrifying organisms, even when the soil or the filter-bed is originally devoid of such base. In the case of a sewage farm in Surrey, where the soil, a ferruginous sandstone, is very deficient in lime, I found that the calcium carbonate increased through the treatment of the land with sewage, and the quality of the effluent also improved:

\begin{tabular}{|c|c|c|c|c|}
\hline$\cdot$ & & $\begin{array}{l}\text { I. } \\
\text { Land before } \\
\text { Treatment. }\end{array}$ & $\begin{array}{l}\text { II. } \\
\text { After I8 months. } \\
\text { Field I. }\end{array}$ & $\begin{array}{l}\text { III. } \\
\text { After I } 8 \text { months. } \\
\text { Field II. }\end{array}$ \\
\hline \multirow{2}{*}{\multicolumn{2}{|c|}{$\begin{array}{lrl}\text { Moisture } & \ldots & \ldots \\
\text { Mineral matter } & \ldots \\
\text { Organic } & \ldots & \ldots\end{array}$}} & $\begin{array}{r}10 \cdot 96 \\
80 \cdot 34 \\
8 \cdot 70\end{array}$ & $\begin{array}{r}\text { I } 3 \cdot 56 \\
82 \cdot 76 \\
3 \cdot 68\end{array}$ & $\begin{array}{r}I 4^{\cdot 20} \\
8 I \cdot 04 \\
4^{\cdot} \cdot 76\end{array}$ \\
\hline & & $100^{\circ} 00$ & $1000^{\circ} 00$ & 100.00 \\
\hline $\begin{array}{l}\text { Lime ... } \\
\text { Equal to } \mathrm{CaCO}_{3} \\
\text { Organic nitrogen }\end{array}$ & $\begin{array}{l}\cdots \\
\cdots \\
\cdots\end{array}$ & $\begin{array}{l}0 \cdot 224 \\
0.40 \\
0.064\end{array}$ & $\begin{array}{l}0.54 \\
0.96 \\
0.193\end{array}$ & $\begin{array}{l}I \cdot 23 \\
2 \cdot 20 \\
0 \cdot 230\end{array}$ \\
\hline
\end{tabular}

I have obtained the following results in an inquiry in which alternative sites were available for a sewage farm :

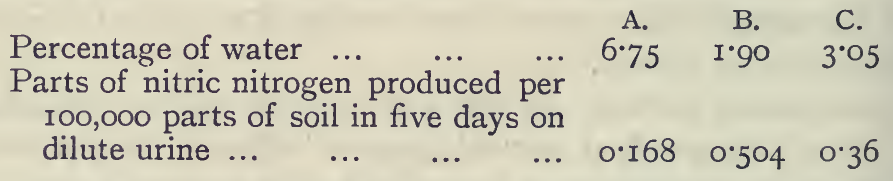

Showing that the dryest of the soils was the most active bacteriologically.

Both a mechanical and chemical analysis of samples of soil is necessary in the selection of proposed sites. The most unsuitable conditions are stiff tenacious clays, peaty or boggy ground, and coarse gravel with hard conglomerated layers. In India, where the temperature is higher, all bacterial change, including nitrification, occurs more rapidly, the growth continues for a longer time in the year, and the sewage is generally less voluminous than in England ${ }^{1}$; hence a less area per person

${ }^{1}$ A. E. Silk instances a sewage at Calcutta which consisted of fæcal matter and urine mixed with only 3 gallons of water per head. 
is found requisite; thus, Jones ${ }^{1}$ recommends at least I acre of good soil for 500 persons at 15 gallons per head. Professor Robinson gives the average of English sewage farms as I49 people to each acre irrigated with 38 gallons of sewage per head per day, and this is frequently too limited an amount of land.

Madras in I90I daily disposed of some 4,000,000 gallons of its sewage on farms in various parts, and eventually the whole $15,000,000$ gallons are to be dealt with on a farm with sandy soil near the sea, where indefinite extension is possible. Nothing but successive crops of Harriali grass were grown on the farms by the contractor, who paid an annual rent of 50,000 rupees. In the transit for three to six miles a considerable amount of nitrification occurs in the sewage. Sydney and Melbourne, and some other places in Australia, have large sewage farms on areas of sandy soil.

At Berlin, on a sand subsoil, I to $2 \frac{1}{2}$ tons of "waste lime" per acre have been spread with benefit over fields previously drenched with sewage. For clay, ashes from the town refuse are dug or ploughed in. Deep steam-sloughing, and even subsoiling to turn in the sludge, are at intervals necessary, since crude sewage discharged direct on land rapidly coats it with a felted layer of black decomposing matter, which hinders the access of oxygen, chokes the plants, and soon creates a nuisance.

Dr. Divers describes the cultivation of rice in Japan by surface irrigation on clay land. The sewage as collected is placed in large tanks in the fields, covered over with a loose roof of straw, where it is allowed to ferment for some time, till all the urea is converted into ammonia. The liquid passes over terraces from field to field till it reaches the watercourse in the valley. Dr. Kellner ascertained that the crops were good; the liquid flowing over the soil gave up much of the mineral constituents, nitrates were formed and absorbed, and the effluent was very satisfactory.

In broad irrigation there is always a risk that a portion of the raw sewage may escape wholly unpurified. On clayey soils the liquid passes almost entirely over the surface, and this, if a sufficient distance be given, has been found, as above, to effect a great purification, with, however, generally a nuisance. Mere deep trenching of heavy soils, laying pipe drains, and filling up with ballast, etc., yields an almost unoxidized and

1 "Manual of Hygiene," 1896, p. 484. 
very impure effluent; the same occurs from the production of cracks in clay by drying, or from the fissures so common in chalk formations. At Beverley, in Yorkshire, the top layer of clay had become extensively cracked in the summer, allowing raw irrigation sewage to reach the chalk beneath, whence it travelled through fissures about half a mile to a deep well that was a portion of the water-supply of Beverley. ${ }^{1}$ The reports to the Royal Commission on Sewage ${ }^{2}$ give examples of underdrained farms with shallow surface soil over clay, where "the sewage partly finds its way into the drains through cracks"; in one case the effluent contained pieces of straw up to $\frac{1}{2}$ inch long, which had reached it through these cracks, and the effluents were generally of very bad quality.

Stretford Sewage Farm (Mersey and Irwell watershed) reports that the drains should be laid in parallel lines, not in herringbone fashion. Trouble has been encountered from worms and rats causing holes, which allow sewage to run straight to the drains.

"In dealing with an infected worm area, we pump the very strongest sewage we can from the bottom of the tank, and on some occasions, previous to dosing the land with strong sewage, have sunk down to the drains and temporarily blocked them up, and have thus been so far successful in killing them that the land has again continued to produce as good an effluent as before. The worms do not die in their holes, but come to the surface. They have caused an imperfect effluent even when the drains have been as much as $4 \frac{1}{2}$ feet in depth."

Dr. Houston has counted the number of bacteria and spores present in twenty-one different soils. Among them he finds :

I. Sandy soil near the sea...

Organisms per

2. Suburban garden soil, not recently manured $\quad \ldots \quad$ 518,000

3. Dark garden soil, manured six months previous ... $\quad 795,000$

4. Light-coloured soil, not recently manured or disturbed... $\quad \ldots \quad$... $\quad \ldots \quad \ldots$

5. Black loamy soil, occasionally having farmyard manure ... $\quad \ldots \quad \ldots \quad \ldots . \quad \ldots$

6. Rich heavy clay, periodically manured ...

7. No. 3 above, after recent manuring ...

8. Garden soil treated with human fæces and urine for six months previous $\ldots \quad \ldots \quad \ldots$

9. Sewage field, from a trench along which sewage had been running a short time before

... I I 5,000,000

1 See p. 9, also a report to the War Office by Davies and Tyndale in 1902.

2 Vol. iv., part ii., I904, pp. 243-249. 
B. coli and its allies are not discoverable, or are present in small numbers only, in virgin soils, such as those from uncultivated uplands. ${ }^{1}$ Dr. W. G. Savage obtained similar results from a number of mountain samples, and concluded that if present in ordinary hillside soils the coli has been derived from animal excreta. ${ }^{2}$

Dr. Sidney Martin has proved that $B$. typhosus in virgin soils attenuates and after a short time disappears, but in those which contain large quantities of organic matter, particularly from sewage, it will multiply even through extremes of heat and cold (from $37^{\circ}$ to $3^{\circ} \mathrm{C}$.), and under conditions of dryness, and will survive for at least $45^{\circ}$ days alone, or 50 days in presence of other bacteria.

Although no injury to health has been directly attributed to sewage farms, the possibility of the survival, or even the multiplication, of pathogenic organisms on such farms must be taken into account when the drainage waters pass into or near drinking-water supplies. (See further p. I93 et seq.)

\section{Suitable Crops.}

Unless proper cultivation is adopted on sewage farms, the soil is given up to a profuse growth of weeds, which have to be removed and the soil broken up to keep it porous, without any return for the labour. The conditions are different from those of ordinary agriculture, inasmuch as, although the liquid undoubtedly contains the elements of plant food, they are supplied too continuously and in too great dilution with water, while the volume is usually greatest at a season when it is absolutely injurious to crops. Therefore for successful cultivation the plants must only receive the sewage as they want it, the remainder being treated by other methods. It is also necessary that the plants should be of such a character as can be grown on a ridge, so as to prevent the liquid at any time flooding their growing tops. The difficulties are obviously lessened under the "separate system" of sewerage, in which surface and storm water are excluded (see Fourth Report of Royal Commission on Sewage, Ig04, part iv., p. 5).

Déhérain ${ }^{3}$ has determined the quantity of water exhaled in one hour by certain growing leaves exposed to the sun: p. 5 Io.

1 Report of the Medical Officer of the Local Government Board, I899-I900,

2 Fournal of Hygiene, July, I902, p. 33 I.
3 Chimie Agricole, p. 28I. 


\begin{tabular}{|c|c|c|c|c|c|}
\hline \multicolumn{2}{|l|}{ Plant. } & $\begin{array}{l}\text { Temperature of } \\
\text { the Air. }\end{array}$ & \multicolumn{3}{|c|}{$\begin{array}{l}\text { Weight of Water transpired by } \\
\text { I00 Parts of Leaves. }\end{array}$} \\
\hline $\begin{array}{l}\text { Colza } \ldots \\
\text { Colza } . . .\end{array}$ & & $\begin{array}{l}25^{\circ} \mathrm{C} \\
36^{\circ}\end{array}$ & $\begin{array}{l}\text { I. } \\
\text { I.3 } \\
\text { I } 2 \cdot 0\end{array}$ & $\begin{array}{l}\text { II. } \\
\text { I.5 } \\
\end{array}$ & $\begin{array}{l}\text { III. } \\
\text { I.O } \\
-\end{array}$ \\
\hline Wheat & .. & $\left\{\begin{array}{l}19^{\circ} \\
28^{\circ}\end{array}\right.$ & $\begin{array}{l}74 \cdot 2 \\
88 \cdot 2\end{array}$ & $\underline{71 \cdot 8}$ & - \\
\hline Rye & $\therefore$ & $36^{\circ}$ & IOO' & $99^{\circ} 0$ & 92 \\
\hline
\end{tabular}

Therefore in one hour a young leaf of a cereal can evolve about its own weight of water. Hellnegel and Wollny found that the transpiration of water varies from 233 to 912 pounds for every I pound of plant tissue formed, according to the leaf surface and length of growth, being greatest in clovers and grasses, and least in roots and potatoes. Lawes estimated that 250 to 300 parts of water are evaporated for every I part of dry solids elaborated by the plant. The transpiration of Gramineæ (grasses and cereals) is greater than other plants; hence they are indicated as absorbing a larger quantity of sewage. At the Berlin sewage farms the proportion grown is, in acres, cereals 3,000, grass (rye grass and Timothy) 2,000, root crops I,000, oil seeds (colza, etc.) 250, with rotation.

Italian rye grass, according to Rawlinson and Read's report to the Local Government Board in 1876 , " absorbs the largest volume of sewage, occupies the soil so as to choke down weeds, comes early into the market, bears five to seven cuttings in the year, and produces 30 to 50 tons of wholesome grass per acre." It generally exhausts itself in about three years, when it is ploughed up and replaced by root crops (usually mangolds) or cabbages (Beddington), with a return afterwards to rye grass. Mangolds yield a heavy but rather watery crop. Wheat and oats are stated to run to straw rather than to grain. Leguminous plants, which are capable of taking up nitrogen from the air, are not adapted for an object which aims at reducing the organic nitrogen. The Royal Agricultural Society's Report on the Bedford Sewage Farm mentions one plant, "prickly comfrey," useful for horse fodder, "which it seems impossible to damage by sewage, as it was completely flooded for three weeks in succession, with benefit, and yielded three crops in a year." Celery also flourishes, and sunflowers have been successful. Generally the plants that are found to suit 
best are those that are commonly grown in the neighbourhood.

At Berlin, before reaching the grass plots, the sludge is removed by catch-pits, as a coating of sludge interferes with the growth. For cereals and seeds unstrained sewage is only applied while the crops are underground, so that it does not come in direct contact with the plant, but roots and grass are irrigated all the year round. The farms have an area one and a half times that of the city, and lie about six to ten miles distant. The surface is divided into level beds $I_{50}$ to 200 feet square, separated by distributing embankments and ditches, with underdrains 4 to 6 feet deep and $r 6$ to 30 feet apart, according to the nature of the ground. The effluents, which are clear and without odour, are collected by main channels and carried to the nearest watercourse. The sewage is admitted to the carriers from the forcing mains through checking chambers, made of woven willow and posts driven into the sand; thence it passes through wooden sluices to the beds. Average amount dealt with: 6 to $7 \frac{1}{2}$ million gallons per acre per annum, or I acre to $75^{\circ}$ people. The best paying crop is rye grass, of which six to seven crops are raised each year; turnips, beet, cabbage, and other water-absorbing plants are raised in larger quantities. The farms are said to yield a small profit over the working expenses, excluding the cost of pumping.

At Brighouse, Yorkshire, it was reported in 1903 that the sewage, treated with 18 grains per gallon of lime and sedimented, gives good crops of rye grass and mangolds, and that cabbages make an excellent crop providing no stagnant water is allowed to remain about the plants. The sludge is used freely, and is found to be a good manure on the lands at present not irrigated, and is taken by farmers. The provision for land and works was unusually liberal, and had cost $£$ roo,ooo.

Details of a number of sewage farms are given in the Fourth Report of the Royal Commission on Sewage, I904.

Analyses of drainage from land receiving raw and chemically treated sewage show that nitrification takes place more rapidly with the latter, as the felting of the solids on the surface prevents air from passing into the soil for oxidation when untreated sewage is passed directly on the land. ${ }^{1}$

${ }^{1}$ For an interesting example vide Ashton, "Treatment of Wigan Sewage," Transactions of the Institute of Sanitary Engineers, November, 1899; see also pp. 147 and 159 . 
Osier beds are often planted, and act partly as strainers; watercress and many aquatic plants have been found useful.

With careful management the sale of produce from a sewage farm may be made to yield a small balance over working expenses, but not sufficient to repay the capital, which is estimated to be about five times that required for an ordinary farm. There is a better prospect where a large area of vacant seashore is available, as in the case of Dantzig, where a daily sewage flow of over $3 \frac{1}{4}$ million gallons (in I894) was disposed of by irrigation on "dune sand." The liquid sank rapidly, leaving the suspended matter on the surface and in the pores of the soil. The land, originally let at $4 \frac{1}{2} \mathrm{~d}$. per acre, was subsequently leased to a contractor for thirty years at $£$ I IIs. 6 d. per acre, and the scheme is said to have been in every way successful. The depth of humus or vegetable soil was increased by the continued irrigation of about 5,500 gallons per acre per day, and the effluent would have satisfied the requirements of our Rivers Pollution Commissioners. ${ }^{1}$

In America, especially in Massachusetts, where there is sufficient area of sandy soil, the sewage is successfully treated by intermittent filtration at the rate of 50 to 90 thousand gallons per day. In a great number of localities the treatment is screening, sedimentation, and filtration through land which is prepared by removing the loam and levelling. The land is ploughed and harrowed, and planted with corn or other crops every spring.

Some statistics of sewage farms are given on p. I4I. The first series was published in 1896 ; the Berlin figures are dated 1890 ; and the subsequent ones are of 1900 , from the Fourth Report of the Royal Commission on Sewage, I904, vol. iv., part i., p. 7 . In each of the latter cases only a fraction of the irrigable area (one-sixth to one-half) is sewaged at one time, in order to allow the remaining land a resting period.

${ }^{1}$ Proceedings of the Institute of Civil Engineers, vol. xliv. 


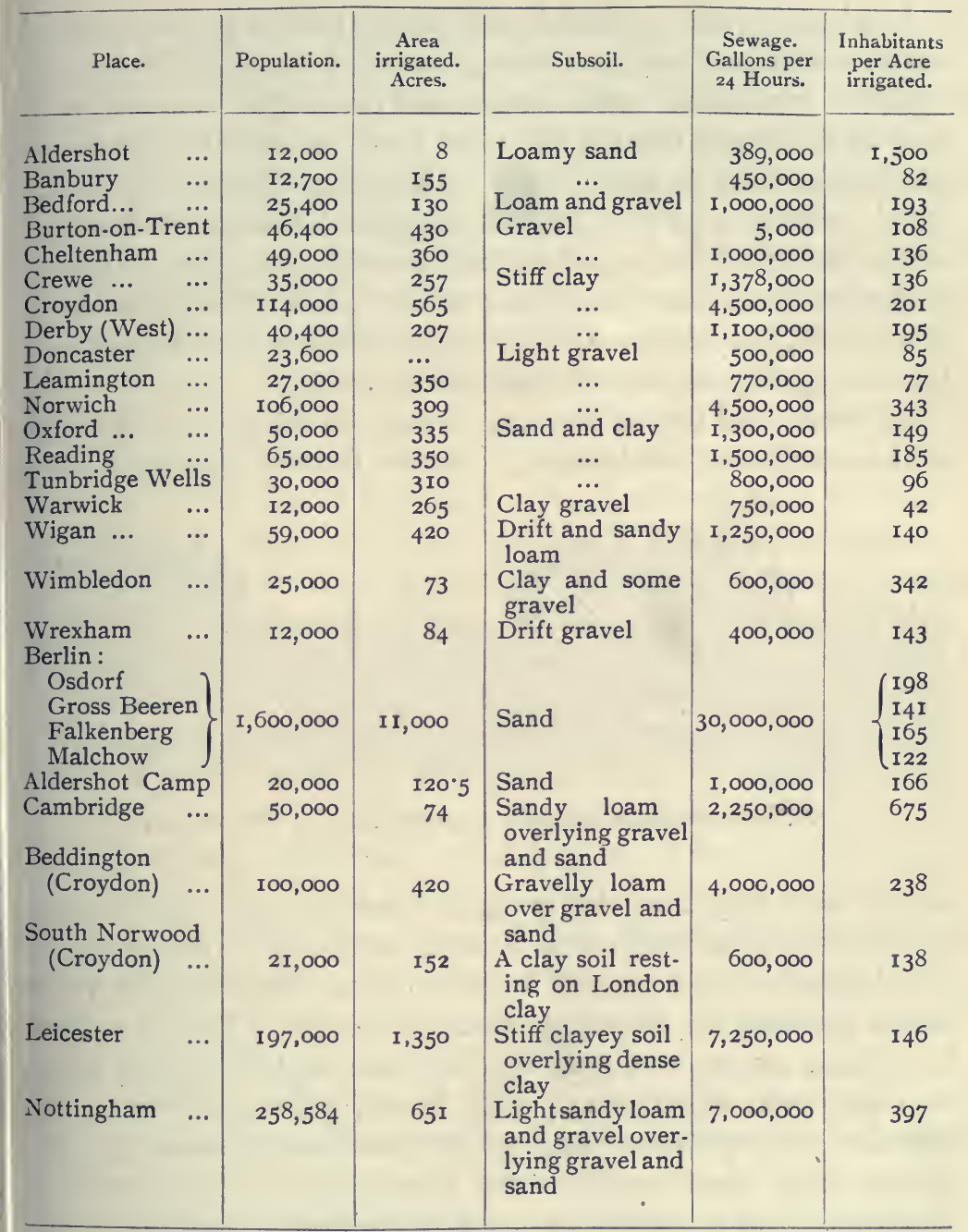

\section{Systems of Distribution.}

I. Ridge and Furrow.-Flat and heavy soils are laid in ridges to feet apart, sloping 20 feet on either side, at an incline of $I$ in 50 to $I$ in $I 50$, to furrows in the centre. From a transverse main carrier at the upper end the sewage passes into distributing channels on the ridges, whence it flows in a uniform layer down the slopes, any not absorbed running from the furrows into a lower plot. The distributing channels (with the ridges) have a longitudinal slope of $I$ in 600 to $I$ in 300 . The main carriers must be lined; the channels may be dug in the soil. 
In places where the soil is sufficiently porous the land is laid out in a different way, the sewage being fed along the furrows with the vegetation on the ridges, and the underdrains between, so that the liquid reaches the roots from underneath, the excess passing laterally to the drains. This method seems to be recognised as the best for avoiding water-logging, "sewage sickening," and other evils of sewage-farming by broad irrigation. It must be remembered that the reliance is here on the filtering qualities of the soil, the plants playing a subordinate part in utilizing the nitrogen of the soil afterwards (Fig. I9).

At Paris a portion of the city sewage is treated in this way at Gennevilliers and Achères. At the former the soil is sand

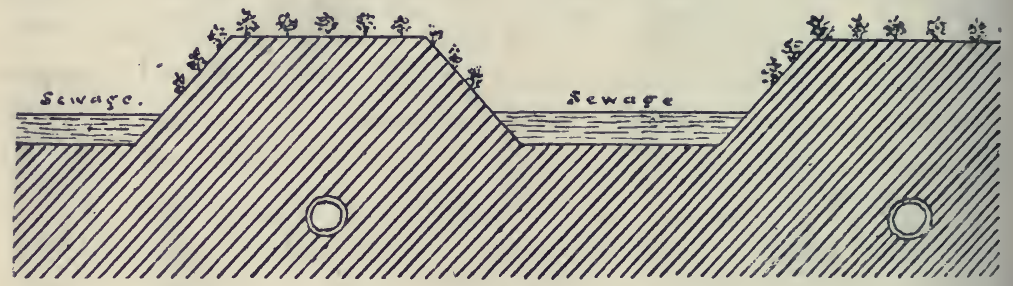

Fig. I9.-Section Showing Underdrains in IrRigation.

mixed with clay, and the crops are various, but chiefly vegetables, with also fruit-trees, flowers, and some meadow land. The irrigation is managed by flooding at intervals, the vegetables growing on ridges as described above. Part is worked by private lessees and part by the State, and the results seem to have been satisfactory until lately, when, owing to the increase of population and greater volume of sewage, complaints have been made to the municipality of flooding and nuisance. For a number of years experiments have been conducted at Gennevilliers and Achères to ascertain the amount of sewage that may be applied to land without injuring the crops. It is stated that I44,000 cubic metres per hectare (13,000,000 gallons per acre) annually may be turned on a field of lucerne and I70,000 (I5,000,000 per acre) on meadow land. These figures are far in excess of anything hitherto accomplished in regular daily work.

Bechmann states that the experiments at the model garden of Genevilliers show that from 80,000 to 130,000 cubic metres of sewage per hectare (7,000,000 to II, 500,000 gallons per acre) annually can be applied without prejudice to the success of the 
crops or the purification of the sewage. The lowest of these figures is equal to 20,000 gallons per acre per twenty-four hours; the Berlin farms (see table) only take 2,730. It must be remembered that in cases where such large quantities are supplied frequently after a time the land becomes "sick," and great nuisance has been occasioned.

During I 900 the Gennevilliers farm of goo hectares received $54,223,620$ cubic metres of sewage, equal to about $\mathrm{I} 4,500$ gallons per acre per twenty-four hours. On a report of M. Launay, who is known as an advocate of the tout à l'égout system, it has been decided to experiment with the English bacterial methods on the Paris sewage, which is organically stronger than the average met with in England. At the same time it is contemplated to extend the irrigation area. "Intensive irrigation" has been tried with rather satisfactory results at Gennevilliers, and later at Achères. Instead of supplying the land with the amount of water requisite for culture, the amount was increased ten and twelve times, accompanied with successive ploughings whenever the superficial soil became caked with an impermeable layer of mud. Not only did the soil retain its filtering properties, but also all the decomposing substances were completely absorbed and assimilated without the aid of any'vegetation.

At Milan the sewers join in a canal, the Vettabia, which dis. charges into about 4,000 acres of land arranged in terraces, the final effluent falling into the river about ten miles below the city. The proportion of sewage applied is calculated as that of forty persons per acre of land.

At Dantzig, Breslau, and other places on the Continent, sewage farms are also at work, but almost invariably on light soil.

2. Catchwater.-On irregular ground an upper main carrier is made $I$ to 2 feet wide and 6 to Io inches deep. The sewage overflows from it at any point by temporarily damming, and, after spreading over the ground, the excess collects in a lower catchwater gutter made to the contour of the land, from which it is dammed and released on the same principle. This method requires much control.

Growing plants, especially of certain species, are capable to a certain extent of absorbing and using as food the organic and ammoniacal constituents of raw sewage, and, by means of the numerous enzymes they secrete, are able to dissolve and utilize organic suspended matter. But vegetation ordinarily 
absorbs most of its carbon from the air and its nitrogen from nitrates, and requires its food to be well prepared before it is assimilated. Excess of ammonia acts very unfavourably. S. Cloetz found that Io parts of ammonia in I00,000 (a strength not uncommon in sewage) was injurious. Déhérain showed that ammonium salts were prejudicial, and that soils which had received a dose of them un peu forte remained sterile for several years. ${ }^{1}$

In the ditches conveying sewage that used to be so common, and even in the open drains from cottages, it is noticed that the channel remains black and barren till the sludgy solids have had time to deposit or become fermented, and the soil to reassert its action, when the liquid clears and loses its odour, and a copious growth of vegetation arises. Therefore, in cottage gardens and allotments the sewage is not applied to the ground till it has been dissolved and fermented in pits or cesspools. Such a process, when scattered over a neighbourhood, is sure to create a nuisance, but carefully managed and conducted collectively in special large areas it has proved to be fairly successful, as shown by the late Dr. Poore. ${ }^{2}$

The main faults of irrigation with raw sewage are therefore-

(a) Choking and felting of the surface by organic slime.

(b) A surplus of unprepared organic matter and of ammonia over the wants of the plants.

(c) In consequence of the above, a deficiency of oxygen and of healthy action in the body of the soil.

(d) Great inconstancy owing to season, temperature, and cultivation.

The faults $(b)$ and $(c)$ are avoided to a certain extent by the second system - that of

B. Intermittent irrigation with copious underdrainage, which is really using the land as a partially-regulated bacterial tank and filter. If properly arranged, the drains act also as aerators, so that the soil is more thoroughly supplied with oxygen, allowing nitrification to proceed more actively and to greater depths. At Merthyr Tydvil in I87I " 20 acres of a porous soil, drained from 5 to 7 feet deep, were arranged by Mr. Bailey Denton in four series of beds; and over each series in succession the drainage water from 50,000 inhabitants, more than one-third of whom were connected with the sewers, was poured for six

1. Chimie Agricole, 1892.

2 "The Earth in Relation to Contagia," I902. 
hours at a time," by the ridge and furrow system, with intervals of eighteen hours per day for rest and aeration, crops of cabbages being grown. The works were suggested by the experiments of Sir E. Frankland in the laboratory of the Royal Commission. It is reported that the crops at Merthyr were healthy and luxuriant, and were valued in 1872 at $£ 42$ to $£ 45$ per acre, also that no nuisance had arisen. From Frankland's analyses of the effluents in $\mathrm{I} 87 \mathrm{I}-\mathrm{I} S 72$. I have calculated the following averages, adding also his " proposed standards of purity ":

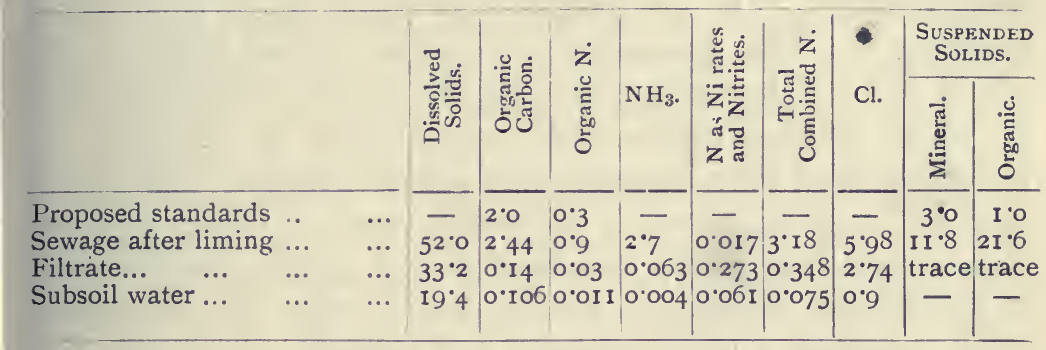

In the use of land by any system there is always a variable dilution with rain and subsoil water, so that the improvement effected by soil, as indicated by the quality of sewage and effluent, would appear to be greater than it is, unless we take this feature into account. Frankland ${ }^{1}$ applies the formula

$$
x=\frac{a+c}{c+b}
$$

" in which $a, b$, and $c$ represent the amount of chlorine in I00,000 parts of sewage, subsoil water, and effluent respectively, and $x$ the required volume of the subsoil water which has thus become commingled with each volume of the original sewage." In this case he finds that each gallon of the sewage had become mixed with from I*9 to $2 \cdot 2$ gallons of subsoil water, and probably also with some rain, as the mean dissolved solids of the sewage and subsoil water are about the same as those in the effluent, while the chlorine in the effluent is less than half that in the sewage. But even with this allowance the result justifies Frankland's statement that "the effluent water on all occasions was purified to an extent much beyond that required by the standards of pollution suggested by us as those below which refuse liquids should not be permitted to enter rivers." The analyses are of further interest at the present time, as we 1 "Experimental Researches," p. 763. 
can see from them that-(I) The reduction of the total $\mathrm{N}$ by about 75 per cent. (making allowance for dilution) is not accounted for by the somewhat meagre production of nitrate and nitrite. (2) Since the sewage "gradually sank into the soil as it flowed," this improvement can only be partially due to volatilization of free ammonia, of which soils, as is known, are very retentive. (3) The organic nitrogen may at first have been largely absorbed by the soil; but as the analyses extended over nearly a year and a half, and the later ones showed the same changes, this mechanical absorptive active is of minor importance. The explanation is rather to be found in the life of the soil bacteria, acting by the process of denitrification, in which free nitrogen and lower oxides of nitrogen are generated from both ammonia and organic matter, and evolved as gas. In fact, the whole process, instead of being, as it was then considered, partly mechanical and partly chemical, was in its essence bacterial. But as this sewage was admittedly weak, Frankland over-estimated the efficiency of the method when he stated that "the application of the sewage of more than I,000 persons to an acre of land is consistent with the growth of crops and a superabundant purification of the effluent water," and that "the sewage of a much larger number could be effectually purified on an acre if the growth of crops were given up." The Local Government Board, on the other hand, prescribed "for intermittent filtration without precipitation, through sandy gravel, I acre for every 100 to 300 persons."

c. Irrigation with Filtration or Precipitation. - From the faults and difficulties we have mentioned, it is rare for any sewage system to depend on the land solely. Even in the Merthyr Tydvil trials the raw sewage was previously treated with lime, and "a roughing filter" of gravel, coke, broken ballast, or some other suitable material, is almost universally used, and often by itself effects considerable bacterial improvement in proportion to the time the liquid remains in contact, although its functions are primarily to strain off the solids. At Leicester, fair success was attained ${ }^{1}$ by broad irrigation on clay land after clarifying by coarse banks of clinker, $\frac{3}{4}$ to 2 inch size, from the refuse destructor.

1 Society of Engineers, December, 1898. 
Later a bacterial scheme was introduced, and in Igoo Mr. Mawbey issued his report on the experiments. These were of limited scope and open to some objections, but under local conditions it was considered that the best results were obtained by passing the raw sewage through (I) a "closed detritus tank," (2) "clarifying bacteria beds, single contact, and three fillings a day," followed by one application to old pasture. The system has been adopted by the Corporation. ${ }^{1}$

It is obvious that the solids are an integral part of sewage, and that their removal, entirely or in part, by any system of straining, settlement, precipitation, or filtration, results in the production of a "sludge," which has to be separately treated; also that precipitation, if the effluent is afterwards to be applied to crops, must not involve such use of chemicals as may be injurious to the vegetation. Iron and aluminium salts, such as alumino-ferric, followed by lime, give a muchpurified effluent which has proved to be innocent in agriculture, although both this and simple sedimentation or filtration remove from the liquid some of the constituents which, when properly fermented, are capable of assimilation by plants, and also, along with the suspended solids, many of the bacteria which affect these changes.

The areas that have been officially demanded in England for the purification of sewage according to the process adopted are as follows; a much less amount has been often used successfully with proper management and care, but local conditions may even demand larger quantities:

\section{Population per Acre of Land.}

I. Irrigation without precipitation-
Stiff clay
... I acre for every 25 persons
Loamy gravel ...

2. Intermittent filtration without precipitation-

Sandy gravel ... I acre for every Ioo to 300 persons

3. Irrigation and precipitation-

$\begin{array}{llllll}\text { Clay } & \ldots & \ldots & \ldots & \text { I acre for every } & 200 \text { persons } \\ \text { Loamy gravel } & \ldots & \ldots & \|, \quad " \quad 400 \text { persons }\end{array}$

4. Intermittent filtration and precipitation-

Sandy gravel ... I acre for every 500 to 600 persons

${ }^{1}$ See further Mr. Mawbey's paper, Congress of the Royal Institute of Public Health, Exeter, I902. 
5. Precipitation and filtration through specially-prepared filters, followed by irrigation-I acre for every 2,000 persons.

The Local Government Board have required, in the construction of special filtration areas, that provision shall be made for-

I. A rainfall and sewage calculated at three times the dryweather flow.

2. Above three times and up to six times to be treated on a further special area of storm-water filters, and not until the flow is above six times may it be discharged into a stream or on to prepared land without passing through the filters or other method of treatment.

3. The capacity of the filters to be taken at one-third for the fluid and two-thirds for the filtering material.

4. A cycle of eight hours for filling, emptying, and rest for aeration.

In any system of sewage-farming the difficulties of controlling the drainage area, so as to provide for the varying amounts and qualities of the sewage, will always exist. If the land be sufficiently porous and well drained to prevent its being waterlogged, and to allow the free passage of the effluent during wet seasons, in dry weather it will permit it to run through too rapidly, and the effluent will not be purified. A denser soil adapted for ordinary weather will be entirely clogged by unusual rains, and therefore unsuited for any broad irrigation scheme, unless a very large area is available. ${ }^{1}$

Another obstacle is the distance to be traversed before reaching a suitable site. Thus at Wigan the sewage had to be conveyed to the farm for $7 \frac{1}{4}$ miles through a 27 -inch cast-iron main costing $£ 50,000$, with three siphons; it took ten hours in transit, and on arrival was more or less charged with sulphuretted hydrogen and other foul gases. ${ }^{2}$ I have drawn attention $^{3}$ to a further disadvantage of land treatment-the risk of polluting the subsoil water. The present Royal Commission on Sewage ${ }^{4}$ state that these effluents contain large numbers of organisms, "many of which appear to be of intestinal derivation, and some of which are of a kind liable, under certain circumstances, to give rise to disease "; 5 they

I See a paper by S. Krawkow, F. Landw., I900, xlviii., 209, on "The Movement of Aqueous Fluids in Soils.'

2 Institute of Sanitary Engineers, November I6, I899.

3 Engineering Conference, Institute of Civil Engineers, I903. Section VI.

4 Interim Report, I90I, p. Io.

${ }_{5}$ Ibid., vol. iv., part i., section 9. 
also find that the effluents from land possess a bacterial flora characteristic of sewage, and that the microbes characteristic of soil are relatively absent.

The chief objections to land filtration have been summarized as follows : I. Generally the worst part of the sewage-the sludge-is $\uparrow$
not dealt with at all.

2. As crops are usually grown, their cultivation is often considered, by those left in charge, as more important than the purification of the sewage, and so the latter is not fully treated except where irrigation is of advantage to the crops.

3. Unless the land receives very careful attention, a bad result is generally produced from even the best farm, and it is difficult for anyone but a highly-trained man to keep the works under proper control.

4. There are many possibilities whereby land which has been laid out carefully may fail, even with careful working, such as the cracking of the land, admitting crude sewage into the drains without filtration.

5. Land of sufficient quantity or quality, and at a reasonable price, is often unattainable.

The strongest argument for sewage farms and irrigation must always be the restoration to the land of the matter taken away from it, without which there must be a continual impoverishment. This aspect of the question was brought into prominent notice by Sir W. Crookes. ${ }^{1}$ I point out in later chapters how, under graduated bacterial purification, an effluent containing practically all the nitrogen, phosphates, and other mineral constituents, is obtained in a condition suitable to be returned to the soil without loss, and available for plant life.

Insistence on final land treatment is now decidedly a mistake, as where a proper process is used no further purification will be necessary; indeed, in many instances an originally good effluent suffers deterioration by subsequent passage through land, and as the sewage in passing through the filters falls 6 to 8 feet, the expense of pumping may have to be added. At Newcastle-under-Lyme in September, Igor, the Local Government Board sanctioned a loan for a scheme of disposal by bacterial treatment, and consented, for the first time, to waive their usual requirements with respect to land treatment for the filtered effluent, having regard to the limited area and unsuitable nature of the land available. 


\section{CHAPTER VII}

\section{SUBSIDENCE AND CHEMICAL PRECIPITATION}

Screens-Settling tanks-Roughing filters-Clarification-LimeAluminium sulphate-Ferric sulphate-Ferrous sulphate-Alumino-ferric-Sludge: its composition, volume, and disposal.

Mechanical separation, used as an adjunct to many processes, deals with suspended solids, inorganic or organic :

(I) Grit and detritus, small stones and sand, carried down largely by sewers of steep gradient, or in periods of storm, under the combined system, will be always present, but even under a separate system, intended to take only excretory and household waste, cannot be entirely avoided. They are removed by settlement without nuisance, since any entangled organic matter rapidly disintegrates, as in gravel soil. They collect in the street gullies, in sumps in the line of the sewers, and the remainder in grit chambers at the sewage works. Processes using mixing machinery require careful removal of hard matters.

(2) Organic residues-vegetable, fæces, paper, fibres, woodin great part float, owing to lightness, or to gases generated by fermentation. Their inclusion or exclusion constitutes a main difference, as we shall see further, between some modern methods of ultimate treatment; and the question as to whether a sewage is dealt with strained, settled, or absolutely raw is a matter of very great importance.

Screening is often used to prevent the clogging of filters. The screens are either cleared at intervals by hand labour or continuously by automatic contrivances, one of the most effective being a revolving wire drum, rotated by a paddle wheel moved by the current of sewage (Fig. 20). At Leeds the solids thus removed, and requiring separate treatment, were estimated to be thirty barrow-loads, or, say, 2 or 3 tons daily, mainly consisting of fæces, paper, and vegetable residues. The screens 
should be in duplicate, and some have been made with sharp edges to cut up the organic matter.

Grease, which is often a great difficulty, may be intercepted by grease-traps, or it may be broken up into an emulsion with lime or other materials for subsequent treatment. The

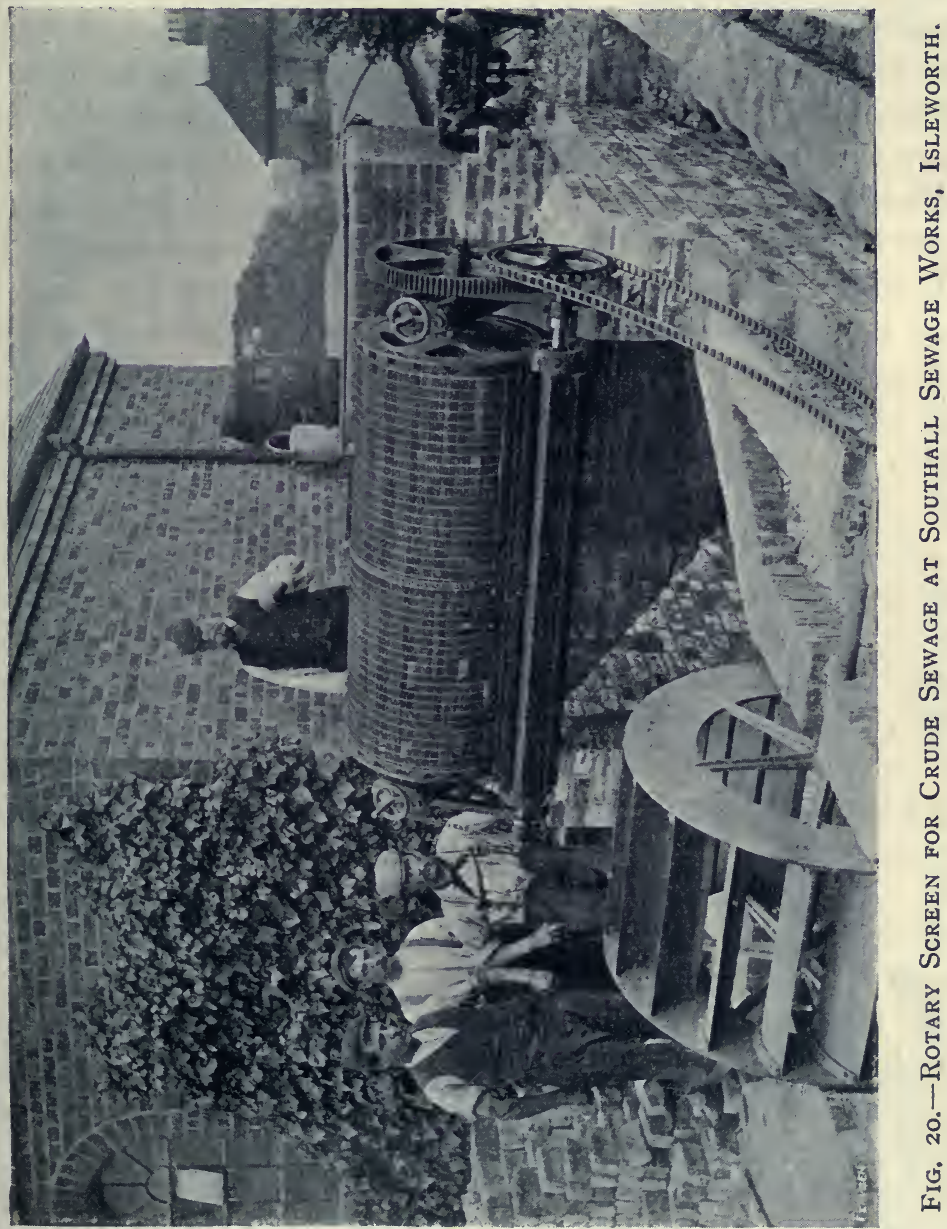

methods used at Bradford and other towns will be described in Chapter XIV. Grease from ordinary soap-suds does not seem to admit of profitable extraction, as the fat is so much contaminated.

The amount of suspended matter in sewage is greatly influenced by its history before arrival at the works. Where the sewers are long and have a varying gradient, much deposi- 
tion and dissolving may occur. Pumping causes some of the organic matter in suspension to disintegrate, and thus renders it more easily soluble. Agitation with pulverization of the organic solids has been the subject of many patents.

At Manchester up to 1897 the heavy insoluble matter brought down with the sewage (sometimes as much as 300 tons after a flood) was deposited in the precipitation tanks, from which it had to be removed by manual labour at considerable cost. Catchpits were then interposed "to intercept large solids which might cause damage to the machinery," with movable coarse screens balanced by weights so that they could be raised for cleaning. Finer screens, with mechanical rakes, were fixed at the outlet.

London sewage is screened through iron gratings, and in I 897 it was stated that the weight of the screenings was between 80 and 100 tons per week. A destructor furnace built close by was used for destruction of the refuse. Screening is also mentioned at Friern Barnet, Oldham, Swinton ("strainer with cleaning rakes attached"), Glasgow ("wrought-iron grid to catch heavy and floating matter"), Accrington ("screening chamber where detritus is deposited, with wrought-iron grid to prevent floating and large substances from passing into the precipitation tanks. A revolving fork arrangement cleans the screen by lifting the deposited material to the surface. The chamber has also a hopper-dredger for removing the detritus that accumulates at the bottom "), Kingston ("Native Guano process"), Launceston ("ferrozone and polarite"); in fact, all places and systems except those with a preliminary hydrolysing tank find it necessary to separate the coarser organic matters mechanically.

At Melbourne, Victoria, the city sewage is pumped into "straining-cages," and the material caught in them is subjected to steam at $292^{\circ} \mathrm{F}$. (45 pounds pressure), "which should effectually render the material innoxious." The dry result is destroyed in a furnace, as of no manurial value. In I899-Igoo it amounted to $96 \mathrm{I}$ tons, or I4I tons after drying. ${ }^{1}$

Roughing Filters.- In Colonel Waring's, used in the first stage of his system in the United States, a ro-inch suction-pump delivered the solids and liquids on to a shallow bed of broken stone, divided by a vertical partition; when one side became choked the other was used. From this it passed into "strainers"

${ }^{1}$ Report by W. Thwaites, Chief Engineer to Melbourne Board of Works, April, I901. 
of stones, pebbles, and coarse gravel. Although it is claimed that the "function of the strainers is merely mechanical sedimentation," they also perform a bacterial office, as can be judged from his report. All materials used-stones, broken bricks, coal, ballast, or large coke - exert at first simply a mechanical action, but after a time develop coatings of organisms which greatly extend their effect. The Massachusetts Report stated that "with the gravels and sands, from the coarsest to the finest, we find that nitrification takes place in all, when the quantity of sewage is adapted to their ability, and the surface is not allowed to become clogged by organic matter to the exclusion of air."

\section{Subsidence and Mechanical Clarification.}

After any method of straining, sewage remains turbid from a large quantity of suspended matter, which, as shown in the second chapter (p. 28), contains about one-third of the organic nitrogen and half the carbonaceous matter of the sewage. Settling basins were once almost the only means of clearing a strained sewage, the deposit being at intervals cleaned out and thrown on land, or even into the nearest ditch or watercourse. The deposition was sometimes supplemented by adding clay, ashes, slag, shale, peat, or charcoal, so that these in settling down should entangle the solid impurities. But except with weak liquids the result was not good, as the fermentation kept the organic matter in suspension, and a nuisance was also occasional.

P. F. Frankland's experiments in 1885 on clarification with chalk, animal charcoal, coke, spongy iron, china clay, brick dust, plaster of Paris, oxide of manganese, etc., with special reference to the removal of organisms, showed that although suspended matters were at first carried down, they rose again subsequently, and the organisms, particularly those which were motile, multiplied in the liquid. ${ }^{1}$ Krüger, in I889, confirmed these conclusions. ${ }^{2}$ Therefore, at a time when it was sought to remove all micro-organisms from sewage, mechanical clarification was proved to be unsatisfactory, and it had little or no effect on organic matter in solution.

Moreover, any such system results in the formation of

1 Proceedings of the Royal Society, I885; Proceedings of the Institute of Civil Engineers, 1886.

${ }^{2}$ Zeits. f. Hy giene, vii., 86. 
"sludge," which is the greater in amount as the straining medium is finer, and is also increased by the precipitant. A great difficulty in dealing with sludge is that its bulk is swelled by its containing 92 to 98 per cent. of water. If it be tried to obtain it in a denser condition by longer deposition, obnoxious gases are certain to be produced. Spreading it over the soil to dry, and finally digging or ploughing in, is in some places possible, but for filling up low-lying land ${ }^{1}$ it is unsuited through its density, wetness, and unsanitary character.

In I 886 the adoption of destructor furnaces at Southampton and Ealing led to experiments at Leyton and Cardiff, founded on the hope that sludge could be burned remuneratively and without offence with the aid of a certain amount of coal to dry the cake, the ammonia evolved being collected, and the volatile matters passed through the fire. The net cost of incineration was not to exceed sixpence per ton, the coke produced paying for the coal and working expenses. But in all the numerous attempts at utilization of sludge either as manure or by chemically extracting some of its constituents, it was found that the agricultural value was disappointing, while in combustion processes the cost of machinery and fuel absorbed all the profits.

The object now being merely to reduce the bulk and avoid nuisance, sludge was compressed in filter-presses of various constructions to a cake containing 25 to 50 per cent. of water, with usually an addition of lime or other substance to facilitate pressing. The cost was still great, and the product nearly worthless. The following are analyses of two examples:

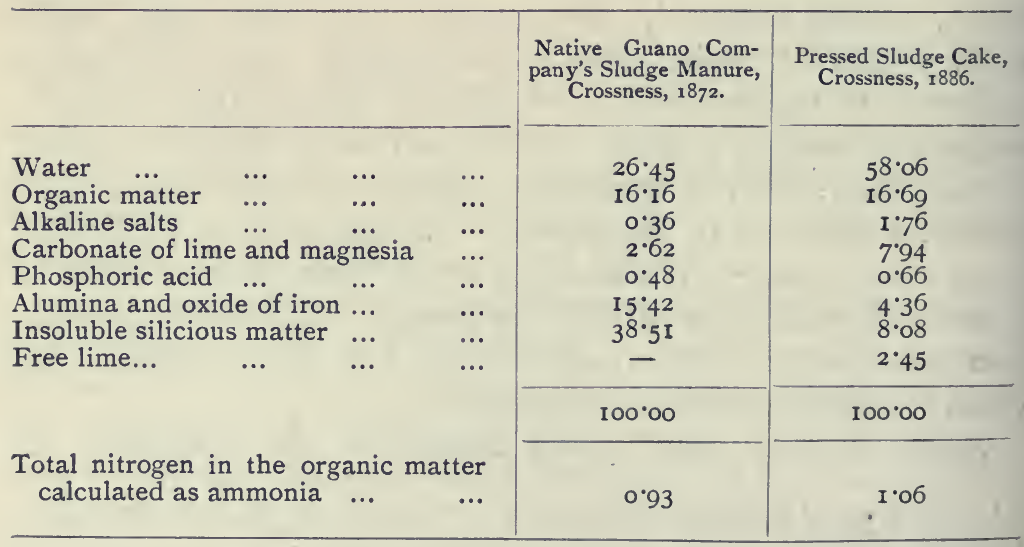

${ }^{1}$ L. Flower and others, Royal Commission on Metropolitan Sewage, 1875. 


\section{Chemical Clarification or Precipitation.}

Lime, since the success of Clark's process for treating waters, has been very widely used for sewage, either alone or as an accompaniment to other precipitants. ${ }^{1}$ The Rivers Pollution Commission of 1868 made their first experiments on the precipitation of sewage with milk of lime alone, and pronounced it to be a failure, as, although the liquid was rendered clear, it was not sterilized, was rendered alkaline, ammonia was developed, and the whole rapidly became foul. Where Local Boards have used lime and sedimentation alone before discharge into rivers, a prosecution for nuisance has almost invariably followed.

At Birmingham, for example, systematic sewerage of the borough was commenced in 1852 , liquids and solids being discharged direct into the river Tame. In I858 tanks were constructed, and various methods of purification by precipitation, sedimentation, and filtration tried. Treatment with about I2 grains per gallon of lime, with subsequent sedimentation, was adopted in 1872 and continued till I9oo. The sludge was collected in three large tanks of a total capacity of 440,400 cubic feet, with sixteen smaller tanks of 729,000 cubic feet capacity. The effluent and sludge were both treated separately on land, the area of which increased from a few acres round the tanks in 1870 to 2,800 acres in $1902 .{ }^{2}$

The results of the lime treatment led to a series of legal proceedings and an injunction, on account of the great pollution of the Tame. In some cases $\frac{1}{3}$ grain per gallon of chloride of lime added with the lime used for precipitation was said to have beneficial results and to prevent the growth of fungus, total cost being stated at eightpence per head of population per annum. But the precipitant rendered the effluent alkaline, and its discharge into rivers gave rise to nuisance, and was destructive to fish. Afterwards a bacterial process was adopted, and septic tank effluent is being treated on land with success.

1 Clark's patent, I84I. In 1846 Higgs patented the use of lime for sewage, which seems to have been the earliest chemical method adopted on a large scale. $\mathrm{H}$. Stothert introduced the alumina process in 1852 , and the use of salts of iron, first known as Dover's process, was brought out in 185I. For further historical details, see Baldwin Latham's address to the Association of Managers of Sewage Disposal Works, April I 5, 1905.

2 O'Shaughnessy on Birmingham Sewage, Fournal of the Society of Chemical Industry, May 31, 1902, p. 665. 
The land is laid out in various ways, partly as intermittent filters, and the greater part in broad irrigation. ${ }^{1}$

Whatever be the cheapness of lime, therefore, it has not been found to be successful alone, but as an adjunct to other processes it is frequently of great use, and may be absolutely necessary in some cases where the sewage is strongly acid from trade effluents.

A good quality of lime is slaked, and then ground with a portion of the sewage or other water to an even cream. The quantity to be added must be regulated by the content of actual free lime; this should be determined at intervals by diluting a measured sample (5 c.c.) of the well-mixed cream with recently boiled distilled water to 250 c.c. in a stoppered flask, well agitating, allowing to settle, withdrawing an aliquot portion of the clear liquid with a pipette, and testing the alkalinity by $\frac{\mathrm{N}}{10}$ hydrochloric acid and phenolphthalein. Quicklime sometimes contains large quantities of impurities, and in all forms it loses strength by absorption of carbonic acid if exposed to air; therefore bins, vats, or tanks for storage require to be carefully covered. The usual dose of lime, when used alone, has been one ton to each million gallons, or $5^{\circ} 68$ grains per gallon. The following conditions must be observed:

I. Sufficient must be used, in the case of acid or trade effluents, for neutralization and precipitation.

2. In ordinary cases enough must be added to combine with the free carbonic acid and half of that combined as bicarbonate, as in ordinary water softening; the precipitated carbonate of lime carries down much organic matter.

3. A slight excess is generally needed to precipitate organic acids and colouring matters of a humous character.

4. Best results are obtained when the lime is in solution; if only suspended it is less active as a chemical precipitant, while all the insoluble impurities are added to the sludge.

5. The effluent must not be rendered more than faintly alkaline, and determinations of the alkalinity of raw sewage and effluent must be made.

6. The amount used will vary according to the quality of the sewage and of the lime.

Dibdin has drawn attention to the solvent action of lime on many of the suspended matters in sewage, so that "the addition of an excessive quantity of lime, while affording a rapid settle-

${ }^{1}$ Report of the Royal Commission on Sewage, 1902, vol. ii., p. 536. 
ment of the sludge, and a more or less clear effluent, dissolves a by no means inconsiderable quantity of the offensive matters previously in suspension, and this is apt to render the last state of the liquid worse than the first. The well-known offensive character of the liquids from sludge-presses when lime has been used is an example of its solvent action."

If other water than sewage is used for making up the lime mixtures, the corresponding dilution of the effluent must be remembered in judging of its quality.

When lime is used in conjunction with salts like sulphates of alumina and iron, there will be no free lime left if the molecular proportions are observed, thus:

$$
\begin{aligned}
\mathrm{Al}_{2}\left(\mathrm{SO}_{4}\right)_{3}+3 \mathrm{Ca}(\mathrm{OH})_{2} & =\mathrm{Al}_{2}(\mathrm{OH})_{6}+{ }_{3} \mathrm{CaSO}_{4} . \\
\mathrm{FeSO}_{4}+\mathrm{Ca}(\mathrm{OH})_{2} & =\mathrm{Fe}(\mathrm{OH})_{2}+\mathrm{CaSO}_{4} . \\
\mathrm{Fe}_{2}\left(\mathrm{SO}_{4}\right)_{3}+3 \mathrm{Ca}(\mathrm{OH})_{2} & =\mathrm{Fe}_{2}(\mathrm{OH})_{6}+{ }_{3} \mathrm{CaSO}_{4} .
\end{aligned}
$$

Only sulphate of lime will be left in the liquid, increasing its permanent hardness, and sometimes affording a measure of the sewage when discharged into rivers (p. 40).

Alumina or Iron Clarification.-The use of aluminium and iron salts as clarifiers and deodorizers has long been known. It depends on several actions, namely:

I. Forming in neutral solutions insoluble compounds (called generally "lakes"), with colouring matters and other dissolved substances.

2. Antiseptic power of the metallic salts themselves, and also, in commercial specimens, of the excess of acid, generally sulphuric, with which they are mixed. The latter, when they are used conjointly with lime, or when the acid is neutralized by the ammonia or other alkalies of sewage, will, of course, not count as an antiseptic.

3. In an alkaline solution the gelatinous precipitate of hydroxides entangles and carries down suspended matters, including organisms. The latter, however, rapidly rediffuse in the liquid, as with mechanical agents, so that the precipitate must be quickly separated. This separation by deposition and filtration, with subsequent sludge-press, adds a great difficulty and expense to the method.

4. Aluminium and iron salts neutralize ammonia and basic compounds; iron salts also destroy sulphuretted hydrogen, giving a black sulphide, $\mathrm{FeS}$ (plus free sulphur in the case of ferric), eventually oxidized to red-brown ferric sulphate, 
$\mathrm{Fe}_{2}\left(\mathrm{SO}_{4}\right)_{3}$, forming an ochreous deposit which acts as a further purifier. This red deposit often occurs from iron naturally present, and shows generally that the liquid has been so far oxidized.

Aluminium Sulphate is made from bauxite or clay, by treatment with sulphuric acid. As sold, it often contains excess of the acid, and samples should always be tested, as the more neutral it is the better. Freedom from iron is not requisite for this purpose ; in fact, "Spence's Alumino-ferric" is a mixture of the crude sulphates of iron and alumina, made in blocks which slowly dissolve. The amount of iron is generally small. At Glasgow 5 grains per gallon of alumino-ferric were used with 7 grains of lime, or $2 \frac{1}{2}$ grains (or more) of sulphate of alumina with 5 grains (or more) of lime, resulting in a production of over a million gallons of wet sludge from 200 million gallons daily flow of sewage.

Alum, the double sulphate of aluminium and potash, or ammonium, has the advantage of a definite composition, so that an exact quantity can be used, but is precluded by its cost, and also by its leaving behind the alkaline sulphates. In local purifications on the small scale it has often been of use.

Iron Salts. - When chemical precipitation was prevalent there was much controversy as to whether ferrous or ferric salts should be used. The former were cheaper, in the form of ferrous sulphate or "green copperas," but had the disadvantage of being reducing. Copperas with lime was largely used for London sewage. The precipitate of ferrous hydroxide, $\mathrm{Fe}(\mathrm{OH})_{2}$, absorbed oxygen from the air, and to a certain extent communicated it to the organic matter, acting as a carrier.

Ferric Salts not only possess a higher power of clarification, but also act as direct oxidizers. A solution of ferric sulphate has been used in several systems of purification, and the small quantity present in "alumino-ferric" may consequently be advantageous. Ferric chloride with lime was formerly employed, especially at Northampton. The presence of arsenic in it was commented on by Letheby, Hofmann, and Frankland. "Clarine" was a basic ferric chloride. "Ferrozone," at one time much used as a precipitant, is a mixture of ferrous, ferric, and some aluminium salt, with a less quantity of calcium and magnesium sulphates.

An important difference between the behaviour of ferrous 
and ferric salts as precipitants is not only that the former act as reducers, diminishing the amount of free oxygen available, but that ferrous oxide is soluble in alkaline liquors, while ferric oxide is almost entirely precipitated, so that a liquid treated with ferric or per-salts of iron after filtration or deposition may contain no iron, whereas one from ferrous or proto-salts, such as copperas, retains iron dissolved in the ferrous state, and on exposure to the air gradually oxidizes and gives rusty deposits.

When iron salts have been added to sewage, I have observed that a residue of the metal was always left in solution, with ferrous salts from the solvent action of alkalies already mentioned, with ferric compounds from the well-known fact that organic matter prevents their precipitation by alkalies. After a time, if not thoroughly aerated, a black deposit of sulphide of iron is liable to form, and is often seen on sides of channels. Aluminium salts have not these disadvantages. The presence of any of these chemicals in more than traces is injurious to fish and hinders nitrification.

In the Massachusetts experiments on the effect of different amounts of chemicals in removing micro-organisms it was found better to add the metallic salts first, and then an equivalent amount of lime afterwards. Ferric sulphate gave the best results as to removal of organisms and organic matter, copperas or alum acting about equally in the second place. In cost, their table gives the preference to copperas (ferrous sulphate) and lime.

At the London County Council's Works, Mr. Dibdin adopted I grain of copperas and 4 grains of lime to I gallon sewage, after a long series of experiments with various amounts of different precipitants. ${ }^{1}$ His conclusions are that the following rules should, as far as practicable, be observed: (I) The sewage should be diluted as little as possible; (2) agitation after mixing should be avoided; (3) unless absolutely necessary, no pumping should take place before precipitation, the reason apparently being that the entanglement of air with the precipitate prevents settling. He also infers that with lime iron is superior to alumina and also cheaper, and that a large increase in the quantity of chemicals yields no advantage.

At York in 1896 the sewage was chemically treated with

1 His results were given in detail in the second edition of the present work, p. I4I. 
alumino-ferric and lime, in proportions adjusted to the volume and to some extent to the strength, and averaging about 5 grains of each per gallon. During this period ${ }^{1}$ the average results in parts per 100,000 are given as: Oxygen consumed-sewage, 4.92 ; effluent, I.58. Albuminoid ammonia-sewage, 0.469 ; effluent, O.III. But beyond its organic impurity, the effluent was made too alkaline by the lime, and complaints arose as to its action on fish in the river; therefore during 1897 aluminoferric alone was used, and the average results are recorded as follows: Oxygen absorbed-sewage, 7*95; effluent, 2*36. Albuminoid-sewage, $I \cdot 2 I$; effluent, $0^{\cdot 266}$. As the results were so unsatisfactory, biological treatment was commenced in 1899 . It is reported that during fifty-six days of the first working of an open septic tank and continuous filter the sludge was only one-ninth of that produced by the former chemical precipitation, and the effluent was of good quality.

At Kingston-on-Thames the "A B C" process has been for some time in operation. This method is of early date; the letters originally signified alum, blood, and clay as precipitants, but it is now stated that the three principal ones are sulphate of alumina, clay, and carbon, and that 50 grains "of materials including sulphate of alumina" are used per gallon of sewage, with a purification measured by albuminoid ammonia of 83 per cent. An essential feature is the production by sludge-pressing and drying of a manure called "Native Guano," offered at $£ 3$ Ios. perton. Sir Alexander Binnie reported to the Corporation of Kingston in 1903 that the process was very expensive and not protected by patent, nor, probably, patentable. The effluent, under proper working, was clear and bright, but appeared in the conduits and near the river outfall to cause the growth of considerable quantities of sewage fungus. The sludge produced was comparatively free from odour, and amounted, at 90 per cent. moisture, to 27 tons per million gallons of sewage. Pressed, dried, and ground, it gave about 2,000 tons per annum of manure.

Metallophilic organisms-a convenient term I would suggest for vegetable and animal species whose growth is encouraged by the presence of small quantities of metals in solution, especially iron, aluminium, and manganese, which they secrete in their tissues or as an incrustation (see Chapter IV., p. 79)-

1 "Sewage Disposal, York," A. Creer, City Engineer and Surveyor, Public Health Engineer, May 21, I904. 
have often caused inconvenience by developing luxuriantly in effluents from treatment by metallic precipitants, or from various chemical trades. In October, I902, I examined the growths at Kingston in the channels and on the top of the continuous filter. In different parts of the latter there were gelatinous grayish-white flocculi, and reddish and nearly black slimy coatings. These consisted of Spharotilus natans (p. 79), Crenothrix ochracea, and abundance of a cyanophycaceous alga, probably Sirosiphon. The growths in the channel were of similar character. The flakes of both kinds stained with logwood a deep purple, like an iron-alumina reaction. Iron and aluminium were found in solution in the effluents in larger amounts than usual, and sometimes one and sometimes the other predominated.

The real strength of all precipitants must be periodically ascertained by analysis. Where they do not deteriorate on keeping, a large weighed quantity can be dissolved in a definite volume of water or effluent, stored in covered tanks, and drawn off by suitable measuring arrangements in proportion to the flow and strength of the sewage. The whole process must be quantitative, and it is hardly necessary to warn against the practice of turning so many hundredweights of crude chemical into a tank of raw sewage, stirring roughly, and taking little notice of imperfect solution or admixture. Many inventions have had for object the automatic supply of precipitants to sewage according to the flow, ${ }^{1}$ but the fault of these appliances has been that the sewage varies so much in composition that the chemicals will be sometimes in excess and sometimes in deficiency.

For separating the clarified liquid from the precipitate, either siphoning, a floating arm drawing off from cocks at different levels, or letting out the sludge at the bottom, is applied, with a large number of patented modifications.

Settling tanks may be constructed on the intermittent system, in which the liquid is allowed to rest quiescent for a certain number of hours, and the clear portion is then decanted. A more usual method is continuous sedimentation, when the whole runs very slowly through a tank of sufficient depth to allow the solids to gravitate, while the clear solution overflows from the top. Santo Crimp stated that the minimum size of the tanks should be such as to hold two hours' sewage flow during the

${ }^{1}$ See Colonel Moore's "Sanitary Engineering," 1898, p. 443. 
period of maximum discharge, and this quantity may be roughly estimated at one-seventh of the whole day's flow.

In cases in which it is proposed to adapt tanks constructed for chemical precipitation to the settling of sewage prior to bacterial treatment their size must be augmented sufficiently to allow time for the solution of the organic solids. Such tanks are originally too large to act as grit chambers, and too small if sludge is to be dissolved.

The relation between occasional flushes and the steady ordinary flow will vary with locality, and has to be specially determined by gauging at intervals. A fairly constant average from day to day will be found, with irregular interferences from storms. On the combined system of sewerage these render necessary the large surplus capacity given in the Local Government Board regulations; but even on the separate system they temporarily increase the volume.

Forms of Settling Tanks. - These at first were simply earth or clay-lined reservoirs with flat bottoms, from which the settled liquid was drawn by siphon-pipes at a little distance from the bottom, the soakage into the porous sides allowing great foulness. Then iron tanks were constructed, with flat bottoms, and outlet pipes placed generally at too low a level, the removal of the sludge at intervals requiring emptying and drawing off with considerable labour. A further improvement was to make the tank rectangular, four times as long as broad, with its lower surface inclined I in 80 to $I$ in Ioo towards the inlet end. Transverse walls, coming near to the surface, divided the tank, so as to allow the sewage to deposit and flow over them, while "scum plates" dipped from above, and intercepted any floating matters. At the base of the transverse walls there were openings allowing the sludge to gravitate, or be carefully swept down, to a sump at the lowest point at the inlet end. At the other end, the clarified liquid was drawn by a valve or a floating arm. Santo Crimp gave as examples of the capacity of settling tanks: Coventry, 42 per cent. of the day's flow; Birmingham and Burnley, 56; Leicester, 40 ; Wimbledon, 80 (designed for a large increase in population). In Germany it is claimed that the best results are obtained from long, narrow and shallow tanks.

The quantity of sludge made is stated to average $\frac{3}{4}$ ton per day per $\mathrm{I}, 000$ inhabitants, and the cost of filter-pressing to vary from Is. Iod. to $2 \mathrm{~s}$. $6 \mathrm{~d}$. per ton of sludge cake produced. The 
pressed out water must be taken back to the tanks for retreatment.

The Dortmund Tank is circular and deep, with the lower part conical, and with a vertical cylinder fixed in the middle. The strained sewage, after treatment with lime and aluminium sulphate, passes downwards through, the central cylinder, and is then distributed horizontally by specially constructed arms. The sludge deposited in the cone is withdrawn by suctionpumps through a 6-inch pipe opening near the bottom, at a uniform rate of $I_{5}$ feet per hour. This tank had its origin in the Röckner-Rothe process, and was first used at Dortmund in Germany, subsequently at the Chicago Exhibition, and at Alfreton and Ilkeston in England. The deposition in conical vessels has been long known in laboratories as a means of concentrating precipitates. The idea aimed at in the Dortmund is timing the deposition with the withdrawal of clear liquor. The fault of conical, as distinguished from cylindrical vessels, is that the former allow deposition on their sides, the greater in proportion to their low angle. Hence the working is sometimes deficient, "the sides of the cone being coated with filth, which decomposes, making the effluent very unsatisfactory."

At Essen (Röckner-Rothe principle) shallower tanks are adopted with pneumatic raising.

Cosham's Tank has the advantage of compactness, by means of a radial arrangement with two concentric circles, the middle one being divided into two, the outer space into eight compartments, the whole arrangement being conical, so that the inner two divisions are deepest, and the shallower outside ones encircle them. The sewage passes into the centre and overflows gradually through the other compartments, with deposition in each. Arrangements are made by which the sediment can be withdrawn from the bottom of each chamber, or passed into the centre divisions and siphoned out collectively. ${ }^{1} \mathrm{~A}$ rectangular form is also included. This system is said to have worked satisfactorily in twenty-five places, amongst which is Tibshalf, Derbyshire.

The Ives' Tank (patent I6,724 of I894) is also circular, and includes arrangements for aeration and, as a preliminary, a centrifugal reducer of coarser solids, with a "chemical cage"

1 For details see Moore's "Sanitary Engineering," p. 452. 
for regulating the supply of precipitant. The details, including a "flocculent flue," are very elaborate.

The sludge or precipitate left after either subsidence or filtration putrifies very rapidly in warm weather, therefore requires rapid removal from filters or tanks. It was formerly intended to disinfect it at great cost. It is of very varying composition, and is disposed of at the present time by many processes, namely:

I. Drying in open air on specially-prepared beds.

2. Running on to land a few inches thick, and then ploughing or digging in.

3. Running into deep valleys.

4. Transport to sea in specially-constructed barges.

5. Mechanical pressing and disposal to farmers, or tipping.

6. Drying mechanically, pressing, and using as a basis for fertilizers.

7. Centrifugal drying.

The centrifugal drying-machine and the filter-press were first introduced about 1855 at Leicester Sewage Works under Wickstead.

The Ashton-Booth sludge-remover now in course of installation at Bolton claims to take the place of the old methods of manual labour. This remover is propelled by pressure from the inflowing sewage, can be worked by two men, and takes fifteen minutes to clean a tank 400 feet long. It is applicable to any tank having a flat bottom, and claims to effect economy in tank construction, owing to the absence of channels and underground sludge-pipes.

Pressed sludge from the London sewage at Crossness averages, according to Dibdin's analysis-

\begin{tabular}{|c|c|c|c|c|}
\hline $\begin{array}{l}\text { Water } \quad \ldots \\
\text { Organic matter } \\
\text { Inorganic or ash }\end{array}$ & $\begin{array}{l}\cdots \\
\cdots \\
\cdots\end{array}$ & $\begin{array}{l}\cdots \\
\cdots \\
\cdots\end{array}$ & $\begin{array}{l}\cdots \\
\cdots \\
\cdots\end{array}$ & $\begin{array}{l}58 \cdot 06 \\
16 \cdot 69 \\
25 \cdot 25\end{array}$ \\
\hline & & & & 100.00 \\
\hline $\begin{array}{l}\text { Saline ammonia } \\
\text { Organic nitrogen }\end{array}$ & & $\begin{array}{l}\cdots \\
\cdots\end{array}$ & ... & $\begin{array}{l}0.035 \\
0.87\end{array}$ \\
\hline
\end{tabular}

The composition of the mineral matter was affected by the treatment with lime and ferrous sulphate, being-

1 For details see Moore's “Sanitary Engineering," p. 453. 


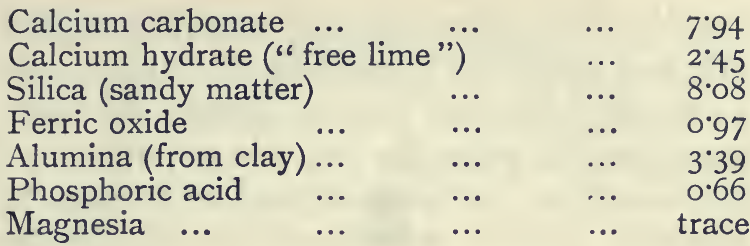

the total amount of wet sludge being 30 tons per million gallons.

With regard to the effluent, Mr. Dibdin estimates that the organic matter put into the Thames estuary in the course of twelve months is equal to only $\frac{1}{10}$ grain per ton of water, "but as the organic matter probably does not last in any form longer than a week, there would be at no time more than, on an average, $\frac{1}{500}$ grain per ton of water." 1

At Wimbledon in 18938.2 tons of pressed sludge cake were obtained per million gallons sewage, the average for a number of towns where filter-presses are used being $9^{*} 28$ tons per million gallons. In pressing sludge, lime is generally added to make the substance more manageable; as much as 2 per cent. is often used. The result, as we have indicated, is a dissolving of the organic matters and an extra foulness of the pressed liquid, besides the additional bulk. At Ealing, Bolton, and some other places, the sludge has been mixed with town ashes and burnt in a refuse destructor. James Ashton reports that sludge cake cannot produce a clinker, but when burned either falls to dust and is blown over the grate into the flues, or falls out on breaking the hard clinker obtained from the ashpit refuse. At Birmingham the sludge was mixed with the general refuse and offered as manure.

Although free lime tends to inhibit the multiplication of micro-organisms, we have already noticed that large quantities of it, added either to the raw sewage or mixed with the sludge to assist consolidation, increase the amount of organic matter in the effluent or in the sludge-press water, so that these liquids, after their alkalinity has been diminished by dilution or absorption of carbonic acid from the air, readily putrefy.

Sludge includes the greater proportion of the organisms of the original sewage, and when fresh may contain, according to Professor Boyce, I50 millions per c.c., but on standing the

1 Fournal of Preventive Medicine, July, 1905; see also Royal Commission on Sewage, vol. iii., I904, pp. 47,75 , etc., as to the volume of the Thames and of the sludge discharged. 
number slowly diminishes, reaching 90 millions after twentyfour hours, and falling to 7 millions in three months. With regard to sludge cake, the further addition of lime, together with abstraction of water by the presses, renders the mass almost sterile at first, but when exposed to the weather and to dust a ripening process takes place on the development of bacterial life.

Bradford, Yorkshire, has met with great difficulty on account of the large quantity of grease, mainly wool-fat, amounting sometimes to 20 per cent. of the dry solids, preventing the squeezing out of more than 25 per cent. of water. The usual percentage of water in the wet sludge of other towns is 90 per cent., the increase from 90 to 98 per cent. at Bradford making a vast difference in the total bulk. Thus, wet sludge

with 90 per cent. water $=9$ vols. $\mathrm{H}_{2} \mathrm{O}$ to I of solids;

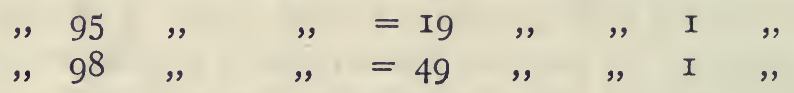

Therefore, I0o tons with 90 per cent. water become 200 tons with 95 , and 500 tons with 98 per cent., so that the watery character of the Bradford sludge caused its volume to be increased five times. Being so thin and greasy, it was difficult to press, and after being pressed in the most improved machines it left fully 75 per cent. of water in the cake.

Sludge cake can be brought to 50 per cent. water by pressing, and to I2 per cent. by air-drying. As the value, either as manure or fuel, is inversely proportional to the amount of water present, it follows that in all cases air-drying should be used before disposal. In the table (p. I67) the monetary value of air-dried sewage sludges is given, while their calorific value is roughly proportional to the organic matter. Since the latter is largely nitrogenous in character, its value as fuel is much lower than that of coal, and, of course, the remaining water associated with it must be evaporated before any energy is available. Santo Crimp estimated that in an efficient chemical process Io cwt. per head per year of wet sludge with 90 per cent. water was obtained, equal to $2 \mathrm{cwt}$. of dried sludge with 50 per cent. moisture.

The following are analyses of air-dried sludges as given by Professor Robinson: 
CHEMICAL PRECIPITATION

\begin{tabular}{|c|c|c|c|c|c|}
\hline 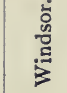 & 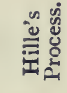 & $\underset{\sim}{\stackrel{\leftrightarrow}{心}}$ & 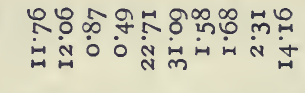 & $\begin{array}{c}R \\
\dot{\infty} \\
o\end{array}$ & 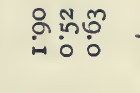 \\
\hline 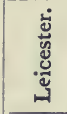 & $\stackrel{\leftrightarrows}{\leftrightarrows}$ & 灾 & 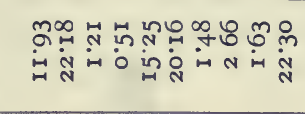 & $\begin{array}{l}\dot{m} \\
\dot{\sigma}\end{array}$ & tơ \\
\hline \multirow{2}{*}{ 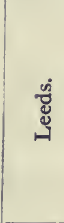 } & 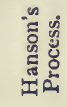 & 灾 & 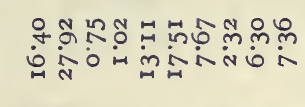 & $\begin{array}{l}0 \\
m \\
\dot{0} \\
0\end{array}$ & 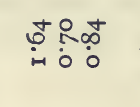 \\
\hline & 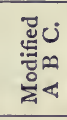 & 灾 & 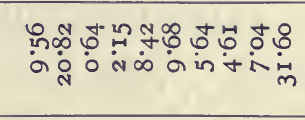 & 움 & mito \\
\hline \multirow{2}{*}{ Uे } & \multirow{2}{*}{ 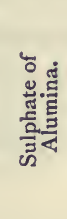 } & 灾 & 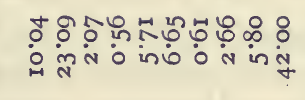 & $\begin{array}{l}\stackrel{2}{1} \\
\dot{\alpha}\end{array}$ & 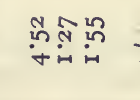 \\
\hline & & 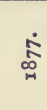 & 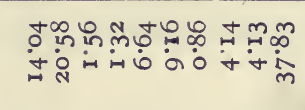 & $\begin{array}{l}0 \\
0 \\
0 \\
0 \\
0\end{array}$ & 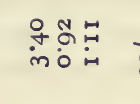 \\
\hline \multirow{2}{*}{ 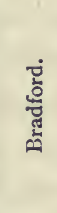 } & \multirow{2}{*}{ : } & s. & 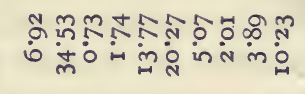 & : & ภำ \\
\hline & & 灾 & 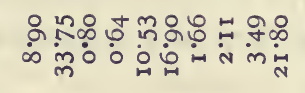 & $\stackrel{\infty}{\dddot{0}}$ & 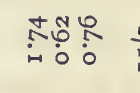 \\
\hline 产 & 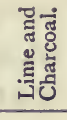 & 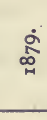 & 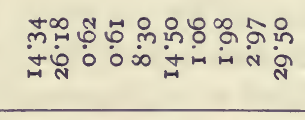 & : & 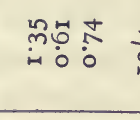 \\
\hline \multirow{2}{*}{ 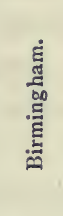 } & \multirow{2}{*}{ نं } & 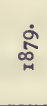 & 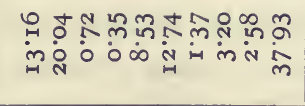 & ़ֻ̃ & 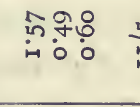 \\
\hline & & م્ & 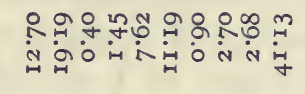 & : & 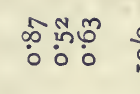 \\
\hline$\frac{\sqrt{3}}{4}$ & $\underset{\sim}{0}$ & 灾 & 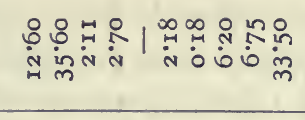 & in & 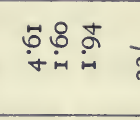 \\
\hline$:$ & $\vdots$ & 立 & $\vdots \vdots \quad \vdots \vdots \vdots \quad \vdots \quad \vdots \quad \vdots \quad \vdots$ & & $\vdots \vdots \vdots$ \\
\hline : & $\vdots$ & $\vdots$ & 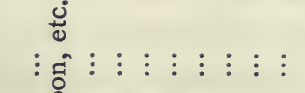 & & $\vdots \vdots \vdots$ \\
\hline 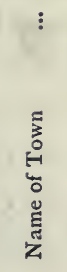 & 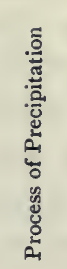 & 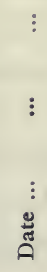 & 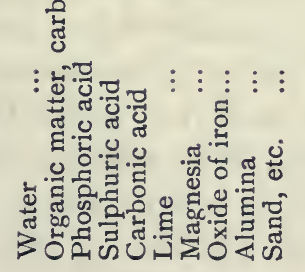 & & 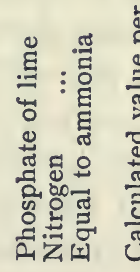 \\
\hline
\end{tabular}




\section{CHAPTER VIII}

\section{STERILIZATION BY HEAT, CHEMICALS, AND ELECTRICITY}

Removing odour-Metallic salts-Action of manganates and permanganates-Oxynite process-Chlorine and hypochloritesBleaching powder - Hermite - Electrozone - OxychlorideAcids-Bergé-Ozone-Liernur process-Disposal of refuseDestructors.

In the foregoing methods for the mechanical separation of the solids and the production of a clear effluent chemicals were sometimes employed, but almost solely with a view to clarification. The Rivers Pollution Commission and a large number of legal actions led to attempts at "disinfection" of the raw material or its products by processes aimed at removing or preventing smells or destroying the bacteria, at a time when all organisms were held to be dangerous. Odour and appearance were often the only things considered. In these earlier attempts at disinfection on a practical scale disinfectants like mercuric chloride and carbolic acid were soon seen to be too costly when used in effective strength.

It was therefore found that the complete sterilization of crude sewage was impracticable on a large scale. Later, when it became acknowledged that the attempt was in general on the wrong lines, and that biological change was, on the whole, the most economical and efficient means of purification, and should be encouraged and not inhibited, the bacterial flora of an effluent which was inoffensive to sight and smell and conformed to certain chemical standards excited little attention. This attitude was generally right, as I have frequently contended that it is no part of a sewage scheme to convert sewage into drinking-water, and that where the water of a river must be used for drinking, it is always necessary to purify it by efficient filtration or by other means. In Chapter IV. I have already reviewed the question of the survival of pathogenic 
organisms in bacterial sewage treatment. Filtration has a marked effect in keeping back $B$. enteritidis sporogenes (see p. 9I), and the number of $B$. coli is diminished during the stay in a septic tank. A septic tank liquid is inimical to $B$. coli and to other more delicate pathogenic bacteria. Experiments of my own at Caterham proved that nitrifying filters removed 98.5 per cent. of the coli organisms, and all or nearly all of the enteritidis. Fuller states that in America sewage filtered intermittently through sand contains only about I per cent. of the bacteria present in the raw liquid. ${ }^{1}$ So that we were justified in concluding that effluents from an efficient bacterial treatment were, with the limitations I have above indicated, perfectly safe to discharge into rivers, and that the greater the aeration and nitrification, the less the possibility of survival of pathogenic organisms.

Judged from a bacterial standard, and sometimes from a chemical one, there is not a river whose waters are safe to drink without purification, and my contention many years ago that a good effluent frequently improved a river has been recognised as true, and is conceded in the report of the Royal Commission. ${ }^{2}$ Therefore there does not seem to be much advantage in insisting, in the language of the Commission, on the "fundamental difference between the discharge of effluents into drinking-water and non-drinking-water streams." In most cases it is only practicable, in the majority it is alone necessary, and in all cases it should be compulsory, to carry the purification of sewage to a stage when, in my words at the time mentioned, "such factors as time, light, volume of oxygen, and various life in the river, will be more than sufficient to deal with the effluent," leaving, in the instance of "drinking-water streams," the removal of the reduced number of bacteria to the water companies, with, as I have indicated elsewhere, ${ }^{3}$ a final line of defence in domestic sterilization.

The suggestion that local authorities should in general be further hampered by increasing their existing burdens in treating sewage, so as to produce effluents equal to drinkingwater, is obviously absurd and unjust. The means by which sterilization of effluents can be effected when necessary will be presently described.

1 Transactions of the Ancrican Society of Civil Engincers, vol. liv., part E, 1905.

2 Vol. iv., part i., I904, p. 105.

3 Rideal, Cantor Lectures, Society of Arts, I902, p. 27 ; also Fournal of the Socicty of Arts, December 17, I897, p. 86. 
Much sewage is still, however, locally discharged without any treatment, or with only screening or a rough sedimentation. The Rivers Pollution Act, 1876 , restrains such a practice as regards "rivers, streams, canals, lakes, and watercourses, other than watercourses at the passing of the Act mainly used as sewers and emptying direct into the sea or tidal waters" (section 20). Under the provisions of this Act, and the supplementary one of 1893 , damages have been obtained and injunctions granted. But the working, on the whole, has not been satisfactory, and the Royal Commission on Sewage observes: ${ }^{1}$ "At an early stage of our investigation we were struck by the fact that in many parts of England the pollution of rivers goes on unchecked, notwithstanding the fact that the Rivers Pollution Prevention Act has been on the statute book for over a quarter of a century, and in our Interim Report we deemed it necessary to state that the protection of our rivers is a matter of such grave concern as to demand the creation of a supreme rivers authority." They give, further, an outline of the powers and duties of such a central authority and of proposed River Boards.

In certain estuaries the polluted water is carried up and down by the tide, and is only slowly cleared out to sea; and yet tidal waters, as will be seen by the quotation we have given from the Rivers Pollution Act, are exempted from its operation; as a consequence raw sewage continues to be discharged from a large number of sea-coast towns. Recent cases at Emsworth and Southend have, however, shown that pollution of oyster beds, if proved to be due to such discharge, is actionable at common law.

The risks to health, especially from the contamination of fisheries and shell-fish layings, claimed early scientific attention. In India it has been held from ancient times that uncooked shell-fish are a cause of bowel affections and even of cholera. In $188 \mathrm{o}$ Sir $\mathrm{C}$. Cameron pointed to the possible relation of typhoid in Dublin to the consumption of specifically polluted oysters. Sir R. Thorne Thorne, in the Local Government Board Report for I894, expressed his conviction that the distribution of shell-fish from certain centres had been concerned in the diffusion of cholera over a somewhat wide area in England. In the same year Dr. Newsholme commenced his investigations as to the connection of typhoid at Brighton with

1 Third Report, I903, p. 26. 
sewage-polluted shell-fish, and afterwards proved that the percentage of cases due to this cause was in I894, I895, I896, and I $897,3^{\circ} 2,33^{\circ} 9,3 I^{\circ} 8$, and $30^{\circ} 7$ respectively, ${ }^{1}$ and that at least one-third of these cases are due to mussels. ${ }^{2}$ Dr. Nash in Igoo obtained clear evidence that a severe outbreak of typhoid fever at Southend was originated by infected cockles. ${ }^{3}$ These had been obtained from a sewage-polluted creek in another district; had been scraped up with an ample amount of mud attached, then washed on a sieve in the creek water, and partially cooked by being plunged into an open copper containing very hot water. In a few minutes, when the shells opened, the cockles were removed, the shells separated by sifting, and the fish either sold at once or pickled in brine for transport.

The important points are that the usual cleansing is delusive, and the parboiling commonly practised is no protection. Dr. Thresh, in an experiment with these cockles, washed them twice with pure water, and then plunged them into boiling water. At the end, living sewage bacteria were present in the liquid draining from them, a result confirmatory of conclusions previously arrived at by Dr. Klein, working with oysters, cockles, and mussels, and with typhoid and cholera organisms, who, moreover, found that the organisms remained even when the infected water had been replaced for three days by clean sea water, and that they actually increased in numbers within the bodies of the shell-fish. ${ }^{4}$ Dr. Nash also remarks ${ }^{5}$ that inquiries should not be limited to the eating of shell-fish, but should extend to the handling of such from suspicious sources, since germs can easily be carried from the hands to the mouth.

The proofs of the connection between polluted shell-fish and typhoid are clear and numerous, and have been summed up by Newsholme, ${ }^{6}$ and also in the Fourth Report of the Royal Commission on Sewage, vol. i., p. xv. In the careful surveys of the gathering-grounds of England and Wales in I894 and 1895, and of Ireland in I903, conducted for the Local Government Board, it became evident that a number of them were liable to invasion by recent sewage. Its discharge into tidal waters came into wide public notice in I903, in connection with serious

1 Fournal of the Royal Sanitary Institute, vol. xvii., part iv., January, 1897.

2 Ibid., vol. xxv., part iii., October, 1904.

3 Ibid., vol. xxiii., part iv., January, I903.

4 Report of Medical Officer to Local Government Board, I900-I90I, p. 567.

5 Public Health, August, 1902.

6 Fournal of the Royal Sanitary Institute, October, 1904, p. 454. 
illness following mayoral banquets at Winchester and Southampton, which illness was traced to Emsworth oysters. Legislation had been widely demanded for the prohibition of the laying down of shell fish in sewage-polluted water or other dangerous localities, and the protection of those laid down in hitherto unpolluted places. The whole subject was therefore dealt with as urgent by the Royal Commission in their Fourth Report, I904. They concluded that (vol. i., p. xi), "generally speaking, it may be said that the Statute Law does not prohibit the discharge of polluting liquids into tidal waters." From the mass of evidence collected, they gave official confirmation to facts of which others, including myself, had long been awarethat sewage from towns and tidal rivers on the coast is usually discharged in an unpurified condition, that injuries to health and to fisheries may be thereby caused, and that some alteration of the law was necessary. In many layings of oysters the sewage can reach them in a very short time after its discharge, and organisms of intestinal origin can be taken up by the shellfish and remain alive in them for several days, and can produce diseases (ibid., p. xv).

In the evidence it was urged ${ }^{1}$ that every endeavour should be made by local authorities to prevent typhoid bacilli or other pathogenic organisms from gaining access to sewage, by sterilization of the excreta of patients. It was admitted, however, that in the large discharge of typhoid bacilli in the urine during prolonged convalescence there would be almost insurmountable difficulty.

We gather, therefore, from the Royal Commission's Report that sterilization of effluents is necessary-

I. Where shell-fish or vegetables commonly eaten raw are liable to be infected, provided it is necessary for them to lie in such situations.

2. Where disease organisms are discharged in large numbers, as in the instance mentioned above, and in fever hospitals. ${ }^{2}$

3. Where the effluent is discharged into streams from which water is subsequently taken without proper purification.

In their Third Report the Royal Commissioners had stated, "We are continuing the investigations referred to in our Interim Report (IgOI), for the purpose of ascertaining whether it is practicable to destroy those micro-organisms which are common to sewage effluents, and which may be dangerous if the

1 Vol. ii., 1904, p. Ioo.

2 Interim Report, vol. ii., p. 538. 
effluent flows into a river from which water for drinking is obtained, and we are generally considering what measures may be desirable to lessen dangers so arising" (p. 29). It was hoped that the Commission would have followed by information as to processes of destroying micro-organisms or sterilization of effluents on the large scale, but although evidence on the subject was given before them by Drs. Klein, Thresh, myself, and others, and one of their references was as to what remedies were practical and available for injuries caused by sewage, sterilization finds no further mention in their conclusions. The nearest approach is in their Fourth Report, vol. i., p. 20, under "Remedies Suggested," where the proposal that all sewage should be purified is met by two objections : nonnecessity, and non-efficiency.

Non-necessity, because there are " many cases where shell-fish are not concerned .... and to require purification in all cases would lead to the waste of large sums of money."

Non-efficiency, because they consider that no treatment at present in use can be relied on as safe.

They seem to have ignored the point that sterilization of a partially purified effluent when necessary was possible, and had been achieved in several places without ruinous expense. And yet the keynote to this idea had been struck shortly before in the Report of the Local Government Board for Ireland, I903, p. 7 , in the phrase, "Short, however, of the sterilization of sewage effluents discharging in the immediate vicinity of shellfish beds, no other form of treatment at present in use is likely to be effectual in destroying or removing, although it may succeed in reducing, the number of pathogenic germs."

Owing to the foul condition of rivers near or within large towns, vigorous attempts have been made to disinfect them with chemicals, or to add the latter to the sewage, with the object of removing or neutralizing free ammonia, compound ammonias, and sulphuretted hydrogen, and so to render the liquids almost inodorous for the time, and to hinder further decomposition of the organic matters. Any acid or acid salt would neutralize the ammonia; many metallic solutions would absorb sulphuretted hydrogen, and also precipitate much of the organic matter, and a clear effluent without much odour and almost colourless would be obtained. But several difficulties occur :-

I. It is a mistake to suppose that the odorous ingredients 
of sewage are all basic like ammonia, or readily combine with chemical reagents. Acids and many other chemicals, when added to urine, fæces, or vegetable refuse, develop a very unpleasant odour, which may be often noticed in the vicinity of works where organic matters are treated. Substances like indol and skatol, from fæces, are very weak bases, and readily escape in the vapour even from acid solutions.

In distilling sewages or contaminated waters for ammonia and albuminoid, the distillate will be found to have a peculiar nauseous, somewhat aromatic odour, which is so constant that in waters it points strongly to sewage admixture. When in considerable quantities, the compound causing the smell collects as a greasy white scum on the top of the distillate. On account of its ready volatility, and its not combining with reagents, it is very difficult to separate, but from large volumes of sewage I have obtained it as a white neutral crystalline substance. In small quantities, it floats like a grease on the surface of water : from its odour and general occurrence, though in minute amount, it would seem to be an important cause of the residual sewage odour when ammonia, etc., have been removed.

The volatile oil giving the chief odour to urine has also been isolated: it is neutral and does not readily combine; the same would be the case with essential oils from vegetables, hydrocarbons like naphthalene from gas-tar, etc. Among acid compounds, phenylacetic acid, which I have isolated from effluents, has a strong odour. Ethereal salts, like mercaptan, may also be mentioned among the many substances which may render chemical deodorization inefficient.

2. Chemicals, in the quantities that were applied, did not kill the organisms of putrefaction, and only to a slight extent reduced the organic matters in solution, therefore the effluent soon resumed a condition of turbidity and foulness. Some chemicals render the liquid acid, others unduly alkaline-both objectionable features. We have already spoken of the increase of the sludge by precipitants; while the difficulty of sterilizing it is well known.

Where expense is a secondary factor, as, for instance, in some of the effluents from hospitals, metallic salts are of service, notably those of copper, on account of their combining with sulphur and ammonia, and their marked germicidal properties. The easy removal by lime and sand filtration, with 
subsequent recovery of the copper from the material, induced Kroncke $^{1}$ to adopt cuprous chloride; others-e.g., the French authorities in combating the cholera in I892-used the cheaper cupric sulphate. Mr. Shrapnell Smith, of Liverpool, stated at the Leeds Sanitary Congress, I897, that he was using salts of copper, and drawing air through the filter-beds by fans. More recently sulphate of copper has been somewhat extensively used in America and India for the removal of algæ and the bacterial contamination of rivers and reservoirs, but owing to the expense this method is only of very limited application.

In $1904^{2}$ I confirmed the results obtained by Dr. Moore, ${ }^{3}$ and found that copper chloride could be substituted for the sulphate, and that the quantities required were so small as to cause little apprehension as to injury to fish.

The efficiency of different copper compounds depends on the percentage of copper present in the salt; for instance, ${ }^{4}$ I in 8,500 of copper sulphate, or I in 13,500 of copper chloride, killed $B$. coli in three hours; I in $7,000^{\circ}$ of sulphate, or I in I0,000 of chloride, killed Staphylococcus pyogenes aureus in two hours.

Hence it appears that these salts might be useful in sterilizing oyster or watercress beds without danger.

Even plates of metallic copper ${ }^{5}$ in ordinary water give off enough of the metal in a so-called colloidal state to make the liquid toxic to many algæ and bacteria, and I am trying the effect on sewage filtrates of passing them through copper gauze to reduce the number of pathogenic organisms, with a view to protecting watercress beds and oyster layings.

Bassett Smith ${ }^{6}$ experimented with $B$. typhosus, coli, enteritidis, B. dysenterice (Flexner), Micrococcus melitensis (the organism of Mediterranean fever), and with ordinary water organisms, comparing the effect of copper with that of iron, zinc, lead, and tin. His copper sulphate solutions were of $I$ in $I, 000, I$ in $I 0,000$, and $I$ in roo,0oo strength, and he observed that in all the dilutions with distilled water $B$. typhosus was killed in under one hour; but in tap water the highest dilution required twenty-four hours; I in I0,000 required twelve hours. With $B$. coli in distilled or tap water the highest dilution was insufficient to kill in twenty-

I Fourn. f. Gasbelencht, xxxvi., 5 I3.

2 Fournal of the Royal Sanitary Institute, vol. xxv.

3 Bulletin, Department of Agriculture, Washington, 1903.

4 See also Green, Zeits. f. Hygiene, r 893, p. 495.

5. For details I must refer to my paper, mentioned above.

6 Fournal of Preventive Medicine, July, I904. 
four hours, but I in I,000 was fatal under that time. B.enteritidis was very similar. With $B$. dysenterice and $M$. melitensis fifteen hours was effective.

A ferrous sulphate solution was also tried in comparison. One in 100,000 was ineffective; I in 10,000 was fatal to $B$. typhosus under seven hours, and to $B$. enteritidis under forty-eight hours; $I$ in $\mathrm{I}, 000$ killed $B$. coli in less than twenty-four hours. $\mathrm{He}$ therefore finds ferrous sulphate almost as effective as copper sulphate, but it has the disadvantage of rendering the water yellow and turbid.

He confirmed the germicidal power of bright copper surfaces. $B$. typhosus in a copper vessel was still living at twelve hours, but was dead at twenty-four. With ordinary tap-water organisms, the number being $\mathrm{I}, \mathrm{O} 20$ per c.c. at first, only 8 per c.c. were left after twenty-four hours; the main decrease occurred in the first hour, and the liquefying bacteria decreased from sixteen to two in three hours, and to none in twenty hours. No copper was found in solution:

He concluded that clean iron was nearly equal to copper, and zinc had almost the same effect; but as the metals must be bright, iron soon loses its value by rusting, and zinc also becomes oxidized. Strips of ordinary zinc foil up to forty-eight hours had not sterilized any of the organisms. Iron coated with zinc, or galvanized iron, should give good results.

An attempt to sterilize urine containing pathogenic organisms, by keeping it in a copper vessel, was not successful after twentyfour hours' contact, and it was considered that this was due to the action of the urine on the metal.

Lead, tin, and a control glass vessel showed practically no effect. The conclusions of the paper are that in tanks for the storage of water, iron, copper, and zinc as galvanized iron show only a slight difference in bactericidal power, and that "zinc, or iron, coated with zinc, though less rapid in action than copper, yet after twenty-four to forty-eight hours appears to free the water from typhoid organisms."

It is possible to thoroughly deodorize sewage by permanganate and sulphuric acid (giving ozonized oxygen), either before or after the removal of the suspended matters by precipitation. ${ }^{1}$ Sodium manganate, as a cheaper salt, was used for the London sewage from $I 884$ to $I 887$ by introducing it into sewers at different

1 See Report of Commission of $\mathrm{I} 882$, on the effects of the discharge of the sewage of London into the Thames, vol. xi., p. I42. 
points; being strongly alkaline, it disengaged ammonia, which was neutralized by acid treatment at the outfall.

The amount of oxygen liberated from manganates and permanganates depends upon the way they are applied. The maximum, when permanganate with sulphuric acid acts on organic matter, is 5 atoms, thus :

$$
\mathrm{K}_{2} \mathrm{Mn}_{2} \mathrm{O}_{8}+{ }_{3} \mathrm{H}_{2} \mathrm{SO}_{4}=\mathrm{K}_{2} \mathrm{SO}_{4}+2 \mathrm{MnSO}_{4}+3 \mathrm{H}_{2} \mathrm{O}+5 \mathrm{O} \text {. }
$$

If the acid be insufficient, a brown precipitate of hydrated peroxide falls, and only 3 atoms of oxygen are liberated :

$$
\mathrm{K}_{2} \mathrm{Mn}_{2} \mathrm{O}_{8}+\mathrm{H}_{2} \mathrm{SO}_{4}+{ }_{3} \mathrm{H}_{2} \mathrm{O}=\mathrm{K}_{2} \mathrm{SO}_{4}+2 \mathrm{Mn}(\mathrm{OH})_{4}+3 \mathrm{O} \text {. }
$$

Manganate spontaneously gives up $\mathrm{I}$ atom of oxygen with great readiness :

$$
\mathrm{Na}_{2} \mathrm{MnO}_{4}+3 \mathrm{H}_{2} \mathrm{O}=2 \mathrm{NaOH}+\mathrm{Mn}(\mathrm{OH})_{4}+\mathrm{O} \text {. }
$$

With a dilute acid, even carbonic, in excess, it yields permanganate and hydrated peroxide:

$$
3 \mathrm{Na}_{2} \mathrm{MnO}_{4}+2 \mathrm{H}_{2} \mathrm{SO}_{4}=\mathrm{Na}_{2} \mathrm{Mn}_{2} \mathrm{O}_{8}+\mathrm{Mn}(\mathrm{OH})_{4}+2 \mathrm{NaSO}_{4} \text {; }
$$

the permanganate further changing as shown above.

Processes for recovery of the manganese or iron oxides from the pressed sludge have not been commercially successful.

Manganates and permanganates are rapidly destroyed by harmless organic matter and other substances, so that there is often no remainder left for bactericidal action. They were formerly much used in street watering-carts, and an experiment of my own may be illustrative. ${ }^{1}$

The Westminster Vestry had for some time used permanganate in their water-carts in the proportion of 2 ounces to 400 gallons, or I in 32,000 , the 400 gallons covering about 600 square yards on a dry and 3,000 square yards on a wet day. The reasons given for discontinuing it are interesting: (I) That it was complained of as damaging the asphalt ; (2) that it was more costly than other disinfectants ; (3) that being without odour the ratepayers had no belief that a place had been disinfected; (4) that it attacked the iron tanks and fittings ; $(5)$ that children collected the pink liquid in various utensils, and sometimes drank it.

To test the bacterial efficiency of a I in 5,000 solution, at the rate per yard mentioned above, I watered two plots of asphalt roadway in Victoria Street, under ordinary day conditions of horse droppings, etc., (a) with ordinary water, and the other

${ }^{1}$ Sanitary Record, July 27, 1900. 
(b) with the permanganate $I$ in 5,000 . The liquid running off was collected and bacterially examined. The rapid destruction of the permanganate was again noted.

The permanganated sample was almost free from odour, and on keeping for three days smelt much less foul than the other. The cultivation experiments showed the following results:

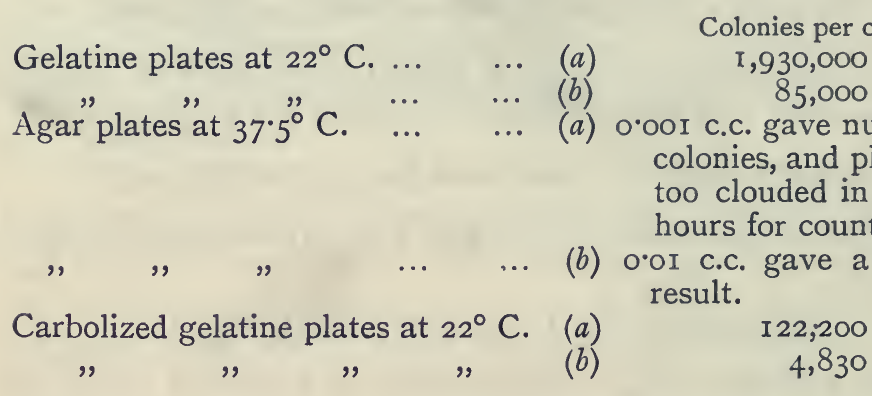

Although the permanganate has exercised considerable influence, destroying about 96 per cent. of the bacteria, the result cannot be considered sterilization, and it will be noticed that its effect upon those growing at blood heat and on carbolized gelatine, which include those of the "coli" group, was similar to that on those growing on the ordinary gelatine plate. I did not specially test in these experiments as to the survival of spores of $B$. enteritidis sporogenes, but from previous work with this organism I believe it to be extremely resistant to permanganate. (See also p. I86, use of chlorine for this purpose.)

An important point in this treatment is that lower oxides of manganese are always left in the sludge. Any metal having two oxides which easily pass one into the other may act as a carrier of oxygen from the air to organic matter, as is the case with iron. Manganese has a still higher range of activity, hence its oxygen compounds have long been used as destructors of organic matter. The native mineral pyrolusite, $\mathrm{MnO}_{2}$, has been used in the granular state in filters, or added in very fine powder to sewage; but beyond mechanical action it gives no oxygen, and remains practically unchanged. A better result occurs when it is mixed with carbonaceous matters and heated in closed retorts, so as to reduce it to a lower state of oxidation. On exposure to air and water a film of flocculent hydrated peroxide is formed, which readily parts with oxygen to organic matter in solution, reabsorbing oxygen from the air when the 
water has drained away. Such a material has high oxidizing powers, the expense being the main objection.

Bertrand, ${ }^{1}$ in his investigation of oxydases (p. Iro), pointed out the invariable presence of traces of manganese, and suggests that the oxydases are compounds of manganese in which the acid radicle is of a proteid character, and of sufficient activity to keep the metal in solution, whilst the manganese is the real carrier of oxygen. Antoine Villiers ${ }^{2}$ and Achille Livache $^{3}$ confirm this view of the agency of very small quantities of manganese in transferring oxygen from one compound to another, and it seems probable that the traces of manganese in coke, clinker, and other materials of filter-beds may be helpful to oxidizing action by supplying this element to oxidizing enzymes. In the natural oxidations that occur in ferruginous waters, the action of enzymes has also been asserted.

Adeney, in $1894,{ }^{4}$ observed that the sludge from sewage that had been treated with manganate of soda slowly evolved carbonic acid and nitrogen gas. This oxidation of the organic matter was clearly traced by him to the available oxygen of the hydrated peroxide of manganese in the precipitate, as he found that the peroxide became completely converted into manganous carbonate, $\mathrm{MnCO}_{3}$. The process is exactly parallel to denitrification (p. 125), and is similarly dependent on organisms, as McWeeney ${ }^{5}$ found that in sterilized media the reduction of peroxide to carbonate did not occur. In his "Oxynite" process the sewage first deposited nearly 90 per cent. of the solid matters "unmixed with precipitating chemicals," and then was precipitated by manganate of soda and sulphate of alumina; this sludge underwent the spontaneous oxidation described above, and admits of the recovery of the manganese. ${ }^{6}$ The effluent was mixed with nitrate of soda to supply more oxygen.

Chlorine and Chlorine Compounds as conveyers of oxygen have been often used. Chlorine by itself may act in different ways. When concentrated it can combine directly with organic matters or replace the hydrogen in them, precipitating all albuminous substances ${ }^{7}$ and rendering them imputrescible,

1 Comptes Rendus, I896, cxxiii., 463, and I897, cxxiv., I355.

2 Ibid., I349. 3 Ibid., 1520.

${ }^{4}$ Proceedings of the Royal Dublin Society, viii., 247.

5 Transactions of the Royal Dublin Society, August, 1897.

- See also Wilson, Patent 1725 , r891.

7 Rideal and Stewart, Analyst, 1897, p. 228. 
besides killing all life. In localized situations, therefore, chlorine and its compounds are effectively used for dealing with special nuisances. The offensive gases of putrefaction are decomposed, sulphuretted hydrogen being resolved into sulphur and hydrochloric acid-

$$
\mathrm{H}_{2} \mathrm{~S}+\mathrm{Cl}_{2}=2 \mathrm{HCl}+\mathrm{S}
$$

phosphuretted hydrogen being also decomposed, while ammonia and compound ammonias give a corresponding chloride and nitrogen-

$$
8 \mathrm{NH}_{3}+{ }_{3} \mathrm{Cl}_{2}=6 \mathrm{NH}_{4} \mathrm{Cl}+\mathrm{N}_{2}
$$

hence the copious white fumes frequently noticed when a chlorine mixture is thrown into a dung-pit. With more chlorine intensely acrid vapours, which attack the eyes and lungs, due to chlorides of nitrogen and chloropicrin, $\mathrm{C}\left(\mathrm{NO}_{2}\right) \mathrm{Cl}_{3}$, are produced. In dealing with cesspools, ashbins, or privies this becomes strongly prominent in chlorine disinfection. Chlorine acts as an oxidizing agent by decomposition of water-

$$
\mathrm{H}_{2} \mathrm{O}+\mathrm{Cl}_{2}=2 \mathrm{HCl}+\mathrm{O} \text {, }
$$

the nascent oxygen so liberated being far more energetic than atmospheric oxygen, and acting directly on organic substances. A cheap source of chlorine is chloride of lime or bleaching powder, $\mathrm{CaCl}_{2} \mathrm{O}$, which, on dissolving in water, breaks up into calcium chloride, $\mathrm{CaCl}_{2}$, and calcium hypochlorite, $\mathrm{Ca}(\mathrm{ClO})_{2}$; the latter only is available for chlorinating or oxidizing. The commercial dry powder contains as a rule about one-third of its weight of active or "available" chlorine. ${ }^{1}$ When mixed

1 "Available chlorine" means that portion of the whole chlorine which liberates oxygen on reaction with water. Hydrochloric acid and most chlorides liberate none. Free chlorine, for every molecule $\mathrm{Cl}_{2}$, or $7 \mathrm{I}$ parts by weight, sets free $\mathrm{I}$ atom, weighing $\mathrm{I} 6$ parts, of oxygen :

$$
\mathrm{Cl}_{2}+\mathrm{H}_{2} \mathrm{O}=2 \mathrm{HCl}+\mathrm{O}
$$

that is, the weight of chlorine used is about $4 \frac{1}{2}$ times the oxygen obtained.

Hypochlorous acid and hypochlorites can break up directly into hydrochloric acid or chlorides and oxygen :

$$
\begin{aligned}
\mathrm{HClO} & =\mathrm{HCl}+\mathrm{O} \\
\mathrm{Ca}(\mathrm{ClO})_{2} & =\mathrm{CaCl}_{2}+2 \mathrm{O}^{\prime} \\
\mathrm{NaClO} & =\mathrm{NaCl}^{2}+\mathrm{O}
\end{aligned}
$$

Hence pure hypochlorous acid, or a purc hypochlorite, would give I atom of oxygen for I of chlorine, or double the amount yielded by free chlorine. Commercially, however, the hypochlorite is always obtained mixed with an equivalent amount of the inert chloride, as in the formation of solutions of chloride of lime and chlorinated soda :

$$
\begin{aligned}
2 \mathrm{NaOH}+\mathrm{Cl}_{2} & =\mathrm{NaCl}+\mathrm{NaClO}+\mathrm{H}_{2} \mathrm{O} . \\
2 \mathrm{Ca}(\mathrm{OH})_{2}+2 \mathrm{Cl}_{2} & =\mathrm{CaCl}_{2}+\mathrm{Ca}(\mathrm{ClO})_{2}+2 \mathrm{H}_{2} \mathrm{O} .
\end{aligned}
$$

Therefore, apart from the question of difference of activity, the total amount of chlorine present in these chlorinated products bears the same relation to the 
with ordinary water containing carbonic acid, the latter decomposes the hypochlorite, setting free hypochlorous acid-

$$
\mathrm{Ca}(\mathrm{ClO})_{2}+\mathrm{CO}_{2}+\mathrm{H}_{2} \mathrm{O}=\mathrm{CaCO}_{3}+2 \mathrm{HClO} \text {. }
$$

Hypochlorous acid can either combine with organic matter directly, forming innocuous compounds, or can furnish hydrochloric acid and nascent oxygen.

"Chloros" is a solution of sodium hypochlorite $\mathrm{NaClO}$, containing ro per cent. of available chlorine. It has recently been used by the Metropolitan Water Board for sterilizing the effluents from the Hertford Sewage Works, as the outfall is not far from the intake of the Lea water-supply to London. Allusion has already been made to the use of chloride of lime at Birmingham (p. I55) in small quantity along with slaked lime; as the latter absorbs the carbonic acid, the action of the hypochlorite is extremely slow. Chloride of lime was used before 1884 , and again in 1887 , for the river Thames during the hot weather, but it was shown that "unless large and continuous doses were kept up," the foulness of the stream was not controlled. Hofmann and Frankland found in 1859 that it required 400 pounds of chloride of lime to deodorize a million gallons of London sewage, the effluent remaining inoffensive for three days. On the river Brent in 1896 , when complaints were made of the effluvium, chloride of lime was scattered on each bank during the warm weather. Its use in dustbins, gulleys, streets, and urinals is well known. Louis Parkes, ${ }^{1}$ speaking of the insanitary condition of wood pavements during dry weather where horse-droppings are frequent, recommends that "wood-paved streets should be watered from carts containing a weak antiseptic and deodorant solution, which will inhibit the growth of the putrefactive microbes on the wood surface. Probably the best would be a weak chlcrine solution, say I part of chlorine in I0,000 to 20,000 parts of water . . . being volatile, it leaves no residue on the road." But free chlorine, even in this dilution, would attack the iron fittings of the carts and the grids of the sewers, and be itself removed as basic ferric chloride. A I per cent. solution of

oxygen yielded as it does in solutions of the free element. In the manufactured products lime or soda is always present in excess for the sake of stability; but all of them deteriorate when stored, especially in presence of light. The available chlorine requires to be frequently controlled by analyses. In "chloride of lime" it is expected to be 33 to 34 per cent. ; in "chloros" solution it is regulated to Io per cent.

${ }_{1}^{1}$ British Medical Fournal, December 9, 1899. 
bleaching powder ( $\mathrm{I}: 300$ available chlorine) was used by Sims Woodhead for sterilizing the Maidstone water-supply during the I897 typhoid epidemic. Schumacher, working at the Hamburg Hygienic Institute, has also recently conducted a long series of experiments which demonstrate the disinfectant value of chloride of lime and its applicability for sewage treatment. ${ }^{1}$

Although powerful disinfectants, chlorine and the hypochlorites have several disadvantages:

I. Their own odour, and the persistent odours they create and leave behind, lead often to their use irregularly, or in ineffective quantities.

2. The action on metals, wood, leather, and caoutchouc. Lead even is corroded, so that in water-closets with leaden siphons the pipe would be eaten through rapidly. Free chlorine, or acidified chlorine mixtures, exert rapid action on iron, cutting the fittings generally just at the level of the liquid, and even, owing to evolved gas or spray, corroding the metal some distance above. The hypochlorites, being alkaline, are much less destructive, as shown by the fact that iron tanks are largely used to store strong "bleach liquor" in factories.

3. Their immediate destruction by amido-compounds like urea or by ammonium salts, with loss of nitrogen, so that the chlorine may be entirely used up in dealing with inodorous and inoffensive matters, unless a large excess be employed. One reaction between chlorine and ammonia has already been given (p. I8o). The complete decomposition would be-

$$
2 \mathrm{NH}_{3}+{ }_{3} \mathrm{Cl}_{2}=\mathrm{N}_{2}+6 \mathrm{HCl} \text {. }
$$

With hypochlorous acid:

$$
2 \mathrm{NH}_{3}+3 \mathrm{HClO}=\mathrm{N}_{2}+3 \mathrm{HCl}+{ }_{3} \mathrm{H}_{2} \mathrm{O} .
$$

Urea and hypochlorous acid :

$$
\mathrm{CO}\left(\mathrm{NH}_{2}\right)_{2}+{ }_{3} \mathrm{HClO}=\mathrm{N}_{2}+3 \mathrm{HCl}+\mathrm{CO}_{2}+2 \mathrm{H}_{2} \mathrm{O} \text {. }
$$

Urea and a solution of bleaching powder react thus :

$$
{ }_{3} \mathrm{Ca}(\mathrm{ClO})_{2}+2 \mathrm{CO}\left(\mathrm{NH}_{2}\right)_{2}=2 \mathrm{~N}_{2}+2 \mathrm{CO}_{2}+{ }_{3} \mathrm{CaCl}_{2}+4 \mathrm{H}_{2} \mathrm{O} \text {. }
$$

Soap and domestic slop waters rapidly exhaust chlorine liquors, while paper, fibre, etc., absorb chlorine readily. Although deodorization, and still more sterilization, can only occur when the agent is in excess, an effluent containing free chlorine or its oxides would not be allowed to be discharged

\footnotetext{
1 Public Health Engincer, March and April, I906.
} 
into main rivers. Care and certain precautions have, therefore, to be adopted. The presence of excess of chlorine, or its oxides, is tested for by adding a solution of iodide of potassium and starch, which is turned blue.

The soluble hypochlorites are alkaline; when acidified they give off chlorine or hypochlorous acid in vapour, so that the walls of sewers and culverts can be thoroughly disinfected in special cases, as in the drains from hospitals. On the other hand, the action of unacidified hypochlorites is very slow, especially on organic colouring matters as derived from trade effluents. In the Manchester report of 1898 a portion of the Swinton sewage is thus described:

"Raw Serwage.-Pink colour; slight purple suspended matter; smells of bleach liquor; neutral to litmus."

"Tank Effluent.-Slight pink colour; brown precipitate of ferric hydroxide"; lime and copperas had been added (see p. I59); "smells of bleach ; neutral."

There was an excess of chlorine compounds, since "on the addition of acid, chlorine was liberated equivalent to 0.08 grain per gallon of oxygen" (0.II4 part per 100,000). The incubator tests given show a slight, but distinct, effect of the chlorine in the bleach, indicated by the "three minutes oxygen absorption ":

\begin{tabular}{|c|c|c|c|}
\hline Grains per Gallon. & $\begin{array}{c}\text { Before } \\
\text { Incubation. }\end{array}$ & $\underset{\text { Incubation. }}{\text { After }}$ & Putrescibility. \\
\hline 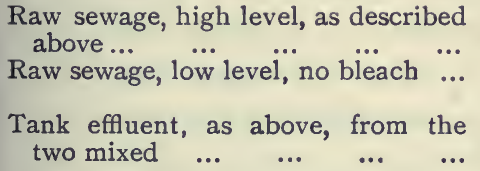 & $\begin{array}{l}\text { I.90 } \\
0.68\end{array}$ & $\begin{array}{l}2.15 \\
\mathrm{I} \cdot 86\end{array}$ & $\begin{array}{l}\text { Slight after } 5 \text { days. } \\
\text { Quite putrid after } \\
4 \text { days. } \\
\text { Putrid after } 4 \text { days. }\end{array}$ \\
\hline
\end{tabular}

Sterilization of septic tank effluents has been successfully effected by chlorinated lime in some experiments carried out by the Indian Government on the Hooghly River. This investigation showed that 5 grains per gallon of bleaching powder, equal to less than 2 grains of available chlorine, rendered the fluid virtually sterile, and that a tank effluent from 2,000 people could be rendered inodorous and sterile at from Rs. Io to I4 per month. The time of contact to complete the action was found to be about one hour, as little or no improvement was noticed when plates were taken after a longer period. At the Tittagurh installation, near Calcutta, this treatment was applied to latrines, 
and was proved to be cheaper than sand filtration ( 3 feet thick and at the rate of $\frac{1}{2}$ gallon per square foot), combined with the application of copper sulphate, which was suggested as an alternative method for dealing with the problem.

\section{Electrolytic Processes.}

About I 859 Charles Watt first introduced electrolysed solutions of the chlorides of alkalies or alkaline earths as bleaching liquids. They contained chlorides and hypochlorites, but apparently were more active than a solution prepared by passing chlorine into an alkali. Magnesium chloride was said to be preferable.

The Webster process allowed ordinary sewage to flow through channels between iron electrodes, so that the chlorides were electrolysed, the chlorine and oxygen liberated at the positive pole deodorizing the sewage, while the iron salts formed assisted in the purification. Later aluminium plates were substituted for iron, and the aluminium hydrate generated acted as the precipitant. A fault in practice was that a great part of the sewage passed between the plates nearly or quite unaltered.

Hermite electrolysed sea water, and either added it to sewage or used the liquid for flushing latrines and sewers. Piton's report on the trials at Nice illustrates a point now well established, that an attempt to disinfect hinders or prevents the natural bacteria from breaking down organic débris, in his remark that "the Hermite solution, diluted to a strength of about 0.25 gramme of chlorine per litre, does sterilize the fæcal matter in the sewers, but that, in spite of the rapid absorption of chlorine, the disintegration of paper and fæcal matter is no more rapid than when ordinary water is employed." The system was tried at Worthing in 1894, and later at Ipswich, and was fully examined by many authorities. ${ }^{1}$

The Lancet Commission (I894) found that in Hermite's electrolysis of sea water the sodium chloride was not decomposed, only acting as a conductor; but that the magnesium chloride was converted into hypochlorite, which then deposited magnesic hydrate, and left free hypochlorous acid in solution-

$$
\mathrm{Mg}(\mathrm{ClO})_{2}+2 \mathrm{H}_{2} \mathrm{O}=\mathrm{Mg}(\mathrm{OH})_{2}+2 \mathrm{HClO} \text {. }
$$

The Hermite fluid agreed in properties with a solution of hypochlorous acid, made by passing carbonic acid through a bleach-

1 For further details of chlorine disinfection, see Rideal's "Disinfection and Disinfectants," I903, pp. 77-98. 
ing powder solution of the same strength in available chlorine, except that in the bacterial tests the two, for some unexplained reason, were not found to act exactly alike.

The standard strength of Hermite solution was 0.5 gramme of available chlorine per litre. When dilute it rapidly deteriorated, but this defect has now been overcome.

More recently Dr. Alexander, at Poplar, has installed a plant at the municipal electricity works, and now uses the Hermite fluid for all disinfectant purposes in the district, including street watering.

About I 895 Woolf introduced in America, for water purification, a liquid similar to "Hermite," called "Electrozone," obtained by electrolysing brine containing 2 or 3 per cent. $\mathrm{NaCl}$, or sea water. In I897 a plant was erected for supplying the liquid to the sewage of Maidenhead, England (after previous precipitation with "ferrozone" and filtration through "polarite"), I part being added to from 400 to 600 of effluent. In an examination of the process in 1898 , with Professors Robinson and Kanthack, I found that the solution had the properties of sodium hypochlorite, with chloride, the available chlorine being 0.355 per cent., or practically decinormal; and that although the treated sewage gave at the outfall a blue reaction with potassium iodide and starch, showing excess of the reagent, the amount of organic matter was hardly reduced. On the other hand, the bacterial examinations proved that the germicidal action was very marked, so that "an effluent nearly colourless, free from odour, and containing very few bacteria," was left. The electrozone process has been discontinued at Maidenhead, but it was subsequently employed (July, I899) at Havana, Cuba, for streets, sewage, and harbour, reports stating that it kept the city practically free from yellow fever, and that the cost of generating was 50 cents per I,000 gallons. ${ }^{1}$

Lately I have had a further opportunity of investigating the application of oxy-compounds of chlorine to sewage treatment at the Guildford Sewage Works. ${ }^{2}$ The electrolytic chlorine used in these tests were generated from brine in a special form of electrolyser owned by the "Oxychloride" Company, which claims certain economic advantages over the earlier types of apparatus.

2 Fournal of the Royal Sanitary Institute, vol. xxvi., No. 7, 1905. 
Raw sewages from this and other places, and effluents from septic tanks, primary, secondary, and tertiary filters, were treated with the solution under varying conditions to ascertain its efficiency as regards (I) putrefactive organisms, and (2) sewage organisms comparable in origin and vitality with those which cause typhoid fever and cholera. The tests were also directed to secure such freedom of the effluent from suspended solid material as would prevent the formation of mud banks, and from organic matter in solution, as to render it impossible for it to become putrid when subsequently mixed with water.

My experiments indicated that the germicidal value of the electrolytic solution, containing chlorine oxides and other compounds, was greater than that of the equivalent of free chlorine liberated chemically. I have, however, always stated the strength of the addition in parts of available chlorine ( $a v . C l$, as ordinarily measured by arsenious acid), added to I0o,000 parts of sewage or effluent. The actual volume used would depend upon its strength: at Guildford the machine gave a solution containing $0^{\circ} 2$ to $0^{\circ} 5$ per cent. of available chlorine. By daily bacterial and chemical analyses I was enabled to establish at Guildford, in reference to the amount of reagent required, an easy practical guide that may be applied to other places. There was a very nearly constant relation between the five minutes' oxygenconsumed figure, representing the amount of the agent that would be at once taken up by the organic matter, and the quantity of the oxychloride that was needed, so that there should be an excess capable of killing the bacteria. The five minutes' oxygen multiplied by $\mathrm{I}^{\prime} 7$ gave the amount of available chlorine required in parts per 100,000, and the strength of the solution being determined, the proportion to be added is easily calculated.

Raw Sewages.-The following is a type of the results :

The untreated sewage had a very foul odour : it gave, in parts per $100,000, \mathrm{Cl}$ in chlorides 18.6 , oxygen consumed in five minutes $4^{\circ} \mathrm{I} 4$, in two and a half hours 18.8 , free and saline ammonia $7^{*} 2$, albuminoid $2{ }^{*} 4, B$. coli $\mathrm{I}, 000,000$ per c.c. The addition of 3 parts of available chlorine per I00,000 reduced the coli to less than I per c.c., and spores of $B$. enteritidis sporogenes to less than Io per c.c., after four and a quarter hours' contact. With 5 to 7 parts of av. $\mathrm{Cl}$, negative results were obtained for both these organisms with 5 c.c. after four and a quarter hours' contact. The total number of organisms 
was reduced by 3 parts of av. $\mathrm{Cl}$ from several millions to 50,000, by 5 parts to 20 , and by 7 parts to Io, per c.c.

Incubation tests by dilution with 9 volumes of river water and keeping at $20^{\circ} \mathrm{C} .: 3$ parts av. $\mathrm{Cl}$, very slightly foul after three days; 5 and 7 parts av. $\mathrm{Cl}$, inoffensive after four days' incubation.

In another case 3.7 parts per 100,000 of av. $\mathrm{Cl}$ added to raw sewage reduced the coli from over I,000,000 per c.c., so that none were found in I c.c.; the enteritidis spores from over I,000 to less than Io; and the total organisms from $23,200,000$ to $54^{\circ}$ per c.c.

Experience showed that considerably smaller quantities of the solution could be used with sewages of average strength, and within limits a longer period of treatment allows of reduction in the amount of available chlorine. Taking the raw sewage as it entered the works, it was found practicable to treat it direct with an electrolysed salt solution in place of chemical precipitants in settling tanks. Much less sludge was produced than by ordinary chemical treatment, and neither sludge nor effluent readily decomposed. The expense of chemicals, power for the mixers, and labour in slaking lime and in other operations, must thus be balanced against the cost of the sterilizing solution. The effluent from the latter was fit for discharging direct on to land, and the final effluent from the underdrains was suitable for passing into any body of water. The sludge when spread upon land remained sweet as compared with that from ordinary chemical treatment.

It was further found that nearly a constant proportion, about 60 per cent., of the available chlorine was taken up almost immediately, while about 40 per cent. remained and declined more gradually, pointing distinctly to the chlorine existing in the reagent in two forms-one which acts at once on readily putrescible matter, the other remaining to attack bacteria and resistant organic substances.

Septic Tank Effluents.-It was found better in most cases to deal with the sewage after it had undergone a preliminary septic treatment, since thereby it was carried a stage further in its resolution. But the most important reason was that vegetable masses (and, still more, solid excreta) are, as is well known, very difficult to sterilize by any means, because there is little penetration; and the difficulty is encountered in the disinfection of the stools of fever patients. A fault of the Hermite process as 
tried at Worthing was that it failed to sterilize the interior of solid fæces, and the trials at Nice showed, as I have already mentioned, that an attempt to disinfect hinders or prevents the natural bacteria from breaking down organic débris, therefore the disinfectant should be applied after the breaking down. In the septic tank the suspended substances are reduced to a much finer state of division, and the bacteria are thus more readily attacked. I found, somewhat unexpectedly, that ammonia did not react with oxychloride in the dilutions employed in treatment, so that the solution was not destroyed or wasted by the ammonia produced in the tank. Urea also did not interfere with the first action of oxychloride, but tends to remove any trace of the reagent remaining after the process.

The simple treatment of raw sewage by means of a septic tank and then addition of the solution would be sufficient for a large number of cases where the organic purity was of less importance than the removal of pathogenic organisms, as in localities close to shellfish gathering-grounds or watercress beds. For both of these, and particularly for vegetables, complete organic purification might be a disadvantage, as depriving them of food. In places where open septic tanks had been objected to on account of suggested nuisance, closed tanks could be adopted of a rather smaller size than usual, the solution being added in a covered carrier with baffle plates as the effluent passed out, with a certainty of removing all objectionable odours. If existing tanks are divided by a party wall into two unequal chambers; in the first of say twenty hours' dryweather capacity, the anaerobic preparation could go on as at present; while in the second, of say four hours' capacity, the chlorine solution would be added in sufficient quantity to cause the remaining suspended solids to subside in a more or less sterilized condition, and the effluent to be free from smell and objectionable organisms. The cost and space required for primary, secondary, and tertiary beds would in this way be saved. I believe that the method, in the case of seaside towns and those discharging into estuaries, would greatly contribute to local healthy conditions, and would insure the absence of unsightly sewage matter on the shores.

In the septic tank effluents at Guildford the total organisms were $2,500,000$ to $4,500,000$, the coli 100,000 to $1,000,000$, and the spores of $B$. enteritidis sporogenes Io to I,000, per c.c. After the addition of available chlorine (regulated by the five minutes' 
oxygen consumed) from 2.5 to 4.4 parts per 100,000, and a contact of from one to four hours (Experiments I2 to 59), the coli and the enteritidis spores were absent from I c.c., and in most cases from 5 c.c. The total organisms were very greatly reduced : they were not regularly counted, as of less importance, but on four occasions they have been lowered from the many millions originally present to 20 , IIO, I4O, and 600 per c.c. Even the last number is below that usual in rivers.

The anaerobic organisms were found to have been reduced from an average of $2,500,000$ per c.c. in the untreated septic effluent; to 200 after one and a half hours' contact with the chlorine solution, and I50 per c.c. after three hours.

Incubation tests, by mixing with 3 parts of the river water, showed that the untreated effluents had a smell at first, which progressively increased, while the dissolved oxygen rapidly disappeared; but the mixture with treated effluent kept sweet, and the dissolved oxygen did not sensibly decrease in twentyfour hours, and did not fall below 3 c.c. per litre in the closed vessel for three or four days.

A feature common to all oxidation treatments, the rapid disappearance of the reagent at the first onset, suggested that there might be an advantage in adding the solution in successive portions. This modification takes a longer time, and is apt to leave a residue of available chlorine, requiring a storage of 8 to 18 hours for its disappearance. Where such storage is possible it tends to a complete sterilization of the liquid.

By estimating the dissolved oxygen in mixtures of 3 parts river water to I of septic effluent, I proved that with untreated effluents after I9 hours the oxygen had entirely disappeared; while with the treated, after an initial fall, it rose, so that after 3 days it was higher than at first, and almost equal to the river water. It remained throughout well above the quantity essential to fish life. This proportion of effluent is larger than in practice would be discharged into river waters. The result may be due to the destruction of the putrefactive bacteria by this treatment, leaving the oxidizing organisms predominant, so that the river does not foul. Two or three days, the time of the incubation tests, brings the whole liquid down to the sea.

Primary, Secondary, and Tertiary Contact-Beds.-In a large number of experiments I found that, as in the different stages 
the organic matter decreased, the amount of available chlorine consumed was correspondingly lessened, and the proportion of I to I'7 between five minutes' oxygen and available chlorine still remained a guide.

The primary effluent at Guildford required 2 parts of av. $\mathrm{Cl}$ per I00,000 to reduce the coli from I00,000 per c.c. to less than I per 5 c.c. after 40 minutes' contact, and the $B$. enteritidis spores from 20 per c.c. to nil in 5 c.c. after 2 hours' contact. After being kept for 4 days, the untreated had a strong sewage odour, the treated remained odourless.

In the secondary effluent, with $\mathrm{I}^{\circ} \mathrm{o6}$ parts av. $\mathrm{Cl}$, coli was reduced from $\mathrm{I}, 000,000$ per c.c. to none per 5 c.c.; $B$.enteritidis spores from roo to $\mathrm{I}, 000$ per c.c. to none in 5 c.c.; and the total organisms from $1,000,000$ to 40 per c.c. Incubation 48 hours : untreated, sewage smell; treated, inodorous.

In the tertiary effluent the small amount of 0.25 part of av. $\mathrm{Cl}$ reduced the coli from over Io,0oo per c.c. to mil in 5 c.c. in I hour, and the B. enteritidis spores to less than I per c.c. in $4 \frac{1}{2}$ hours. $0^{\circ} 5$ part av. $\mathrm{Cl}$ reduced the coli from over Io, 000 per c.c. to less than I per 5 c.c. in 30 minutes, and the $B$. enteritidis spores to less than I per 5 c.c. in four and a half hours. The incubation tests gave after 4 days a distinct odour in the untreated, none in the treated. Decided chemical improvement was shown, and the treatment caused an increase of free, with a decrease in albuminoid, ammonia, showing a breaking down of the organic matter.

The effect of treating infected drinking-water was tried. A tap water contained 90 organisms per c.c., and coli was present in 4 c.c. After treatment with 0.075 part of available chlorine (Exp. 54), the total organisms were reduced in 5 hours to I4 per c.c., and coli was then absent from 20 c.c. Another portion was mixed with $\frac{1}{500}$ of its volume of tertiary effluent, and 0.08 part of available chlorine added (Exp. 58). The infected tap water had contained roo coli per c.c., but after one hour's action of the oxychloride there were none present in 20 c.c., and this condition remained through a channel more than roo feet long. The water after standing did not retain any taste or smell of the treatment, and the chloride as measured by chlorine was only increased by $I \cdot 75$ to 2 parts per I00,000, which is obviously of no significance. The tap water at this time contained more total organisms and more coli than remained in the sewage after the chlorine treatment, 
so that the extraordinary result was realized of obtaining at the sewage works an effluent which had a greater bacterial purity than the town water-supply.

The general conclusion was that, with a good effluent, sterility can be insured by the addition of about 5 parts per 100,000 of available chlorine. If removal of coli and enteritidis only is aimed at, one-tenth of this amount $\left(=0^{\circ} 5\right.$ part), or sometimes even less, is sufficient, as would be the case in a discharge near shell-fish gathering-grounds, into watercress beds, or into rivers that are used as a source of supply by water companies.

Absolute Sterility.-Even the tertiary effluent contained some thousands of spores per c.c., of which forty to fifty are capable of resisting the temperature of boiling water for several minutes; therefore I soon found that absolute sterility was not practical, not merely on account of the cost of the large quantity of disinfectant required, but also because the residual disinfectant would be inadmissible in an effluent. For this reason it became necessary to discover what the highlyresistant organisms were, and particularly whether they could be injurious. I found that they were constant in character throughout the sewages and effluents, and consisted of a group of bacteria of the hay-bacillus type, non-pathogenic, not producing smell, and of great assistance towards the resolution of organic matter. Absolute sterility, therefore, is not required, and, if attained, would not be maintained.

When chlorine or its oxy-compounds are used as sterilizers, the cost of their production becomes important. It is obvious that the economy of a process will be determined by the quantity of "available chlorine" produced in a continuous process for a given expenditure of electrical energy, or, in other words, the cost of electrolytic chlorine per kilo, in comparison with chloride of lime, hypochlorous acid, and free chlorine obtained chemically. ${ }^{1}$

In the Digby process, which I have recently had occasion to critically examine, the costs are reduced to a minimum by insuring a greater percentage of free chlorine being produced from a given quantity of salt. This is attained by enclosing the electrodes in asbestos diaphragms, which prevent the salt solution from passing with the liberated ions from the cell. In

1 As to cost of chlorine electrolytic plant, see Häussermann, Dingler's Polyt. Fourn., I895, 296, p. I89; Schoop, Zeits. f. Electrochemie, 1895, ii. [10], 209 ; Electrical Review, I898, April 29. 
this way the amount of salt required to yield a given amount of available chlorine is considerably reduced.

The higher oxides of chlorine have been employed for disinfection and destruction of organic matter, but expense has militated against their use on a large scale for sewage. The Bergé process prepares peroxide of chlorine thus:

$$
3 \mathrm{KClO}_{3}+2 \mathrm{H}_{2} \mathrm{SO}_{4}=\mathrm{KClO}_{4}+2 \mathrm{KHSO}_{4}+\mathrm{Cl}_{2} \mathrm{O}_{4} \text {. }
$$

The gas is passed into water, and this solution allowed to mix with the polluted effluent. Organic matter is quickly oxidized by the gas, so that the liquid shows after treatment less organic matter and an increase in the chlorides formed by the reaction of the oxide on the carbonates in solution. The quantity required to produce sterility in drinking-waters or effluents practically free from organic matter, by contact for at least fifteen minutes, is given at I gramme of potassium chlorate per cubic metre of water. B. coli and typhosus in Seine water were killed in three hours' contact by $0^{*} 24$ part of $\mathrm{Cl}_{2} \mathrm{O}_{4}$ per I00,000, and even when the amount does not exceed 0.08 (or say I part per million) considerable reduction in the number of bacteria is assured. The solution used contains $0^{\circ}$ or 3 per cent. of peroxide, and is added to the effluent or water to be purified in the proportion of about I per cent.

In Germany Wiederhold used chlorate and hydrochloric acid during the cholera epidemic. The expense, offensive odours, and danger of explosion, caused their discontinuance.

Sterilization by Acids. - The large majority of bacteria, especially the pathogenic forms, have a preference for neutral or slightly alkaline solutions, and it has long been known that in culture liquids they refuse to grow, and die, even with small amounts of acid. Koch first noticed the fact with regard to the cholera organism, Kitasato showed that it was killed by dilute sulphuric or hydrochloric acid in a few hours, and A. Stutzer found that $0^{\circ} 05$ per cent. of sulphuric acid was fatal in fifteen minutes, $0^{\circ} \mathrm{O} 2$ per cent. in twenty-four hours. Ivanoff, with $0^{\circ} 04$ to 0.08 per cent. sulphuric acid, destroyed cholera organisms in Berlin and Potsdam sewage. In the Liernur process, and in that of Beck and Henkel's of Igor, sewage is sterilized by sulphuric acid. The successful use of acids in disinfection is very old, and was limited by inconveniences, which, however, would not affect their employment for liquids in the very dilute state shown above to be effective. Stronger 
solutions of mineral acids have long been used in medicine, and have probably owed a great part of their efficiency to their action against bacteria. Organic acids also possess this property, as in the example of the ancient employment of vinegar, and there is a great probability that the almost universal practice of using vinegar or lemon juice with salads, shellfish, or other foods, has been a piece of natural selection founded on experience of the danger of intestinal or parasitic diseases originating from such sources. I may quote an experiment of my own. I added $B$. coli to a good table vinegar $\left(5^{\circ} 3\right.$ per cent. acetic strength), and to the same diluted to twice and to ten and fifty times its volume with distilled water. In the weaker two liquids the bacillus was alive after forty minutes, in the half strength it was killed in fifteen minutes, and in the undiluted vinegar in five minutes.

Vegetable acids are, of course, too expensive for treating effluents, but cheap mineral acids, like sulphuric, are practicable and efficient in cases of serious infection. I have found ${ }^{1}$ that 0.072 per cent. of sulphuric acid is effective against typhoid organisms in fifteen minutes; Kitasato practically agrees, as he finds 0.08 fatal. In sterilizing with acids an additional quantity must be added to balance the alkalinity of the liquid: in sewage this ranges usually between 0.2 and 60 parts per I00,000, and 4 grammes of sulphuric acid per gallon is sufficient for causing the death of the typhoid bacillus in the usual drainage from an isolation hospital or other infected area. The free acidity is soon neutralized when such liquid becomes mixed with ordinary sewage. $B$. enteritidis is killed by the reagent, and $S p$. cholere succumbs with great rapidity. It also kills intestinal worms and their ova. ${ }^{2}$ These observations suggest that it should be added to the water in which vegetables are washed, especially those which are to be eaten as salads; in tropical countries these are habitually fertilized with fresh manure, which may be often infected. For many purposes, instead of the corrosive sulphuric acid, I have succeeded in using bisulphate of soda, which is portable and not dangerous, ${ }^{3}$ and is added in the proportion of 15 grains per pint, equal to 0.17 per cent.

I do not know that disease has been conclusively traced to vegetables which have been grown in connection with sewage

1 Parkes and Rideal, Epidemiological Society, I90I ; Lancet, January 26, I90I.

2 Galli Valerio, Bull. Soc. Vaudoise des Sciences Naturelles, I902, No. I43.

3 Parkes and Rideal, loc. cit. 
or effluents ; in fact, English experience with the land plants grown on sewage farms has pronounced them to be safe. Wurt $z$ and Bourges ${ }^{1}$ grew cress, radishes, and lettuce in earth watered with various pathogenic cultures, and found the bacilli on the stalks of the plant at a height of even a foot above the ground. Potatoes infected with anthrax and planted were allowed to grow: the bacillus was recovered from the stalks as long as IoI days afterwards. It is noted that out-of-door conditions, such as the cleansing effect of rain, and the bactericidal action of sunlight, are different from those in the laboratory. But in heavy storms mud may be splashed to a great distance, and so contaminate the leaves or fruit. A French Commission was appointed in I902 on the subject of possible dangers from raw vegetables and fruit grown on sewage farms, and recommended to the Comité d'Hygiène Publique that vegetables and fruit intended to be consumed in the raw state should not be allowed upon land fed with sewage.

Many attempts have been made to use ozone, either in admixture with air, to be passed through or over the sewage, or to be generated electrolytically in the sewage itself. Hagen (I88I) ozonized air by the silent discharge, passed it through sewage, then ozonized it again, absorbing the carbonic acid by lime, so making the process continuous. Marmier and $\mathrm{Abraham}^{2}$ have used ozone for sterilizing the water-supply at Lille, and state that it removes nitrates and organic matter, and all germs except $B$. subtilis. The cost of the plant is given at $£ 500$ for sterilizing 5,000 cubic metres per day.

\section{Thermal Methods.}

To raise the entire volume of sewage to a heat sufficient to sterilize it would be obviously impossible in practice; in addition, besides the odours evolved, it would leave a liquid which, on fresh inoculation with microbes from air, water, or earth, would become as foul as before.

The Liernur process is a combination of conservancy, pneumatic removal, and disinfection. At Amsterdam in $187 \mathrm{I}$ a trial was made on a small quarter of 15,000 inhabitants for the conveying of the fæcal matter and closet water, excluding the household slops. The system was applied at Leyden, Riga, and other places, and afterwards carried out more completely

1 Archives de Médecine Expérimentale, July, Igor.

2 Comptes Rendus, I899, cxxviii., I034; Revule d'Hygic̀ne, I899, 32 I, 540. 
at Trouville, in France, where about half of the 1,800 houses were connected up and worked at the company's expense at an average annual charge of $I 6 \mathrm{~s}$. per house. The method is based on the separation of "excrementitious" and "non-excrementitious" matters. The latter, including rain, storm, and surface water and industrial effluents, are conveyed by separate conduits, "utilizing as much as possible the existing sewers of towns." It is said that these liquids " in consideration of their pathogenic inoffensiveness can be safely delivered into the nearest watercourse, after being clarified, if necessary." It must be remarked that, as we have shown in the first chapter, road and field drainage is by no means inoffensive, that industrial effluents are frequently putrescent, and that the droppings of animals are often highly pathogenic.

The "polluted liquids, including fæcal matter, sink slops, soapy and dirty water," pass through iron pipes into closed iron underground receptacles, thence by 4 -inch pipes to "district reservoirs," communicating by pipes of to to 30 inches internal diameter with the central pumping station. A slight vacuum is continually maintained, and at intervals the whole system is exhausted by sections into a main reservoir. In the original description the excreta, with as little admixture of water as possible, were heated with I to 2 per cent. sulphuric acid, like a Kjeldahl process on a large scale, until the whole was reduced to a brown syrup, containing nearly all the original nitrogen as ammonium sulphate. This was either distilled with lime and the ammonia utilized, or dried up with ashes and sold as manure, containing, however, usually an excess of acid. The cost in Holland was said to amount to 4s. Iod. per head per annum. In this system-(I) Sewers can be laid at a uniform depth, just sufficient to protect them from frost, and at 2 or 3 feet in such countries as India. (2) No flushing is required, which is important in places where water is scarce. (3) No gratings or ventilating columns are needed, as the air pumps remove all gases, and the ordinary manholes are also not required. (4) As the system depends on working of a vacuum, any leak will be at once detected, and percolation of the subsoil will be prevented. (5) There is no dependence on fall, therefore it can be used on land of any contour.

At Trouville ${ }^{1}$ the sewage was stored in a large covered brick tank for about a week (thereby undergoing septic change), then

1 Report of Surveyor to Tendring Rural District Council, Essex, July, r899. 
mixed with "the necessary quantity of sulphuric acid for the purpose of fixing the ammonia," heated in tubular boilers to $120^{\circ} \mathrm{C}$., evaporated till semi-solid, and reduced in a rotary chamber to a dry powder, which is said to be worth $£ 7$ to $£ 8$ per ton. J.A. Jones, sanitary engineer of Madras, has reported in favour of the use of the system in India. It has been in use at Stansted, Essex, since I902.

In large towns evaporation would be impossible; as an alternative, a bacterial treatment was proposed, with sterilization of the sludge by acid and heat and reduction to manure. The process used at Cassel, Germany, for treatment of sludge by sulphuric acid, combined with the extraction of grease, is described later, in Chapter XIV. See also English patent 2I, 856 of Igor.

\section{TOWN REFuse.}

The solid matters included under the general name of " dust," as removed by carts, have of late years been destroyed by heat in place of the former insanitary methods of shoots, sorting yards, and "made ground," especially since a chance has appeared of utilizing the energy derived from the burning. The methods of disposal have included:

I. Carting and Tipping on Waste Land.-Street dust is recommended as manure by Strabo, Pliny, and Columella, and was highly valued during the Middle Ages: its use is still continued in many places where there is plenty of land. ${ }^{1}$ By-laws in London and other localities enact that no land on which refuse has been deposited can be built on until it has remained untouched for at least seven years. Organic matter in such made ground disappears very slowly. At Leicester ${ }^{2}$ some heaps of refuse after one year retained 30 per cent. of organic matter, and after nine years 27 per cent. Hering records a case which indicated that garbage can remain in a decomposing condition for hundreds of years, as evidenced by some excavations in the city of Rome. ${ }^{3}$ We may conclude that "made ground" of this kind remains unhealthy until it has been purified by frequent ploughing and planting. An attempt has lately been made to

1 For analyses, and an advocacy of the practice, see Casali, Staz. Sper. Ital agrar., 1898 , xxxi., 377.

${ }_{2}$ Leicester Meeting of Cleansing Superintendents, 1899.

3 Transactions of the American Public Health Association, xx., I96; also see a paper by Dr. Savage on "The Self-purification of 'Made Soil," " giving chemical and bacteriological analyses; Fournal of the Royal Sanitary Institute, vol. xxiv., p. 442,1903 . 
lighten the clay land, and reclaim the bogs, of Essex by ploughing in street sweepings from the City of London.

2. Barging from Wharves and Carrying out to Sea.-Much nuisance is occasioned, both at the wharves and along the coast : solid refuse in this respect is much worse than strained sewage.

3. Sorting with a view to utilization-now less practised than formerly. When the system was usual in London, for street sweepings, of which some 2,000,000 tons are picked up annually, each public authority required a large space for sorting, sifting, and draining. Some thousands of tons were sent into the country as manure; but the nearest farms are a long way from London, and manuring is done during the season of the year when the amount of street sweepings is the lightest, therefore an allowance of about 2s. per ton had to be made to the farmer to pay the carriage. Even then all tins and glasses had to be sorted out and barged away at a cost of about 4s. per ton. London will produce on a wet day about a hundred times more sloppy street sweepings than on a dry one. Before this could be loaded into railway trucks it had to be drained for some long time upon the depots, then to be picked up and carted to the railway sidings at considerabie expense. There was, therefore, always a large stock of decomposing vegetable matter on hand, and in many depots a mass of slop on the one side, and perhaps forty women screening house refuse on the other.

It is said that the town refuse of Paris, which is systematically collected and carefully sorted by chiffoniers, is worth $£ 2,000$ per annum. Sardine and other tins are made into toys and parts of tinware, while bottles, rags, etc., are more carefully utilized than in English dustyards. ${ }^{1}$ At Chelsea, for some years, an attempt was made to work up the débris by machinesorting with graded sieves, using the fine ash for cement, or mixed with the stones, bricks, and clinker as concrete; the breeze and cinders, with the assistance of a little coal, were burnt as fuel for the boilers by which the machines were driven and the works electrically lighted, while a special feature was the manufacture on the spot of a coarse brown paper from the paper and wood fragments. The thermal value of the breeze

1 For details of a similar mode of collection at Leicester, and the prices realized, see Allen's paper, fournal of the Sanitary Institute, vol. xxv., April, I904. In New York and Boston dry refuse, other than ashes, is sorted as it passes over a moving platform, and only the worthless residue is burnt (Hering, Report of the American Public Health Association, vol. xxii., p. I05). 
and ashes sifted out was found to be one-seventh that of coal. The work, however, was discontinued, as the disinfection or sterilization of the various products added considerably to the expense.

The Bury (Lancashire) Corporation, following the example of a few other towns, recently arranged for the distribution to shops and offices in the town of large bags, into which is placed the waste paper of the establishment, the full bags being collected periodically, and exchanged for empty ones. During the four months in which this system has been in operation there has been collected paper which realized, when sold, about $£ 30 .{ }^{1}$

4. Reduction, so called, applies more particularly to certain portions of the refuse and to certain kinds, and effects utilization by extraction of grease by steam or naphtha, the residue being ground and dried for fertilizer stock. In the United States in I902, according to a report of the American Public Health Association, vol. xxix., "reduction " plant was in use in nineteen cities, and was worked by private companies under contract, the Arnold process being the most frequent. It was concluded in this report that (I) economically the two systems, reduction and cremation, are fairly well balanced, but the former gives rise to a nuisance, whereas the latter can be conducted without it; (2) experience shows that the English and German system of burning the ashes and garbage together in cellular incinerators, with sloping grate bars for-preliminary drying, and forced draught, is cheaper and more satisfactory than the American (single large chamber and horizontal grate); (3) the disposal of garbage in water or on waste land is strongly condemned.

5. Burning.-Although this is the most perfect means of sterilization, the difficulties have been :

(a) The large and varying proportion of water, which often renders the material incombustible without being dried; the nuisance occasioned during drying in air; and the cost of the fuel for drying artificially.

(b) The low combustibility of the material, even after desiccation, requiring assistance by coal, special furnaces, and much labour.

(c) The offensive nature of the gases evolved during the burning.

1 Public Health, September, I905. 
(d) The loss of manurial matter as nitrogen and carbonic acid.

(e) The low value of the products, ash and clinker, and the expense of their removal.

The accumulations could be greatly reduced, and their character made more tractable, if every householder would follow the advice repeatedly given to burn all his vegetable refuse in the kitchen fire, and throw little besides clean ashes in the dustbin, also by the regulations enforced on the Continent and in many places in England against littering the streets.

Town refuse may be roughly divided into that derived from streets, from houses, and from trades, the latter, according to the Public Health Act, having to be separately paid for. House refuse is known to be of most miscellaneous character, both in regard to organic and inorganic constituents. In London the "fairly combustible matter" in the refuse is said to be 64 per cent., in Edinburgh 26 per cent. The average total weight for London in 1895 was stated to be "about I ton per annum for every four inhabitants, or I,250,000 tons for the whole area." The old style of house dustbin was as insanitary as the collection by dustmen was formerly dirty and careless. Many types of portable covered metallic bins, with daily collection, are in use both in London and the provinces.

After the failure to profitably utilize the nitrogenous matters of refuse as manure, its carbonaceous constituents were still available by burning as sources of heat, after drying. Modern dust destructors, therefore, dating from 1876 , generally include some arrangement for steam raising and electric light, with a view to saving to some extent the cost of destruction. But the aspect with relation to health must always be the first consideration.

Modern dust destructors must fulfil the following conditions :

I. A temperature not lower than $\mathrm{I}, 300^{\circ} \mathrm{F}$.: in good forms $\mathrm{I}, 600^{\circ}$ to $\mathrm{I}, 800^{\circ}$ is reached, and with forced draught by a steam jet or fans up to $2,000^{\circ} \mathrm{F}$. can be in many cases attained by the burning of the refuse itself. The earlier forms were of low temperature type, reaching only $750^{\circ}$ to $\mathrm{I}, 000^{\circ} \mathrm{F}$. in the main flue or combustion chamber. This was not sufficient to deal with the effluvia, the destruction was often imperfect, and the resulting clinker, instead of being hard, was soft, friable, and sometimes even putrescible; indeed, it was not uncommon for 
this imperfectly-burned clinker to take fire again after being removed.

2. A supply of sufficient oxygen to maintain steady combustion without over-cooling the gases produced.

3. A suitable site. If this can be central to the district, it will greatly save cost of cartage, etc., and facilitate disposal. Refuse properly cremated, with a high chimney, creates no nuisance, even in populous neighbourhoods. The prevailing winds should be studied, with regard to the carriage of the gases.

4. Carriage to the works without offence. Improved covered carts are now constructed. The supply should be as regular as can be managed.

5. Where used for steam-raising, the boilers must be so placed as not to cool down too much the evolved gases.

Street sweepings, which furnish a large portion of the matter to be treated in a dust destructor, vary very much in composition.

The following analyses are recorded:

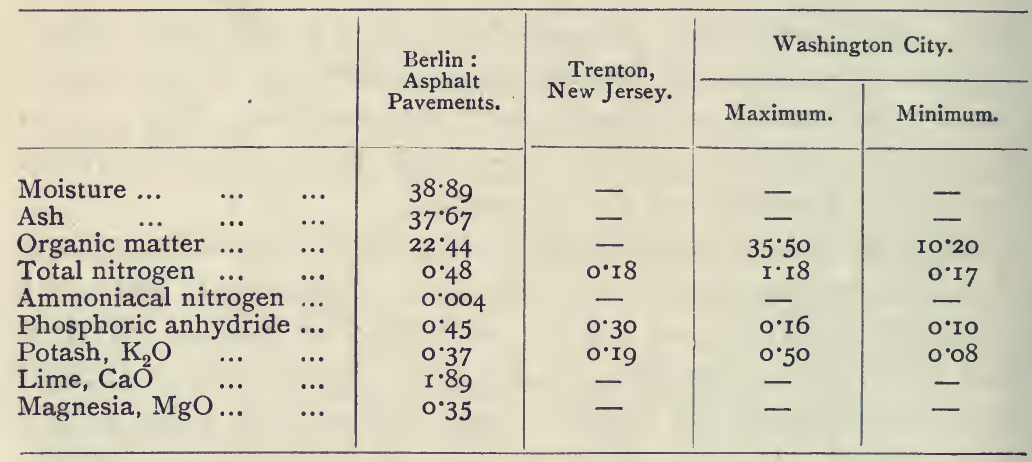

With regard to the fuel value of dry refuse, authorities agree that it is about one-seventh to one-ninth that of coal. The best conditions, both as to prevention of smoke and fume, and the concentration of heat for utilization, being a slow, steady combustion, quick-burning materials do not prove to have any advantage. It is in the drying stage that the main risk of nuisance occurs; in many old processes it has simply amounted to a distillation in which strongly odorous substances have escaped with the water vapour. Therefore the aim has been (I) to raise the drying gases to as high a temperature as possible; (2) to subject the evolved vapours to a secondary cremation by passing through ignited material. 
I must refer to special treatises for details of modern dust destructors. The different types have been adapted in different places to local requirements, and portable destructors are made for thinly-populated places, camps, etc. In Midland towns, where privy middens still exist, their contents have been successfully passed through the destructors along with the ordinary dust.

Wherever possible, the combination of a destructor plant for town refuse with the sewage disposal works has great advantages for the following reasons: (I) The power derived from the burning of the refuse, though not so great as has sometimes been hoped, is available for the pumps and machinery of the sewage works. In this way a scheme that would be preferred but for the cost of pumping is frequently rendered practicable. (2) Larger organic débris screened from the sewage can be burned in the destructor. (3) The clinker from a properlyworked destructor can be used in paving construction, and as a material for filter-beds. (4) A site chosen as suitable for sewage works will also be suitable for a destructor, and the management of the two require similar precautions as to public health. The apparent difficulty of carriage of the town refuse to the works has not been insuperable. As in towns the ratio of the volume of the sewage to that of the solid refuse is more or less constant, it follows that when the steam-raising efficiency of a given type of destructor is known, the height to which the town sewage can be lifted by power derived from the destructor is fixed. 


\section{CHAPTER IX}

\section{BACTERIAL PURIFICATION}

History of the idea and of early experiments-Mueller's process -Mouras' automatic scavenger-Massachusetts-LondonSutton-Oswestry-Leeds-Triple filtration or contact.

IT had been proved early in the nineteenth century that natural destruction of organic matter was due to living organisms, and that these were the actual cause of decay and putrefactive change $;^{1}$ but the powerful advocacy of Liebig and his school of the so-called "Catalytic" theory delayed the general acceptance of the "germ theory" for more than thirty years. "Catalysis" meant that some organic substances, in the act of undergoing decomposition, possessed the power of causing the alteration and decay of other organic substances in contact with them, and this mechanical, as distinct from a biological, explanation survived until Pasteur re-proved that fermentation and putrefaction did not take place in the absence of living organisms. He divided them into aerobic, or thriving in presence of oxygen, and anaerobic, or growing without it, and their life-history and character were elaborated by a number of observers. The purifying action of soil was still regarded as partly mechanical straining and partly chemical oxidation, and the necessity of the co-operation of life in the processes was hardly taken into account, more especially as in the important action of nitrification no causal organism had been then discovered. The Berlin Sewerage Commission, however, reported in 1872 that sewage matter was converted into nitrates, not by a simply molecular process, but by organisms present in natural sewage and soil, and many observers demonstrated in various ways how the purification of sewage was accomplished by bacterial action.

${ }^{1}$ On the history of the subject see J. T. Wood, fournal of the Society of Chemical Industry, February 15, I906, p. I09; Sims Woodhead, "Bacteria and their Products," p. 49. 
Among them Hatton investigated ${ }^{1}$ the conditions under which oxygen was absorbed and $\mathrm{CO}_{2}$ and $\mathrm{H}$ produced by bacteria; he also examined the effect of adding nitre to putrescent organic liquids, and concluded that "during the reduction of nitrates by sewage $\mathrm{CO}_{2}$ is generated in the liquid, and perhaps free $\mathrm{N}$ given off, while $\mathrm{O}$ is absorbed."

Sorby, in $\mathrm{x} 883$, remarked on the very large proportion of the detritus of fæces which was lost in the river Thames, owing to the action of larger organisms. Dupré, in a report to the Local Government Board in 1884 on his experiments on aeration, stated that "the consumption of oxygen from the dissolved air of a natural water is due to the presence of growing organisms, and that in the complete absence of such organisms little or no oxygen would be thus consumed." 2 Notwithstanding this knowledge, the Royal Commission of I882-I884, after deciding against the discharge of crude sewage into any portion of the Thames, prescribed "some process of deposition or precipitation, the solid matters to be applied to the raising of low-lying ground, or to be burnt, or dug into land, or carried away to sea." The latter course was chosen as the only one available for London. In 1896 Dupré proposed "to cultivate the low organisms on a larger scale, and to discharge them with the effluent into the river, as the power these lower organisms had was remarkable"; and at the Sanitary Congress, Bolton, in 1887 , he said, "Whatever scheme may be adopted, except destruction of the sewage material by fire, the agents to which the ultimate destruction of sewage is due are living organisms (not necessarily micro-organisms), either vegetable or animal. Our treatment should be such as to avoid the killing of these organisms, or even hampering them in their actions, but rather to do everything to favour them in their beneficial work."

Meanwhile, Emich in Germany was experimenting on the changes which occurred in water and sewage on exposure to and after agitation with air; also the behaviour of sterilized

1 Chemical Society's fournal, May, I88ז, "Action of Bacteria on Gases," and "Reduction of Nitrates by Sewage."

${ }^{2}$ The Second Report of the Royal Commission on Sewage, I902, p. 9, shows that when sewage is sterilized either by chemicals or heat its oxidation, either by filter or aeration, is almust prevented. The average percentage purification obtained in the experiments was-with sterile filters, 15 ; with normal filters, 42. The average nitrification was-nitrous nitrogen, sterile trace; normal, o*oI 7 ; nitric nitrogen, sterile, $0^{\circ} 027$; normal, $0^{\circ} 45^{2}$. 
water, and the influence of ozone and hydrogen peroxide. His investigations were published in $1885,{ }^{1}$ and show that

"When left standing, and after agitation with air, the self-purification only took place if the water had not been steriiized through boiling, and had not been protected against the entrance of germs during the period of observation. If, however, sterilized water was afterwards fully exposed to the air, or if it was afterwards infected with ordinary water, the same changes took place in it as in nonsterilized water exposed to air, viz., the quantity of potassium permanganate required for the oxidation of the organic matter, and the amount of ammonia, decreased with the formation of nitrous and nitric acid. A direct oxidation through the oxygen of the air did not take place, and even one brought about by ozone and hydrogen dioxide plays only an unimportant part compared with that played by the biological process."

All this had main reference to oxidation, which, as we have seen in earlier chapters, is only a later part of the cycle of changes in the course of purification. The first hydrolytic, or dissolving, stage had been conducted from very early times in a leaky and objectionable way in the old cesspools, which, however, when well managed and under favourable conditions, were quite capable of giving a good result. I have mentioned in Chapter I. an example in 1858 .

About 1865 Dr. Alexander Mueller had come to the following conclusions : ${ }^{2}$

"The contents of sewage are chiefly of organic origin, and in consequence of this, an active process of decomposition takes place in sewage, through which the organic matters are gradually dissolved into mineral matters, or, in short, are mineralized, and thus become fit to serve as food for plants. To the superficial observer this process appears to be a chemical self-reduction; in reality, however, it is chiefly a process of digestion, in which the various-mostly microscopically small-animal and vegetable organisms utilize the organically fixed power for their life purposes. ... The decomposition of sewage in its various stages is characterized by the appearance of enormous numbers of spirilla, then of vibrios (swarming spores), and, finally, of moulds. At this stage commences the reformation of organic substance, with the appearance of the chlorophyll-holding protococcus, etc."

Mueller recognised the importance of a preliminary change, and later patented a process (German patent 9,792 of I878) for utilizing the micro-organic life in sewage in its purification, which was actually in operation at one time to purify the

2 Landwirthschaftliche Versuch-stationen, xvi., 273. 
effluent of some works for the manufacture of sugar from beetroot. ${ }^{1}$

About the same time the "Mouras Automatic Scavenger" was inaugurated in France. According to the Cosmos les Mondes, December, I88I; January, I882; "this mysterious contrivance, which has been used for twenty years, consists of a closed vault with a water seal, which rapidly transforms all the excrementitious matter which it receives into a homogeneous fluid, only slightly turbid, and holding all the solid matters in suspension in the form of scarcely-visible filaments. The vault is self-emptying and continuous in its working, and the escaping liquid, while it contains all the organic and inorganic elements of the fæces, is almost devoid of smell, and can be received into watering-carts for horticultural purposes, or may pass away into the sewer for use in irrigation." As to the theory of the action, it is said, "May not the unseen agents be those vibrions or anaerobies which, according to Pasteur... only manifest their activity in vessels from which air is excluded ?"

Observations with a glass model showed that "fæcal matters introduced on August 29 were entirely dissolved on September I6, while even kitchen refuse, onion peelings, etc., which at first floated on the surface, descended after a time and awaited decomposition. Everything capable of being dissolved acted in a similar way, and even paper wholly disappeared."

"The principle on which M. Mouras bases the action of his machine is that the animal dejecta contain within themselves all the principles of fermentation or of dissolution necessary and sufficient to liquefy them, and to render them useful in their return to the soil, and without appreciable loss."

A later article of January, 1883 , by the Abbé Moigno gives formulæ for the dimensions of the tank, estimating, its superficial area as preferably $\frac{1}{10}$ metre, or about I square foot per person. (The Exeter tank, I may remark in passing, works out to about 0.6 square foot per person.) The article also specifies that "for the complete solution of the floating solid matter a period of thirty days should be allowed," and calculates that this gives-

$$
\frac{\mathrm{I}+2+3+\ldots \ldots+30}{30} \mathrm{M}
$$

1 Roechling, Fournal of the Society of Arts, January 7, 1898; Travis, Transactions of the Civil and Mechanical Engineers' Society, 1906, gives extracts from this specification. 
as the total average amount of suspended matter present in the tank at any instant when $M$ is the weight of suspended organic matter present in the volume of sewage dealt with per day. The size of the tank required is, therefore, not so large as to be impossible with ordinary sewages, but the fact that the effluent from such a tank was not sufficiently purified without further nitrification prevented the "Automatic Scavenger" from being more generally adopted.

About I $88 \mathrm{o}$ E. S. Philbrick, of Boston, Mass., constructed in a number of places in America sewage plants comprising "a tank or tight cesspool in which the solid particles of the sewage may become macerated and finely divided by fermentation before entering the distribution pipes." 1 It was noticed that the scum and deposit increased rapidly at first, and then practically remained constant. In one case after four years it was found that the surface accumulation was very small (about I foot), and the bottom deposit less, showing that septic action was going on, though it was then imperfectly known. These tanks had the submerged inlet and outlet; they were circular, but in other respects were very similar to the Exeter septic tank. Glover in 1882 took out patents in America for liquefying tanks followed by aerating filters. ${ }^{2}$

At the time of the Royal Commission of I882, owing to the failure of most sewage farms to yield satisfactory results, precipitation and attempted disinfection or sterilization, as described in the preceding chapters, were elaborately carried out. In January, I887, Mr. Dibdin observed at the Institution of Civil Engineers that.

"One object claimed for the use of an excessive quantity of lime, and also for some other substances, is that they destroy the living organized bodies, such as bacteria, etc., which give rise to the phenomena known as putrefaction. ... As the very essence of sewage purification is the ultimate destruction, or resolution into other combinations, of the undesirable matters, it is evident that an antiseptic process is the very reverse of the object to be aimed at. . . Very alkaline effluents, such as those produced by the use of lime in excessive quantities are very liable to putrefy instead of becoming purified by oxidizing organisms."

Meanwhile, bacteriology had been advanced by a large number of researches in various countries, at first directed

1 Engineering Record, New York, May Io, 1883, p. 530.

2 For further details see Metcalf's "Antecedents of the Septic Tank," Transactions of the American Society of Civil Engineers, xlvi., No. 909, I901. 
mainly to the special organisms of disease, but gradually developing a knowledge of the larger class that are not pathogenic, but effect ordinary changes in organic matter.

In November, I887, the Massachusetts State Board of Health commenced their experiments on the purification of water and sewage by chemical precipitation and by filter-beds, and in the two first volumes of their reports, extending to I89o, details are worked out of different filtering media, size of grains, thickness of strata, influence of time, temperature, and methods of procedure, the results of about 4,000 analyses of raw sewages and effluents being tabulated. At first they aimed at the removal or destruction " of bacteria by straining and chemical means, without practical success; later they studied intermittent filtration with the actual assistance of aerobic organisms. All that was found necessary to completely destroy dead organic matter was to provide conditions favourable to the action of bacteria, giving suitable material on which the organisms would be retained, surrounding them at certain intervals with air, and providing periods of rest. They selected as suitable, sand from 4 to 5 feet in depth, under-drained, allowing the sewage to flow on the sand only six hours out of each twentyfour.

On this principle at Worcester, Mass., sixteen filtration beds of about I acre each were constructed of coarse sand from which all pockets of clay and quick-sand had been removed. They are separated by dikes, tamped with clay, and drained by ro-inch pipes with open joints, 6 feet deep and 50 feet apart. The feed is by split pipes laid on the beds.

This intermittent sand filtration is capable of purifying per acre about 100,000 gallons of domestic sewage in each twentyfour hours, so far as to remove any danger of subsequent putrefaction; with 20,000 to 30,000 gallons per day, the product is chemically and bacterially exceptional. ${ }^{1}$

On this aerobic plan, if a filter-bed were overworked, it rapidly choked, and putrefaction occurred in the interior owing to a deficiency of aeration, so that it was necessary to have "very slow motion of very thin films of liquid over the surface of particles having spaces between them sufficient to allow air to be continually in contact," a condition, however, which did not prevent the sand filters from becoming over-burdened, and 1 "Purification of Sewage by Bacterial Methods," L. Kinnicut, September,
1900 (Fournal of the New England Water-works Association, xv., 2). 
also greatly limited the amount of sewage treated. Moreover, the "thin film" oxidation of Massachusetts requires large filtering areas with great labour to keep them in order-therefore is exceedingly costly when applied to sewage-it is also attended with certain dangers from "channelling" of the beds by careless or too rapid working, or by frost, whereby it arises that the effluent escapes almost unpurified. In the Massachusetts Report of $1890,{ }^{1}$ the process is compared to a combustion, and was found to be most rapid in the summer months. It must be remembered that sewage in America is usually weaker and of greater volume than it is in Europe, on account of the more abundant supply of water. ${ }^{2}$

In Ohio State there were in I903 eleven plants for intermittent sand filtration without any previous treatment. R. W. Platt reports in 1905 that the best of these, at Mansfield Reformatory, treated 70,000 gallons per diem (from only 700 persons) on seven beds of crushed sandstone, I'I acres total area. There was considerable trouble in winter, and the results were poor, owing to frost, even when the surface was ploughed with deep or with shallow furrows. Sand treatment alone is inadequate over most of this great region, and preliminary processes have had to be adopted. ${ }^{3}$ Barbour finds that in the Middle West U.S. sand filters usually cost from $£ 400$ to $£ 500$ per acre per foot in depth. Ten years' experience in Massachusetts ${ }^{4}$ proves that their cost averages 43 cents per capita per annum, divided about equally between capital charges at 5 per cent. and maintenance. Over the glacial drift area, where porous sand and gravel are available at low cost, intermittent sand filters are used with a measure of success, and when operating at low rates require little attention. The maximum rate in practical design is that possible at the time of lowest temperature. About double the area necessary for summer is required for maintenance of filters in New England after some years' use. It is suggested that mechanical filters could be used as "finishers."

The work of the Massachusetts State Board still left un-

1 Mills, pp. 578,586 .

2 The daily consumption of water per head in New York is 92 U.S. gallons; in New Jersey, 92 gallons ; in Philadelphia, I43 ; in Los Angeles, California, 200 ; in Alleghany, Pennsylvania, as much as 247 gallons. (Ten U.S. gallons $=7$ imperial.)-MAson. See also p. I6.

${ }^{3}$ See Ohio Sanitary Bulletin, ix., I77; Eighteenth Annual Report of the Ohio State Board of Health; Transactions of the American Society of Civil Engineers, liv., E, I905.

$\$$ Report of State Board for 1903 . 
settled-(I) how the sewage of cities could be purified by bacteria where large tracts of sandy soil did not occur; (2) how the large amount of suspended matter, like paper, wool waste, and the other various forms of cellulose not easily acted upon by bacteria, could be prevented from forming a layer over, and clogging up the sand; (3) whether sewage containing large amounts of manufacturing waste, especially free acid and iron salts, could be treated bacterially. The Massachusetts intermittent filtration could treat with permanent success not more than 100,000 gallons per day per acre, much too limited a volume for towns and cities which. would be obliged to construct beds with sand not in situ. This point was quickly perceived in England, where such sand is not of common occurrence, and the bacterial sewage work in England started with the problem: Can the amount of land required by the intermittent filtration method be so reduced that the construction of artificial bacteria beds will be a practical possibility ? ${ }^{1}$

The sewage of Lawrence City, in the Massachusetts investigation, had been run on the filters without any previous purification, or even settlement. On the other hand, the sewage of London had been previously treated with I grain per gallon of ferrous sulphate and 4 grains of lime, the precipitated sludge being then conveyed in boats to be discharged at the mouth of the Thames. It was hoped that the clarified liquid could be discharged into the river direct without creating nuisance. But it still contained about 7 grains per gallon of suspended solids, and was by no means free from odour. The Royal Commissioners of $\mathrm{I} 884$ had decided that the liquid could not be discharged at the outfalls as a permanent measure, and required further purification by application to land.

In 1866 an experiment with London sewage as applied to land had already been made at Barking. The Metropolis Sewage Company obtained a concession to treat the sewage of North London, amounting to about 2,000 tons in nine or ten hours, on 5 or 6 acres of grass land on a light gravelly soil. The experiment was not a success, either culturally or with regard to the cleansing of the effluent. But with the $200,000,000$ gallons daily of London sewage, it was recognised that the requisite area of suitable land is entirely unattainable.

${ }^{1}$ Fuller has calculated the average composition and volume per capita of the sewage of several English cities from published records, I898 to 1902.-Technology Quarterly, June, I903. Also see R. Commission on Sewage, vol. iii., I902. 
An extension of chemical treatment and precipitation having proved to be inadequate as well as costly, the Main Drainage Committee of the County Council in I89I authorized a series of experiments at Barking outfall, on the lines of the Massachusetts researches. From preliminary trials with small filters, coke breeze appeared the most suitable material, although burnt ballast nearly equalled it in purifying efficiency. Sand and gravel effected a greater clarification, but the removal of dissolved organic matter, as measured by the reduction in the oxygen consumed, given by Mr. Dibdin's report was considerably less than with the coarser materials, while there seemed a tendency for this effluent to become putrid, owing to deficient aeration from the closeness of texture, and the filter required frequent scraping and renewals. The average rate of working, including periods of rest, was $4 \mathrm{II}, 000$ gallons per acre, or 250 gallons per square yard in twenty-four hours. For eight hours a day the effluent ran continuously, the filters being kept full; the filter was then emptied, and allowed to rest for sixteen hours. Mr. Dibdin's figures were:

Clarification, as measured by the units of depth required to obscure a standard mark: Burnt ballast, I; coke breeze, I; pea ballast, $\mathbf{I} \frac{3}{4}$; sand, $2 \frac{1}{4}$.

Reduction of Organic Matter (oxygen-consumed): Burnt ballast, $43^{\circ} 3$ per cent.; sand $4^{\circ} 6$; pea ballast, $5^{\circ} 3$; coke breeze, $62^{\circ} 2$.

The report adds significantly, "The number of organisms in the tank effluent before filtration, and in the filtrates, was found to vary very considerably, those in the filtrate being generally present in larger numbers; but it soon became apparent ... that the presence of a large number of organisms was evidence of the activity of the process of splitting up the organic compounds in the sewage matters passing through the filters. Here it is clear that the main purification was bacterial, and only the beginning of a further resolving change to be carried on in the river. It would undoubtedly have been an advantage if the biological process so initiated could have been allowed to develop a further stage in the filter, but the prescribed object of the experiments was 'the attainment of the highest rate of speed consistent with such purification as would remove the obvious objectionable characters such as odour, colour, and liability to putrefaction." "

At this time, the importance of the surface contact action as 
distinguished from the bacterial changes in the chemical constitution was to some extent lost sight of, and it has required subsequent writers to accentuate the proposition that the catalytic theory of Liebig was true in the sense that the reduction of the organic matter from a sewage in a contact-bed was primarily due to absorption, and that this mechanical removal of organic matter was determined by the bacterial surfaces in the bed independent of their vital activity. ${ }^{1}$

In the further experiments with a I-acre coke-breeze filter at Barking it was found, as at Massachusetts, that continuous running resulted in clogging and a foul effluent, and that it was best to commence with small quantities of liquid, the filter ( 3 feet of coke breeze and 3 inches of gravel) being at first merely filled and emptied twice a day, with a view to producing an active bacterial bed. The following are averages computed from the daily analyses :

Average Analyses from i-Acre Filter (Dibdin).

Parts per 100,000.

\begin{tabular}{|c|c|c|c|c|c|c|c|c|}
\hline \multirow[t]{2}{*}{ Date. } & \multirow{2}{*}{$\begin{array}{c}\begin{array}{c}\text { Volume } \\
\text { per Acre } \\
\text { per Day. }\end{array} \\
\text { Gallons. }\end{array}$} & \multicolumn{2}{|c|}{$\begin{array}{c}\text { Oxygen } \\
\text { absorbed in } \\
\text { Four Hours. }\end{array}$} & \multicolumn{2}{|c|}{$\begin{array}{l}\text { Albuminoid } \\
\text { Ammonia. }\end{array}$} & \multicolumn{2}{|c|}{$\begin{array}{l}\text { Nitrogen as } \\
\text { Nitrates. }\end{array}$} & \multirow{2}{*}{$\begin{array}{l}\text { Per cent. } \\
\text { Purification } \\
\text { by Oxygen } \\
\text { absorbed. }\end{array}$} \\
\hline & & Effluent. & Filtrate. & Effluent. & Filtrate. & Effluent. & Filtrate. & \\
\hline $\left.\begin{array}{l}\text { April } 7 \text { to } \\
\text { June } 9, \text { I } 894\end{array}\right\}$ & 500,000 & $5 \cdot 85$ & $I \cdot 23$ & 0.593 & 0.138 & 0.182 & 0.340 & $79 \cdot 3$ \\
\hline $\left.\begin{array}{l}\text { August } 3 \text { to } \\
\text { Nov. } 9,1894\end{array}\right\}$ & 600,000 & $5 \cdot 18$ & $\mathrm{I} \cdot 42$ & 0.565 & 0.158 & 0.032 & 0.200 & $79^{\circ} 6$ \\
\hline $\left.\begin{array}{l}\text { Nov., I894, to } \\
\text { March, I } 895\end{array}\right\}$ & $1,000,000$ & $5 \cdot 87$ & $r \cdot 33$ & 0.545 & 0.160 & 0.565 & $I \cdot 00$ & $77 \cdot 5$ \\
\hline $\left.\begin{array}{l}\text { April } 8 \text { to } \\
\text { April } 20,1895\end{array}\right\}$ & $\mathrm{I}, 000,000$ & $5^{\circ} 00$ & $I \cdot 26$ & 0.514 & 0.146 & 0.204 & I'Io & $75^{\circ} 4$ \\
\hline $\begin{array}{l}\text { May to Sept., } \\
\text { I895 }\end{array}$ & $I, 000,000$ & $6 \cdot 62$ & 0.91 & - & - & - & - & $80 \cdot 7$ \\
\hline
\end{tabular}

The highest efficiency reached was 83 per cent. purification, with $1,000,000$ gallons daily and a shorter time of rest. The filter was finally worked on the system considered to be the best at Barking, Exeter, and Sutton-namely, alternate filling, resting full, and emptying, with a periodical entire rest empty for complete aeration. At Barking the filling occupied two hours, the standing full one hour, the emptying five hours, so that three cycles of eight hours were completed each day.

${ }^{1}$ See, further, Dunbar, Vierteljahrsschf. Med. u. offentl. Sanitälswesen, 3 Folge, xix. ; Kattein u. Jübbert, Gesundheits-Ing, I903 ; Jones and Travis, Proc. I.C.E., 1905-1906; Fermi, Z. Spivit. ind., I906, xxix., 221. 
From Io p.m. on Saturday till 6 a.m. on Monday the filter rested empty, making a period of thirty-two hours each week. This weekly rest involves the storage of the crude effluent in reservoirs for the corresponding period-a practice which has many objections. At Exeter, where the flow through the septic tank is continuous, and no reservoirs are employed, the cycles are continued by means of the automatic gear throughout the entire week; but if a filter shows signs of exhaustion, which occurs at long intervals, or rarely through accident, it is thrown out of use for one or two weeks till recuperated.

The I-acre filter is still in use. After five years' working it was reported to be free from clogging, and not impaired in working capacity. It will be noticed that the filtering material is only 3 feet deep, and that it is used for treating an effluent from precipitation by lime and copperas. In I897-98 new cokebeds were constructed at the northern and southern outfalls for dealing with raw screened sewage, and were made of greater depths-6, 9, 4, I2, and 13 feet. In a report of the London County Council giving the results of the working of these beds up to August 9, I898, Dr. Clowes and Dr. Houston show that they have been continuing the experiments on the lines of Mr. Dibdin, with special reference to the following points :

"(a) The effect of using the coke in fragments about the size of a walnut.

" (b) The effect of increasing the depth of the layer of coke beyond the usual limit.

" $(c)$ The extent to which the raw sewage underwent purification by the treatment.

"(d) The practicability of maintaining the constant" (meaning, clearly, regular intermittent, not continuous) "passage of raw sewage through the same coke-bed without deterioration, either in the bed or in the effluent.

" (e) The amount of sewage which could be treated daily by a superficial unit of the coke-bed.

" $(f)$ The extent to which the effluent underwent further improvement by its passage through a second similar coke-bed.

" $(g)$ The suitability of the effluent for maintaining the life of fish.

" (h) The effect of the treatment on the number and nature of the bacteria which were present in the raw sewage."

The report shows that the size of coke is of importance: 
"The use of ordinary gas coke, in pieces about the size of walnuts, seems to be attended with the following advantages, as compared with the use of smaller coke. The larger coke enables the bed to hold a larger volume of sewage. The beds now in use had an original capacity for sewage which was nearly equal to the volume of the coke which they contained, in place of only 20 or 30 per cent. of that volume, as is shown by beds containing smaller coke. The use of the larger coke also allows the bed to be more rapidly filled and emptied, and to be more completely emptied and aerated."

The increase of depth of the beds beyond 5 feet, as I had predicted in my Cantor Lectures, has not been attended by higher efficiency. The report states that "coke-beds similar in character, but differing in depth, have been found to give practically identical purifying effects ... with a 4 -feet and a 6 -feet bed. A bed $I_{3}$ feet in depth ... has given a purification approximately equal to that effected by the 4 -foot bed." The depth is always of great importance, both as to fall, volume, and cost. In the intermittent system the bed is really used at intervals as a storage tank, so that in this sense greater depth means higher capacity.

In the report of July 28, Igoo (p. 59), Dr. Houston says :

"It must be admitted that the I 3 -feet coke-bed at Crossness yielded very unsatisfactory results from the bacteriological point of view. Thus, although the effluents usually contained fewer bacteria and less of $B$. coli and spores of $B$. enteritidis than the crude sewage, the reduction was not well marked, and, indeed, was immaterial from the epidemiological point of view, considering the actual number still remaining. For, as has been already pointed out, the effuents usually contained more than $\mathrm{I}, 000,000$ microbes, more than 100,000 $B$. coli, and at least Ioo, but less than $\mathrm{I}, 000$ spores, of $B$. enteritidis sporogenes per c.c."

An important point is that the capacity of the 4 -foot bed had during ten months been reduced from 50 to 33 per cent. of the whole volume of the bed, "mainly due to fragments of straw and chaff, apparently derived from horse-dung, and to woody fibre, derived from the wear of the wood pavements. ... The original capacity is not restored in any degree by prolonged aeration, which proves that the deposit on the coke surface was not organic matter of animal origin; but it has been found that the vegetable tissue, which seems to be the main cause of the difference in capacity, can be in great measure separated from the raw sewage by a brief period of sedimentation before the sewage is allowed to flow into the coke-bed." It should be

\footnotetext{
1 Compare Waring's and Lowcock's experiments.
} 
noted that it is earlier stated in the report that "the sewage had been roughly screened before reaching the coke-beds, and was free from larger matter usually described as 'filth,' and from coarse sand and heavy mineral road detritus ....," so that, as I have always insisted, the additional sedimentation would mean a further evasion of complete bacterial treatment, and a production of a further amount of supplementary sludge.

A strong confirmation of the suggested origin of the loss of capacity is found in the remark that "the ash in the coke has been reduced in amount by about 25 per cent. during its exposure to sewage in the coke-beds," cellulose being nearly ashless.

These results confirm the view which has been frequently urged-namely, that these non-animal substances cannot be successfully destroyed without anaerobic action (see Chapter V.), by which they are dissolved with production of gas. They are the great difficulty in all processes where the first or hydrolytic change is not properly specialized. The degree to which the nitrogenous matter is dealt with cannot be traced from the report, as only the "oxygen-absorbed" figures are given, and it is obvious that if the non-nitrogenous matter is arrested by the filter-bed, the improvement in the effluent as measured by the oxygen-consumed figure must in part be attributed to this cause, at the expense of clogging or diminution of capacity.

I have already remarked that the first stage requires no oxygen, and is actually hindered by it, the second requires some, while the third demands a very large and rapid supply. In place of providing three separate areas in which these conditions are carefully and continuously observed, as we should in the culture of plants which required different amounts of water, heat, or manures, it is attempted to alternate them in two receptacles by causing the air in each to be cut off and supplied intermittently, and the sewage to be either stagnant, or run in and out with a rush, with the result that the bacteria are periodically disturbed, and neither class of organisms can work under their normal vital conditions. My own analyses and those of others have proved that under the intermittent system, first adopted from the laboratory experiments of Sir E. Frankland in 1870 , the effluents, although the average results show a great improvement, yet manifest such fluctuations in character, tending to be periodic, as show that the quiet and regular working of the bacteria suffers avoidable interruption 
and interference. A small significant fact is that the discharge from the fine beds at Sutton and Exeter, and I believe in other places, is always, at the first rush, turbid and of inferior quality, as a consequence of disturbance. Dr. Clowes also in the above report remarks on the occasional turbidity of the effluent, "apparently due in ordinary flow mainly to the presence of bacteria."

The want of provision of a separate area for the first stage is often concealed by the fact that where the sewers are old, or of great capacity or length, or when the sewage has been stored for sedimentation, the first, or even a part of the second, stage may have actually been passed through before arrival at the works, so that the liquid may be quite amenable to the third stage of strong aeration, such as is supplied by Lowcock's, Waring's, and Ducat's systems.

A remark in the above report is: "Fish die at once when they are placed in the present effluent produced by chemical precipitation, probably because there is a serious deficiency of dissolved oxygen in the liquid...."1 Various fish "have lived for months in the first effluent from the coke-beds, and would apparently live and thrive in this liquid for an indefinite period."

In a supplementary report by Drs. Clowes and Houston (October 26, 1899), the former finds that the cellulose deposit on the coke containing "some fine coke particles and sand grains, cotton and woollen fibres, and diatoms, but consisting largely of chaff, straw, and woody fibre," caused a diminution of capacity of about I per cent. per week in the I3-foot bed, but that this was reduced to 0.64 per cent. per week by previously sedimenting the sewage in a partitioned wooden trough. The sediment was inoffensive, and contained 52 to 70 per cent. of combustible matter. Dr. Houston found $\mathrm{I}, 800,000$ bacteria per gramme of deposit, not accounting, however, for its amount, as "this number of typhoid bacilli, for example, weigh only 0.0000147 gramme." The character of the bacteria differ somewhat from those in crude sewage. There were more $B$. enteritidis and fewer coli. Proteus-like germs were abundant, with $B$. prodigiosus, arborescens, and an allied form. From colour tests and inoculations he concluded the probable presence of tubercle bacilli; in only one case, however, was a fatal effect produced on animals.

1 See Chapter XIII., and also p. 57. 
In I894, following the success at Barking, experiments on the same principle were started at Sutton, Surrey. The filters were of different materials, but again showed coke breeze to be the best, with burnt ballast as a good second, the latter being very simply constructed by digging out the clay to form a pit about 3 feet deep, and filling it up with the same clay after burning, the cost of a filter of this kind, having an area of rather more than one-tenth of an acre being given as less than $£$ Ioo, including all charges. It will be remembered that the cost of the Barking I-acre coke-filter was stated as $£ 2,000$.

The Sutton sewage (500,000 gallons) was at that time treated with 9 grains of lime and 2 grains of ferrous sulphate per gallon, and the settled liquid passed on to land. The soil, London clay, acting unsatisfactorily, in I895-96, on the advice of Mr. Dibdin, two "fine-grain bacteria filters" were constructed for the treatment of the precipitated effluent. The sludge from the precipitation was pressed into cake at a cost of $£ 7$ per week, but there was no demand for the product, and "the nuisance which is inseparably connected with the process was highly offensive."

In November, I896, chemical precipitation was definitely abandoned, but an important feature of mechanical aid was still retained, since the raw sewage was "screened from grosser solids" by a revolving wire drum (p. I5I). From 2 to 3 tons of solid matter per I,000,000 gallons of sewage thus escape bacterial action. ${ }^{1}$

From the screen the liquid passed on to the top of pits filled with coarse burnt ballast called variously "bacteria tanks" or "coarse filters," analogous to the "roughing filters" of former systems, but differing from them in the intention not only to remove solid matter, but to alter it bacterially. The effluent, though greatly improved, was liable to secondary putrefaction, therefore it was distributed by channels over fine beds of coke breeze, whence it issued at intervals as a liquid usually clear and deprived of offensive character.

The coarse beds were constructed by filling the chemical precipitation tanks with burnt clay ballast $3 \frac{1}{2}$ feet deep, the bottom having a 6 -inch main drain with screw-down outlet valve, and 3-inch branch drains 6 feet apart. The bed is charged to

1 Thudichum, Society of Engineers, December 5, 1898. In I899 the rotary screen was abandoned in favour of a detritus tank, which has now, in its turn, been converted into a septic tank by trapping both inlet and outlet. 
within 6 inches from the surface, and the sewage remains in contact for two hours, after which the valve is opened and the liquid flows on to the fine bed, in which it is similarly treated. The coarse-grain filters are charged three times daily, with an interval of not less than two hours' rest after being emptied. The filling and emptying are controlled by Adams' siphons (Chapter XII.). An additional rest, of about one week in six, is given to each bed.

After three months' working, Mr. Dibdin was able to give a satisfactory report. The oxygen consumed by the organic matter was reduced by the tank 66 per cent., and by the filterbeds 86.5 per cent. The solids in suspension were reduced by the tank 95 per cent., and by the filter $99^{\circ} 6$ per cent., while the filtrate was practically clear, had no objectionable odour, and did not putrefy on keeping. The process has continued to the present time with satisfactory results, except when the filters were overtaxed, "some of them," as Mr. Dibdin reports, "having been purposely worked up to a rate of nearly 3,000,000 gallons per acre per day, with the result that the bacterial action was evidently checked, as shown by the decrease in the production of nitrates, and an increase in the quantity of organic constituents in the effluent. As the result of careful watching, however, no permanent harm was done, as the filters were immediately restored to their usual condition, when they proceeded to give good results."

Here, again, we gather that when there is reliance on presumably aerobic filters and organisms for combined liquefaction and nitration, indiscriminately, in the same receptacles, the result is apt to be variable, and to depend on "careful watching," an inference that is borne out by Mr. Dibdin's analyses during 1896 and 1897 .

Sutton System.

Parts per 100,000.

\begin{tabular}{|c|c|c|c|c|c|c|c|c|c|}
\hline & & $\mathrm{Cl}$. & $\begin{array}{c}\text { Oxygen } \\
\text { absorbed } \\
\text { in Four } \\
\text { Hours. }\end{array}$ & $\begin{array}{c}\mathrm{N} \text { as } \\
\text { Nitrites. }\end{array}$ & $\begin{array}{c}\mathrm{N} \text { as } \\
\text { Nitrates. }\end{array}$ & $\begin{array}{l}\text { Free } \\
\mathrm{NH}_{3} .\end{array}$ & $\begin{array}{c}\text { Albu- } \\
\text { minoid } \\
\mathrm{NH}_{3} .\end{array}$ & $\begin{array}{l}\text { Suspended } \\
\text { Matter. }\end{array}$ & $\begin{array}{l}\text { Residue on } \\
\text { Micro-filter. } \\
\text { Millimetres } \\
\text { per Litre. }\end{array}$ \\
\hline Crude sewage & $\ldots$ & $12 \cdot 8$ & $6 \cdot 49$ & $0.02 \mathrm{I}$ & None & I2. 53 & I'I3 & $85 \cdot 76$ & 3,000 \\
\hline Tank effluent & $\ldots$ & $12 \cdot 8$ & 3.96 & 0.301 & $0.75 \mathrm{I}$ & $3 \cdot 85$ & 0.60 & $5^{\cdot I}$ & 213 \\
\hline $\begin{array}{c}\text { Filtrate from } \\
\text { breeze } \\
\quad \ldots\end{array}$ & $\begin{array}{r}\text { coke } \\
\ldots\end{array}$ & I $2 \cdot 8$ & 3 I'I9 & 0.087 & I 99 & $I \cdot 25$ & 0.316 & $\mathrm{I} \cdot 35$ & 23 \\
\hline
\end{tabular}


The average results in his table (p. 2I7) I have calculated, for the purpose of comparison, to a uniform chlorine content of 12.84 parts, the average given for the Sutton crude sewage.

These figures show the following percentages of purification :

\begin{tabular}{|c|c|c|c|c|}
\hline & $\begin{array}{l}\text { Oxygen } \\
\text { absorbed. }\end{array}$ & Free $\mathrm{NH}_{3}$. & $\begin{array}{l}\text { Albuminoid } \\
\mathrm{NH}_{3} .\end{array}$ & $\begin{array}{l}\text { Suspended } \\
\text { Matter. }\end{array}$ \\
\hline By the " bacterial tank" & 53 & 69 & 47 & 94 \\
\hline By the coke filter & 29 & $2 \mathrm{I}$ & 25 & $4 \cdot 4$ \\
\hline Total purification $\quad \ldots$ & $\delta_{2}$ & 90 & 72 & $98 \cdot 4$ \\
\hline
\end{tabular}

It will be observed that the chief purification occurs in the " bacterial tank," and that a large proportion of it consists in the removal of the suspended solids.

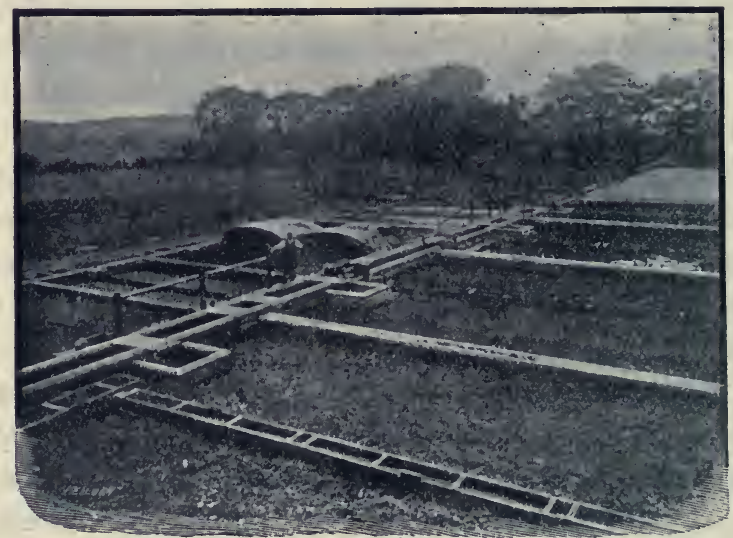

Fig. 21.-Contact, or "Dibdin" Filters on Dual System at Sutton.

During the two hours of resting full, a mixture of organisms, of which I believe a great proportion are anaerobic, as indicated by the large production of nitrites, are liquefying the sludge. It was estimated that in the three tanks 80 tons of dry matter had been thus reduced from November, I896, to December, I897. During the period of resting empty, the aerobic bacteria. are supposed to be at work, although, according to Mr. Dibdin, no air enters except that drawn in while emptying out the liquid. The subsequent coke-breeze filter is intended, under the same conditions, to be entirely aerobic and nitrifying. The Second Report of the Royal Commission on Sewage, I902, No. 2, 
p. 22, says that "the destruction of solid organic matter takes place most advantageously during the period of rest. The sludge of a manufacturing town is more resistant than domestic sludge." I pointed out in 1896 that as the organisms producing nitrates require much oxygen (p. I2I), and we know they do not thrive in a water-logged soil, their action is almost entirely confined to the periods of emptying and resting empty. The prevalent fault of these fine or secondary beds on the Sutton system is the deficiency of aeration, resulting in a generally low nitrification, shown also by the presence of nitrites. Thus at Exeter in I896 I found that the discharge from the Dibdin filters contained ordinarily only $2^{\circ} 7$ to 3 c.c. of oxygen per litre, or less than half saturated, with about I part per 100,000 of nitrogen as nitrates, whereas in a filter which had rested for some time the nitric nitrogen in the first discharge was 2 parts per I00,000. The Leeds report, I900, mentions that large quantities of nitrates were produced in the resting periods. In one instance where the filtrate had deteriorated and the nitric nitrogen was 0.16 part, after a rest of eighteen days it advanced to 3.4 part per 100,000, and the capacity at the same time increased 2I per cent. (see also Chap. XI.). It will be noticed, further, that the Sutton sewage has already. been broken down to a very considerable extent, as shown by the $I 2^{\circ} 53$ parts of free ammonia, and only $I \cdot I 3$ parts of albuminoid.

The total cost of the farm when formerly worked on the chemical precipitation and broad irrigation system was for the year ending March 3I, I895, £I5 IIs. IId. per I,000,000 gallons (taking into account the amount earned by the farm and sale of sludge, which was $£$ II7 7s.); in I899 it was $£ 3$ I9s. with the biological system.

In June, I899, I made an examination of the Sutton results for the Local Government Board. The samples of screened sewage, coarse and fine bed effluents were so collected as to represent the working of one pair of beds on one day, the average samples being obtained by taking equal volumes at intervals of five minutes throughout the whole period of filling or discharge. Gauging of coarse bed, 6,600 gallons; fine bed, 4,369 gallons. The volume sampled was, therefore, approximately I9,800 gallons of screened sewage, of which I3, IO7 gallons were subsequently passed through the fine bed. The flow through the coarse bed $\left(33 \times 55\right.$ feet $=201 \frac{2}{3}$ square yards $)$ 
was 102 gallons per square yard per day, while the fine filter $\left(83^{\circ} 3\right.$ square yards) dealt with the coarse filtrate at the rate of I57 gallons per square yard per day, or approximately, for the double filtration, Io acres for $3,000,000$ gallons of screened sewage.

At that time the distribution of the liquid over the beds was of the simplest type, causing an irregularity of contact between the material and the liquid which was revealed in the analysis.

The suspended solids in passing the coarse bed fell from $6 \mathrm{I}$ to 18 , the difference of 43 being retained. Their resolution, as I have pointed out, is mainly an anaerobic process, actually antagonistic to the oxidizing and nitrifying changes which are intended to occur in the fine bed. It is proved, however, by the increase of combined nitrogen in solution from $3^{\circ} 4$ to $4^{\circ} \mathrm{I}$ parts, that the fine bed had in this case to supplement the coarse bed in dissolving nitrogenous solids.

The general lowness of the free and albuminoid ammonias with high organic nitrogens is probably explained by the fact that the effluents were analysed in such a fresh state that the nitrogen was mainly present as urea, since this compound does not readily yield its nitrogen by distillation with alkali or permanganate, but is completely changed into ammonia by the Kjeldahl process, hence would appear as organic N. It is well known that before urea can be nitrified it must be hydrolysed into ammonia : the first stage should be effected in the coarse bed, the second in the fine.

On the other hand, during the thirteen hours of rest and aeration that had elapsed before the first samples were taken, the coarse bed had temporarily assumed a nitrifying function, as shown by the very considerable amounts of nitric nitrogen found, with a lower quantity of nitrite, and only a slight reduction of the oxygen consumed. Later in the day, when the rest periods are shorter, all this nitrate disappears, with a heavy fall in the total nitrogen, and a considerable lessening of the oxygen consumed. There is little doubt that this is explained by a Gayon and Dupetit reaction, by which nitrates and organic nitrogenous matter decompose one another, the oxygen of the nitrate burning up the carbon, and nitrogen or oxides of nitrogen being evolved as gas. Possibly the disturbance occasioned by the formation of this gas accounts for the extraordinary variations in individual samples, and for the high suspended matter occasionally met with. 


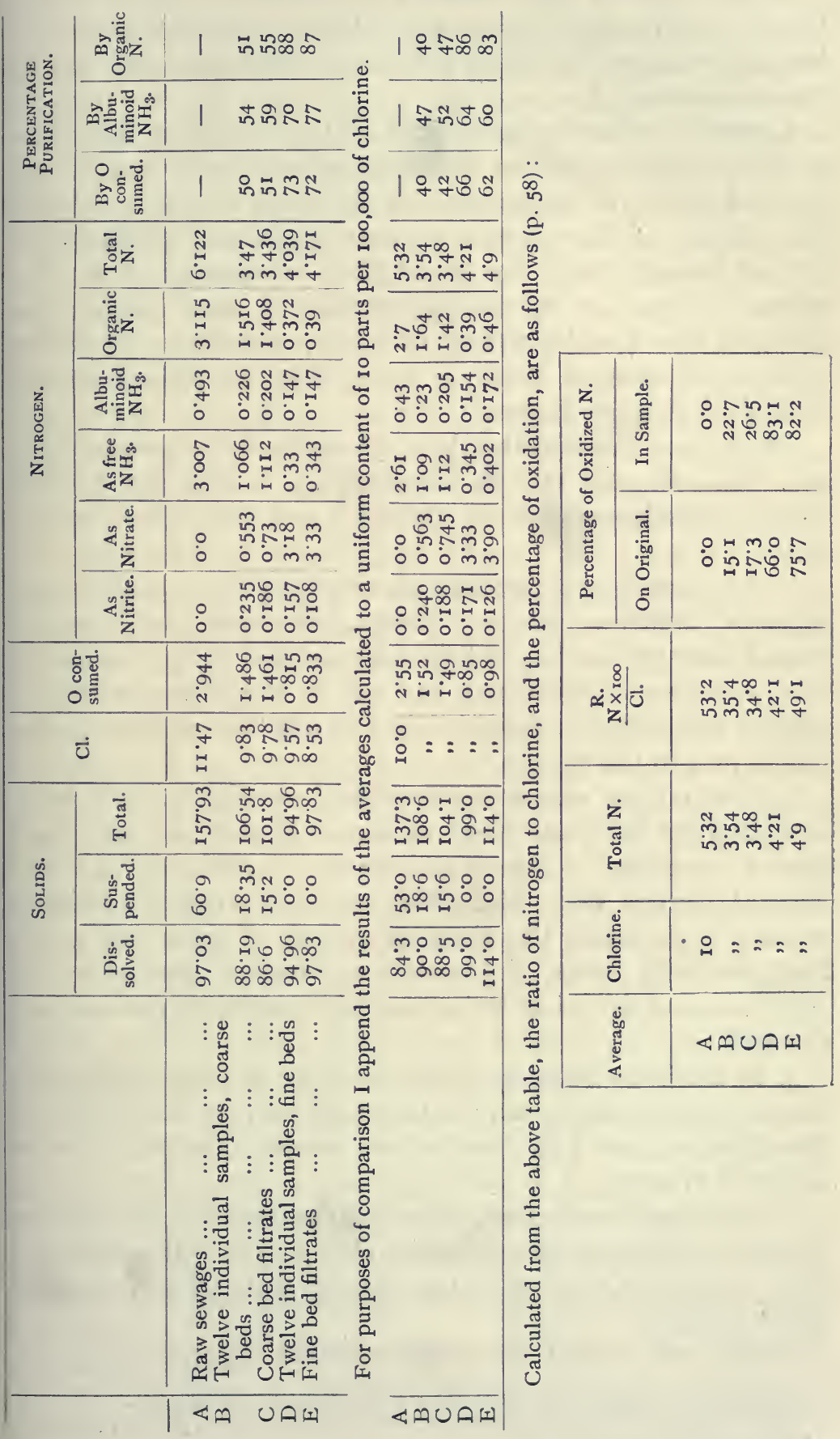


In this case we have actually a reversal for a time of the functions of the two beds, and a violation of the law that "the bacterial changes should be carried out with regularity and in natural sequence."

A great divergency was noticed in the successive individual samples, taken at fifteen minutes' interval, and can be accounted for by the interference of the filling material with the free mixing of the sewage, so that zones and channels are formed through which the liquid flows at varying rates. The effluent issuing at successive intervals of time comes from different layers and parts of the beds, and really represents sewages of different hours or even days, as proved by the individual chlorine figures.

There is a considerable loss of nitrogen in contact-beds (see pp. II8 and 126 in Chapter V.). Letts and Lorrain Smith investigated this at Belfast, ${ }^{1}$ and their chief results are :

I. They confirmed previous observations that a main cause, reaction between nitrates, nitrites, ammonia, and organic matter with production of free nitrogen and $\mathrm{CO}_{2}$, was due to vital processes of organisms and not to enzymic or chemical action, and that the common $B$. coli was one of the species taking part in the change. ${ }^{2}$

2. Green algæ sometimes flourished on the bacteria beds, and absorbed large quantities of ammonia and nitrates; their tissues contained a larger proportion of nitrogen, and less mineral matter, than when they were growing in ordinary waters. $^{3} \quad$ [Compare the vigorous growth of grass and weeds that generally forms, if allowed, on inland filter-beds. In America, sand filtration beds have been regularly planted and cropped.]

3. In the brick beds at Belfast, "I2 to 20 per cent. of the nitrogen disappearing can be recovered as free $\mathrm{N}$ dissolved in the effluents," and a further portion escapes as nitrogen gas or oxides of nitrogen.

4. An uncertain amount passes into the tissues of animalculæ, worms and insects (see Chapter IV., p. 77). The bacterial jelly, or zooglœa, encrusting the filtering material also contains much nitrogen.

Phelps and Farrell have demonstrated experimentally the

1 Belfast City Reports, I90I and I904; Chem. News, No. 2184, I90r.

2 See Pakes and Jollyman's Papers, Trans. Chem. Soc., I901, pp. 322, 386, 459.

3 Belfast Report, I904, p. 46. 
chemical and mechanical actions in contact-beds, ${ }^{1}$ and give curves of the changes agreeing with the explanations I have given. They emphasize the importance of adsorption ${ }^{2}$ by the zooglœal jelly, on which Dunbar and Thumm lay so much stress, but the phenomenon is common to all kinds of bacterial filters. They found the loss of nitrogen in contact-beds to be 29 to 50 per cent. (Clark found 38 to 50 per cent.) ; in continuous or trickling filters it was only I to 6 per cent. (see Chapter X.,p. 27o.)

In I903, the Sutton U.D.C. Surveyor, Mr. Chambers Smith, reported that "the net cost for the year of treating the sewage, including pumping, was $£ 775$, equivalent to a cost of $£ 4$ Is. $7 \frac{1}{2} \mathrm{~d}$. per $\mathrm{I}, 000,000$ gallons, or II'07d. per head of population, whilst the charge on the rates amounted to $I \frac{3}{4} \mathrm{~d}$. only, a figure which compares very favourably with the cost of similar work in other districts. The land on which the sewage disposal works are situated is stiff clay, but a portion has been rendered suitable for sewage farming by ploughing domestic ashes into it. About 8 acres are given up to the production of peppermint, one of the most profitable crops which can be grown on a sewage farm, and from this source alone $£ I 78 I_{5}$ s. was realized in the year I902-I903."

At Oswestry, in $1898,{ }^{3}$ material for beds on the Sutton system was obtained by screening from an old refuse tip, in which "everything excepting hard carbonaceous matter had disappeared," the coarser portions being used for the primary beds, $4 \frac{1}{2}$ feet deep, and the intermediate portions for the secondary filters, 4 feet deep. The total cost of the screened refuse was about Is. 3 d. per cubic yard. The crude sewage was previously clarified by subsidence in a large settling tank in two sections, used alternately. About half the sludge settled in these tanks, and was removed weekly, mixed with the dust screened out of the town refuse, and sold as manure.

The Surveyor writes in Igo6 that three primary beds have since been filled in the same way, but that the refuse of latter years contains a much less proportion of large cinders and is not the best material. The beds have lost a great deal in capacity, chiefly through insufficient settling-tank accommoda-

1 Research Laboratory, Mass. Inst. of Technology ; see fourn. of Infect. Diseases, Chicago, r905.

2 The property by which certain substances, notably colloids, remove dissolved material from solution.

3 Population, 10,000; dry-weather sewage, 300,000 gallons per day; watersupply, 20 gallons per head; "total cost of works, $£$ I,800; annual working expenses, about $£ 80$." 
tion, causing clogging and the close consolidation of rather small material. Present settling-tank capacity 58,000 gallons; average dry-weather flow 350,000 gallons per day. The new scheme provides open sedimentation tanks holding slightly more than a day's flow, with additional beds for storm water.

Leeds, with the Sutton method in 1898 , experienced much difficulty owing to "sludging-up" of the beds, but by increasing the periods of rest, and by the introduction of finer screens, which remove a greater portion of the suspended solids (sludge) to be otherwise dealt with, better results were for a time obtained. The increase of capacity gained by a long rest was rapidly lost on renewal of working; thus the capacity regained by a rest of thirty-eight days fell again in a fortnight from 56,500 to 45,800 gallons. Probably the long aeration had destroyed or enfeebled the anaerobes, and the liquefaction was therefore suspended until an anaerobic state was restored. The drying up of the spongy matter during lengthened rests accounts to a great extent for the increase of capacity. Another cause of diminution of capacity in rough beds of clinker was found to be that the material had sunk and become consolidated, in consequence of the alternate filling and emptying, and the slight rise and settlement at each turn of the work. This is liable to occur with all materials in intermittent filtration.

After three years, in Igoo, the decrease in capacity in contactbeds was still so serious that "they could not be regarded as suitable for Leeds sewage without preliminary treatment." Besides the disintegration and settlement of the coke and clinker, there was an accumulation of sediment in the interstices, much of it irreducible, and therefore unaffected by the periods of rest. If the beds must still be used, " the problem would be (I) to find material of sufficiently even size not liable to degradation; (2) to reduce, as far as possible, the solid matter put on to the rough beds; and (3) to exclude and treat separately all iron liquors."

"Sutton," or "Dibdin," beds were adopted at a large number of places. At Manchester experimental filter-beds on the same principle were named "double contact-beds."

As it became gradually evident that the two beds, coarse and fine, even with preliminary screening or sedimentation, were not exactly adapted to the three processes of bacterial change that we have mentioned, a third bed, or "triple treatment," was in many places adopted. In the Manchester inquiry of 1899 it 
was stated that if the "double contact" did not suffice, they would employ a "third contact." This triple treatment was adopted at the Hampton Sewage Works in the beginning of I899, and also at Lincoln and elsewhere.

In America it is recognised that intermittent filtration is much more expensive than was formerly anticipated. The filters constructed in New England a few years ago are one by one becoming clogged and inoperative except at very low rates, and it is now evident that they necessitate heavy maintenance charges. 


\section{CHAPTER X}

\section{BACTERIAL PURIFICATION (continued)}

Capacity of filters-Nature and size of materials-Gases in filtersDepth of beds-Aerating processes-Lowcock-WaringDucat-Artificial warming-"Thermal aerobic"-Continuous filtration-Salford-Stoddart's filter.

THE regulations of the Local Government Board as to filters originally provided that each set of filters-i.e., both coarse and fine-must be of sufficient capacity to contain the normal dryweather flow for twenty-four hours. Coarse-grain beds can hold 25 per cent. sewage, and fine beds $33 \frac{1}{3}$ per cent. This means, taking an eight-hour cycle, that the beds will be large enough to deal with three times the dry-weather flow-i.e., I volume normal, 2 volumes storm water.

As to material, its size and mode of arrangement have been shown to be more important than its kind, and it has been unfortunate that the Board have not during the past few years allowed considerations of material and distribution to modify their insistence on a fixed filter capacity.

Coke breeze from its porosity exposing a larger surface was recommended by the Barking experiments and has been generally adopted, but it is somewhat expensive when required in large quantities, therefore in many localities local material, when properly screened and graded, can be employed.

The Massachusetts Reports, I898-99, comparing filter-beds of ashes and cinders with those of sand and gravel, state that the former have great advantage as regards rapidity and not becoming clogged, that they are equal or even better in the colour and chemical character of the effluent, though the percentage of bacteria removed is less.

In 1897 fine coal was used as a medium for the filtration of chemically precipitated effluents, at Wolverhampton, Lichfield, and other places. The sewage of the former town is heavily 
polluted with chemicals, that of Lichfield contains a large amount of brewery refuse. I cannot see how the action of coal is different from that of other media, though Dr. Bostock Hill contended that effluents from coal filters show a greater loss of organic carbon as compared to organic nitrogen than in filters made of other materials, and that this is a characteristic property of coal, but Mr. Garfield, now of Bradford, to whom the suggestion is due, has not adopted this material for his present works.

Dr. Fowler, in his report of the Davyhulme experiments in I897, confirms the results of previous observers that coal and burnt clay filters, when worked continuously, rapidly become clogged, and that improved results are obtained with intervals for rest and aeration. He also considers coal to be superior to burnt clay.

The table in my last edition of the comparative nitrification effected by different filters, ranks the Garfield filter as lower than other forms, but, as already mentioned, this result is more likely due to the difference in the mode of working and aeration of the filter than to the material.

Partly for the sake of cheapness, and also because it was expected that coke would in time disintegrate, the use of more compact materials has been suggested. Broken slate ${ }^{1}$ or shale has been much used in the North, and Thudichum even made laboratory experiments with pounded glass, and found a certain amount of efficiency. Burnt ballast, clinker, cinder, slag, polarite and iron sand have their advocates. Non-porous materials might be expected to have a lower capacity, but it is mainly on the surfaces, and not in the interior of the masses, that the bacterial action occurs. At Exeter, Mr. Cameron expresses a general preference for clinker : at Southampton and other places assorted clinkers from the dust destructors are used. But coke, if available, seems the best material for nitrification, and has shown no noticeable disintegration in nine years. Burnt ballast must be carefully made, as many kinds crumble and block up the filter. Road granite, crockery, and old iron and tins are stated to have given satisfactory results, and broken saggers from pottery kilns have been successfully used at Hanley in 1903, and in other places in the Midlands.

Durability of "Ballast." If clay be thoroughly burnt, its

${ }^{1}$ In Nov., I 898, rough state filters were proposed at Festiniog, and in March, I899, Chambers Smith reported to the Sutton Council his trials of various materials. See San. Record, Aug. 9, 1906. 
durability is unquestioned, as shown in brick. But when treated in the cheaper way employed for roads and railway embankments-that of piling the clay in alternate layers with small coal and refuse, firing in places and allowing to burn slowly till the mass has the usual brick-red colour-the burning is apt to be irregular and insufficient, so that much of the material on wetting becomes soft and crumbly. Burnt ballast appears to be almost unknown in America, since the Massachusetts Board did not include it in their investigations of materials, and Rudolph Hering alludes to it in September, I 900,1 as "a material made out of clay which is used in England because they have very little sand." $\mathrm{He}$ says it is not permanent, but crumbles, and adds that unless very hard, coke behaves in the same way, observing that it is a question for calculation whether it is cheaper to get a more expensive permanent material, such as gravel or quartz sand, which will last longer, though it may not purify so much sewage at first, or to occasionally renew the material.

Burnt ballast seems to have been first tried for this purpose by Dibdin at Barking in I89I (see p. 210), and was used afterwards at Sutton and elsewhere for coarse primary beds (the fine secondary ones being generally coke breeze, p. 2I6). At Dorking and some other places besides Sutton, it has since been found faulty, and has been replaced by clinker or other material. That it is capable, if well made, of considerable permanence is shown by an examination of a coarse bed at Harrow, after two and a halt years' working. Washed samples from different depths were "clean and red, and apparently as hard as when it was laid down." In the washings, however, "the heavy particles consisted almost entirely of small sharp particles of ballast"-such would occur with any material, whatever its hardness, that had not been thoroughly washed at first-with " not more than the slightest suspicion of ballastmud." The material lost on washing 4.44 per cent. of its weight, made up of ballast dust and sand I.I4, raw clay $2 \cdot 60$, organic matter 0.7 per cent. The capacity of the beds was considerably less than at first, but this was due, not to disintegration of the ballast, but to clay that had come in from the top. At Belfast broken brick is used for the coarse beds. ${ }^{2}$ At Friern Barnet Sewage Works, Middlesex, it was found that

1 f. New England $W$. Works Assoc., xv. 2. The meaning is not given in Webster's large dictionary, I89o, nor in Nuttall.

2 City Surveyor's Report, I900. 
burnt ballast works better than clinker. The contact beds in this case are 4 feet 6 inches deep, and the flow of sewage 400,000 gallons per day. The amount of nitrate in the effluent has been as high as $5^{\circ} 2$ parts per I00,000. ${ }^{1}$

In some places where the beds have been made by the simple method mentioned in p. 216 , care has not been taken that the work was sound, and earth and clay from the sides have washed into the filter.

From the enormous waste heaps in the neighbourhood of various collieries and iron works, Wake and Hollis, Darlington, separated by special machinery tap cinder, coke breeze, clinker, broken bricks, and "carbonaceous iron sand"; the latter was proposed by them as a suitable and cheap material for bacteria beds. ${ }^{2}$ Its content of iron oxides, with a trace of manganese, suggested the action of these substances as carriers of oxygen to the organic matter (p. 179). But, as in coke, which also contains iron, and often manganese, and in many patented materials prepared by ignition, the density and insolubility make chemical action very slight, and quite subordinate to the use as strainers and bacterial surfaces.

Dibdin and Thudichum compared "carbonaceous iron sand" with other materials in some experiments on triple filtration of crude sewage. In each set the size of the grain was:-

First bed, passed by $\frac{1}{2}$-inch mesh and rejected by $\frac{1}{4}$-inch. Second ," " $\quad \frac{1}{4}$-inch $, \quad " \quad, \quad \frac{1}{8}$-inch.

After five weeks' running with two fillings per day, the effluents were analysed. The composition of the crude sewage, calculated to parts per 100,000 , is given as: Free $\mathrm{NH}_{3} \mathrm{I}_{3}{ }^{\circ} 53$, Albumd. $0^{\circ} 740$, Oxygen consumed $9^{\circ} \mathrm{I} 4$. The effect in reduction of these figures, or "percentage of purification," the water capacity at this stage, and the nitrogen oxidized, is shown in the annexed table. From it we may gather the following conclusions :-

I. The iron sand shows in this case a slight superiority over the coke breeze alone, but, in the words of the report, "it was practically identical in work effected with the other materials, and there was no specific advantage in the use of any one

1 Sanitary Record, April 20, 1905, p. 333.

${ }^{2}$ An analysis by W. F. K. Stock gives-moisture 6.75, $\mathrm{FeO}_{30}{ }^{\circ} \mathrm{I}, \mathrm{Fe}_{2} \mathrm{O}_{3}{ }_{10} 33$, carbon $7 \cdot 53$, rough sand $16 \cdot 70$. 


\begin{tabular}{|c|c|c|c|c|c|c|c|}
\hline \multirow{3}{*}{ 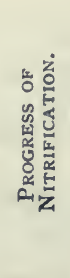 } & \multirow{3}{*}{ 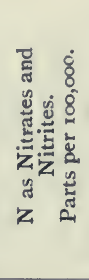 } & 三苛高 & tô & त̂̀ & $\begin{array}{l}\text { o } \\
\text { in }\end{array}$ & $\stackrel{\leftrightarrow}{\leftrightarrow}$ & $\begin{array}{l}80 \\
\text { in }\end{array}$ \\
\hline & & 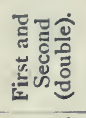 & $\begin{array}{l}8 \\
0 \\
0\end{array}$ & $\begin{array}{l}\stackrel{\infty}{\leftrightarrow} \\
0 \\
0\end{array}$ & 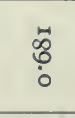 & 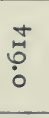 & ָั \\
\hline & & 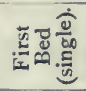 & 0 & 0 & 0 & 0 & $\circ$ \\
\hline$\dot{\vec{t}}$ & \multicolumn{2}{|c|}{ 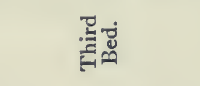 } & 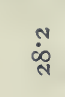 & $\hat{\dot{\infty}}$ & $\stackrel{\circ}{\circ}$ & $\ddot{m}_{m}^{m}$ & in \\
\hline 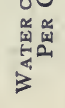 & \multicolumn{2}{|c|}{ 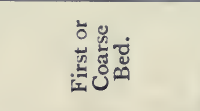 } & $\stackrel{\varphi}{\dot{m}}$ & $i_{7}^{n}$ & $\stackrel{2}{7}$ & $\stackrel{\hat{\alpha}}{\text { d }}$ & $\stackrel{\varphi}{\mathrm{m}}$ \\
\hline \multirow{9}{*}{ 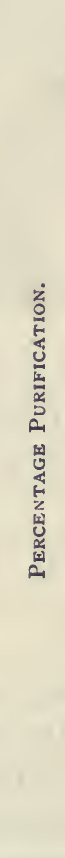 } & \multirow{3}{*}{ 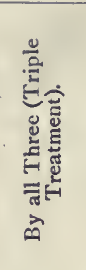 } & 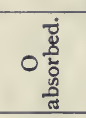 & $\infty$ & 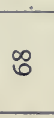 & ลี & $\infty$ & ๓ \\
\hline & & 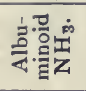 & $\infty$ & $\mathscr{0}$ & $\infty$ & $\infty$ & . \& \\
\hline & & 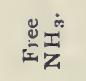 & 8 & ส & \& & ลิ & ฉ \\
\hline & \multirow{3}{*}{ 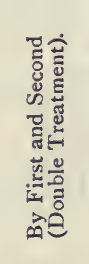 } & 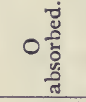 & $\hat{0}$ & $\tilde{0}$ & క & $\stackrel{\wp}{\bullet}$ & $\infty$ \\
\hline & & 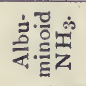 & $\stackrel{\circ}{+}$ & ส & ตे & in & J \\
\hline & & 离网 & 초 & 乞 & ชิ & $\hat{0}$ & $\lesssim$ \\
\hline & \multirow{3}{*}{ 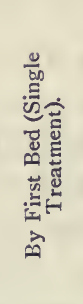 } & ○ & $\stackrel{q}{7}$ & $\dot{F}$ & Z & ๘ & 2 \\
\hline & & 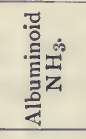 & $m$ & 웁 & 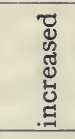 & : & $r$ \\
\hline & & 巡这 & $\Varangle$ & $\stackrel{\infty}{N}$ & $\stackrel{\tilde{m}}{ }$ & 方 & กี \\
\hline 1) & 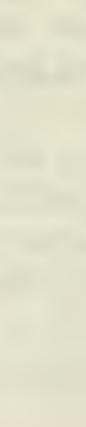 & & 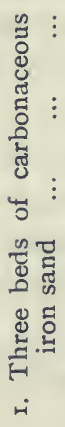 & 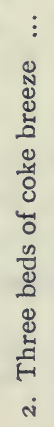 & 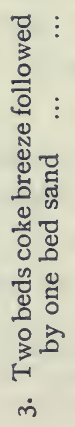 & 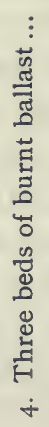 & 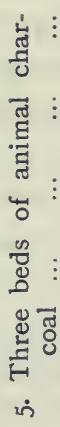 \\
\hline
\end{tabular}


material more than another, so far as the chemical results were concerned. . . . Observations were made as to the bacteria in the respective effluents, but no specific advantage seemed to be shown by any one material in this respect."

As in the Massachusetts, Barking, and Berlin experiments, the sacrifice of capacity and of output on substituting a less porous material, like sand, was not accompanied, in the case of sewage, by an equivalent advantage in purification.

2. That no nitrate or nitrite was produced in any case in the first beds is a strong indication that they were acting hydrolytically and anaerobically, their function being that of an "open septic tank."

3. The double filtration, or result of the second bed, cannot be exactly followed, as the nitrites are not separately given, but it corresponds mainly with the second stage of partial oxidation.

4. In the triple contact, the coke breeze has shown a higher power of nitrification, as noticed by other observers, owing, undoubtedly, to its greater porosity.

It is also important to note that these filters prove that the organic carbon is more easily oxidized than the organic nitrogen, and confirm the criticism on the use of coal (p. 227).

To study the influence on nitrification, in October, I899, I examined six tray filters after running about three months with a hydrolysed sewage. D, E, and F, had an area of roo square feet each; A, B, and C, were one-third the area, and had become much clogged. D was most freely exposed to the air. The filtrates gave on successive days the averages in parts per IOo, 000 on p. 232.

Denitrification with loss of nitrogen is here shown by those filters which are not in proper order. The superiority of a graded filter $(\mathrm{F})$ is also evident, while coal has exhibited the peculiarity that has been noticed in other cases, of encouraging the production of nitrites. Filter $\mathrm{F}$ shows the extraordinary nitration of a strong sewage, resulting in an excellent effluent; in these cases a gain of total nitrogen, presumably from the air, has often been observed. ${ }^{1}$ The great variation produced by the ventilation and aeration of similar filters is also seen in comparing $\mathrm{B}, \mathrm{D}$, and $\mathrm{E}$.

With reference to porous materials the conclusions of the Manchester Report ${ }^{2}$ agree with previous experience in finding-

\footnotetext{
1 Some species of bacilli can assimilate free $\mathrm{N}$, as in the agricultural preparation "nitragin."

${ }^{2}$ Baldwin Latham, P. Frankland, and W. H. Perkin, October, I899.
} 


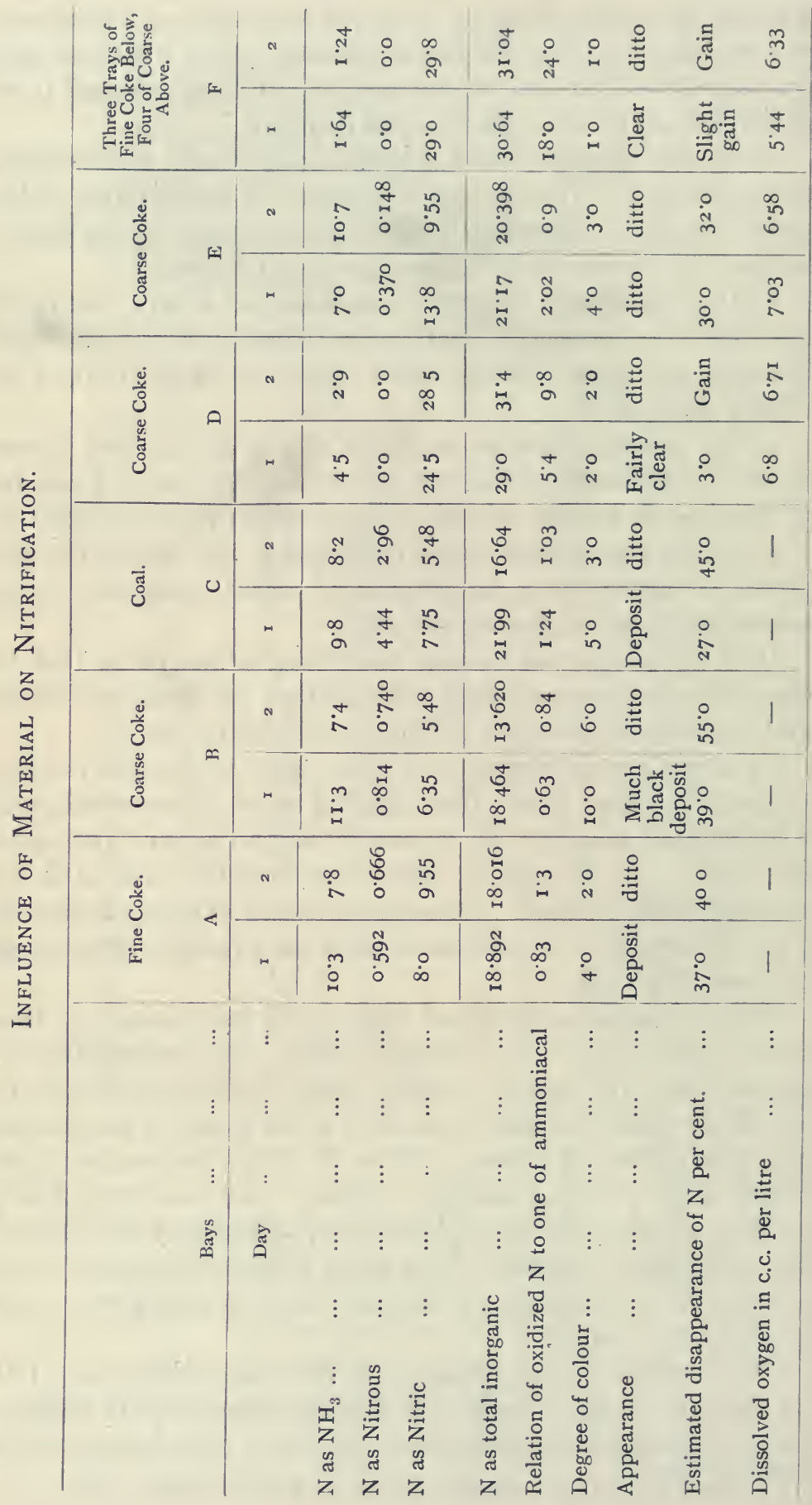


"I. That the initial capacity of a contact bed is practically uninfluenced by the grade of material with which it is filled. ${ }^{1}$

"2. That there is a rapid decrease in capacity during the earlier period of working [before the resolving bacteria become established and active]." (See also ante, p. 224.)

After noticing the increase of capacity during a period of rest, the report concludes that coarse cinders, 3 inches to I inch, permit too free access of sludge to the body of the filter and even into the drains, while "if the material is too fine the beds soon become quite impervious to sewage." With bed C, $\frac{3}{4}$ to $\frac{1}{4}$ inch, followed by $\mathrm{D}, \frac{1}{2}$ to $\frac{1}{8}$ inch, they obained better results, but their final opinion is that the most suitable material for bacterial beds consists of clinkers passing through $I \frac{1}{2}$-inch mesh and rejected by $\frac{1}{8}$-inch.

It was concluded that "contact beds, after a comparatively short space of time, acquire a practically constant capacity," usually found to be about 33 per cent.; that suspended matter must be removed as far as possible by sedimentation, and that any not so removed should be retained on the surface of the bed ; that the surface must be raked or forked over about once a month; and that periodical intervals of rest must be allowed.

At Sutton Mansergh reported that in three years the watercontent of the coarse filters had diminished from 32 to I9 per cent., while the fine filters had not sensibly lost capacity. At Hamburg, with single contact without previous sedimentation, Dunbar and Thumm found that with one filling per day, after 700 fillings the original capacity of 33 per cent. had fallen to 20 per cent., and with two fillings an original 40 per cent. had fallen to I4. Resting, forking, flushing, and altering the direction of supply, did not prevent the clogging, and the only remedy was removal of the material and washing against screens, by which about Io per cent. of the medium was lost.

The London County Council investigated in I 899 the effect of "double treatment"-that is, by an extra coke bed. Their "single treatment" meant two coke beds, the first corresponding to an anaerobic tank, and about 4 feet deep; the second of 6 feet thickness, called the " primary bed, for the first stage of double treatment"; while the third, also 6 feet, was called the "secondary coke bed," corresponding, however, to what is commonly named triple treatment. The coke in all was of uniform size, "about as large as a walnut." The primary and

1 This is only the case within certain limits. See p. 226. 
secondary beds were matured, or inoculated, by frequently charging with crude sewage for about three months to seed them with bacteria.

The aeration of the 6 and 5 foot beds was tested by sinking vertical pipes into the bed and aspirating the gas. The amounts are given as follows:-

\begin{tabular}{|c|c|c|c|c|c|}
\hline \multicolumn{3}{|c|}{ Six-foot Depth. } & \multicolumn{3}{|c|}{ Thirteen-foot Depth. } \\
\hline $\begin{array}{l}\text { Number of } \\
\text { Hours since } \\
\text { Sewage } \\
\text { drained off. }\end{array}$ & $\begin{array}{l}\text { Percentage } \\
\text { of Oxygen in } \\
\text { Air. }\end{array}$ & $\begin{array}{l}\text { Percentage } \\
\text { of Carbonic } \\
\text { Acid in Air. }\end{array}$ & $\begin{array}{c}\text { Number of } \\
\text { Hours since } \\
\text { Sewage } \\
\text { drained off. }\end{array}$ & $\begin{array}{l}\text { Percentage } \\
\text { of Oxygen } \\
\text { in Air. }\end{array}$ & $\begin{array}{l}\text { Percentage of } \\
\text { Carbonic Acid } \\
\text { in Air. }\end{array}$ \\
\hline $\begin{array}{l}4 \\
22 \\
24 \cdot 5 \\
37 \\
40 \cdot 5\end{array}$ & $\begin{array}{r}19 \cdot 8 \\
9 \cdot 8 \\
10 \cdot 0 \\
17 \cdot 8 \\
16 \cdot 8\end{array}$ & $\begin{array}{l}0.4 \\
5 \cdot 8 \\
6.0 \\
2 \cdot 0 \\
2.4\end{array}$ & $\begin{array}{l}22 \\
26 \cdot 75 \\
50 \cdot 75 \\
51 \cdot 25 \\
70 \cdot 0\end{array}$ & $\begin{array}{l}18 \cdot 4 \\
14.0 \\
14.8 \\
15.3 \\
14.7\end{array}$ & $\begin{array}{l}\mathrm{I} \cdot 4 \\
3.8 \\
3.0 \\
3.3 \\
0.8\end{array}$ \\
\hline
\end{tabular}

Later experiments (report of October 26, I899) agree with the above, and in a third report (July, I900) the average of almost daily analyses of the air in a "primary" coke bed about Io feet deep showed after "resting empty" periods of twentyone hours, oxygen $10^{\circ} 3$ and $\mathrm{CO}_{2} 5^{\circ} 7$ per cent.; after five hours' rest, 'oxygen $8{ }^{\circ} \mathrm{O}, \mathrm{CO}_{2} 5^{\circ} 7$ : air containing normally $2 \mathrm{I}$ per cent. of oxygen and $0^{\circ} \mathrm{O} 4$ per cent. of $\mathrm{CO}_{2}$.

At Lawrence, Mass., in I899, a cinder filter which had become clogged and was resting, had air drawn through it constantly for two months except at certain intervals, at a rate suffcient to change the air-contents every three hours. The gas in the filter gave in averages per cent.: $(a)$ aspirator working continuously: $\mathrm{CO}_{2} 0^{\circ} 25, \mathrm{O} 2 \mathrm{O} ;(b)$ aspirator shut off for some hours: $\mathrm{CO}_{2} \mathrm{I}^{\cdot} 3$ to $2 \cdot 6$, O less than $\mathrm{I}^{\circ} \mathrm{O}$. The quantities are irregular, but show that a reduction of the free oxygen occurs from the 2 I per cent. normally present in air. The carbonic acid produced usually corresponds to an equivalent diminution of the organic carbon. A point to notice is that besides the $\mathrm{CO}_{2}$ in the gases an additional quantity, proportional to the vapour tension, is retained dissolved by the liquid remaining in the coke. Several observers have proved the inhibiting action of carbonic acid on bacteria, especially those which are oxidizing, therefore it is important when the third or oxidizing stage is reached that the carbonic acid should be removed by free circulation of air as soon as formed, or the 
failure of nitrification noticed in so many of these filters will follow.

In the Exeter experiments I sunk "compo" tubes to different levels in filter No. 2, 5 feet deep, which had been in constant work for several days, and aspirated the gas for analysis two or three hours after the last discharge. The results were :-

\begin{tabular}{|c|c|c|c|c|c|}
\hline & & Air. & $\begin{array}{l}\text { Tube I, } \\
\text { I8 lnches. }\end{array}$ & $\begin{array}{l}\text { Tube 2, } \\
36 \text { Inches. }\end{array}$ & $\begin{array}{l}\text { Tube } 3 \text {, } \\
54 \text { Inches. }\end{array}$ \\
\hline Per cent. of $\mathrm{CO}_{2}$ by volume & $\ldots$ & 0.04 & 0.375 & 0.98 & $0 \cdot 75$ \\
\hline Relation to volume in air & ... & $I^{\circ} \mathrm{O}$ & 9.4 & 24.4 & I 8.8 \\
\hline
\end{tabular}

Assuming the air in each empty filter to contain I per cent. of $\mathrm{CO}_{2}$, it follows that the volume of carbonic acid removed as gas is also I per cent. of the volume of sewage dealt with in the filters. The weight of organic carbon destroyed in this way is therefore about 50 pounds per $1,000,000$ gallons, or 0.5 part per I00,000, without reckoning the dissolved $\mathrm{CO}_{2}$ in the interstitial liquid.

The interference of this carbonic acid in deep filters seems to account, even more than the insufficient time during which the beds had been working, for the fact that the purification reported by Dr. Clowes, even by his "secondary" (really triple) treatment, is not equal to what has been attained elsewhere. He states that "the purification effected by a single treatment of the raw sewage in the coke beds amounts to a complete removal of the suspended matters, and to a further removal of at least $5 \mathrm{I}^{\cdot} 3$ per cent. of the dissolved putrescible oxidizable matter. The primary 6 -foot coke bed actually removed on the average $49^{\circ} 9$ per cent. of dissolved impurity, and a second process has effected thus far an additional purification of about I9.3 per cent., giving a total average of purification of the clarified vaw sewage amounting to about $69^{\circ} 2$ per cent." With this deeper filter nearly 70 acres of filter I 2 feet deep would be required.

Mr. Dibdin states ${ }^{1}$ that slate or tiles laid in layers and separated by spaces of 2 to 4 inches give a coarse bed effluent from which the solids have practically been removed, and at the same time a working capacity equal to double that of the

1 F. of Preventive Medicine, July, I905; F. Soc. Chem. Ind., May I5, Igo6; also Somerville, Public Health, September, Ig04. 
ordinary coarse bed. The cost of slate beds is from 6s. to Ios. per square yard. Cost per "efficiency yard" 3 s. to $5 \mathrm{~s}$. A bed at Devizes has been working eighteen months, with an abnormally heavy sewage, unscreened and unsettled, followed by a fine bed. Although the raw sewage frequently contains 200 grains of suspended matter per gallon, and the fillings are two or three times daily, the capacity has never been reduced below 50 per cent.; then by opening the valve to full bore it was flushed to 64 per cent. More thorough flushing increased it to the original capacity, 82 per cent. of the cubic content. Thus he finds no necessity for removing or renewal of contact material, while the size of the beds need be only half that of coke coarse beds. The deposit on the slates contained 3,000,000,000 bacteria per c.c.

The Ames-Crosta Co. make a special form of tiles for floors of filters, which are easily set, and allow free and uniform passage of liquid and air.

In the northern portion of the United States, where the severe winter weather interferes seriously with most of the distributing devices, experience at Madison, Wisconsin, and other places has shown that success may follow the application of sewage to filters by means of lines of perforated tile pipes laid close together, and covered to protect them from frost.

We revert to the processes depending mainly on strong aeration, of which the chief are Lowcock's, Waring's, and Ducat's. In Chapter V., p. I2I, we have given a table of the volumes of air required to oxidize the nitrogen of organic matter: a further quantity would be demanded by the carbonaceous matters, measured approximately by the "oxygenconsumed " figure. It has been shown how in an effluent that has properly passed through all the stages, the residual organic carbon can be disposed of by the nitrates, in presence of the appropriate organism; but that for an imperfectly hydrolysed effluent, and still more for a raw sewage, a large volume of air is required, and the action is apt to be slow, irregular, and incomplete. This is well seen from experiments ${ }^{1}$ in which Dr. Fowler exposed a chemically precipitated effluent (lime and copperas) to the air in thin layers, protected from dust, for various periods and under different conditions. In no case was sufficient oxidation effected in twenty-four hours to render the effluent subsequently non-putrefactive. Even after seventy-

1 Manchester City Surveyor's Report for I897. 
two hours' exposure putrefaction took place on afterwards incubating. ${ }^{1}$

In 1892 investigations were begun at Lawrence, Mass., with the artificial aeration of coarse gravel filters to which sewage at relatively high rates was applied, with a view of purifying it partly so that final purification could take place rapidly in a second filter of sand, cinders, or coke. Air was drawn through either upwards or downwards, but in all cases these filters clogged in a manner which indicated that this artificial aeration, while beneficial to a certain degree, was not helpful in proportion to its cost.

Mr. Lowcock, at Malvern, in 1892 , forced in air at a mean pressure of $4 \frac{1}{2}$ inches of water. $\mathrm{He}$ used $^{2}$ a pressure varying from 3.4 to 6 inches, but bearing no relation to the volume of liquid which flowed continuously through the bed. At Malvern the filter was made of sand and gravel(Fig. 22), and later, at Wolverhampton, of sand and coke breeze. The sewage had been screened and chemically

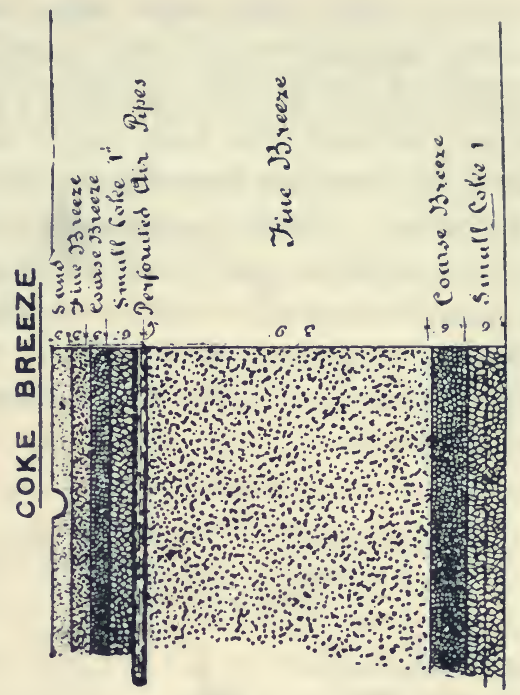

西

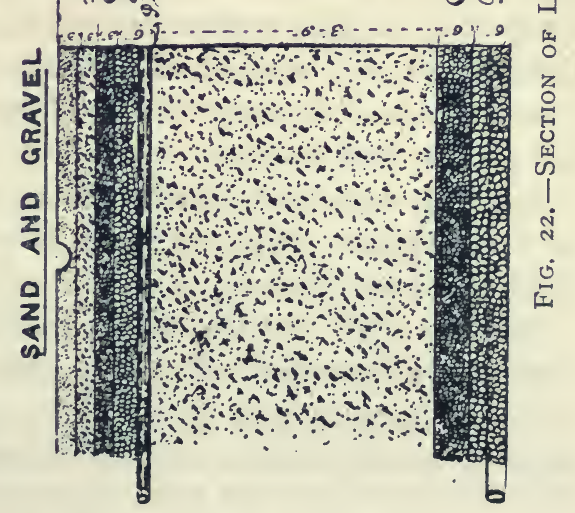

1 See also Chapter V., p. I22.

2 Proc. Inst. C.E., I893. 
precipitated and sedimented before entering the filters. "The quantity applied when the most satisfactory results were obtained was at the rate of 263,780 gallons per acre per day, so that at this rate the area required per I,000,000 gallons of effluent of the same impurity as that experimented upon would be 3.8 acres. The dry-weather flow of the sewage experimented upon is I6 gallons per head per day of the population, so that the quantity treated at the most efficient rate is equal to that from 16,486 persons per acre."

The results are stated in October, I895, as follows in parts per 100,000:-

\begin{tabular}{|c|c|c|c|}
\hline October $8, x 395$ & $\begin{array}{l}\text { Tank Effluent } \\
\text { applied to Filter. }\end{array}$ & $\begin{array}{l}\text { Effluent from } \\
\text { Filter. }\end{array}$ & $\begin{array}{l}\text { Percentage of } \\
\text { Reduction. }\end{array}$ \\
\hline $\begin{array}{llr}\text { Free ammonia } & \ldots & \ldots \\
\text { Albuminoid ammonia } & \ldots & \ldots \\
\text { Oxygen consumed } & \ldots \\
\text { Nitrogen as nitrites and } & \ldots \\
\text { Chlorine } & \ldots & \ldots\end{array}$ & $\begin{array}{l}4^{\circ} \cdot 00 \\
0.35 \\
I \cdot 70 \\
\text { traces } \\
20^{\circ} 00\end{array}$ & $\begin{array}{r}I \cdot 20 \\
0 \cdot 07 \\
0 \cdot 40 \\
2 \cdot 68 \\
24 \cdot 00\end{array}$ & $\begin{array}{l}70 \\
80 \\
77 \\
-\end{array}$ \\
\hline
\end{tabular}

"Calculated on the sewage, the results of the whole treatment, tank and filter, would be a reduction of considerably over 90 per cent. The Wolverhampton sewage is a most difficult one to deal with, as it contains a large quantity of manufacturers' and acid waste."

In the Lowcock filters constructed at Tipton in 1896 the sewage had also been preliminarily treated with lime and alumino-ferric in precipitating tanks. The filters were $3 \frac{1}{2}$ feet deep, with a bottom of coarse coke, a body of coke breeze, and a top layer of fine broken limestone and sand. The outlets of the filters were open, and air was forced in at a pressure of $\frac{1}{2}$ inch of water, the rate of flow of the effluent being 240 gallons per square yard per day.

A purification of the tank effluent of $75^{\circ} 7$ per cent. calculated on the organic ammonia, and 68.5 per cent. on the oxygen absorbed, was obtained. ${ }^{1}$

On this filter Mr. Mansergh, in his report to the Baltimore Sewage Commission, I899, remarks :

"It would seem that the supply of air into the filter enables the bacteria to increase their activity, but the recent practice of resting the filter for twelve hours each day tends to show that natural aeration is necessary to the smooth working of the system. The original

1 See further Lowcock's paper in Proc. Inst. Civ. Engincers, vol. cxv. 
idea that the mechanical forcing of air into the filtering material would enable the tank effluent to be applied continuously has been modified by the adoption of the half-day intermittent working, and this result tends to support the Dibdin process of alternate fillings."

Waring's System.-In I894 a portion of the sewage of Newport, R.I., was treated by this method of forced aeration, which differs from Lowcock's mainly in the separate treatment of the sludge by means of "aerators." The "combined" sewage of this city became frequently mixed with sea water, the effect being an increase of the suspended solids by precipitation of soap and other matters, a result that has been noted in tidal reaches, and has contributed to the formation of mud banks and deposits. The lime and magnesia in ordinary waters do not seem to secure the removal of all the higher fatty acids, as a greasy scum is seen frequently in sewers. I have found the soda salts of oleic and other fatty acids in solution in sewage, especially that of towns with a soft-water supply, owing probably to the influence of the ammonia formed. These soluble soaps are decomposed and precipitated by the high amount of calcium and magnesium salts existing in salt water, so that the sewage of Newport contained unusual amounts of soap curds.

The sewage, after passing through a grit chamber, was pumped alternately through either side of a divided tank containing a shallow bed of broken stone to arrest the coarser solids. "The impurities in the section thrown out of use disappeared rapidly in its interval of rest." The liquid next passed slowly through four straining tanks filled with stones and gravel, whose function was said to be "mere mechanical sedimentation." As soon as these became clogged a plug was drawn, and the sludge emptied into a separate "aerating tank," filled with stones and gravel, where air was driven constantly through the mass, and as soon as active bacterial action had set in, the sludge was rapidly dissolved. Air was also forced through the straining tank till it was again in condition for use. This complex system is another instance of continuous working, assisted by forced aeration for long periods in the hope that in a given tank capacity a larger volume of sewage could be treated. The action here is apparently entirely aerobic, and unaccompanied by previous hydrolysis, except what would have happened in the sewers.

Several alterations have been made in the details, and installations have been constructed at Willow Grove Park, Philadel- 
phia, at East Cleveland, Ohio, and at other places in the States. The roughing filters are masonry tanks filled to a depth of $2 \frac{1}{2}$ feet with Bessemer slag " about egg-coal size." The total area of the strainers (four down-flow and two up-flow beds) is 3,630 square feet, designed to receive 150,000 gallons of sewage per day. The aerators are 6,248 square feet, and the rate of application to them is $1,000,000$ gallons per day of strained sewage, or $66 \mathrm{r}, 000$ gallons per day on the total area. The bottom of the aerators is a false floor of half-round drain-pipes through which the air is forced. Nineteen other installations were also designed, but little is now heard of the method.

At East Cleveland Dr. A. Smith reported "a reduction in the ammonias of 98.8 per cent., in the bacteria of 99 per cent., by double filtration through slag and coke, with aeration under light pressure by a blower."

Ducat Filter.-Colonel Ducat constructed an aerating filter with walls of 3 -inch drain-pipes set nearly horizontally in Portland cement, the inner ends being 3 inches lower than the outer, to prevent the sewage running out. The free exposure to air causes considerable cooling, rendering necessary a special provision by larger pipes for hot-water heating in winter to prevent freezing. It was first tried on crude sewage in 1898 at Hendon, but a large quantity of ammonia was carried off by the air without being nitrified, and sludge collected in the sewer before treatment. Satisfactory continuous working was based on an ample provision of oxygen. The bed was coarsegrained above and fine below, and the action was intended to be exclusively aerobic, as atmospheric oxygen in excess was brought in contact with the contents at once without giving any period of anaerobic incubation, as in a part of the Waring process. I have already observed that in towns with long and old sewers, or where storage is practised, the liquids may have already received sufficient hydrolytic resolution to be quite prepared for such strong aeration. This is illustrated by an analysis furnished by Dr. Houston :-

\begin{tabular}{ll|r|rr|c|c}
\hline & & $\begin{array}{c}\text { Oxygen } \\
\text { absorbed. }\end{array}$ & $\begin{array}{c}\text { Free } \\
\text { Ammonia. }\end{array}$ & $\begin{array}{c}\text { Albuminoid } \\
\text { Ammonia. }\end{array}$ & $\begin{array}{c}\text { Oxidized } \\
\text { Nitrogen. }\end{array}$ \\
\hline Sewage, October 14, 1898 & $\ldots$ & 14.72 & $8 \cdot 7$ & $1 \cdot 6$ & - \\
Filter effluent, ditto & $\ldots$ & $\ldots$ & 0.78 & 0.3 & 0.094 & 0.477 \\
\hline
\end{tabular}


The high free ammonia and the low albuminoid show that the sewage has already undergone the preparation I have mentioned. The nitrification of the effluent has not proceeded as far as might have been expected, notwithstanding the very large loss of ammonia, but better results have since been obtained. ${ }^{1}$ The oxidation of the carbonaceous matter is also marked. Houston's bacteriological examination of this filter has already been referred to (p. 87).

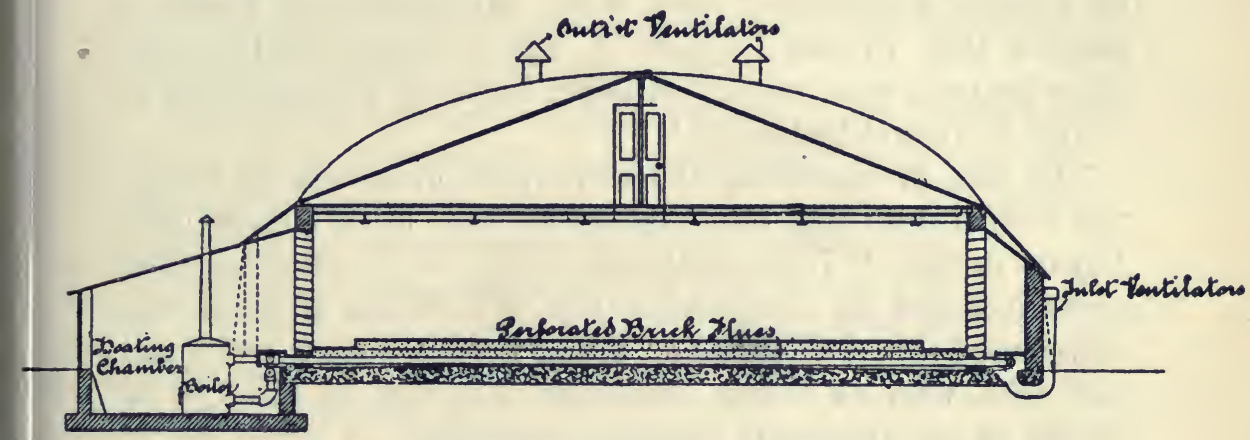

Fig. 23.-Section of Ducat's Filter.

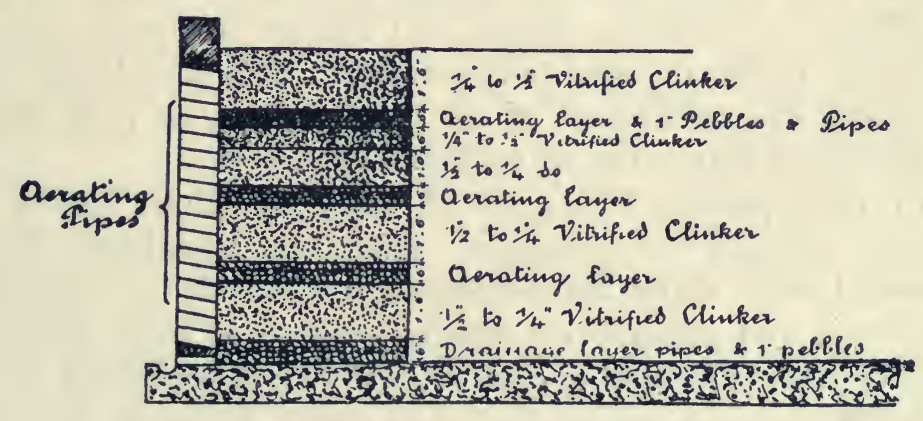

Fig. 24.-Filtering Material.

Figs. 23 and 24 are from Mr. Mansergh's Baltimore Report, I 899 .

A great difficulty attending the processes aiming at the direct oxidation. of sewage by currents of air is the cooling produced, which in winter may actually occasion freezing. To avoid this several inventors have introduced systems of artificial warming, with an additional view of stimulating the bacteria, but also with a considerable added expense. Colonel Ducat, as we have seen, provided a series of hot-water pipes for heating in winter. The effect of cold in diminishing the activity of nitrifying

I Royal Commission, vol. ii., I902, pp. I38, I45. 
organisms was proved repeatedly in the Massachusetts experiments, when the temperature of inception of active nitrification was found to be $39^{\circ} \mathrm{F}$. A number of bacteria, however, are not affected by cold: in the L.C.C. Report of the Barking filter, it is said that it "was able to do its work satisfactorily during the exceptionally severe weather in January and February, I895. A thin coat of ice was formed on the surface, but the filtration proceeded without intermission, the only noticeable change being the decreased production of nitric acid. Macfadyen and Rowland showed that Proteus vulgaris, B. coli communis, and several other bacteria were not killed in ten hours by a temperature of $-250^{\circ} \mathrm{C}$. (liquid hydrogen). ${ }^{1}$

The idea of increasing the activity of organisms by raising the temperature was also applied in 1898 by Whittaker and Bryant in their "Thermal Aerobic Filter," at Accrington. The plant included an open septic tank, the effluent of which was distributed over a filter-bed of 2 feet broken stones, and 6 feet gas coke, with 12 inches limestone chippings on the top, by means of an automatic revolving sprinkler. A small jet of steam was blown into the sewage just as it arrived at the sprinklers "to raise the sewage, and thereby the whole body of the filter to the required temperature." The added heat also promotes the circulation of air in the filter, so that better aeration was claimed to be produced in this way.

In their patent, No. 4,460 of 1899 , the filters consist of several circular or polygonal chambers containing filtermaterial, with shafts between through which air can be drawn or forced, and preferably a central air-shaft in each chamber. On the sloping bottom of each filter were laid perforated pipes, forming channels leading to the air-shafts, to secure free and uniform aeration. The filters were filled with ordinary unbroken gas coke, well forked, to remove all the smaller material, and were $6 \mathrm{I}$ feet diameter and 9 feet deep, each capable of dealing with 200,000 gallons of open septic tank effluent per day, the area covered being 958 square yards.

Whittaker beds were tried at Leeds, and the purification was found to be maintained during severe frost, as the action of the pulsometer raised the temperature of the septic effluent going on to the bed, a few degrees above that of the sewage. Good results were obtained with an open septic tank effluent, and the small amount of suspended matter passing the filter was readily

1 Proc. Roy. Soc., I90o, 1xvi., 488. 
removed by a final small settling tank. The aeration of the effluent was then satisfactory, and was maintained for some days-sufficient, in fact, to allow, in most cases, the effluent to reach the sea or come in contact with a large volume of natural fully-aerated river water.

\section{Various Ways of Constructing the Sides of Bacteria BEDs.}

I. Digging out the soil and replacing it with another material such as ballast, clinker or coke (p. 216).

2. Impervious walls constructed as tanks. These usually are previous chemical-precipitation or sedimentation plants which have been utilized for present practice. In the Manchester experiments they were made with sloping sides (p. 274).

3. Perforated walls, constructed in different ways :-

(a) Col. Ducat's system of sloping drain pipes (p. 24I).

(b) Honey-comb or pigeon-hole brickwork, as in the Whittaker-Bryant (p. 242).

(c) Loose large pieces of clinker or stone, built up as a wall, and filled in with filtering material. This form has been used at Leeds and Guildford. Winslow speaks approvingly of a filter of the kind at West Allis, near Milwaukee, "cinders and clinker, from $\frac{1}{4}$ to $\frac{3}{4}$ in. diam., held together by large clinkers on the outside, piled with a slight batter"; depth $8 \mathrm{ft}$., top area $30 \times 54 \mathrm{ft}$., concrete floor $40 \times 60 \mathrm{ft}$. : covered by a roof supported by brick piers, sides left open in summer and protected by planks in winter. ${ }^{1}$

(d) Palisading of tarred wood, braced and strengthened with hoop-iron; or "expanded metal" lattice work, galvanized or tarred, to support the material of the bed.

4. Sides consisting simply of the filtering material itself, forming its own slope, as in Stoddart's filter (p. 247), and Corbett's (p. 246).

Method I is only possible on the "holding-up" system in a strong clay soil or with puddling. The lower part of the bed is of coarse material, and ventilating pipes run up the sides to above the upper surface. Methods I and 2 are not advisable for sprinkler beds, because they do not allow lateral aeration. In the so-called "streaming" bed, however, in which the liquid is distributed on the surface in periodic flushes, as from a

${ }^{1}$ J. Assoc. Eng. Soc., U.S., xxxiv. 6, 1905, p. 348. 
secondary contact bed, the effluent passing straight through the material to the under drains, the construction may be as in Method I, even if used without clayey ground or puddled sides. Choice of methods to a certain extent depends on the quality of the sewage and local factors.

\section{Continuous Filtration.}

The intermittent system recommended by the Rivers Pollution Commission of 1868 , and enjoined by the second Royal Commission on Metropolitan Sewage Discharge in the words "the intermittency of applications is a sine quâ non," was almost universally adopted. But apart from the labour of regulation and supervision, another fault of the method was that the oscillations of functions between anaerobic and aerobic actions, involved in " resting full " and " resting empty" periods, created disturbance, and was detrimental to the consistent action of bacteria. In Ducat's and Whittaker-Bryant's filters, and formerly in Lowcock's, the working was continuous, but rests at longer intervals were usually found necessary.

At Salford Sewage Works Mr. Joseph Corbett made a series of experiments from 1893 to $1898,{ }^{1}$ on the basis of a continuous passage of both sewage and air simultaneously through filters of gravel and sand, of coke breeze, and of cinders; all were "very good, but the latter the best." The filtrates after fifteen months' continuous working showed an average reduction to free ammonia 0.829 , and albuminoid $0^{\circ} 13$, in parts per 100,000 . The principle of dividing into three or four heights of 20 inches thick with ventilating spaces between was also tried, but the analyses seemed to show a slight difference in favour of the filter in one mass. The distribution was effected at first by wooden troughs with holes, afterwards by spray jets, ${ }^{2}$ with a head of 4 feet pressure, the amount delivered being 500 to I,000 gallons per square yard. The chief requirement was that the filters should be thoroughly open. The Salford Corporation decided to lay down these filters for treating the whole of the sewage at the rate of 500 gallons per square yard on beds 5 feet deep, and on the refusal of the Local Government Board to sanction the scheme unless it included the purchase of land over which the filter effluent should be turned, the Corporation arranged to borrow $£ 80,000$ for the works under Section 35 of the Public

1 Public Health Engineer, February 3, I900.

2 See Chapter XII. 
Health Act, 1875 . It is hoped that the scheme will be completed in 1907 .

It is important to notice that these "bacteria filters" are only dealing with an effluent already artificially purified by subsidence, straining, and precipitation. They were protected by a roughing filter of fine gravel, to arrest any floating fats or any precipitated sludge which might find its way through the subsidence tanks. "This roughing filter required to be cleaned every one or two days. ... The Salford process will then be threefold : first, precipitation by the lime or other chemical process; second, clarification and interception of all suspended matters by roughing filters of coarse gravel; third, purification by means of bacterial filters on the lines above described." The expenses and sludge of the older processes are thus retained.

The works are designed for pumping and fully treating per day 30,000,000 gallons for two or three days together, or about $20,000,000$ gallons for some weeks, the ordinary flow being II,000,000 to $12,000,000$, from a population of 210,000 , with a water-supply of $4,500,000$ to $5,000,000$ gallons, or 25 gallons per head. "The balance, therefore, of half the ordinary sewage is subsoil water, and the sewage requires about 4 grains of oxygen per gallon to oxidize the putrescible matter on arrival at the works."

Of the original twelve tanks, ten, in two sets of five each, were formed into two large tanks, of a total capacity of 4,750,000 gallons; the other two tanks were altered into six roughing filters, of 2,040 square yards area, where the precipitation tank effluent passes through 3 feet depth of fine gravel. "The final filters or 'bacteria beds' are 26,000 square yards in extent; during dry weather the flow will be about 300 gallons per square yard per day, but in wet weather three or fourfold this flow can be satisfactorily purified, and the filtrate averages well within the standard of the Joint Board of the Irwell and Mersey Watershed. The cost of the works, when fully completed, will amount to about $£ 80$,ooo, so the whole cost from first to last will amount to about $£$ I 98,000 , to serve a population of, say, 250,000 , or I6s. per head." 1

The filter plant has been several times modified. In I906 Mr. Corbett writes, " the distributing pipes are placed over the beds. . . . We support the gridiron of pipes on brick piers, and make a central channel for the filtrate below the central piers," which each contain a $9^{\prime \prime} \times 9^{\prime \prime}$ flue with openings at the

${ }^{1}$ Report of Mr. J. Corbett, Borough Engineer to Salford Corporation, I902. 
top for ventilation of the broad beds. The latter have no wall, but the bank of cinders is simply sloped, leaving free airway to the cpen sides of the raised tiled floor. There is an I8-inch supply to a pair of bays, $62 \mathrm{ft}$. width. "We are using a slightly coarser grade of 'medium,' say, $\frac{1}{2}$ to $\mathrm{x} \frac{1}{2}$ ins. diameter, by $7 \mathrm{ft}$. depth, and find this prevents the pooling on the surface, which is the only working defect of our first beds, made with 'medium' from $\frac{3}{16}$ to $\frac{3}{4}$ in. In all cases with some coaser stuff over the tile floor." It is proposed to complete the Roughing Filters by cleansing apparatus including upward air-blowing.

In I893 Mr. Wallis Stoddart published some experiments ${ }^{1}$ on small model filters of coarse chalk, with arrangements for continuous dropping and trickling. He seeded the bed with liquids containing ammonifying, nitrosifying, and nitrifying organisms successively, and obtained different results according to the rate of flow. The organisms were too much mixed in the same area: he secured, however, "a very constant formation of nitrate of lime," and with a polluted well water he records the following purification :

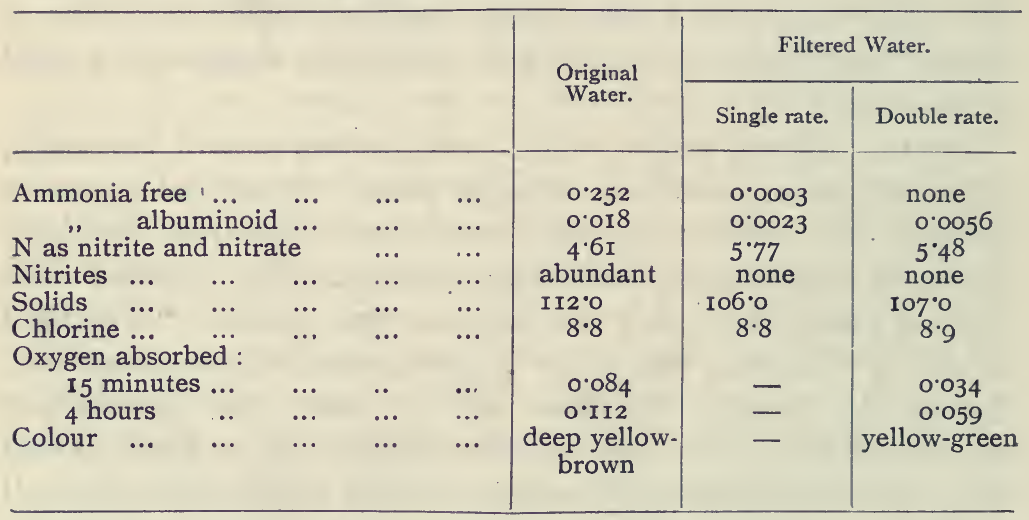

With a sewage percolating continuously through 5 feet of coarse chalk with an upward current of air, the results were:

Sewage. Effluent.

\begin{tabular}{|c|c|c|}
\hline Free ammonia & $3 \cdot 85$ & 0.0013 \\
\hline Albuminoid $\ldots . \quad \ldots$ & O.I 75 & 0.0158 \\
\hline Nitrogen as nitrates... & none & 5.99 \\
\hline Nitrites $\quad \ldots \quad \ldots$ & none & none \\
\hline Chlorine $\quad \ldots, \quad \cdots, \quad \ldots$ & $7 \cdot 9$ & $7 \cdot 8$ \\
\hline Oxygen absorbed I 5 minutes & 0.566 & 0.066 \\
\hline Dissolved solids 4 hours ... & $\begin{array}{l}I \cdot 22 \\
5 I \cdot 0\end{array}$ & $\begin{array}{l}0 \cdot 132 \\
79 \cdot 0\end{array}$ \\
\hline
\end{tabular}

1 Practitioner, 1893; Analyst, 1894, p. 19. 
The flow on the model filter exhibited at the British Medical Association at Bristol, in 1894, was 200 gallons per square yard per day. The first successful working filter on this plan was erected at Horfield, near Bristol, in September, I899, and has since been running continuously night and day. "The composition of the filtering material is immaterial, so long as it is insoluble and not too friable; the size should be $I \frac{1}{2}$ to $\frac{3}{4}$ inches, in no case less than $\frac{1}{2}$ inch, and the depth 6 feet." A chief feature is the distributor (Chapter XII.).

The nitrogen as nitrates and nitrites in samples of the Horfield filtrates is given as $2^{\circ} \mathrm{I} 4,2^{\circ} 57$, and $\mathrm{I} \cdot 8 \mathrm{I}$ parts per roo,000. A recent analysis of the filtrate shows that the oxidation is not complete when the flow is increased: Saline ammonia, $I^{\circ} 90$; albuminoid, $0^{\circ} 12$; oxidized nitrogen, $2 \cdot 80$; oxygen absorbed, 0.88 ; chlorine, 6.14 ; parts per 100,000 . With this filter using the distributor devised by him and with a precipitated sewage or hydrolysed effluent of weak character, the rate of continuous flow can be increased up to I,O00 or I,200 gallons per square yard per day and still yield a final filtrate which is nonputrescible, with an appreciable amount of nitrates and dissolved free oxygen. Stronger sewages require a considerably lower rate, but the fact remains that continuous filters of this type and that used by Moncrieff can deal with sewage at a much greater rate than intermittent ones, when a well-devised distributor is used for insuring that the whole of the filter-bed is utilized.

Other advantages of continuous filters are: (I) The coarsegrain material used in them does not require so deep a construction of the filter as the fine-grain of intermittent filters; (2) it is cheaper than the latter; (3) it does not need washing so often and does not waste so much in washing ; (4) expensive thick walls are not required; (5) from an agricultural point of view, a "contact-bed" wastes about half the nitrogen by dispersal mainly as nitrogen gas, a continuous filter preserves very nearly all of it in fertilizing and innocuous forms (see Chapter IX., p. 222, and Chapter XIV.).

Mr. Stoddart points out that "the improved filter does not constitute a complete system of sewage disposal, as it is not intended to deal with crude sewage."

Repeating the three stages of natural sewage purification-

(I) Anaerobic-hydrolytic solution and ammoniacal change;

(2) Partially aerobic - nitrites and simplified bodies;

(3) Complete oxidation and nitrification; 
it is obvious that a certain preparation is necessary before a sewage liquid can take advantage of an excess of oxygen. Consequently in all systems professing to depend entirely on oxidation we notice that some preliminary treatment, whether natural or artificial, has occurred, and the solids have been avoided by screening, straining, sedimentation, or precipitation, before the continuous and free aeration has been useful in the third stage.

Dr. Geo. Reid ${ }^{1}$ advocates for continuous or "percolating " filters a much finer medium, sifted to $\frac{1}{8}$ inch grain, on the ground that he thus obtains the largest surface for bacterial growth which is compatible with free aeration, and that the bed can be made much shallower and therefore less costly. Such a filter, however, would be liable to rapid clogging unless it was fed with a liquid containing less suspended matter than ordinary septic effluents.

1 " Nitrification of Sewage by Shallow Filters of Fine Particles," British Assoc., York, 1906. 


\section{CHAPTER XI}

\section{BACTERIAL PURIFICATION (continued)}

Unaided bacterial processes-Scott-Moncrieff's tank-Conditions of hydrolysis-The Exeter septic tank-Tank and filter depositsStatistics of septic tank plants-Ames Tank-Hydrolytic Tank - Separate Zones-Moncrieff's trays-Nitrogen and Oxygen relations-Caterham-Manchester experiments-Birmingham -Sheffield-Leeds-American experience.

WE next come to processes that rely for purification on the natural action of bacteria without extraneous aid. This idea had been indicated in the "Automatic Scavenger" of Mouras (p. 205), and could also be gathered from the Massachusetts investigations; but prior to the latter, ${ }^{1}$ in 1890 , ScottMoncrieff made a number of experiments with regard to the observed rapid liquefaction of organic matter in sewers. As he has expressed it, "unless an actively liquefying process was at work it would be impossible for the solid organic matter thrown into a long sewer, with accretions going on more or less all the way, ever to reach its destination along so slight a declivity by any flushing that was available." If this action, which was soon shown to be due to liquefying bacteria, could be intensified and regularly conducted within a small area, it promised to eliminate the sludge difficulty.

It had long been known that in the slow filtration of sewage, more particularly when the direction was upwards, so that little or no mixing with air occurred, very considerable changes in the organic matter were brought about, entirely unconnected with oxidation. Thus in one of Frankland's experiments in I870, when a strong London sewage was made to traverse, "continuously upwards so as to exclude aeration," a layer of sand, the analysis of sewage and effluent given is the more instructive as the meaning of it was not understood at the time.

I The Lawrence, Mass., Experiment Station has been in continuous service since the autumn of 1887 , but the earlier results related to mechanical and chemical treatment. 


\begin{tabular}{|c|c|c|c|c|}
\hline Parts per 100,000 & & & Crude Sewage. & Effluent. \\
\hline $\begin{array}{l}\text { Solid matters in solution } \\
\text { Organic carbon } \quad \ldots \\
\text { Organic nitrogen } \quad \ldots \\
\text { Ammonia ... } \\
\mathrm{N} \text { as nitrates and nitrites } \\
\text { Total combined nitrogen }\end{array}$ & $\begin{array}{c}\ldots \\
\ldots \\
\ldots \\
\ldots \\
\ldots \\
\ldots\end{array}$ & $\begin{array}{l}\ldots \\
\cdots \\
\cdots \\
\ldots \\
\cdots \\
\ldots\end{array}$ & $\begin{array}{l}64 \cdot 5 \\
4 \cdot 39 \\
2 \cdot 5 \\
5 \cdot 5 \\
\text { None } \\
7 \cdot 0\end{array}$ & $\begin{array}{l}80 \cdot 5 \\
3 \cdot 23 \\
I \cdot 4 \\
4 \cdot 6 \\
0 \cdot 328 \\
5 \cdot 5\end{array}$ \\
\hline
\end{tabular}

That is to say, the anaerobic bacteria have acted in the usual way: (I) They have dissolved I6 parts per Ioo,00o of the solid matters or sludge, thereby increasing the solids in solution from 64 to 80 ; (2) Some of the ammonia has been changed into, almost certainly, nitrite; (3) I'I6 parts of carbon ( 25 per cent.) and I'I parts of nitrogen ( 44 per cent.) have been eliminated as non-ammoniacal gases, methane, $\mathrm{N}$, and nitrogen oxides, with probably some $\mathrm{CO}_{2}$.

Mr. Moncrieff constructed at Ashtead in I89I a bacterial tank into which the crude sewage was admitted from below and gradually passed upwards over the surface of a bed of stones. The liquefaction of the solids was so effective that the whole sludge of seven years from a household of ten persons was absorbed on 9 square yards of land. The space beneath the under-grating of the tank had a capacity of less than 5 cubic feet, and would obviously have filled up in a short time but for the liquefying action that had taken place (Fig. 30, p. 268).

In 1892 his process was examined by Dr. Houston and later by Dr. Sims Woodhead and myself. We showed that the effluent retains the ammonia produced by the hydrolysis, together with residues of nitrogenous and carbonaceous dissolved matters, so that judged by ordinary standards of analysis, this liquid contained, as Groves pointed out, a large amount of easily-decomposable nitrogenous organic matter in solution. This great instability of the organic compounds that come over from cultivation tanks is the principal feature of the process.

There was still a belief that hydrolysis and aerobic nitrification could be carried on successfully in the same tank, and at Aylesbury air was forced in by a steam jet with this object in view, but the result was unsatisfactory. It became evident that the nitrogenous organic matter must be as far as possible broken up into ammonia before being oxidized to nitrates, and that these two reactions should be carried on in separate areas, 
the one under anaerobic conditions, and the second with free admission of air but not of light, when the distinctly nitrifying bacteria should be free to work under the most favourable conditions. Even in very strong sewages there seems almost no limit to the capacity of the hydrolytic ferments to break down nitrogenous matter into ammonia. Thus Marchal found that a common organism exercising this function, B. mycoides, could thrive in a medium containing $0^{\circ} 2$ per cent. of caustic potash, equivalent to 660 parts per 100,000 of free ammonia, and in septic effluents in the first stage I have found as much as 30 to 40 parts per I00,000 of $\mathrm{NH}_{3}$.

But there is a limit to the amount of anaerobic change if nitrification in the further stage is to be successful. The prejudicial influence of ammonia on the nitrifying bacteria was pointed out by Warington in I89I (ante, p. I24). Winogradsky and Omeliansky ${ }^{1}$ investigated the influence of different substances, and found that:

I. Sodium carbonate is essential for the growth of both nitrous and nitric organisms. There would always be sufficient in sewage from the presence of washing soda, also from the action of ammonium carbonate on the sodium chloride of urine.

2. Various organic infusions, such as hay, peptone, sugar, broth, etc., have little effect, or are even favourable, except in amounts unlikely to be present in sewage.

3. Urea is without effect when the amount is only $0^{\circ} 05$ per cent., but 0.5 to 0.8 per cent. hinders nitrification. Addition of 2 per cent. of urine results in the time required for oxidation being increased five times, and this result is due to the large excess of ammonia.

4. Iron salts seem to assist the nitrification.

Withers and Frap's results indicate (I) that there are organisms which nitrify organic matters in preference to ammonium salts, (2) that the presence of the latter may hinder the activity of the nitrifying bacteria, and (3) that acids formed in the fermentations may also be a hindrance when insufficient base is present to neutralize them. ${ }^{2}$

By the agency of sewage bacteria in denitrification, nitrates directly oxidize organic matter, producing carbonates and nitrites without any gas, and rendering the liquid strongly

1 Chem. Centralblatt, I899, ii., I32, 217 , and 264 .

'J. Amer. Chem. Soc., xxiii., No. 5. 
alkaline. ${ }^{1}$ On the other hand, when the most complete purification and the highest nitrification are occurring, effluents are either acid or only slightly alkaline, and the poorer the nitrification the greater the alkalinity of the liquids. ${ }^{2}$ This follows from the chemical equations.

At Caterham, with a heavy sewage containing $\mathrm{I} 8$ parts of $\mathrm{Cl}$ per I00,000, Moncrieff began by pushing the preliminary process much further than usual, with the object of ascertaining the most favourable point, by estimating the free ammonia, and finding what amount gave the best results in nitric nitrogen. Exceptionally anaerobic conditions were introduced, by means of inverted open-mouthed glazed earthen vessels, about 400 in

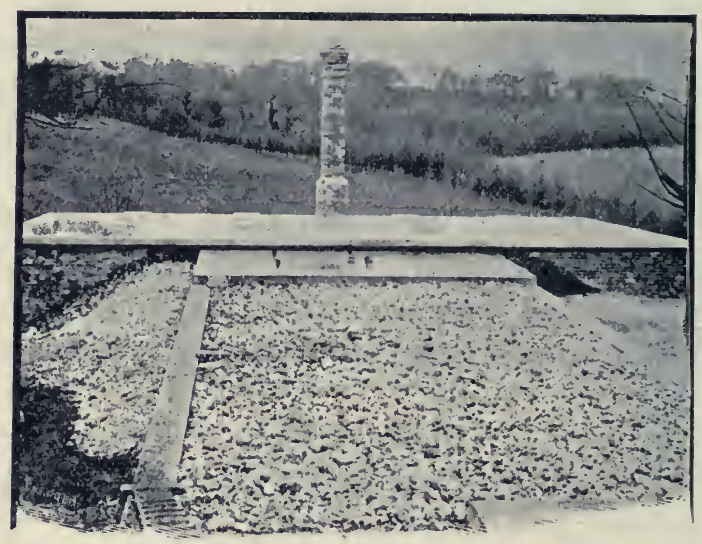

Fig. 25.-Caterham Cultivation Tank.

number, piled in a tank 20 feet by ro feet by 9 feet deep, and kept down by weights. Each pot became filled with gases of the character I have described, devoid of oxygen, so that there were a large number of surfaces on which zooglœa colonies of bacteria could quietly develop in contact with the percolating sewage. The result was an effluent containing 126 parts per I 00,000 of dissolved solids, 35 of free $\mathrm{NH}_{3}$, and $5^{\circ} 3$ of organic nitrogen, which was now highly toxic to any but anaerobic organisms, and absolutely refused to nitrify. When diluted, however, with a few volumes of natural water it rapidly became purified. ${ }^{3}$

UI Pakes and Jollyman, J. Chem. Soc., April, I9or, p. 459.

2 Report Mass. State B. of Health, I905, pp. 227, 229, 238.

3 The Massachussetts Board of Health also observed as to tank and filters at Andover, U.S., that septic action, when carried too far, may make sewage much less amenable to the subsequent action of filters. 
The anaerobic cultivation tank, and Cameron's septic tank, which followed it, do similar work, and both processes to a great extent obviate the sludge difficulty of the precipitation method, and also the choking up of the open downward contactbeds of Dibdin. Kenwood and Butler point out that an upward cultivation has advantages over a septic tank in which there are no surfaces provided for the organisms. They say, "while upward filtration offers a better prospect of effecting the separation and solution of the suspended matters of sewage, it, at the same time, reduces the pollution of the effluent better than any system which aims at their removal by digestion in a hollow chamber, such as the septic tank." Cultivation tanks on these

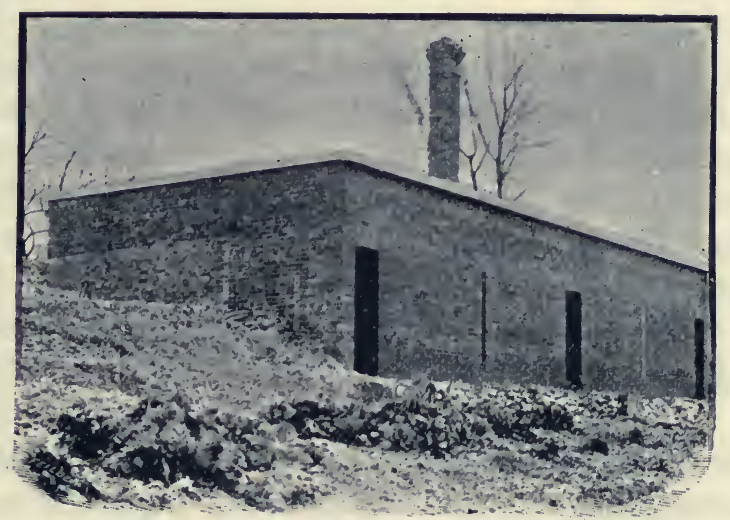

Fig. 26.-Filter House at Caterham.

lines were constructed at Finchley, and are alluded to later. At Maltham, Yorks, as a result of a Local Government Board inquiry in I90I, upward filtration was permitted to be substituted for the scheme sanctioned in I899, which had included chemical precipitation, settling, filtration through coke and magnetite, and finally through land. The new system was in triple series, with detritus tanks 43 feet by $5 \frac{1}{2}$ feet by 4 feet, holding .21,000 gallons or 4 hours' flow, from which the sewage, after passing over a weir into a supply chamber, flowed upwards through the cultivation tanks, 43 feet by 43 feet by 4 feet, containing stone or hard clinker riddled to between 2 inches and 5 inches in size. The effluent was collected above by perforated troughs 3 feet apart, and at the rate of 200 gallons per square yard per day rapid liquefaction and hydrolytic change is reported.

In I895 Mr. Cameron introduced his "septic tank" process 
for the treatment of a portion of the sewage of Exeter, about 50,000 gallons, from 1,500 to 2,000 persons, on the combined system. The tank is cemented watertight, and banked below the ground to keep it from changes of temperature, the top being arched over and covered with turf, so that light and air are excluded. The raw unscreened sewage enters by two inlets 5 feet below the surface, in order that the entry may be quiet, so as not to disturb the bacterial layers, also that air may not be carried in, nor any gases escape back to the sewer. After passing through a "grit chamber," Io feet deep by 7 feet long, and of the same width as the tank ( 8 feet), the sewage flows over a wall submerged I foot below the surface into the main portion of the tank, which is $5^{6}$ feet Io inches in length, 7 feet 6 inches in depth, and 18 feet wide, its capacity up to the level of the liquid being 53,800 gallons, or approximately a day's supply. Hence the transit of the sewage is ordinarily very gradual, averaging about twenty-four hours in the tank, so as to give ample time and quiet for the changes. The Local Government Board at one time asked for a septic tank capacity equal to one and a half times the dry-weather flow. I believe that this is in excess of what is necessary, even when stormwater up to six times the dry-weather flow passes through the tank.

Thus the whole sewage becomes mixed and averaged, and the bacteria have a chance of working during the passing through the $65-\mathrm{ft}$. length of flow, which the sewage traverses at the rate of a little more than 2 feet per hour. No obstruction is present, and the entire space is available, differing from what we have seen of tanks partially filled with stones or coke. In the latter the dimensions must either be larger in proportion, or the sewage must pass at a greater rate, the bacteria also are not so freely distributed through the liquid. From the inspection chamber it is seen that a leathery scum from 2 to 6 inches thick, according to the position, collects on the surface and renders the whole anaerobic. Below this is a zone of fermentation, in which the sewage is mainly clear, but bubbles of gas keep the liquid in a state of quiet admixture. At the bottom of the tank there is a layer of dark peaty deposit, so small in amount that during a period of one year's working it did not require to be removed, and after three years-without clearing the sediment was less than 4 feet deep. The insoluble organic matter was gradually broken up, while the inorganic substances 
were kept in suspension by the gases and passed off in the flow, so that the quantity did not sensibly increase.

At the end of 1898 I found this peaty deposit to contain :-

\begin{tabular}{|c|c|c|c|c|}
\hline Distance from bottom, inches & $\ldots$ & $\begin{array}{c}\text { No. } \\
3\end{array}$ & $\begin{array}{c}\text { No. } 2 . \\
9\end{array}$ & $\begin{array}{l}\text { No. } 3 . \\
\text { I } 5\end{array}$ \\
\hline Organic matter, per cent. & $\cdots$ & $32 \cdot 35$ & 32.40 & $3 I \cdot 3 I$ \\
\hline Ash, per cent. $\quad \ldots$ & .. & $67 \cdot 65$ & $67 \cdot 60$ & $68 \cdot 69$ \\
\hline Nitrogen, per cent. $\quad$.. & ... & $2 \cdot 38$ & $2 \cdot 34$ & $2 \cdot 45$ \\
\hline Percentage of $\mathrm{N}$ in organic ma & ter & $7 \cdot 36$ & $7 \cdot 22$ & $7 \cdot 8$ \\
\hline
\end{tabular}

Microscopical Characters.-No. I. Black amorphous matter, small sand particles, fragments of muscular fibre, dark coloured and corroded, and of other animal tissue ; large amœbæ, cladothrix, micrococci and bacilli, fragments of fæcal matter, vegetable tissue and hairs.

No. 2. Spiral vessels of a plant, anguillulæ, egg of an entozoon, fewer amœbæ, otherwise like the last.

No. 3. Anguillulæ, vegetable hairs and spiral vessels, fæcal fragments rather abundant, sponge spicules, animal hairs. No amœbæ and very few muscle fibres: otherwise similar to the preceding. It will be seen that the older matter is mixed with recent substances lately arrived in the tank.

A sample from the top of the deposit contained 88.8 per cent. of moisture, from mid-depth $83^{\circ} 9$ per cent., from the bottom 80 per cent. Comparing the last with the 90 per cent. moisture in ordinary sludge, it will be seen that the difference reduces the bulk of the deposit by one-half, even if no liquefaction had taken place. Clowes tabulates the moisture in septic tank deposits in a number of towns (the average is 86 per cent.), ${ }^{1}$ also the reductions effected by the tank in the sewage solids. It is generally agreed that this should in good working be not less than 50 per cent.

The deposit from an open septic tank at Manchester in April, I900, contained organic matter $5^{\circ} 24$, inorganic matter 6.78 , water $87^{\circ} 98$ per cent., or in the solids 57 per cent. inorganic and 43 per cent. organic. ${ }^{2}$

In the sediment from a septic tank at Hanwell Sewage Works in July, I905, I found amorphous granular matter, numerous fragments of disintegrating muscular fibre and particles of fæces, cladothrix and gelatinous colonies of micrococci, numerous ova of aquatic worms and large numbers of paramœcium and

1 Fourth Report to London County Council.

2 Royal Commission on Sewage, Second Report, I902, No. 2. 
other infusoria, proving that a sufficient residue of oxygen had remained to enable some resolving aerobic organisms to assist in breaking down the solids.

My analysis of the black deposit from the first contact-bed at Hampton, in June, Igoo, gave :-

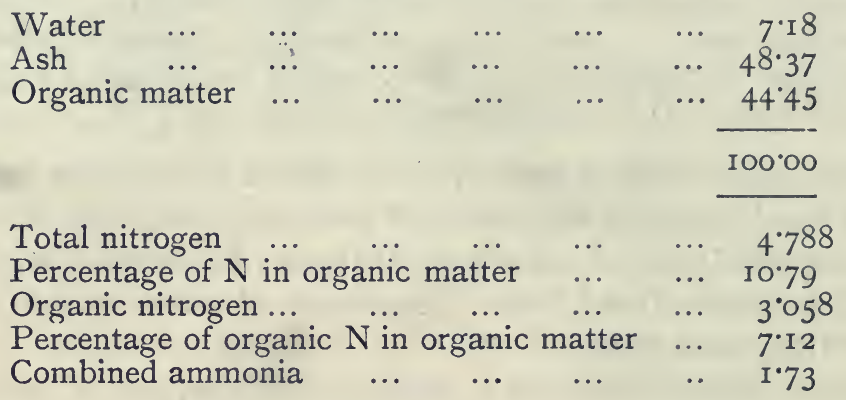

The ash contained :-

$\begin{array}{llll}\text { Oxide of iron and mineral salts... } & \ldots & \ldots & \text { I } 7^{\circ} \circ 0\end{array}$

$\begin{array}{llllllll}\text { Coke } & \ldots & \ldots & \ldots & \ldots & \ldots & \ldots & 4 \cdot 18\end{array}$

$\begin{array}{lllllll}\text { Silicious matter } & \ldots & \ldots & \ldots & \ldots & \ldots & 27^{\circ} 19\end{array}$

$48 \cdot 37$

The organic matter was therefore closely related to humus, and was similar to that found in the septic tank. A microscopical examination showed large numbers of anguillulæ, with amœbæ, a few rotifers and flagellate infusoria, aquatic larva cases and portions of . insects, a few animal hairs, possibly human, and some isolated fragments of muscular fibre, diatoms and desmids (synedra, etc.), vegetable débris, fragments of wood, epidermis, leaf hairs, ducts of ferns, spiral vessels, straw and grass stems. A large quantity of dark brown amorphous matter of humous character. Crimson particles and dyed fibres, blue and orange, fragments of coke and coal, sand, and carbonate of lime crystals.

In September, I900, I found that the black matter collected in Stoddart's continuous filter at Knowle, Bristol, amouted to 4.37 parts per Ioo,000 of effluent, and contained :-

$\begin{array}{lllllll}\text { Mineral matter } & \ldots & \ldots & \ldots & \ldots & \ldots & 3 I^{\circ} 9 \mathrm{I}\end{array}$

$\begin{array}{lllllll}\text { Organic matter } & \ldots & \ldots & \ldots & \ldots & \ldots & 68.09\end{array}$

$100 \cdot 00$

$\begin{array}{llllll}\text { Organic nitrogen } \ldots & \ldots & \ldots & \ldots & \ldots & 4 \cdot 69\end{array}$

$\begin{array}{llllll}\text { Combined ammonia } & \ldots & \ldots & \ldots & \ldots & 0.57\end{array}$

Percentage of organic $\mathrm{N}$ in organic matter $\ldots \quad 6.88$ 
Under the microscope it showed aquatic larva cases, fragments of winged insects, numerous anguillulæ, crustacea (Daphnia), rotifers, infusoria (monas, paramœcium, vorticella), algæ (cladophora and species of conferva), cladothrix, beggiatoa, fungus-mycelium, black particles, probably coke, brown amorphous matter, silicious particles, vegetable hairs and fibre. ${ }^{1}$

Humous matter is favourable and even necessary for subsequent nitrification (p. I23). Humic acid in presence of water absorbs large quantities of ammonia. ${ }^{2}$

Dibdin and Thudichum found that the suspended solids in the tank effluent averaged nearly 20 parts per I0o,00o less than those in the sewage, equivalent to $24^{\circ} 6$ tons of solid matter removed by the tank in a year. In August, I897, one year after the tank had been started, the solid matter in it was found to be 5 tons, therefore the difference, nearly 20 tons, had dissolved and in great part disappeared as gas. This result has been confirmed in other cases: Mr. Fowler found that in the experimental tank at Manchester about two-thirds of the suspended solids were removed with the production of little sludge.

At Oldham it was estimated that $15^{\circ} 63$ grains per gallon of suspended solids were equal to I ton of sludge per million gallons : the quantity of sludge entering the septic tank in Igor was 278 , and the amount leaving II 7 tons, the difference, I6I tons, "having been either left in the tank, converted into gas, or liquefied." After I2 months' working the water in the tank was lowered, and there was found to be not more than $2 \mathrm{ft}$. of sludge at the bottom, in a very liquid condition. "The smell from the sludge was not so objectionable as in the case of ordinary sludge from a fresh tank." It readily dried, and then had an earthy odour and the appearance of garden mould. ${ }^{3}$

Evidence before the R. Commission on Sewage confirmed this digestion of organic matter and showed its variations. ${ }^{4}$

The flow through the tank is continuous, and requires no attention, while the submergence of inlet and outlet minimises disturbance of the contents. At the far end, a transverse iron pipe, about a foot below the level of the liquid, with a slot on the under surface extending its length, forms an exit for the effluent, which passes into a small cistern with a V-gauge, and

1 Trans. Soc. Engineers, 1900, p. 247.

2 Oesterr. Chem. Zeit., I900, iii., 5 I6.

3 Report by Dr. Wilkinson, M.O.H. to County Borough of Oldham.

4 Interim Report, vol. ii., IgO2. 
then falls in a thin stream over an aerating weir, with a view to restore aerobic conditions, by allowing products of fermentation such as hydrogen and methane to escape, and introducing some oxygen. It then flows through distributing channels on to filters of coke breeze or clinker, similar to those at Barking and Sutton, four of which are used at a time, and one kept in reserve. Cameron's automatic gear ${ }^{1}$ regulates the cycles of filling, resting full, emptying, and aeration, so that here again no attention is required. The Local Government Board inquiry of 1897 approved of the system being applied to the whole of the city, of a population of 46,000 , with the usual proviso as to

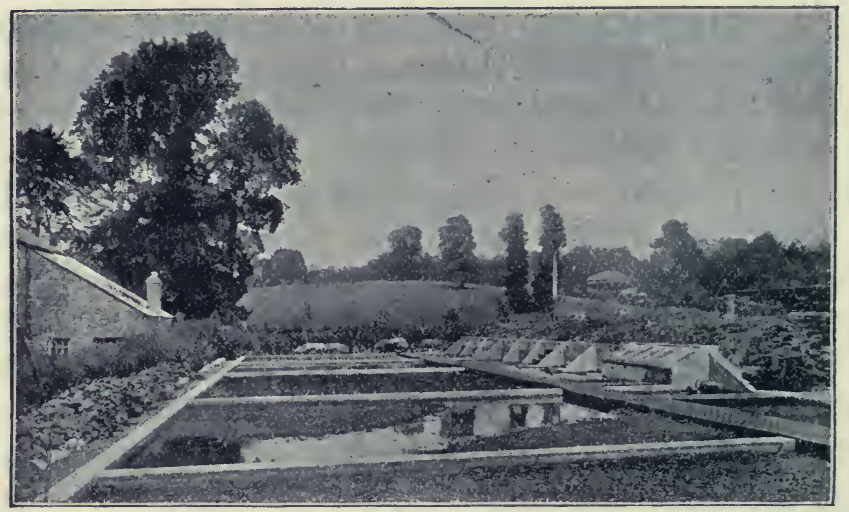

Fig. 27.-Experimental Septic Tank and Filters, Belle Isle, Exeter. The gas-lamp is lighted by the gases from the tank.

land. For the daily flow of $1,064,610$ gallons there are now six tanks $I 8 I \times 35 \times 7 \mathrm{ft}$. deep, with a capacity of 262,422 cubic feet; and eight filters, of 13,600 square feet each (total $2 \frac{1}{2}$ acres), having a depth of $3 \frac{1}{2} \mathrm{ft}$. of crushed furnace clinker on 6 in. of coarse gravel, and a working capacity of $2 \frac{1}{2}$ million gals. a day, operating with alternating gear as before.

Cameron, like Scott-Moncrieff, carefully differentiates between the hydrolytic or solution process, and the subsequent oxidation required for final purification. Sims Woodhead has shown that while the anaerobic organisms are more numerous in the tank, a number of liquefying aerobic organisms are still present, and increase on passing over the aerating weir. The filters are, of course, intended for aerobic working, but are open to the objections already urged against intermittent filters.

1 See Chapter XII. 
The changes occurring in the tank are complex. From analyses by myself and others it appears that the total dissolved solids are increased somewhat, but not in relation to the organic débris that has passed into solution. A large proportion has undergone the hydrolytic decomposition, producing nitrogen, methane, a small quantity of hydrogen, ammonia, and carbonic acid. The result is the production of a large quantity of inflammable gas, which according to Clark amounts

\section{Diagram of Overflow Pipes.}
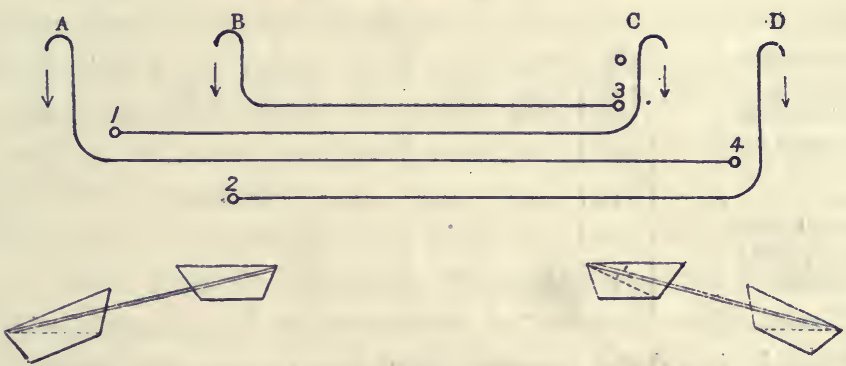

Diagram showing successive states of Filters corresponding to successive positions of alternating gear.

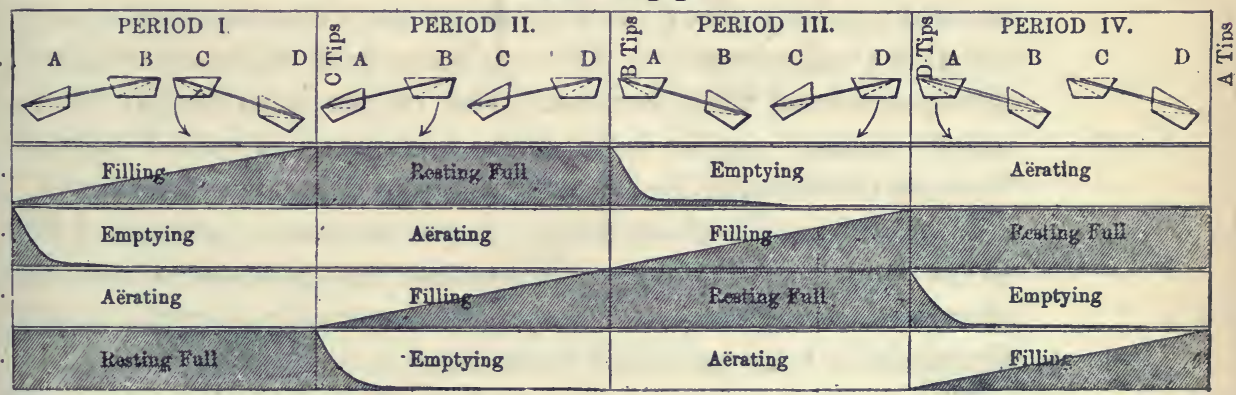

Fig. 28.-Working of Cameron's Automatic Gear.

to half a cubic foot per Ioo gallons of sewage, and as previously mentioned, has been successfully utilized.

A few explosions have occurred through the ignition of the tank gas. Except near houses or highways, tanks are now usually either left open, or are covered with light iron roofs.

The ammonia and the major part of the $\mathrm{CO}_{2}$ remain in the solution, which contains on an average 33 per cent. more of free $\mathrm{NH}_{3}, 29$ per cent. less of organic matter as measured by the oxygen consumed, and 46 per cent. less of albuminoid ammonia. If we knew the nature of all the bacterial changes, 
then the determination of the volume and character of the gases evolved would give an indication of the nature and energy of the bacterial action.

In the first Massachusetts experiments (Report State Board, I899), the average of monthly analyses gave in parts per 100,000 :-

\begin{tabular}{|c|c|c|c|c|c|c|c|c|c|c|}
\hline \multirow{2}{*}{ f } & \multirow{2}{*}{ Temp. } & \multirow{2}{*}{$\begin{array}{l}\text { Free } \\
\mathrm{NH}_{3} .\end{array}$} & \multicolumn{3}{|c|}{ Albuminoid $\mathrm{NH}_{3}$. } & \multirow{2}{*}{ Cl. } & \multirow{2}{*}{$\begin{array}{l}\text { O con. } \\
\text { sumed. }\end{array}$} & \multirow{2}{*}{$\begin{array}{c}\text { Nitric } \\
\text { N. }\end{array}$} & \multirow{2}{*}{$\begin{array}{c}\text { Nitrous } \\
\text { N. }\end{array}$} & \multirow{2}{*}{$\begin{array}{l}\text { Bacteria } \\
\text { per c.c. }\end{array}$} \\
\hline & & & Total. & $\begin{array}{c}\text { Dis- } \\
\text { solved. }\end{array}$ & $\begin{array}{c}\text { Sus- } \\
\text { pended. }\end{array}$ & & & & & \\
\hline $\begin{array}{l}\text { Raw sewage } \\
\text { Tank effluent } \\
\text { Coke filtrate } \\
\text { Percentage } \\
\text { change by } \\
\text { tank } \\
\text { Per cent. im- } \\
\text { provement } \\
\text { at finish... }\end{array}$ & $57^{\circ}$ & $\begin{array}{l}4^{\cdot} \cdot 44 \\
4^{\cdot} \cdot 86 \\
I \cdot 74\end{array}$ & $\begin{array}{l}0.79 \\
0.41 \\
0.104\end{array}$ & $\begin{array}{l}0.47 \\
0.32 \\
0.104\end{array}$ & -72 & $\begin{array}{c}9.21 \\
10.11 \\
10.53\end{array}$ & $\begin{array}{l}4^{\circ} 00 \\
2 \cdot 29 \\
0 \cdot 62\end{array}$ & $\begin{array}{c}0 \\
0 \\
I \cdot 80\end{array}$ & $\begin{array}{c}0 \\
0 \\
0.0056\end{array}$ & $\begin{array}{r}2,000,000 \\
324,500 \\
44,100\end{array}$ \\
\hline
\end{tabular}

This is in close accord with my results at Exeter in 1896 and later. At first the tank effluent, according to the usual American practice, was sent over a sand filter, with, not unnaturally, a bad effect, on account of the closeness and lack of aeration; afterwards a Dibdin coke bed with intermittent filling was used with success. The report is in favour of "a much smaller septic tank than has been proposed abroad, because the sewage has travelled far and has lost its oxygen," and already undergone much of the anaerobic change. The State Board of Health of Minnesota has prohibited the discharge of sewage unless " first passed through a septic tank or filter-bed or both tank and filter-bed."

The organic matter is now in a readily oxidizable state, and passes on to the second or aerobic stage, in which it is dealt with by the filters. A large amount of carbonic acid is produced in the filters by oxidation of the organic matter, and is partly driven out in the stages of filling. Much of the combined nitrogen now changes into nitrates; the average at Exeter was about one per 100,000 of nitric N. After a period of long rest, the greatest amount of nitric $\mathrm{N}$ makes it appearance in the first runnings, showing that it is during the period of rest that the nitric acid is formed. I found in these cases 3 to 5 parts of nitric N. ${ }^{1}$ 
The percentage purification found in Exeter in 1897 was :-

\begin{tabular}{|c|c|c|c|c|c|c|c|c|}
\hline \multirow{2}{*}{ Observer. } & & & \multicolumn{3}{|c|}{ Albuminoid Ammonia. } & \multicolumn{3}{|c|}{ Oxygen Consumed. } \\
\hline & & & Tank. & Filter. & Total. & Tank. & Filter. & Total. \\
\hline Dupré ... & $\ldots$ & $\ldots$ & - & - & $84^{\circ} 9$ & - & - & $88 \cdot 3$ \\
\hline 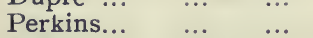 & $\begin{array}{l}\cdots \\
\ldots\end{array}$ & $\begin{array}{l}\cdots \\
\cdots\end{array}$ & 二 & - & $64^{\circ} 4$ & - & - & $78 \cdot 7$ \\
\hline Dibdin and Thudichum & $\ldots$ & $\ldots$ & - & - & $63 \cdot 2$ & - & - & $80 \cdot 9$ \\
\hline Pearmain and Moor... & $\ldots$ & $\ldots$ & - & - & $80^{\circ} 0$ & - & - & $90 \cdot 0$ \\
\hline Rideal ... $\quad \ldots \quad \ldots$ & $\cdots$ & $\ldots$ & 46 & $3 \mathrm{I}$ & $77^{\circ} \mathrm{O}$ & 29 & 53 & $82 \cdot 0$ \\
\hline
\end{tabular}

The analyses of the raw sewage and tank effluent do not, however, give a complete idea of the purification, since the effluent is the sewage minus a certain quantity of organic matter that has been removed, and plus another quantity that has been dissolved from the sludge.

In Cameron's patent $567 \mathrm{I}$, of 1898 , the tank has two or more decks or floors, to facilitate the separation of the solids, and allow the deposit to come better in contact with the fresh sewage. Depressions or pockets may be provided into which the sediment may drift, and from which it may be removed without emptying the tank. For the utilization of the gas generated, two or more outlets are constructed at different levels: when the lower ones are closed, the liquid in the tank rises and so creates a pressure by which the gas can be expelled.

At Yeovil and other places it has been proved that the septic tank process is not affected by manufacturing refuse. The smoothing and diluent effect in the volume of sewage, and the room for precipitation and neutralization by the ammonia, seem to obviate these difficulties. The works at Exeter and Yeovil are in the neighbourhood of houses, and are quite inoffensive.

With reference to the action of the grit chamber; on entering, the heavy particles of gravel and sand at once sink, while the organic refuse almost entirely floats and passes over the submerged wall into the tank. The result is that very little solid sewage remains in the grit chambers, and the gravel may at intervals be dredged out without disturbing the contents of the tank. This is not at all parallel to the action of screens or straining filters, which arrest a large amount of solid organic matter, and form a subsidiary sludge.

As to the stay in the tank. The flow of the liquid through 
the tank in dry weather occupies 24 hours or more, and in wet weather may be reduced to 7 hours. But the more intractable solids remain much longer: they are entangled by the active zooglœa scum on the surface, or may slowly sink to the bottom; and they accumulate in the tank until the rate of dissolution is equal to the accretion of the fresh solids. When equilibrium is established, the scum and the sediment, though showing some fluctuation, should have an approximately constant volume. A capacity equal to 24 hours' flow is generally advisable: in America, with much weaker sewages, 8 hours has been found sufficient.

Possible survival of pathogenic organisms has been dealt with in Chapter IV., p. 84.

Notes on Septic Tank Plants.-Barrhead, near Glasgow (Septic Tank Syndicate) Works, opened in I899, deal with a population of ro,000 and a maximum daily flow of 400,000 gallons including storm water, and have provision for larger amounts. Two grit chambers, four septic tanks, and eight aerating bacterial filters, the whole built in concrete. Each tank roo ft. long by $\mathrm{I} 8 \mathrm{ft}$. wide and $7 \mathrm{ft}$. deep at low water, roofed by concrete arches on rolled steel joists with brick piers. Total dryweather capacity, 312,500 gallons, with storm allowance for a rise of 18 inches, or an additional 70,000 gallons, the flow to the filters maintained constant by two controlling modules. Each filter is $55 \mathrm{ft}$. by $54 \mathrm{ft}$. with $4 \mathrm{ft}$. depth of broken furnace clinker; total filtering area 2,540 square yards. Two of the filters are usually kept in reserve. Arrangements as at Exeter. A report after 6 years' working ${ }^{1}$ states that, with periodical turning over on the surface, the filters have kept their capacity, and produce without fail a good effluent, and that the septic tank has never been interrupted nor cleaned out: the grit tanks are emptied 2 or 3 times a year. Total cost of works and land $£ 6,776$.

Overbrook, New Jersey, U.S., on Exeter principle. Concrete tank $50 \times 18 \times$ Io $\mathrm{ft}$. deep, $=65,000$ gallons : four filters I $4 \times 14 \times 5 \mathrm{ft}$. deep, at first filled with sand as at Lawrence, which rapidly clogged, afterwards with coke breeze. As a nuisance occurred, two larger beds, $4,500 \mathrm{ft}$. area and $3 \mathrm{ft}$. deep, were made, and gave a good effluent. The tank effluent lost its odour after standing for three hours, and there was no subsequent putrefaction, but a strong growth of algæ. Total cost

\footnotetext{
1 Ex-Provost Shanks, Glasgow Congress of Sanitary Institute, 1904.
} 
about $£ 800$. Sewage averages 80,000 gals. per day, so that it ordinarily flows through the tank in 20 hours.

Independence, Missouri. Two sets of circular septic tanks, each $50 \mathrm{ft}$. diam., divided by an annular wall of loosely laid bricks. The flow can be reversed by valves to prevent clogging. Two circular filters, to which the flow can be switched at intervals, constructed on the Moncrieff system, with 4 coke breeze trays separated by air spaces.

Baltimore. Septic tank treatment approved by the Baltimore Commission in Igor. The experimental works resulted in the recommendation in 1906 of a scheme in which the sewage ( 75 million gals.) remains 6 to 8 hours in the tanks, is then sprayed on to sprinkling filters of broken stone about $9 \mathrm{ft}$. deep, from nozzles $I_{5} \mathrm{ft}$. apart, then stays in settling basins for $3 \mathrm{hrs}$. (by which altogether about 95 per cent. of the bacteria are removed), and is to be finally purified by sand filters in preference to mechanical filters with a coagulant, which had also been suggested.

Holland, Michigan. Tank constructed of 3 in. tongued and grooved pine planks in I9oo, Ioo ft. long by $\mathrm{I} 4 \mathrm{ft}$. in width, with a water depth of $6 \frac{1}{2} \mathrm{ft}$. Enclosed in wooden building, with galvanised iron roof. Beyond the grit chamber the tank is divided into three long compartments, each holding 18,850 gallons: total capacity, including the grit chamber, 63,375 gallons. Turning the sewage through only one compartment gives a rest period of 40 per cent. of the total capacity, and with two compartments 70 per cent. The three may be used as one long tank, the sewage passing direct through the first, back through the second, and out through the third. This arrangement is thought to facilitate cleaning. ${ }^{1}$

La Grange, Illinois. Septic tank divided lengthways into three compartments, each Ioo ft. long, Io ft. wide, and Io ft. deep, with a concrete roof 6 in. thick; in continuous operation since November, I90r. Sewage in each tank is $7 \mathrm{ft}$. deep, is stored from I 2 to 18 hours, and flows from the tanks over three weirs in thin sheets, dropping 18 ins. into a shallow basin, from which it discharges back into the main sewer. Each compartment has a regulating valve at the inlet, and baffle boards near the outlet to prevent gas from escaping or scum from passing over the weirs. The previous offensive sewage odours are not now observed. ${ }^{2}$ 
Champaign, Illinois, is remarkable for the rate at which the septic tank, started in 1898 , has dealt with a weak sewage. A flow of 300,000 gals. per day, from 3,500 persons, fills the tank I3 times in $24 \mathrm{hrs}^{1}$

A report by Winslow on sewage disposal plants in 1905 in Ohio, Wisconsin and Illinois, gives working details and analyses from a number of places. ${ }^{2}$

Downers Grove, Ill. (pop. 3,000), works completed Sept., I905. Grit chamber, tank $60 \times I 8 \times 7 \mathrm{ft}$. deep at inlet and $9 \mathrm{ft}$. at outlet, $=64,000$ gals. Flat concrete cover on beams and piers. Upward filter, then distribution by automatic valves and wooden troughs over filters of gravel and sand. Gross cost, $£$ Io,8oo.

Marion, Ohio (pop. I5 $_{5} 000$ ), works opened end of 1905. Dry weather flow 250,000 gals., but plant for 500,000 gals. Grit chamber, 3 covered tanks with baffle boards, an aerating chamber, and 6 contact beds, 5,000 sq. $\mathrm{ft}$. area and $4 \mathrm{ft}$. deep, filled with broken limestone: distribution by sluices and troughs. Finally 6 intermittent filters, each $5,200 \mathrm{ft}$. area, with $2 \mathrm{ft}$. fine gravel and 8 in. sand. Works combined with an incinerator, which ventilates the tanks and filters.

Centerville, Iowa (pop. 6,00o). Double tank, 6o,ooo gals., $8 \mathrm{ft}$. deep, 8 hrs.' capacity, baffle boards at entrance and exit. Tank effluent passes over measuring weirs into the creek. Cost $£ 604 .^{3}$

Columbus, Ohio, Experiments.-In I905 the effects of plain sedimentation and septic action were compared by means of 5 tanks: three $40 \times 8 \times 8 \mathrm{ft}$., a fourth circular $\mathrm{I} 2 \frac{1}{2} \times 5 \frac{1}{2} \mathrm{ft}$. ; the fifth, a boiler shell $15 \times 6 \mathrm{ft}$. diam., depth of sewage $5 \mathrm{ft}$., had a pipe leading to a meter for registering the evolved gas. The sewage had been screened, and, except in the last case, had also passed through a grit chamber. The conclusions only apply strictly to Columbus conditions, but some of them are general. From 8 to I7 days was necessary for septic action to become established, less in summer than in winter. A well-defined scum was not a regular accompaniment. When run at such a rate that the volume was displaced every $8 \mathrm{hrs}$., the volume of gas ranged from $\mathrm{I}^{\prime} 5$ to 7 per cent. of that of the sewage. The amount of dissolved solids was almost unchanged, even with

1 "Economical Disposal of Sewage," by Robert Fletcher, New Hampshive Sanitary Bulletin, I900.

2 fourn. of Amer. Assoc. of Eng. Societies, vol. xxxiv., No. 6.

3 Eng. Record, N.Y., March, 1906. 
24 hrs.' stay, but the free ammonia increased from 3 to 34 , averaging 17 , per cent. [The loss from this cause must have been replaced by the liquefaction of suspended matter.] About 50 per cent. of the fats was removed. ${ }^{1}$ At no time were there offensive odours round the tanks, and the sludge had little odour. In plain sedimentation the deposit averaged $3.3 \mathrm{cub}$. yd., in the septic tanks $I^{*} 33$ cub. yd. per million gallons, therefore the sludge liquefied in the latter averaged 60 per cent. of the total entering. The closed tank, receiving crude sewage, showed 50 per cent. reduction in the solid matter deposited as sludge, and this is considered a sound general average. There was no appreciable reduction of sulphates in the tank. It was demonstrated that uncovered tanks and sprinkling filters could be used in the open air in the cold winter climate of Northern Ohio. The scheme selected as best includes open septic tanks holding 8 hrs.' flow, sprinkling filters passing 2 million gals. per acre daily, and final settling basins holding 2 hrs.' flow ; the result being "a non-putrescible effluent of satisfactory appearance from which about 90 per cent. of the bacteria in the raw sewage are removed." 2 Works are now being constructed for the city under contract for a 20 million gallon plant at $£ 87,000$, excluding pumps and mains. Septic tanks are now in regular use in more than thirty cities and towns in the United States. ${ }^{3}$

Details of the working of English plants are given in the evidence before the R. Comm. on Sewage, Interim Report, vol. ii., I90 $2^{4}$; also in a Report to the London County Council by Clowes and Houston, Division III., p. I5I, I904.

At York, two open septic tanks, each $\mathrm{I} 64 \mathrm{ft}$. long by $40 \mathrm{ft}$. wide, are used, the flow from the first passing through the second; the velocity of the flow for some days before and after was $0.28 \mathrm{ft}$. per minute, or $I 6 \frac{3}{4} \mathrm{ft}$. per hour, and the quantity passing, 628,000 gallons per 24 hours. Samples of the flow were taken at the inlet (raw sewage) and at various distances between the inlet and the outlet, where it passed to the continuous filter. The results are given in the following table :-

1 In 1902 I found the removal of the fats by a septic tank was 78 per cent., the raw sewage containing 3.08 per cent. of fat, the effluent 0.68 per cent.

${ }_{2}$ Report on Sewage Purification at Columbus, Ohio; Nov. I0, 1905. Eng. Record, N.Y., Dec. 30, 1905.

${ }^{3}$ Hering, Gray and Stearns, Sewerage Commission, Baltimore, I9o6.

"A full review of this evidence is given in "The Sewage Problem," by A. J. Martin, I905: San. Publishing Co. 
Analysis of Septic Tank Contents taken on March i5, igo4.

\begin{tabular}{|c|c|c|c|c|c|c|}
\hline $\begin{array}{l}\text { Distance from } \\
\text { Sewage Inlet. }\end{array}$ & $\begin{array}{c}\text { Free } \\
\text { Ammonia. }\end{array}$ & $\begin{array}{l}\text { Albuminoid } \\
\text { Ammonia. }\end{array}$ & $\begin{array}{c}\text { Oxygen } \\
\text { Absorbed. }\end{array}$ & $\begin{array}{c}\text { Total } \\
\text { Suspended } \\
\text { Solids. }\end{array}$ & $\begin{array}{l}\text { Mineral } \\
\text { Suspended } \\
\text { Solids. }\end{array}$ & $\begin{array}{l}\text { Organic } \\
\text { Suspended } \\
\text { Solids. }\end{array}$ \\
\hline \multicolumn{7}{|l|}{ Feet. } \\
\hline & 2.555 & 0.665 & $3^{\circ} 160$ & $34^{\circ} 3$ & $8 \cdot 4$ & $25^{\circ} 9$ \\
\hline 18 & $\mathrm{I} \cdot 435$ & 0.595 & $2 \cdot 673$ & $30^{\circ} \mathrm{I}$ & $8 \cdot 4$ & $2 \mathrm{I}^{\circ} 7$ \\
\hline 72 & $\mathrm{I} \cdot 400$ & 0.560 & 2.43 & 28.0 & $7 \% 7$ & $20 \cdot 3$ \\
\hline 102 & I.085 & 0.420 & 2.43 & $25^{\circ} 9$ & $7 \circ$ & 18.9 \\
\hline 132 & $I \cdot 260$ & 0.420 & $2 \cdot 31$ & 22.4 & $6 \cdot 3$ & I6.I \\
\hline I95 & I.575 & 0.385 & I.944 & $21^{\circ} 0$ & 4.9 & I6.I \\
\hline 225 & I.575 & 0.315 & $I \cdot 6$ & $20 \cdot 3$ & $4^{\circ} 9$ & 154 \\
\hline 255 & I. 260 & 0.315 & $1 \cdot 6$ & 17.5 & $4^{\circ} 9$ & $\begin{array}{r}12 . \\
12.6\end{array}$ \\
\hline 308 & I'Igo & 0.315 & $\mathrm{I} \cdot 6$ & 14.7 & $3 \cdot 85$ & 10.85 \\
\hline 326 & I.I I & 0.315 & I.6 & 14.35 & 3.85 & 10.5 \\
\hline
\end{tabular}

In septic tanks the sewage enters and emerges at practically the same level, so that, for the first part of the process, no pumping is required, nor difference of level necessary in the land, as in most other processes. A certain time is, as usual, required after a new installation for the bacteria to attain full activity, but on account of the absence of interruption this would appear to be short, especially if inoculated with scum from an old active tank, after which the process goes on automatically. Loss of capacity in the tank, due to collection of solid matters, does not, unless in extreme cases, affect the quantity of sewage which can be dealt with by it daily; whereas the loss of capacity in a bacteria bed does diminish the volume of sewage which it can pass; and in the event of cleansing becoming necessary, the work of removing the deposit from a septic tank is very light, compared with that which would be required to wash the bed material of a bacteria bed of equal working capacity.

The principle of the septic tank is quiescence of the sludge and removal only at long intervals. The following forms of plant diverge from this idea, and approach to the old simple sedimentation tank, which required frequent emptying and produced large quantities of sludge. In Dunbar and Thumm's trials at Hamburg the contents of the tank were drawn off much too quickly on to the contact beds.

The "Ames Tank," used at the Iowa State College at Ames, is a semi-anaerobic arrangement in which the contents of the receiving chamber are removed intermittently every 6 or 7 hours instead of continuously, air being drawn in at each discharge, whereby "escape is provided for the gases of decomposition which have been found injurious to the purifying organisms of 
the filter-beds, therefore there has been no difficulty in establishing nitrification." This remark of course applies to the use of a close-textured filtering material afterwards, in this case gravel and sand. But the preliminary resolution of the solids is very imperfect, and the sludge has to be removed from the chambers once a month, amounting to 6 or 8 loads, the sewage being 40,000 gallons daily. At intervals a sediment has also to be removed from the surface of the filter-beds, and every few weeks they require raking, or clogging and offensiveness would occur.

"Hydrolytic Tank." Observations in glass bottles or tanks, such as those of Mouras about I880 (see Chap. IX.), Kenwood and Butler and other investigators, and those commenced by Travis with a large glass model at the Hampton Sewage Works in I904, are often very useful, but, besides the difference of scale, there are other divergences from actual practice, such as the usual working in light instead of in darkness, and with a smooth, almost sterile, instead of a rough fertile, surface. Travis's patents, IIO73 of 1903 and 4980 of I905, have been for some time in operation at Hampton. The sewage passes through a screen and detritus chamber into a tank divided longitudinally into 3 parts by flagstones sloping outwards, so that the centre compartment resembles in section an inverted funnel, and the lateral ones are wedge-shaped. Entering first these side "sedimentation chambers," the sewage deposits a great part of its remaining solids, which pass, with a portion of the liquid, through holes at the bottom of the wedges, into the central "liquefying" or "reduction" chamber, in which fermentation goes on, much gas is evolved, and the sludge accumulates. The tanks are in duplicate ; every fortnight the flow is diverted from one to the other, and the sludge is run out from the full tank through valves at the bottom. From the tank the sewage passes over weirs into an upward anaerobic filter, which at first was practically the same as Moncrieff's cultivation tank (p. 268), and later was fitted with inclined plates, like some of the machines used for removing lime-deposit in water-softening. In these " hydrolysing chambers" (four in number, arranged in sequence) the sludge is again removed frequently through openings below. The plant is roofed, and the gases are drawn off by a fan into a chimney. ${ }^{1}$

1 Jones and Travis, Proc. Inst. Civ. Engineers, 3599, 1905; Travis, Trans. Civ. and Mechan. Eng. Soc., May 3, Igo6. 
Separate Zones.

It has been already pointed out how in ordinary bacteria beds the natural reactions are somewhat fortuitously reversed and confused, according to the periods of filling or rest, the fault being caused by mixing all the different bacteria in one or two large filters.
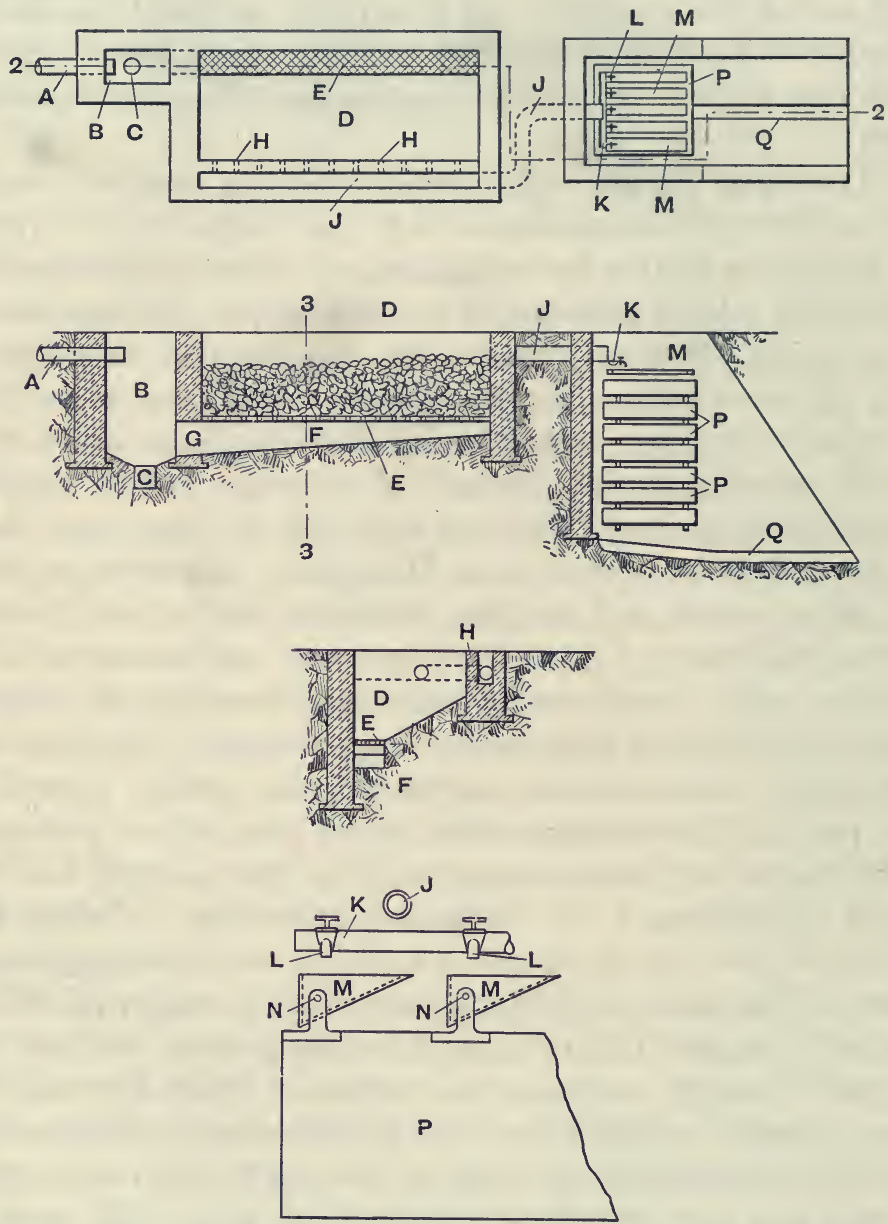

A, Sewage inlet; B, C, Grit chamber and Sump; D, Cultivation tank; E, grating ; $F, G$, underspace ; $H$, Outlets to channel $J ; K, L$, valves ; $M, N$, Tippers; $P$, Nitrifying trays; $Q$, exit.

Fig. 29.-Ashtead Cultivation Bed and Zonal Tray Filters.

By using a series of smaller, separate areas, and passing the effluent continuously and progressively through them, with ample opportunity for the access of the air where it is required, 
the organisms gradually chose their own conditions, and allied groups gather together at different levels as coatings on the filtering material. The advantage of separating the organisms appeared early from a remark of Jordan and Richards, in the Massachusetts Report of 1890 (ii., 877), that "in the filtertanks at the Lawrence Experiment Station, speedy nitrification was always coincident with a marked decline in the numbers of bacteria. The more complete the nitrification, the fewer were the bacteria in the effluent." In the latter sections the nitrifying organisms should be almost alone, and therefore able to exert their full activity. In this way Moncrieff secured a much higher nitrification than was obtained by the other processes.

This he has accomplished by spreading the "tank effluent" by tipping troughs or distributors over the uppermost of a series of "nitrifying trays." (See Fig. 29.). In experiments at Ashtead with a domestic sewage, nine perforated trays, each having an effective area of I square foot and containing 7 inches of coke broken to I inch in diameter, were supported vertically over one another at about three inches apart. It required only from eight to ten minutes for the liquid to pass through all the trays. In 1898 , after the apparatus had been running continuously for three months at a flow equal to one million gallons per acre per 24 hours, I collected on two occasions samples from the different trays and examined them separately.

The results of these analyses of the tank effluent and final filtrate from the ninth tray are given in the table:-

PARTS PER IOO,OOO.

\begin{tabular}{|c|c|c|c|c|c|c|c|}
\hline & & \multicolumn{2}{|c|}{ I. } & \multicolumn{2}{|c|}{ II. } & \multicolumn{2}{|c|}{ III. } \\
\hline & & $\circ$ & 9 & $\circ$ & 9 & $\circ$ & 9 \\
\hline Chlorine & .. & $9^{\circ} \mathrm{O}$ & 7.5 & $6 \cdot 3$ & $6 \cdot 4$ & $5 \cdot 5$ & 5.5 \\
\hline Ammonia $\quad \ldots$ & $\ldots$ & II 5 & 0.25 & $4 \cdot 25$ & 0.755 & $4 \%$ & 0.42 \\
\hline Albuminoid ammoni & a... & $I \cdot 5$ & 0.60 & 2.93 & 0.475 & $I \cdot 472$ & 0.107 \\
\hline Nitric nitrogen... & $\ldots$ & 0.12 & $9^{\circ} \mathrm{O}$ & none & 5.98 & none & $4.34^{\circ}$ \\
\hline Nitrous nitrogen & $\ldots$ & none & $\begin{array}{l}\text { slight } \\
\text { trace }\end{array}$ & none & 0.06 & none & 0.034 \\
\hline Total unoxidised $\mathrm{N}$ & $\ldots$ & 12.35 & 0.60 & $6 \cdot 60$ & $I \cdot 12$ & $5 \cdot 35$ & 0.148 \\
\hline Organic $\mathrm{N} \quad \ldots$ & $\ldots$ & $2 \cdot 05$ & 0.394 & $3 \cdot 10$ & 0.50 & $2 \cdot 06$ & 0.113 \\
\hline Total nitrogen ... & $\ldots$ & $12 \cdot 47$ & $2 \cdot 60$ & $6 \cdot 60$ & $7 \cdot 16$ & $5 \cdot 35$ & 4.522 \\
\hline Oxygen consumed & $\ldots$ & 9.84 & 0.589 & 9.05 & 0.608 & 7.52 & 0.632 \\
\hline
\end{tabular}




\section{Percentage Purification.}

\begin{tabular}{|c|c|c|c|c|c|}
\hline & & 1. & II. & III. & Average \\
\hline $\begin{array}{l}\text { (I) Oxygen consumed ... } \\
\text { (2) Oxidation of nitrogen }\end{array}$ & $\begin{array}{l}\ldots \\
\ldots\end{array}$ & $\begin{array}{l}94 \\
93.7\end{array}$ & $\begin{array}{l}93.3 \\
84.3\end{array}$ & $\begin{array}{l}91 \cdot 6 \\
96 \cdot 7\end{array}$ & $\begin{array}{l}93 \\
91 \cdot 6\end{array}$ \\
\hline
\end{tabular}

The intermediate stages of the first sample are expressed in the curve (Fig. 30), in which the horizontal figures indicate the trays and the vertical ones the parts of nitrogen. We notice that :-

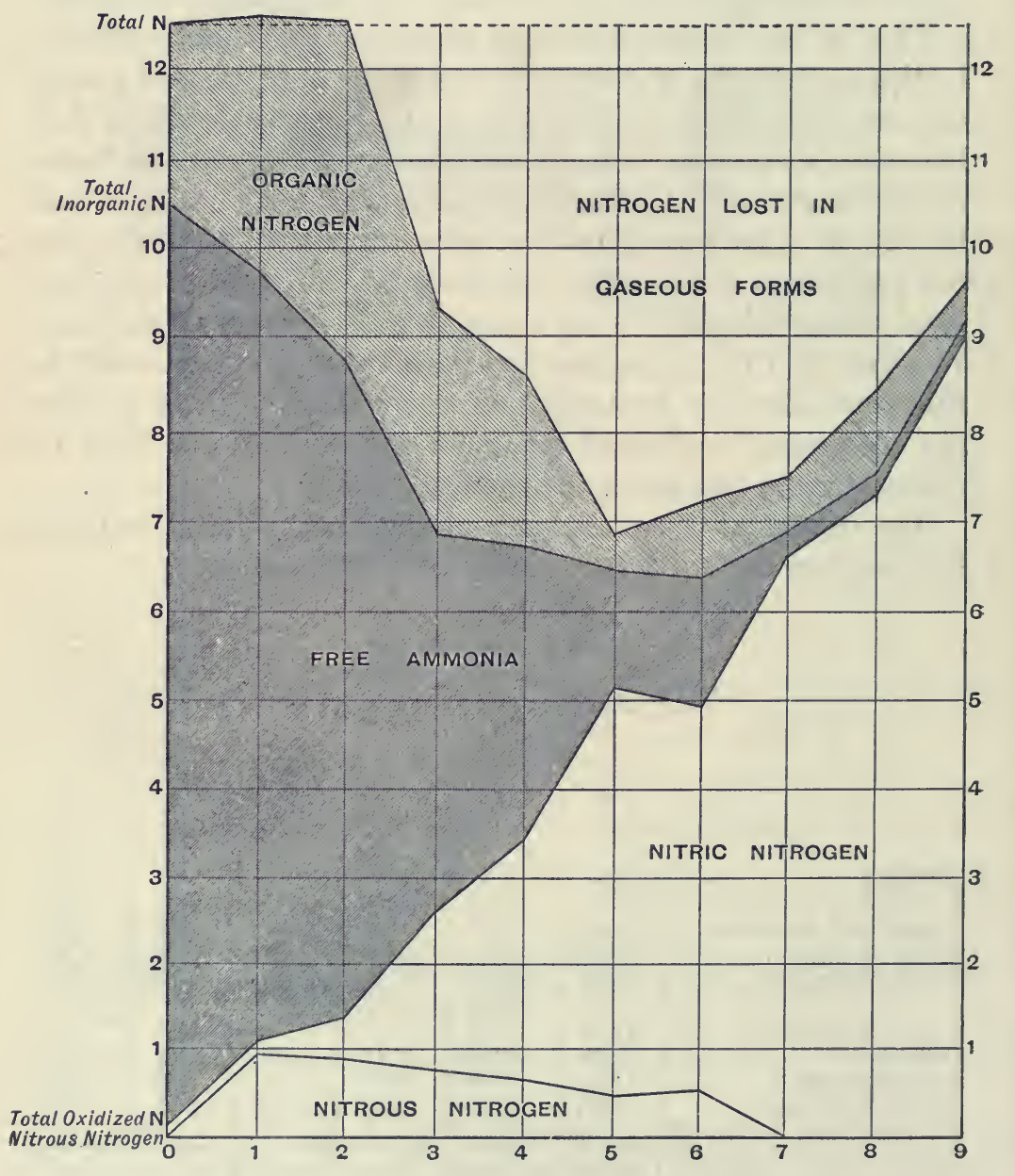

Fig. 30.-Changes of Nitrogen in Oxidizing Trays. 
I. The nitrate has developed with extraordinary rapidity.

2. The formation of nitrite is much less marked; it rapidly reaches a maximum and then declines.

3. The free ammonia has been almost completely oxidized; at the same time it was noticed that the original yellowish colour, black suspended matter and sewage odour had disappeared. ${ }^{1}$

The following figures give the oxygen relations which I found for the first and last trays :-

PARTS PER IOO,OOO.

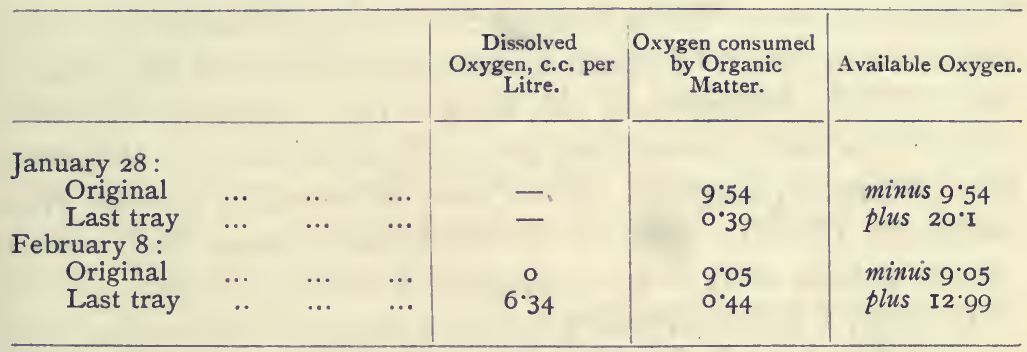

The organic matter therefore had been very rapidly reduced, and the effluent was in a state of active natural purification by means of its available oxygen. When allowed to stand, the oxygen of the nitrate is utilized for the burning up of organic matter, provided the latter has been properly fermented as in this case, and the effluent can be finally purified by a denitrifying bed.

In the trays described above the quantity of available oxygen is obviously far greater than would be supplied by any process of mere aeration, hence such an effluent can be easily " finished " by a fine filter without fouling the latter, or can be beneficially applied to a small area of land, or mixed with a river of moderate volume not only without pollution, but possibly with an actual benefit to the stream.

The principle of dividing the bacteria into separate zones, where each class can naturally choose its own habitat and work successively to others, is paralleled by the rotation of crops. Of the antagonism and symbiosis of bacteria we have already spoken in Chapter V.

1 It is stated that " by transposing the trays so as to upset the natural survival of organisms in the sequence, the whole process was arrested, a high-coloured and inferior effluent being the result, and one or two days were required to re-establish the conditions that had been disturbed." 
Sims Woodhead proved that in coke-breeze upward filters at Claybury, in the deeper parts of the filters anaerobic organisms were more numerous, with high ammonia; while near the surface aerobic organisms prevailed and nitrates were predominant. From other experiments he recognised "that there was a sharp line of distinction between the work done by the anaerobe, and that by the aerobe, and that the two processes should be kept as separate as possible." In these filters, natural working had established separate zones for the two operations, but being too close in one apparatus, they were liable to vary and intrude on one another, and a smell was sometimes present.

Installations on Scott-Moncrieff's principle have been working in many places in South Africa, where frost does not present any difficulty by retarding the work of the organisms. In cold countries a slight protection seems to be sufficient. At Caterham Barracks, England, works were constructed for the War Office, in 1898 , to deal on the Moncrieff system with about I6,000 gallons daily of an exceptionally strong sewage.

In I899, I collected and examined samples representing two cycles of 24 hours, when the filter was producing effluent at an average rate of 340,000 gallons per acre. The average results were :-

\begin{tabular}{|c|c|c|c|c|c|}
\hline & & & Raw Sewage. & Tank Effluent. & Finished Effluent. \\
\hline Chlorine ... & $\ldots$ & & I $5^{\circ} \mathrm{I}$ & $14 \cdot 8$ & $13 \cdot 3$ \\
\hline $\mathrm{O}$ consumed $\quad \ldots$ & $\ldots$ & $\ldots$ & 14.97 & $9 \cdot 25$ & $2 \cdot 71$ \\
\hline Nitrous nitrogen & $\ldots$ & $\ldots$ & trace & trace & $0 \cdot 346$ \\
\hline Nitric nitrogen ... & $\ldots$ & $\ldots$ & - & - & $9 \circ$ \\
\hline Organic nitrogen & $\ldots$ & $\ldots$ & 4.0 & $2 \cdot 7$ & 0.67 \\
\hline Ammoniacal nitrogen & $\ldots$ & $\ldots$ & $13 \cdot 2$ & $14^{\circ} 9$ & $5 \cdot 0$ \\
\hline Total nitrogen $\quad \ldots$ & $\ldots$ & $\ldots$ & $17 \cdot 2$ & $17 \cdot 6$ & 15.02 \\
\hline
\end{tabular}

The percentage purification was :-

\begin{tabular}{|c|c|c|c|c|}
\hline & & & $\begin{array}{c}\text { Oxygen } \\
\text { Consumed. }\end{array}$ & Organic Nitrogen. \\
\hline $\begin{array}{l}\text { Raw sewage to tank effluent } \\
\quad, \quad, \quad \text {, to finished effluent ... }\end{array}$ & $\begin{array}{l}\cdots \\
\cdots\end{array}$ & $\begin{array}{l}\cdots \\
\cdots\end{array}$ & $\begin{array}{l}40 \\
82\end{array}$ & $\begin{array}{l}32 \cdot 5 \\
83\end{array}$ \\
\hline
\end{tabular}

Subsequently on my suggestion two denitrifying tanks were placed after the nitrifying filter. These tanks receive the overflow from the hydrolytic tank, together with the nitrated effluent, and in this way the oxidizing filters can work to their 
best advantage, the purification of the effluent being completed by denitrification of the mixed liquids.

\section{The Manchester Experiments.}

The disposal of the sewage of 564,000 inhabitants, with much manufacturing refuse, has been a difficult problem, which has been carefully investigated. Formerly it was treated at Davyhulme on the London plan of screening, adding milk of lime, then ferrous sulphate, sedimentation, and discharge of the clarified or filtered liquid into the Ship Canal, while the sludge was stored in two tanks, holding $\mathrm{I}, 000$ tons each, thence flowing at intervals into a sludge steamer which carried it to sea. Pollution of the Canal led to interference from the Mersey and Irwell Joint Committee, and to the necessity of the adoption of some other system. The Manchester Corporation in 1898 instructed Baldwin Latham, Percy Frankland, and W. H. Perkin, to examine into the merits of various processes, following a report of the Rivers Committee:-

I. "That filtration by land is altogether impracticable, as no land obtainable in the district is suitable for such process," as proved by the experiments which, at great cost, had been made upon 25 acres of land at the works. Visits to the works of other authorities had shown that " in all cases the land filtration is ineffective, and is, in many cases, to be superseded by artificial methods of filtration. The imposition of conditions by the Local Government Board, making the purchase of large areas of land compulsory, should be removed."

2. "That no practicable system of precipitation by chemicals alone has been laid before them which will meet the requirements of the Mersey and Irwell Joint Committee." [The experiments had been very elaborate, and are detailed in the City Reports of 1897 and of previous years.]

3. They agreed that the method nearest to natural action and "most reasonably practicable and reasonable for adoption" was the biological filter or bacteria bed, such as had been seen in operation at various places.

The land available at Davyhulme for all disposal purposes is I65 $\frac{1}{2}$ acres, and the three experts soon concluded that this area was ample for the necessary works to purify the sewage including storm-water-the works existing at the time occupied $27 \frac{1}{2}$ acres. They pronounced adversely on the alternative proposals of treatment of a tank effluent on land, and the Culvert 
scheme for conveyance of the present effluent through a tunnel to the tidal part of the Mersey.

The experimental plant of 1899 consisted of three independent sections.

I. Five "Bacteria Beds," with sloping sides, ${ }^{1}$ filled with $3 \mathrm{ft}$. of clinker of the following sizes: $\mathrm{A}, 3$ in. to $\mathrm{I}$ in.; $\mathrm{B}, \mathrm{I}$ in. to $\frac{1}{4}$ in. ; C, $\frac{3}{4}$ in. to $\frac{1}{4}$ in. ; D and E (extra bed), $\frac{1}{2}$ in. to $\frac{1}{8}$ in.

Distribution by perforated wooden troughs, collection by drain pipes below. Area of A to D $\frac{1}{76}$ acre. A and B were started with settled sewage in September, 1898 , run on at first once, then twice, and finally three times a day. A month later raw sewage, screened through a grid, was applied at a rate of four fillings per day, each cycle including: filling $\frac{3}{4}$ hour, resting full 2 hours, emptying $\frac{3}{4}$ hour, resting empty $2 \frac{1}{2}$ hours. After a week the surface of bed A showed signs of clogging, so settled sewage was again used. Subsequently the time of filling A was shortened $\frac{1}{4}$ hour, and of emptying to $\frac{1}{2}$ hour, to give a longer period of rest, and also because it was thought that by " rushing" sewage on to the filter a larger amount of air would be entangled with it. The result would belong to the partially aerobic class, but with as much as possible avoidance of suspended solids. Samples were taken at short intervals and mixed for analyses. Beds C and D were first used together, being filled twice a day with settled sewage, with $\frac{1}{4}$-hour filling and two hours contact. As A was too coarse, it was changed to $\frac{3^{\prime \prime}}{4}$ to $\frac{1 \text { " }}{8}$ mesh.

II. Septic Tank System.-Concrete tank $40 \times$ I2 ft., with arched roof $9 \mathrm{ft}$. high, and air-tight manholes; rest of construction as at Exeter. Six filter-beds with vertical concrete walls; total area I96 sq. yds., and depth $4 \mathrm{ft}$., containing from the bottom upwards - I ft. clinker between 3 in. and I in. mesh: $2 \mathrm{ft} .9$ in. clinker between $\frac{3}{4}$ in. and $\frac{1}{8}$ in. mesh : 3 in. residue from above, passing at $\frac{1}{8}$ in. mesh.

Raw unscreened sewage was passed through, but not so regularly as at Exeter.

III. Two Roscoe Filters, first used in December, I895, were I $2 \mathrm{ft}$. 6 in. by $18 \mathrm{ft}$., or $25 \mathrm{sq}$. yds., with $3 \mathrm{ft}$. of rough clinker, graded coke or cinders, and a covering of I $\mathrm{ft}$. of clean gravel. They were worked like the bacteria beds, but with chemically precipitated effluent.

${ }^{1}$ Sloping sides obviously give greater surface and aeration at a sacrifice of capacity which can be calculated from the angle of inclination of the sides. Hence the adoption of this shape, lately recommended, would largely increase area, and would only be justified by increased efficiency, on which further experiments are needed. 
It became evident that the main difficulties with contact beds were due to their being used chiefly as simple strainers, and that a previous preparation of the sewage was necessary. Except with the septic tank, this had taken the form of screening, sedimentation, or precipitation.

The enquiry included a comparison between a closed and an open septic tank. For the latter one of the large precipitation tanks at Davyhulme was used, raw sewage being allowed to flow over the end sill in a very thin stream, passing through the tank almost continuously at a rate of I,700,000 gallons per 24 hours. Similar phenomena to those at Exeter are described, the liquid becoming covered with a scum which excluded the air, while " up to the present time the only notable quantity of sludge which can be perceived. . . is immediately beneath the inlet penstocks. ... An enormous quantity of the sludge which would otherwise accumulate has been destroyed in this way." The effiuents from both closed and open tanks are shown to be closely similar. ${ }^{1}$

With reference to the question of closed or open septic tanks, I may remark that some of the advantages of the former are that the gases can be utilized and all smell avoided, that the temperature is more even, and interference from frost or wind is prevented. ${ }^{2}$ At the same time it was found at Manchester that the outfall sewage was $10^{\circ} \mathrm{F}$. warmer than the temperature of the air.

The deposit from this open septic tank in April, I9oo, contained organic matter $5^{\cdot} 24$, inorganic $6{ }^{*} 78$, water $87^{*} 98$ per cent. ; or in the solids, 57 per cent. inorganic matter and 43 per cent. organic. The sludge of the chemical precipitating tank was much more prone to putrefactive decomposition than that of the septic tank.

It was agreed that in the management of contact beds :-

1 In an enquiry at Yeovil, in March, 1900, the balance of opinion was that in the case of a strong sewage a closed tank is necessary. Open septic tanks are now often called "scum tanks." Drs. Kenwood and Butler state (Sanitary Institute, April. IgoI) that in the Willesden and Finchley scum tank the sludge maintains a fairly uniform bulk, and certainly does not accumulate sufficiently to require removal for many months, and that at Acton after a year's working the deposit averages only a few inches with a spongy scum 8 to ro inches deep. The albuminoid ammonia is reduced 40 per cent., the sludge contains 78 per cent. of non-volatile matter, while the scum contains 39 per cent. The deposited sludge can be removed with little offence, and at Finchley has been spread over small areas of land, with no offence, even in the immediate neighbourhood.

${ }^{2}$ Mr. Barbour states that at Saratoga, in the winter of I903-4, the scum froze to a depth of 4 in. under the concrete groined roof covered with I 8 in. of soil ; " what would have happened if the tanks had been uncovered is a question worth considering." -Trans. Am. Soc. C.E., LIV., part E, I905. 
I. The suspended matter must be previously removed by sedimentation;

2. If any passes over it must be retained as far as possible on the surface of the bed;

3. The surface of the bed must be raked over from time to time.

4. Periodical intervals of rest must be allowed.

Professor Boyce found in 1900 : in the effluent from the first contact bed 33I,700 bacteria and I,420 coli per c.c.; from final (second) contact II5, Ioo bacteria and 329 coli. The Ship Canal contained some 6,000 coli per c.c. above the sewage outfall.

The closed tank and single contact gave an effluent which "generally resisted putrefaction in the incubator test, in consequence of its containing a comparatively high proportion of nitrate." The effluent from the open tank was passed through the beds C and D, and by the "double contact" a better result was naturally obtained. "With four fillings per day, every sample was non-putrescible, and well within the limit of impurity." In other instances where the Mersey and Irwell Joint Committee's standard ( $\mathrm{I}$ grn. per gal. of $\mathrm{O}$ absorbed in four hours, and $O^{\circ} \mathrm{I}$ grain albuminoid $\mathrm{NH}_{3}$ ) was infringed, it was shown to be due to trade refuse, "which, being non-putrescible, does not cause nuisance in the Ship Canal." "The object of purification is primarily the production of an effluent free from putrescibility, and not one in which the chemical ingredients are below some necessarily more or less arbitrary standard." (See Chapter III., p. 56 ; Chapter V., p. I30.)

The report confirmed previous observations by Adeney (Proc. R. Soc. Dublin, September, I895), myself (J.San.Inst., vol. xviii., part i., I896), Fowler (summer of I896), Scott-Moncrieff (patent 4994 of 1898 ), and others, as to the utility of mixing a nitrated effluent from a "second contact" bed with that from a first, whereby a liquid was obtained which satisfied the incubator test, so that "only one-fifth of the filter acreage need be at a low level," and the area of the second contact beds could be considerably reduced. I had also before suggested the introduction of a portion of the nitrated effluent into the septic tank itself, as the denitrification change which takes place on mixing is due to the reaction between the nitrates and the organic matter, and could be induced earlier in the process as soon as the organic matter is in a soluble reacting condition, while it is 
more economically conducted in a tank which is continuously full, than in a filter bed constructed for aeration. Nitrification is usually most energetic in liquids in which the organic matters, especially carbohydrates, ${ }^{1}$ are a minimum, and therefore a denitrification change effected during the anaerobic preliminary stage, by reducing the oxygen-consumed figure to a greater extent than would be the case if the change were only due to hydrolysis, yields an effluent which contains its nitrogen in the most available form for the changes of which nitrification is the final result. Thus, for example, a hydrolysed effluent with, say an oxygen-consumed figure of 3 , and unoxidized nitrogen Io parts, on passing through the filters often yields not more than 3 parts of nitric $\mathrm{N}$; if, however, a portion of this liquid be returned to the tank, it will so reduce the $\mathrm{O}$ consumed figures, as to allow the nitrification to approximate to the theoretical amount.

The Report of the experts finally recommended that the sewage be submitted to an efficient process of screening (or to roughing tanks), then passed through open tanks with submerged walls and floating scum-boards, and afterwards over 60 acres of double-contact beds $3 \cdot 33 \mathrm{ft}$. deep, with four fillings per 24 hours. As the dry-weather flow was 30 million gallons, the filters dealt with half a million gallons per acre, allowing one day per week rest. The open tanks were to hold I $_{5}$ million gallons, and would therefore change their fluid contents in dry weather every twelve hours. ${ }^{2}$

As to storm-water it was found that there was even a greater amount of oxidizable matter in the first flush than in ordinary sewage. They advise that the storm-flow should be dealt with in the same system, and the excess, after passing through roughing tanks, should be taken to specially-prepared bacteria beds of at least 25 acres area. No decrease in efficiency was noticed after the storm had passed. ${ }^{3}$

The Local Government Board decided that a larger area of land must be purchased, "over or through which the sewage after it had left the bacteria beds should pass," also (Oct. 4, I899) "that not less than 92 acres of filter beds shall be provided for the treatment of sewage by double contact; and that the filter beds be worked in cycles with the usual provisions as

1 R. Warington, f. Chem. Soc., May, Igoo.

2 Report Manchester Rivers Committee, Jan. 22, 1900.

3 A critical analysis of the Manchester experiments, by Boyce and McGowan, is given in the 2 nd Report of the R. Sewage Commission, IgO2. 
to storm-water" (Chapter VI., p. I48). These requirements were unnecessarily onerous, and in a later report of Dec., I899, the experts confirm their estimate of 60 acres, and state that by "preliminary septic sedimentation" they have obtained an improved effluent, also that they work most successfully with 6 hour cycles 6 days per week, but that the exact length of the cycle must vary according to the nature of the sewage. Continuous incubation experiments showed that the effluent improved the water of the Ship Canal, that by subsequent land filtration the effluent was actually deteriorated, and that therefore the land clauses were superfluous. The engineer reported (Sept., I900) that the experts' scheme would cost $£ 337,000$, the culvert plan $£ 350,000$. The L.G.B. consented to a modification as follows: (a) 46 acres of primary filters at Davyhulme; (b) 46 acres of secondary beds at Carrington (which involved the purchase of 213 more acres of land), the primary effluent being conveyed to the secondary beds by means of a culvert; (c) special storm-filters at Davyhulme for the treatment of excess storm-water (say 63,000,000 gallons per diem) at a rate not exceeding 500 gallons per square yard per diem. Cost $£ 487,000$, finally accepted by the Manchester Council.

Chemical treatment was entirely discontinued in Aug., I904, and the works now deal by bacterial methcds with the whole sewage, averaging 30 to 35 million gals. per day, or 52-62 gals. per head : daily water supply 29 gals. per head, rainfall 26-34 in. The sewage passes through screens and catch-pits with submerged walls, scum boards and outlet sills, into open septic tanks, and then on to the half-acre bacteria beds; or in excessive rains it flows, after simple sedimentation, on to the $26 \cdot 8$ acres of storm beds. The latter beds sometimes require forking over to a depth of 4 or 5 inches. By opening each of the valves in turn for a short time, as much as 200 tons of sludge containing $87 \%$ of water can be removed from a septic tank without running off the top water. In 1904 and 1905 the sludge removed averaged per million gals. of sewage $8 \frac{3}{4}$ tons containing $85 \%$ water, as distinguished from over I 8 tons per million, containing $88 \%$ water, during the former chemical treatment. The suspended matter passing away from the bacteria beds has somewhat increased, averaging 5 parts per I00,000, and secondary beds are being constructed. ${ }^{1}$

${ }^{1}$ For further details see the annual reports of the Rivers Department, City of Manchester. 
The plant and working at Manchester still admit of improvement. The sewage is a difficult one to deal with, but is not worse than that of other centres which have met with better success. The resolution of solids in the septic tank, estimated as from 25 to $30 \%$, is lower than at other places owing, as is implied in the reports, ${ }^{1}$ to the irregularity and frequent disturbance in operating. The mode of distribution on the beds by radiating troughs on the surface is not a good one, and as to the unsuccessful trials with sprinklers, the report of 1903 itself says (p. 29) "it is difficult to draw trustworthy conclusions from comparative experiments made in this manner."

At Birmingham, since the abandonment of the lime process (ante, p. I55) in I900, the plant has been used for a modified septic treatment. In 1902 out of $24 \frac{1}{2}$ million gals. of sewage per day only 3 million gals. were domestic, the remainder being chiefly trade effluents, into which sulphuric, hydrochloric and nitric acids and salts of heavy metals had passed. It was noticed that the nitrates disappeared in the sewage in hot weather. The flow is received into three large tanks, each divided into three parts by submerged walls rising to within $2 \mathrm{ft}$. of the surface. The first chamber retains the heavier detritus, the other two arrest the bulk of the residual suspended matter, and are used alternately and cleaned out once a fortnight. The sewage passes on to 16 smaller septic tanks, where it stays 8 hours, and finally is distributed over land at an average rate of 15,000 gallons per acre per day. It is reported that "an enormous quantity of gas escapes from the septic tank, resulting in a loss of about 8 per cent. of the solid matter which enters these tanks," that the suspended solids are very much altered in quality, and that the sulphides developed precipitate most of the heavy metals in solution. The effluent " is not merely harmless, but has considerable manurial properties; for in grass land irrigated by it the path of the water may be traced by the increased vigour of the herbage." 2 An important point is that "the enormous fall in liquid sludge" - from 28I,000 cub. yds. for 20,000,000 gallons daily dry-weather flow in 1896 , to $\mathrm{I} 28,000 \mathrm{cub}$. yds. for $2 \mathrm{I}, 500,000$ gallons in I $90 \mathrm{I}-$ " is largely due to the cessation of the use of lime and adoption of septic treatment." With regard to organic improvement the analyses given show that the arrangement of the tanks should be different.

1 Manchester Rivers Department, I903, p. 20 ; I904, p. I7.

2 F. Soc. Chem. Industry, May 3I, Igo2. 
The septic tank is too small, and the "roughing tank" too large. ${ }^{1}$

At Sheffield (population about 400,000, average dry-weather sewage $I 7^{\circ} 3$ million gals. per day, water supply per head $2 I^{\circ} 89$ gals.; hence the sewage contains much surface water), the local Act of Igoo allowed a scheme without land treatment, to include open septic tanks, II million gals. capacity, 32 acres of coarse-bed filters, 33 acres of fine-bed filters, and a small area of storm filters. Following the satisfactory results from continuous filters at Leeds, the Sheffield Council began experiments on their use instead of double contact, as the Leeds experiments showed that it would be possible to replace the 65 acres of double contact beds by about 17 acres for continuous filters.

At Leeds ${ }^{2}$ the first open septic tank had an area of 6,000 sq. ft. and a capacity of 250,000 gallons, or 24 hours' flow, which proved to be the best rate of transit. The advantages found were: "(I) The production of a practically uniform effluent from sewage of such varying composition as that of Leeds : (2) the digestion of part of the solids in suspension, amounting at Leeds to 40 per cent.: (3) the anaerobic putrefaction which takes place facilitates subsequent filtration, rendering the filtrate less liable to secondary putrefaction." As at Manchester, the results with open and closed tanks were practically identical, the scum itself soon giving a cheap roof and preserving the heat, which averaged only $0.8^{\circ} \mathrm{F}$. less in the open than in the closed. ${ }^{3}$ It was recommended that the tanks should be in series, the first being in duplicate so as to be emptied from time to time. The gas produced did not occasion nuisance.

Continuous filtration of septic effluent over very coarse material, ${ }^{4}$ spreading the liquid like rain over coke of not less than $I \frac{1}{2}$ in. diameter, well aerated at the bottom and sides, gave, in so short a time as the 15 minutes required to pass through the bed, better results than double contact, if the solids in suspension which pass through are afterwards settled. These solids are largely mineral, non-putrescible, subside easily, and the drying does not give rise to evil odours, while it would seem that their coming through ensures the permanence of the beds. It was found practicable, for long periods, to work continuous beds Io $\mathrm{ft}$.

1 Vide the author's remarks in the discussion of the above report, ibid., p. 669.

2 City Report, I90o.

${ }^{3}$ See evidence R. Comm. on Sewage, vol. ii., I902, questions 7258 and 8232.

4 Chapter X, p. 246 
deep at the rate of 200 gals. per square yard, or I million gals. per acre per day for septic effluent, with over $90 \%$ purification after settlement, the beds being occasionally washed out by storm-water.

American experience has been that, working with preliminary septic treatment, contact filters are able to produce a non-putrescible effluent at rates several times as great as intermittent sand filters, and sprinkling filters can produce corresponding results even with much higher rates. The latter give a better opportunity for oxidation, and the films deposited on the filtering material become detached from time to time and pass off with the effluent. Contact filters are generally more expensive in working than the sprinkler type with settling basins: the effluent from the latter contains only from 3 to $5 \%$ of the bacteria in the crude sewage, and in most cases requires no further treatment before discharge. 


\section{CHAPTER XII}

\section{DISTRIBUTION AND DISTRIBUTORS}

Intermittent-Continuous - Stationary Sprayers-Moving Distributors-Tippers-Testing Apparatus.

CHOICE of methods in great part depends on the character of the site, as in many places the sewage has to be raised by pumps, lifts, or ejectors, and the problem becomes an engineering one. A really anaerobic treatment in the first stage, like Cameron's or Moncrieff's, requires no fall, the sewage simply flowing in below and flowing out above. With terraced beds fed from the top, the fall to be provided includes the sum of the depths of the beds and of the distributing apparatus : increasing the depth of material may economize surface area, but adds to the expense of raising.

Ordinarily, the sewage, owing to its fluctuations, has to be controlled by penstocks and valves at the entrance and exit. A restraint at the entrance involves storage. "Holding up" is temporarily closing the outlet valve so that the filter fills with fluid. In the Lowcock filter and others, the entrance is controlled and the outlet always open. Variation in flow occasions great difficulty where the admission is direct to bacteria beds, but in septic tanks of sufficient capacity the irregularity is : not felt. In any case, the flow of sewage can be regulated by means of "modules." The first module, introduced in Piedmont, for the purpose of giving a uniform discharge of water out of a main channel or canal, was a chamber commanded by a sluice, and with a square orifice of suitable size below. The sluice was opened till the flowing water remained at a fixed level in the chamber.

Such a module, though giving for the purpose a sufficiently uniform flow, would not adjust itself except within narrow limits. A great number of self-acting modules were used on the Indian canals, especially one devised by Lunt Jarrols. In the Piedmont form a free fall is a necessity, but with self-adjusting modules this is not required, those at Barrhead (Fig. 58, 
Chap. XIII.) working with a difference of level of about an inch. The arrangement consists of a module chamber having a circular opening in the bottom; through this opening is a body, conoidal in shape, attached to a float. As a head of liquid falls, so do the float and cone, making the opening larger, and vice versâ.

\section{Distributors.}

A. In the intermittent or "holding up" system the sewage has to be applied at intervals to a number of beds. The chief automatic apparatus for this purpose are the following:
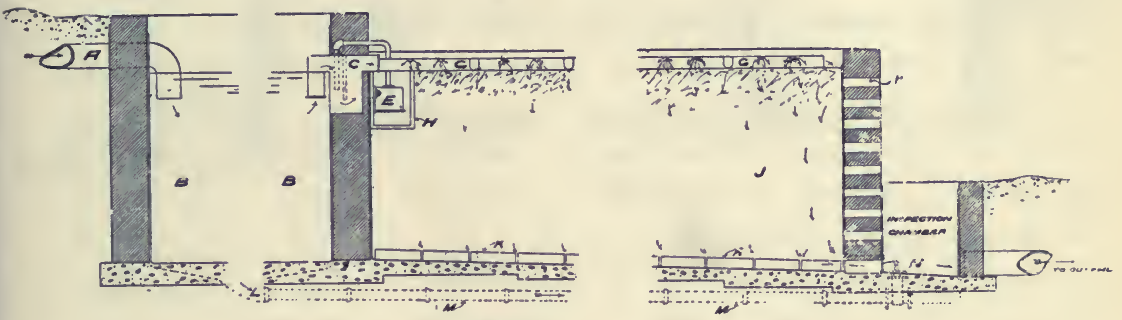

SECTION

Fig. 3i.-Section of Intermittent Supply by Adams' Syphon.
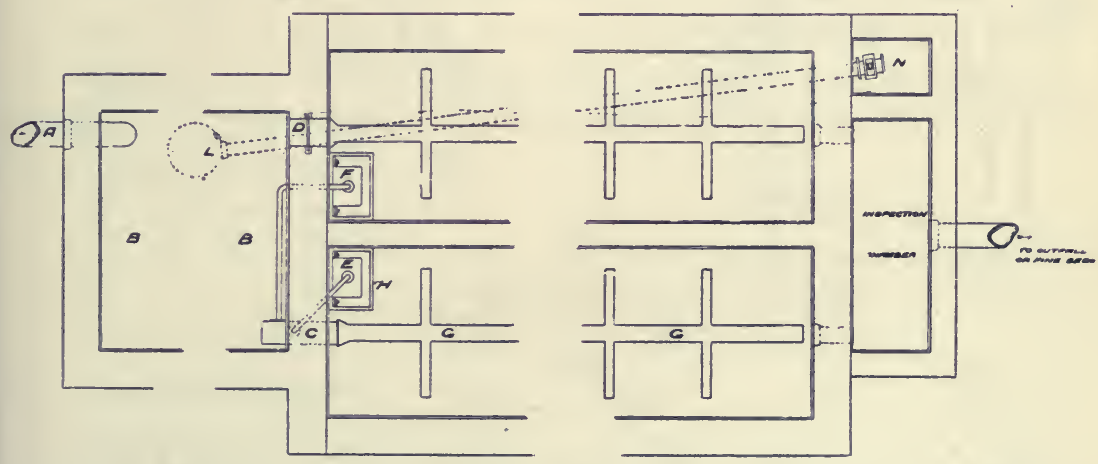

FLAN

Fig. 32. - Plan of Intermittent Supply by Adams' Syphon.

I. Adams' Syphon (Adams' Hydraulics Limited, York), also adapted to the continuous systems. In the intermittent form (Figs. 3I, 32) A is the inlet, B a scum or resolving tank, C a syphon feeding the first bed, coupled by air pipes with the domes $\mathrm{E}$ and $\mathrm{F}$. The sluice supplying the second bed is closed while the first is filling from the feed $\mathrm{C}$ through the distributor $\mathrm{G}$.

The feed apparatus is a plain trap-like casting through which liquid passes freely from the source of supply to the bed to be 
filled, until the air contained in its attached dome $\mathrm{E}$ is transferred by the pressure of liquid around it, as the bed fills, through a trapped air-pipe to the interior of the feed, creating an airlock, and blocking the further passage of liquid so that the latter rises to a higher level in the source of supply until the inlet sluice to the next bed is reached. Where an automatic discharge is also used (Figs. 33, 34), the liquid contents of the first bed will in the meantirne have been discharged through syphon M, and the overdraw pipe $\mathrm{K}$ attached. A tap $\mathrm{L}$ delivers
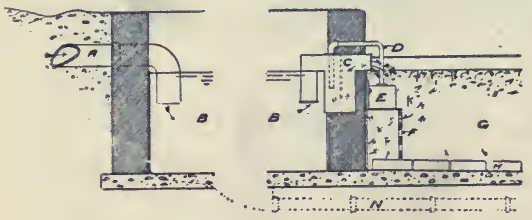

SECTION

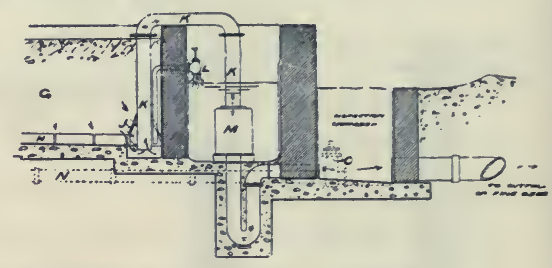

Fig. 33.-Section of Automatic Discharge by Adams' Syphon.

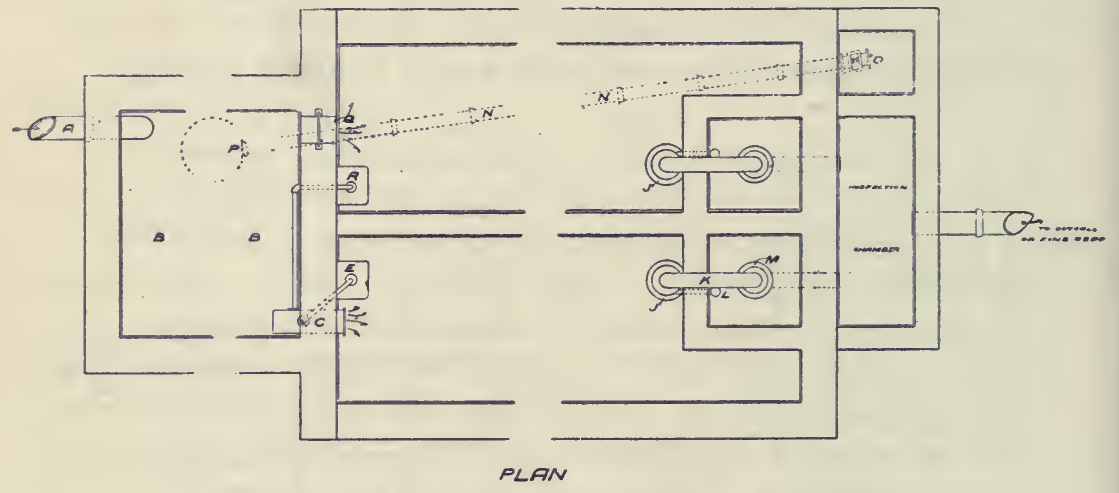

FIG. 34.-PLAN.

liquid to the syphon chamber, and the time occupied in the filling of this chamber will be that for which the sewage is held up on the bed in contact with the filtering material. The fact that the feed and discharge apparatus are quite distinct, enables users to fix any desired time of contact. The second bed thus fills and its liquid in turn displaces air from dome R (Fig. 34); thus air is transferred to the feed $\mathrm{C}$, its added bulk forcing the water seal, freeing the confined air, and again bringing on the supply to the first bed. At $\mathrm{N}$ is a pipe dotted, through which any accumulation in tank $B$ may be drawn off by valve $O$.

As applied to continuous filters, the feed $\mathrm{C}$ discharging to 
filter No. I gradually fills a receptacle into which dome E dips. The taps supplying the inlet and outlet may be set so that the receptacle fills in any given time, when, as in Fig. $3 \mathrm{I}$, the air will be transferred to the feed $\mathrm{C}$, causing an air lock which will divert the sewage to the next feed or bed. "With this apparatus any desired area may be flooded for a given time, sewage being sent to one area or bed after the other, regardless of the numbers used or volumes dealt with, automatically and without movement."

II. Ridgway Automatic Distributor (Mather and Platt, Manchester). Screened or sedimented sewage is received into a syphon chamber built to hold a given number of gallons according to the average volume to be treated. When full, the syphon discharges this amount into the " Distributing Chamber." At the same time, a hollow cylindrical float, which has been previously raised by the filling of the syphon chamber, descends to the bottom, and by a pawl and rachet wheel causes a horizontal shaft to revolve, and, by means of cams, to open or close in succession a series of valves communicating with different beds [patent I2287 of I9OI].

At Hale, near Manchester, Dr. Garstang reported in I899 that this distributor was passing 72,000 gallons per day on to I 80 sq. yds. of single contact beds ( 2 million gals. per acre per diem), during a period of ro months. He gives the following average analyses :

\begin{tabular}{|c|c|c|c|c|}
\hline \multirow[t]{2}{*}{ t } & \multicolumn{3}{|c|}{ PARTS PER IOO,OOO. } & \multirow{2}{*}{$\begin{array}{l}\text { Per cent. Puri- } \\
\text { fication by } \\
\text { O consumed. }\end{array}$} \\
\hline & O consumed. & Free $\mathrm{NH}_{3}$. & $\begin{array}{c}\text { Albuminoid. } \\
\mathrm{NH}_{4} \text {. }\end{array}$ & \\
\hline Crude sewage (screened) & $5^{\circ} 0$ & $2 \cdot 184$ & 0.668 & - \\
\hline Effluent from bed & I'O & $0.84 \mathrm{I}$ & 0.215 & 80 \\
\hline Final land effluent & 0.43 & 0.668 & 0.126 & 92 \\
\hline
\end{tabular}

It appears from the report that the effluent remains at the bottom of the bed for two hours before being expelled by the next succeeding charge. This involves an increase in the capacity of the bed, and renders denitrification changes possible.

III. Cameron's Automatic Alternating Gear at Exeter has been already mentioned (Chap. IX.). At Barrhead six of the eight filters are in use at once, one being filled at a time. As soon as a filter is full, the flow of tank effluent is automatically 
diverted to the next filter, and after a certain time, the contents of the full filter are discharged by lines of drain pipe into a stoneware main collector running into the discharge valve box. Both the admission and discharge valves are suspended by valve rods from a lever, which is pivoted on a bearing between the admission valve chamber and the discharge well. At one end of this lever is a counterweight, so adjusted as to hold the admission valve open and the discharge valve down on its seat.

The gearing used later, while similar to that at Barrhead, embodies several improvements, chiefly stated as follows:

I. The discharge well and admission valve chamber are made in cast-iron and mounted on a bed plate of the same material so as to be entirely independent of the walls.

2. The mechanical details of the gear have been greatly simplified.

3. Before each filter is filled, the tank effluent is held back for a period of from one to two hours, the quantity so accumulated filling the filters in a much shorter time than if it had been allowed to flow continuously.

This obviates Mansergh's criticism of the automatic gear, that the decreased flow in the night fills one filter so slowly that the corresponding one in the resting-full stage remains charged so long as to seriously interfere with its aerobic action. The machinery works without loss of head, so that its employment does not increase the fall which the filters would require if used without gear.

At Lake Forest, Illinois, and Wauwatosa, Wisconsin, the apparatus used for dosing the sand filters consists of a float which lifts a cannon ball in one of a set of hollow wooden columns arranged in series; at a certain height the ball rolls through a trough from one column to the next, its passage striking a catch which opens an air-valve attached to one of a series of bell syphons discharging in rotation on the sand filters.

Various forms of automatic gears are given in English patents 2647 of I900; 5834, I0346 and II368 of I90I; 9247 of I902.

We have seen that in the intermittent or holding-up system the main work is done almost anaerobically in "resting full," and aerobically in "resting empty." The filling drives out carbonic acid and other gases formed by decomposition, the emptying renews the air in the filter bed. The first and last stages of the cycle can be shortened so as to leave more time for the fermentations, but ( $\mathrm{r}$ ) the entrance must not be so rapid 
as to disturb the filter, (2) for proper aeration the bed should be run out completely after each discharge, (3) the opening of the discharge valve should be gradual, so as to prevent any initial rush of effluent, such as I have frequently found to render the first runnings from these filters turbid and inferior.

B. In the Contimuous System, it is of extreme importance that the liquids should be distributed uniformly over the material. The cost of so doing is only a small fraction of the total cost of the material of a bed, and by attention to distribution the amount of material required for dealing efficiently with a given sewage may be reduced considerably.

The problem of spreading a liquid issuing from a narrow channel evenly over a broad area is not a simple one. In upward filtration it is easy; the liquid rising from the bottom naturally distributes itself throughout the filter. But when the introduction occurs from the top, there are considerable mechanical difficulties. Where sand filtration is used, it is chiefly necessary to protect the sand from disturbance by a coarser heavy layer of flint or stones, to run the liquid on the top, and trust to the evenness of the fine layer for equal distribution. The deficiency of aeration, and blocking of the beds, are faults of this method when applied to sewage (see Chapter IX.).

With aerating filters of open material, flushing the liquids, however rapidly, from penstocks at the sides or in the middle, leads to the formation of channels, and only a local use of the filtering mass; therefore many arrangements for spreading the fluid more equally have been devised. Networks of split pipes or iron or wooden troughs are not satisfactory. Perforated pipes occasion trouble, through blocking by solid matters, therefore the ends have to be made with openings, so that the tubes can be brushed through at intervals: the corrosion of the iron by the chlorides and nitrates in the liquid also blocks up the holes. In some cases the tubes have been made of gun-metal, but this also is liable to corrosion, particularly along the lines where it may have been joined or soldered. These difficulties, however, have not prevented many of these contrivances from being made to work well.

\section{Stationary Sprayers.}

(a) Mr. Stoddart, of Bristol, introduced a distributor depending on the dropping of the sewage from vertical points and not 
from holes. It consisted of a number of gutters arranged at right angles to the supply channel, provided with a series of points on their under surface, from which the overflowing

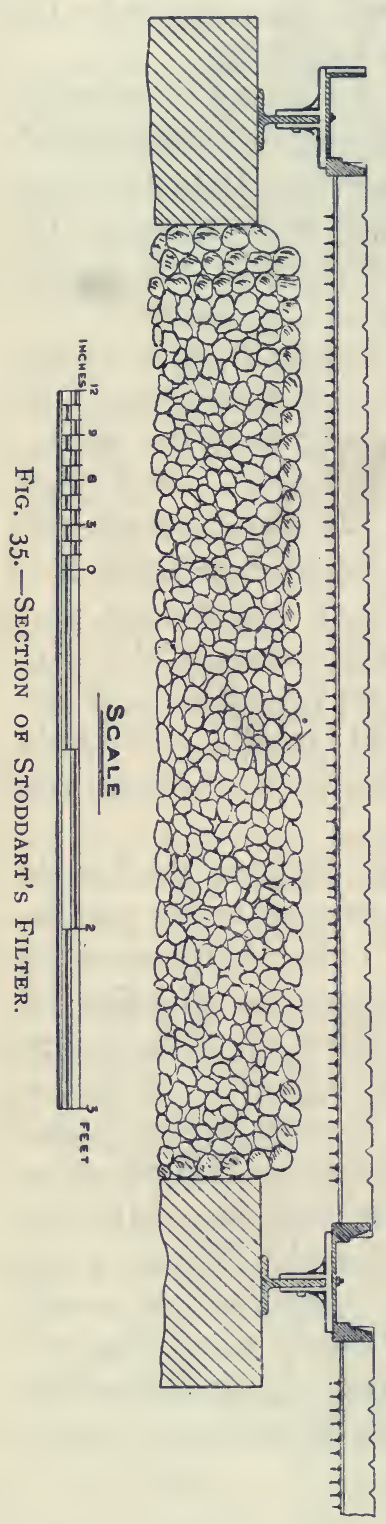
sewage or tank effluent fell in a series of fine drops.

It is said to work with only three inches of head, and to be unaffected by accidents such as a discharge of sludge or continued frost. Suspended matter settling in the troughs of the distributor is removed by a brush from time to time.

A later form of the Stoddart Continuous Sewage Filter is made in one piece of corrugated iron sheeting fixed just clear of the surface of the filter bed and filled with septic effluent from transverse fixed troughs. The edges of the corrugation are notched every few inches, and as the hollows fill up they overflow through the notches and the sewage falls from points attached to the under surfaces of the hollows. In this way, if the corrugated sheeting is kept absolutely true and horizontal, a good and uniform distribution can be effected. The difficulty is to keep the ridges absolutely true and level and to prevent inequalities due to changes of temperature, sinking of the supports, or displacement due to high winds. The improvements are intended to reduce these difficulties (Figs. 35 to 37 ). Fig. 36 shows the triangular projections on which the corrugated sheeting is supported (the inner surfaces only of the ridges are carried), and Fig. 35 the sheeting in position. The distributors are constructed in sections of 2 sq. yds each, so that any desired area can be built up. Mr. Stoddart prefers to limit beds to 500 square yards. The cost of the

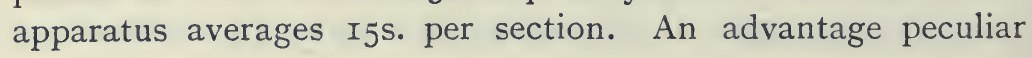


to this type is that in the event of accident a section can be removed for repair, but the whole bed is not thrown out of action as in the case of a moving distributor. The Stoddart apparatus seems to be working well in a number of small installations, but owing to the extended exposed surface of the septic sewage on the corrugated sheeting, precautions have frequently to be taken to prevent smell or nuisance arising, so that the filter bed is frequently covered over.

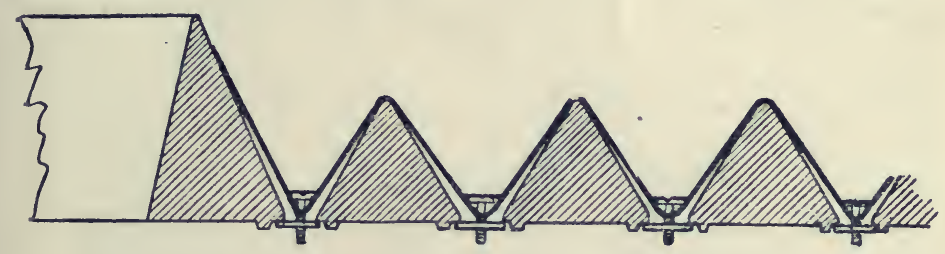

Fig. 36.-Attachment of Distributor to Channel.

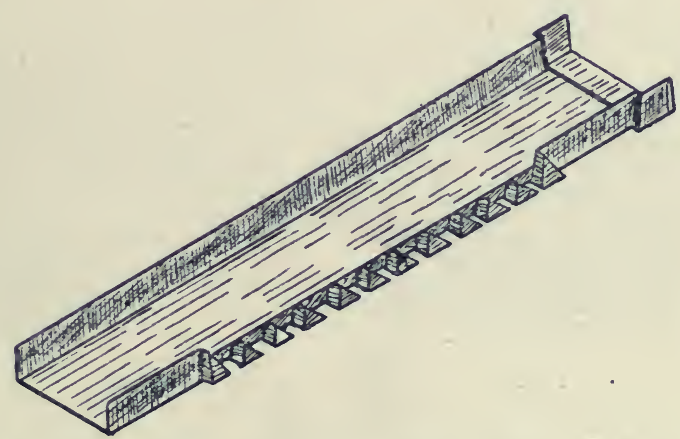

Fig. 37.-Trough Sheeting.

The following are types of upward jet sprayers. Obviously this system of sewage fountains is not to be recommended in exposed situations in the neighbourhood of dwellings where a fine spray can be blown about to some distance, both on account of aerial nuisance and the possibility of the distribution of pathogenic organisms.

(b) Spraying. Nozzles at Salford Sewage Works. The general arrangements have been described in Chap. X. The nozzles are fixed on the gridiron of pipes, and work with a head of 3 or 4 feet, but there is commonly sufficient pressure to cause the liquid to spout out to a height of 5 to $8 \mathrm{ft}$., and it then falls like rain on the surface of the filter. The delivery is about 
500 gals. per sq. yd., to be increased when necessary to I,000 gals. The total dry weather flow to be treated in this way will be 8 million gals.

The nozzles used in the earlier experiments were in the form of a jet playing against a disc or cone, "but these only threw a ring of water, not an area." Afterwards the " Simplex Sprayer" (Gjers and Harrison's patent) was employed: it has two impinging jets like the fishtail gas burner, and throws a "very even spray over an oval area, and so suits our spacing of 5 to Io ft." later used type is more complicated, and "throws an even

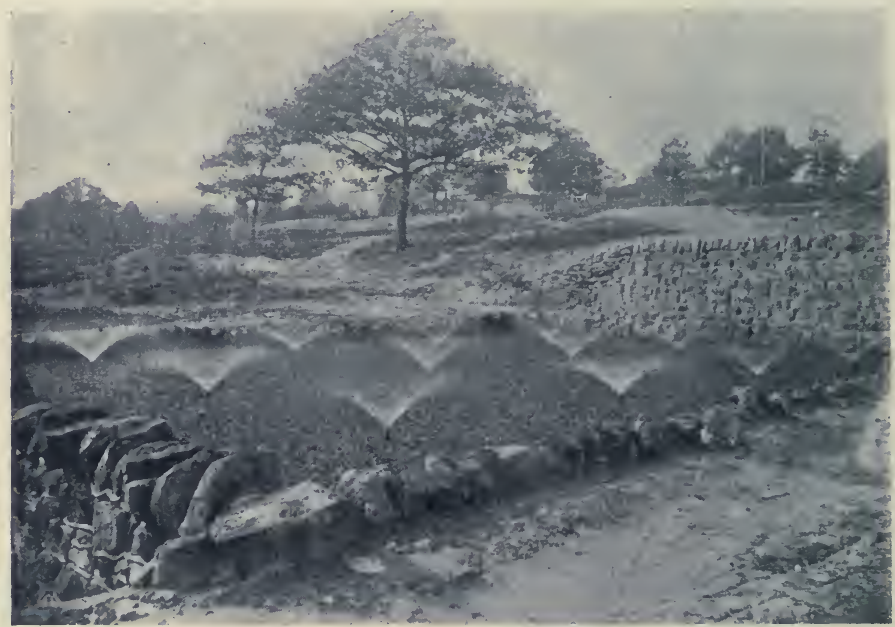

Fig. 38.-" Acme" Fixed Sprays.

circular area of spray": it has six holes in the base disc, bored obliquely like a siren, so as to set the water whirling as it passes out.

(c) "Acme" Fixed Sprays (Ames-Crosta Sanitary Engineering Co., Ltd.). The jets are screwed into vertical Tee pieces forming connectors in horizontal pipes run 4 or 5 inches below the surface of the filter bed. The jets are spaced about $7 \mathrm{ft} .6$ in. apart on the pipes, and the pipe runs themselves are at $7 \mathrm{ft} .6$ in. centres. Head recommended I ft. 6 in. minimum and $3 \mathrm{ft}$. maximum, giving a contracting spray from $4 \mathrm{ft}$. 6 in. radius to the jet centre. Rate of discharge estimated at $2 \frac{1}{2}$ gallons per minute per jet or about 735 gallons per square yard per 24 hours. The supply to the submerged pipes is regulated by an automatic

${ }^{1}$ Letter from Mr. Corbett, Borough Engineer, May 29, 1906. 


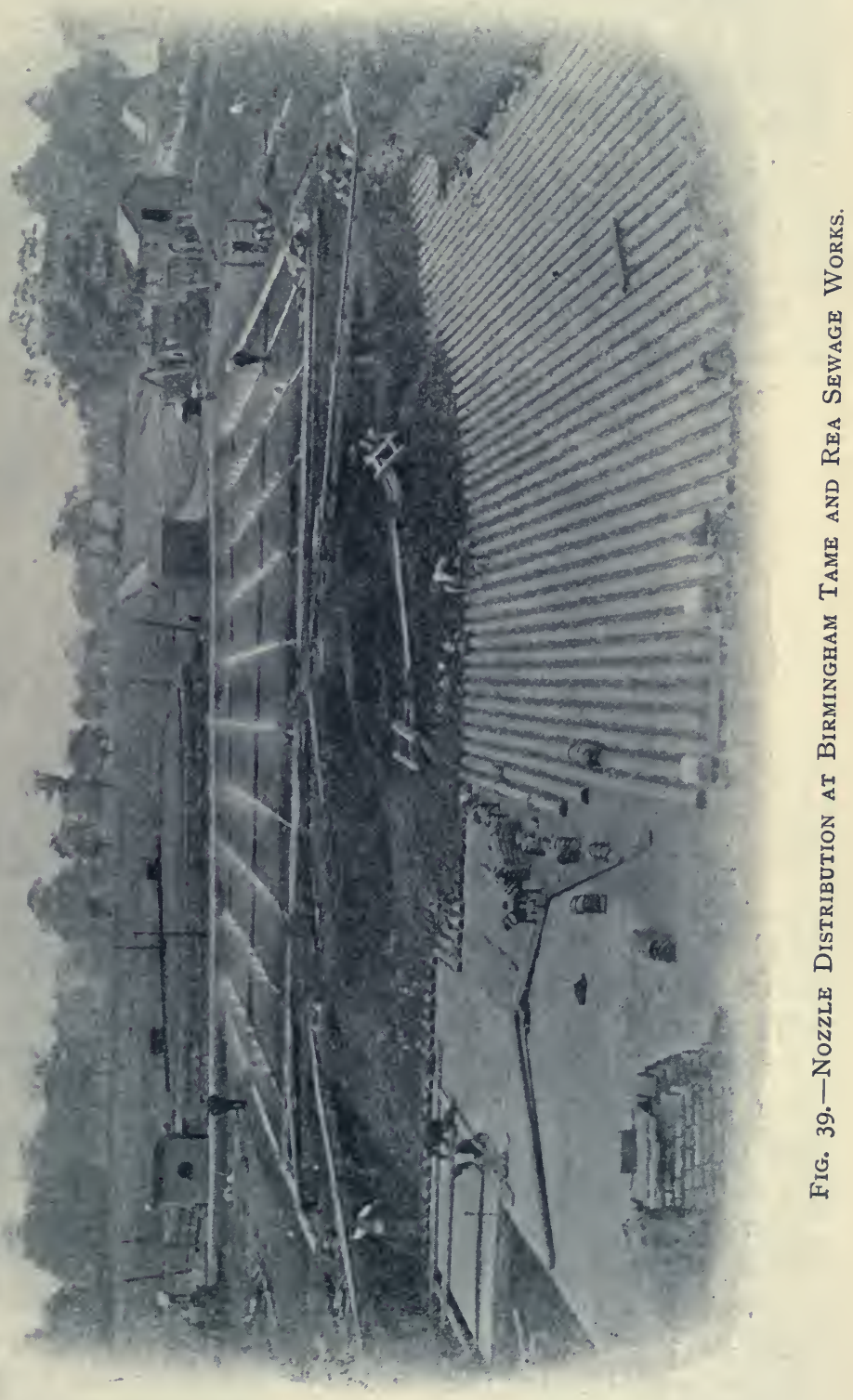


valve which opens and closes in such a way that as the pressure at the orifice of the jet slightly increases, the filter bed is covered from the centre of each jet gradually until the maximum radius of $4 \mathrm{ft}$. $6 \mathrm{in}$. is obtained, and then the pressure falls off and the jet gradually dies away. The pipe lengths are fitted with cleaning caps, and an emptying pipe for use in frosty weather (see Fig. 38).

(d) Ham and Baker's Nozzle Distributor and its application at Birmingham are shown in Figs. 39 and 40. Their Revolving Sprinkler is represented later in Fig. 50.

(e) Columbus, Ohio. Hering and Fuller kindly give me the following details of the proposed arrangements for the Io acres

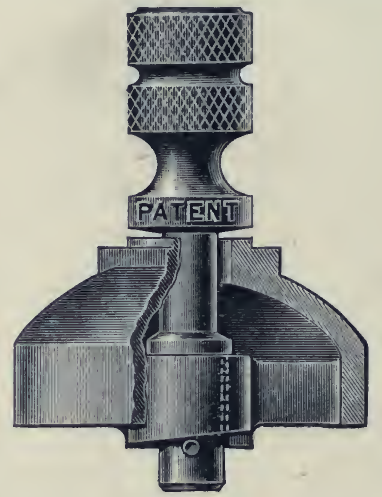

[Fig. 40.-Ham and Barer's Nozzle as used at Birmingham.

of filter beds. Each bed, $2 \frac{1}{2}$ acres in area, is estimated to yield two million gallons per acre per $24 \mathrm{hrs}$, dealing with septic tank effluent only, with an average period of flow through the tank of about $8 \frac{1}{2}$ hours. The rows of sprinklers are to be worked from 6-in. underground mains, the nozzles being $15 \mathrm{ft} .4$ ins. and the mains $13 \mathrm{ft} .3$ ins. apart. Each nozzle will be mounted on a 3 -in. cast-iron rising branch from the 6-in. supply main. After extended experiments the type of nozzle chosen was of brass, having a single orifice $\frac{9}{16}$ in. diam. with rounded edges, above which an inverted cone is held by two thin arms, the axes of the cone and orifice coinciding. The jet of liquid impinges against the cone and is transformed into a thin sheet which spreads out radially and then breaks into a mass of drops, which fall on the area included between two concentric circles. For each nozzle to discharge 13.5 gals. per minute, a head of $5 \mathrm{ft}$. is required. In operating it is intended to vary the head 
so as to cover as much of the surface as possible. From a minimum of $2 \mathrm{ft} .9$ in., with a discharge of Io gals. per min., to a maximum head of $5 \mathrm{ft}$. and a discharge of $13^{\circ} 5$ gals., it is expected that $77 \%$ of the area will be covered in a satisfactory manner. The two arms which hold the inverted cone on the nozzle will be ground down to sharp edges in a vertical radial plane; "in consequence the sheet of liquid after passing heels up so that trouble from these obstructions is eliminated." Figs. 4I, 42 show the nozzle and its arrangement on the
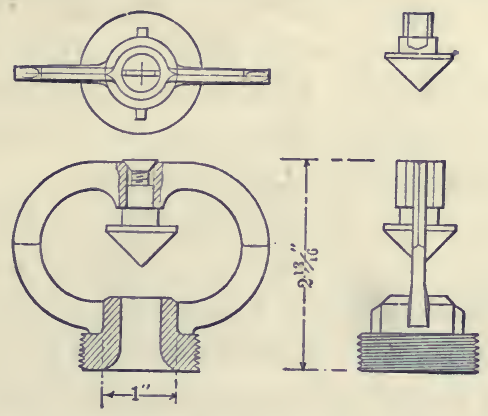

Fig. 4I.-Sprinkler Nozzle, Columbus, Ohio.

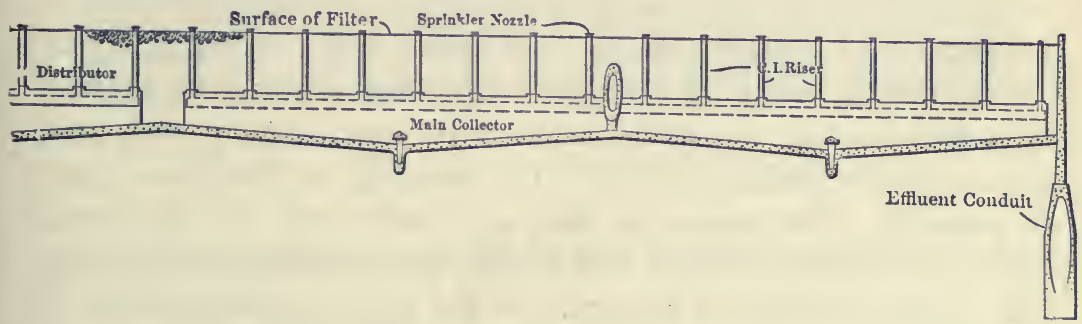

Fig. 42.-Section of Bed, Columbus, Ohio.

filter bed. For flushing and other purposes a Io-in. water main has been run to the works, and to maintain "an uniform distribution at the nozzles and to keep the consequential losses low in the main collectors it has been necessary to use depositing velocities."

A similar nozzle distribution is a part of the works authorized for the city of Baltimore, Md., and a description and drawings of the whole scheme, and of a testing plant, with several valuable comments, are given in the Report of the Advisory Engineers (Hering, Gray, and Stearns), May 3I, Igo6. 


\section{Moving Distributors.}

In Nos. I to 5, 7 and 8 of the following, the principle is that of "Barker's Mill"; or of the still more ancient " Eolipile" (described by Hero of Alexandria about 200 B.c.) - rotary motion produced by the recoil from jets of fluid issuing from holes on one side of suspended and balanced tubes.

I. Candy-Caink "self-propelled revolving sprinkler and aerator" (International Purification Syndicate). This form was installed at Reigate, Southampton, and Southwold, where the sewage, after passing a catch-pit, or after a first anaerobic treatment, was distributed by the sprinkler over aerobic beds. Mr. Caink seems to have been the first person to introduce revolving sprinklers into sewage treatment.

2. Candy - Whittaker Sprinklers (Patent Automatic Sewage Distributors, Ltd.). In the smaller sizes the arms are attached to a revolving cylinder suspended from an overhead ball-bearing attached to a fixed central column. The sewage enters the cylinder through ports in the column, and then flows into the perforated arms. The patent joint between the moving cylinder and the fixed standard is formed with a trap of mercury, so as to be water-tight and almost frictionless. Variations in water pressure are guarded against by a check ring. Oscillation of the distributor arms in a vertical direction is guarded against by a ball-bearing in combination with the mercury seal, and precautions are taken to render the bearings as moisture-proof as possible. Variations in flow are dealt with by the usual device, by means of which two additional perforated arms come into action as soon as the level of the liquor in the cylinder is sufficient. For large sprinklers the weight, which may be as much as 2 or 3 tons, is carried by means of a circular buoy floating in a small tank of water in the centre of the bed. This method is said to require only a fourth of the power (as compared with ball-bearing distributors) to set it revolving. There are two of these buoyant distributors of $120 \mathrm{ft}$. diameter at Harrogate and Birmingham, and six of $200 \mathrm{ft}$. diameter are in course of construction for Worcester. Non-buoyant distributors of $8 \mathrm{o} \mathrm{ft}$. diameter are at work at Redhill, Wednesbury, and elsewhere, and smaller ones of $8 \mathrm{ft}$. diameter and upwards are made. The average price may be taken as 20s. for each foot diameter of bed, exclusive of an automatic flusher, which is usually supplied (see Fig. 43). 
3. Mather and Platt, Ld., Manchester, supply a Patent Revolving Spreader driven by the head of sewage through a turbine at the centre of the bed (Fig. 44). The arms are open troughs, perforated along the bottom of one side of each. This arrangement is easier to clean than perforated tubes. The Spreader is hung from a cast-iron standard, and in the larger sizes it is found desirable to steady the outer end of each arm by guide wheels running on a circular rail track. Trough arms are more affected by wind than tubes, but with outer rails a motor can be added for driving during high winds. It is

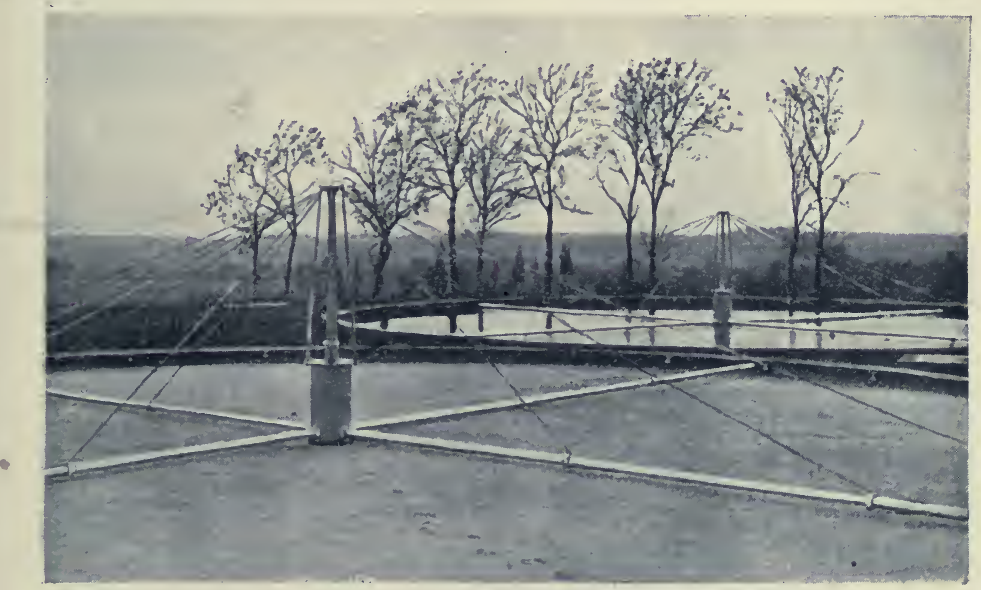

Fig. 43.-Candy-Whittaker Distributor at Bedford.

always desirable to work this form of distributor with automatic flushing gear.

4. Adams' Hydraulics, Ltd., Yorks, make several forms of revolving Distributors. The "Cresset" differs from others mainly in the air-lock water-seal between the fixed standard and the revolving body, to which the spray arms are connected (see Fig. 45). A fixed tank has an inner division in which the revolving body rotates, and an outer division which when filled with water develops an air-lock between it and the revolving body, and thus prevents the escape of the sewage between those two portions. The whole weight is carried by a crosshead on the top of the central column. At Derby there are I8 "Cressets," each Ioo ft. diam., at Birmingham one I2o ft., at Hurlford five of $40 \mathrm{ft}$., and smaller sizes are made down to Io ft. diam. Exclusive of supply pipes, valves, or flushing 
gear, carriage, and erection, the cost is as follows : $25 \mathrm{ft}$. diam., $£ 35 ; 50 \mathrm{ft}$., $£ 55$; $100 \mathrm{ft}$., $£$ IOO; and so on in proportion. "The least head required is that which would cause the sewage to gravitate to a point 6 " above the centre of the surface of the filter bed, but it is advisable to allow not less than $9^{\prime \prime}$ for a constant uniform supply." If the supply is variable, the head must be greater in proportion. The maximum head is not stated, but apparently there is a limit beyond which there may be an overflow of sewage from the central air-lock. The apparatus is intended to work with an automatic flushing tank when the rate of distribution falls below a certain quantity per

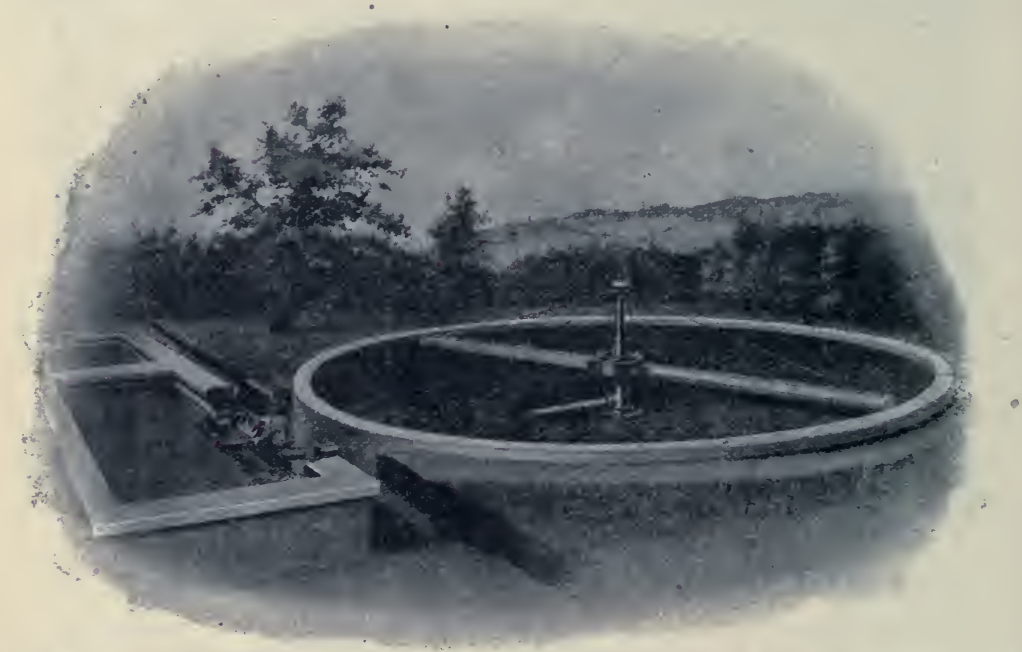

Fig. 44.-Patent Revolving Spreader, in conjunction with a Patent Automatic Measuring Valve, for either Continuous or Intermittent Feeding (Mather and Platt).

sq. yd., and under these conditions it is said to distribute as much as Ioo gals. per sq. yd. per 24 hrs. The effect of wind pressure is naturally much the same as on other types of the Barker's Mill, and if this be taken into account at least $12^{\prime \prime}$ of head would be required to drive it against an ordinary wind. Messrs. Adams are now constructing distributors to be driven by power, which appears to indicate that for the larger sizes, at all events, automatic distributors cannot be entirely relied on. In one of the latest forms the arms are fitted with two rows of. spray holes, the lower for the minimum, and the upper for the maximum discharge. In this case the minimum and maximum 


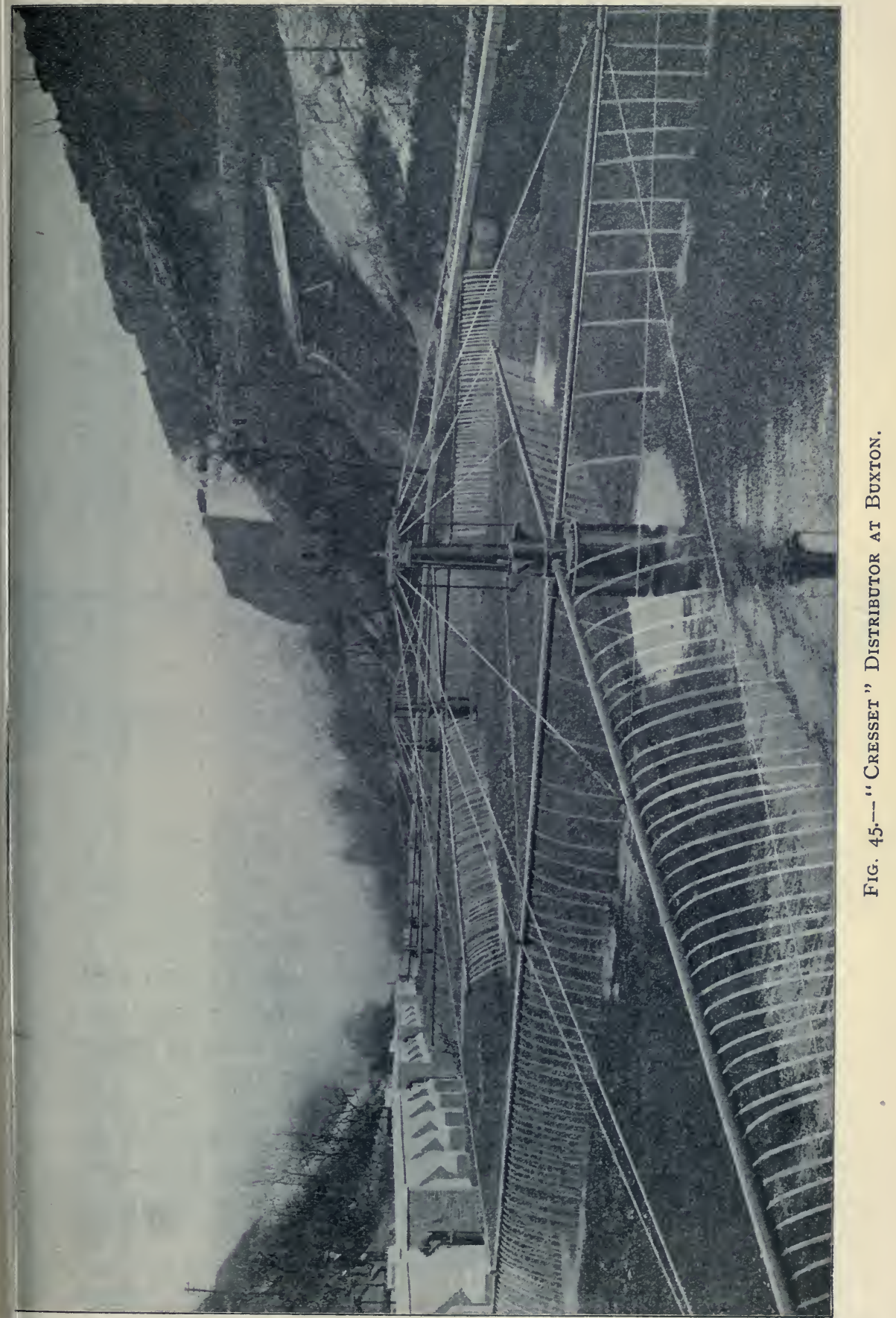


heads are expected to be $7^{\prime \prime}$ and $15^{\prime \prime}$. Suitable vanes may be attached to the ends of the arms, and controlled by a master vane, so that the wind pressure may be utilized to help the propelling arrangements during times of storm.

5. Jennings' Patent Automatic Sprinkler claims among special features that the arms are jointless, and carried on protected ball-bearings, and that the loss of head in the Distributor itself is negligible. The centre tank T (Fig. 46) is fixed, and the arms alone rotate, their weight being carried on the moving vertical shaft $S$, which runs on ball-bearings. An overdraw syphon $O$ supplies each arm from the central tank. The syphon is kept full by water traps at the inlet and outlet ends, but it has to be filled in the first place by means of a pump. The perforations in the arms are arranged with

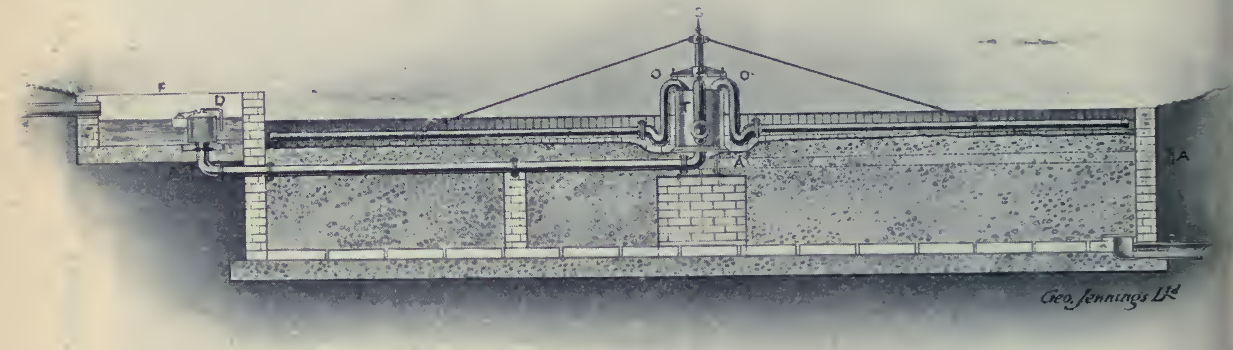

Fig. 46. -Jennings' Patent Automatic Sprinkler for Sewage and Water Filtration.

the object of distributing equally over each sq. yd. of filtering area. The feed supply $F$ to the central tank $T$, through the underground pipe A, is regulated by an automatic syphon $\mathrm{D}$, governed according to the volume of sewage by a syphon valve and ball float. The head is kept constant by a weir. When the flow increases two additional arms come into operation as in some other forms; in this way it is said that the maximum flow may be four times as great as the minimum. The pattern shown is adapted for filters up to $50 \mathrm{ft}$. diam.; above this size a fixed central column is used. It is not explained how the central bearing would be affected if one arm of the distributor became filled before the other, and consequently threw the distributor out of balance. Jennings' sprinklers, $80 \mathrm{ft}$. diam., are in operation at the sewage works, Cole Hall, Yardley, and Kenilworth, and smaller ones of 10 to $40 \mathrm{ft}$. at St. Leonards, 


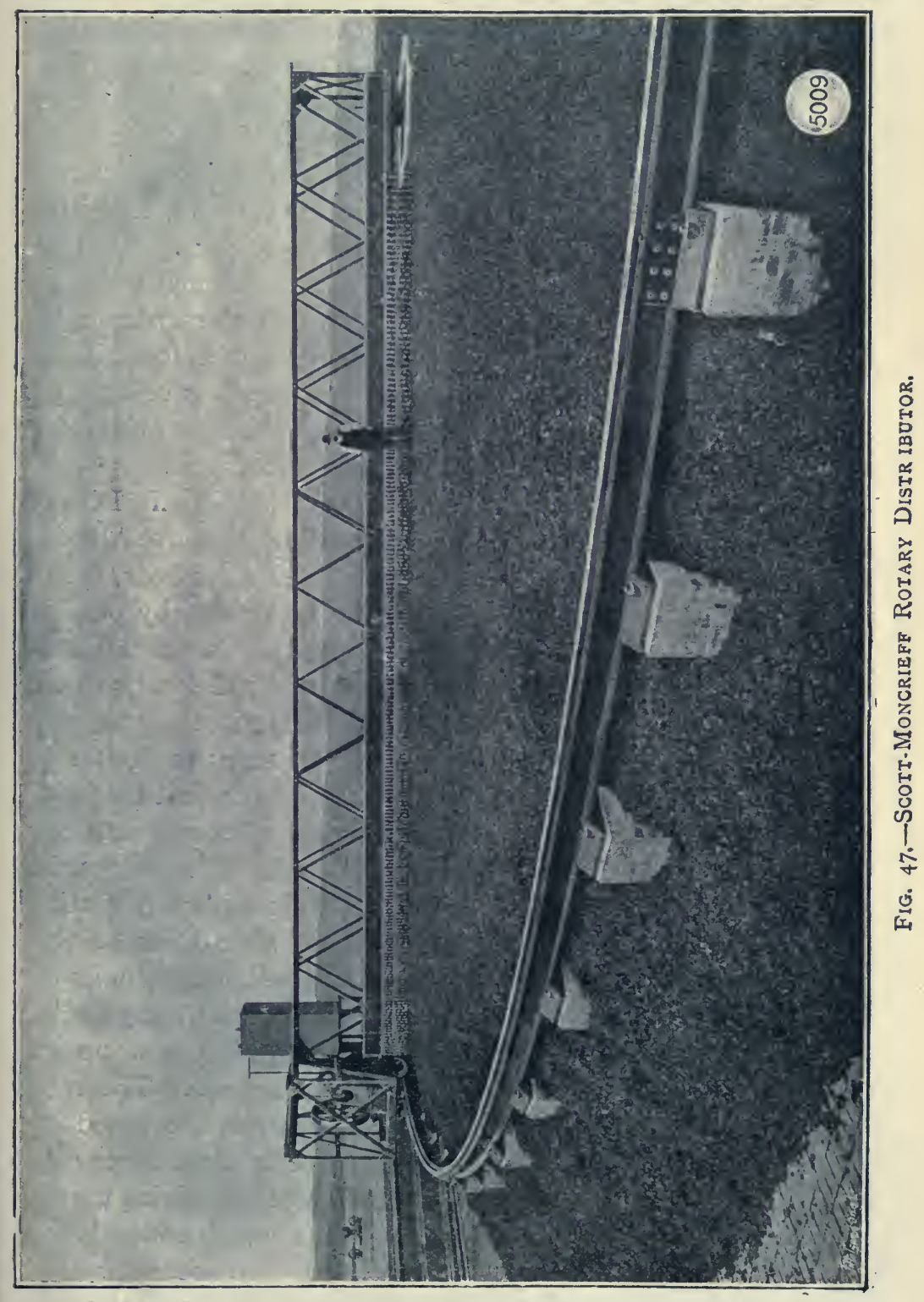


Windsor, Eastwood, and Greasley Sewage Works, and elsewhere. Prices : $25 \mathrm{ft}$. diam., $£ 25$ to $£ 3 \mathrm{I} ; 50 \mathrm{ft}$., $£ 50$ to $£ 56$; IOo ft., $£$ IOO to $£$ I22; delivery and erection, $£ 5$ to $£$ Io extra.

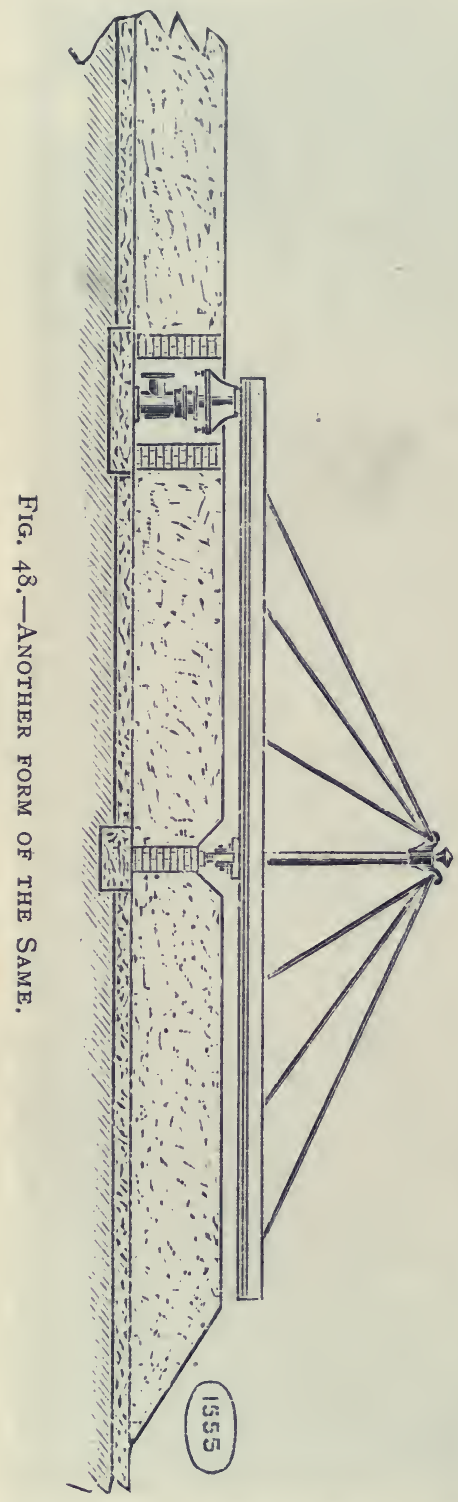

The head required is stated as from $2 I^{\prime \prime}$ to $9^{\prime \prime}$, with a flushing tank, and $15^{\prime \prime}$ to $9^{\prime \prime}$ in continuous working, with a maximum distribution of $\mathrm{I}, 000$ gals. per sq. yd. per 24 hours, and the minimum 150 gals. Below I50 gals. an automatic flushing tank is found essential, and is usually provided for higher rates. Jennings' gauging apparatus is on the float principle, graduated over a weir.

6. Scott-Moncrieff Distributor, made by Manlove Alliott, Ltd., for large filter beds, is intended to be driven by power. In this form the distribution can be effected over the entire bed with mathematical accuracy, while all passages or openings are of such a size that they are readily accessible and can be easily cleansed. Variations in flow are dealt with automatically without alterations to the distributor itself. The limits of distribution range from 50 gals. per sq. yd. per $24 \mathrm{hrs}$. up to 2,000 gals. or more. The rate does not control the speed of revolution as in most other distributors, since the driving motor works quite independently of the sewage, and consequently each yard of the bed gets just the same dose at equal intervals of time. The loss of head is practically negligible, being only that which is absorbed by the pipe connections from the external carrier to the centre of the bed. The apparatus is of a heavier 
and more massive description than other makes, and consequently the first cost is also greater, but there appears to be no doubt that, owing to the equality of distribution, a greater average rate of flow can be allowed, and a higher class effluent secured. The makers contend that the combin?d cost of filter bed and distributor to produce a given standard of effluent from a given volume of sewage is less if this distributor be used than with any other. Two forms of the distributor are given in Figs. 47,48 , the latter representing an equally efficient, but less costly, form than the former. The sewage flows from a central standpipe along a main trough to the extremity of the rotating arm. Alongside the main trough (which is supported by lattice work) runs a small subsidiary trough, which is subdivided into compartments. Each compartment is connected with the main trough by a port-hole, the size of which varies with the distance of the section from the centre of the filter bed. The sewage overflows from the subsidiary

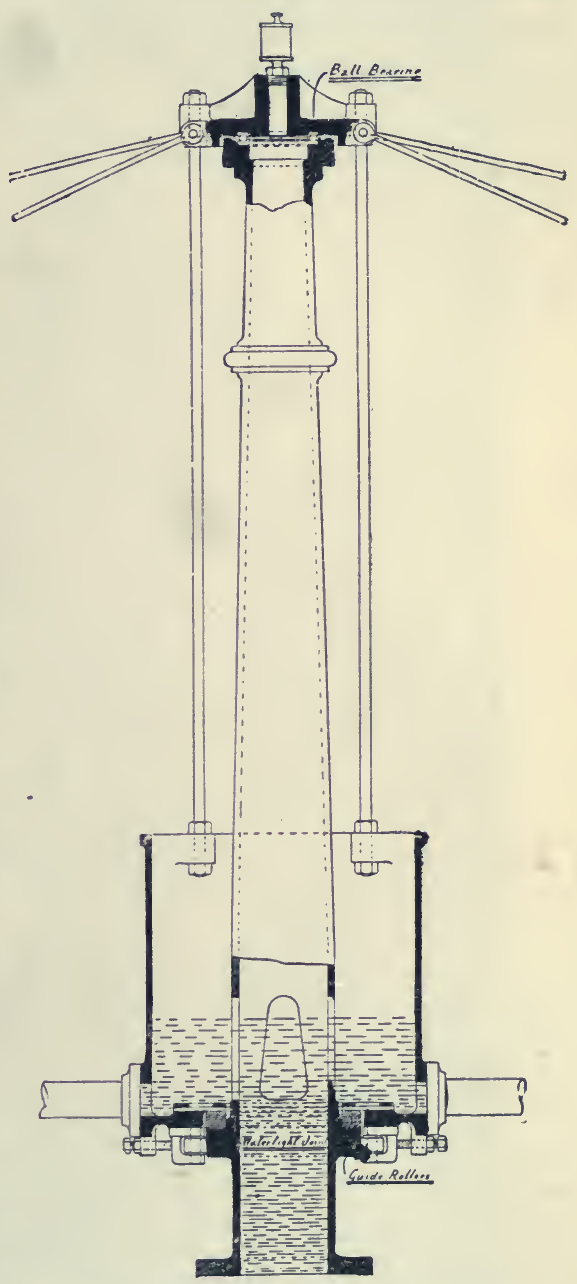

Fig. 49.- "Simplex" Spreader. troughs on to the filter bed. The subsidiary troughs are each fitted with adjustable weirs, and drip points coming close to the surface of the bed. The first cost per square yard of area covered has been found to lie between that of the Barker's Mill type of distributor and the fixed type of distributor. The sizes made are for $\frac{1}{4}$ acre beds and upwards. 
7. Simplex Spreader (Ames-Crosta Sanitary Engineering Co.). A central pillar supports a weatherproof cap running on ball-bearings and supporting the arms. Oscillation is prevented

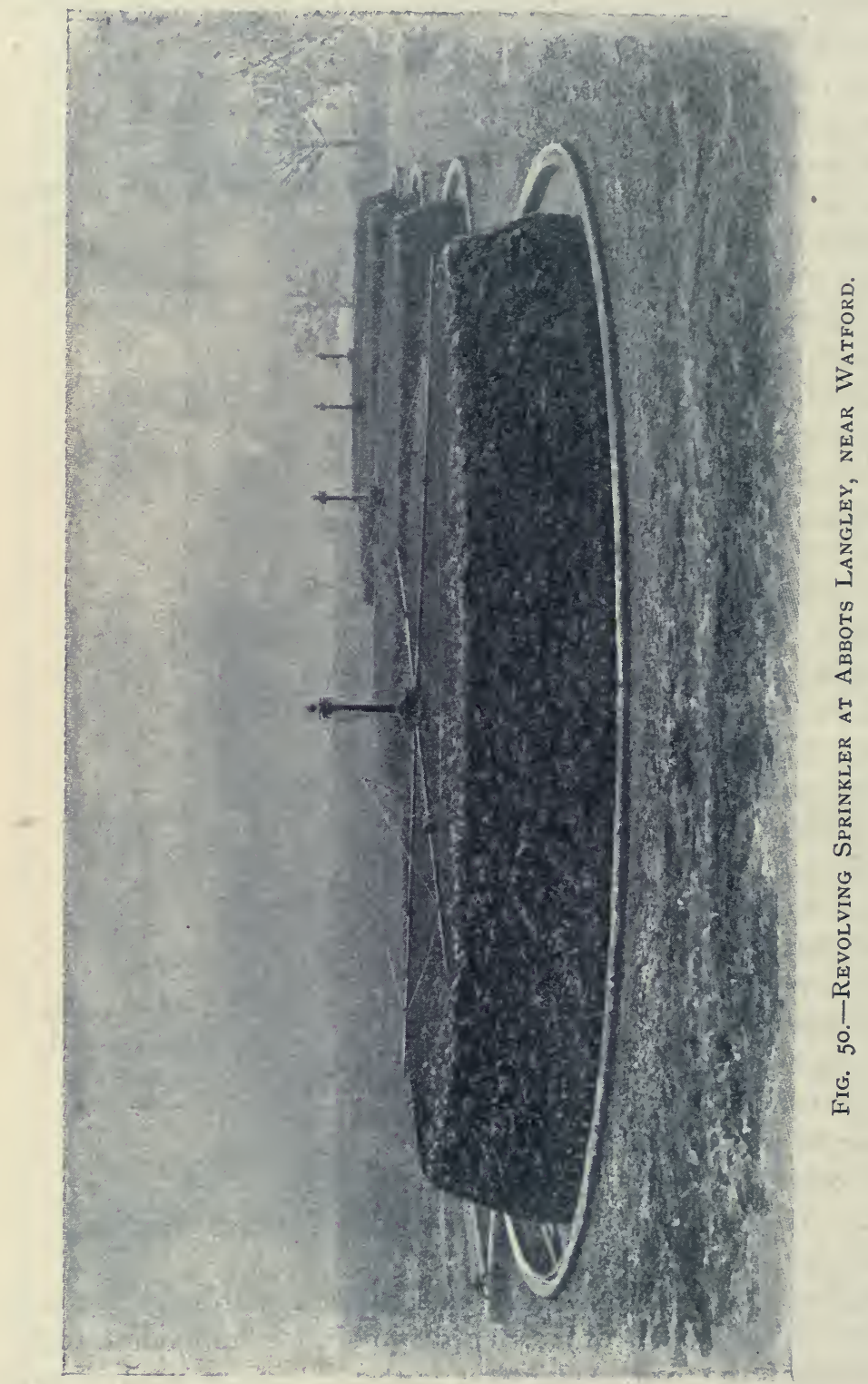

by adjustable guide rollers fixed on the underside of the bucket, which revolves with the arms (Fig. 49). The guide rollers run on a machined surface on the central pillar. The joint between 
the central rotating bucket and the fixed central pillar is made by means of two anti-friction rings and a resilient washer of rubber or corrugated copper. Arrangements are made for an easy inspection of the bearings. The least head desirable is stated to be $4^{\prime \prime}$, and to give three times the dry weather flow a head of $28^{\prime \prime}$ would be required, unless extra arms are placed at slightly higher levels on the central bucket. For intermittent working an automatic flushing tank is recommended.

8. Ham and Baker's Revolving Sprinkler at Abbots Langley, near Watford, is illustrated in Fig. 50.

The Fiddian Automatic Distributor (Birch, Killon and Co.) consists of one or more elongated water wheels $9^{\prime \prime}$ to $18^{\prime \prime}$ diameter, which roll bodily over the surface of a filter on

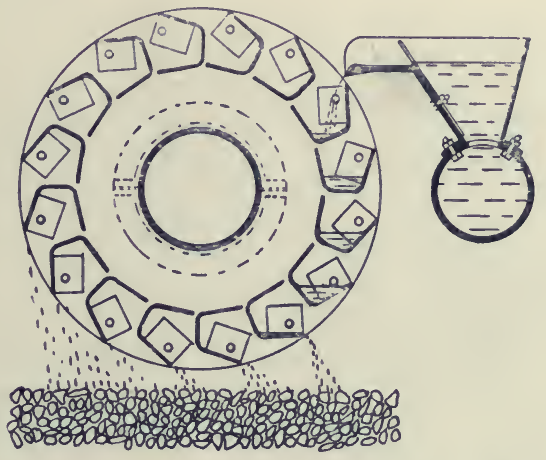

Fig. 51.-Section of Fiddian Water Wheel.

circular rail tracks about a central pivot. Each rolling drum has a pipe connecting it to a supply of tank effluent, which falls into the buckets of the wheel. The water-wheel buckets are divided transversely into sections, each section being supplied from a separate opening in the feed-tube (Fig. $5 \mathrm{I}$ ). The openings are fitted with adjustable weirs of a width proportional to their distance from the centre of the filter bed. It is claimed by this system that equal distribution can be obtained without the sewage passing through any restricted areas, or any power other than the head of the sewage itself being utilized. Filters up to $20 \mathrm{ft}$. diameter have the rolling drum supported on one roller track in addition to the central standpipe. A second rolling track is provided when the filter is between 20 and $30 \mathrm{ft}$. in diameter. A balancing arm or second rolling drum is required when the bed exceeds $30 \mathrm{ft}$. diameter, 
and is less than $54 \mathrm{ft}$. diameter. Above $54 \mathrm{ft}$. diameter a third rolling drum is introduced together with an intermediate track, which is usually carried upon cast-iron columns. This system is suitable for beds up to I20 ft. diameter. The interval between the application of each dose to the filter bed surface is from 3 to 6 minutes, thus giving the bed time for aeration. The standard sizes actually erected so far are on filters from $9 \mathrm{ft}$. (Wolverley, Loughborough) to roo ft. diameter. Various sizes are in use at Ford House, Shrivenham, Alvechurch, Atherstone, Walsall, Sileby, and a distributor for Ioo ft. bed (of clinker, 0.18 acre, to purify 250,000 gals. per day) has been

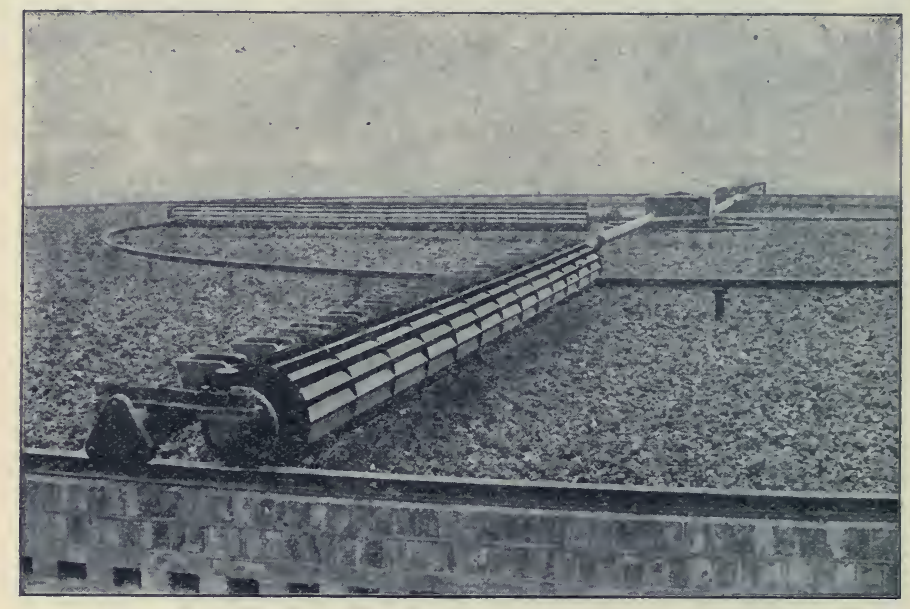

Fig. 52.-Fiddian Revolving Distributor at Enfield.

erected at Enfield (Fig. 52). Prices quoted are: $25 \mathrm{ft}$. diam., $£ 50$; $50 \mathrm{ft}$., $£ 106$; I00 ft., $£ 225$; not including the iron tracks. It is stated that only $x 8^{\prime \prime}$ of head is required between the sill of the Septic Tank and the top of the filtering medium, not only for driving the distributor, but also to overcome pipe friction and clearance underneath the rolling drum. The flow of sewage may vary within wide limits: the makers state that the test at Tividale shows that the Distributor can work with 50 gals. per sq. yd. per diem, and according to Dr. Reid the mean fluctuations over or under the mean delivery per yard of filter only amounted to $10 \%$. No flushing tank or automatic valves are required.

The Septic Tank Company, Ltd., have a "turbine ring" revolving distributor with graduated trough arms. The sewage 
entering the central chamber drives the turbine ring attached to the open-trough revolving arms, from one edge of which the sewage overflows on to the bed through slots graduated in size according to the distance from the centre, with the object of attaining equality of distribution. The troughs have corrugated pendent rims like Stoddart's on their under sides. The quantity of sewage delivered is restricted by regulators or equilibriumintermitting valves, such as are used by the Company for land irrigation. The distributors are offered in sizes from $I_{5} \mathrm{ft}$. to roo ft. diam.

"Travelling distributors" is the trade term for those which

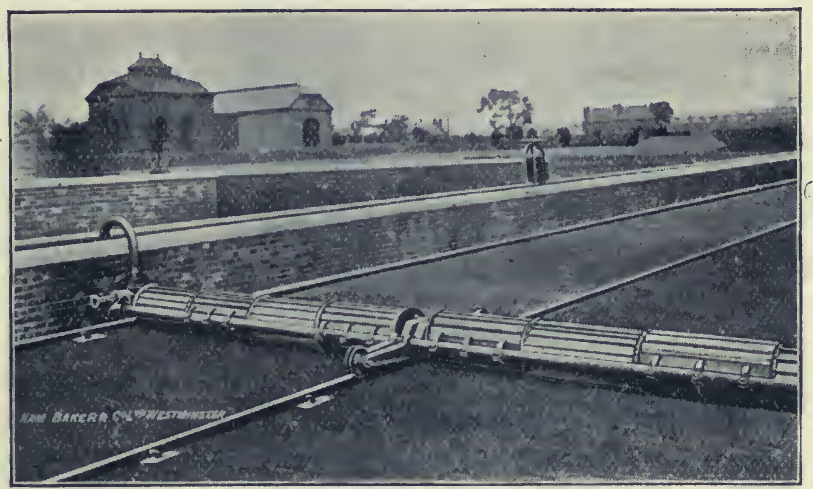

Fig. 53.-Travelling Distributor for Rectangular Beds at WEDNESBURY.

pass backwards and forwards over a rectangular bed (Fig. 53). They are not of such general application as revolving sprinklers, and are more affected by wind resistance. They can be driven by the recoil from jets, the liquid being automatically made to issue alternately from each side, or can be actuated by other available means, such as by wires worked by a small waterwheel, with reversing arrangements. They are sometimes supported by floats placed in the feed channel. Hartley's (patent 29,203 of I904) has a travelling syphon, and is worked by wire ropes actuated by independent power.

\section{Distributors with Tippers.}

The Ashtead tippers have already been described (Fig. 29): in the later form at Caterham and other places they were double $\mathbf{V}$-shaped trays mounted on trunnions and automatically 
discharging on alternate sides when the liquid reaches a level which upsets their equilibrium.

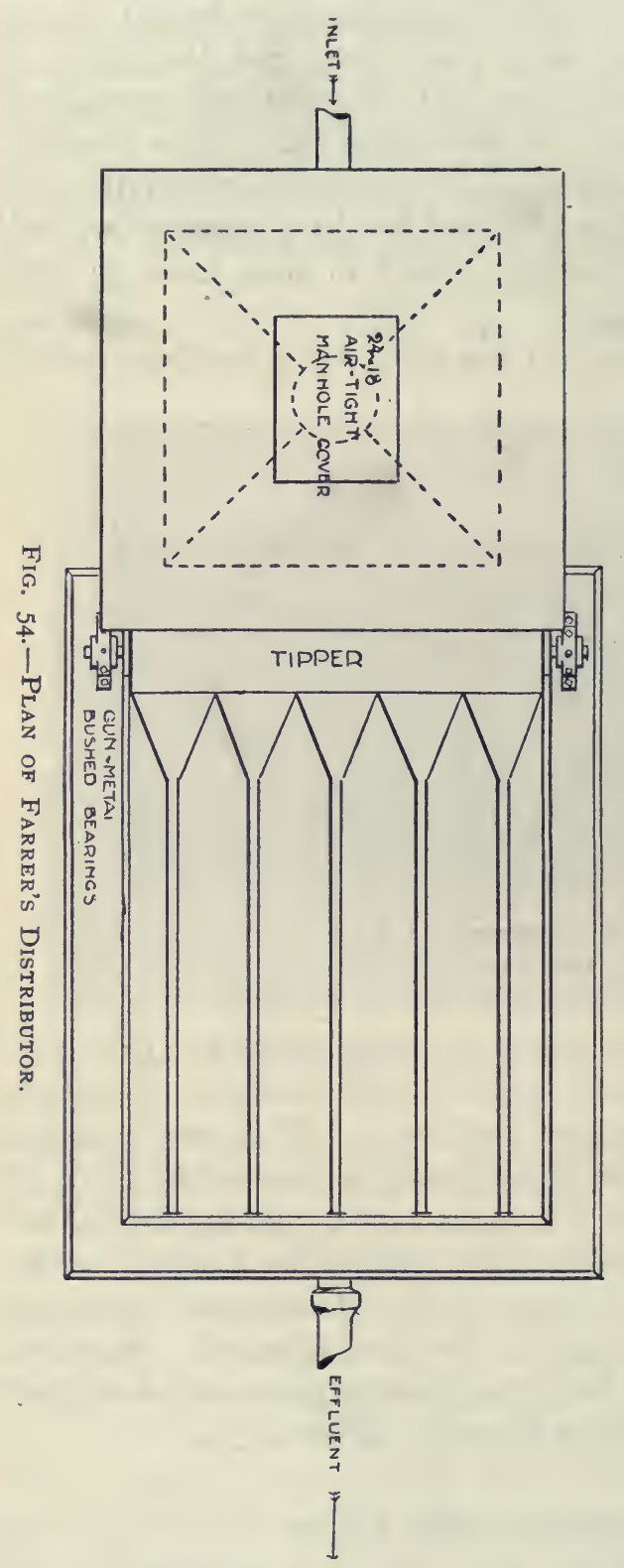

Farrer's Automatic Distributor (Figs. 54, $55,56)$ is mainly suitable for smaller installations; the largest at present is on a bed 32 by $20 \mathrm{ft}$. Septic effluent is discharged into a tipper which supplies distributing channels on the beds, whence it flows along troughs perforated on the lower sides; these being made with a concave bottom, clear themselves readily. The maximum head required is stated to be I4" for small installations, increasing for larger ones on account of the section of the tipper varying with the greater volume. Converging shoes underneath the tipper cause equal quantities of sewage to pass along each distributing channel.

Continuous and intermitten $t$ filtration, apart from the differences between the results obtained, present a contrast both in the mechanical arrangements and in the bacterial process itself.

In the case of contact beds, except when they are used in series, there is no differentiation of the organisms in relation to 
the food supply, because, although the conditions are changed from being purely anaerobic to those more or less favourable to

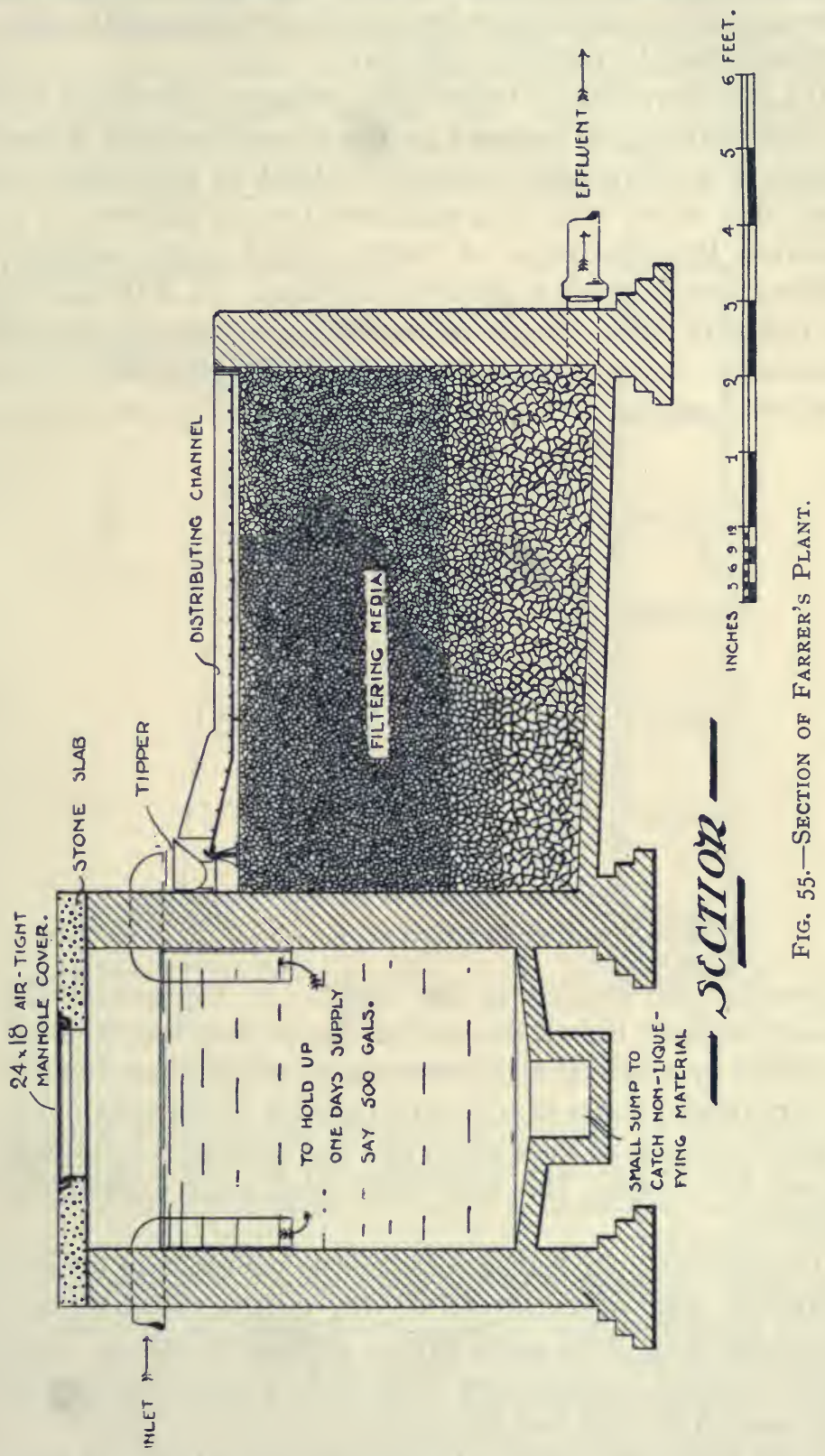

aerobic action, these are conducted in such a way as to provide neither condition continuously, and the results obtained have already been dealt with and explained in previous chapters. 
When an apparatus is designed from the point of view of overcoming these objections, it is obvious that the methods of bringing about the contact between the sewage and the bacterial surfaces must be radically different.

In the filtration of hydrolysed effluents, whenever there is a continual dripping upon a particular spot, growth is liable to occur of a filamentous character allied to Crenothrix, but it has been found that if a sufficient time is allowed to elapse between the discharges of liquid on the upper surfaces, this filamentous clogging is generally avoided. In a Whittaker bed at Leeds in May, I899, a falling off in the results was due to the surface being covered by an abundant gelatinous growth of Pylobolus, which prevented aeration and appeared to be pro-

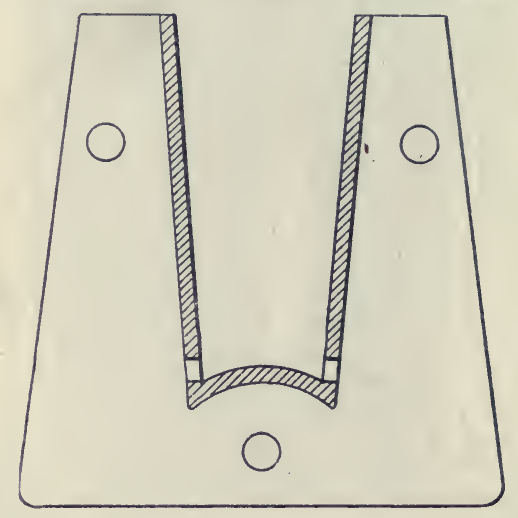

Fig. 56.-Distributing Channel, showing Flange at End.

moted by the heating of the liquid. As the growth did not penetrate more than a few inches, the surface was removed and replaced by a foot of very coarse coke, which proved effectual.

Mr. Dibdin states that some streaming filters were objectionable on account of their smell, and at Carshalton relief had been found by covering the beds with peat moss carried on wire network.

Continuous filter beds are frequently constructed for aeration purposes with lower layers of very coarse material, but it is found better to build them with a perforated base or "aerating floor," arched or supported by girders, leaving an air space at the base of the bed (see Chap. X.).

Scott-Moncrieff's Sewage Testing Apparatus (Fig. 57) has been in operation at Staines, Keighley, and elsewhere. It consists of a box about $8 \mathrm{ft}$. high, $3 \mathrm{ft}$. wide, and I foot broad, filled to a depth of exactly $6 \mathrm{ft}$. with the filtering material to be tested, 
gauged to any required size. The sewage to be tested is distributed on the top by a tipper working at a measured rate. The filter effluent can be drawn off at any one of six levels. By means of a water tank and syphon arrangement the amount of air which is supplied to the filter bed can be measured. Mr. Moncrieff claims that the apparatus is capable of determining the depth of the filter required to produce the necessary

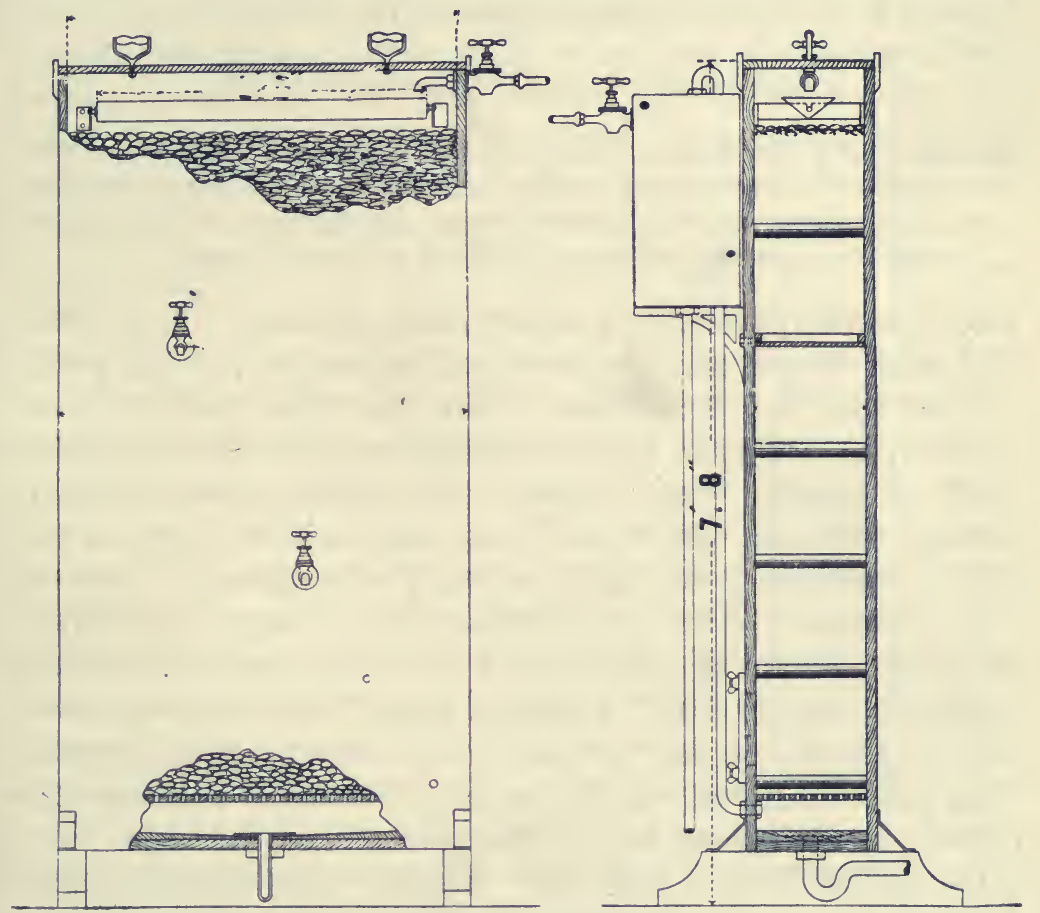

Fig. 57.-Scott-Moncrieff Sewage Testing Apparatus.

standard of purity in the effluent, the quantity of air necessary for the life processes of the organisms, the proper rate of flow per unit of filter bed surface in order to obtain the best results, and the best period of rest between every discharge. The apparatus is likely to be of great use in competent hands provided that due allowances are made for the smallness of the quantity of sewage it is possible to experiment with on an area of only three square feet, and for this, provision has been made by an ingenious device for gauging the liquid without having any small orifices. It is maintained that one square foot of filter bed is as good a unit as any other for estimating surface distribution, and as the testing machine is six feet in depth it is of full size in this particular. 


\section{CHAPTER XIII}

\section{SEWAGE OUTFALLS AND DISCHARGE}

Rainfall and storm-water-Separate and combined systems-Storm overflows-Position of outfalls-Objections and legal remedies -Foreshore smells-Unsightliness-Mud banks-Fish-Water supplies-Contamination of shellfish and watercress.

THE general principles guiding final discharge have been explained in previous chapters (see especially pp. I4, 55-60, I30 and I72), but it has been shown that there must be some elasticity according to local circumstances, and that at present many anomalies have arisen. In manufacturing districts streams still exist which are "inky black sewers," and at one point a community may have been at great expense to turn out a good effluent, while, a few miles above, a large town is discharging millions of gallons of a foul liquid daily. An early suggested remedy was "a sliding scale," enforcing that each effluent should be, say 20 per cent. better than the stream: " the effect would be that the towns on the upper part would be turning in something better than the stream, and the towns below would have to comply." If there were sufficient space between the towns for natural purification in the river, the latter would remain in good condition throughout its course. The present Royal Commission on Sewage find that "in many parts of England the pollution of rivers goes on unchecked," and recommend the creation of a supreme rivers authority, with Rivers Boards having control also of estuaries and foreshores, ${ }^{1}$ and such an organization has been long necessary. In most other countries a special administration of the kind has been for many years in operation.

\section{RAINFALl AND STORM-IVATER.}

Provision for these is essential in all systems of sewage disposal. A rainfall of $0^{*} \mathrm{I}$ to $0^{*} 2$ inch in an hour increases the out- 
flow of a sewer to five or more times its volume, but there is no exact relation between the rainfall as ordinarily recorded and the increment of flow at the outlet, the size, length, and inclination of the sewer greatly influencing the result. At Exeter five-eighths of the ordinary rainfall is estimated to find its way into the sewers. Mr. Silcock ${ }^{1}$ estimated from gaugings at King's Lynn that " the ordinary dry-weather flow of sewage per acre of a purely urban district, with an average population of seventyfive persons per acre, consuming 20 gallons of water per head per day, is 20 cubic feet (I25 gallons) per hour. A rainfall of $\frac{1}{4}$ inch in 25 hours, or approximately $\frac{1}{100}$ inch per hour, will amount to the same discharge as the dry-weather flow per acre, assuming that the streets are paved, and that only 50 per cent. of the actual rainfall finds its way into the sewers. In other words, a rainfall of $\frac{1}{100}$ inch per hour will double the ordinary dry-weather flow. Now a rainfall at the rate of $\frac{1}{4}$ inch per hour is a common occurrence, which would mean multiplying the ordinary sewage flow by 25 , and short storms at the rate of $\frac{1}{2}$ inch per hour are not infrequent when the ordinary sewage flow is augmented 50 times. . . . For a town with a population of I0o,000, if the whole of the sewage and rainfall had to be taken to the purification works, the ordinary maximum sewage flow at 20 gallons per head would be at the rate of 4,000,000 gallons per 24 hours, and if the sewage were treated on bacterial intermittent filters, 4 acres of filters would be required, but to deal with a rainfall of $\frac{1}{4}$ inch per hour would require Ioo acres of filters, and if the sewage had to be pumped it would require 25 engines and pumps each capable of dealing with a dry-weather flow to cope with the combined rainfall and sewage. It is therefore evident that the whole of the rainfall cannot be taken to the purification works, and that after a certain degree of dilution has been reached, the storm-water must be discharged into the streams."

Both the quality and quantity of the local sewage have to be considered in choosing a sewerage scheme. The effect of rain must not be considered as simple dilution, since the rain-water carries the washings of the surfaces over which it has travelled. Where the rock, or a clay-bed, is near the surface, the showers will run off almost unchanged. From manured or peaty land there will be an addition of brown humous liquids which are particularly difficult to decolorize. See also pp. 6 and 27 , and

1 Leeds Sanitary Congress, 1897. 
the Manchester observations in Chap. XI. I have repeatedly observed storm-water to be even more impure than the ordinary sewage; a sample I analysed in I905 contained in parts per I00,000, free ammonia $\mathrm{I} \cdot 6 \mathrm{I}$, albuminoid $\cdot 40$, oxygen consumed $6 \cdot 01$, chlorine $5 \%$, nitrogen as nitrates and nitrites 197 ; whereas the sewage gave generally better results, and the land effluent from the same works yielded an average of 6 free ammonia, 'I2 albuminoid, 0.53 oxygen consumed, and 57 of oxidized nitrogen. The Royal Commission on Sewage also found, ${ }^{1}$ that storm-water was almost invariably impure, both chemically and biologically, that street washings were all impure biologically, even when they contained only a small quantity of organic matter, and that the liquid might even be very impure after long continued rain; and remarked that "the practical advantages of the separate system may be great, and doubtless storm overflows are necessary, but the fact that storm liquids may be so impure, both chemically and bacteriologically, is a point of considerable importance."

For the safety of the sewers and the avoidance of flooding of basements, it is always necessary to construct storm overflows. Without these in a sewage farm scheme the ground is liable to become waterlogged, and in a filtration process the excess of water by its volume and velocity tends to derange the purification plant, hence it is usually allowed to escape from the sewers by special outlets when above a certain amount, carrying with it a mixture of the unpurified sewage. The combined system also involves the construction and maintenance of sewers very much larger than the volume of the regular flow, in order to provide for occasional contingencies. This greater capacity presents inducements to the disposal of grosser refuse which would not be tolerated in a smaller sewer, and often it is impossible-except at rare intervals-to properly flush the entire surface of these large channels.

The "separate system," in which the sewage proper is kept apart from rainfall and storm-water, has conduits of such size only as to preclude the possibility of the sewage becoming stagnant therein, the size being governed by the bore of the water main, since if a given diameter of pipe supplies all the water needed, a little above the same diameter should be sufficient for an exit. Mr. Silcock proposes that the rainfall sewers of a separate system should be provided with leaping weirs dis-

\footnotetext{
1 I904 Report, vol. iv., part i., p. 105.
} 
charging into the sewage sewers to separate the foul street washings from the later discharges of heavy rainfalls.

Storm-water passing rapidly off the land carries with it disease germs, as is shown by the repeated occurrence of epidemics when a sudden storm succeeds a period of drought. But the liquid is ordinarily supplied with abundance of the liquefying and oxidizing bacteria, which if it be allowed to subside in auxiliary reservoirs will effect its purification rapidly, aided by the oxygen derived from the air, and by the nitrites and nitrates that rain-water always contains. The sand, chalk, or especially the clay, may be a long time in subsiding, but when deposited will leave the water comparatively pure, and fit for flushing sewers, watering roads, or for supplying the deficiency in rivers during dry seasons.

Whatever system be adopted the raw storm-water of populous districts should never be allowed to pass in large volumes at the beginning of a storm directly into a stream. The general consensus of opinion is that if the first foul storm-water be treated as ordinary sewage, the subsequent rain-flow becomes so dilute that it can be discharged, with only a slight treatment, into a river. The Manchester experts placed a limit of time of two hours after the commencement of the storm. Many towns adopt a volume limit. Thus, Mr. A. M. Fowler, at. Stockport, made provision for an escape after eight times the dry-weather flow; other places in Lancashire and Yorkshire allow 6 or even 5 to I. By the Leicester Extension Act, I89I, the overflow culvert came into action when the rainfall increased the dry-weather flow of 35 gallons per head to 60 gallons, but in this case the overflow passes into the river Soar, which has a flow during dry weather of only about 6 or 7 million gallons per day, so that the stormwater is actually useful for flushing the river bed.

I have found from analyses-

I. That, after the first flush, the chlorine content varies with the rainfall.

2. That with low chlorine and high rainfall, higher nitrification is obtained.

3. That, as might be expected, the later diluted sewage comes within the usual standards of permissible impurity, therefore could not, under them, be excluded from streams.

As I remarked at the Manchester Congress of the Royal Sanitary Institute, ${ }^{1}$ purification to a bacterial standard of the

${ }^{1}$ Journ. R, San. Inst., vol. xxiii., part iv., I903, p. 6I7. 
I20 million gallons daily of Manchester sewage would involve works similar to waterworks as an adjunct to the sewage works, but six times the size of the waterworks already existing.

With contact beds, Mr. Dibdin considered "it was not a question of whether they had more or less water, it was the amount of the organic matter that was put on the bed, and if that was not materially increased it mattered not how much storm-water was put upon it. They had been able (at Sutton) to put three or four times the quantity of storm-water on to a bed than the volume of sewage they had put previously." As a matter of fact, an occasional flush of storm-water through a bacterial system is advantageous, as it removes some of the products, and so stimulates the bacteria to fresh activity.

The present regulations of the Local Government Board have been already given (p. I48), and several towns have now provided special storm. filters of sufficient extent to allow a rate of filtration of 500 gallons per square yard per diem for the balance of three times the dry weather flow in excess of that required to be fully treated. Lloyd-Davies ${ }^{1}$ has described in detail the design of the storm-water overflow chambers at Birmingham, and discusses the various discharge formulæ which have been suggested by Santo Crimp (the one preferred), Burkli-Ziegler, McMath, Kuichling, and others.

A. J. Martin ${ }^{2}$ remarks on the wide difference between the dry-weather sewages of different towns, so that if a hard and fast relation of volumes be prescribed as above, "the diluted sewage which one public body may discharge without treatment will be considerably stronger than that which another authority will be called upon to purify."

The Local Government Board insists that fixed weirs shall be used, which will only come into operation when the sewage, as mentioned above, has been diluted with five times its volume of storm-water, that is, when a certain rate of flow in the sewer is reached. But Martin proves that the amount of dilution secured by a fixed weir is variable, and will at times be considerably less than the works are intended to secure.

Among the advantages of the bacterial processes involving a large anaerobic preliminary chamber, is the ease with which the works can be adapted for dealing with storm-water. In such systems provision is made for the subsidence of solids, as well as for their liquefaction, as a tank constructed to hold the

1 Proc. I.C.E., 1905-6.

${ }^{2}$ J. San. Inst., xx., 4, p. 624 . 
dry weather flow of a sewage for 24 hours would admit of six times the dry-weather flow passing through such tank by reducing the time of stay from 24 hours to 4 hours. The rate of flow under such conditions would still be so slow as to ensure the retention in the tank of nearly all the suspended solids, and these would therefore accumulate during stormy weather to be
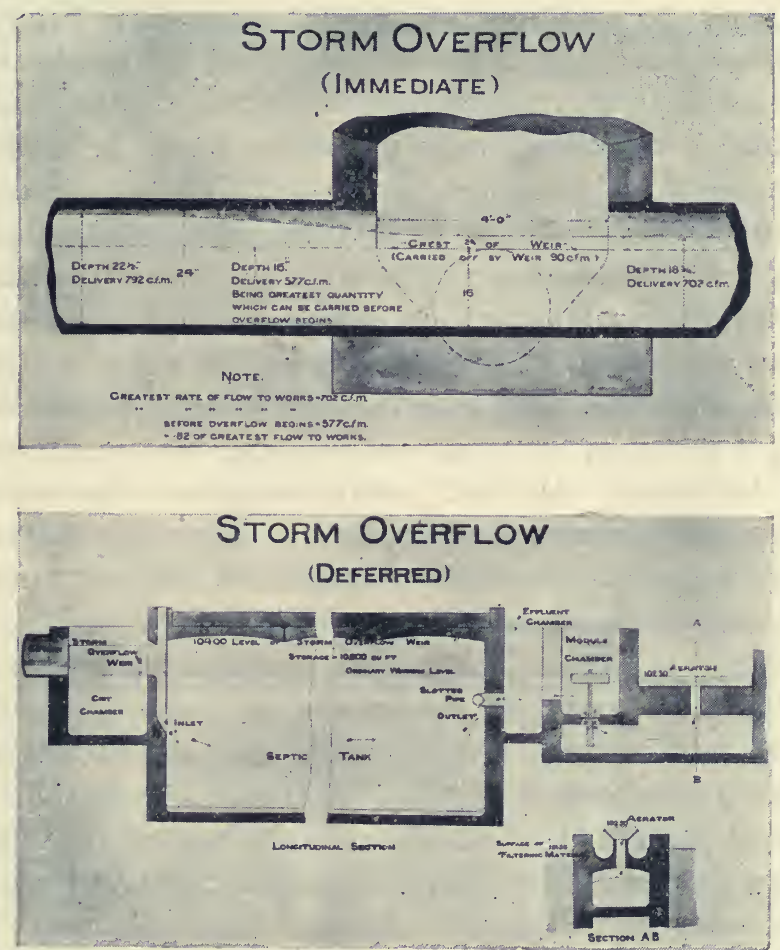

Fig. 58.-STORM Overflows at Barrhead.

digested by the tank at leisure during the dry-weather periods. A curious anomaly arises out of these considerations. If the time of sojourn in the tank is reduced owing to the rate of flow through the tank being increased, the liquid products of hydrolysis usually contributed to the effluent from the stay in the tank will not exist in the effluent water to the same extent. In other words, the effluent from such a tank during a storm will be purer than from the tank in dry weather proportionately to the rate of flow, even after due allowance has been made for dilution, provided only the rate be not so high as to bring 
untreated suspended matter to the outlet. Mr. Martin shows that at the Barrhead Works the velocity of flow in the tanks with three times the volume of the dry-weather flow passing through them only amounts to $I \frac{7}{8}$ in. per minute. With six times the dry weather flow, therefore, the velocity does not exceed $3 \frac{3}{4}$ in. per minute, which is so slow a rate as to be powerless to disturb solid matter in the tank. Martin's arrangement of weir and regulated flow by modules is shown in Fig. 58.

In bacterial treatment, whether by tanks, filters, or land, it is known that the resolving organisms are most active, especially in the final or oxidizing stage, when the liquid is of moderate strength, since undue concentration retards the growths, while too rapid a flow is liable to wash them away. Chernical processes of precipitation or sterilization on the other hand find concentration an advantage, so much so that some of them, as for instance the Liernur process, require the aid of evaporation. It is clear, therefore, that in both cases heavy dilution is to be avoided, if possible, for other reasons than that it increases the size of the works. Modern practice suggests the importance of making the sewers watertight, and of disposing separately of subsoil water, which is usually innocent of contamination.

The conclusions, therefore, are :-

I. Subsoil and deep drainage water can as a rule be separately pumped and discharged, if the sewers are properly constructed. The relief that may result to a system of sewage treatment has been shown in a recent instance at Kathmines, Dublin, where the normal sewage of $2 \frac{1}{2}$ million gallons per day is swelled to 6 millions by subsoil drainage. A similar observation has been made in other towns.

2. Road washings are dangerous, and especially under the separate system should be sterilized in situ by sprinkling the surface with effective disinfectants.

3. Storm water should be impounded and stored or otherwise treated, and must never be allowed to pass in large volumes directly into a stream. The larger the volume of liquid the more dilute it will generally be, and proportionately so much less of a disinfectant will be required.

\section{Position of Outfalls.}

This is not always a matter of choice, and is affected by questions of cost and engineering. Among the varieties of final discharge are:- 
(a) Sewers and drains opening directly into the nearest body of water. This primitive method is still common, although it is not even excusable in remote districts, as it is now known that small and simple installations with tank and filters can be easily constructed and work well.

(b) Tunnels or pipe lines to convey the sewage to a long distance. The Manchester "Culvert Scheme" of I899 proposed to convey the effluent to the tidal river Mersey at Randall's sluices, by a circular tunnel $6 \frac{1}{2} \mathrm{ft}$. diam., with a fall of $\mathrm{I}$ in $2, \mathrm{roo}$, and a full discharging capacity of about $67,000,000$ gallons a day. The scheme was not adopted, as considerable nuisance was anticipated. Eventually a tunnel-syphon $5 \mathrm{ft}$. diam., carrying bacteria-bed effluent under the river Mersey, with a shaft at each end, was constructed. On the further side of the river the tunnel communicates with a supply channel I3 feet wide, following the contour of the high land, from which the effluent radiates over the land in subsidiary carriers 18 inches wide, with disc valves on the upper ends in the carrier wall, so that any length can be opened or shut at will. The main drain lies midway between these carriers, communicating with an open channel delivering into the Ship Canal at a point over a tumbling bay, placed sufficiently far back from the canal bank to minimise any current prejudicial to navigation.

In Chap. I., p. I9, I have already discussed sewage discharge into the sea. Letts and his colleagues have studied the effect of the admixture of sewage with a body of sea water, ${ }^{1}$ and conclude that (I) the first effect is chiefly absorption of $\mathrm{O}$ and production of almost the equivalent amount of $\mathrm{CO}_{2}$; (2) comparisons between the "oxygen-consumed" test and the $\mathrm{O}$ actually absorbed as determined by analyses of the dissolved gases prove that "a more energetic oxidation is induced by micro-organisms and free oxygen than by the nascent oxygen of the permanganate solution"; (3) the nitrifying organism can grow in sea water, but a large quantity of free ammonia remains for a long time unnitrified; (4) under no circumstances is a nuisance likely to arise from sea water contaminated by sewage up to I per cent.; but the changes in the nitrogenous constituents as measured by the free and albuminoid ammonia and the nitrates are very slow. (See further Chap. I., p. I9.)

Purvis and Coleman in a series of experiments just published ${ }^{2}$

2 F. K. San. Inst., xxviii., No. 8, I906, p. 433. 
have not obtained any nitrification in mixtures of sea-water with one per cent. of sewage, although there was a rapid breaking down of organic matter with formation of ammonia and odorous compounds. By trials with the marine salts separately and together they found that they had an inhibitive effect on oxidizing changes. Their conclusions are strongly against sewage being discharged untreated.

The principal objections to sewage outfalls that appear in most official enquiries are:-(I) Smells; (2) Unsightliness and inconvenience through turbidity of the water or floating débris, formation of mud banks, and unpleasant deposits on the shores; (3) Destruction of fish, and sometimes of aquatic vegetation; (4) Contamination of water supplies drawn from rivers and lakes; and in special cases, (5) Pollution of shell-fish or of watercress beds.

As a result of the enquiries it has been frequently found that the faults were not entirely due to crude sewage, and only exceptionally to purified effluents. Taking the above points in detail :-

(I) Smells. Many sewage- and water-bacteria effect liquefaction without creating any offence. On the other hand we have described at p. 8I a number of natural causes of objectionable odours unconnected with sewage.

(2) Faults above mentioned that are occasioned by suspended solids. Screening and roughing tilters prevent the more glaring evils, and in many cases this is all that is done, but it is rightly made an essential of satisfactory treatment that the effluent should contain very little suspended matter. As an example of pollution, 26 miles of the river Severn were examined for the Royal Commission on Sewage. ${ }^{1}$ This stretch receives the untreated sewage of Shrewsbury (pop. 28,396, dry weather flow about 900,000 gallons, mixing with about Ioo volumes of river water), besides less amounts from other sources. Chemically the river shows a marked recovery from its Shrewsbury pollution within some 20 miles from the town, and it still further recovers as it proceeds, in spite of some additional contaminations. $^{2}$ Hence it is fair to infer that with a good effluent there would not have been any injury. But the results of discharging sewage entirely untreated were found to be:

(a) The bed of the river consists of putrefying sludge, and the velocity of the stream is always tending to spread the

1 Reports, vol. ii., I902, pp. 93-133.

2 Ibid., p. I32. 
deposit to a great distance down, and to shift it from place to place.

(b) Although on emerging from the sewers the solids are for the most part well broken down, yet a very considerable amount of the lighter fæces, various débris, and pieces of disintegrated paper float for a long distance down the stream, and disfigure the banks. In the little bays where these accumulate, the mud is blacker than elsewhere, and the willows have strained out a considerable quantity of the floating material ; offensive decompositions occur; the water usually presents a scum; the bacteria are more numerous and $B$. coli more abundant. The course taken by floating matters was traced by throwing large numbers of coloured corks into the river. Some of them were followed for 8 miles, where the observation stopped, and were seen even 6 months after they had been thrown in, showing how long solids may remain, even in a rapid river.

Mud banks can obviously form independently of the solids of sewage, which in many cases amount to only a small portion of their volume, or to merely a film on their surface. Besides the presence of coal dust or soot, they often acquire a dark colour from the production of black sulphide of iron, as described on p. II5. Quantities of shrimps, mussels, and marine or fluviatile organisms are usually found on them, which shows that they are not poisonous to such life.

(3) Destruction of fish and sometimes of aquatic vegetation.-The two are connected, as the water plants not only themselves serve for food for certain fishes, but also harbour the lower forms of animal and vegetable life which help to support fish. In the Severn, where the deposit is at all abundant, there is no growth of aquatic plants, and " the absence of a clean bottom, supporting weeds, will most probably act injuriously on fish." 1

"The absorption of oxygen and the evolution of not only $\mathrm{CO}_{2}$, but of other gases such as $\mathrm{H}_{2} \mathrm{~S}$, must act injuriously on fish life. Indeed, König and Haselhoff have shown that carp and tench are injuriously affected by 8 milligrammes of $\mathrm{HS}_{2}$ per litre.",2

That greater care is necessary in securing the cleanliness of shores and estuaries has been for some time obvious, from the

1 Reports, vol. ii., 1902, p. 97.

2 Ibid., p. ro6. Further authorities on this subject are Nitsche and Tharaud, Weigelt, J. König, Hoppe-Seyler, Duncan, Saare and Schab (Verunreinigung der Gewasser, vols. i. and ii., by Dr. König), U.S. Fish Commission, 188o, Bulletin, vol. v. See also evidence given before R. Sew. Commission, Interim Report, vol. ii., I902, especially pp. 485-496. 
nuisances that have been occasioned in many localities by the presence of foul matter on foreshores and on the banks of tidal rivers. Experience as to the dangers to health has already been given (ante, pp. I7O, I72), but apart from this aspect, it is not to the advantage of any local body to be continually in danger of a fine, and large law costs, now that the liability has been proved in the Courts, in spite of the almost complete exemption that ivas granted to tidal waters by the Rivers' Pollution Act of 1876 .

At present in England there exists no authority with powers to prohibit the laying down of shellfish in sewage-polluted water or other dangerous localities, and to ensure the protection of unpolluted layings, storage ponds, fattening beds, and other places where shellfish are laid or stored, against contamination by sewage. The Royal Commission recognise the deficiency, and outline an administrative change to comprise a Central Water Authority with Rivers Boards exercising jurisdiction over separate water sheds, including shores, as an extension of the Rivers Pollution Act of 1876 , the new authority to be well equipped for carrying on the necessary scientific work as part of regular duties. (Fourth Report, I904, vol. i., p. xxv).

This remedy is practically the same as they have already suggested in the third report for inland towns, and does not, after all, give any immediate answer to any particular offending locality. Until legislation is passed and the new controlling authorities have had years of experience, it will still be difficult in many cases to decide how much or how little treatment is required.

In the case of Rivers Boards having tidal waters under their jurisdiction, the Commissioners think that the Fisheries Committee should be empowered to appoint representatives thereon, and this would transfer to the new board the powers of the Salmon Conservators and other similar bodies.

The improvement on our coasts that would ensue if good bacterial effluents only were discharged can readily be appreciated.

The law with reference to the pollution of tidal waters is thus at the present time in a more hopeless condition than that of non-tidal waters. Thus, for example, the Section $I 7$ of the Public Health Act of 187.5 , under which, in the past, many injunctions have been obtained for prohibiting the discharge of noxious matter into streams, watercourses, canals, ponds, or 
lakes, has usually been held not to apply to tidal waters; and similarly the provisions of the Rivers Pollution Prevention Act of 1876 can only be operative after the Local Government Board have made a local enquiry, and declared that for the purposes of the Act the estuary or tidal portions of a river shall be deemed a part of the river on sanitary grounds.

The Salmon Fishery Acts are also equally unsatisfactory, and the Royal Commission on Salmon Fisheries in I902 has pointed out serious defects in the existing Acts.

On the other hand, we may note that under the common law, when injury to others has been proved, a local authority may be restrained from discharging sewage into tidal waters.

The case of Lord Gifford against the Corporation of Chichester in I9oI is illustrative, and after this decision several oyster fisheries and owners of fishing rights in tidal waters have taken steps in a similar way to enforce the purification of sewage discharged into tidal waters by local authorities, when such sewage has been detrimental to their trades. In the above case the evidence was partly bacteriological, and the action was won largely on the fact, which was undisputed, that "coli" organisms were found in the mud of the estuary below the outfall, but the present works, approved by the Local Government Board to meet the injunction, will no more stop the passage of coli into the estuary than bacteriological treatment of London sewage would sterilize the Thames.

Although the extent of illness attributable to the consumption of contaminated shellfish is difficult to gauge, the present Sewage Commission find the evil sufficiently great to demand a remedy, and thus save the expenses and uncertainty of these actions. In I899 a Government Bill was introduced, but not passed, for the protection of public health against dangers arising from the consumption of unwholesome oysters. The interests of the industry, which is estimated to have a capital value of from six to eight million pounds sterling, still remain sufficiently great to warrant serious consideration, as the oyster scares have, from time to time, brought about severe disturbance to the trade.

The remedies suggested are threefold: (I) Purification of sewage; (2) seizure and destruction of unwholesome fish exposed for sale; (3) the creation of a competent authority to deal with tidal waters.

With regard to the first, the Commissioners recognise that 
there are difficulties in the way of the sterilization of sewage effluents, but these I have dealt with in Chapter VIII. It would appear that as, failing such sterilization, all sewage outfalls must necessarily more or less contaminate shellfish, watercress, or drinking-water below, either the sewage outfall must be removed, or nothing in the contaminated area should be offered for internal consumption without purification.

A bacteriological examination associated with topographical evidence may even be misleading, as there are nodoubt many cases daily in which temporary pollution of a fishery or oyster laying may take place by, say, fæcal discharge from closets on board a ship, and there is little evidence at present as to distance, time, dilution, tides, and other factors which determine the possibility of infection of shellfish by estuary waters.

In a report by Dr. Houston to the Commission, ${ }^{1}$ a careful investigation of over $\mathrm{I}, 000$ oysters, from various layings throughout the country, shows that nearly all contained B. coli communis or closely allied organisms. It cannot be too widely known that the Commission are clearly of the opinion that the mere presence of $B$. coli microbes in an oyster does not justify its condemnation.

With regard to foreign shellfish, the Commissioners are satisfied that in the interests of public health some safeguards are necessary in connection with their importation and sale. A suggestion was made that all consignments of foreign shellfish should be required to be relaid for some period, in approved waters, before being sold to the public. The Commissioners doubt if such a requirement could be justified in the case of all foreign shellfish. For the present, they think that it would be a sufficient precaution to require a guarantee on the part of each Government concerned that all oysters, or other shellfish, imported into this country for human consumption had been procured from localities where they were not liable to be contaminated by sewage or other objectionable filth.

Watercress, being at times almost immersed, may become coated with polluted lime-crusts and not be easily cleaned by washing. The London County Council's report of February 7, 1905, on watercress beds supplying London, concludes that, "having in view the extent to which careful washing eliminates impurity, it may be assumed that there is under existing cir-

${ }^{1}$ Fourth Report, 1904, vol. iii. 
cumstances no material risk in consuming the watercress supplied from the majority" of these beds. Objection is taken on topographical, chemical, and bacteriological grounds to certain beds where there was actual gross pollution, " and effort should be made to prevent the consumption of watercress from these beds in their present condition."

The annual consumption of watercress in London is about I, 500 tons, and the I20 beds examined, with areas from less than $\frac{1}{4}$ to 40 acres, comprise all those within 50 miles known to supply the London market. In most cases the waters were examined by the chemist, who gives his own classification according to the albuminoid ammonia as follows :-

\begin{tabular}{c|c|c}
\hline Group. & No. of Samples. & Nitrogenous Organic Matter. \\
\hline A & 53 & $\begin{array}{c}\text { About the same as the filtered (Thames- } \\
\text { derived) London supply. } \\
\text { About the same as in the Thames at Hampton } \\
\text { and Sunbury above the intakes. } \\
\text { B }\end{array}$ \\
C & 47 & $\begin{array}{l}\text { Large in quantity. } \\
\text { Very large in quantity. }\end{array}$ \\
\hline
\end{tabular}

Thirteen of the waters were submitted to the bacteriologist, and those containing coli in I cc. or less are condemned. It will be seen that our Guildford chlorine-treated effluents would have easily passed this test (pp. I89, rgo). The two worst samples were effluents from sewage farms, and contained ro,ooo coli-like microbes per c.c., and enteritidis spores in 'I c.c.

Dr. Houston concludes that "no ordinary amount of washing could be relied on to rid cress grown in polluted waters of all undesirable microbes." It was of great moment to ascertain whether pathogenic organisms could exist and multiply in the interior of plants, and this was partially studied by analogy with $B$. coli. The results on the whole were against the hypothesis, as Sir Shirley Murphy notices in his summing up, although Dr. Houston lends some probability to the idea that the leaf and stalk of cress " may foster undesirable organisms." Even if it were true that pathogenic infection of the interior of living plants were occasionally possible, I believe that in the acid washings I have described at p. I93, the acid, being more diffusible than the bacteria, would reach them in sufficient quantity to destroy them, and then be removed in the subsequent washing with water. A point in favour of the success of cleansing is that the $B$. typhosus is actively motile, and therefore would 
probably be removed more easily than $B$. coli. The subject demands further investigation.

I have already pointed out that, in the contamination of shellfish gathering-grounds and watercress beds, sewage and sewage effluents are not always in fault, and that some of the other occasional polluting matters, being more recent, are more dangerous in character. The L.C.C. Watercress Report, just noticed, specifies beds polluted by cattle, by house drainage, by trade effluents, adjacent farms and stables, and " occasional deposit of human excreta near the intake." In my inspection of the Medway fisheries I found that no adequate sanitary provision was made for the men engaged in the industries, and, as I should surmise in other fisheries, local contamination may arise from this cause. Evidence before the Royal Commission on Sewage as to another locality stated that "a large number of barges after unloading refuse pump out the offensive and highly polluted bilge water into the creek," and the oysters in the neighbourhood are found to be infected although there is no discharge of sewage in the vicinity.

In an analogous case within my own experience, oysters from a laying far from any source of sewage pollution had been condemned independently by Dr. Klein and by myself, and it appeared that some other form of contamination must be present. On an inspection I found in a creek joining the channel a heap of about 5,000 tons of town refuse which had been discharged partly below high-water mark, and was draining into the creek, and another screened heap about half the size near by. Other objectionable cargoes were also being unloaded on the banks. In a case that has just occurred where crabs were condemned, and were reported to be "swarming with organisms which would cause serious illness," it was suggested that they had been contaminated by the flooding of a barge while being brought to London.

If the damage, on the other hand, is clearly traced to the sewage, the remedy lies at law. The sequel to the Emsworth outbreak of typhoid has been an action ${ }^{1}$ by the owner of the beds for an injunction to. restrain the District Council from placing or maintaining their sewage outfalls in the neighbourhood of his oyster beds, and from delivering sewage on the said foreshore so as to contaminate the same, and to render the oysters liable to be infected and unsafe for food, with damages

1 Foster v. The Warblington Urban District Council, Dec. to Jan., I905. 
to the business. The judge allowed the claim that these were private oyster beds, and disallowed the defence of prescriptive right to discharge of sewage, chiefly on the ground that the Sea Fisheries Act, I868, made it criminal to discharge sewage so as to contaminate private oyster beds, and there could be no prescriptive right to commit a criminal act. Further, no one can acquire by prescription a right to pollute a public fishery. He would not, however, grant an injunction on the grounds stated in the analogous case of Harrington v. Derby, in Dec., I904, when similarly there was judgment for the plaintiff with damages. At Southend also the owners of the oyster beds were successful on their appeal.

The law, therefore, as defined by these recent instances, is that a corporation may continue the pollution and be fined at intervals to an indefinite amount when injury is proved.' This liability is further foreshadowed by a well-known case lately decided in which a large dairy company had to pay heavy damages, upheld by the Court of Appeal, on account of a death assigned to the presence of typhoid germs in milk supplied by them (see later, p. 326). It seems obvious that the same might apply to a pollution of water, and to a public authority. It is clear that public interest in the prevention of disease, as well as economy and the avoidance of trouble, indicate the sterilization of effluents as a general course.

At places of holiday resort where large numbers of people consume shellfish that they have gathered on the shore, enteric fever often results. These shellfish are not owned by anyone, and the site cannot be registered. Therefore no sewage should be allowed to be discharged in an unpurified state, otherwise it would be almost impossible to compel authorities to exercise supervision over the whole foreshore.

On the gathering-grounds for the Glasgow market, Dr. Chalmers ${ }^{1}$ found that the regular trade gatherers of shellfish are in the habit of rejecting those lying on the surface and regarded by them as "sick," and of only collecting those which have embedded themselves in the sand, and therefore have been to a great extent protected from the sewage. These regular collectors were quite aware of the danger attached to certain contaminated areas, and mussels were not taken from places near sewer outfalls. Visitors, however, were not so careful, with the result that there had been a number of cases of typhoid

1 Report of Med. Off. of Health, Glasgow, I905. 
associated with the collection and consumption of shellfish by excursionists, but there was little evidence throwing suspicion on the market supply. Dr. Chalmers finds that the information is not at present sufficient to define the distance from outfalls that would render shellfish safe to gather: it would be much influenced by tides and currents.

But there are large cities, such as London and Manchester, whose sewage is of such immense volume that the cost of sterilization may be beyond present possibility. It seems that the difficulty must here be solved as a financial question, namely (in the words of Rudolph Hering, speaking of similar cases in America, notably New York and Baltimore), "whether the city is to purify its sewage, or whether the oysters that may be polluted by the same will have to be grown elsewhere,"1 like other cultivation industries that have to be moved in the extension of cities. Dr. Buchanan has shown ${ }^{2}$ that shellfish collected one or two miles from a sewer outfall were free from contamination. But the Royal Commission had before them evidence that many established beds could not be moved without great loss, nor suitable sites found elsewhere.

The Duty of the Vendor. - The decision in a High Court of Justice appeal, Frost v. Aylesbury Dairy Co., Feb. 24, I905 (the case I have alluded to above), laid it down as common law that on the sale of an article for a specific purpose (in this case for consumption as an article of food), there was a warranty implied by the vendor that it was reasonably fit for the purpose, and there was no exception as to latent undiscoverable defects.

It is only very recently that the communication of disease has been considered as a ground for recovering damages. Even if the giving of a warranty be avoided by putting up a notice, liability for negligence or want of care will still remain. It seems, therefore, that an action for damages could be laid by the customer against the vendor, and that the latter could recover from the polluters of his beds; but this is an expensive and dilatory process. One of the safeguards for vendors is the inspection of supplies. In London the power exists, through the Fishmongers' Company, of prohibiting the importation of polluted fish to the metropolitan markets. I may notice, in passing, that sprats, whitebait, and smelts, as they are eaten uncleaned, and the cooking is often not sufficient to ensure

1 Trans. Amer. Soc. C.E., vol. liv., part E, 1905.

${ }^{2}$ Journ. R. San. Inst., vol. xxv., part iii., I904, p. 466. 
sterilization, require bacteriological attention, and that in the examination for coli and enteritidis it is not the presence, but the frequency or number of these organisms that is of most import.

Taken together, the precautions that lie in the hands of the trader, and finally in those of the consumer, are the following:-

I. Selection and maintenance of clean beds.-That good shellfish can be raised under such circumstances is proved by the Report of the Local Government Board for Ireland, 1904, and by evidence before the Royal Commission on Sewage, vol. ii., I904, showing that many of the best brands come from localities free from dangerous pollution. With regard to watercress, the London County Council Report, already referred to, shows that cress of the best quality can be grown under conditions to which, from a public health point of view, no exception can be taken (p. 7), and that the best beds were, generally speaking, found on a bottom of hard clean gravel : such beds are regularly cleansed, and in some cases a light dressing of lime is used at each cleansing in order to destroy organisms deemed to be injurious (p. 6).

2. Relaying of shellfish in purer water.-Although in common use, and recommended by a large number of witnesses before the Royal Commissioners, the purifying value of this practice was defined in the Report as "at present uncertain." Referring to the work of Herdman, Boyce, and Klein, it was said ${ }^{1}$ that "judged from these experiments it would seem that polluted oysters placed in approved waters might free themselves from dangerous organisms in the course of a comparatively short period [ten days to a month were mentioned], but as regards cockles and mussels, relaying might be less effective."

3. Sterilizing objectionable organisms in the beds themselves.Better precede by cleansing as far as possible. How chlorine, acids, or copper can then be used I have indicated: the first would probably be the cheapest, and at the seaside electrolysed sea-water would readily be attainable (Chapter VIII.).

It is customary to lay the oysters required for market in pits at high-water mark, so that they shall be readily available for transport. In these pits it is easy to add a sterilizing agent and keep for a period of, as it were, quarantine, and to inspect them as to objectionable organisms being killed. This would be cheaper than attempting to sterilize the whole of the estuary or

1 R. Comm. on Sewage, Fourth Report, vol. i., p. 40. 
sewage discharging therein, or even to ensure the non-coli environment of the oyster beds themselves. Such sterilization is on the principle I have always advocated-that it should be as near the consumer as possible, and should be confined to the thing consumed. Actual details have to be worked out for the particular industry. The similar removal and temporary storage apart of the watercress required for market seems possible. It is conceivable that sterilizing, with chlorine or other agent, the beds where shellfish spat or young watercress is present might have an injurious effect on the young growth, therefore that treating the adult product would be preferable.

4. Sterilizing by Cooking. - Where this can be done thoroughly it is effective, and the Commission found that cockles and mussels can be so thoroughly boiled as to bring about the destruction of pathogenic organisms without rendering the mollusc itself uneatable. An incidence of typhoid at Glasgow in I903 was due to raw cockles; those who had eaten cooked mussels and clams escaped injury. ${ }^{1} \quad$ The heating is very often imperfectly done: thus a number of enteric cases in South London two years ago were due to cockles which were stated to have been boiled for three minutes, but this had not sterilized the interior. I have also quoted earlier an instance at Southend (p. I7I). When, as is frequently the practice, cockles are put into the boiler in a bag, the centre portions may easily fail to reach the temperature, a little above $60^{\circ} \mathrm{C}$., necessary to sterilize $B$. typhosus; hence it is better to put them in loose or on a grating, and stir at first. The adoption of precautions without injury to the trade is exemplified in Dr. Nash's report to the Borough of Southend for I904, in which he states that the shellfish are now drawn from purer sources, and that nearly every seller in the town subjects them to the action of live steam under pressure for four or five minutes, the result being that not a single case of typhoid due to cockles occurred during the year. ${ }^{2}$

5. Sterilization by the Consumer, the last line of defence.-I have suggested how this has been done instinctively, with a measure of success, in the usual consumption of vinegar with these foods, and have indicated how it may be more certainly

1 fourn. R. San. Inst., vol. xxv., part iii., I904, p. 467.

2 Local vigilance is, however, maintained, and I notice that at Southend on Nov. 8, 1904, a fisherman was fined for selling mussels unfit for food. Dr. Klein stated that 80 per cent. of these mussels contained a very large quantity of sewage organisms, and the water from the spots at which they were taken was polluted.-Public Health, Jan., 1905, p. 266. 
accomplished by washing with weak chlorine or acids. Obviously, the vendor is not thereby absolved from his attention to the quality of his goods, nor the local authority from the duty of obviating pollution where it is dangerous. We must remember that most articles of the kind we are discussing are habitually washed at least twice, by the retailer and by the private purchaser, before consumption, and that sterilization of dangerous organisms at the same time would scarcely add appreciably to the trouble or cost.

The danger that has been so much urged of admitting effluents to drinking-water streams, and a great deal of the expense of sterilizing effuents and water-supplies, would be minimized if the consumer also sterilized the small quantity of water used for drinking (estimated at about a gallon per head per day) in a way that I have for some years advocated. ${ }^{1}$

During the passage to houses through pipes there is a constant risk of contamination from the liability of the pipes, even under pressure, to suck in polluting matter from the soil, so that it has been frequently demonstrated that the supply to houses is often much inferior to the filtered waters in the reservoirs and mains. Here again a final line of defence is necessary. I pointed out that as sterilization, so far as concerns dangerous organisms, is essential for safety, much of the expense might be saved by making the treatment at the works less costly, since it was superfluous to purify water required for a large number of domestic uses, for flushing the streets, or for sanitary purposes. It became a question whether we should aim at the whole public supply being purified up to the maximum standard of a good drinking-water, with a great extension of stringency as regards discharging effluents, or whether we should be content with a somewhat less purified water for the general supply, and sterilize separately in each house, under some conditions of municipal control, such portions as should be required for food purposes. Of the three methods I have described for rendering the fluid germ-free, the chemical one, by ozone or chlorine for instance, could be employed at the works, while the heatsterilizer, or Pasteur filter, could be put into the consumer's house by the municipality or by a water company-preferably by the former-as an integral part of the ordinary water fittings, and the duty of keeping it cleansed and in order secured by official inspection.

${ }^{1}$ Cantor Lectures, Fourn. Soc. of Arts, Aug. I, I902, p. 749; also fourn. R. San. Inst., vol. xxii., part iv., p. 565 . 


\section{CHAPTER XIV}

\section{AGRICULTURAL VALUE OF BACTERIAL EFFLUENTS- TRADE EFFLUENTS}

Conservation of the valuable constituents of sewage-Economic value of nitrated effluents-Trade effluents-ClassificationChemical and mechanical treatment-Recovery of productsWool grease-Relation to the bacterial process-Recommendations of the Royal Commission.

THE earlier attempts to utilize sewage and its sludge for agricultural purposes have been discussed in Chapter VI. Sludge in its various forms has never been of great value, and the analyses show that it is not rich in plant food, especially when large quantities of lime have had to be added in order to make it into a marketable cake. Sewage effluents, on the other hand, contain all the soluble constituents of the original sewage, and after oxidation the nitrogen in the form of nitrates is easily and quickly assimilated by plants. Maerker, ${ }^{1}$ from agricultural experiments in Germany, considered roo parts of nitrogen, as albumen, equal to 90 , as ammonia, and 60 , as nitrate, so that for economic utilization the organic nitrogen should be nitrated as far as possible; and denitrification changes, as already seen, must also be avoided in order to prevent loss. Sir William Crookes estimated that in the sewage and drainage of towns we "hurry down to the sea fixed nitrogen to the value of $£$ I6,000,000 per annum.",

Estimates of the agricultural value of human excreta. Annual value per adult $6 \mathrm{~s} .6 \mathrm{~d}$. to $20 \mathrm{~s}$. (various authorities). I lb. human excreta $=I_{5} \mathrm{lb}$. horse dung or $6 \mathrm{lb}$. cow dung (Macaire and Marcet). Mechi ranks the droppings of a sheep at the same value as the total excreta of one human adult. Voelcker reckons the yearly excreta of an adult as equal to $75 \mathrm{lb}$. of

1 Kew Bulletin, 1899, No. I +4 .

2 "The Wheat Problem," Murray, London, 1899. 
Peruvian guano. Tidy tabulates the components of urine and fæces as follows ${ }^{1}$ :-

\begin{tabular}{|c|c|c|c|c|c|}
\hline \multirow[b]{2}{*}{ Constituents per Ton. } & \multirow{2}{*}{$\begin{array}{c}\text { Ammonia } \\
\text { at } 7 \mathrm{~d} \text {. } \\
\text { per } 1 \mathrm{~b} \text {. }\end{array}$} & \multicolumn{2}{|c|}{ PHOSPHORIC ACID. } & \multirow{2}{*}{$\begin{array}{l}\text { Potash at } \\
\text { 3d. per lb. }\end{array}$} & \multirow{2}{*}{$\begin{array}{c}\text { Estimated Value } \\
\text { per Ton. }\end{array}$} \\
\hline & & Solubl & Insoluble & & \\
\hline & lbs. & lbs. & lbs. & lhs. & $£$ s. d. \\
\hline Urine in natural state ... & $23^{\circ} 94$ & 2॰94 & & $3 \cdot 34$ & O I5 IO \\
\hline $\begin{array}{l}\text { Fæces in natural state ... } \\
\text { Mixed excreta of a popu. }\end{array}$ & $35^{\circ} 45$ & - & $26 \cdot 62$ & $9 \cdot 46$ & I 76 \\
\hline lation $\ldots$ & $23^{\circ} 13$ & $2 \cdot 79$ & I.93 & $3 \cdot 83$ & O I5 \\
\hline I,000 tons of London & & & & & \\
\hline crude sewage ... $\quad .$. & 219.37 & $27^{\circ} 6 I$ & $24^{\circ} 20$ & 5065 & I $\frac{3}{4}$ \\
\hline
\end{tabular}

The Royal Commission of 1858 - 1865 concluded after exhaustive experiments that sludge contained only one-eighth of the value of the sewage from an agricultural point of view, and thus encouraged the principle of sewage farms, with direct application to the land. The chief causes of failure were (I) the very large volume of sewage that had to be continuously dealt with, (2) its property of fouling or clogging, (3) the relatively small amount of important manurial ingredients like phosphates, potash, and nitrogen it contained in proportion to the quantity of water, (4) the unsuitable form in which the organic nitrogen existed. The last difficulty suggested that if the liquid was properly prepared or matured by a fermentation process analogous to that by which a farmer "ripens" manure, this nitrogen might be more readily utilized by plants. Mr. Davies ${ }^{2}$ held out great hopes in this direction, while Mr. Daniel Pidgeon ${ }^{3}$ dealing with the bacterial purification of sewage, showed forcibly the practical value of highly nitrified effluents for all kinds of cultivation.

Scott-Moncrieff ${ }^{4}$ pointed out that a $90 \%$ nitrification of the total nitrogen in ordinary sewage would, based on the cost of nitrate of soda, amount to $£$ I $4,000,000$ per annum on the whole sewage of the United Kingdom, a saving which nearly recovers the waste mentioned by Sir W. Crookes. These highly nitrated effluents also contain plant-food in nearly ideal pro-

1 Fournal of the Society of Arts, Oct. 8, 1886. See also " Collection and Utilization of Excreta," James Ashton, Inst. San. Engineers, Wolverhampton Meeting, 1903.

2 Fourn. R. Agric. Soc., Oct., 1899.

3 Ibid.

4 Southampton Sanitary Congress, I899; J. San. Inst., vol. xx., part iv. 
portions, according to the standard solution adopted by Nobbe, which contained in parts per 100,000 :-

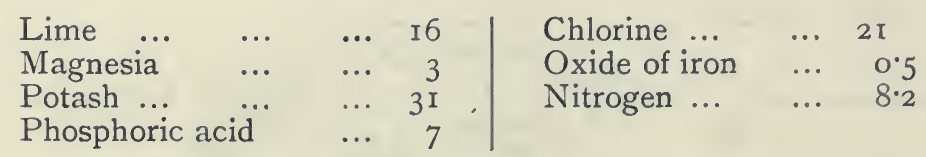

By experiments on plants I have found these effluents to give great fertility. While some plants (Leguminosæ) can assimilate free nitrogen, others organic compounds, and still others nitrogen in the form of ammonia, nitrates appear to be the form in which nitrogen is taken up with the greatest readiness by most plants. The change of sewage into a fertilizing effluent is favoured by a higher temperature. In India a report of Igor states that at Bombay, Poona and Calcutta septic tanks and bacteria beds produced an effluent that gave much better crops than the poudrette manure and irrigation with canal water previously employed, and that at the Matunga Asylum farm, Bombay, irrigation with the septic tank effluent alone gave a gross profit of over $£ 60$ per acre per annum.

As regards the mineral constituents of different sewage effluents not much information is recorded. An average sample of the final flow from the Sutton beds showed :-

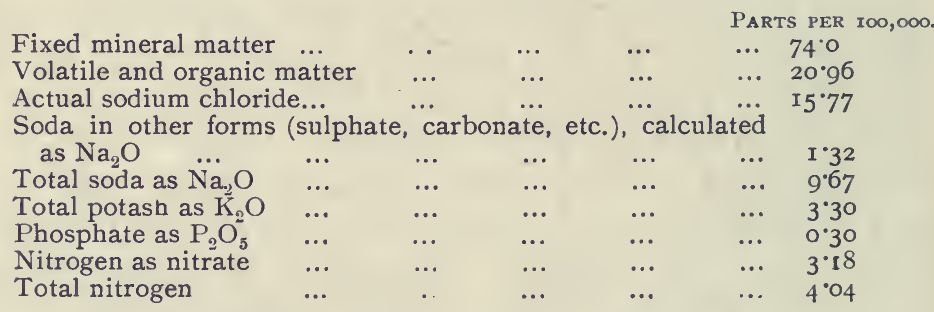

Ioo parts of total solids would correspond to-

$$
\begin{aligned}
& \text { Total } \mathrm{N}_{4 \cdot 25}: \mathrm{K}_{2} \mathrm{O}_{3} \cdot 48: \mathrm{P}_{2} \mathrm{O}_{5} 0^{\circ} 32 \\
& \text { Mineral matters } 77 \cdot 93: \text { Organic } 22 \cdot 07
\end{aligned}
$$

Probably coke in the filters absorbs much of the phosphorus as phosphate of iron, and accounts for the small amount of phosphoric acid. Polarite and other highly ferruginous mixtures would have a still greater effect. Disused filtering materials must consequently contain a large proportion of phosphate.

The difficulty of utilizing any of the valuable constituents of sewage resulting from their extreme dilution, prevents evaporation, distillation, or any of the ordinary chemical methods 
from being economical. The free ammonia present would be a marketable article if it could be cheaply extracted. In I882I883, Dupré suggested its separation by blowing air through the liquid and absorbing the ammonia in acid, the aeration at the same time improving the sewage and reducing the nuisance at discharge. He states with reference to London, that the sewage contains 3 to 4 grains of ammonia per gallon, equal to $3 \mathrm{I}$ tons of ammonia in $\mathrm{r} 4 \mathrm{O}$ million gallons-one day's discharge, giving I 20 tons of sulphate of ammonia, worth from $£ \mathrm{I}_{4}$ to $£ 20$ per ton, or a total value per annum of about $£ 400$,ooo. "By blowing air into the sewage much of the ammonia would be expelled, and if only a fraction of it were recovered, the expense of aeration would be covered."

It does not seem that this idea has been attempted on a large scale. It would include, in common with other artificial methods that we have seen, a continuous mechanical expense, hence natural nitrification is more economical. See also p. I94.

Besides the plants mentioned in Chap. VI. as being grown on sewage farms, the Sutton Urban District Council have found peppermint a lucrative crop and one very suited to irrigation with a bacterial effluent. The oil can be easily distilled on the works with waste steam. The yield from the $2 \frac{3}{4}$ acres cultivated at Sutton in 1898 was $6 \mathrm{I}_{2}^{\frac{1}{2}} \mathrm{lbs}$. sold as firstclass oil at 24s. $3 \mathrm{~d}$. per $\mathrm{lb}$., realizing $£ 75$. The amounts and acreage since then are reported as: 1902, 8 acres, $£ 235$; 1903,

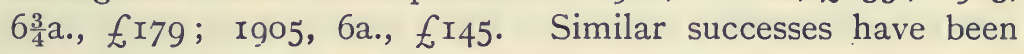
recorded in connection with one or two other sewage works.

\section{Trade Effluents.}

Where land or precipitation is solely relied on, trade effluents are a source of great difficulty. For instance, in a town in the north "they had six times the ordinary flow of sewage, owing to brewery refuse, complaints were very numerous, and they had to reconstruct their sewers and get a farm of 500 acres, at a cost of $£^{250,000 . ~ W h e r e v e r ~ t h e y ~ h a d ~ a ~ s t a p l e ~ t r a d e ~ t h e y ~}$ could not rigidly enforce the law, and they frequently had water discharged into the sewers at $2 \mathrm{I}^{\circ} \mathrm{F}$." The Belgian Government are experimentally treating trade wastes at a special station at Verviers.

The investigation of the sediment at the bottom of a stream is of great importance. An instructive case is cited by Marsson ${ }^{1}$

1 Mitteilungen aus der Königlichen Prüfungsanstalt, Berlin, Heft 2, pp. 28-31. 
of an effluent from a works producing nitro-naphthalene. When diluted by cooling and condenser water, it was apparently harmless to fish under the conditions at the point of discharge. On investigation of the mud near the outfall, however, it was found to have a strong smell of naphthalene products, and all signs of the organic life, necessary for the gradual breaking down of putrefactive matter, had disappeared. This effect was discernable 400 metres below the outfall. In a recent case of alleged contamination from a paper-mill I found a considerable amount of gypsum, chalk and various pigments in the river mud. In another instance, below a copper works, although the water appeared to be free from dissolved copper, the metal was present in the mud, and had an injurious effect on fish.

Especially in the North of England, processes for treatment of factory waste-waters on the works themselves have been greatly improved, and in a large number of cases made remunerative by recovery of products. Mr. Tatton, inspector of the Mersey and Irwell Board, classifies these liquors into those from (I) print works, (2) dye works, (3) bleach works, (4) waste bleach works, (5) paper-mills, (6) paper stainers, (7) tanners and leather dressers, (8) fellmongers, (9) woollen trades, (IO) silk trades, (II) coal slack washers, (I2) soapmakers, (I3) stone polishers, (I4) chemical manufacturers, (I5) brewers, (I6) unclassified. ${ }^{1}$ The discharges are mostly dealt with, after screening, by precipitation with iron and lime, and as mentioned in Chapter VII., a ferric salt is found to be more effective than a ferrous salt (copperas).

Bleach, Dye, Finishing and Calico-printing Works.-The waste liquors contain various dyes and mordants, soap, starch, soda or acids, exhausted bleach, etc. They are generally screened and settled, and in some works traverse a long channel in which blocks of iron alum (ferric ammonium sulphate) are suspended and gradually dissolve, precipitating most of the colouring and other matters. Lime is added either before or after the iron precipitation, in various amounts according to quality of the liquids. After again settling in tanks, the liquid is usually drawn off by floating outlets and passed through shallow ( $\mathrm{I} \frac{1}{2}$ to $3 \frac{1}{2} \mathrm{ft}$.) graded filters of stones and clinkers covered with 6 to 18 in. of fine ashes, which are renewed at intervals. Owing to biological action and the formation of

1 "Purification of Water after Use in Manufactories," by R. A. Tatton, M.I.C.E., Proc. Insi. Civ. Engineers, Jan. 9, 1900. 
films, the filters gain in purifying power by use as long as they pass the effluent freely.

Logwood liquor is reported to present special difficulties and to require separate precipitation, "though the product is at present valueless, even for manure, as it generates fungus; it is simply pressed and burnt." Bichromate liquors in some cases are pumped into the boilers for preventing scale: "no other boiler composition has been found necessary, and the valves have lasted better than previously." It is usually more profitable to recover bichromate by precipitation.

The recovery of indigo is now profitably adopted, according to Mr. Tatton, at all large works. In a Mersey print factory about $£$ I,200 a year was recovered on $£ 4$, 000 worth of raw material. Wash waters are precipitated with alumino-ferric and soda (aluminium chloride partially saturated by sodium carbonate is said to be better ${ }^{1}$ ), and the solids, with the vat sediments, treated chemically to separate pure indigo

Considerable saving is effected in materials by the necessity for preventing pollution of rivers. "Formerly, if a mixing was wrong it was sent down the drains into the river, now it has to be taken to the tip and the error is detected." The West Riding Rivers Board report, I903, states that many manufacturers found their purification works profitable. One paper-maker found that his purification plant resulted in a saving of $£ 500$ a year, while a colliery manager similarly effected a saving of 300 tons of coal a fortnight, which formerly went into the river.

One of the most polluting liquids is the water from the kiers in which cloth, rags, esparto, and straw are boiled-a strongly alkaline fluid which alone is difficult to treat. Judicious mixture with acid liquors and precipitation are used, while at one works carbonic acid is forced in to reduce the caustic alkalinity.

\section{Disposal of Grease.}

The average amount of grease contained in the sewage of various towns is given as, in parts per I00,000:-Ilkley $I \cdot I$, Keighley $9^{*} 8$, Harrogate ${ }_{3} 3$, Huddersfield $\mathrm{r}_{5}{ }^{\circ}$, Cassel I8, Hemsworth $39^{\circ} 6$, Bradford (Frizinghall) $45^{\circ} 3$, Pudsey $46 \cdot 8 .{ }^{2}$

Grease from wool is peculiarly intractable, owing to the partial replacement of the glycerin of ordinary fats by choles-

2 J. Garfield, Sanitary Kecord, Feb. 2, I905, p. 87. 
terin, $\mathrm{C}_{20} \mathrm{H}_{43}(\mathrm{OH})$, a solid insoluble alcohol with a distinct affinity for water, insoluble in alkalies and in acids except concentrated sulphuric. The cholesterides show a remarkable adhesion to water, not rising to the surface like ordinary fats, but remaining suspended, so as not to be separated by centrifugal machines without concentration. Ferric sulphate, with lime, carries down the greater part, giving a sludge difficult to press (p. I66), and containing about $25 \%$ of grease; moreover, an inordinate amount of chemicals is required.

Wool-grease has a special commercial value, when purified, as "lanoline"; it also contains considerable quantities of potash, which pays for separation along with the alkali from the potash or soft soaps used for scouring. Grease is now recovered at some of the larger factories, and if smaller firms combined and conveyed their suds by pipe sewers to one or more centres, they could be dealt with collectively. ${ }^{1}$ This suggestion of co-operative treatment applies to other trades, and economy of neutralization might sometimes be effected by mixing alkalies with acid waste.

At a flannel and dye works near Rochdale the following treatment is pronounced to be very effective:-The liquid first passes through a fine copper sieve to remove wool fibres: the sieve is cleaned by a revolving brush, and the flocks of value collected. It is then mixed by a water-wheel with milk of lime, afterwards with a solution of ferric chloride I2 feet further on, next passes through five settling tanks (arranged so that any one of the first three can be thrown out for cleansing, and each provided with scum-boards), on to two filters of fine ashes, used alternately, thence into the streams.

The sludge is treated with sulphuric acid to break up lime soaps, and pressed through cocoanut matting, the acid filtrate being used again. The sludge cake is further pressed to recover oil, various products from which are made and sold; the refuse is burnt.

At a print works on the Mersey, soap liquor is treated with lime and iron alum, pressed, the cake steamed with acid, the grease separated, and the acid and alum from the press-filtrate used again. The grease is stated to be worth at least $£ 7$ per ton, but even at $£ 4$ Ios. it pays the whole of the expenses of recovery, the quantity being $I_{5}$ to 20 tons a year.

In a large number of woollen mills, simpler works have given

1 Borough Surveyor's Report, Bradford, September, 1896. 
excellent results. They consist of "Sap-tanks" (in which the water from the scouring processes, which contains most of the grease, is treated with acid and the grease recovered), also precipitation tanks and filter-beds.

Dr. Beckhold's ${ }^{1}$ report on the sewage sludge in the precipitation basins at Frankfort, Germany, states that (r) the sludge contains an easily saponified mixture of fats and fatty acids ( $27^{\circ} 8$ per cent. of the latter being combined with bases), the total fatty matters varying from 3 to 27 per cent.; (2) the scum contains 80 per cent. of mixed fats; (3) the annual amount of fat lost in the sewage is over $\mathrm{I}_{2}^{\frac{1}{2}}$ million pounds, or about $8 \mathrm{lbs}$. per head; (4) the amount of sulphuric acid required for complete decomposition is very large, 35 to $50 \%$ by weight ; (5) the iron in the sludge is wholly in the ferrous state; (6) the fat collected in the basins is reduced in a few months by bacteria to a small fraction of the original, more rapidly in the dark and at summer temperature.

Several special processes are used in connection with wool. See also p. I98.

I. Degreasing. Treatment with volatile solvents, such as bisulphide of carbon, benzene, or light petroleum in an apparatus similar to Leuner's, used for degreasing bones; the fat is thus extracted almost unaltered, and the solvent used again. At present this method has not been found commercially successful. The Delattre Process treats first with sulphuric acid, then with steam and benzene: it is said that it can be applied economically to wool-suds or to a very dense sludge. The apparatus is an inclined cylinder, $4 \mathrm{ft}$. diam. and $200 \mathrm{ft}$. long, in three horizontal sections. The wet sludge is pumped in at the top, and in flowing down the incline, meets the benzene or other volatile solvent pumped in from below, mixture being attained by revolving paddles at short intervals. The solvent charged with grease is separated and distilled, the distillate being used again, and the residue of grease run into barrels. The extracted sludge is steamed to recover remaining solvent, and pressed hot, resulting in a dry cake, which can be sold as manure. The method has been applied at the sewage works, Roubaix, France, and was tried in Igoo on a ferricsulphate sludge sent from Bradford, but it was found that it would be necessary to reduce the bulk to about one-fifth in the process of precipitation. The grease was valued at $£ 9$ per ton.

1 Zeits. angew. Chemie, xxxvi., 849. 
II. The Ayrshire Process (Biggart \& Co., Dalry), specially applicable for certain classes of wool and potash soaps. The sedimented suds are evaporated, and the grease which separates is removed. The residue is calcined, and yields a crude carbonate of potash, which is either dissolved and used again for scouring, or refined, when it sells at $£ \mathrm{I} 6$ Ios. per ton. The grease is boiled with sulphuric acid, and may be sold at about $£^{6}$ per ton, or purified further. The process is said to be worked at a profit.

III. Kimmins and Craig's patent (adopted by Holden and Sons, Bradford, I89o); coagulating the liquor by chloride of calcium to obtain a clarified neutral liquid.

IV. Ordinary or Sulphuric Acid Process. When the suds are treated or "cracked" with sufficient acid to decompose the soaps, the grease and fatty acids rise as a dark scum and are collected and filtered, pressed hot, and sold as "Yorkshire Brown Grease."

V. Mechanical or "Battage" Process of Motte \& Co., Roubaix, France. The suds are agitated by beaters, raising a froth which carries to the surface the globules of insoluble fats, this is skimmed off by travelling scrapers and heated to $60^{\circ} \mathrm{C}$. with one-thousandth of sulphuric acid to clarify and separate it. The grease is strained through canvas bags, and the refuse is sold as manure. The acidified effluent is precipitated by lime, and is then said to be neutral and perfectly clear.

VI. Lagerie Process, Roubaix. In France and Belgium and in a few cases in England (as at Alston Works, Bradford), the potash and much of the organic matter is extracted by hot water from the wool before scouring, and the liquor evaporated and calcined as above.

VII. Vial process. This method has special mechanical arrangements for efficient sedimentation. The sludge after treatment with sulphuric acid and straining is passed into vats containing agitators and scrapers, and dried by steam coils and finally by superheated gases. The dry residue is extracted by a solvent in a vessel provided with rotating screw mixers and conveyors.

VIII. Spence process. The sewage is precipitated by quantities of ferric sulphate and sulphuric acid ascertained by tests as to alkalinity and impurity, the sludge further acidulated, heated, pressed, dried, and extracted with a solvent.

IX. The Cassel Process, used at Cassel, Germany, is on similar 
principles. The screened sludge is acidified with sulphuric acid, heated to $100^{\circ} \mathrm{C}$. and pressed (the pressing requires I2 hours); dried by steam till the moisture is reduced to I5 per cent., and afterwards extracted three times by benzene. 300 to 450 tons of liquid sludge, containing about go per cent. moisture, are dealt with per week. From each charge of cake, some 800 kilos. of crude grease are obtained by the use of 1320 gallons of benzene (or petroleum spirit), 99 per cent. of which is recovered by distillation. The dry extracted residue contains 3 per cent. of nitrogen, and fetches 30 s. per ton as manure. The crude grease is treated by vacuum distillation, at a cost of $7 \mathrm{~s}$. to Ios. per ton: 7 tons crude grease yield I ton of water, 5 tons of distillate (valued for soap and candle making at $£$ I9 per ton), I ton of tar, and a little gas, which is burned under the boilers. ${ }^{1}$

$\mathrm{X}$. The Smith-Leach Process, used at Bradford, consists in first driving off about four-fifths of the water in a Yaryan multiple evaporator, when the concentrated suds can be centrifuged into (I) mud, (2) concentrated potash soap solution, and (3) crude lanoline. At the Fieldhead Mills the potash soap is then further concentrated, and finally burnt in a revolving cylindrical incinerator to crude carbonate of potash, which is either sold, or used again for washing wool. No effluent remains, and the distilled water from the evaporator is utilized for wool-washing, and from its softness effects a saving of $I_{5}$ to $30 \%$ in the quantity of soap required. The trials show a considerable profit, as the grease sells at nearly $£ 20$ per ton and the potash at $£ 23$.

The Bradford sewage at the Frizinghall works is at present passed through a detritus tank of 260,000 gallons capacity and then treated by a modification of the Cassel process. The press-cake contains so much grease as to be unsuitable for manure. At Frizinghall a plant is being erected for extracting the grease by distillation, as it has been found that in this way practically all the grease can be extracted, and the cake left in a dry powder containing all the nitrogen. About 25 tons of sulphuric acid are required per day for $12,000,000$ gallons of sewage, and 300 tons of sludge are pressed per day, producing 60 tons of cake.

Paper Works. The process must vary with the materials used. Caustic liquors from esparto or straw are evaporated

1 For details of cost, and analyses of products, see Garfield's paper, loc. cit. 
and the soda-ash recovered by incineration. The wash waters are economized by being used over and over again and finally are precipitated and filtered as above. Wood-pulp works introduce much less pollution : the whole of the pulp, which is usually prepared abroad, is of value, and is kept back by a variety of "save-alls" (revolving sieves of fine gauze), and settling tanks.

At Chorley Paper Mill, Lancashire, it was decided in August, I9oo, to try the effect of bacterial treatment on their waste, with highly satisfactory results, the turbidity being removed by the coagulating effect of the sewage. In almost all mills where esparto grass is used, much difficulty is experienced in obtaining a clear effluent, even after filtration through very fine ashes. After admixture with sewage, however, and sprinkling, the final effluent contains much less suspended matter than that from brewery waste. ${ }^{1}$

Tanners' and Fellmongers' Waste is generally admitted to the sewers after deposition of the grosser solids. If precipitation is practised, the tanks require to be cleaned out frequently in warm weather, and suitable land or double filtration is resorted to afterwards.

Breweries. A large quantity of water is used for cooling; this does not require treatment. The washings of barrels, vats, and tanks are precipitated and filtered, but in many breweries they are discharged direct into the sewers. All these wastes are preferably treated by bacterial methods. ${ }^{2}$

Sewage consisting largely of brewery waste was singularly intractable under the old methods of purification, and neither chemical precipitation nor the most favourable land treatment effected much improvement. At Burton-on-Trent (pop. 40,000, sewage for 24 hours 5 to 6 million gallons) the sewage was first precipitated, then filtered through 450 acres of land-less than 90 persons per acre-yet the farm had never been able to produce a good effluent. ${ }^{3}$ But it has been found amenable to bacterial treatment by septic tanks and filters that have been properly managed and matured, and a successful instance is given by Anson and Shenton ${ }^{4}$ at Ash in Kent using a septic tank and triple contact.

1 “Bacterial Treatment of Trade Waste," W. Naylor, p. 223.

2 J. Soc. Chem. Ind., June, rgor.

3 Dr. S. Barwise, Royal Commission on Sewage, vol. ii., 1902, p. 240 . See also Mr. Chatterton's evidence, ibid., p. 354.

* "Purification of Sewage and Brewery Refuse," published by Davis, Epping, I903. 
Hops in large quantities are particularly difficult to deal with, and may be easily intercepted at the breweries.

At many places, as for example Dorchester, when brewery refuse is present in the sewage in large quantities, a "pig-pen" odour is noticed at the septic tanks and sprinklers, and the author has suggested in order to obviate this aerial nuisance, a partial treatment with chlorine. When the works are far removed from habitations, bacterial treatment of such sewage, as shown by Dr. Barwise at Burton, and Dr. Maclean Wilson in the West Riding of Yorkshire, can be accomplished without any difficulty.

The treatment of "burnt ale," or " pot ale," from distilleries has received much attention in Scotland: it contains about 45 times as much total solids as ordinary sewage, and when precipitated by lime it gave a manure worth about 70s. per ton, but the liquor that was left was quite unfitted to be turned into any stream without further purification. Evaporation, and blowing into furnaces or smoke stacks in spray, have presented difficulties owing to its stickiness and corrosive action on metals. At Mortlach distillery, according to Dr. Cowie, it had been treated successfully by tanks, coke beds, and coarse sand filters. ${ }^{1}$ But by themselves brewery and distillery wastes are treated with difficulty on bacterial filters directly, owing to the formation of acids. The Hook Norton Brewery Company in Igoo, according to Naylor, impounded the strong liquor in a settling tank for not less than 24 hours in contact with putrid sludge from sewage, and when the putridity had once been established throughout the liquid, sewage-sludge was no longer necessary. The contents of this tank, which may be termed an "antisouring" rather than a septic tank, are pumped continually on to a coal filter; the little suspended matter present after the first filtration is intercepted by shallow sand filters, and the effluent is clear, neutral, colourless, sweet, contains nitrates, and about $0^{\circ}$ I part per I0o,00o of albuminoid ammonia. The diminution of dissolved oxygen after saturation is less than 30 per cent. Naylor states that a number of works in the north of England now use a septic tank holding not less than 3 days' flow, started by old sewage sludge, and fed with a mixture of waste liquors with not less than $5 \%$ of domestic sewage. He finds that the species of bacteria so introduced have the effect, partly by generating ammonia and so neutraliz- 
ing acids, and partly by competitive growth, of almost completely preventing souring of liquors containing starch or other carbohydrates. The outflow from the tank is delivered by a revolving sprinkler on a bed of furnace-ashes or coal, and after passing through a small sand filter is as satisfactory as the one last mentioned. The sewage has a coagulating effect in removing turbidity from difficult liquors such as those from esparto, china clay, etc.

Slack-washing, practised at some collieries for separating small coal, gives a water which readily clears in settling tanks, and can be used again and again. As to neglect of this precaution, the Royal Commission on Salmon Fisheries, I902, says of the river Rhymney, that on account of the coal washing from collieries the bed is in a filthy state and the beach is covered with coal dust.

Chemical works give waste water of so various a character that each case must be decided separately.

In a number of experiments on trade effluents, Meade-King ${ }^{1}$ found that the addition of salt water greatly helped the precipitation, either by iron alum, which he considers the most useful precipitant, or by tannin (from oak bark, leaves or galls), which is specially useful in gelatinous effluents like those from print works, but is rather an expensive precipitant.

Gas Liquors. At Rotherham the waste water from sulphate of ammonia plant occasioned trouble, as it has in other places when not controlled. The suspended matter can very easily be removed, but the purification of the liquid portion is quite another thing. When much of this refuse is present in the sewage, there is no process that can be adopted on a large scale that will precipitate the cyanogen compounds. H. W. Crowther (patent II,964 of I893) precipitates and recovers them by cuprous oxide, which has been replaced by a solution of cupric and ferrous sulphates followed by lime, but the process is hardly applicable to sewage. Kershaw found at times as much as I Io parts $\mathrm{NH}_{4} \mathrm{SCN}$ per I00,000 in these liquors. This class of refuse is present in the sewage of many towns, and if there is any place where it is satisfactorily dealt with it is largely due to the fact that its strength is greatly reduced by the volume of sewage. In this condition it can be purified biologically to a considerable extent. He further pointed out in his evidence to the Commission, that very often sulphocyanides in filtrates,

1 Proc. Inst. Civ. Engineers, Jan. 9, I9oo. 
etc., disappear on keeping, which indicates that the satisfactory purification of sewage containing this class of refuse is not beyond the range of possibility. ${ }^{1}$

On the whole, the effect of trade liquors generally has been greatly exaggerated. In the case of small settlements collected round factories, the domestic products may be only in small proportions, and the effluent must be treated specially by chemical methods and not as a sewage proper. In large towns these discharges are usually so largely diluted that they cannot interfere with a bacterial process when rightly carried out.

It has been said that the antiseptic action of some chemicals would arrest the bacterial changes. But by actual cultures it has been shown that the amount of disinfectant required to kill or even inhibit the organisms is far in excess of what can be present in the mixed sewage. For example, at Yeovil, where arsenic as sulpharsenite of calcium is derived from the refuse of glove-making, I found that the maximum quantity of orpiment, $\mathrm{As}_{2} \mathrm{~S}_{3}$, that could enter the sewers per week, if the whole amount escaped, was 2 cwt., equal in I20,000 gallons of sewage daily to $3^{\circ} 9$ parts of $\mathrm{As}_{2} \mathrm{O}_{3}$ per 100,000, or 0039 per cent., whereas Miquel observed that 0.6 per cent., or 600 parts per I00,000 of $\mathrm{As}_{2} \mathrm{O}_{3}$ was required to prevent bacterial growth, and Frankland and Ward assert that it has little effect on lower forms of life.

In December, I899, I examined the waste liquors from two of these factories, and found :-

\begin{tabular}{|c|c|c|c|c|c|}
\hline Arsenic (As) parts per Ic & ... & & & $6 \cdot 86$ & \\
\hline Equal to arsenious acid & & $\ldots$ & & $9^{\circ} \circ$ & I2. 48 \\
\hline Total bacteria per c.c. & $\ldots$ & $\ldots$ & $\ldots$ & 16,900 & 3,300 \\
\hline Rapidly liquefying ditto & ... & & ... & 7 & 100 \\
\hline $\begin{array}{llll} & \ldots & & \end{array}$ & $\ldots$ & $\ldots$ & $\ldots$ & 100 & $\mathrm{I}, \mathrm{OOO}$ \\
\hline
\end{tabular}

Therefore, although arsenic in this quantity has an inhibitory effect on some organisms, the liquid still contains a large number, including those of a rapidly liquefying character, and spores, so that the bacterial work would not be arrested, even if the liquid reached the tanks undiluted with sewage or stormwater. In comparative trials with the sewage alone, and mixed with $\frac{1}{12}$ of waste liquor, I found that both denitrifying and nitrifying changes proceeded similarly with either. As a matter of fact, the total volume of trade liquors in the Yeovil sewage on any one day does not exceed one-fortieth of the estimated dry-weather flow.

1 Kershaw, Association of Sewage Disposal Managers, 1905. 
Tannery liquors in the United States are said to contain such a quantity of arsenic, even after sedimentation, as to hinder bacterial treatment. The Massachusetts State Board (Report, I898) found that passing through a coke strainer completely removed the arsenic as ferric arsenate, and that by afterwards filtering through beds of sand and gravel at the same rate as ordinary town sewage, a satisfactory effluent, fairly nitrified, could be obtained. The fats, retained by the filter for a time, were destroyed by bacteria. A similar process was used successfully with the waste liquor of paper mills. With that from wool-scouring it was found impossible to filter the heavy liquors, as they quickly clogged the surfaces of either coke or sand. After neutralizing with sulphuric acid to remove the fat, the liquid was mixed with 5 times its volume of city sewage, when the bacterial action became very vigorous, finally high nitrification set in, and a sand filter gave a good result.

As an instance of an acid effluent, I found that a soap works at Exeter was discharging $\frac{1}{2}$-ton of acid liquor daily. Even if this contained I per cent. of sulphuric acid, it would amount on a million gallons of sewage to $0^{\circ} \mathrm{I}$ part per I00,000. But the crude sewage has sufficient alkalinity to neutralize more than this amount of acid provided the latter be not supplied in spurts as when poured direct on a filter. I have already remarked on the beneficial mixing and "smoothing" effect of the septic tank on the great fluctuations that occur at different times in all varieties of sewage. I believe that the same natural neutralization and precipitation would dispose of most metallic admixtures such as iron salts, galvanizing pickle, etc.

With regard to tanning refuse, the antiseptic power of tannin itself is very small, and, moreover, it does not pay to let much of it escape. At Exeter I estimated the daily quantity from the large tannery in that town as equivalent to that in six fluid ounces of brewed tea per head of population, and it certainly could have no influence.

Popp and Becker" found that "liquefying bacteria" were killed by $0.5 \%$ of sulphuric acid or by $\mathrm{I} \%$ of sodium carbonate, an acidity or alkalinity that would be higher than the ordinary factory runnings, and would be brought down when mixed with the whole of the sewage to an unimportant factor. As an example I ascertained that at a certain paper mill $35 \mathrm{lbs}$. of soda-ash were used daily: the maximum addition to the

\footnotetext{
1 Chem. Hyg. Inst., Frankfort, I896.
} 
alkalinity of the whole daily sewage was 0.3 parts per I00,000 or $0003 \%$.

Gas liquor and the effluents from timber works often contain a large quantity of suspended tar, which clogs up filter beds and presses, and fouls the catch-pits and sewers. Therefore they must usually be excluded. A sample of refuse from a timber yard which I examined in May, I899, contained, in parts per I00,000 :-

Heavy petroleum

Pieces of wood, straw, leaves $\quad \ldots$

Earthy matter and oxide of iron ...

Solids in solution

$\begin{array}{rrrr}\ldots & \ldots & \ldots & 1560 \\ \ldots & \ldots & \ldots & 210 \\ \ldots & \ldots & \ldots & 827 \\ \ldots & \ldots & \ldots & 33\end{array}$

This is an example of discharges that are easily dealt with by a catch-basin and straining, as the filtrate was nearly clear, almost inodorous, neutral, and not injurious to bacteria. Without such treatment the floating tarry film might possibly somewhat hinder the activity of the upper bacterial layer of a septic tank, but the aqueous liquid itself in its dilution would not be likely to interfere either by its sulphides, cyanides, ammonia or tar-acids, inasmuch as many bacteria generate and live in a medium impregnated with ammonium sulphide, while cyanogen compounds are far less poisonous to lower organisms than to higher animals, and the strongest of the tar derivatives are not bactericidal under $0.5 \%$, or 500 parts per $100,000,-$ an impossible amount to be present in the mixed sewage.

In exceptional cases, however, where intense acidity or other strong admixture cannot be avoided, the use of lime and a settling tank would become necessary: in this case a sludge would be created which would not be that of sewage.

Neutralization of acid sewage containing galvanizing pickle by lime, and subsequent passage through contact beds, has been found satisfactory at Bilston, Staffordshire.

Kinnicutt and Eddy examined the action of the septic tank on the acid iron sewage of Worcester, Massachusetts, which contained in parts per I00,000, $\mathrm{FeSO}_{4} \mathrm{I}_{5}{ }^{\circ} 77, \mathrm{Al}_{2}\left(\mathrm{SO}_{4}\right)_{3} 0^{\circ} 44$, free $\mathrm{H}_{2} \mathrm{SO}_{4}$ IO $^{\circ} 32$. They concluded that (I) about one-fourth of the total solids was removed by passage through the tank; (2) about 2I per cent. of the soluble matter, and 25 per cent. of the suspended matter, was removed, the former being greater, and the latter much less, than the proportion usual with sewages; the result being due to the change of the soluble sulphate of iron into insoluble sulphide of iron, a part of which 
is carried out of the tank in the effluent; (3) the action of a septic tank removes a large amount of iron from an acid iron sewage; (4) the reduction of organic matter, 26 per cent., is much less than occurs with an alkaline domestic sewage; (5) the quantity of gas given off depends greatly on the amount and character of the sludge at the bottom of the tanks, and on the temperature, and is less in winter than in summer; (6) the average volume of gas, $2 \cdot 2$ gallons per Ioo gallons of sewage, is probably less than would be obtained where the sludge contains more organic matter: (7) its composition is $\mathrm{CH}_{4}, \mathrm{~N}, \mathrm{CO}_{2}$, with little, if any, hydrogen; (8) the amount of sludge changed into soluble or gaseous substances, 28 per cent., is probably less than usual on account of the presence of so much ferrous sulphide; (9) the top crust or scum here contains much more organic matter than the sludge; (IO) the formation, non. formation, and disappearance of the crust appears to be an incident, rather than a result, of bacterial action. ${ }^{1}$ Lime is now added to this sewage.

Effluents from oil, wool, and dye works at Trowbridge, Wilts (Dibdin's report of Sept., I90o), interfered little with bacterial treatment, and not at all when diluted, with the exception of bichromate liquors. None of the fourteen effluents tried, when added singly or in mixture, in the proportion of one per cent. to sewage I5 minutes before cultivation, had any antiseptic effect, while with seven per cent. of the mixture the influence was only slight.

Fibrous matters, such as those from wool manufacture, and from horse-dung and wood-pavements, as mentioned in Dr. Clowes' L.C.C. Report of I899, seriously interfere with the action of the bacterial filters, but are easily dealt with by hydrolysis in a septic tank.

In England, ${ }^{2}$ at present, the relations between local authorities and manufacturers in regard to the disposal of manufacturing effluents are contained in Section $2 \mathrm{I}$ of the Public Health Act, I875, which reads :-

"The owner or occupier of any premises within the district of a local authority shall be entitled to cause his drains to empty into the sewers of that authority, on condition of his giving such notice as may be required by such authority."

And in Section 7 of the Rivers Pollution Prevention Act, 1876:-

1 Third Annual Report of the Connecticut Sewerage Commission, I902.

2 Roy. Com., 3rd Report, I903. 
"Every sanitary or other local authority having sewers under their control shall give facilities for enabling manufacturers within their districts to carry the liquids proceeding from their factories or manufacturing processes into such sewers."

But the efficiency of this section is practically neutralized by the ensuing provisos:-

"Provided that this section shall not extend to compel any sanitary or other local authority to admit into their sewers any liquid which would prejudicially affect such sewers or the disposal by sale, application to land, or otherwise, of the sewage matter conveyed along such sewers, or would from its temperature or otherwise be injurious from a sanitary point of view.

"Provided also that no sanitary authority be required to give such facilities as aforesaid, where the sewers of such authority are only sufficient for the requirements of their district, nor where such facilities would interfere with any order of any court of competent jurisdiction respecting the sewage of such authority."

Local Acts have in some cases accentuated these provisos, and actions have been successful in prohibiting trade wastes from gas-works and factories, when it was proved that such discharges interfered with the treatment of the sewage at the outfall. Thus, at present, local authorities are not generally bound to provide such sewers as may be necessary to carry off all the trade effluents and liquid refuse coming from manufactories, but only to provide for sewage in the ordinary sense of the term, including "water produced in the ordinary course of domestic management," and surface water.

The Commission reported as follows (3rd Report, p. xvii) :-

"Purification of trade effluents by the local authority is, in the great majority of cases, practicable; purification by the manufacturer is in some cases difficult, if not impracticable, and would generally be more costly than purification by the local authority. Local authorities, as well as manufacturers, are of opinion that there should be laid upon the local authority a distinct obligation to receive trade effluents. Further advantages which would follow from such a change in the law would be that the average standard of purification which would be reached throughout the country would be higher than if each manufacturer separately attempted to purify his own effluent, and also that the work of preventing the pollution of rivers would be 
greatly assisted, in that the number of purification works to be kept under observation would be diminished."

They find that it should be "the duty of the local authority to provide such sewers as are necessary to carry trade effluents as well as domestic sewage, and that the manufacturer should be given the right, subject to the observance of certain safeguards, to discharge trade effluents into the sewers of the local authority, if he wishes to do so. . . . In each district it would probably be desirable that the local authority should frame regulations, which should be subject to confirmation by a Central Authority. .. . It appears from the evidence that manufacturers would much prefer to have standards to work to."

This alteration in the law should involve "no charge on the manufacturer, in those cases in which the regulations as to preliminary treatment are complied with." ... Where the effluent must not be discharged into the sewer because the water is obtained from a stream and must therefore be returned to it, the duty of purification will rest with the manufacturer, " but they do not consider that this will be a serious grievance, as he obtains his water without charge, and this advantage may be set against the cost of purification."

With regard to Shudge Removal from Mamufactories (3rd Report, p. xxii), manufacturers are generally willing to adopt reasonable means for the removal of solids from their effluents before entering the sewers. But sedimentation, and still more precipitation, involved the production of "sludge," which was a cause of difficulty. The Salford Corporation undertake to dispose of such sludge; and in London the sanitary authority removes trade refuse at a reasonable cost.

They further urge the need of setting up a Central Authority as a new department under the Local Government Board for-

(a) The settlement of differences between manufacturers and local authorities;

(b) The general protection of sources of water supply.

(c) The collection of facts, and the scientific investigation of questions of general importance relating to the protection of water.

The recommendation also includes the formation of Rivers Boards throughout the country, each to have jurisdiction over the whole of a watershed, and to be a first tribunal of appeal. 


\section{N D.E X}

A

$\mathrm{ABC}$ process, 160

Accrington, sewage treatment, $1_{52}, 242$

Acetates, fermentation of, 109

Acidity of sewage, 32, 344

Acids organic, rog

". ", sterilization by, I92

Acreage of land required, 147

Acts, Rivers Pollution, I70

Adams' Automatic Syphons, 283

Adeney's limit of impurity, 58

Adsorption, 133, 223

Aeration figure, 50,53

, of water, 48,189

," processes, 122, 234, 236

", stage, I2I

Aerobacter, II4

Aerobic bacteria, 63, 72, I I0

Africa, South, sewage treatment in, 272

Agar-agar, 62

Agriculture, relation of sewage to, 137, 331

Algæ, 78,82

Alkalies in sewage, 4I, 200, 332

Alkalinity, fixed and volatile, 28, 32, I24 I25, 206

Albuminoid (see Ammonia albuminoid)

Albuminous substances, decomposition of, $98,105, \mathrm{II}_{7}$

Alumina process, I 57

Aluminium salts, precipitation by, 157,335

Alumino-ferric, $84, \times 58,335$

Alum, 158

Alternating gear, 258, 283, 285

Ames tank, 266

America, discharge of sewage into streams, $15,18,56$

, Massachusetts experiments, 46, $84,159,207,209,226,269$ sewage methods, 2I, 140, 206.209, $225,28 x$

street sweepings, 198,200

typhoid from sewage mud, 4 water-supply, 4, 84, 208

Ammonia, absorption, I73

", albuminoid, meaning of, 57,108 , 238

decompositions, 99, 25 I

effect on nitrification, 124

, plants, 330

free and albuminoid, determination of, $35,45,174$

recovery from sewage, I95, 333

Amido-compounds, changes of, 106

Amines, ro8

Anıœbæ, 78

Anabæna, 82

Analysis, bacterial processes, 6 I

" chemical processes, $3 I-54$
Anaerobic bacteria, $64,72,189$

," changes, 98, II2, 252

", cultures, 64

", tanks (see Septic tanks)

Anguillula, 77

Antagonism of bacteria, 100

Antiseptic treatment (see Chemical)

Antiseptics, interference with bacterial action, 66, 343

Area of land required, $\mathbf{I} 47$

Aromatic comipounds, I IO

Arsenical liquors, 343,344

Ash of sewage, determination of, 33

Ashes, 10, 197

Ashtead experiments, 250, 269

Ashton-Booth sludge remover, 164

Asparagin and aspartic acid, I07

Australia, II5, I52

Automatic gear, 259, 283.287

". scavenger, 205

Available chlorine, 180

,. oxygen, 16, 130, 271

B

Bacillus amylobacter, 72,75 , I 10

, anthracis, 93, 94

, aquatilis, 72, 128

, arborescens, 72, 215

", coli comnunis, $66,72,74,89,92$,

$97,102,129,137,160,175,188$, 193,215

", denitrificans, Ior, 127, I29

"desulphuricans, II4

" enteritidis sporogenes, $73.87,88$,

$89,104,169,175, x 88,193,215$

ery throsporus, 77

" fermentationis cellulosæ, III

", fluorescens liquefaciens, 72, IO4, 129

, mesentericus, 74, III, 129

," mycoides, 72, 97

" prodigiosus, 9, I0I, 108, 215

" pseudo-tuberculosis, 93

", pyocyaneus, $73,93,97$, Ior, 127, 129

, $\quad$ subtilis, $73,74,97$, I9I, I94

, tuberculosis, 105, 215

, typhosus, 86, 89, 105, I37, I75

ureæ, 73 , 108

". See also Chap. IV., p. 72, etc.

Bacteria as a test for pollution, 8

", beds, 75, 100, 210

, counting, 63,77 , ror

, colonies of, 62

, cultivation media, $62,66,67$

, in sludge. 165

,, in soil, 136

, pathogenic, 84,100 
Bacteria, spores of, 64,74 stages of action, IOO, 272

Bacterial efficiency, testing, 68 samples, 6r
", Nitrification)

Bacterium sulphureum, 73

Ballast, 210, 227

Baltimore, 295

Barking filter, 98, 2 I I

Barrhead installation, $262,3^{1} 5$

"Battage " of grease, $33^{8}$

Beggiatoa alba, 73,78

Berlin sewage farms, I35, r39

,. Sewerage Commission, 202

, Street sweepings, 200

Belfast, 80, 222

Bergé process, I92

Bichromate liquors, 335

Birmingham, sewage disposal at, $\mathrm{r}_{55}, \mathrm{I}_{5}$

Bleach liquor, 183,334

Bleaching powder, $180, I_{3}$

Blood-heat organisms, 64

Bradford, sewage disposal at, r66

$$
\text { , wool-scouring refuse, 336, } 339
$$

Brent, use of chloride of lime on, I8r

Brewery waste, 34I

Brighton, r7o

Broad irrigation (see Irrigation)

Burning, disposal by, $x, x_{54}, x 98$

Burton-on-Trent, $\mathrm{I}_{4} \mathrm{I}$

Bury, dust disposal, 198

By-laws, 8, 55, 347

\section{C}

Calcutta sewage, footnote, $\mathbf{r} 34,332$

Cameron's alternating gear, 259, 286

Candy-Caink sprinkler, 294

Capacity of beds, 213, 226, 233

Carbohydrates, decomposition of, Iro, II 3

Carbonaceous iron sand, 229

Carbonic acid in sewage and effluents, 5I, 75

, , , in air of filters, 125, 234

Carchesium lachmanni, 80

Carriage of sewage and refuse by carts, 6 , 196

$$
\text { " } \quad \text { ", } \quad \text { water, } 4,7,1_{3}
$$

Cassell process, 196

Catalytic theory of putrefaction, 202, 2 I I

Catch-pits, 7, 345

Catchwater system, I43

Caterham works, 91, $25^{2}$

Cellulose, $x 13,215$

" hydrolysis of, $\mathrm{x}$ ro, $\mathrm{II} 7$

Centrifugal method for solids, 34

Cesspits, ro

Cesspools, 2, 3, 8, 206

Chalk for earth closets, II

," as a filtering medium, 246

" infiltration through, $8, \mathrm{r}_{3} 6$

Chemical precipitation, I55 sterilization, 168

Chemicals injurious to plants, $\mathbf{r} 47$

Chichester, 83, 84

Chloride of lime, $\mathrm{r} 8 \mathrm{o}, \mathrm{r} 83$

Chlorine and its compounds as disinfectors, $87,179-192$

, as measuring strength of sewage, I3. 35, I 45

" as a finısher, 87

, determination of, 34
Chlorine ratio to nitrogen, 58 , loss of, 125, 18I, 189

Chloros, r8r

Chlorates, rg2

Cholera organisms, $192, \mathrm{r} 93$

Cinders as filtering material, 234

Cladothrix, 78,84

Clarification, $x x, 153,2$ ro

Clarine, 158

Claybury, bacterial treatment at, 272

Clay soils, 133,136

Clinker as a filtering medium, 228

Closets, dry, 8

", earth, $\mathrm{rr}$

" water, 12

Clostridium butyricum and fœtidum, 73 , $75, \mathrm{x}_{3}$

Coal as a filtering medium, 226

Coarse filters, 227, 232, 240

Coke beds, 2ro, 2r2, 227

Cold, influence on purification, 242

Coli (see B. coli communis)

Collection of samples, Chapter II.

", ", bacterial, 6I

Colonies of bacteria, 62

Columbus, Ohio, investigations, 208, 264

Combined system of sewerage, $150,162,3^{12}$

Combustion of excreta, I

$$
\begin{aligned}
& \text { ", sewage gases, II6, II7 } \\
& \text {, town refuse, } 198
\end{aligned}
$$

Commissions on sewage, $\mathrm{r} 9,34,47,55,85$, I68, r $7 x, 202,203,347$

Conservancy systems, 9, II

Contact beds, I89, 2 ro

Continuous filtration, 280

Copperas, I 58 , I 59

Copper salts for sewage treatment, 174

Corrosion of fittings, 182

Coshan's tank, I63

Cost of purification, 168,194

Counting bacteria, $63,7 \mathbf{r}$

Cremation of effete matters, r, r 54, rg8

Crenothrix, 78, 82, I61, 308

Cultivation tanks (see Septic tanks)

Culture media, 62,67, II 4

Cultures, anaerobic, 64

, plate, 62

, stab and streak, 65

II surface, 66,72

Cytase, ro4, II3

\section{D}

Dejecta, burning, r

, covering by earth, $x, 2$

", quantities and manurial value, 40, $33 \mathrm{r}$

" removal by screening (see Screening)

Delattre process for grease recovery, 337

Denitrification, r25, 23r, 25I by soil, $x_{33}$

Depth of filters, $2 r_{3}$

Derbyshire County Council standards, 55

Destructors, 154, 199-20r

Detritus, road, composition of, $6,7,200$ , tanks, 23, 253

Detroit, water-borne typhoid of, 4

Diastase, ro4, $\mathrm{x}_{3}$

Dibdin beds, $71,75,221$

Dibdin's experiments, 206, 217

, fish test, 56

Digby process, 191 
Dilution by subsoil water, I45, 3II calculation of, 35

". effects of, 14

" methods for bacteria, 6r, 72

Discharge into rivers, $4,14,169,310$

, into the sea, 19, 20, 317

," into tidal estuaries, $19,170,319$

Disinfection of sewage and excreta (see Sterilization)

, by chlorine, I 82

Distribution on beds, 283

$$
\text { ," over land, I4I }
$$

Distributors, 282-308

Dortmund tank, $16_{3}$

Double treatment, 216, 231

Dover's process, I55

Drainage waters from farms, 5, 8, 149

Dry-rot, III

Dublin, 20, 316

Ducat's filter, $87,236,240$

Dust collection, 6 , 196

," destructors, 199, 201

", methods of disposal, I96

, use of screened for beds, 223

Dye-water, 334

\section{E}

Earth closets, II

," committal to, I, II, I32

Electrolytic processes, 184

Electrozone, 185

Energy produced by bacterial changes, II6

Entersc (see 'Typhoid)

Enteritidis bacillus (see B. enteritidis)

Enzymes, I02, I43

Essen tank, 163

Estuaries, 19, 170, 317

Excreta, burning, $x, 198$

, chemical treatment, 187

", nature of, $5,40,33 \mathrm{~T}$

, primitive disposal of, I

" removal in scavenging, II

,. weights per day per person, 40, 54

Exeter sewage treatment at, 18, 86, 254

Exothermic change, Ir6

\section{F}

Facultative aerobes and anaerobes, $6_{5}, 72$

Fæces, 5, II, 40, 54, 99, I87, 33I

Farm pollution, 5

Farms, sewage (see Sewage farms)

Farrer's distributor, 306

Fats, decomposition of, $98, \mathrm{II}_{3}$

, removal of, 265

, utilization, 336

Fatty acids, 80, 98, rog, III, 337

Ferments and fermentations, Chap. V.

Ferric and ferrous salts, $1_{57}, x_{58}, 1_{7} 6$

Ferrous sulphide (see Sulphuretted hydrogen)

Ferrozone, $15^{8}$

Fibre, resolution of, I ro

Fiddian distributor, 304

Filter presses, I 54

Filters, aerating, 240

" capacity of, 226
" contact, 243
continuous, 244
distribution on (see Distributors)
gases in, 125, 234
materials for, 227,248
oxidizing, 206,240
roughing or straining, $28, \mathrm{r}_{52}$

Filters, zonal, 75,9 r, 268

Filtration areas, 147,207

,. through land, 93, Chap. IV.

upward, 249

Finishers, 87, 175, 194

Fish test for effluents, 56,215

,. as conveying coli, 92

"I injury to, by sewage, 319, 334

Fisheries, contamination of, I70

Flies, infection by, I4

Float method of gauging, 20, 22

Flow, gauging the, 22, 23

," regulation of, 282,3 I I

, variations of, $28,3 \mathrm{I} 2$

Foreshores, 19, 80, 170, 318

Formulæ: Mouras' Scavenger, 205

, discharge of sewage, I6

, ratio of $\mathrm{Cl}$ to $\mathrm{N}, 5^{8}$

". volume of subsoil water, I45

, V-notch, 23

, weirs, 22

France, pneumatic emptying of cesspools, 4

, pollution of river Seine near Paris, 4

, Roubaix method of extracting waste wool fat, 337

", treatment of Paris sewage, I43

Frankfort sewage sludge, 337

Friern Barnet, 228

Frost, effect on purification, 208, 242, 265. 275

Fungi, 78, ro3, r ro

Furnaces for refuse, 199

\section{G}

Garfield filter, 227

Gas in cesspools, 2

Gas from sewage, utilization of, I I 5, 259

Gas-liquor, 342, 345

Gases from refuse, 200

" produced by bacteria, 65,97 , го6, Chap. V.

, from tanks, 97, II5, 259

Gauging, 22

Gayon and Dupetit reaction, 126, 220

Gelatine cultures, 62 .

" hydrolysis, 98, ro2

Germany, sewage treatment in, $1_{35}, 1_{39}$,

$143,196,202,204,223,337$

Germ theory of putrefaction, 202

Germicidal action, Chap. VIII., r68

Glasgow, sewage treatment at, ${ }_{52}$

Glover's tank, 206

Glycerine, fermentation of, II3, II4

Glycocine (amido-acetic acid), ro7

Gooch crucible, 33

Goux-Thulasne method of disposal, II

Grasses on sewage farms, ${ }^{1} 3^{8}$

Gravel, 3, 7, II, 210

Grease, II3

, traps, $\mathbf{1}_{5} \mathbf{I}$

") (see Útilization)

Grit chambers, 28, 162, 261

, and detritus, 150

Guildford investigations, $73,87,185$

$\mathrm{H}$

Hagen's process, I94

Hampton, 224, 267

Hanging-drop cultivations, 69

Harriali grass, I35

Havana, sewage disinfection at, 185

Heat, evolved in bacterial changes, 116

," sterilization by, 19.5, 199 
Heating of bacteria beds, 240, 242

Hendon, Ducat filter at, 240

Hermite solution, 184

Holding up, 283

Horfield, sewage treatment at, 247

Hospitals, discharges from, 172, 193

Household waste, 5

Humus, 96, I $13,123,140$

Hydrogen, anaerobic cultivations in, 64 production of, 96,97

Hydrolysis of organic matter, I4, 96, 99, I05, 250

Hydrolytic tank, 267

Hypochlorous acid and hypochlorites, r8o

\section{I}

Impression preparations, 69

Incubation temperatures, $62,64,71$

Incubator tests, 52

India, sewage disposal in, 134, 183, 195

Indigo solution for nitrates, 43

Indol, 9r

Infiltration of soil, $2,3,8$

Infusoria, 78

Inoculation of beds, 75

Intermittent filtration, 2 Ir

$$
\begin{array}{ll}
\text {," } & \text { irrigation, I44 } \\
\text {," } & \text { subsidence, I6 } 1 \text { }
\end{array}
$$

Invertase, $\mathrm{IO}_{4}, \mathrm{II}_{3}$

Ireland, 20, 80, I70, I73, 222

Iron, corrosion by chlorine, 182

," salts as precipitants, $15^{8}, 334$

, , on sewage farms, 147

,. sand as a filtering medium, 229

Irrigation, Chap. VI., ${ }^{1} 32$

"intensive, 143

Irwell, pollution of, 4

Italian rye grass, 138

Ive's tank, I63

$$
\text { J }
$$

Japan, sewage treatment in, 135

Jelly, nutrient for bacterial cultures, 62 " silicd, 67

\section{$\mathrm{K}$}

Katabolic, I03, footnote

Killon's automatic regulator, 303

Kingston-on-Thames, sewage treatment at, I 52, I60, I6 I

Kjeldahl process, 45 , 108

\section{L}

Lactic fermentation, Iog, II 3

Land filtration, Chapter VI., p. $\mathbf{r}_{32}$

, official requirements as to, 147,149

," restoring valuable matters to, $\mathbf{1} 49,330$

, of sewage farms, 134

Lanoline from waste wool fat, 336

Lawrence city, sewage treatment, 209

Leeds, sewage treatmient at, 224, 280

Legal actions for nuisance, 321, 326

Leguminous plants, 332

Leicester, sewage treatment at, 146

Leptomitus lacteus, 79

Leucine, ro7

Lichfield, sewage treatment at, 227

Liebig's theory, 202

Liernur process, 194

Lime, addition to sludge, 165

", application of waste, I35

, as a purifier, 155,206

,, effect of in soils, 134
Lime, effect:s of in waters, 157

,' soaps, 28

Limestone in filters, 264

Lipase, r04, II 4

Liquefaction of gelatine, 62, 104

Liquefying organisms, 62,70

Liverpool, pollution of wells by cesspools, 3

Local Government Board, 8, I9, I47, 148, $277,314,321,327,348$

London County Council experiments, 72, $74,88,98,159,210,212,322,327$

London sewage, 152,209

Loss on ignition, 33

Low cock's filter, 236

M

MacConkey's medium, 67

Madras sewage farms, 135

Maidenhead, sewage experiments, $87, \mathbf{r} 85$

Maidstone, 8

Malvern, Lowcock's filter at, 237

Manchester experiments, $54, \mathrm{I}_{52}, 183,224$,

$273-279,313,317$

Maltose, ro4

Manganates, 177

Manganese, use of compounds of, I76-I79

Manufacturing refuse and effluents, 32,55 , $26 \mathrm{r}, 333-348$

Manure, decompositions of, 128,330

" from sewage, II, I $52,160,330$

", treatment in farmyards, 5

" value of sewage as, 4 I, 33I

Marsh gas (see Methane)

Massachusetts experiments (see America)

Materials for filters and bacteria beds, 227 , size of, 229,248

" comparative efficiency, 227, 230

Media for bacterial cultivations, $62, \times 23$

Mechanical separation of solids, 152 (see Screening and Sedimentation)

Melbourne, II 5, I $_{5} 2$

Melosira and Meridion, 80

Mersey and Irwell Board, 39, 56, 273

Merthyr Tydvil sewage disposal, 144

Mercaptan, I05

Merulius lachrymans, III

Metallic salts for sewage treatment, 174 ," surfaces as sterilizers, I76

Metallophilic organisms, I60

Metals, action of chlorine on, 182

Meters, 24

Methane, I05, I09, I Io

Methylamines, 108

Microcosci, 73

Micrococcus aquatilis, 77

$$
\text { , candicans, } 75
$$

, urea, 73

Microscopical examination of bacteria, 69

Mineral constituents of sewage, $40,43,33^{2}$

Middens, 2, Io

Midden heaps, 2

Midden towns, 12

Milan, disposal of sewage at, 143

Mixing of sewage liquids, 272,276

Modules for regulating flow, 282, 316

Moncrieff (see Scott-Moncrieff)

Motility of bacteria, 69

Moulds, II 3

Moule's earth closet system, II

Mouras' Automatic Scavenger, 205, 249

Mudbanks, 4, 3r9

Mucor, II3

Mueller's process, 204 
$\mathbf{N}$

Nais, 77

"Native Guano" process, 160

Nesslerizing, 35, 45

Night-soil, ro

Nitrates, 16, 17, 99, 100

, addition to effluents, 179, 276

" determination of, 43

,I in soil, 124

Nitrification, 58, 68, 77, 121, 202, 232, 251, 317

Nitrifying organisms, 66,77

". trays, 65,268

Nitrites, $16,17,49$

" determination of, 44

, as oxygen carriers, II9

Nitrogen, disappearance of, 99, 220

" dissolved, 50

" forms of, 30,59

". gain of, 23т

" loss of, 58, 105, 119, 126, 222, $33^{\circ}$

" production of free, 119,126

" organic, 28,59

" oxygen required to oxidize, $\mathbf{x} 2 \mathrm{x}$

" determination of, 45

, ratios, 30, 59

, restoration to the land, 33

Nitrobacter, 76 , ror

Nitrosification, 68, I1 8

Nitrosomonas, 76 , I0I, II 8

Nitrous oxide, production of, $x 26,127$

Nobbe's solution for plant food, $33^{2}$

Nuisance actions, 188, $34 \mathrm{I}$

Nutrient media for bacteria, 62,123

\section{0}

Obligate aerobes and anaerobes, 64,72

Odour, removing, 168. x74, 180, 18I, 34I

Odours from sewage, $80,173,3^{18}$

,. from organisms, 80,82

Oldham sewage, $x 2$

One-acre filter at Barking, 98, 2 II

Organic acids, 107, rog

Organisms, larger, effecting purification, 77

" causing odours, 80

", methods of counting number of, 63

Oscillaria, 80,83

Osier beds, 140

Oswestry, Sutton system at, 223

Outfalls, position of, 316

Overflows, storm-water, $3 x_{5}$

Oxidation by manganese compounds, i79 ratios, 30

Oxidizing agents, 56, I77, x79, 192, 194

Oxychlorides, $x 85-190$

Oxydases, 110

Oxygen, available, 16, 130

" consumed or absorbed, determination of, 37

" consumed process, criticism of, 37

$$
\text { ". ". " modifications }
$$

, dissolved, $47,48,189$

", liberated from manganates and permanganates, 177

required for nitrification, $\mathbf{1 2 x}$

Oxynite process, 179

Oysters, 21, 170, 320-322

Ozone, 194

\section{$\mathrm{P}$}

Pail system, ro

Paper dissolved anaerobically, xro
Paris, disposal of dust, 197

" pollution of Seine at, 4

", treatment of sewage at, $x_{43}$

Pasteur's researches, 65,202

Pasteur-Chamberland filter for sterilizing, $68,70,329$

Pathogenic organisms, $75,84,100,186$, 215,327

Pavements, 6, x8I

Peat and peaty matters (see Humus)

Penicillium glaucum, Ir4

Peptones, 62

Permanganate alkaline, 36

$$
\text { " test, } 37
$$

Permanganates, use of, for sewage, 176

Peroxide of chlorine, $\mathrm{x} 92$

" of manganese, 178

Per-salts of iron (see Ferric Salts)

Petri dish, 62, 63, 67

Phenol derivatives, 100, 107, IIo

", in cultivations, 67

Phenylacetic acid, I74

Phosphates in sewage, 4I, 200, $33^{2}$

Pipe lines, 2I, 148,317

Plants, on sewage farms, $137, \mathbf{1 9 4}, 333$

, water, 78

Plate cultures, 62

Ploughing in, $135, x_{54}$

Pneumatic control (see Adams)

$$
\begin{gathered}
\text { disposal of sewage, Liernur's, } \\
\text { I94 }
\end{gathered}
$$

Podura aquatica, 78

Polarite, 227, 322

Pollution of rivers (see Rivers)

Pollution of drinking water and wells, 3, 8, ro

Population per acre of land, $x_{47}$

Potassium in sewage, $4 \mathrm{r}, 33^{2}$

Precipitation before application to land, $x_{46}$

Pressing sludge, I66

Primary beds, 2x6

Privies, 8

Proteus vilgaris and other species, 73, 74

Proto-salts of iron (see Ferrous)

Protozoa, 84

Ptomaines, 93, 108

Pumping sewage, I 52, 201

Putrefaction, theories of, 95, 202

Pyrolusite, $\mathbf{1} 78$

\section{Q}

Quality of sewages, 28, 3II

Quantities excreted daily, 40, 54, 33I

Quantity of land required, I47

\section{$\mathrm{R}$}

Rainfall, 6, 27, 148, 310

Rathmines, 20, 3 r6

Recovery of grease, 335

$$
\text { " of manganese, } 179
$$

" of waste products (see Utilization)

"Reduction" of refuse, 198

Refuse, as filtering material, 223

, classification of, 5, x99

", destruction and disposal, Iç6

, trade, 55, I99, 312, 335

Regulations (see Local Government Board and By-laws)

" of Massachusetts Board, 7

Reversible reactions, 104

Retting of flax, III 
Ribble Joint Board, 55

Rideal's formula for dilution of sewage, I6

Ridge and furrow irrigation, 137, I4I

Ridgway Automatic Distributor, 285

Rivers Board, $34^{8}$

, disinfection of, $169, x 73$

", pollution of, $4,14,18,4 \mathrm{I}$

", Pollution Commissions, I9, 55, I68, $310,320,329$

, purifying action of, $14,18,130$

" pernissible admixture of sewage or effluent, I5, I8, 169

Road detritus, 6, 28

Rochdale, ro

Rockner-Rothe tank, 163

Roll cultures, 66

Root crops on sewage farms, $1_{3} 8$

Roscoe filters, 274

Rotary screens for sewage, I 50

Roubaix process of exiracting waste wool fat, 337,338

Roughing filters, ${ }^{5}{ }^{2}$

Royal Commission reports, $34,47,85, I_{54}$, I7 I, I72, 203, 320, 327, 347

Rye-grass in irrigation, ${ }_{13} 8$

\section{$\mathrm{S}$}

Salford sewage treatment, 244

Samples, method of collecting, 27 bacterial, 6r

Sand' filters, 207-209, 210, 263

Sandy soils, Chap. VI.

Sarcina, Ic5

Scavenging, 6

Scott-Moncrieff, 250, 268-272, 300, 309

Screening, I50, 21 4, 216

Scum, bacterial, 254, 264, 275

", harbour, 80

", plates, 162,263

, tanks, footnote, 275

Sea, discharge into, $19,20,170,317$

, lettuce, 80

", water admixture, $3^{\mathrm{I}} 7$

, ", electrolyzed, 184

, weed, 80, $8 \mathbf{I}$

Secondary beds, 217,221

Sedimentation (see Settling)

Separate system, 12, 137, 312

Septic fermentations, Ioo

, tank, antecedents of, 204, 250

" , effluents, 108, 187

tanks, 253, 258-267

" closed and open, 259, 275, 280

"' " duration of stay in, 254, 26I

Settling tanks, I6r

Sewage, application to land, Chap. VI., 209 classification of, 5, II

", discharge into cesspools, 2

" ", ", rivers, $4, x 4,56,169$

., ", ." the sea, I9, I70, 217

, farms, suitable crops, I37

". farm effluents, 40, r45

". farms, pollution by, 9, I93

, flow of (see Gauging and Flow)

,. fungus, 78,79

", precipitation by chemicals, $\mathbf{I} 55$

,i strength of, 13,161

Sewer gas, 2 (see also Gases)

Shake cultures, 65

Sheffield, sewage treatment at, 280

Shellfish, I70, 327

Ship Canal, Manchester, 276, 3I7

Shores (see Foreshores)
Silica jelly for nitrifying organisms, 67

Silicates for cultures, 123

Sirosiphon, I6r

Slate in filters, 235

Slop closets, 13

Slop-water, 5,12

Sludge, 55, I 54, 164, I87, 255, 319, 337, 348 ,. cake, analyses of, 167

Smith-Leach process for recovering grease, 339

Soap-water, 6, 12, 27, I 13

Soil, action of, on sewage, 93

, infiltration of, 2, 3, 8, 9

, nitrificalion by, 124

', suitability for sewage farms, I34

Soils, organisms in, 136

Solids of sewage, determination of, 32

South Africa, 14, 29, 272 suspended, $12,28,33, I_{5}$

Sphærotilus natans, 79, I6r

Spirilla, 72, II4

Spores, method of counting, $6_{3} 6_{4}$

Sprinklers, 287-308

Stab cultures, 65

Staining bacteria, 70

Standards for effluents, 15,55

Stages of purification, I00

Starch, hydrolysis of, $98, \mathrm{II}_{3}$

Steam blown into filters, 242

Sterility, absolute, I9I

Sterilization by chemicals, I68-r94

$$
\begin{array}{ll}
, & \text { filtration, 70, } 329 \\
, & \text { heat, } 62,70, \mathbf{I}_{71}
\end{array}
$$

Storm-water, 5, 12, 312-3I 5

Stoddart's distributor, 288

$$
\therefore \text { filters, } 246
$$

Straining for analysis, 29

$$
\text { , sewage, } 28 \text {, } 150
$$

Straw, influence on denitrification, 129

", anaerobic solution, II 2

$\because$ presence in primary bacteria beds, 215

Street cleansing, 6

, gullies, 7

,, sweepings, 200

, washings, 6

Streak cultures, 65

Streptococci, 75, 128

Streptothrix chromogena, footnote, 123

Sub-cultures, 68

Subsidence, I50

Subsoil water, I45, 316

Sugars, fermentation of, $\mathrm{Ir}_{3}$

Sulphates in sewage and waters, 40

Sulphide of iron, II5, 3I9

Sulphur compounds, $8 \mathrm{r}, 97, \mathrm{Ir}_{4}$

Sulphuretted hydrogen, 28, II4

Surface plate cultures, 66,72

Survival of pathogenic organisms, 84, I86

Sutton, analyses of sewages and effluents, 216

," system, 217, 222

Sydney, N.S.W., 19, 21

Symbiosis and synergetic, I00, I0I, II2

Syphons, automatic, 283

$\mathrm{T}$

Tanks, aerating, 239

,, anaerobic (see Septic)

," Dortmund, $16_{3}$

, sedimentation (see Settling)

," septic, 187

, settling, $16 r, r 62$ 
Tanks, straining, 152

Tanning liquors, 344

Temperatures of incubating cultures, 62, 64, 71
of oxygen consumed test, 39
influence of, on bacterial
action, 242,275

Tertiary beds, I90, 224

Thames Conservancy, 55

, river, $5 \mathrm{r}, 18 \mathrm{r}, 203$

Thermophilic organisms, 63, I I I

Thermal methods, I94, 242

Thermal aerobic filter, 242

Tidal discharge, I9, 20, 2I, 170, 3I7

Tiles in filters, 236

Tipping of dust, 196

Tipping troughs, 268, 305

Town refuse, I96-20I

Trade refuse and effluents, 12, 36, 55, 333

Trays, nitrifying, 65,269

Treble contact (see Triple contact)

Triniethylamine, 108

Triple contact, 224

Trowbridge, waste liquors at, 346

Tubercle bacilli (see B. tuberculosis)

Typhoid bacilli, (see B. typhosus)

Typhoid from sewage mud-banks, 5 " vitality of the bacillus in soils, $\mathbf{r} 4$,

Tyrosine, ${ }^{1} \mathbf{3} 37$

\section{U}

Ulva latissima, 80

Urea, 36, 98, 106, 116, 220

,. decomposition by chlorine, 182

U'rine, 5, II, 27, 33I

, chlorine in, 35

", daily amounts of, 40,54

, of animals, I2, 4I

,. volatile oil from, I74

Utilization of ammonia from sewage, 333

,. effluents agriculturally, 330

, gases from sewage, II 5, II6, 259 night soil, ro

", sewage and sludge as manure,

" $154,160,164,195,341$

, sewage on land, I $_{32}$

, town refuse, 197

, waste products, 335

\section{$\mathrm{V}$}

V-notch for gauging, 23

Valves, control of sewage by (see Distribution)

Variations in sewage, 27, 28

Vegetable débris and washings, 5, II, 28, II2

Vegetables on sewage farms, $13^{8}$
Vegetation, aquatic, 78

,. growth of, 144

" encouraged by effluents, $33^{2}$

Venturi meter, 24, 26

Vinegar, 193

Volatile boaies from sewage, $\mathbf{1} 74$

Volume of sewage and storm-water (see Gauging and Flow)

Volvox, 80

W

Wanklyn, albuminoid ammonia process, 36

amounts of solids and of sulphates, 40

Waring's system, $152,236,239$

Warming, artificial, of bacteria beds, 24I, 242

Waste, manufacturing (see Trade effluents)

Water carriage, $2,7,14$

," closets, I2

," cress, 323

", exhaled by plants, $13^{8}$

,. logging of soils, $\mathbf{I}_{4} 8$

, plants, 78

," subsoil, dilution of sewage by, $\mathbf{1 4 5}$

," supplies, $35,4 \mathrm{I}$

." . $\quad$ in United States, I 8

Wébster process, 184

Weirs, aerating, $25^{8}$

") gauging by, 22

"l, overflow, 3 I2

Wells, pollution of, $3,8,10,148$

Whittaker - Bryant thermal-aerobic filter, 242

Whittaker sprinkler, 242, 294

Wimbledon, sewage at, $\mathrm{I}_{5}$

Wolverhampton, Lowcock filter at, $23^{8}$

Woody fibre, solution of, I Io

Wool fibre and scourings, $336,33^{8}$

Worcester, Mass., sewage, 207, 345

Worms in sewage farms, $1_{3} 6$

," water, 77

\section{$\mathrm{X}$}

"X" nitrogen, 46, 47

Xylane or wood-gum, 129

Y

Yeast, 65

Yeovil, 93, 343

York, sewage treatment at, 159,265

Z

Zones of bacteria, 75, 268

Zooglæa, II 5

Zymase, ro4

Zymosis, ro3

THE END 




$$
593
$$







\section{PLEASE DO NOT REMOVE}

CARDS OR SLIPS FROM THIS POCKET

\section{UNIVERSITY OF TORONTO LIBRARY}

TD

755

R 53

1906 


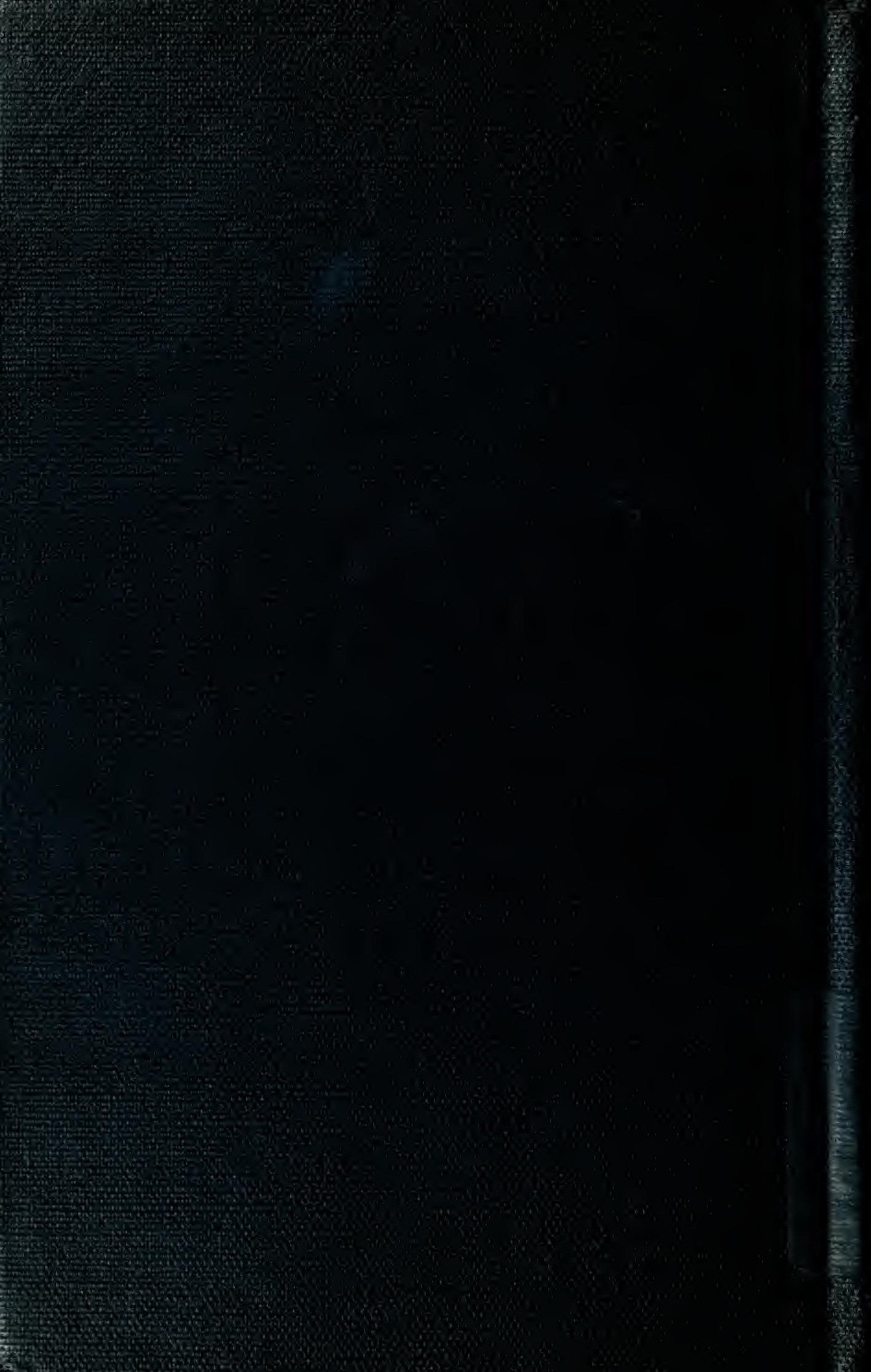

